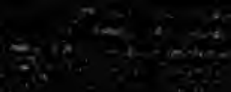
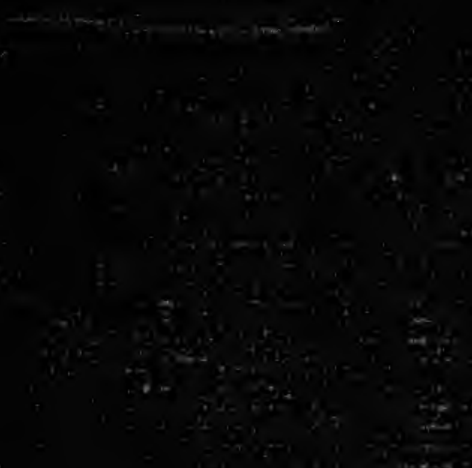


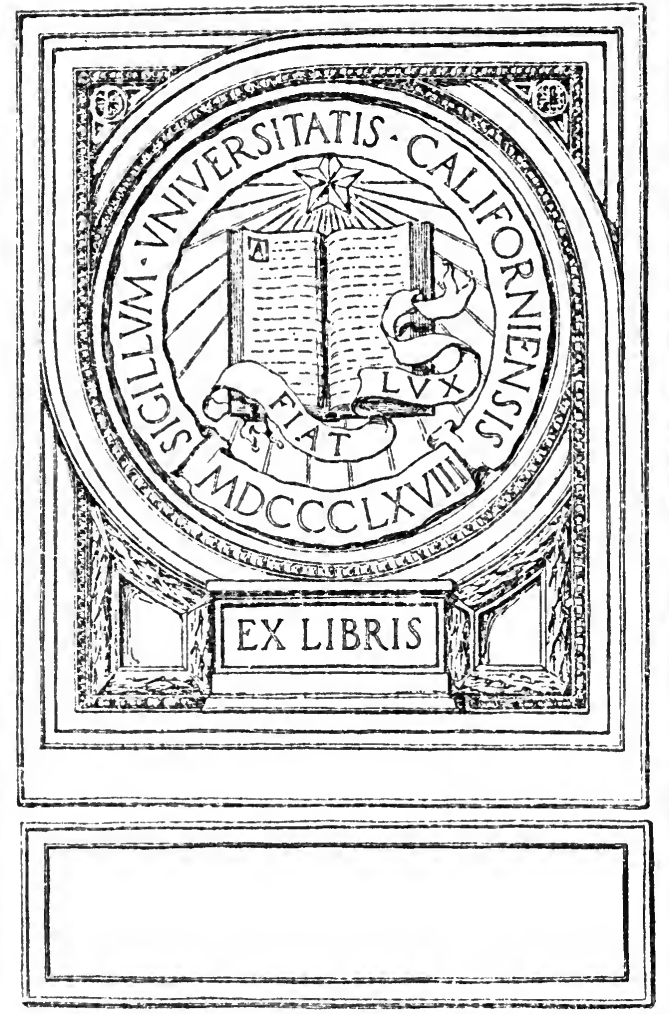





\title{
THE DESIGN OF
}

\section{STELL MILL BUILDINGS}

AND

\author{
THE CALCULATION OF \\ STRESSES IN FRAMED \\ STRUCTURES
}

BY

MILO S. KETCHUM, C. E. 11.

Assistant Professor of Civil Engineering, Universily of Illinois: Associate Member American Society of Civil Engineers; Member Society for

Promotion of Engineering Education.

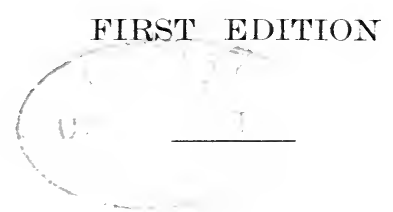

NEW YORK :

THE ENGINEERING NEWS PUBLISHING CO.

1903. 


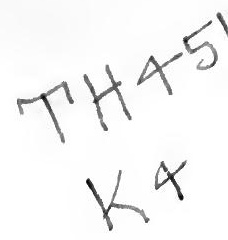

\section{GENERAL}

Copyright, 1903,

by

MiLo S. Ketchum. 


\section{PREFACE}

This book is intended to provide a short course in the calculation of stresses in framed structures and to give a brief discussion of mill building construction. The book is intended to supplement the elementary books on stresses on the one hand, and the more elaborate treatises on bridge design on the other. While the book is cuncerned chiefly with mill buildings it is nevertheless true that much of the matter will apply equally well to all classes of steel frame construction.

In the course in stresses an attempt has been made to give a concise, logical and systematic treatment. Both the algebraic and graphic methods of calculating stresses are fully described and illustrated. Each step in the solution is fully explained and analyzed so that the student will get a definite idea of the underlying principles.

Attention is called to the graphic solutions of the transverse bent, the portal and the two-hinged arch, which are believed to be new, and have proved their worth by actual test in the class room. The diagram for finding the stress in eye-bars due to their own weight is new, and its use will save considerable time in designing bridges.

In the discussion of mill building construction the aim has been to describe the methods of construction and the material used, together with a brief treatment of mill building design, and the making of estimates of weight and cost. The underlying idea has been to give methods, data and details not ordinarily available, and to discuss the matter presented in a way to assist the engineer in making his designs and the detailer in developing the designs in the drafting room. Every engineer should be familiar and be provided with one or more of th: standard handbooks, and therefore only such tables as are not ordinarily available are given. 
The present book is a result of two years experience as designing engineer and contracting agent for the Gillette-Herzog Mfg. Co., Minneapolis, Minn., and four years experience in teaching the subject at the University of Illinois. This book represents the course given by the author in elementary stresses and in the design of metal structures, preliminary to a course in bridge design. While written primarily for the author's students it is hoped that the book will be of interest to others, - especially to the younger engineers.

As far as practicable credit has been given in the body of the book for drawings and data. In addition the author wishes to acknowledge his indebtedness to various sources for drawings and information to which it has not been practicable to give proper individual credit. He wishes to thank Messrs. C. W. Malcolm, L. G. Parker and R. H. Gage, Instructors in Civil Engineering in the University of Illinois, for assistance in preparing the drawings, especially Mr. Malcolm who made a large part of the drawings.

The author will consider it a favor to have errors brought to his notice.

Champaign, Ill.,

M. S. K.

August 17, 1903. 


\section{TABLE OF CONTENTS}

\section{INTRODUCTION}

PAGE.

Steel Frame Mill Buildings.................... I

Steel Mill Buildings with Masonry Filled Walls........... 2

Mill Buildings with Masonry Walls................ 3

PART I. LOADS.

Chapter I. Dead Loads.

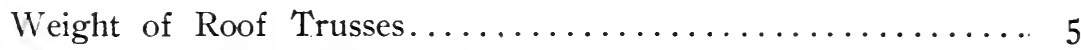

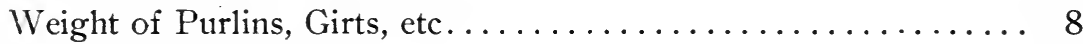

Weight of Covering $\ldots \ldots \ldots \ldots \ldots \ldots \ldots \ldots \ldots \ldots \ldots \ldots$

Weight of Structure $\ldots \ldots \ldots \ldots \ldots \ldots \ldots \ldots \ldots \ldots \ldots$

Chapter II. Snow Loads.

Snow Loads $\ldots \ldots \ldots \ldots \ldots \ldots \ldots \ldots \ldots \ldots \ldots$ Io

Chapter III. Wind Loads.

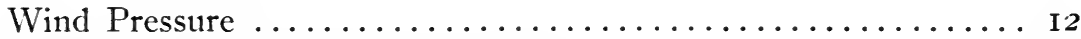

Wind Pressure on Inclined Surfaces................. 13

Chapter IV. Miscellaneous Loads.

Live Loads on Floors..................... I7

Weight of Hand Cranes $\ldots \ldots \ldots \ldots \ldots \ldots \ldots \ldots \ldots \ldots \ldots$

Weight of Electric Cranes ..................... I 8

Weights of Miscellaneous Material ................ I9 


\section{PART II. STRESSES.}

Chapter V. Graphic Statitics.

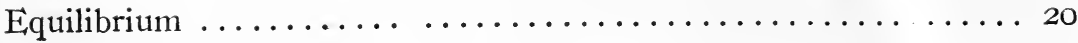

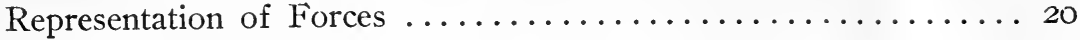

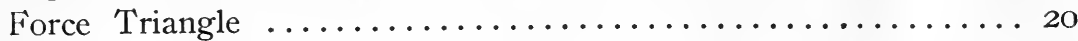

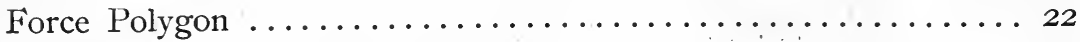

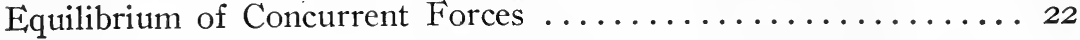

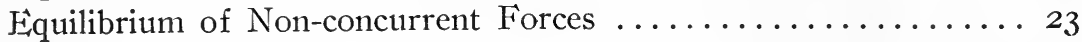

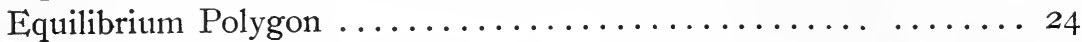

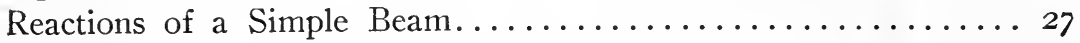

Reactions of a Cantilever Truss .................. 28

Equilibrium Polygon as a Framed Structure.............. 29

Graphic Moments .......................... 44

Bending Moments in a Beam ...................... I $^{\mathrm{I}}$

To Draw an Equilibrium Polygon Through Three Points...... 3I

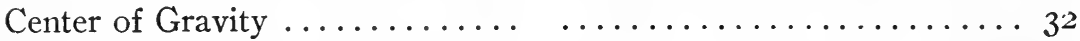

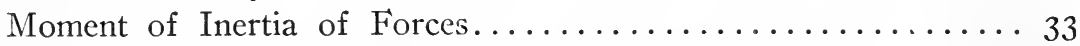

Moment of Inertia of Areas ......................... 36

Chapter VI. Stresses in Framed Structuris.

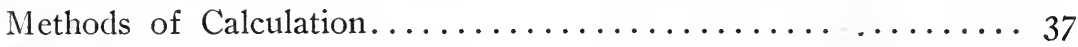

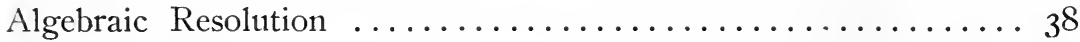

Graphic Resolution ....................... 40

Algebraic Moments ......... ............... 42

Graphic Moments .......................... 30

Chapter VII. Strresses in Simple Roof Trusses.

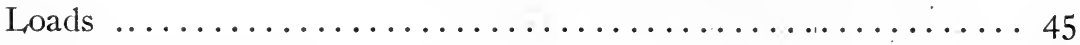

Dead Load Stresses ....................... 45

Dead and Ceiling Load Stresses ................. 46

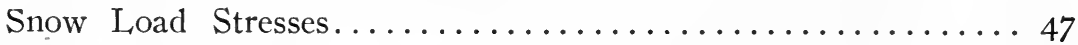

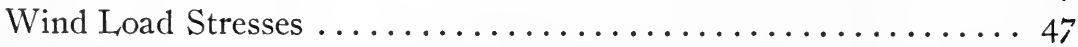

Wind Load Stresses: No Rollers.................... 48

Wind Load Stresses: Rollers ................. 49

Concentrated Load Stresses ..................... $5^{\text {I }}$ 
Chapter VIII. Simple Beams.

Reactions

Moment and Shear in Beams: Concentrated Loads......... 54

Moment and Shear in Beams: Uniform Loads............ 55

Chapter IX. Moving Loads on Beams.

Uniform Moving Loads ..................... 57

Concentrated Moving Loads.. .................. 59

Chapter X. Stresses in Bridge Trusses.

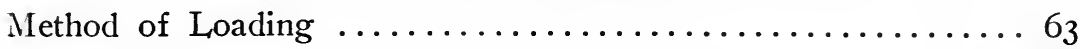

Algebraic Resolution . ....................... 63

Graphic Resolution ......................... 68

Algebraic Moments . ....................... 70

Graphic Moments .....................

Wheel Loads.$\ldots \ldots \ldots \ldots \ldots \ldots \ldots \ldots \ldots \ldots \ldots \ldots \ldots \ldots \ldots \ldots$

Chapter XI. Stresses in a Transverse Bent.

Dead and Snow Load Stresses................... 75

Wind Load Stresses $\ldots \ldots \ldots \ldots \ldots \ldots \ldots \ldots \ldots \ldots \ldots \ldots$

Algebraic Calculation of Stresses:

Case I. Columns Hinged at the Base............ 76

Case II. Columns Fixed at the Base........... 79

Maximum Stresses $\ldots \ldots \ldots \ldots \ldots \ldots \ldots \ldots \ldots \ldots \ldots \ldots$

Stresses in End Framing $\ldots \ldots \ldots \ldots \ldots \ldots \ldots \ldots \ldots \ldots \ldots$

Bracing in the Upper Chord and Sides............. 84 Graphic Calculation of Stresses :

Data ................................. 85

Case I. Permanent Dead and Snow Load Stresses........ 86

Case II. Wind Load Stresses; Wind Horizontal ; Columns Hinged ......................... 88

Case III. Wind Load Stresses; Wind Horizontal; Columns

Fixed at Base .................... go

Case. IV. Wind Load Stresses: Wind Normal ; Columns Hinged $\ldots \ldots \ldots \ldots \ldots \ldots \ldots \ldots \ldots \ldots$ 9

Case V. Wind Load Stresses: Wind Normal; Columns

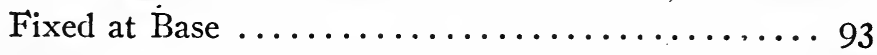


Chapter XII. Stresses in Portals.

Introduction $\ldots \ldots \ldots \ldots \ldots \ldots \ldots \ldots \ldots \ldots \ldots \ldots \ldots \ldots$

Case I. Stresses in Simple Portals: Columns Hinged.

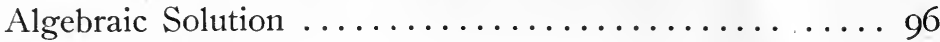

Graphic Solution ........................ $9^{8}$

Simple Portal as a Three-hinged Arch............ Ioo

Case II. Stresses in Simple Portals: Columns Fixed.

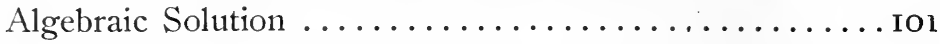

Anchorage of Columns ...................

Graphic Solution ...................... Io3

Stresses in Continuous Portals .................... I03

Stresses in a Double Portal ................. 04

Chapteb XiII. Stresses in Three-hinged Arch.

Introduction $\ldots \ldots \ldots \ldots \ldots \ldots \ldots \ldots \ldots \ldots$. . . . . .

Calculation of Stresses ........................

Calculation of Reactions: Algebraic Method............... I06

Calculation of Reactions: Graphic Method................. Io7

Calculation of Dead Load Stresses .................... Io8

Calculation of Wind Load Stresses ................. II I

Chapter XIV. Stresses in Two-hinged Arch.

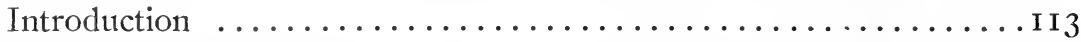

Calculation of Stresses $\ldots \ldots \ldots \ldots \ldots \ldots \ldots \ldots \ldots \ldots \ldots \ldots \ldots \ldots \ldots \ldots$

Calculation of the Reactions.................... I 4

Algebraic Calculation of Reactions.......................

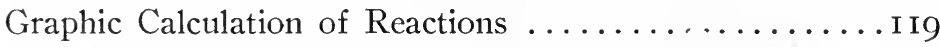

Calculation of Dead Load Stresses in Arch.............. I2 I

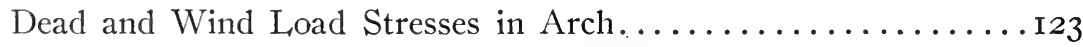

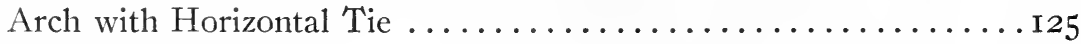

Temperature Stresses ........................ 26

Design of Two-hinged Arch........................

Chapter XV. Combined and Eccentric Stresses.

Combined Direct and Cross Bending Stresses.............. I29

Combined Compression and Cross Bending .............. I $3^{1}$

Combined Tension and Cross Bending.............. 34 
Stress in a Bar Due to its Own Weight................ 35

Diagram for Stress in Bars Duè to Their Own Weight.......... 35

Eccentric Riveted Connections $\ldots \ldots \ldots \ldots \ldots \ldots \ldots \ldots \ldots \ldots \ldots \ldots \ldots$

\section{PART III. DESIGN OF MILL BUILDINGS.}

Chapter XVi. General Design.

General Principles .141

Chapter XVII. Framework.

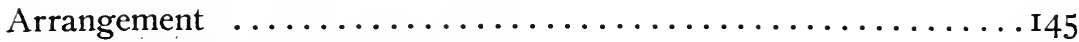

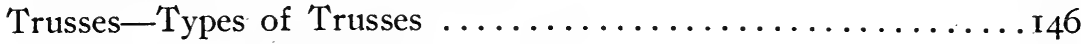

Saw Tooth Roof $\ldots \ldots \ldots \ldots \ldots \ldots \ldots \ldots \ldots \ldots \ldots \ldots \ldots$

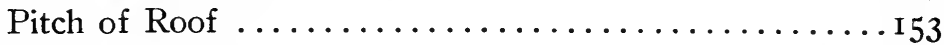

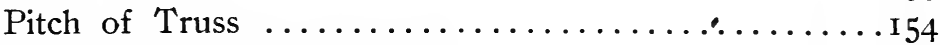

Economic Spacing of Trusses ................ 154

Transverse Bents ............................. 157

Truss Details ................................. 59

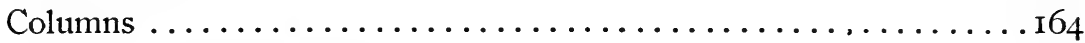

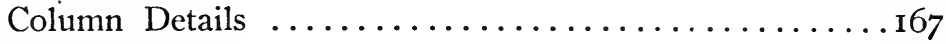

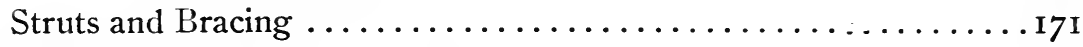

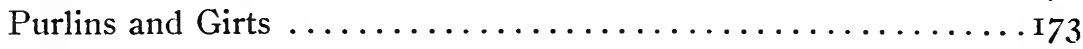

Design of Parts of the Structure $\ldots \ldots \ldots \ldots \ldots \ldots \ldots \ldots \ldots \ldots \ldots$

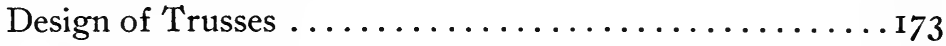

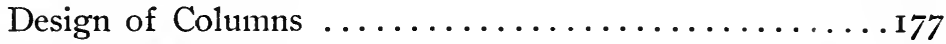

Design of Girders ...................

Crane Girders .184

\section{Chapter XViII. Corrugatepd Steel.}

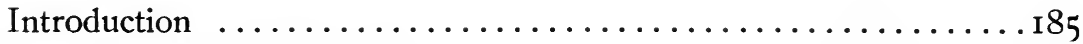

Fastening Corrugated Steel $\ldots \ldots \ldots \ldots \ldots \ldots \ldots \ldots \ldots \ldots \ldots \ldots$

Strength of Corrugated Steel $\ldots \ldots \ldots \ldots \ldots \ldots \ldots \ldots \ldots \ldots \ldots$ I90

Corrugated Steel Details . . . . . . . . . . . . . . . . . I92

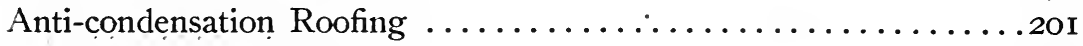

Corrugated Steel Plans .........................204

Cost of Corrugated Steel .........................204 
Chapter XIX. Roof Coverings.

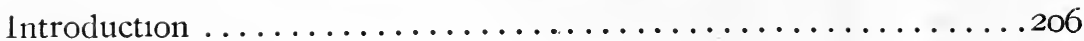

Corrugated Steel Roofing ......................... 206

Slate Roofing ............................20?

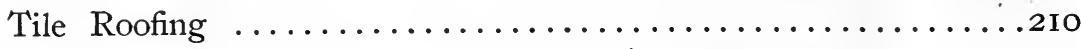

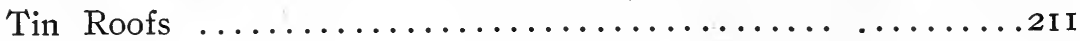

Sheet Steel Roofing $\ldots \ldots \ldots \ldots \ldots \ldots \ldots \ldots \ldots \ldots \ldots \ldots \ldots \mathbf{1}_{3}$

Gravel Roofing ..........................

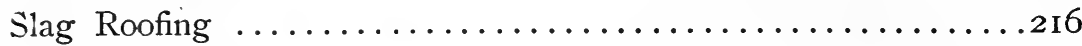

Asphalt Roofing .............................

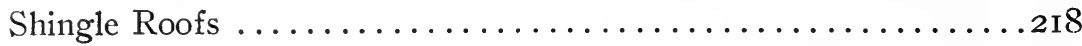

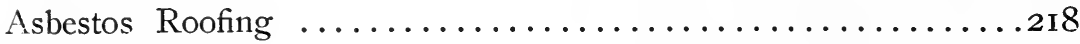

Carey's Roofing . ............................

Granite Roofing .............................. 19

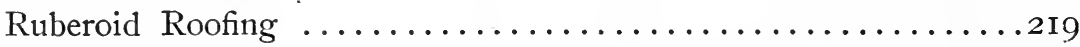

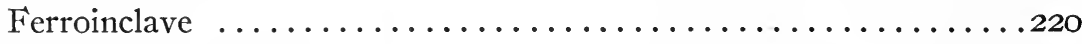

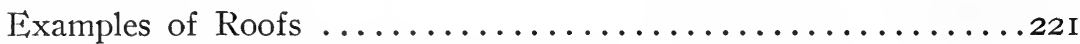

Roof Coverings for Railway Buildings $\ldots \ldots \ldots \ldots \ldots \ldots$. 2 I

Chapter XX. Side Walis and Masonry Walls.

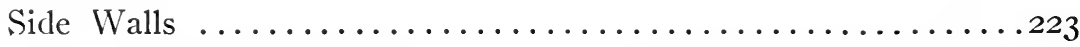

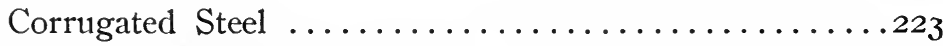

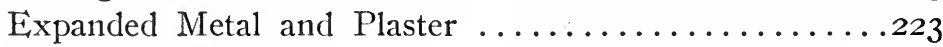

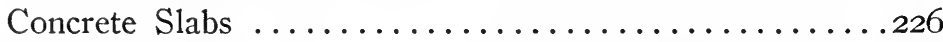

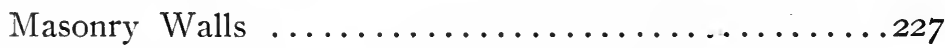

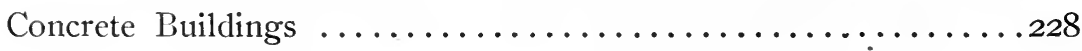

Chapter XXI. Foundations.

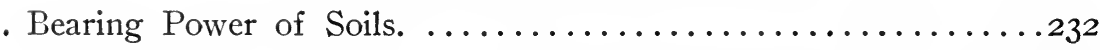

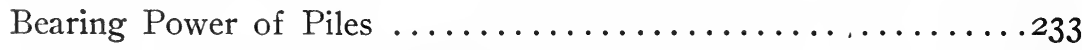

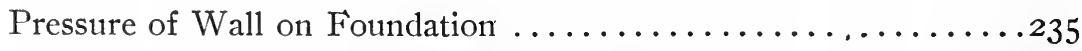

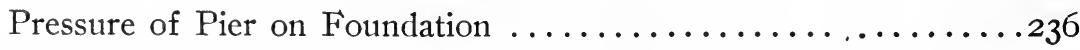

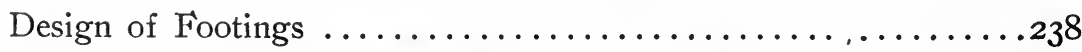

Pressure of Column on Masonry $\ldots \ldots \ldots \ldots \ldots \ldots \ldots \ldots \ldots . \ldots \ldots$ 
Chapter XXII. Floors.

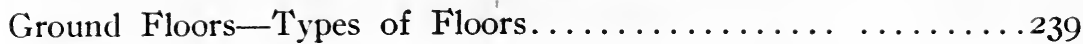

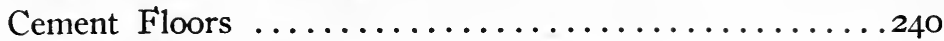

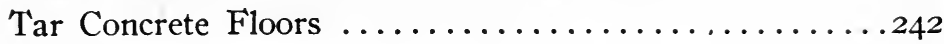

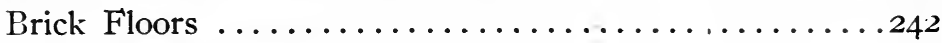

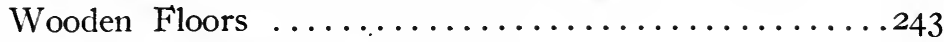

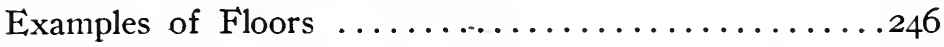

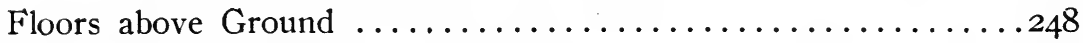

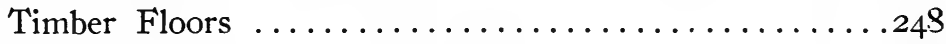

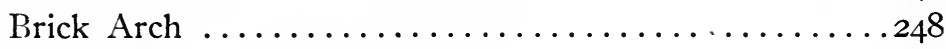

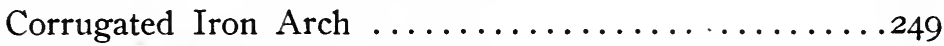

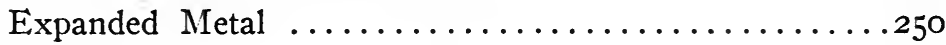

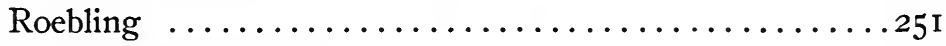

"Buckeye" Fireproof .....................252

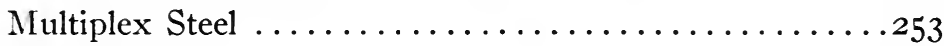

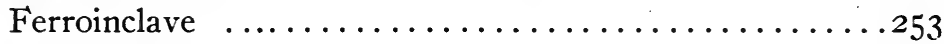

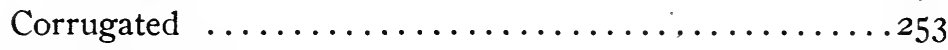

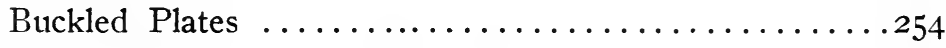

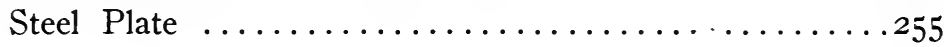

Chapter XXIII. Windows and Skylights.

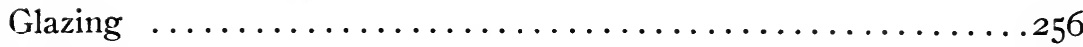

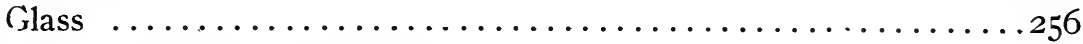

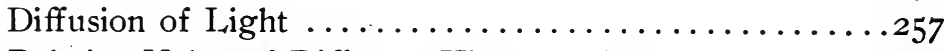

Relative Value of Different Kinds of Glass........259

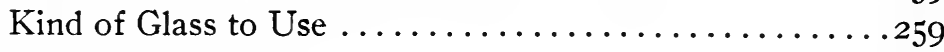

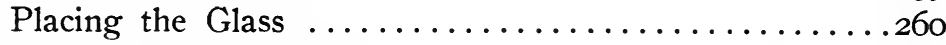

Use of Window Shades ...................

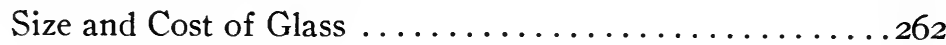

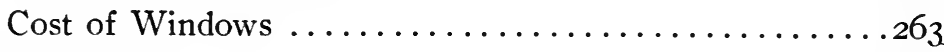

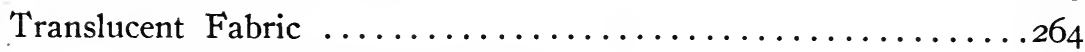

Cost of Translucent Fabric ................... 265

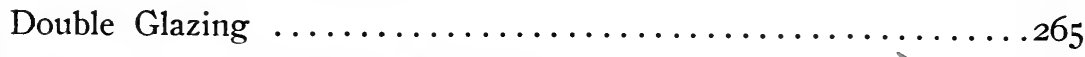

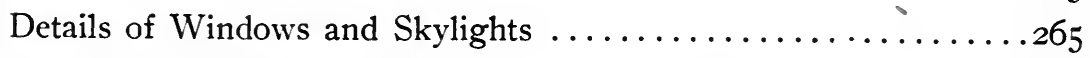

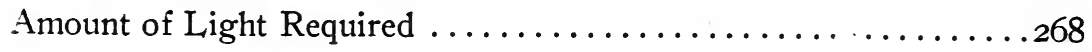




\section{Chapter XXIV. Ventilators.}

Ventilators

Monitor Ventilators

Cost of Monitor V'entilators

Circular Ventilators

Chapter XXV. Doors.

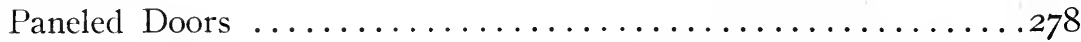

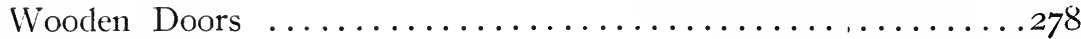

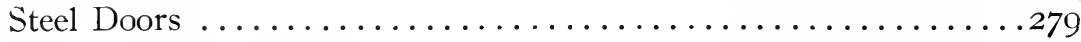

Cost of Doors ........................

Chaptéb XXVI. Shop Drawings and Rules.

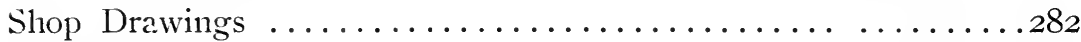

Erection Plan .................................283

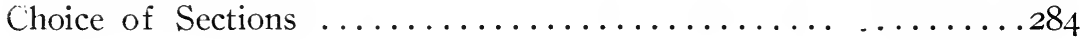

Chapter XXVII. Paints and Painting.

Corrosion of Steel ..........................286

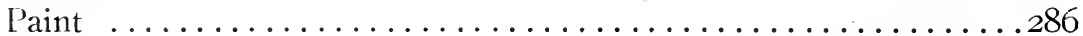

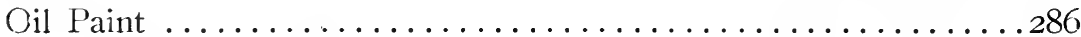

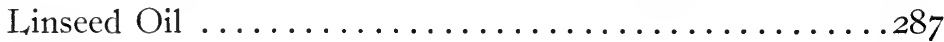

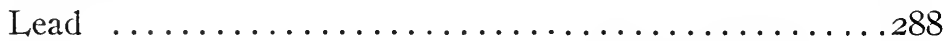

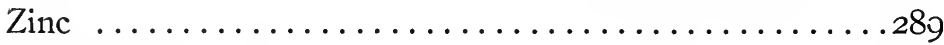

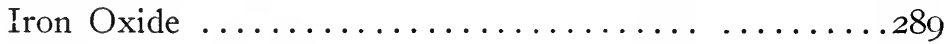

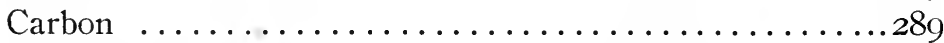

Mixing the Paint .........................290

Proportions ............................290

Covering Capacity .......................290

Applying the Paint .......................29I

Cleaning the Surface .......................292

Cost of Paint ...........................292

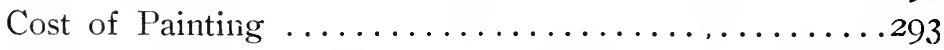

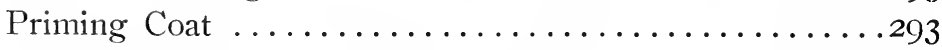

Finishing Coat ...........................294

Asphalt Paint 


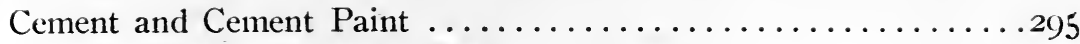

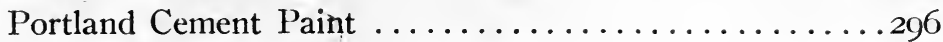

References on Paint and Painting ..................... 296

Chapter XXVIII. Estimate of Weight and Cost.

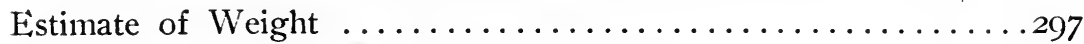

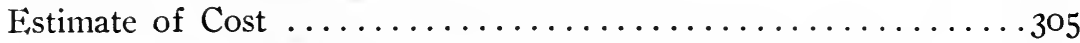

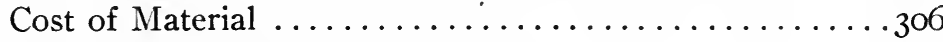

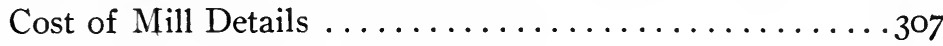

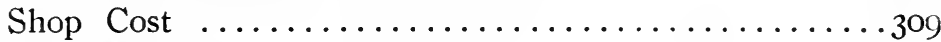

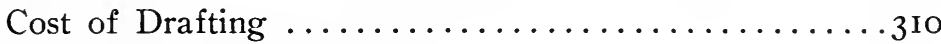

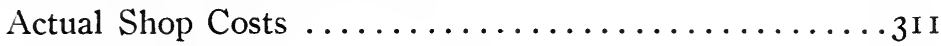

Cost of Erection $\ldots \ldots \ldots \ldots \ldots \ldots \ldots \ldots \ldots \ldots \ldots \ldots \ldots \ldots \ldots \ldots$

Cost of Miscellaneous Material $\ldots \ldots \ldots \ldots \ldots \ldots \ldots \ldots \ldots \ldots \ldots$ I I

PART IV. MISCELLANEOUS STRUCTURES.

Steel Dome for West Baden, Ind., Hotel. ...............

The St. Louis Coliseum ........................

The Locomotive Shops of the Atchison, Topeka and Sant Fe R. R. 323 The Locomotive Erecting and Machine Shop, Philadelphia and

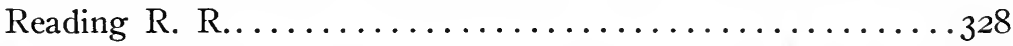

The New Steam Engineering Building for the Brooklyn Navy Yard 327 APPENDIX I.

Specifications for Steel Frame Mill Buildings............ 


\section{,}




\section{STEEL Mill BUILdings}

\section{INTRODUCTION.}

Steel mill buildings may be divided into three classes as follows: (1) steel frame mill buildings; (2) steel mill buildings with masonry filled walls; and (3) mill buildings with masonry walls.

I. Steel Frame Mill Buildings.-A steel frame mill building is made by covering a self-supporting steel frame with a light covering, usually fireproof. The framework consists of transverse bentis firmly braced by purlins, girts and diagonal braces. The usual methods of arranging the framework are as shown in Fig. I.

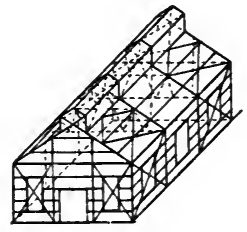

(a)

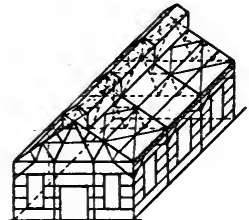

(b)

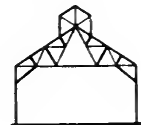

(c)

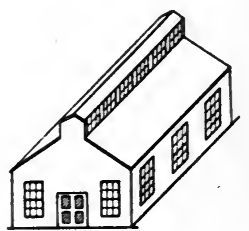

(d)

FIG. I.

An intermediate transverse bent (c), Fig. I, consists of a steel roof truss with its ends supported on steel posts, and is made rigid by knee braces. The posts are either supported on the foundations or are anchored by them. The end bents are made either by running the end posts up to the end rafters as in (a), or by means of an end trussed bent as in (b) Fig. I. The end trussed bent (b) is usually preferred where extensions are contemplated, although the end post bent (a) is equally satisfactory and is usually somewhat cheaper. 
The building is firmly braced transversely by means of bracing in the planes of the upper and lower chords and in the end bents, and longitudinally by means of bracing in the sides and in the planes of the upper and lower chords.

The roof covering is supported on steel purlins placed at right angles to the trusses and rafters. The side covering is fastened to horizontal girts which are fastened to the side and end posts. Where warmth is desired the roof and sides are lined.

Steel frame mill buildings are usually covered with corrugated iron or steel fastened to sheathing or directly to the purlins and girts. Expanded metal and plaster, or wire netting and plaster has been used to a limited extent for covering the sides and for sheathing the roof, and will certainly be much used in the future where permanent structures are required. in the latter case slate or tile roofing is commonly used.

The buildings are lighted by means of windows in the side walls and the clerestory of the monitor ventilator shown in Fig. I, or by means of windows in the side walls and skylights in the roof. Ventilation is effected by means of the monitor ventilator shown in Fig. I or by means of circular ventilators. Where glass is used in the clerestory of monitor ventilators the sash are made movable. The glass in the clerestory of monitor ventilators is often replaced by louvres which allow a free circulation of air and keep out the storm. In foundries and smelters the clerestory is often left entirely open or is slightly protected by simple swinging shutters.

2. Steel Mill Buildings with Masonry Filled Walls.-In mill buildings of this type part of the bracing in the side walls is usually omitted and the space between the columns is filled with a light wall of brick, stone, concrete or hollow tile. The construction of the roof and other constructional details are essentially the same as for steel frame mill buildings. Buildings of this type are quite rigid and are usually somewhat cheaper than type (3). 
3. Mill Buildings with Masonry Walls.-Buildings of this type are made by supporting the roof trusses directly on brick, stone or concrete walls. The construction of the roof is essentially the same as for types (I) and (2), except that the trusses are somewhat lighter on account of the smaller wind stresses.

The discussion of the simple steel frame mill building shown in Fig. I includes practically all the problems and details which are encountered in the design of steel mill buildings of all types.

The problems involved in the design of mill buildings will be divided into Part I, Loads; Part II, Stresses ; Part III; Design of Mill Buildings; and Part IV, Miscellaneous Structures. In general the discussion will relate to the design of mill buildings but in a few cases, particularly in stresses, quite a number of problems will be discussed that are only indirectly related to the subject. 


\section{PART I.}

\section{LOADS.}

The loads to be provided for in designing a mill building will depend to a large degree upon the use to which the finished structure is to be put. The loads may be classed under ( I) dead loads; (2) snow loads; (3) wind loads; and (4) miscellanéous loads. Concentrated floor and roof loads, girder and jib crane, and miscellaneous loads should receive special attention, and proper provision should be made in each case. No general solution can be given for providing ior miscellaneous loads, but each problem must be worked out to suit local conditions.

\section{CHAPTER I.}

\section{DEAD LoADS.}

Dead loads may be divided into (a) weight of structure; (b) concentrated loads.

The weight of the structure may be divided into (I) the weight of the roof trusses; (2) the weight of the roof covering; (3) the weight of the purlins and bracing; (4) the weight of the sicle and end walls. The first three items, together with the concentrated roof loads, constitute the dead loads used in designing the trusses.

The weights of mill buildings vary so much that it is not possible to give anything more than approximate values for the different items which go to make up the dead load. The following data will, however, materially assist the designer in arriving at approximately the proper 
dead load to assume for computing stresses, and the approximate weight of metal to use as a basis for preliminary estimates.

Weight of Roof Trusses.-The weight of roof trusses varies with the span, the distance between trusses, the load carried or capacity of the truss, and the pitch.

The empirical formula

$$
W=\frac{P}{45} A L\left(1+\frac{L}{5 \sqrt{ } A}\right)
$$

where

$W=$ weight of steel roof truss in pounds;

$P=$ capacity of truss in pounds per square foot of horizontal projection of roof ( 30 to 80 lbs.) ;

$A=$ distance center to center of trusses in feet (8 to 30 feet);

$L=$ span of truss in feet;

was deduced by the author from the computed and shipping weights of mill building trusses. The trusses were riveted Fink trusses with purlins placed at panel points, and were made up of angles with connecting plates; minimum size of angles $2^{\prime \prime} \times 2^{\prime \prime} \times 1 / 4^{\prime \prime}$, minimum thickness of plates $1 / 4 "$.

The trusses whose weights were used in deducing this formula had a pitch of $1 / 4$ ( $\left(6^{\prime \prime}\right.$ in $\left.12^{\prime \prime}\right)$, but the formula gives quite accurate results for trusses having a pitch, of $1 / 6$ to $1 / 3$. The trusses were designed for a tensile stress of $15000 \mathrm{lbs}$. per square inch and a compressive stress of $15000-55 \frac{l}{r}$ bs. per square inch, where $l=$ length and $r=$ the radius of gyration of the member, both in inches.

The weight of steel roof trusses for a capacity, $P$, of $40 \mathrm{lbs}$. per square foot for different spacings is given in Fig. 2. The weights of trusses for other capacities can be obtained by multiplying the tabular values by the ratio of the capacities.

Dividing (I) by $A L$ we have the weight of roof truss, $W_{\mathrm{s}}$, per square foot of horizontal projection of the roof

$$
W_{s}=\frac{P}{45}\left(1+\frac{L}{5 \sqrt{ } A}\right)
$$




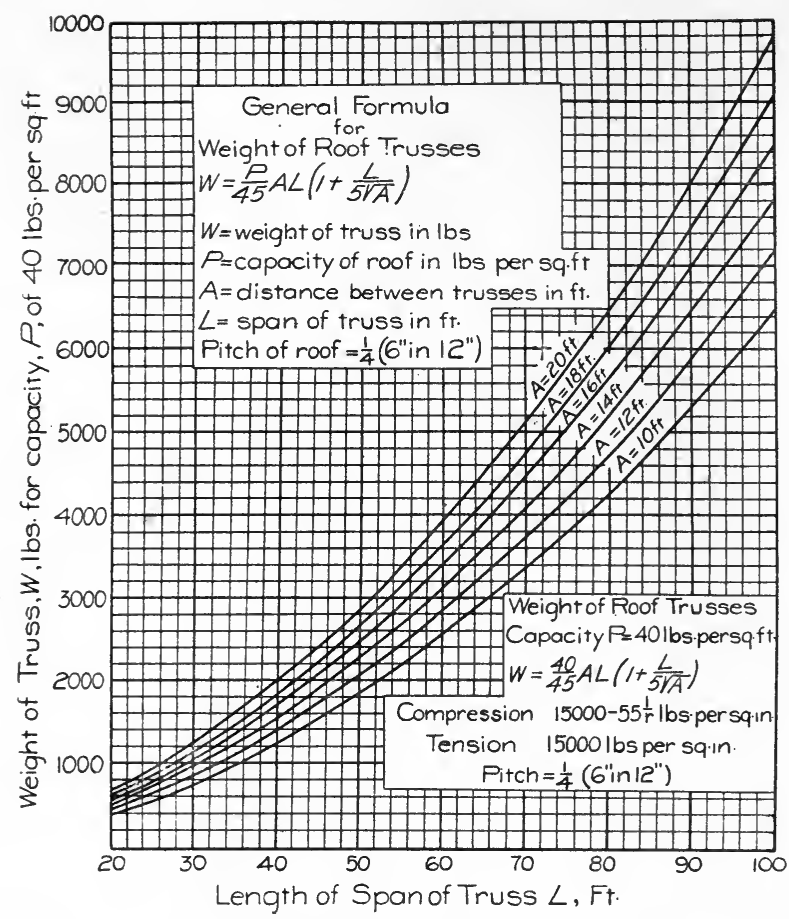

Fig. 2. WFight OF ROOF TRUSSES FOR A CAPACITY OF 40 LBS. PER SQUARE, FOOT.

The weight of steel roof trusses per square foot of horizontal projection of roof for a capacity, $P$, of $40 \mathrm{lbs}$. per square foot is given in Fig 3.

It should be noted that $W_{\mathrm{s}}$ is the dead load per square foot carried by an interior truss. The actual weight of trusses per square foot of horizontal projection for a building with $n$ panels will be $W_{\mathrm{s}} \frac{(n-1)}{n}$ where end post bent (a), Fig. I, is used, and $W_{\mathrm{s}} \frac{(n+1)}{n}$ where end truss bent (b), Fig. I, is used, assuming that all trusses are made alike.

Weight of Light Trusses.-Formula ( I) gives the weight of mill building trusses and will usually cover the weight of knee braces and ventilator framing. By reducing the minimum thickness of metal and 


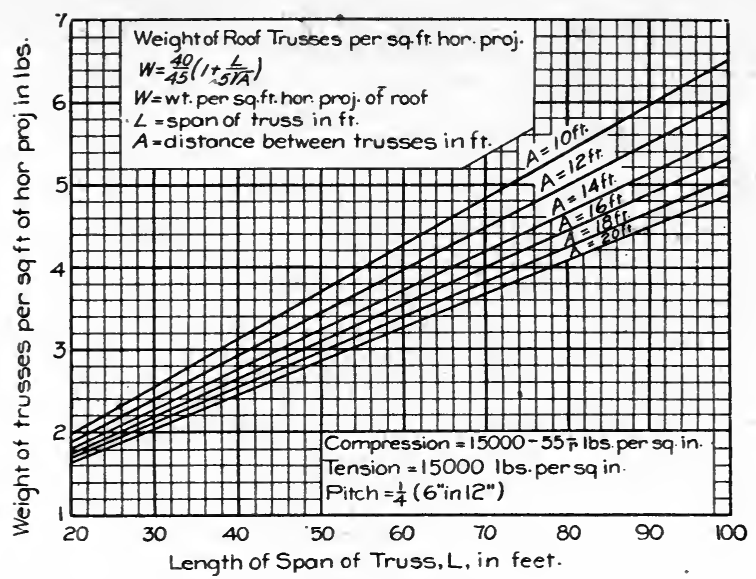

Fig. 3. WEIGHT OF ROOF TRUSSES PER SQUARE FOOT OF HORIZONTAL, PROJECTION FOR A CAPACITY OF 40 LBS. PER SQUARE FOOT.

by skinning the sections it is possible to materially reduce the weights. Weight of Simple Roof Trusses.-Simple roof trusses supported

\section{TABLE, I.}

WEIGHT OF FINK TRUSSES, SUPPORTED ON MASONRY WALLS, DESIGNED FOR A VERTICAL LOAD OF 40 POUNDS PER SQUARE FOOT OF HORIZONTAL, PROJECTION OF ROOF.

\begin{tabular}{|c|c|c|c|c|c|}
\hline $\begin{array}{l}\text { Span, L, } \\
\text { in Feet }\end{array}$ & $\begin{array}{c}\text { Distance } \\
\text { between } \\
\text { Trusses, A. } \\
\text { in Feet }\end{array}$ & $\begin{array}{l}\text { Weight of } \\
\text { Truss, w, } \\
\text { in Pounds }\end{array}$ & $\underset{\text { in Feet }}{\text { Span, L, }}$ & $\begin{array}{c}\text { Distance } \\
\text { between } \\
\text { Trusses, A, } \\
\text { in Feet }\end{array}$ & $\begin{array}{l}\text { Weight of } \\
\text { Truss, W. } \\
\text { in Pounds }\end{array}$ \\
\hline 30 & 16 & 741 & 65 & 20 & 3226 \\
\hline 30 & 14 & 621 & 70 & 20 & 3951 \\
\hline 35 & 16 & 910 & 75 & 20 & 4564 \\
\hline 40 & 16 & 1211 & 75 & 14 & 3200 \\
\hline 40 & 14 & 976 & 80 & 20 & 5160 \\
\hline 45 & 16 & 1423 & 85 & 25 & 6730 \\
\hline 50 & 16 & 1865 & 85 & 14 & 4000 \\
\hline 50 & 14 & 1550 & 90 & 25 & 8010 \\
\hline 55 & 16 & 2103 & 95 & 25 & 8600 \\
\hline 60 & 20 & 2870 & 100 & 25 & 9392 \\
\hline 60 & 14 & 2120 & & & \\
\hline
\end{tabular}


on walls will usually weigh somewhat less than the value given by Formula ( $\mathrm{I}$ ). The computed weights of Fink roof trusses without ventilators and with purlins spaced from 4 to 8 feet are given in Table I.

These trusses were designed by two different bridge companies to serve as standards and represent minimum. weights. The trusses with a spacing of 14 feet were designed with minimum thickness of metal $3^{-1} 6^{\prime \prime}$ and minimum size of angles $2^{\prime \prime} \times 13 / 8^{\prime \prime} \times 3-16^{\prime \prime}$. In the remainder of the trusses the minimum thickness of plates was $1 / 4^{\prime \prime}$ and minimum size of angles $2^{\prime \prime} \times 2^{\prime \prime} \times 1 / 4^{\prime \prime}$. The trusses are all too light to give good service although their use in temporary structures may sometimes be allowable.

Weight of Purlins, Girts, Bracing, and Columns.-Steel purlins will weigh from $\mathrm{I} / 2$ to 4 pounds per square foot of area covered, depending upon the spacing and the capacity of the trusses and the snow load. If possible the actual weight of the purlins should be calculated. Girts and window framing will weigh from $\mathrm{I} / 4$ to 3 pounds per square foot of net surface. Bracing is quite a variable quantity. The bracing in the planes of the upper and lower chords will vary from $\mathrm{I} / 2$ to I pound per square foot of area. The side and end bracing, eave struts and columns will weigh about the same per square foot of surface as the trusses.

Weight of Cuvering.-The weight of corrugated iron or steel covering varies from $\mathrm{I} / 2$ to 3 pounds per square foot of area.

WEIGHT OF FLAT AND CORRUGATED STEEL SHEETS WITH $2 \frac{1}{2} \quad$ INCH CORRUGATIONS.

\begin{tabular}{|c|c|c|c|c|c|}
\hline \multirow{2}{*}{ Gage No. } & \multirow{2}{*}{$\begin{array}{c}\text { Thickness } \\
\text { in } \\
\text { inches }\end{array}$} & \multicolumn{2}{|c|}{ Weight } & per & Square ( 100 sq.ft.) \\
\cline { 3 - 6 } & \multicolumn{2}{|c|}{ Flat. Sheets } & Corrugated Sheets \\
\cline { 3 - 6 } & Black & Galvanized & Black Painted & Galvanized \\
\hline 16 & .0625 & 250 & 266 & 275 & 291 \\
18 & .0500 & 200 & 216 & 220 & 236 \\
20 & .0375 & 150 & 166 & 165 & 182 \\
22 & .0313 & 125 & 141 & 138 & 154 \\
24 & .0250 & 100 & 116 & 111 & 127 \\
26 & .0188 & 75 & 91 & 84 & 99 \\
28 & .0156 & 63 & 79 & 69 & 86 \\
\hline
\end{tabular}


In estimating the weight of corrugated steel allow about 25 per cent for laps where two corrugations side lap and 6 inches end lap are required, and about 15 per cent for laps where one corrugation side lap and 4 inches end lap are required. Nos. 20 and 22 corrugated steel are commonly used on the roof and Nos. 22 and 24 on the sides.

Weight of Roof Covering.-The approximate weight per square foot of various roof coverings is given in the following table:

Corrugated iron, without sheathing....... I to $3 \mathrm{lbs}$.

Felt and asphalt, without sheathing...... 2 "

Felt and gravel, without sheathing....... 8 to Io "

Slate, $3-16^{\prime \prime}$ to $1 / 4^{\prime \prime}$, without sheathing....7 7 to 9 "

Tin, without sheathing $\ldots \ldots \ldots \ldots \ldots$ I to $11 / 2$ "

Skylight glass, $3-16^{\prime \prime}$ to $1 / 2$ ", including frames 4 to Io "

White pine sheathing $\mathrm{I}^{\prime \prime}$ thick $\ldots \ldots \ldots \ldots$.

Yellow pine sheathing $I^{\prime \prime}$ thick......... 4 "

Tiles, flat $\ldots \ldots \ldots \ldots \ldots \ldots \ldots \ldots \ldots$ I5 to 20 "

Tiles, corrugated $\ldots \ldots \ldots \ldots \ldots \ldots \ldots .6$ to го

Tiles, on concrete slabs............. 30 to 35

Plastered ceiling .............. ro

For additional data on weight of roof coverings, see Chapter XIX. The actual weight of roof coverings should be calculated if possible.

Weight of the Structure.-The weight of the roof can now be fcund. The weight of the steel in the sides and ends is approximately the same per square foot as the steel work in the roof.

A very close approximation to the weight of the steel in the entire structure where no sheathing is used and the same weight of corrugated iron is used on sides as on roof, may be found as follows: Take the sum of the horizontal projection of the roof and the net surface of the sides and ends, after subtracting one-half of the area of the windows, wooden doors and clear openings; multiply the sum of these areas by the weight per square foot of the horizontal projection of the roof, and the product will be the approximate weight of the steel in the structure. 


\section{CHAPTER II.}

\section{SNOW LOADS.}

The annual snowfall in different localities is a function of the humidity and the latitude and is quite a variable quantity. The amount of snow on the ground at one time is still more variable. In the Lake Superior region very little of the snow melts as it falls, and almost the entire annual snowfall is frequently on the ground at one time; while on the other hand in the same latitude in the Rocky Mountains the dry winds evaporate the snow in even the coldest weather and a less proportion accumulates. In latitudes of 35 to 45 degrees the heavy snowfalls are often followed by a sleeting rain, and the snow and ice load on roofs sometimes nearly equals the weight of the annual snowfall.

From the records of the snowfall for the past ten years as given in the reports of the U. S. Weather Burean and data obtained by personal experience, in British Columbia, Montana, the Lake Superior region and central Illinois the author presents the values given in Fig. 4 for snow loads for roofs of different inclinations in different latitudes. For the Pacific coast and localities with low humidity, take one-half of the values given. The weight of newly fallen snow was taken at 5 lbs. and packed snow at 12 lbs. per cubic foot.

A high wind may follow a heavy sleet and in designing the trusses the author would recommend the use of a minimum snow and ice load as given in Fig. 4 for all slopes of roofs. The maximum stresses due to the sum of this snow load, the dead and wind loads; the dead and the wind loads; or of the maximum snow load and the dead load being used in designing the members. 


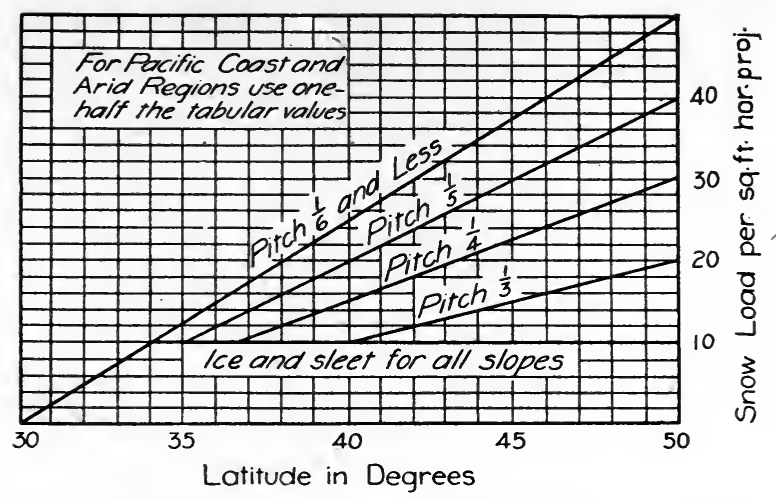

Fig. 4. SNOW LOAD ON ROOFS FOR DIFFERENT LATITUDES, IN LBS. PER SQUARE FOOT.

Snow loads per square foot of horizontal projection of roof are specified in various localities as follows: Chicago and New York, 20 lbs.; Cincinnati and St. Louis, ıo lbs.; New England, 30 lbs. The Baltimore and Ohio Railroad specifies $20 \mathrm{lbs}$. per square foot of horizontal projection of roof. 


\section{CHAPTER III.}

\section{Wind LOADS.}

Wind Pressure.-The wind pressure $(P)$ in pounds per square foot on a flat surface normal to the direction of the wind for any given velocity $(V)$ in miles per hour is given quite accurately by the formula

$$
P=0.004 V^{2}
$$

The following table gives the pressure per square foot on a flat surface normal to the direction of the wind for different velocities as calculated by formula (3).

Vel. in miles Pressure, 1bs. per

per hour. square foot.

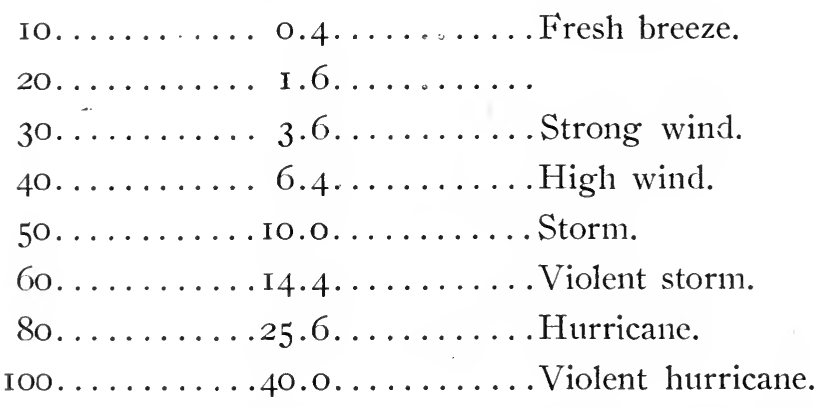

The pressure on other than flat surfaces may be taken in per cents of that given by formula (3) as follows: 80 per cent on a rectangular building; 6o per cent on the convex side of cylinders; II 5 to I30 per 
cent on the concave side of cylinders, channels and flat cups; and I 30 to 1 7o per cent on the concave sides of spheres and deep cups.

The pressure on tne vertical sides of buildings is usually taken at $3 \mathrm{C}$ pounds per square foot, equivalent to $P$ equals $37^{1 / 2}$ pounds in formula (3). This would give a velocity of 96 miles per hour, which would seem to be sufficient for all except the most exposed positions. The velocity of the wind in the St. Louis tornado was about 120 miles per hour. The records of the U. S. Weather Bureau for the last ten years show only one instance where the velocity of the wind as recorded by the anemometer was more than 90 miles per hour. The actual pressure of wind gusts has been found to be about 60 per cent and the actual steady wind pressure only about 36 per cent of that registered by ordinary small anemometers, which further reduces the intensity of the observed pressures. The wind pressure has been found to increase as the distance above the ground increases.

Recent German specifications for design of tall chimneys specify wind loads per square foot as follows: 26 pounds on rectangular chimneys ; 67 per cent of 26 pounds on circular chimneys; and 71 per cent of 26 pounds on octagonal chimneys.

The building laws of New York, Boston and Chicago require that steel buildings be designed for a horizontal wind pressure of 30 pounds per square foot. The Baltimore and Ohio Raiiroad specifies a horizontal wind pressure of 30 pounds per square foot.

From the above discussion it would seem that 30 pounds per square fcot on the sides and the normal component of a horizontal pressure of $3^{0}$ pounds on the roof would be sufficient for all except exposed locations. If the building is somewhat protected a horizontal pressure of 20 pounds per square foot on the sides is certainly ample for heights less than, say, 30 feet.

Wind Pressure on Inclined Surfaces.-The wind is usually taken as acting horizontally and the normal component on inclined surfaces is calculated. 
The normal component of the wind pressure on inclined surfaces has usually been computed by Hutton's empirical formula

$$
P_{n}=P \sin A \quad 1.842 \cos A-1
$$

where $P_{n}$ equals the normal component of the wind fressure, $P$ equals the pressure per square foot on a vertical surface, and $A$ equals the angle of inclination of the surface with the horizontal, Fig. (5).

The formula due to Duchemin

$$
P_{n}=P \frac{2 \sin A}{1+\sin ^{2} A}
$$

where $P_{n}, P$ and $A$ are the same as in (4), gives results considerably larger for crdinary roofs than Hutton's formula, and is coming into quite general use.

The formula

$$
P_{n}=\frac{P}{45} A
$$

where $P_{n}$ and $P$ are the same as in (4) and (5), and $A$ is the angle of inclination of the surface in degrees ( $A$ being equal to or less than $\left.45^{\circ}\right)$, gives results which agree very closely with Hutton's formula, and is much more simple.

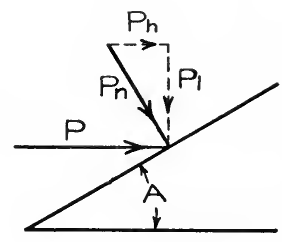

FIG. 5 .

Hutton's formula (4) is based on experiments which were very crude and probably erroneous. Duchemin's formula (5) is based on very careful experiments and is now considered the most reliable formula in use. The Straight Line formula (6) agrees with experiments quite closely and is preferred by many engineers on account of its simplicity.

The values of $P_{n}$ as determined by Hutton's, Duchemin's and the 
Straight Line formulas are given in Fig. 6, for $P$ equals 20,30 and 40 pounds.

It is interesting to note that Duchemin's formula with $P$ equals 30 pounds gives practically the same values for roofs of ordinary inclination as is given by Hutton's and the Straight Line formulas with $P$ equals 40 pounds.

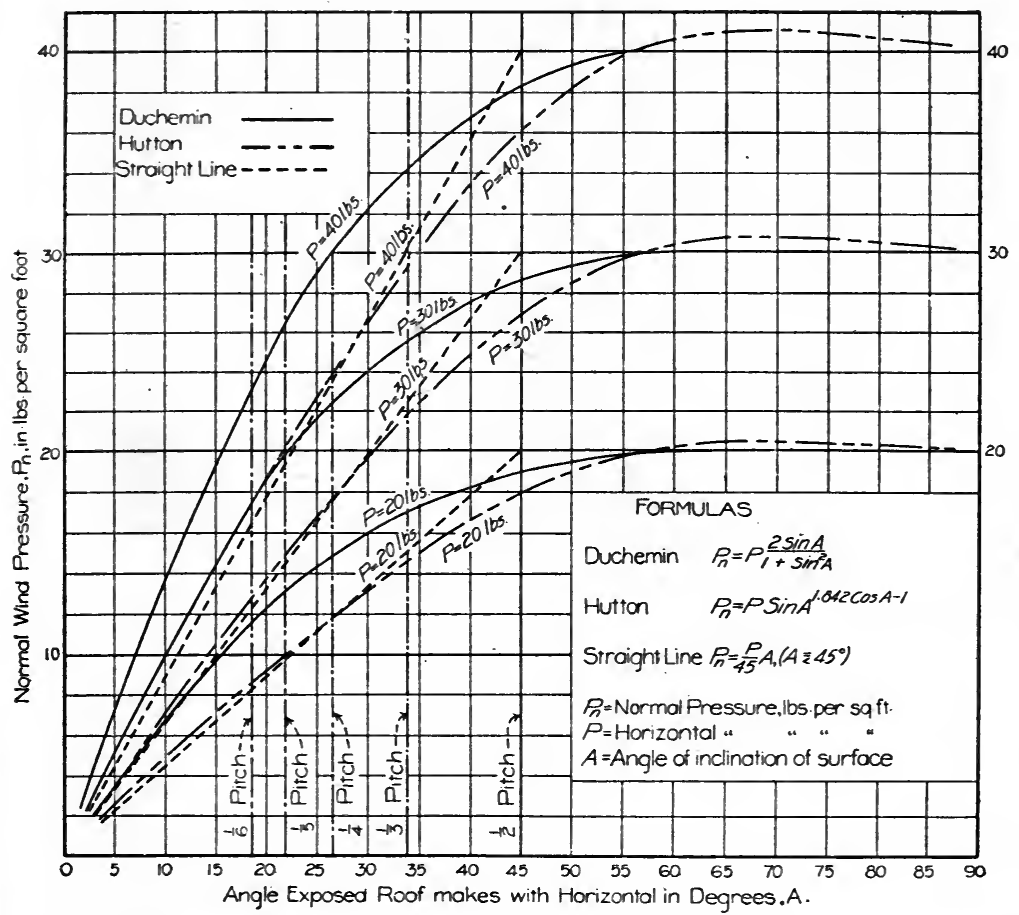

FIG. 6. NORMAL WIND LOAD ON ROOF ACCORDING TO DIFFERENT FORMULAS.

Duchemin has also deduced the formula

$$
P_{h}=P \frac{2 \sin ^{2} A}{1+\sin ^{2} A}
$$

where $P_{h}$ in $(7)$ equals the pressure parallel to the direction of the wind, Fig. 5: and

$$
P_{l}=F \frac{2 \sin A \cos A}{1+\sin ^{2} A}
$$


where $P_{l}$ in (8) equals the pressure at right angles to the direction of the wind, Fig. 5. $P_{l}$ may be an uplifting, a depressing or a side pressure. With an open shed in exposed positions the uplifting effect of the wind often requires attention. In that case the wind should be taken normal to the inner surface of the building on the leeward side, and the uplifting force determined by using formula (8). If the gables are closed a deep cup is formed, and the normal pressure should be increased 30 to 70 per cent.

That the uplifting force of the wind is often considerable in exposed localities is made evident by the fact that highway bridges are occasionally wrecked by the wind. The most interesting example known to the author is that of a Ioo-foot span combination bridge in Northwestern Montana which was picked up bodily by the wind, turned about go degrees in azimuth and dropped into the middle of the river. The end bolsters were torn loose although drift-bolted to the abutments.

The wind pressure is not a steady pressure, but varies in intensity, thus producing excessive vibrations which cause the structure to rock if the bracing is not rigid. The bracing in mill buildings should be designed for initial tension, so that the building will be rigid. Rigidity is of more importance than strength in mill buildings.

For further information on this subject see a very elaborate and valuable monograph on "Wind Pressures in Engineering Construction," by Capt. W. H. Bixby, M. Am. Soc. C. E., published in Engineering News, Vol. XXXIII., pp. I75-I84, March, I895. 


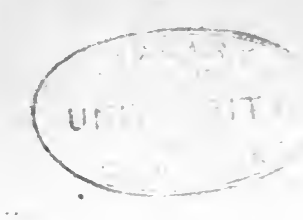

\section{CHAPTER IV.}

Miscellaneous Loads.

LIVE LOADS ON FLOORS.-Live loads on floors for mill buildings are very hard to classify and should be calculated for each case.

Floor loads as specified in the building laws of various cities are given in Table II, and the engineer should govern himself accordingly.

TABLE II.

FloOR LOADS IN POUNDS PER SQUARE FoOt AS SPECIFIEd IN VARIOUS CITIES.

\begin{tabular}{|c|c|c|c|c|}
\hline s & New York & Chicago & Philadelphia & Boston \\
\hline Dwellings...... . & $\left\{\begin{array}{lr}\text { Upper floors } 75 \\
1 \text { st floor } \quad 150\end{array}\right.$ & 100 & 100 & 100 \\
\hline $\begin{array}{l}\text { Public Buildings.. } \\
\text { Light Manufac- }\end{array}$ & 90 & 100 & 120 & 150 \\
\hline 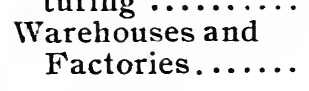 & 150 and up & 100 & 150 and up & 250 and up \\
\hline Sidewalks ........ & 300 & & ............. & $\ldots \ldots \ldots \ldots$ \\
\hline
\end{tabular}

Without reference to building laws the live loads per square foot, exclusive of weight of floor materials, given below are about standard practice.

Dwellings $\ldots \ldots \ldots \ldots$. 7 o lbs. per sq. ft.

Offices $\ldots \ldots \ldots \ldots \ldots$, 70 to $100 \mathrm{lbs}$. per sq. ft.

Assembly halls ........ I20 to I5o lbs. per sq. $\mathrm{ft}$.

Warehouses ........250 and up, lbs. per sq. ft.

Factories ...........200 to 450 lbs. per sq. ft. 
The weight of floors above ground in mill buildings varies so much that it is useless to give weights. For a few data on weights of floors see Chapter on Floors.

WEIGHT OF HAND CRANES.-The approximate weight of a few of the common sizes of hand cranes made by Pawling and HarTABLE III.

WEIGHT OF TRAVELING HAND CRANES.

\begin{tabular}{c|c|c|c|c|c}
\hline \hline $\begin{array}{c}\text { Capacity of } \\
\text { Crane in } \\
\text { Tons }\end{array}$ & $\begin{array}{c}\text { Distance } \\
\text { c to c of } \\
\text { end wheels }\end{array}$ & $\begin{array}{c}\text { 20-FÓT SPAN } \\
\begin{array}{c}\text { Weight of } \\
\text { Crane } \\
\text { 1bs. }\end{array}\end{array}$ & $\begin{array}{c}\text { Maximum Load } \\
\text { on each Wheel } \\
\text { lbs }\end{array}$ & $\begin{array}{c}\text { 30 FOOT SPAN } \\
\text { Weight of } \\
\text { Crane } \\
\text { lbs. }\end{array}$ & $\begin{array}{c}\text { Maximum Load } \\
\text { on each Wheel } \\
\text { lbs. }\end{array}$ \\
\hline 3 & $3^{\prime}-0^{\prime \prime}$ & 4500 & 4500 & 5000 & 5000 \\
5 & $3^{\prime}-0^{\prime \prime}$ & 5500 & 7000 & 6000 & 7500 \\
$71 / 2$ & $3^{\prime}-8^{\prime \prime}$ & 8000 & 10500 & 9000 & 11500 \\
10 & $8^{\prime}-0^{\prime \prime}$ & 15000 & 18000 & 17000 & 20000 \\
15 & $8^{\prime}-0^{\prime \prime}$ & 16000 & 20000 & 18000 & 21000 \\
20 & $8^{\prime}-6^{\prime \prime}$ & 20000 & 26000 & 22000 & 27000 \\
\hline
\end{tabular}

nischfeger, Milwatkee, Wis., and the maximum load on each wheel when the loaded trolley is at one end is given in Table III.

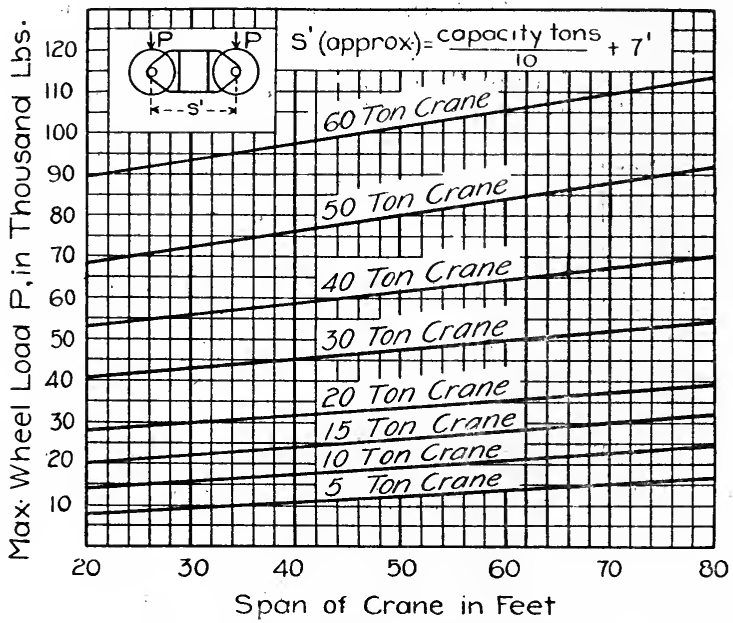

Fig. 7 .

WEIGHT OF ELECTRIC CRANES.-The maximum load on each of the end wheels for common sizes. of electric cranes made by 
Pawling and Harnischfeger is given in Fig. 7. Cranes made by different manufacturers differ considerably in weight.

WEIGHTS OF MISCELLANEOUS MATERIAL.-The weights of various kinds of merchandise are given in Table IV. For weights of other materials consult steel makers hand books.

TABLE IV.

WEIGHTS OF MERCHANDISE.*

\begin{tabular}{|c|c|c|c|}
\hline Commodity & $\begin{array}{l}\text { Weight in lbs. } \\
\text { percubic foot }\end{array}$ & Commodity & $\begin{array}{l}\text { Weight in lbs. } \\
\text { per cubic foot }\end{array}$ \\
\hline Wool in Bales........ & 5 to 28 & Caustic Soda......... & 88 \\
\hline IVoolen Goods ....... & 13 to 22 & Barrel Starch...... & 23 \\
\hline Baled Cotton ........ & 12 to 43 & Barrel Lime . . . . . & 50 \\
\hline Cotton Goods......... & 11 to 37 & “ Cement..... & 73 \\
\hline Rags in Bales........ & 7 to 36 & Plaster...... & 53 \\
\hline 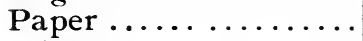 & 10 to 69 & .. Lard Oil ... & 34 \\
\hline Wheat $\ldots \ldots \ldots \ldots$ & 39 to 44 & Rope ........ & 42 \\
\hline Corn.......... & 31 & Box Tin ........ & 278 \\
\hline Oats $\ldots \ldots \ldots \ldots \ldots$ & 27 & Box Glass ........ & 60 \\
\hline Baled Hay and Straw. & 14 to 19 & Crate Crockery..... & .40 \\
\hline Bleaching Powder.... & 31 & Bale Leather........ & 16 to 23 \\
\hline Soda Ash . . . . . . . . & 62 & 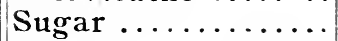 & 45 \\
\hline Box Indigo.......... & 43 & 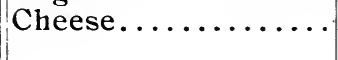 & 30 \\
\hline
\end{tabular}

*From Report V. Insurance Engineering Experiment Station. Edward Atkinson, Director, Boston, Mass. 


\title{
PART II.
}

\author{
STRESSES.
}

\section{CHAPTER V.}

Graphic Statics.

Equilibrium.-Statics considers forces as at rest and therefore in equilibrium. To have static equilibrium in any system of forces there must be neither translation nor rotation and the following conditions must be fulfilled for coplanar forces (forces in one plane).

$$
\begin{aligned}
& \Sigma \text { horizontal components of forces }=0 \\
& \Sigma \text { vertical components of forces }=0 \\
& \Sigma \text { moments of forces about any point }=0
\end{aligned}
$$

Representation of Forces.-A force is determined when its magnitude, line of action, and direction are known, and it may be represented graphically in magnitude by the length of a line, in line of action by the position of the line, and in direction by an arrow placed on the line, poinfing in the direction in which the force acts. A force may be considered as applied at any point in its line of action.

Force Triangle. - The resultant, $R$, of the two forces $P_{1}$ and $P_{2}$ meeting at the point $a$ in Fig. 8 is represented in magnitude and direction by the diagonal, $R$, of the parallelogram $a b c d$. The combining of the two forces $P_{1}$ and $P_{2}$ into the force $R$ is termed composition of forces. The reverse process is called resolution of forces. 


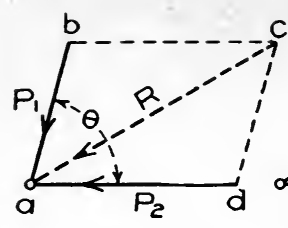

(a)

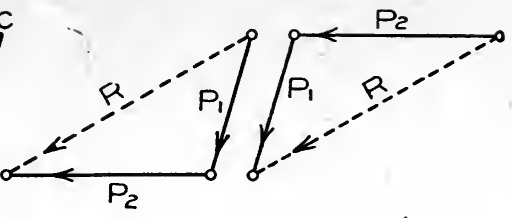

(b)

(c)

FIG. 8.

The value of $R$ may also be found from the equation

$$
R^{2}=P_{1}^{2}+P_{2}^{2}+2 P_{1} P_{2} \cos \theta
$$

It is not necessary to construct the entire force parallelogram as in (a) Fig. 8, the force triangle (b) below or (c) above the resultant $R$ being sufficient.

If only one force together with the line of action of the two others be given in a system containing three forces in equilibrium, the magnitude and direction of the two forces may be found by means of the force triangle.

If the resultant $R$ in Fig. 8 is replaced by a force $E$ equal in amount but opposite in direction, the system of forces will be in equilibrium, (a) or (b) Fig. 9. The force $E$ is the equilibrant of the system of forces $P_{1}$ and $P_{2}$.

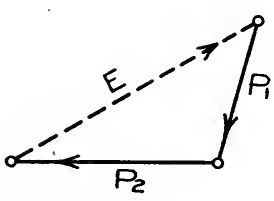

(a)

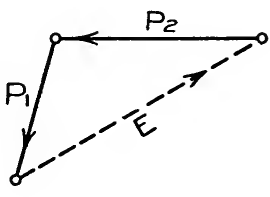

(b)

FIG. 9.

It is immaterial in what order the forces are taken in constructing the force triangle, as in Fig. 9, as long as the forces all act in the same direction around the triangle. The force triangle is the foundation of the science of graphic statics. 
Force Polygon.-If more than three concurrent forces (forces which meet in a point) are in equilibrium as in (a) Fig. Io, $R_{1}$ in (b) will be the resultant of $P_{1}$ and $P_{2}, R_{2}$ will be the resultant of $R_{1}$ and $P_{3}$,

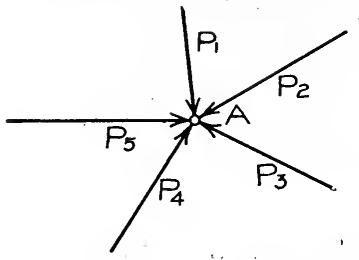

(a)

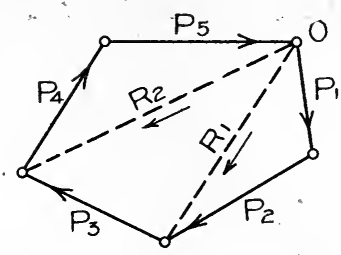

(b)

FIG. IO.

and will also be the equilibrant of $P_{4}$ and $P_{5}$. The force polygon in (b) is therefore only a combination of force triangles. The force polygon for any system of forces may be constructed as follows:-Beginning at any point draw in succession lines representing in magnitude and direction the given forces, each line beginning where the preceding one ends. If the polygon closes the system of forces is in equilibrium, if not the line joining the first and last points represents the resultant in magnitude and direction. As in the case of the force triangle, it is immaterial in what order the forces are applied as long as they all act in the same direction around the polygon. A force polygon is analogous to a traverse of a field in which the bearings and the distances are measured progressively around the field in either direction. The conditions for closure in the two cases are also identical.

It will be seen that any side in the-force polygon is the equilibrant of all the other sides and that any side reversed in direction is the resultant of all the other sides.

Equilibrium of Concurrent Forces.-The necessary condition for equilbrium of concurrent coplanar. forces therefore is that the force polygon close. This is equivalent to the algebraic condition that $\Sigma$ horizontal components of forces $=0$, and $\Sigma$ vertica! components of forces $=0$. If the system of concurrent forces is not in equilibrium the resultant can be found in magnitude and direction by completing 
the force polygon. The resultant of a system of concurrent forces is always a single force acting through their point of intersection:

Equilibrium of Non-concurrent Forces.-If the forces are non-concurrent (do not all meet in a common point), the condition that the force polygon close is a necessary, but not a sufficient condition for equilibrium. For example, take the three equal forces $P_{1}, P_{2}$ and $P_{3}$, making an angle of $120^{\circ}$ with each other as in (a) Fig. II.

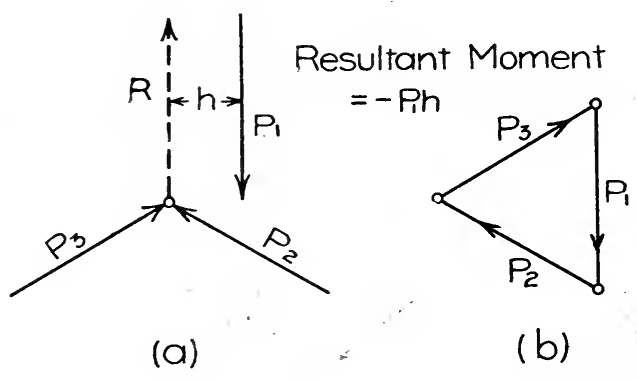

(a)

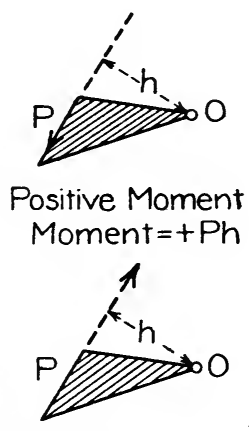

Negative Moment Moment $=-\mathrm{Ph}$

(C)

FIG. II.

The force polygon' (b) closes, but the system is not in equilibrium. The resultant, $R$, of $P_{2}$ and $P_{3}$ acts through their intersection and is parallel to $P_{1}$, but is opposite in direction. The system of forces is in equilibrium for translation, but is not in equilibrium for rotation.

The resultant of this system is a couple with a moment $=-P_{1} h$, moments clockwise being considered negative and counter clockwise positive, (c) Fig. II. The equilibrant of the system in (a) Fig. II is a couple with a moment $=+P_{1} h$.

A couplc.-A couple consists of two parallel forces equal in amount, but opposite in direction. The arm of the couple is the perpendicular distance between the forces. The moment of a couple is equal to one of the forces multiplied by the arm. The moment of a couple is constant about any point in the plane and may be represented 
graphically by twice the area of the triangle having one of the forces as a base and the arm of the couple as an altitude. The moment of a force about any point may be represented graphically by twice the area of a triangle as shown in (c) Fig. II.

It will be seen from the preceding discussion that in order that a system of non-concurrent forces be in equilibrium it is necessary that the resultant of all the forces save one shall coincide with the one and be opposite in direction. Three non-concurrent forces can not be in equilibrium unless they are parallel. The resultant of a system of nonconcurrent forces may be a single force or a couple.

Equilibrium Polygon.-First Method.-In Fig. I2 the resultant, $a$, of $P_{1}$ and $P_{2}$ acts through their intersection and is equal and parallel to $a$ in the force polygon (a) ; the resultant, $b$, of $a$ and $P_{3}$ acts through

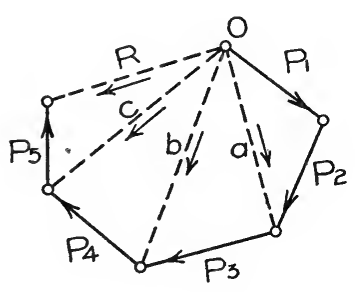

(a)

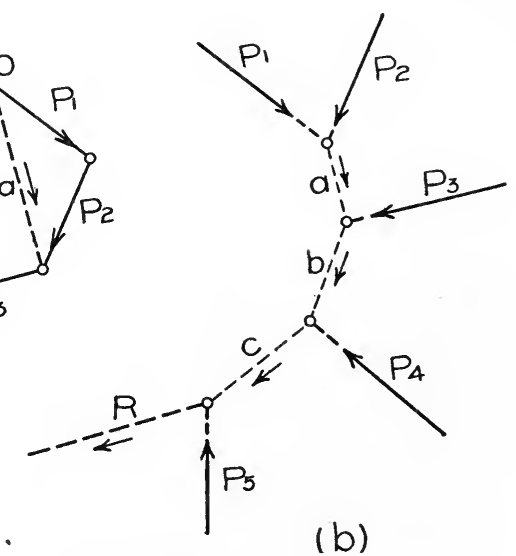

FIG. I2.

(b)

their intersection and is equal and parallel to $b$ in the force polygon; the resultant, $c$, of $b$ and $P_{4}$ acts through their intersection and is equal and parallel to $c$ in the force polygon; and finally the resultant, $R$, of $c$ and $P_{5}$ acts through their intersection and is equal and parallel to $R$ in the force polygon. $R$ is therefore the resultant of the entire system of forces. If $R$ is replaced by an equal and opposite force, $E$, the system of forces will be in equilibrium. Polygon (a) in Fig. I2 is called 
a force polygon and (b) is called a funicular or an equilibrium polygon. It will be seen that the magnitude and direction of the resultant of a system of forces is given by the closing line of the force polygon, and the line of action is given by the equilibrium polygon.

The force polygon in (a) Fig. I 3 closes and the resultant, $R$, of

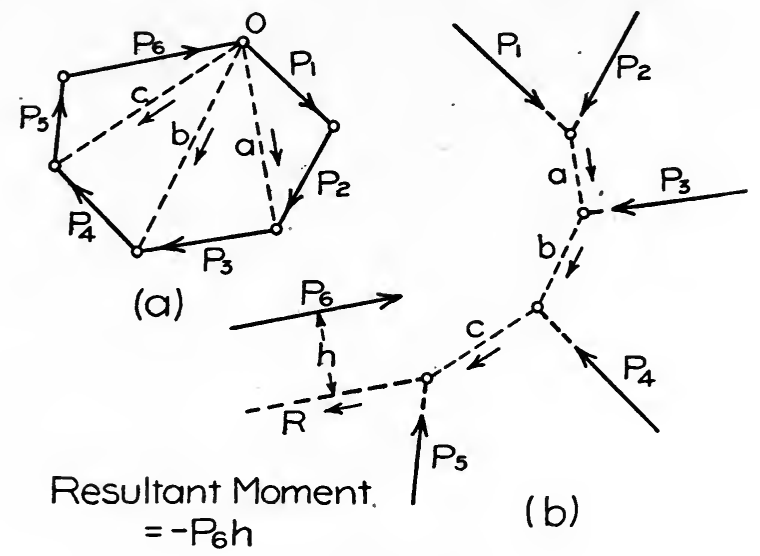

FIG. I3.

the forces $P_{1}, P_{2}, P_{3}, P_{4}, P_{5}$ is parallel and equal to $P_{6}$, and is opposite in direction. The system is in equilibrium for translation, but is not in equilibrium for rotation. The resultant is a couple with a moment $=-P_{6} h$. The equilibrant of the system of forces will be a couple with a moment $=+P_{6} h$. From the preceding discussion it will be seen that if the force polygon for any system of non-concurrent forces closes the resultant will be a couple. If there is perfect equilibrium the arm of the couple will be zero.

Second Method.-Where the forces do not intersect within the limits of the drawing board, or where the forces are parallel, it is not possible to draw the equilibrium polygon as shown in Fig. 12 and Fig. r 3 , and the following method is used.

The point $o$, (a) Fig. 14, which is called the pole of the force polygon, is selected so that the strings $a o, b o, c o, d o$ and $e o$ in the equilibrium polygon (b), which are drawn parallel to the corresponding 
rays in the force polygon (a), will make good intersections with the forces which they replace or equilibrate.

In the force polygon (a), $P_{1}$ is equilibrated by the imaginary forces represented by the rays $o a$ and $b o$ acting as indicated by the arrows within the triangle; $P_{2}$ is equilibrated by the imaginary forces repre-

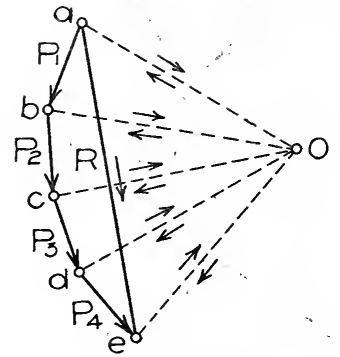

(a)

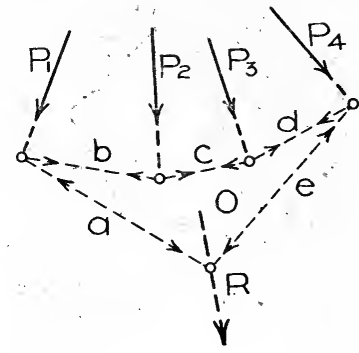

(b)

"FIG. I4.

sented by the rays $o b$ and $c o$ acting as indicated by the arrows within the triangle; $P_{3}$ is equilibrated by the imaginary forces represented by the rays $o c$ and $d o$ acting as indicated by the arrows within the triangle; and $P_{4}$ is equilibrated by the imaginary forces $o d$ and $e o$ anting. as indicated by the arrows within the triangle. The imaginary forces are all neutraíized except $a o$ and $o c$, which are seen to be components of the resultant $R$.

To construct the equilibrium polygon, take any point on the line of action of $P_{1}$ and draw strings $o \quad a$ and $o b$ parallel to rays $o \quad a$ and $o b$, $b o$ is the equilibrant of $o a$ and $P_{1}$; through the intersection of string $o b$ and $P_{2}$ draw string $c o$ parallel to ray $c o, c o$ is the equilibrant of $o b$ and $P_{2}$; through the intersection of string $c o$ and $P_{3}$ draw string $d o$ parallel to ray $d o$; $d o$ is the equilibrant of $c o$ and $P_{3}$; and through the intersection of string $d o$ and $P_{4}$ draw string $e o$ parallel to ray $e o$, $e o$ is the equilibrant of $d o$ and $P_{4}$. Strings $o a$ and $e o$ acting as shown are components of the resultant $R$, which will be parallel to $R$ in the force polygon and acts through the intersections of strings $o \cdot a$ and $e o$. 
The imaginary forces represented by the rays in the force polygon may be considered as components of the forces and the analysis made on that assumption with equal ease.

It is immaterial in what order the forces are taken in drawing the force polygon, as long as the forces all act in the same direction around the force polygon, and the strings meeting on the lines of the forces in the equilibrium polygon are parallel to the rays drawn to the ends of the same forces in the force polygon.

The imaginary forces $a o, b o, c o, d o, e o$ are represented in magnitude and in direction by the rays of the force polygon to the same scale as the forces $P_{1}, P_{2}, P_{3}, P_{4}$. The strings of the equilibrium polygon represent the imaginary forces in line of action and direction, but not in magnitude.

Reactions of a Simple Beam.-The equilibrium polygon may be used to obtain the reactions of a beam loaded with a load $P$ as in Fig. 15 .

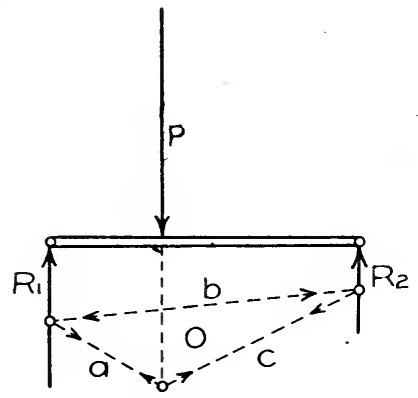

(a)

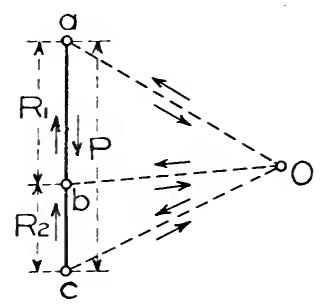

(b)

FIG. 15 .

The force polygon (b) is drawn with a pole $o$ at any convenient point and rays $o a$ and $o c$ are drawn. Now from the fundamental conditions for equilibrium for translation we have $P=R_{1}+R_{2}$. At any convenient point in the line of action of $P$ draw the strings $o a$ and $o c$ parallel to the rays $o a$ and $o c$, respectively, in the force polygon. The imaginary forces $a o$ and $o c$ acting as shown equilibrate the force $P$. 
The imaginary force $a$ acting in a reverse direction as shown is an equilibrant of $R_{1}$, and the imaginary force $c o$ acting in a reverse direction is an equilibrant of $R_{2}$. The remaining equilibrant of $R_{1}$ and of $R_{2}$ must coincide and be equal in amount, but opposite in direction. The string $b o$ is the remaining equilibrant of $R_{1}$ and of $R_{2}$ and is called the closing line of the equilibrium polygon. The ray $b o$ drawn parallel to the string $b o$ divides $P$ in two parts which are equal to the reactions $R_{1}$ and $R_{2}$ (for reactions of overhanging beam see Chapter VIII).

Reactions of a Cantilever Truss.-In the cantilever truss shown in Fig. 16 , the direction and point of application $B$ of the reaction $R_{1}$

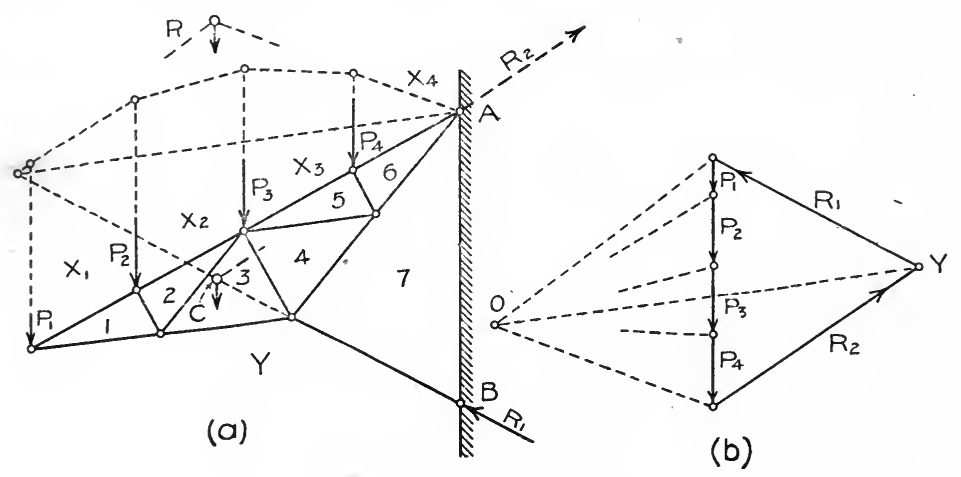

FIG. I6.

are known, while the point of application $A$ of the reaction $R_{2}$ only is known. The direction of reaction $R_{2}$ may be found by applying the principle that if a body is in equilibrium under the action of three external forces which are not parallel, they must all meet in a common point, $i$. e., the forces must be concurrent. The resultant of all the loads acts through the point $c$, which is also the point of intersection of the reactions $R_{1}$ and $R_{2}$. Having the direction of the reaction $R_{2}$, the values of the reactions may be found by means of a force polygon.

The direction of reaction $R_{2}$. may be found by means of a force and equilibrium polygon as follows: Construct the force polygon (b) with pole $o$ and draw equilibrium polygon (a) starting with point $A$, the 
only known point on the reaction $R_{2}$, and draw the polygon as previously described. A line drawn through point $o$ in the force polygon parallel to the closing line of the equilibrium polygon will meet $R_{1}$, drawn parallel to reaction $R_{1}$, in the point $y$, which is also a point on $R_{\mathbf{2}_{2}}$. The reactions $R_{1}$ and $R_{\mathbf{2}}$ are therefore completely determined in direction and amount.

The method just given is the one commonly used for finding the reactions in a truss with one end on rollers. (see Chapter VII).

Equilibrium Polygon as a Framed Structure.-In (a) Fig. I 7 the rigid triangle supports the load $P_{1}$. Construct a force polygon

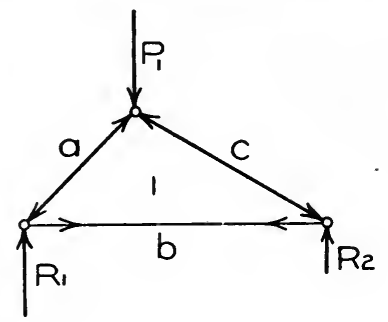

(a)

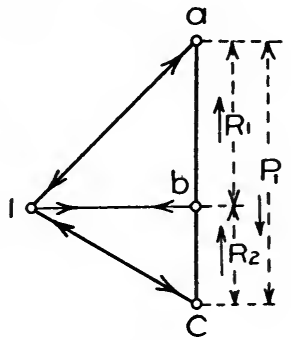

(b)

FIG. 17.

by drawing rays $a \mathrm{I}$ and $c \mathrm{I}$ in (b) parallel to sides $a \mathrm{I}$ and $c \mathrm{I}$, respectively, in (a), and through pole I draw I $b$ parallel to side $\mathrm{I} b$ in (a). The reactions $R_{1}$ and $R_{2}$ will be given by the force polygon (b), and the rays I $a$, I $c$ and I $b$ represent the stresses in the members I $a$, I $c$ and I $b$, respectively, in the triangular structure. The stresses in I $a$ and $I c$ are compression and the stress in $I b$ is tension, forces acting toward the joint indicating compression and forces acting away from the joint indicating tension. Triangle (a) is therefore an equilibrium polygon and polygon (b) is a force polygon for the force $P_{1}$.

From the preceding discussion it will be seen that the internal stresses at any point or in any section hold in equilibrium the external forces meeting at a point or on either side of the section. 
Graphic Moments.-In. Fig. I8 (b) is a force polygon and (a) is an equilibrium polygon for the system of forces $P_{1}, P_{2}, P_{3}, P_{4}$. Draw

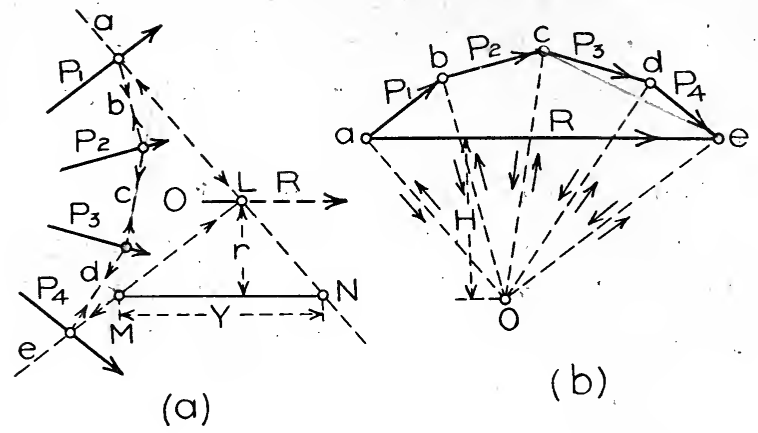

FIG. I8.

the line $M N=Y$ parallel to the resultant $R$, and with ends on strings . $o e$ and $o$ a produced. Let $r$ equal the altitude of the triangle $L M N$ and $H$ equal the altitude of the similar triangle $o e$ a. $H$ is the pole distance of the resultant $R$.

Now in the similar triangles $L M N$ and $o e a$

$$
R: Y:: H: r
$$

and

$$
R r=H Y
$$

But $R r=M=$ moment of resultant $R$ about any point in the line $M N$ and therefore

$$
M=H Y
$$

The statement of the principle just demonstrated is as follows : The moment of any system of coplanar forces about any point in the plane is equal to the intercept on a line drawn through the center of moments and parallel to the resultant of all the forces, cut off by the strings which meet on the resultant, multiplied by the pole distance of the resultant. It should be noted that in all cases the intercept is a distance and the pole distance is a force.

This property of the equilibrium polygon is frequently used in finding the bending moment in beams and trusses which are loaded with vertical loads. 
Bending Moments in a Beam.- It is required to find the moment at the point $M$ in the simple beam loaded as in (b) Fig. 19. The

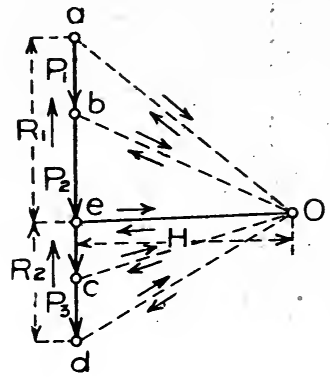

(a)

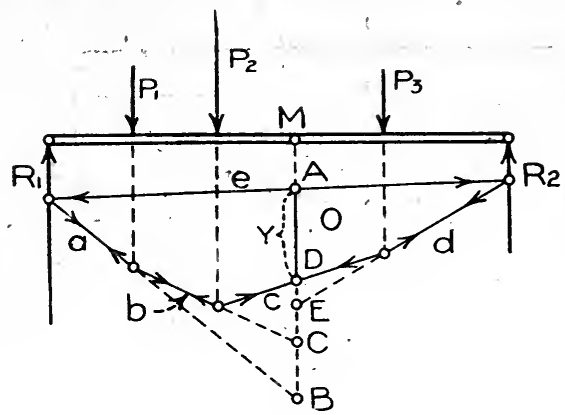

(b)

FIG. I9.

moment at $M$ will be the algebraic sum of the moments of the forces to the left of $M$. The moment of $P_{1}=H \times B C$, the moment of $P_{2}=$ $H \times C D$ and the moment of $R=-H \times B A$. The moment at $M$ will therefore be

$$
M_{1}=H \times B C+H \times C D-H \times B \dot{A}=H \times A D=-H y
$$

The moment of the forces to the right of $M$ may in like manner be shown to be

$$
M_{1}=+H y
$$

In like manner the bending moment at any point in the beam may be shown to be the ordinate of the equilibrium polygon multiplied by the pole distance. The ordinate is a distance and is measured by the same scale as the beam, while the pole distance is a force and is measured by the same scale as the loads.

To Draw an Equilibrium Polygon Through Three Points. Given a beam loaded as shown in Fig. 20, it is required to draw an equilibrium polygon through the three points $a, b, c$. Construct a force polygon (b) with pole $o$, and draw equilibrium polygon $a b^{\prime} c^{\prime}$ in (a). Point $b^{\prime}$ is determined by drawing through $b$ a line $b b^{\prime}$ parallel to $b_{1} b^{\prime \prime}$ which is the line of action of the resultants of the forces to the 

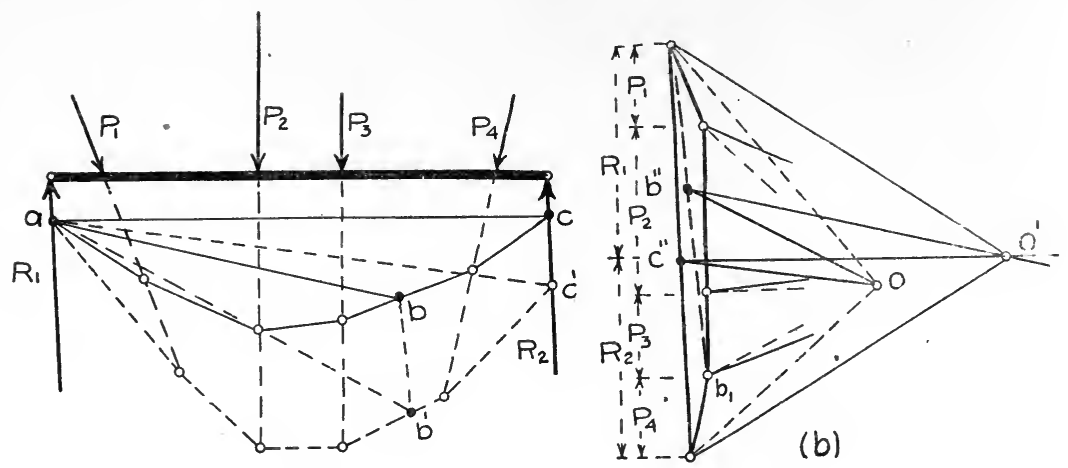

(a)

FIG. 20.

left of $b$, acting through points $b$ and $a$. Through $o$ draw $o c^{\prime \prime}$ and $o b^{\prime \prime}$ parallel to closing lines $a c^{\prime}$ and $a b^{\prime}$, respectively. Point $c^{\prime \prime}$ determines the reactions $R_{1}$ and $R_{2}$, and point $b^{\prime \prime}$ determines the reactions acting through $a$ and $b$ of the forces to the left of point $b$.

Points $c^{\prime \prime}$ and $b^{\prime \prime}$ are common to all force polygons, and lines $c^{\prime \prime} o^{\prime}$ and $b^{\prime \prime} o^{\prime}$ drawn parallel to the closing lines of the required equilibrium polygon, $a c$ and $a b$ will meet in the new pole $\jmath^{\prime}$. With pole $o^{\prime}$ the required equilibrium polygon $a b c$ can now be drawn.

Center of Gravity.- To find the center of gravity of the figure shown in (a) Fig. 2I, próceed as follows: Divide the figure into elementary figures whose centers of gravity and areas are known. Assume that the areas act as the forces $P_{1}, P_{2}, P_{3}$ through the centers of gravity of the respective figures. Bring the line of action of these forces into the plane of the paper by turning them downward as in (b) and to the right as in (c). Find the resultant of the forces for case (b) and for case (c) by means of force and equilibrium polygons. The intersection of the fesultants $R$ will be the center of gravity of the figure. The two sets of forces may be assumed to act at any angle, however, maximum accuracy is given when the forces are assumed to act at right angles. If the figure has an axis of symmetry but one force and equilibrium polygon is required. 


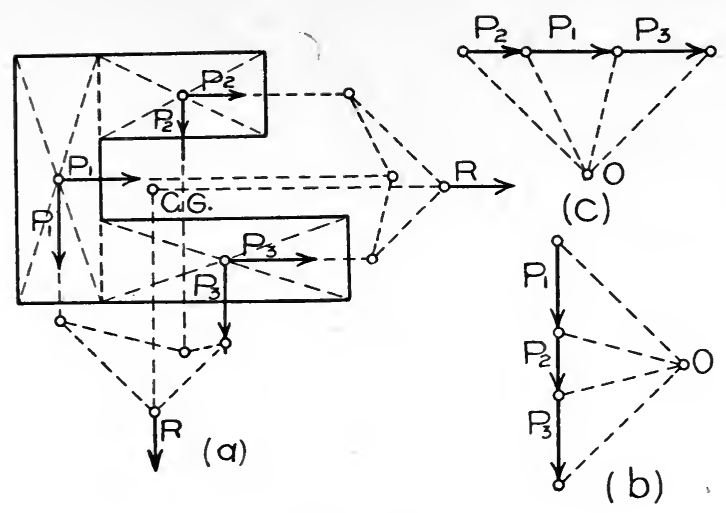

FIG. 2 I.

Moment of Inertia of Forces.-The determination of the moment of inertia of forces and areas by graphics is interesting. There are two methods in common use: (I) Culmann's method, in which the moment of inertia of forces is determined by finding the moment of the moment of forces by means of force and equilibrium polygons; and (2) Mohr's method, in which the moment of inertia of forces is determined from the area of the equilibrium polygon. The moment of inertia of a force about a parallel axis is equal to the force multiplied by the square of the distance between the force and the axis.

Culmann's Method.-It is required to find the moment of inertia, $I$, of the system of forces $P_{1}, P_{2}, P_{3}, P_{4}$, Fig. 22, about the axis $M N$. Construct the force polygon (a) with a pole distance $H$, draw the equilibrium polygon $a b c d e$, and produce the strings until they intersect the axis $M N$. Now the moment of $P_{1}$ about axis $M N$ equals $E D \times H$; moment of $P_{2}$ equals $D C \times H$; moment of $P_{3}$ equals $C B \times$ $H$; moment of $P_{4}$ equals $B A \times H$; and moment of resultant $R$ equals $E, A \times H$. With intercepts $E D, D C, C B, B A$, as forces acting in place of $P_{1}, P_{2}, P_{3}, P_{4}$, respectively, construct force polygon (b) with pole distance $H^{\prime}$, and draw equilibrium polygon (c). As before the moments of the forces will be equal to the products of the intercepts and pole distance ,and the moment of the system of forces represented by the 


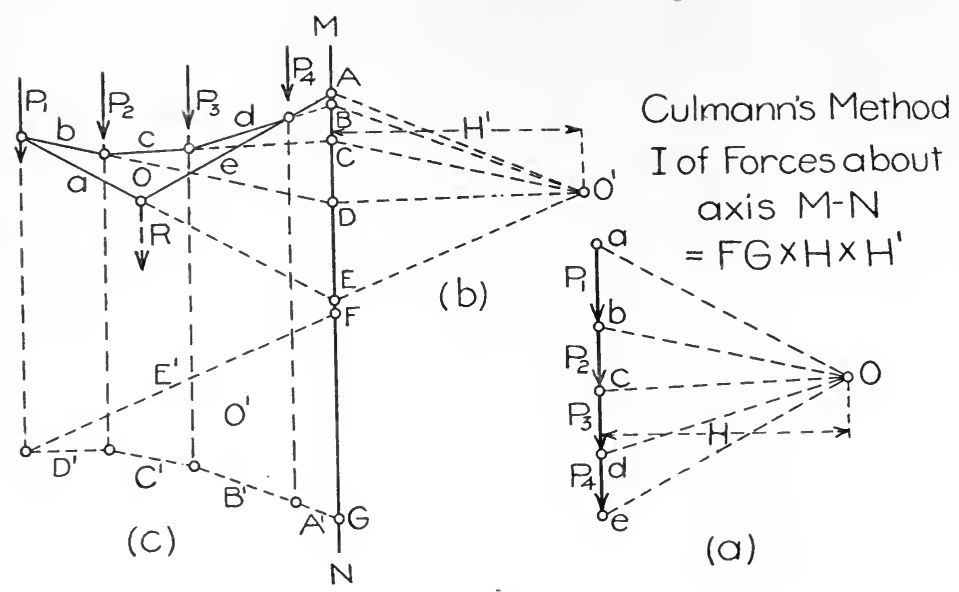

FIG. 22.

intercepts will be equal to the intercept $G F$ multiplied by pole distance $H^{\prime}$. But the intercepts $E, D, D, C B, B A$, multiplied by the pole distance $H$ equal moments of the forces $P_{1}, P_{2}, P_{3}, P_{4}$, respectively, about the axis $M N$, and the moment of inertia of the system of forces $P_{1}, P_{2}, P_{3}, P_{4}$, about the axis $M N$ will be equal to the intercept $G F$ multiplied by the product of the two pole distances $H$ and $H^{\prime}$, and

$$
I=F G \times H \times H^{\prime} \text {. }
$$

Mohr's Mcthod.-It is required to find the moment of inertia, $I$, of the system of forces $P_{1}, P_{2}, P_{3}, P_{4}$, Fig. 23, about the axis $M N$. Construct the force polygon (a) with a pole distance $H$, and drow the equilibrium polygon (b). Now the moment of $P_{1}$ about the axis $M N$ equals intercept $F G$ multiplied by the pole distance $H$, and the moment of inertia of $P_{1}$ about the axis $M N$ equals the moment of the moment of $P_{1}$ about the axis, $=F G \times H \times d$. But $F G \times d$ equals twice the area of the triangle $F G A$, and we have the moment of inertia of $P_{1}$ equal to the area of the triangle $F G A \times 2 H$. In like manner the moment of inertia of $P_{2}$ may be shown equal to area of the triangle $G \mathrm{HB} \times 2 \mathrm{H}$; moment of inertia of $P_{3}$ equal to area of the triangle $H I C \times 2 H$; and moment of inertia of $P_{4}$ equal to area of the triangle $I J D \times 2 H$. Summing up these values we have the moment of inertia of the sys- 


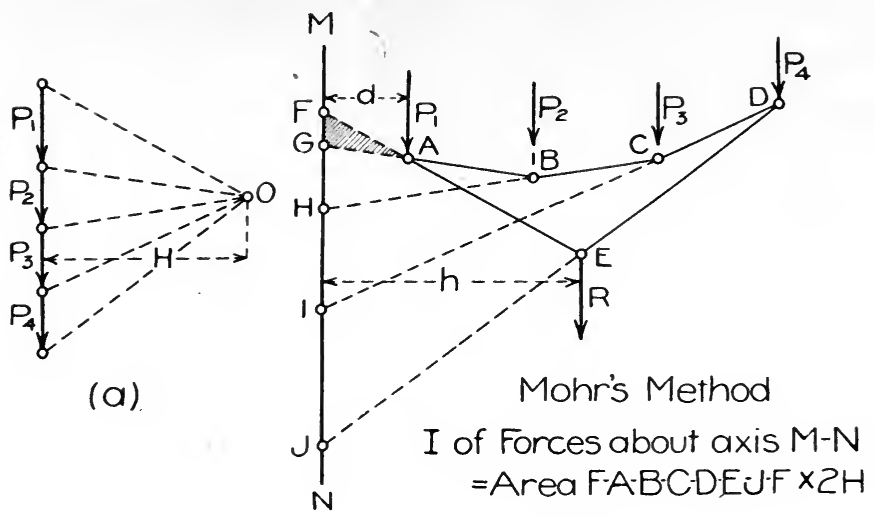

(b)

FIG. 23.

tem of forces equal to the area of the equilibrium polygon multiplied by twice the pole distance, $H$, and

$$
I=\operatorname{area} F A B D E J F \times 2 H
$$

To find the radius of gyration, $r$, we use the formula

$$
I=R r^{2}
$$

In Fig. 23 the moment of inertia, $I$, of the resultant of the system of forces about the axis $M N$, can in like manner be shown to be equal to area of the triangle $F E J \times 2 H$.

If the axis $M N$ is made to coincide with the resultant $R$ the moment of inertia $I_{c . g}$. of the system will be equal to the area of equilibrium polygon $A B C D E \times 2 H$. This furnishes a graphic proof for the proposition that the moment of inertia, $I$, of any system of parallel forces about an axis parallel to the resultant of the system is equal to the moment of inertia, $I_{\text {c.g. }}$, of the forces about an axis through their centeroid plus the moment of inertia, $I_{r}$, of their resultant about the given axis.

$$
\begin{aligned}
I & =I_{\text {c.g. }}+R r^{2} \\
& =I_{c . g .}+I_{r}
\end{aligned}
$$

It will be seen from the foregoing discussion that the moment of inertia of a system of forces about an axis through the centeroid of the system is a minimum. 
Moment of Inertia of Areas.-The moment of inertia of an area about an axis in the same plane is equal to the summation of the products of the differential areas which compose the area and the squares of the distances of the differential areas from the axis.

The moment of inertia of an area about a neutral axis (axis through center of gravity of the area) is less than that about any parallel axis, and is the moment of inertia used in the fundamental formula for flexure in beams

where

$$
M=\frac{S I}{c}
$$

$M=$ bending moment at point of inch-pounds ;

$S=$ extreme fibre stress in pounds;

$I=$ moment of inertia of section in inches to the fourth power;

$c=$ distance from neutral axis to extreme fibre in inches.

An approximate value of the moment of inertia of an area may be obtained by either of the preceding methods by dividing the area into laminae and assuming each area to be a force acting through the center of gravity of the lamina, the smaller the laminae the greater the accuracy. The true value may be obtained by either of the above methods if each one of the forces is assumed to act at a distance from the given axis equal to the radius of gyration of the area with reference to the axis, $d=\sqrt{a^{2}+r^{2}}$, where $a$ is the distance from the given axis to the center of gravity of the lamina and $r$ is the radius of gyration of the lamina about an axis through its center of gravity. If $A_{0}$ is the area of each lamina the moment of inertia of the lamina will be

$$
I=A_{0} d^{2}=A_{0} a^{2}+A_{0} r^{2}=A_{0} a^{2}+I_{c . g .}
$$

which is the fundamental equation for transferring moments of inertia to parallel axes. 
CHAPTER VI.

Stresses in Framed Structures.

Methods of Calculation.-The determination of the reactions of simple framed structures usually requires the use of the three fundamental equations of equilibrium

$$
\begin{aligned}
& \Sigma \text { horizontal components of forces }=0 \\
& \Sigma \text { vertical components of forces }=0 \\
& \Sigma \text { moments of forces about any point }=0
\end{aligned}
$$

Having completely determined the external forces, the internal stresses may be obtained by either equations (a) and (b) (resolution), or equation (c) (moments). These equations may be solved by graphics or by algebra. There are, therefore, four methods of calculating stresses:

$$
\begin{gathered}
\text { Resolution of Forces }\left\{\begin{array}{l}
\text { Algebraic Methor } \\
\text { Graphic Method }
\end{array}\right. \\
\text { Moments of Forces }\left\{\begin{array}{l}
\text { Algebraic Method } \\
\text { Graphic Method }
\end{array}\right.
\end{gathered}
$$

The stresses in any simple framerl structure can be calculated by using any one of the four methods. However, all the methods are not equally well suited to all problems, and there is in general one. method that is best suited to each particular problem.

The common practice of dividing methods of calculation of stresses into analytic and graphic methods is meaningless and misleading for the reason that both algebraic and graphic methods are analytical, $i$. $e$. capable of analysis.

The loads on trusses are usually considered as concentrated at the jcints in the plane of the loaded chord. 
Algebraic Resolution.-In calculating the stresses in a truss by algebraic resolution, the fundamental equations for equilibrium for translation

$$
\begin{aligned}
& \Sigma \text { horizontal components of forces }=0 \\
& \Sigma \text { vertical components of forces }=0
\end{aligned}
$$

are applied (a) to each joint, or (b) to the members and forces on one side of a section cut through the truss.

(a) Forces at a Joint.-The reactions having been found, the stresses in the members of the truss shown in Fig. 24 are calculated as

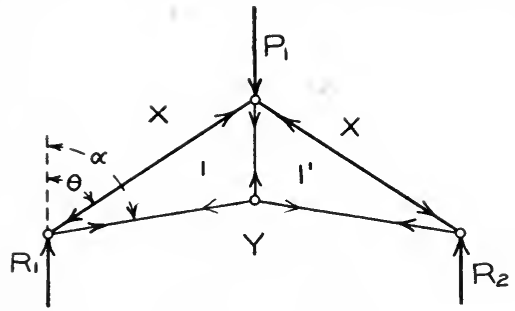

(a)

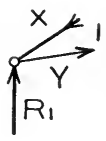

(b)

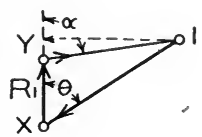

(C)

FIG. 24 .

follows: Beginning at the left reaction, $R_{1}$, we have by applying equations (a) and (b)

$$
\begin{aligned}
& 1-x \sin \theta-1-y \sin \propto=0 \\
& 1-x \cos \theta-1-y \cos \propto-R_{1}=0
\end{aligned}
$$

The stresses in members $I-x$ and $I-y$ may be obtained by solving equations (9) and (10). The direction of the forces which represent the stresses in amount will be determined by the signs of the results, plus signs indicating compression and minus signs indicating tension. Arrows pointing toward the joint indicate that the member is in compression; arrows pointing away from the joint indicate that the member is in tension. The stresses in the members of the truss at the remaining joints in the truss are calculated in the same way.

The direction of the forces and the kind of stress can always be determined by sketching in the force polygon for the forces meeting at the joint as in (c) Fig. 24. 
It will be seen from the foregoing that the method of algebraic resolution consists in applying the principle of the force polygon to the external forces and internal stresses at each joint.

Since we have only two fundamental equations for translation - (resolution) we can not solve a joint if there are more than two forces or stresses unknown.

Where the lower chord of the truss is horizontal as in Fig. 25, we

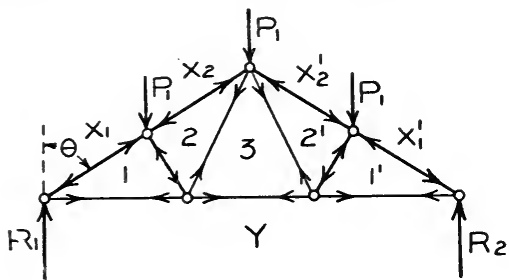

(a)

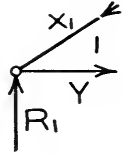

(b)

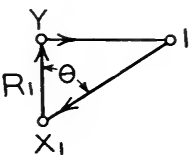

(C)

FIG. 25.

have by applying fundamental equations (a) and (b) to the joint at the left reaction

$$
\begin{aligned}
& 1-x=+R_{1} \sec \theta \\
& 1-y=-R_{1} \tan \theta
\end{aligned}
$$

the plus sign indicating compression and the minus sign tension. Equations (II) and (I2) may be obtained directly from force triangle (c). Equations (II) and (I2) are used in calculating the stresses in trusses with parallel chords and lead to the method of coefficients (Chapter X).

(b) Forces on One Side of a Scction.-The principle of resolution of forces may be applied to the structure as a whole or to a portion of the structure.

If the truss shown in Fig. 26 is cut by the plane $A A$, the internal stresses and external forces acting on either segment, as in (b) will be in equilibrium. The external forces acting on the cut members as shown in (b) are equal to the internal stresses in the cut members and are opposite in direction. 
Applying equations (a) and (b) to the cut section

$$
\begin{aligned}
& 3-y+2-3 \cos \propto-2-x \sin \theta=0 \\
& 2-3 \sin \alpha-2-x \cos \theta+R_{1}-P_{1}=0
\end{aligned}
$$

Now, if all but two of the external forces are known, the unknowns may be found by solving equations (I3) and (14). If more

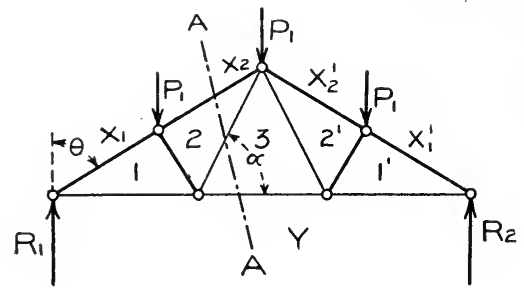

(a)

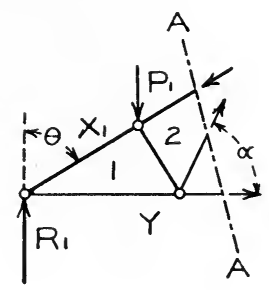

(b)

FIG. 26.

than two external forces are unknown the problem is indeterminate as far as equations (I3) and (I4) are concerned.

Graphic Resolution.-In Fig. 27 the reactions $R_{1}$ and $R_{2}$ are found by means of the force and equilibrium polygons as shown in (b) and (a). The principle of the force polygon is then applied to each joint of the structure in turn. Beginning at the joint $L_{0}$ the forces are shown in (c), and the force triangle in (d). The reaction $R_{1}$ is known and acts up, the upper chord stress $\mathrm{I}-x$ acts lownward to the left, and the lower chord stress I- $y$ acts to the right closing the polygon. Stress $\mathrm{I}-x$ is compression and stress $\mathrm{I}-y$ is tension, as can be seen by applying the arrows to the members in (c). The force polygon at joint $U_{1}$ is then constructed as in (f). Stress I- $x$ acting toward joint $U_{1}$ and load $P_{1}$ acting downward are known, and stresses I-2 and $2-x$ are found by completing the polygon. Stresses 2- $x$ and $\mathrm{I}-2$ are compression. The force polygons at joints $L_{\mathrm{i}}$ and $U_{2}$ are constructed, in the order given, in the same manner. The known forces at any joint are indicated in direction in the force poly- 


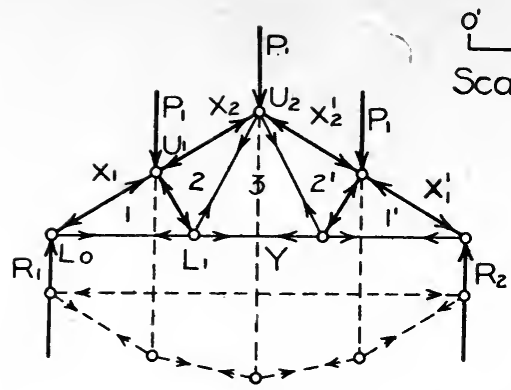

(a)
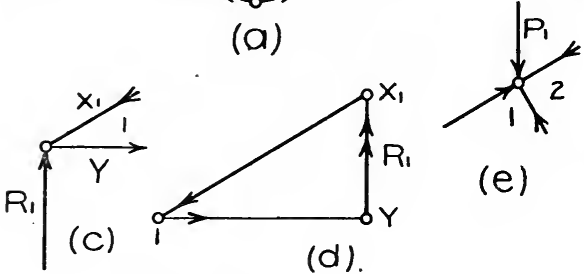

(e)
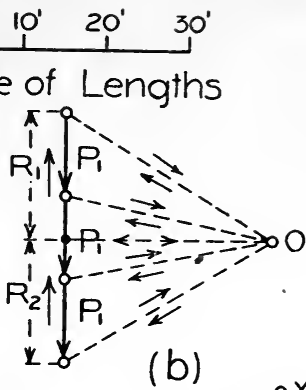

Joint Lo

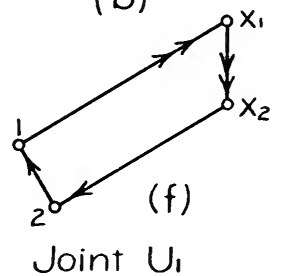

Joint $U_{1}$

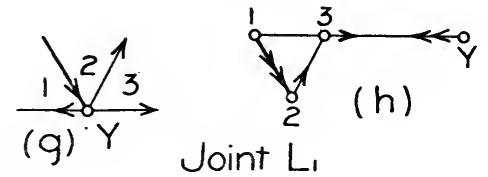

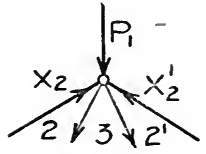

(i)

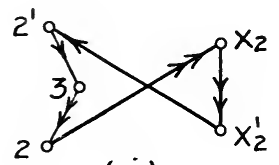

( j)

Joint $U_{2}$
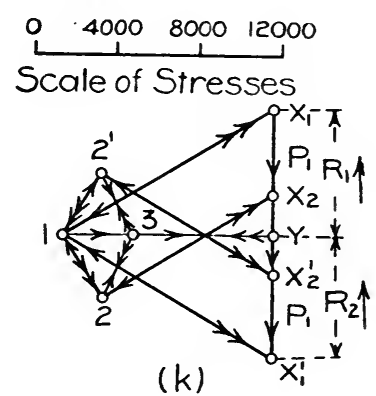

Stress Diagram

FIG. 27.

gon by double arrows, and the unknown forces are indicated in direction by single arrows.

The stresses in the members of the right segment of the truss are the same as in the left, and the force polygons are, therefore, not constructed for the right segment. The force polygons for all the joints of the truss are grouped into the stress diagram shown in $(\mathrm{k})$. Compression in the stress diagram and truss is indicated by arrows acting 
toward the ends of the stress lines and toward the joints, respectively, and tension is indicated by arrows acting away from the ends of the stress lines and away from the joints, respectively. The first time a stress is used a single arrow, and the second time the stress is used a double arrow is used to indicate direction. The stress diagram in $(\mathrm{k})$ Fig. 27 is called a Maxwell diagram or a reciprocal polygon diagram. The notation used is known as Bow's notation. The method of graphic resolution is the method most commonly used for calculating stresses in roof trusses and simple framed structures with inclined chords.

Algebraic Moments.-The reactions may be found by applying the fundamental equations of equilibrium to the structure as a whole. In the truss in (a) Fig. 28 by taking moments about the right reaction we have

$$
\begin{aligned}
& R_{1} \times 6 d=5 P \times 3 d \\
& R_{1}=\frac{5}{2} P_{1}=R_{2}
\end{aligned}
$$

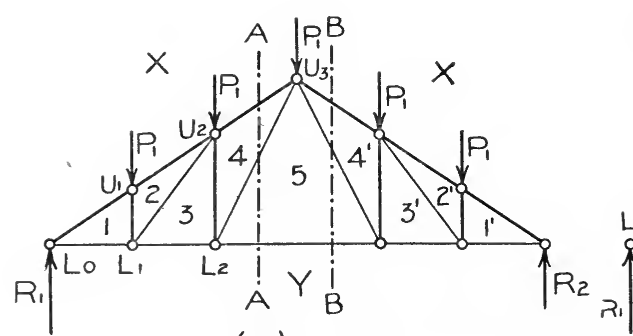

(a)

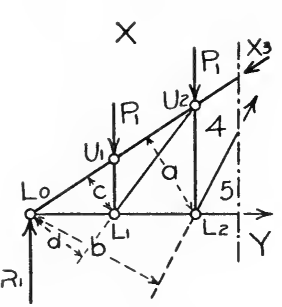

(b)
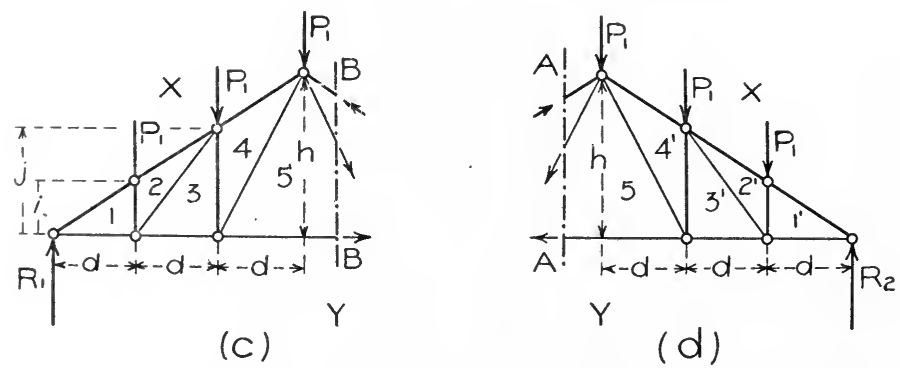

FIG. 28. 
To find the stresses in the members of the truss in (a) Fig. 28, proceed as follows: Cut the truss by means of plane $A A$, as in (b), and replace the stresses in the members cut away with external forces. These forces are equal to the stresses in the members in amount, but opposite in direction, and produce equilibrium.

To obtain stress $4^{-x}$ take center of moments at $I_{r_{2}}$, and take moments of external forces

$$
\begin{aligned}
& 4-x \times a+P_{1} \times d-R_{1} \times 2 d=0 \\
& 4-x=\frac{R_{1} \times 2 d-P_{1} d}{a}=\frac{4 P d}{a} \text { (compression) }
\end{aligned}
$$

To obtain stress in 4-5 take center of moments at $L_{0}$, and take moments of external forces

$$
\begin{aligned}
& \text { 4-5 } \times b-2 P_{1} \times{ }_{2}^{3} d=0 \\
& 4-5=\frac{3 P_{1} d}{b} \text { (tension) }
\end{aligned}
$$

To obtain the stress in $5^{-y}$ take center of moments at joint $U_{3}$ in (c), and take moments of external forces

$$
\begin{aligned}
& 5-y \times h-R_{1} \times 3 d+3 P_{1} d=0 \\
& 5-y=\frac{3 R_{1} d-3 P_{1} d}{h}=\frac{9 P_{1} d}{2 h} \quad \text { (tension) }
\end{aligned}
$$

To Determine Kind of Stress.-If the unknown external force is always taken as acting from the outside toward the cut section, $i$. $e$. is always assumed to cause compression, the sign of the result will indicate the kind of stress. A plus sign will indicate that the assumed direction was correct and that the stress is compression, while a minus sign will indicate that the assumed direction was incorrect and that the stress is tension.

In calculating stresses by algebraic moments, therefore, always observe the following rule:-

Assume the unknown external force as acting from the outside toward the cut section; a plus sign for the result wili then show that the stress in the member is compression, and a minus sign will indicate that the stress in the member is tension.

The stresses in the web members $3-4,2-3,1-2$, are found by 
taking moments about joint $L_{0}$ as a center. The stresses in $y-3$ and $y$-I are found by taking moments about joints $U_{2}$ and $U_{1}$, respectively; and the stresses in $x-2$ and $x$ - I are found by taking moments about joint $L_{1}$.

The method of algebraic moments is the most common method used for calculating the stresses in bridge trusses with inclined chords and similar frameworks which carry moving loads.

Graphic Moments.-The bending moment at any point in a truss may be found by means of a force and equilibrium polygon as

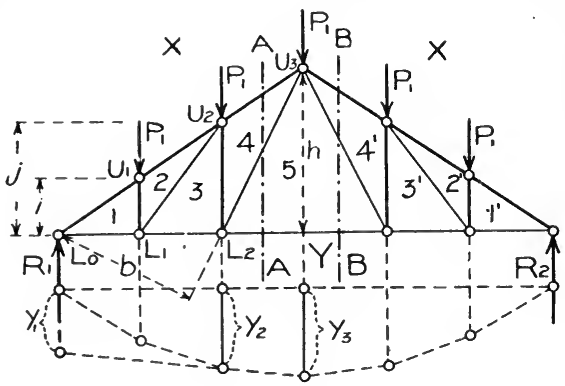

(a)

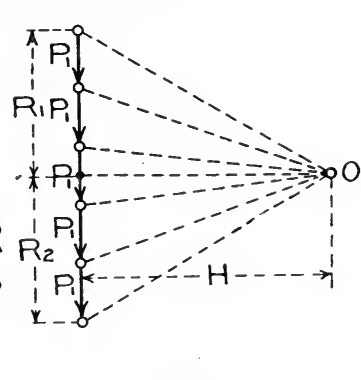

(b)

FIG. 29.

in (b) and (a) Fig. 29. To determine the stress in 4 -x, cut section $A A$ and take moments about joint $L_{2}$ as in Fig. 28. The moment of the external forces on the lefi of $L_{12}$ will be $M_{2}=-H y_{2}$, and stress

$$
4-x=-\frac{M_{2}}{a}=+\frac{H y_{2}}{a}
$$

To obtain stress iri 4-5 take center of moments at joint $L_{0}$, and stress

$$
4-5=\frac{M_{1}}{b}=-\frac{H y_{1}}{b}
$$

To obtain stress in 5-y take center of moments at joint $U_{3}$, and stress

$$
5-y=\frac{M_{3}}{h}=-\frac{M y_{3}}{h}
$$

The method of graphic moments is principally used to explain other methods and is little used as a direct method of calculation. 


\section{CHAPTER VII.}

STRESSES IN SIMPLE ROOF TRUSSES.

Loads. - The stresses in roof trusses are due ( $\mathrm{I}$ ) to the dead load. (2) the snow load, (3) the wind load, and (4) concentrated and moving loads. The stresses due to ciead, snow, wind and concentrated loads will be discussed in this chapter in the order given.

Dead Load Stresses.-The dead load is made up of the weight of the truss and roof covering and is usually considered as applied at the panel points of the upper chord in computing stresses in roof trusses. If the purlins do not come at the panel points, the upper chord will have to be designed for both direct stress and stress due to flexure.

The stresses in a Fink truss due to dead load are calculated by graphic resolution in Fig. 30.

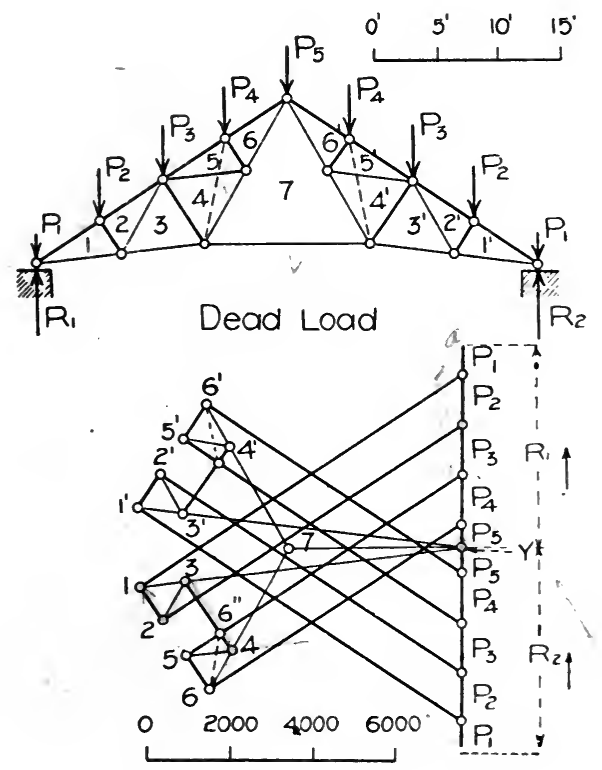

FIG. 30. 
The loads are laid off, the reactions found, and the stresses calculated beginning at joint $L_{0}$, as explained in Fig. 27. The stress diagram for the right half of the truss need not be drawn where the truss and loads are symmetrical as in Fig. 30 ; however it gives a check on the accuracy of the work and is well worth the extra time required. The loads $P_{1}$ on the abutments have no effect on the stresses in the truss and may be onitted in this solution.

In calculating the stresses at joint $P_{3}$, the stresses in the members 3-4, 4-5 and $x-5$ are unknown, and the solution àppears to be indeterminate. The solution is easily made by cutting out members 4-5 and 5-6, and replacing them with the dotted member shown. The stresses in the members in the modified truss are now obtained up to and including stresses $6-x$ and 6-7. Since the stresses 6- $x$ and 6-7 are independent of the form of the framework to the left, as can easily be seen by cutting a section through the members 6- $x$, 6-7 and $7-y$, the solution can be carried back and the apparent ambiguity removed. The ambiquity can also be removed by calculating the stress in $7-y$ by algebraic moments and substituting it in the stress diagram. It will be noted that all top chord members are in compression and all bottom chord members are in tension.

The dead load stresses can also be calculated by any of the three remaining methods, as previously described.

Dead and Ceiling Load Stresses.-The stresses in a triangular Pratt truss due to dead and ceiling loads, are calculated by graphic resolution in Fig. 3 $\mathrm{I}$.

For simplicity the stresses are shown for one side only. The reaction $R_{1}$ is equal to one-half of the entire load on the truss. The solution will appear more clear when it is noted that the stress diagram shown consists of two diagrams, one due to loads on the upper chord and the other due to loads on the lower chord, combined in one, the loads in each case coming between the stresses in the members on each side of the load. 'The top chord loads are laid off in order downward, while the bottom chord loads are laid off in order upward. 

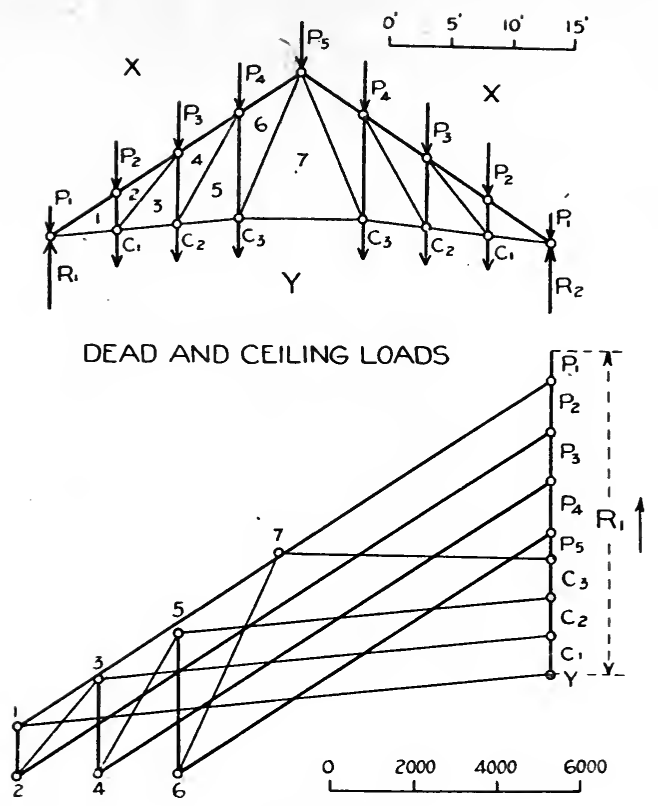

FIG. 3I.

Snow Load Stresses.-Large snow storms nearly always occur in still weather, and the maximum snow load will therefore be a uniformly distributed load. A heavy wind may follow a sleet storm and a snow load equal to the minimum given in Fig. 4 should be considered as acting at the same time as the wind load. The stresses due to snow load are found in the same manner as the dead load stresses.

Wind Load Stresses.-The stresses in trusses due to wind load will depend upon the direction and intensity of the wind, and the condition of the end supports. The wind is commonly considered as acting horizontally, and the normal component, as determined by one of the formulas in Fig. 6 , is taken.

The ends of the truss may ( $I$ ) be rigidly fixed to the abutment walls, (2) be equally free to move, or (3) may have one end fixed and the other end on rollers. When both ends of the truss are rigidly fixed to the abutment walls (1) the reactions are parallel to each other 
and to the resultant of the external loads; where both ends of the truss are equally free to move (2) the horizontal components of the reactions are equal; and where one end is fixed and the other end is on frictionless rollers (3) the reaction at the roller end will always be vertical. Either case (I) or case (3) is commonly assumed in calculating wind load stresses in trusses. Case (2) is the condition in a portal or framed bent. The vertical components of the reactions are independent of the condition of the ends.

Wind Load Stresses: No Rollers.-The stresses due to a normal wind load, in a Fink truss with both ends fixed to rigid walls, are calculated by graphic resolution in Fig. 32 . The reactions are parallei

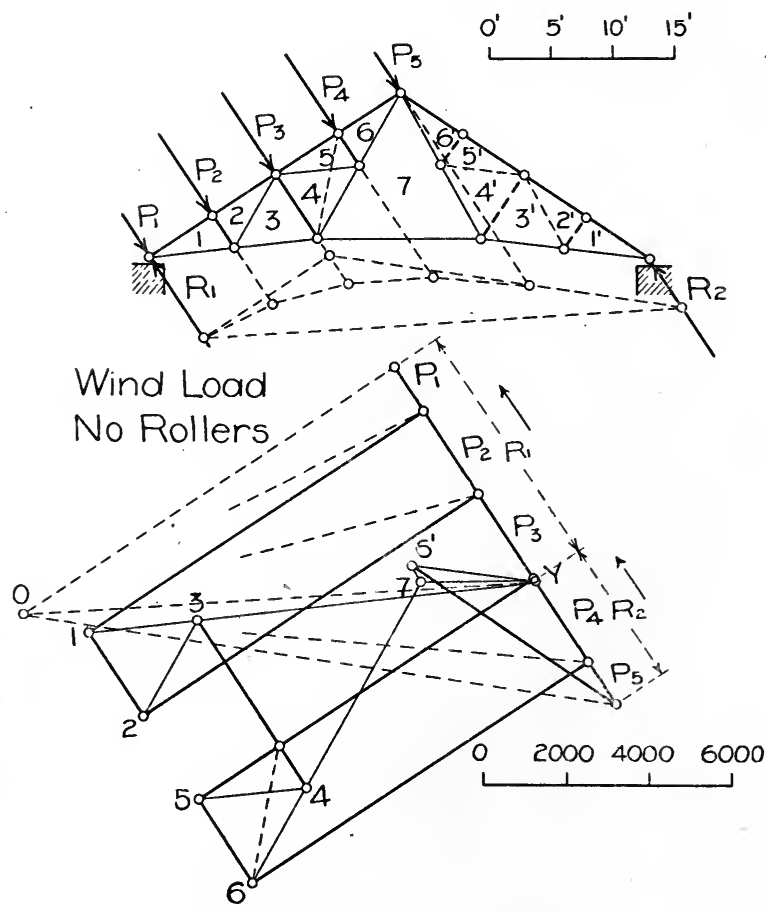

FIG. 32.

and their sum equals sum of the external loads; they are found by means of force and equilibrium polygons as in Fig. ${ }_{5}$ and Fig. 27. 
The stress diagram is constructed in the same manner as that for dead loads. Heavy lines in truss and stress diagram indicate compression, and light lines indicate tension.

The ambiguity at joint $P_{\mathbf{3}}$ is removed by means of the dotted member as in the case of the dead load stress diagram. It will be seen that there are no stresses in the dotted web members in the right segment of the truss. It is necessary to carry the solution entirely through the truss, beginning at the left reaction and checking up at the right reaction. It will be seen that the load $P_{1}$ has no effect on the stresses in the truss in this case.

Wind Load Stresses: Rollers.-Trusses longer than 70 feet are usually fixed at one end, and are supported on rollers at the other end. The reaction at the roller end is then vertical-the horizontal component of the external wind force being all taken by the fixed end. The wind may come on either side of the truss giving rise to two conditions ; ( I) rollers leeward and (2) rollers windward, each requiring a separate solution.

Rollers Leew'ard.-The wind load stresses in a triangular Pratt truss with rollers under the leeward side are calculated by graphic resolution in Fig. 33.

The reactions in Fig. 33 were first determined by means of force and equilibrium polygons, on the assumption that they were parallel to each other and to the resultant of the external loads. Then since the reaction at the roller end is vertical and the horizontal component at the fixed end is equal to the horizontal component of the external wind forces, the true reactions were obtained by closing the force polygon.

In order that the truss be in equilibrium under the action of the three external forces $R_{1}, R_{2}$ and the resultant of the wind loads, the three external forces must meet in a point if produced. This furnishes a method for determining the reactions, where the direction and line of action of one and a point in the line of action of the other are known, providing the point of intersection of the three forces comes within the limits of the drawing board. 


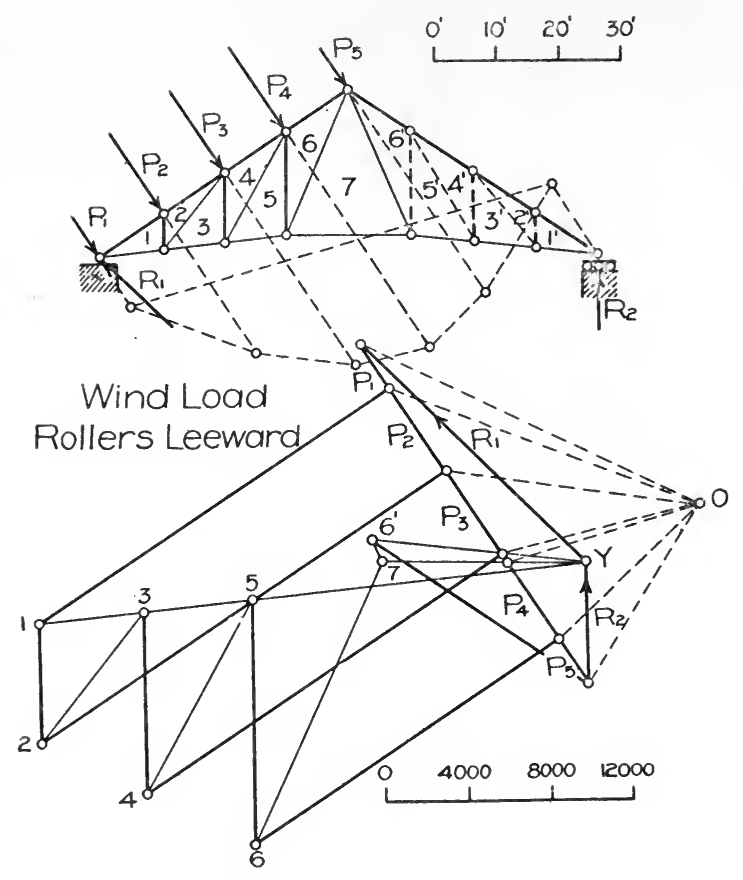

FiG. 33.

The stress diagram is constructed in the same way as the stress diagram for dead loads. It will be seen that the load $P_{1}$ has no effect on the stresses in the truss in this case. Heavy lines in truss and stress diagram indicate compression and light lines indicate tension.

Rollers Windward.-The wind load stresses in the same triangular Pratt truss as shown in Fig. 33, with rollers under the windward side of the truss are calculated by graphic resolution in Fig. 34 .

The true reactions were determined directly by. means of force and equilibrium polygons as in Fig. I6. The direction of the reaction $R_{1}$ is known to be vertical, but the direction of the reaction $R_{2}$ is $11 n$ known, the only known point in its line of action being the right abutment. The equilibrium polygon is drawn to pass through the right abutment and the direction of the right reaction is determined by connecting the 


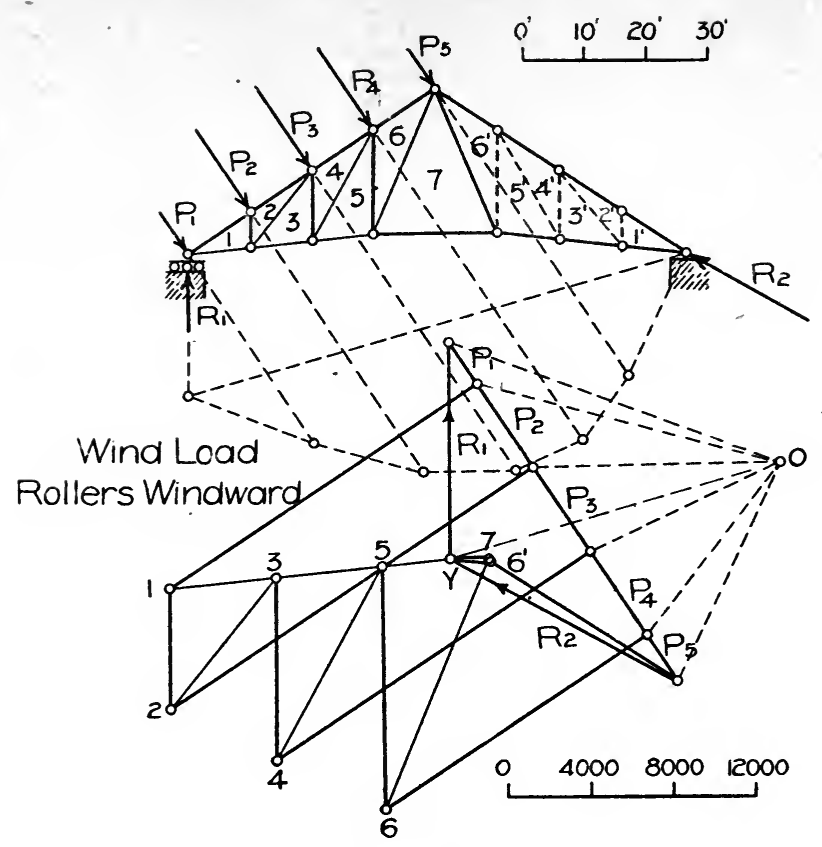

FIG. 34.

point of intersection of the vertical reaction $R_{1}$ and the line drawn through $o$ parallel to the closing line of the equilibrium polygon, with the lower end of the load line.

Since the vertical components of the reactions are independent of the conditions of the ends of the truss, the vertical components of the reactions in Fig. 33 and Fig. 34 are the same. It will be seen that the load $P_{1}$ produces stress in the members of the truss with rollers windward. If the line of action of $R_{2}$ drops below the joint $P_{5}$ the lower chord of the truss will be in compression, as will be seen by taking moments about $P_{5}$.

Concentrated Load Stresses.-The stresses in a Fink truss due to unequal crane loads are calculated by graphic resolution in Fig. 35 .

The reactions were found by means of force and equilibrium polygons. The truss is reduced to three triangles for the loading shown. The solution of this problem is similar to that for ceiling loads in Fig. 
3I. The moving crane trolley will produce maximum moment when it is at the center of the truss, and this case should be investigated in solving the problem.

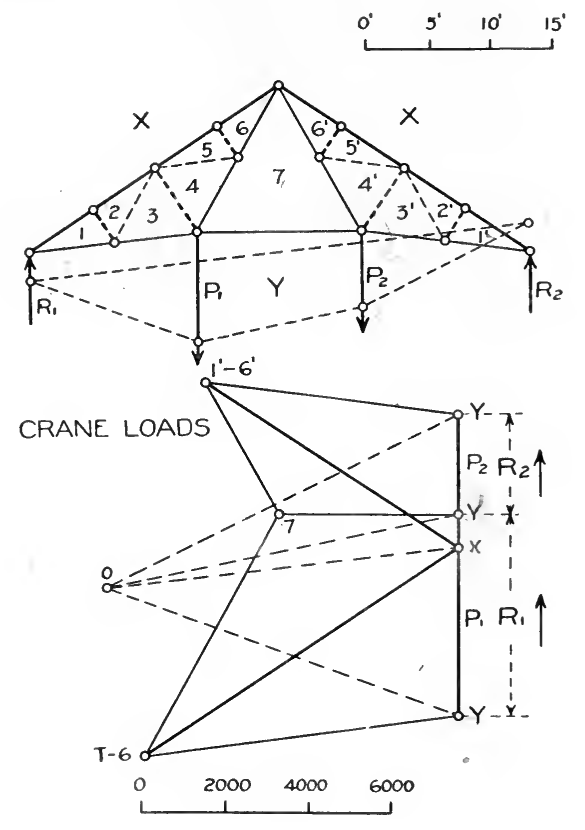

FIG. 35 .

The method of graphic resolution is commonly used for calculating the stresses in roof trusses and similar structures. For examples of the calculations of stresses in trusses by algebraic resolution, algebraic and graphic moments, see Chapter X. 


\section{CHAP'TER VIII.}

\section{Simple Beams.}

Reactions.-The reactions of beams may be found by the use of the force and equilibrium polygon as shown in Chapter V. As a second example let it be required to find the reactions of the overhanging beam shown in Fig. 36 .

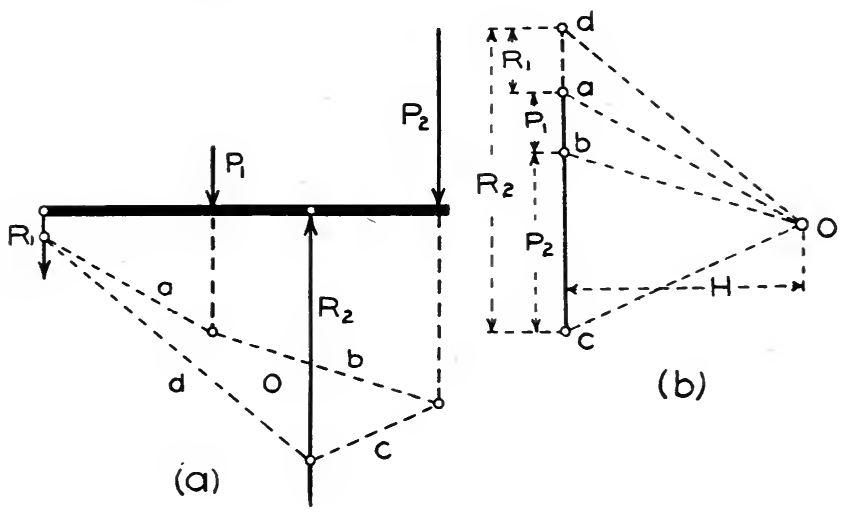

FIG. 36.

Construct a force polygon with pole $o$, as in (b), and draw an equilibrium polygon, as in (a). The ray o $d$ drawn parallel to the closing line $o d$ in (a) determines the reactions. In this case reaction $R_{1}$ is negative. It should be noted that the closing line in an equilibrium polygon must have its ends on the two reactions.

The ordinate to the equilibrium polygon at any point multiplied by the pole distance, $H$, will give the bending moment in the beam at a point immediately above it. 
Moment and Shear in Beams : Concentrated Loads.-The bending moment in the beam shown in Fig. 37 may be found by constructing the force polygon (a) and equilibrium polygon (b) as shown.

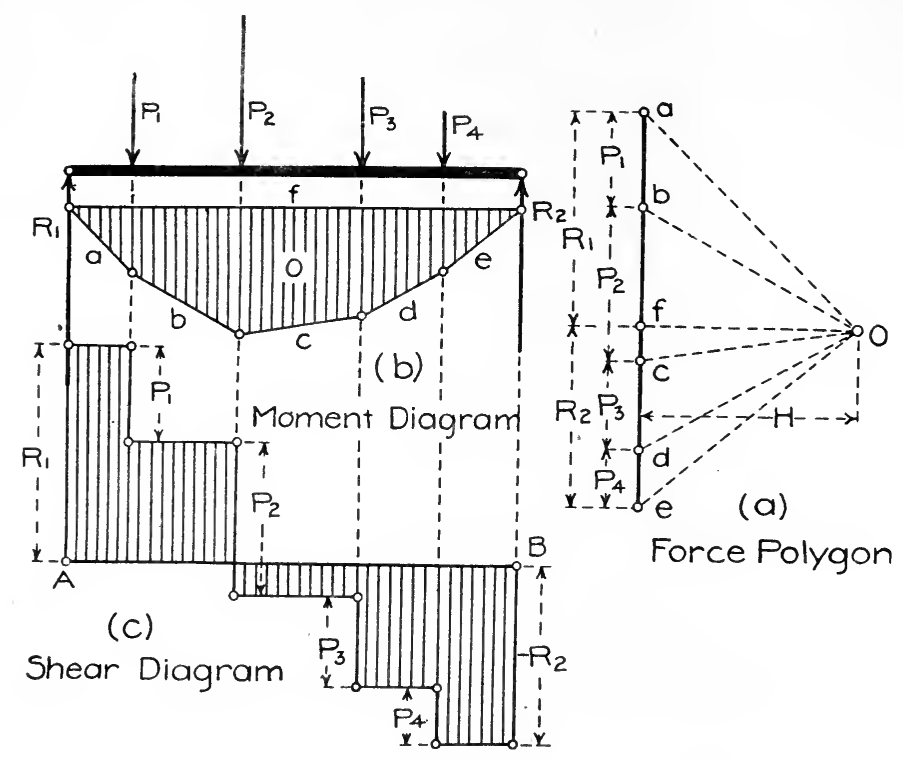

Fig. 37 .

The bending moment at any point is then equal to the ordinate to the equilibrium polygon at that point multiplied by the pole distance, $H$. The ordinate is to be measured to the same scale as the beam, and the pole distance, $H$, is to be measured to the same scale as the loads in the force polygon. The ordinate is a distance and the pole distance is a force.

Or, if the scale to which the beam is laid off be multiplied by the pole distance measured to the scale of the loads, and this scale be used in measuring the ordinates, the ordinates will be equal to the bending moments at the corresponding points. This is the same as making the pole distance equal to unity. Diagram (b) is called a nıment diagram.

Between the left support and the first load the shear is equal to 
$R_{1}$; between the loads $P_{1}$ and $P_{2}$ the shear equals $R_{1}-P_{1}$; between the loads $P_{2}$ and $P_{3}$ the shear equals $R_{1}-P_{1}-P_{2}$; between the loads $P_{3}$ and $P_{4}$ the shear equals $R_{1}-P_{1}-P_{2}-P_{3}$; and between load $P_{4}$ and the right reaction the shear equals $R_{1}-P_{1}-P_{2}-P_{3}-P_{4}=-$ $R_{2}$. At load $P_{2}$ the shear changes from positive to negative. Diagram (c) is called a shear diagram. It will be seen that the maximum ordinate in the moment diagram comes at the point of zero shear.

The bending moment at any point in the beam is equal to the algebraic sum of the shear areas on either side of the point in question. From this we see that the shear areas on each side of $P_{2}$ must be equal. This property of the shear diagram depends upon the principle that the bending moment at any point in a simple beam is the definite integral of the shear between either point of support and the point in question. This will be taken up again in the discussion of beams uniformly loaded which will now be considered.

Moment and Shear in Beams: Uniform Loads.-In the beam loaded with a uniform load of $w$ lbs. per lineai foot shown in Fig. 38, the reaction $R_{1}=R_{2}=1 / 2 w L$. At a distance $x$ from the left support, the bending moment is

$$
M=R_{1} x-\frac{w x^{2}}{2}=\frac{w}{2}\left(L x-x^{2}\right)
$$

which is the equation of a parabola.

The parabola may be constructed by means of the force and equilibrium polygons by assuming that the uniform load is concentrated at points in the beam, as is assumed in a bridge truss, and drawing the force and equilibrium polygons in the usual way, as in Fig. 38. The greater the number of segments into which the uniform load is divided the more nearly will the equilibrium polygon approach the bending moment parabola.

The parabola may be constructed without drawing the force and equilibrium polygons as follows: Lay off ordinate $m n=n p=$ bending moment at center of beam $=1 / 8 w L_{L}^{2}$. Divide $a p$ and $b p$ into the same number of equal parts and number them as shown in (b). Join the points with like numbers by lines, which will he tangents to the 


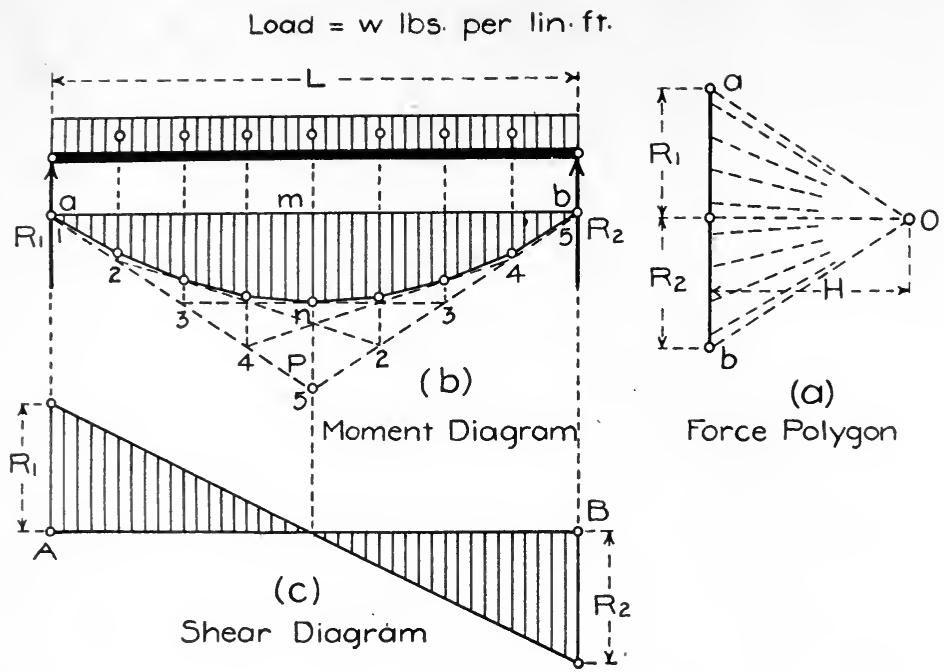

FIG. 38.

required parabola. It will be seen in Fig. 38 that points on the parabola are also obtained.

The shear at any point $x$, will be

$$
S=R_{1}-w x=\frac{1}{2} w L-w x=w\left(\frac{L}{2}-x\right)
$$

which is the equation of the inclined line shown in (c) Fig. 38. The shear at any point is therefore represented by the ordinate to the shear diagram at the given point.

Property of the Shear Diagram.-Integrating the equation for shear between the limits, $x=o$ and $x=x$ we have

$$
\begin{aligned}
\int_{0}^{x} S & =\int_{0}^{x} w\left(\frac{L}{2}-x\right) \\
& =\frac{w}{2}\left(L x-x^{2}\right)
\end{aligned}
$$

which is the equation for the bending moment at any point, $x$, in the beam, and is also the area of the shear diagram between the limits given. From this we see that the bending moment at any point in a simple beam uniformly loaded is equal to the area of the shear diagram to the left of the point in question. The bending moment is also equal to the algebraic sum of the shear areas on either side of the point. 


\section{CHAPTER IX.}

Moving Loads on Beams.

: Uniform Moving Loads.-Let the beam in Fig. 39 be loaded with a uniform load of $p$ lbs. per lineal foot, which can be moved on or off the beam.

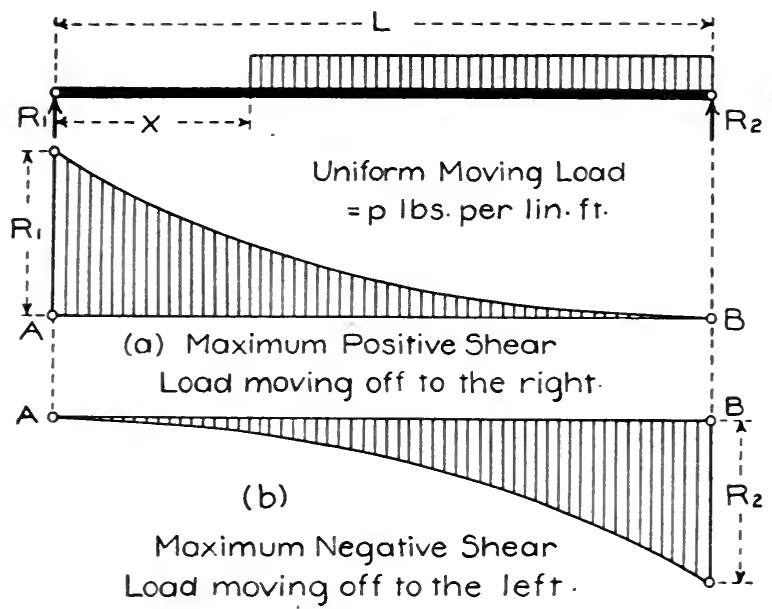

Fig. 39.

To find the position of the moving load that will produce a maximum moment at a point a distance $a$ from the left support, proceed as follows: Let the end of the uniform load be at a distance $x$ from the left reaction. Then taking moments about $R_{2}$ we have

$$
R_{1}=\frac{(L-x)^{2}}{2 L} p
$$

and the moment at the point whose abscissa is $a$ will be

$$
M=R_{1} a-\frac{(a-x)^{2}}{2} p=\frac{(L-x)^{2}}{2 L} a p-\frac{(a-x)^{2}}{2} p
$$


Differentiating (16) and placing derivative of $M$ with respect to $x$ equal to zero, we have after solving

$$
x=o
$$

Therefore the maximum moment at any point in a beam will occur when the beam is fully loaded.

The bending moment diagram for a beam loaded with a uniform moving load is constructed as in Fig. $3^{8}$.

To find the position of the moving load for maximum shear at any point in a beam loaded with a moving uniform load, proceed as follows: The left reaction when the end of the moving load is at a distance $x$ from the left reaction, will be

$$
R_{1}=\frac{(L-x)^{2}}{2 L} p
$$

and the shear at a point at a distance $a$ from the left reaction will be

$$
S=R_{1}-(a-x) p=\frac{(L-x)^{2}}{2 L} p-(a-x) p
$$

which is the equation of a parabola.

By inspection it can be seen that $S$ will be a maximum when $a=x$. The maximum shear at any point in a bean will therefore occur at the end of the uniform moving load, the beam being fully loaded to the right of the point as in (a) Fig. 39 for maximum positive shear, and fully loaded to the left of the point as in (b) Fig. 39 for maximum negative shear.

If the beam is assumed to be a cantilever beam fixed at $A$, and loaded with a stationary uniform load equal to $p$ lbs. per lineal foot, and an equilibrium polygon be drawn with a force polygon having a pole distance equal to length of span, $L$, the parabola drawn through the points in the equilibrium polygon will be the maximum positive shear diagram, (a) Fig. 39. The ordinate at any point to this shear diagram will represent the maximum positive shear at the point to the same scale as the loads (for the application of this principal to bridge trusses see Fig. 50, Chapter X). 
Concentrated Moving Loads.-Let a beam be loaded with concentrated moving loads at fixed distances apart as shown in Fig. 40.

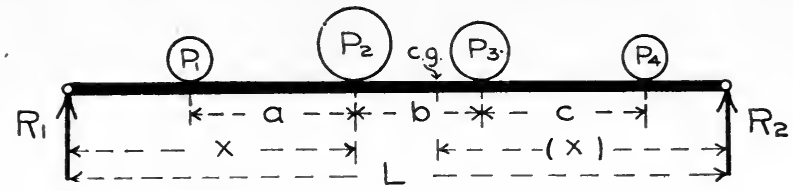

Fig. 40.

To find the position of the loads for maximum moment and the amount of the maximum moment, proceed as follows: The load $P_{2}$ will be considered first. Let $x$ be the distance of the load $P_{2}$ from the left support when the loads produce a maximum moment under load $P_{2}$.

Taking moments about $R_{2}$ we have

$$
\begin{aligned}
R_{1}= & \frac{P_{1}(L-x+a)+P_{2}(L-x)+P_{3}(L-x-b)+P_{4}(L-x-b-c)}{L} \\
& =\frac{(L-x)\left(P_{1}+P_{2}+P_{3}+P_{4}\right)+P_{1} a-P_{3} b-P_{4}(b+c)}{L}
\end{aligned}
$$

and the bending moment under load $P_{2}$ will be

$$
\begin{aligned}
M & =R_{1} x-P_{1} a \\
& =\frac{x(L-x)\left(P_{1}+P_{2}+P_{3}+P_{4}\right)+x\left(P_{1} a-P_{3} b-P_{4}(b+c)\right)}{L}-P_{1} a
\end{aligned}
$$

Differentiating (20) we have

$$
\frac{d M}{d x}=\frac{(L-2 x)\left(P_{1}+P_{2}+P_{3}+P_{4}\right)+P_{1} a-P_{3} b-P_{4}(b+c)}{L}=0
$$

and solving (2I) for $x$ we have

$$
x=\frac{L}{2}-\frac{P_{1} a-P_{3} b-P_{4}(b+c)}{2\left(P_{1}+P_{2}+P_{3}+P_{4}\right)}
$$

Now $P_{1} a-P_{3} b-P_{4}(b+c)$, is the static moment of the loads about $P_{2}$ and 


$$
\frac{P_{1} a-P_{3} b-P_{4}(b+c)}{P_{1}+P_{2}+P_{3}+P_{4}}=\text { distance from } P_{2} \text { to }
$$

center of the gravity of all the loads.

Therefore, for a maximum moment under load $P_{2}$, it must be as far from one end as the center of gravity of all the loads is from the other end of the beam, Fig. 40.

The above criterion holds for all the loads on the beam. The only way to find which load produces the greatest maximum is to try each one, however, it is usually possible to determine by inspection which load will produce a maximum bending moment. For example the maximum momẹnt in the beam in Fig. 40 will certainly come under the heavy load $P_{2}$. The above proof may be generalized without diffculty and the criterion above shown to be of general application.

For two equal loads $P=P$ at a fixed distance, $a$, apart as in the case of a traveling crane, Fig. 4I, the maximum moment will occur under one of the loads when

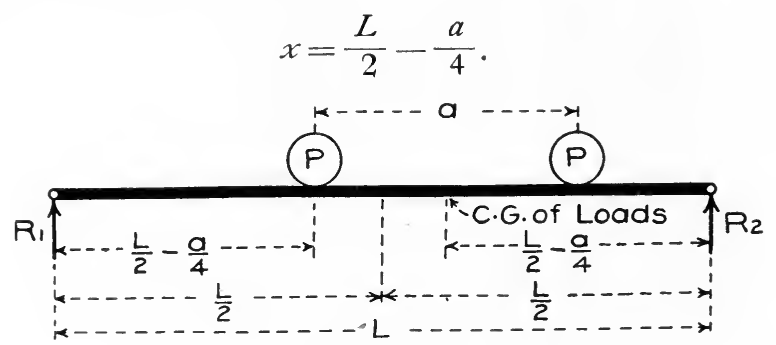

FIG. 4I.

Taking moments about the right reaction we have

$$
R_{1}=\frac{P\left(L-\frac{a}{2}\right)}{L}
$$

and the maximum bending moment is

$$
\begin{gathered}
M=R_{1}\left(\frac{L}{2}-\frac{a}{4}\right) \\
=\frac{P\left(L-\frac{a}{2}\right)^{2}}{2 L}
\end{gathered}
$$


There will be a maximum moment when either of the loads satisfies the above criterion, the bending moments being equal.

By equating the maximum moment above to the moment due to a single load at the center of the beam, it will be found that the above criterion holds only when

$$
a<0.586 L
$$

Where two unequal moving loads are at a fixed distance apart the greater maximum bending moment will always come under the heavier load.

The maximum end shear at the left support for a system of concentrated loads on a simple beam, as in Fig. 40, will occur when the left reaction, $R_{1}$, is a maximum. This will occur when one of the wheels is infinitely near the left abutment (usually said to be over the left abutment). The load which produces maximum end shear can be easily found by trial.

The maximum shear at any point in the beam will occur when one of the loads is over the point. The criterion for determining which load will cause a maximum shear, at any point, $x$, in a beam will now be determined.

In Fig. 40, let the total load on the beam, $P_{1}+P_{2}+P_{3}+P_{4}=$ $W$, and let $x$ be the distance from the left support to the point at whicin we wish to determine the maximum shear.

When load $P_{1}$ is at the point, the shear will be equal to the left reaction, which is found by substituting $x+a$ for $x$ in (19) to be

$$
S_{1}=R_{1}=\frac{(L-x-a) W+P_{1} a-P_{3} b-P_{4}(b+c)}{L}
$$

and when $P_{2}$ is at the point the shear will be

$$
S_{2}=\frac{(L-x) W+P_{1} a-P_{3} b-P_{4}(b+c)}{L}-P_{1}
$$

Subtracting $S_{2}$ from $S_{1}$ we have

$$
S_{1}-S_{2}=\frac{P_{1} L-W a}{L}
$$


Now $S_{1}$ will be greater than $S_{2}$ if $P_{1} L$ is greater than $W a$, or if

$$
\frac{P_{1} L}{a}>W
$$

The criterion for maximum shear at any point therefore is as follows :

The maximum positive shear in any section of a beam occurs when the foremost load is at the section, provided $W$ is not greater than $\frac{P_{1} L}{a}$ If $W$ is greater than $\frac{P_{1} L}{a}$, the greatest shear will occur when some succeeding load is at the point.

Having determined the position of the moving loads for maximum moment and maximum shear, the amount of the moment and shear can be obtained as in the case of beams loaded with stationary loads. 


\section{CHAPTER X.}

Stresses in Bridge Trusses.

Method of Loading.- The loads on highway bridges, and in many cases on railway bridges as well, are assumed to be concentrated at the joints of the loaded chord, and if the panels of the truss are equal the joint loads are equal. The assumption of joint loads simplifies the solution and gives values for the stresses that are on the safe side. Equal joint loads will be assumed in this discussion.

Algebraic Resolution.*-Let the Warren truss in Fig. 42 have dead loads applied at the joints as shown. From the fundamentai ecuations for equilibrium for translation, reaction $R_{1}=R_{2}=3 \mathrm{~W}$.

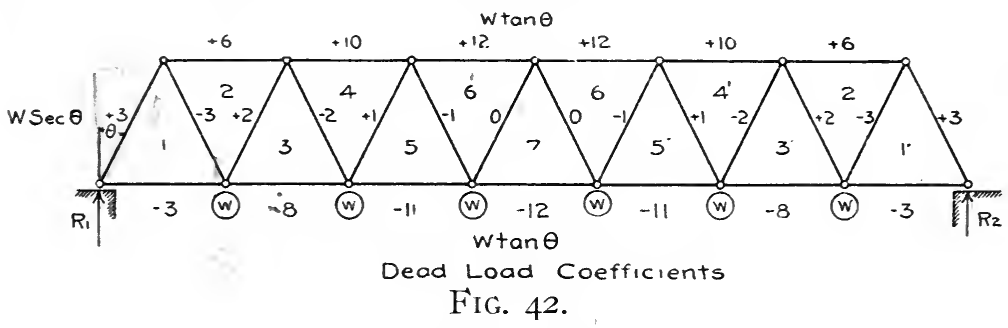

The stresses in the members are calculated as follows: Resolving at the left reaction, stress in $\mathrm{I}-x=+3 W \sec \theta$, and stress in $\mathrm{I}-\boldsymbol{y}=$. $-3 W \tan \theta$. Resolving at first joint in upper chord, stress in $\mathbf{I}-2=$ $-3 W \sec \theta$, and stress in $2-x=+6 W \tan \theta$. Resolving at second joint in lower chord, stress $2-3=+2 W \sec \theta$, and stress $3-y=-$ $8 \mathrm{~W} \tan \theta$. And in like manner the stresses in the remaining members are found as shown. The coefficients shown in Fig. 42 for the chords are to be multiplied by $W \tan \theta$; while those for the webs are to be multiplied by $W \sec \theta$.

\footnotetext{
*Also called "Method of Sections."
} 
It will be seen that the coefficients for the web stresses are equal to the shear in the respective panels. Having found the shears in the different panels of the truss, the remaining coefficients may be found by resolution. Pass a section through any panel and the algebraic sum of the coefficients will be equal to zero. Therefore, if two coefficients are known, the third may be found by addition.

Beginning with member $\mathrm{I}-x$, which is known and equals -3 ;

coefficient of $2-x=-(-3-3)=+6$;

coefficient of $3-y=-(+6+2)=-8$;

coefficient of $4-x=-(-8-2)=+10$;

coefficient of $5-y=-(+\mathrm{IO}+\mathrm{I})=-\mathrm{I}$ I ;

coefficient of $6-x=-(-\mathrm{II}-\mathrm{I})=+\mathrm{I} 2$;

coefficient of $7-y=-(+\mathrm{I} 2+0)=-\mathrm{I} 2$,

Loading for Maximum Stresses.-The effect of different positions of the loads on a Warren truss will now be investigated.

Let the truss in Fig. 43 be loaded with a single load $P$ as shown.

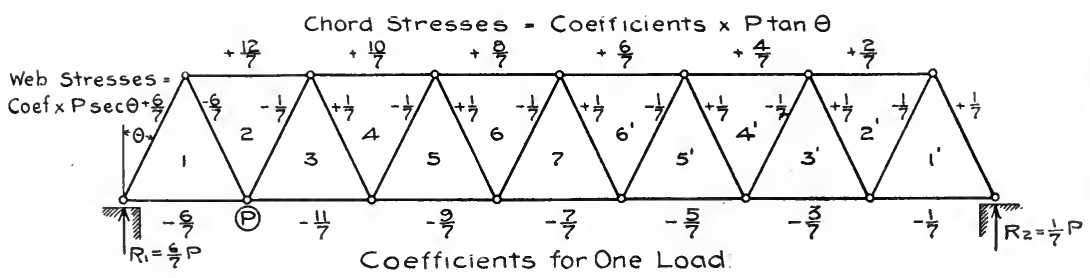

FIG. 43 .

The left reaction, $R_{1}=\frac{6}{7} P$, and the right reaction, $R_{2}=\frac{P}{7}$. The stress in $\mathrm{I}-y=-\frac{6}{7} P \tan \theta$, and stress in $\mathrm{I}-x=+\frac{6}{7} P \sec \theta$. The stress in $\mathrm{I}-2=-\frac{6}{7} P \sec \theta$ and stress in $2-3=-\frac{1}{7} P \sec \theta$, etc. The remaining coefficients are found as in the case of dead loads by adding coefficients algebraically and changing the sign of the result.

In Fig. 44 the coefficients for a load applied at each joint in turn are shown for the different members; the coefficients for the load on left being given in the top line. 


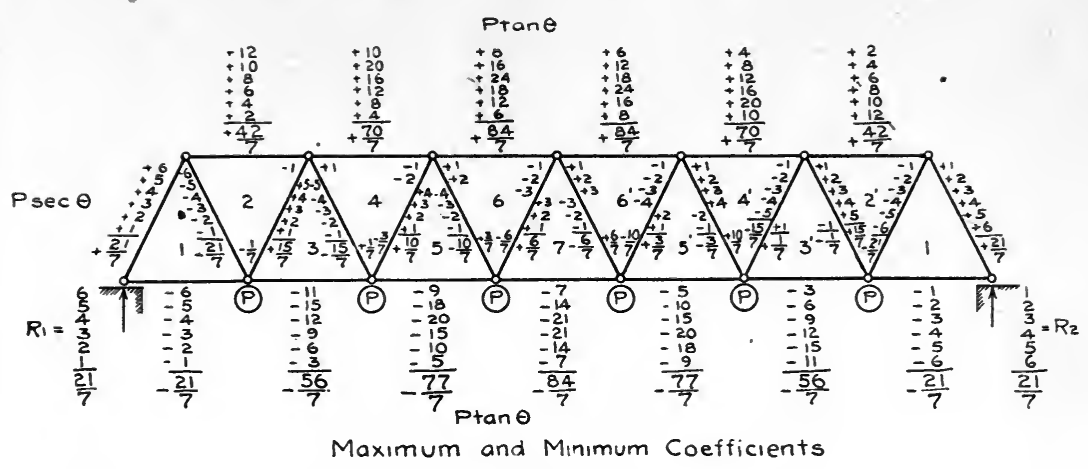

FIG. 44.

The following conclusions may be drawn from Fig. 44.

(I) All loads produce a compressive stress in the top chord and a tensile stress in the bottom chord.

(2) All the loads on one side of a panel produce the same kind of stress in the web members that are inclined in the same direction on that side.

For maximum stresses in the chords, therefore, the truss should be fully loaded. For maximum stresses in the web members the longer segment into which the panel divides the truss should be fully loaded; while for minimum stresses in the web members the shorter segment of the truss should be fully loaded.

The conditions for maximum loading of a truss with equal joint loads are therefore seen to be essentially the same as the maximum loading of a beam with a uniform live load.

Stresses in Warren Truss.-The coefficients for maximum and minimum stresses in aWarren truss due to live load are shown in Fig. 45.

These coefficients are seen to be the algebraic sum of the coefficients for the individual loads given in Fig. 44. The live load chord coefficients are the same as for dead load, and if found directly are found in the same manner.

The maximum web coefficients may be found directly by taking off one load at a time beginning at the left. The left reartion, which may be found by algebraic momerts, will in each case be the coefficient of 
the maximum stress in the panel to the left of the first load. A rule for finding the coefficient of left reaction for any loading is as follows : Multiply the number of loads on the truss by the number of loads plus unity, and divide the product by twice the number of panels in the truss and the result will be the coefficient of the left reaction.

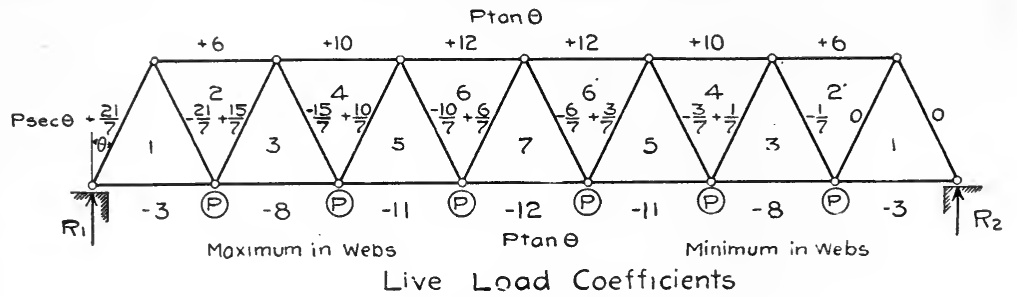

FIG. 45.

If the second differences of the maximum coefficients in the web members are calculated, they will be found to be constant, which shows that the coefficients are equal to the ordinates of a parabola.

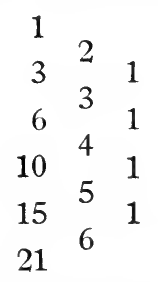

SECOND DIFFERENCES OF NUMERATORS OF WEB COEFFICIENTS.

This relation gives an easy method for checking up the maximum web coefficients, since the numerators of the coefficients are always the same beginning with unity in the first panel on the right and progressing in order I, 3, 6, Io, etc.; the denominators always being the number of panels in the truss.

It should be noted that in the Warren truss the members meeting on the unloaded chord always have stresses equal in amount, but opposite in sign.

Stresses in Pratt Truss.-- In the Pratt truss the diagonal members are tension members and counters (see dotted members in (c) Fig. 46) must be supplied where there is a reversal of stress. The coefficients for the dead and iive load stresses in the Pratt truss shown in (a) and (b) 
Fig. 46, are found in the same manner as for a Warren truss. The member $U_{1} L_{1}$ acts as a hanger and carries only the load at its lower end. The stresses in the chords are found by multiplying the coefficients by $W \tan \theta$, and in the inclined webs by multiplying the coefficients by $W \sec \theta$ The stresses in the posts are equal to the vertical components of the stresses in the inclined web members meeting them on the unloaded chord.

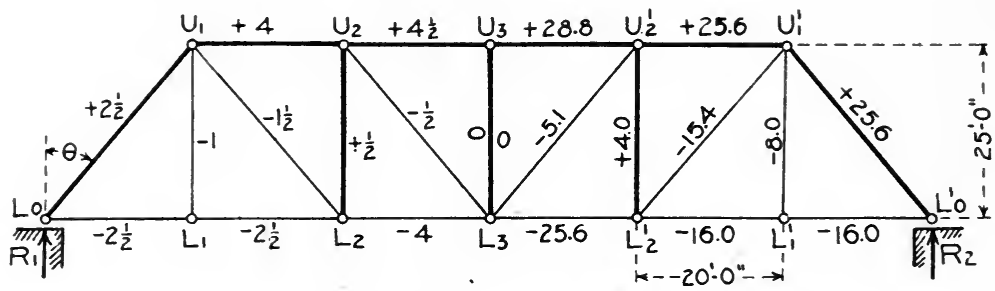

Dead Load Coefficients

Debd Load Stresses

Dead Load $=8$ Tons per Joint. $\operatorname{Sec} \theta=1.28$. Tan $\theta=0.80$

(a)

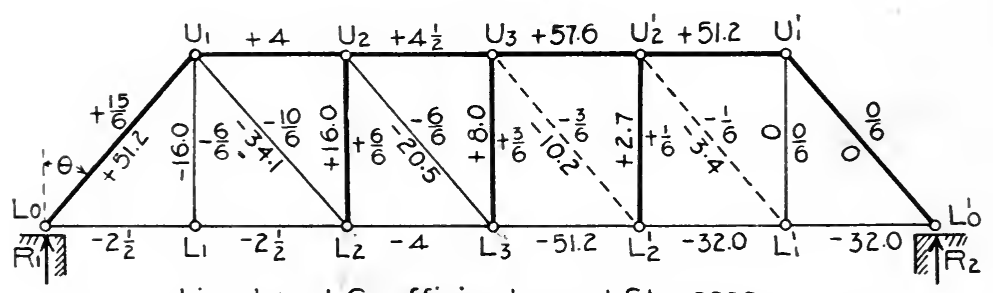

Live Load Coefficients and Stresses

Live Load $=16$ Tons per Joint. $\operatorname{Sec} \theta=1.28 \cdot \operatorname{Tan} \theta=0.80$

(b)

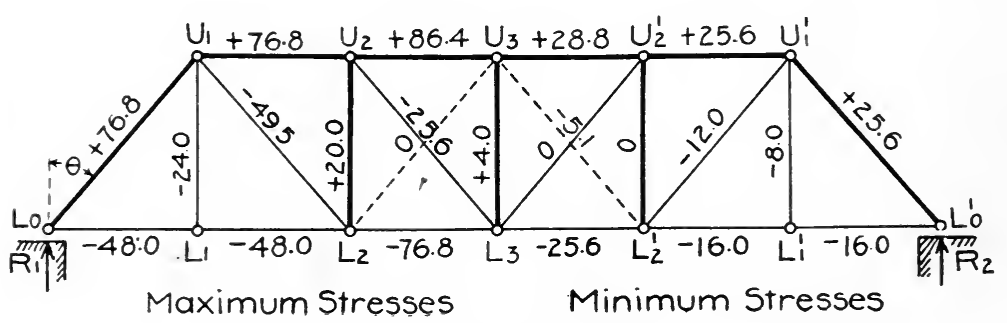

(C)

FIG. 46. 
The maximum chord stresses shown on the left of (c) are equa! to the sum of the live and dead load chord stresses. The minimum chord stresses shown on the right of (c) are equal to the dead load chord stresses.

The maximum and minimum web stresses are found by adding algebraically the stresses in the members due to dead and live loads.

Since the diagonal web members in a Pratt truss can take tension only, counters must be supplied as $U_{3} L_{1}{ }_{2}^{1}$ in panel $L_{1}^{1}{ }_{2} L_{13}$. The tensile stress in a counter in a panel of a Pratt truss is always equal to the compressive stress that would occur in the main diagonal web member in the panel if it were possible for it to take compression. Care must always be used to calculate the corresponding stresses in the vertical posts.

Graphic Resolution.-The stresses in a Warren truss due to dead loads are calculated by graphic resolution in Fig. 47. The solution is the same as for ceiling loads in a roof truss. The loads beginning with the first load on the left are laid off from the bottom upwards. The analysis of the solution is shown on the stress diagram and truss and needs no explanation.

From the stresses in the members it is seen (a) that web members neeting on the unloaded chord have stresses equal in amount but opposite in sign, and (b) that the lower chord stresses are the arithmetical means of the upper chord stresses on each side.

The live load chord stresses may be obtained fro'n the stress diagram in Fig. 47 by changing the scale or by multiplying the dead load stresses by a constant.

The live load web stresses may be obtained by calculating the left reactions for the loading that gives a maximum shear in the panel (no loads occurring between the panel and the left reaction), and then constructing the stress diagram up to the member whose stress is required. In a truss with parallel chords it is only necessary to calculate the stress in the first web member for any given reaction since the shear is constant between the left reaction and the panel in questicn. 
The live load web stresses may all be obtained from a single diagram as follows: With an assùmed left reaction of, say, I00,000 lbs. construct a stress diagram on the assumption that the truss is a cantilever fixed at the right abutment and that there are no loads on the

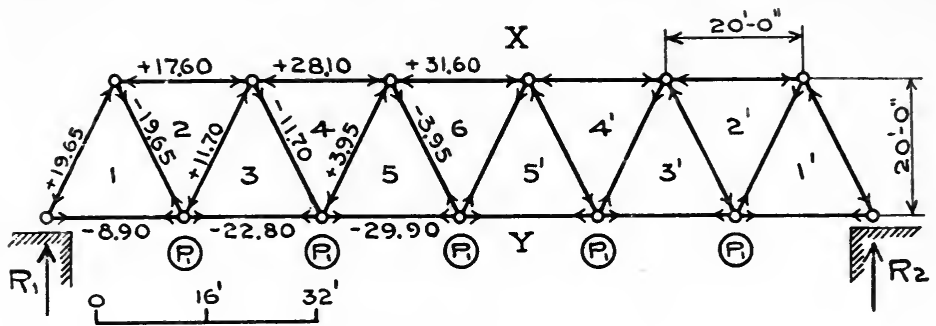

Warren Truss.

Span 120.0".

$P_{1}=7$ Tons.

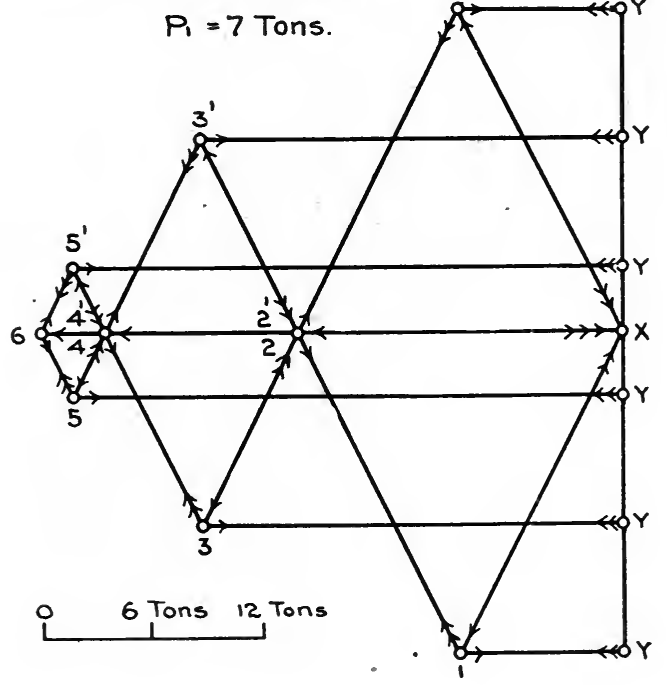

FIG. 47 .

truss. Then the maximum stress in any web member will be equal to the stress scaled from the diagram, mutilplied by I0J,000, divided by the left reaction that produces the maximum stress. This method is a very convenient one for finding the stresses in a truss with inclined chiords. 
Algebraic Moments. - The dead and live load stresses in a truss with inclined chords are calculated by algebraic moments in Fig. 48. The conditions for maximum loading are the same in this truss as in a truss with parallel chords, and are as follows: Maximum chord stresses occur when all loads are on; minimum chord stresses occur when no live load is on; maximum web stresses in main members occur when the longer segment of the truss is loaded; and ninimum stresses in main members and maximum stresses in counters occur when the shorter segment of the truss is loaded. An apparent exception to the intter rule occurs in post $U_{2} L_{2}$ which has a maximum stress when the trıss is fully loaded with dead and live loads.

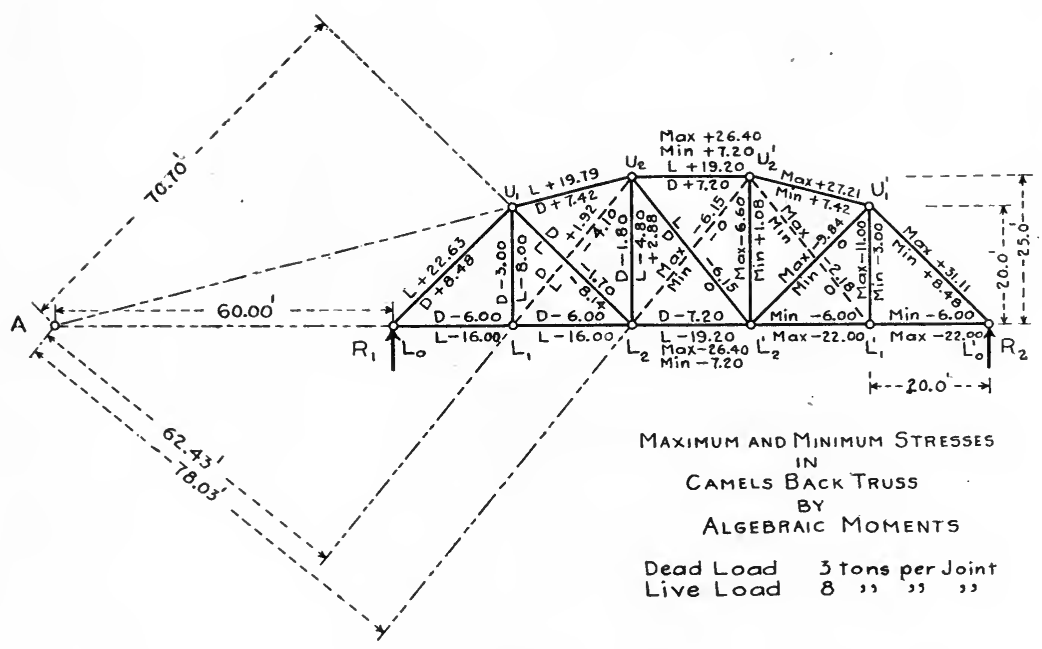

FIG. 48.

To find the stress in member $U_{1} L_{2}$ take moments about point $A$, the intersection of the upper and lower chords produced. The dead load stress is then given by the equation

$$
\begin{aligned}
& U_{1} L_{2} \times 70.7+R_{1} \times 60-W \times 80=0 \\
& U_{1} L_{2} \times 70.7=-6 \times 60+3 \times 80=-\mathrm{I} 20 \text { foot-tons } \\
& U_{1} L_{2}=-\mathrm{I} .70 \text { tons }
\end{aligned}
$$


The maximum live load stress occurs when all loads are on except $L_{1}$, and

$$
\begin{aligned}
& U_{1} L_{2} \times 70.7+R_{1} \times 60=0 \\
& U_{1} L_{2} \times 70.7=-\frac{6}{5} P \times 60=-576 \text { foot-tons } \\
& U_{1} L_{2}=-8.14 \text { tons }
\end{aligned}
$$

The maximum live load stress in counter $U_{2} L_{1}$ occurs with a load at $L_{1}$, and is given by the equation

$$
\begin{aligned}
& -U_{2} L_{1} \times 62.43+R_{1} \times 60-P \times 80=0 \\
& U_{2} L_{1} \times 62.43=\frac{4}{5} P \times 60-8 \times 80 \\
& U_{3} L_{1}=-4.10 \text { tons }
\end{aligned}
$$

The dead load stress in counter $U_{2} L_{1}$ when main member $U_{1} L_{2}$ is not acting will be

$$
\begin{gathered}
U_{2} L_{1} \times 62.43=+\mathrm{I} 20 \text { foot-tons } \\
U_{2} L_{1}=+\mathrm{I} .92 \text { tons }
\end{gathered}
$$

The maximum stress in $U_{1} L_{2}$ is therefore $-1.70-8.14=-$ 9.84 tons, and the minimum stress is zero. The maximum stress in counter $U_{2} L_{1}$ is $+1.92-4$. Io $=-2.18$ tons, and the minimum stress is zero.

The stresses in the remaining members may be found in the same manner. To obtain stresses in upper chords $U_{1} U_{2}$ and $U_{2} U_{2}$, take moments about $L_{2}$ as a center; to obtain stress in lower chord $L_{0} L_{1}$ take moments about $U_{1}$ as a center. The dead load and maximum live load stress in post $U_{2} L_{2}$ is equal to the vertical component of the dead and live loads, respectively, in upper chord $U_{1} U_{2}$. The stresses in $L_{0} U_{1}$, $L_{0} L_{1}, L_{2} L^{1}{ }_{2}, U_{2} U^{1}{ }_{2}$ and $U_{2} L_{1}{ }_{2}$ are most easily found by algebraic resolution.

Graphic Moments.-The dead load stresses in the chords of a Warren truss are calculated by graphic moments in Fig. 49.

Bending Moment Polygon.-The upper chord stresses are given by the ordinates to the bending moment parabola rirect, while the lower chord stresses are arithmetical means of the upper chord stresses 
on each side, and are given by the ordinates to the chords of the paraboia as shown in Fig. 49.

The parabola is constructed as follows: The mid-ordinate, $4 j$, is made equal to the bending moment at the center of the truss divided by the depth; in this case the mid-ordinate is the stress in 6- $x$; if the num-

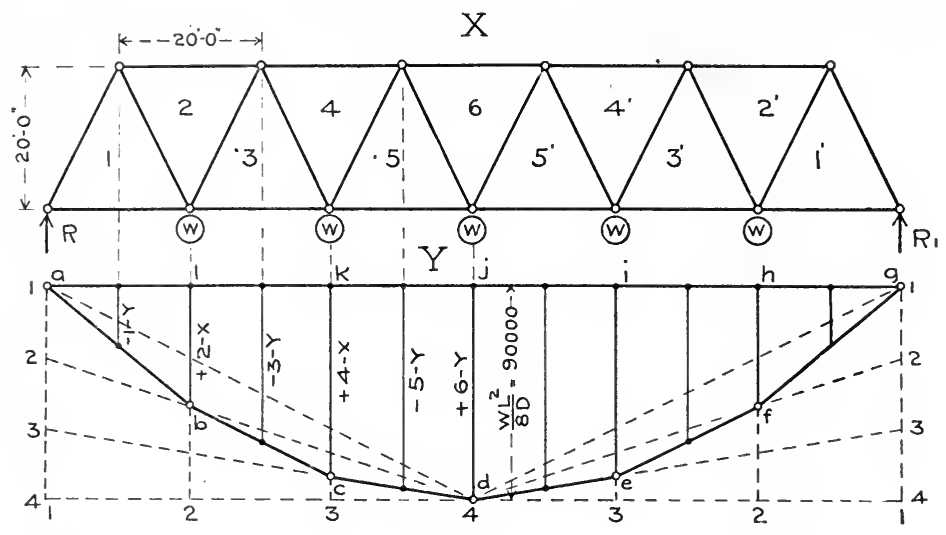

FIG. 49.

ber of panels in the truss were odd the mid-ordinate would not be equal to any chord stress. The parabola is then constructed as shown in Fig. 49. The live load chord stresses may be found from Fig: 49 by changing the scale or by multiplying the dead load chord stresses by a constant.

Shear Polygon.-In Chapter IX it was shown that the maximum shear in a beam at any point could be represented by the ordinate to a parabola at any point. 'The same principle holds for a bridge truss loaded with equal joint loads, as will now be proved.

In Fig. 50 assume that the simple Warren truss is fixed at the left end as shown, and that right reaction $R_{1}$ is not acting. Then with all joints fully loaded with a live load $P$, construct a force polygon as shown, with pole $o$ and pole distance $H=\operatorname{span} L$, and beginning at point $a$ in the load line of the force polygon construct the equilibrium polygon $a g h$ for the cantilever truss.

Now the bending moment at the left support will be equal to 


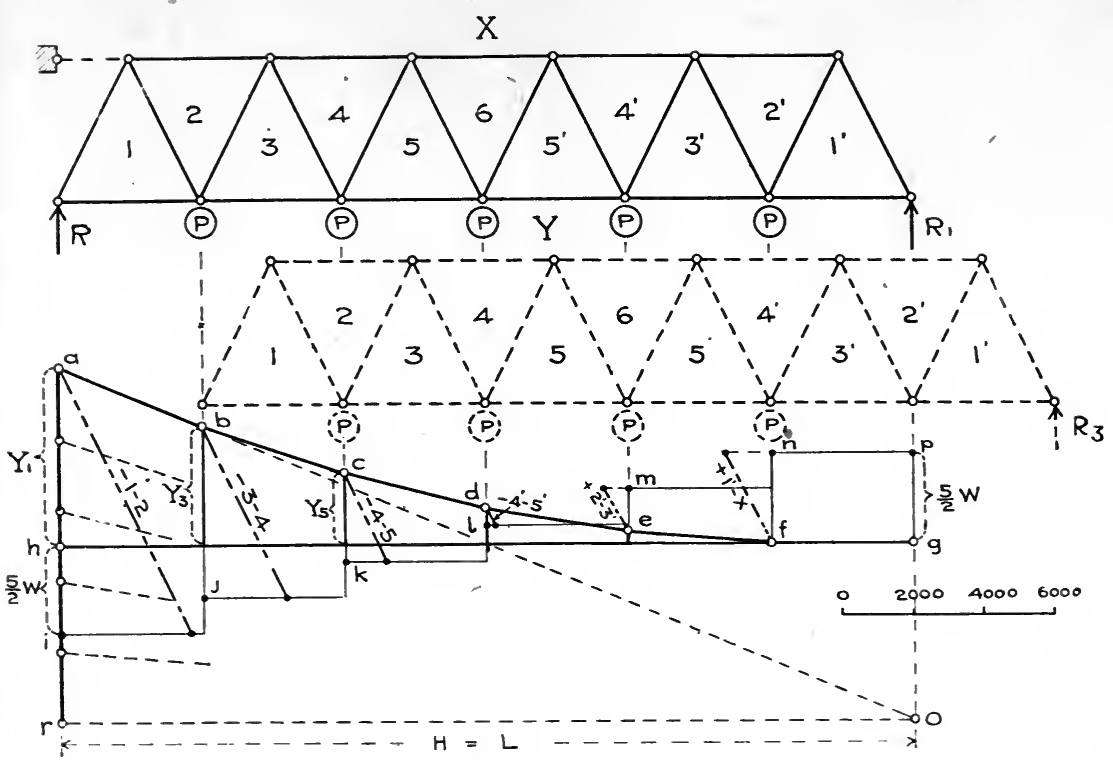

FIG. 50 .

ordinate $Y_{1}$ multiplied by the pole distance $H$. But the truss is a simple truss and the moment of the right reaction will be equal to the moment at the left abutment and

$$
Y_{1} H=R_{1} L
$$

and since $H=L$

$$
\begin{aligned}
-Y_{1} L & =R_{1} L \\
Y_{1} & =R_{1}
\end{aligned}
$$

and

Now, with the loads remaining stationary, move the truss one panel to the right as shown by the dotted truss. With the same force polygon draw a new equilibrium polygon as above. This equilibrium polygon will be identical with a part of the first equilibrium polygon as shown. As above, the bending moment at left reaction is $Y_{3} H=Y_{3} L=$ $R_{3} L$, and $Y_{3}=R_{3}$. In like manner $Y_{5}$ can be shown to be the right reaction with three loads on, etc. Since the bridge is symmetrical with reference to the center line, the ordinates to the shear polygon in Fig. 50, are equal to the maximum shears in the panel to the right of the ordinate as the load moves off the bridge to the right. 
To draw the shear parabola direct, without the use of the force and equilibritum polygons proceed as follows: At a distance of a panel length to the left of the left abutment lay off to scale a lond line equal to one-half the total load on the truss, divide this load line into as many parts as there are panels in the truss, and beginning at the top, which call I, number the points of division of the load line I, 2, 3, etc., as in Fig. 49. Drop vertical lines from the panel points and number them $\mathrm{I}, 2$, 3, etc., beginning with the load line, which will be numbered I, the left reaction numbered 2 , etc. Now connect the numbered points in the load line with the point $f$, which is under the first panel to the left of the right abutment; and the intersection of like numbered lines will give points on the shear parabola. It should be noted that the line $h g$ is a secant to the parabola and not a tangent as might be expected.

The dead load shear is laid off positive downward in Fig. 50 to the same scale as the live load shears, and the maximum and minimum shears due to dead and live loads are added graphically. The stresses in the web members are calculated graphically in Fig. 50.

Wheel Loads.-The criteria for maximum moments and shears in bridge trusses loaded with wheel loads are as follows:

(I) Maximum Moment at any joint in a bridge loaded with wheel loads will occur when the average load on the left of the section is the same as the average load on the whole span.

(2) Maximum Shear in any panel in a bridge loaded with wheel loads will occur when the load on the panel is equal to the load on the bridge divided by the number of panels.

For the proof of these criteria and for a more complete discussion of the subject, see the various standard text books on bridges. 


\section{CHAPTER XI.}

\section{Stresses in a Transverse Bent.}

Dead and Snow Load Stresses.-The stresses due to the dead load in the trusses of a transverse bent are the same as if the trusses were supported on solid walls. The stresses in the supporting columns are due to the dead load of the roof and the part of the side walls supported by the columns, and are direct compressive stresses if the columns are not fixed at the top. If the columns are fixed at the top the deflection of the truss will cause bending stress in the columns. The dead load produces no stress in the knee braces of a bent of the type shown in Fig. I except that due to deflection of the truss, which may usually be omitted The stresses may be computed by algebraic or graphic methods.

The stresses due to snow load are found in the same way as the dead load stresses. In localities having a heavy fall of snow the freezing and thawing often cause icicles to form on the eaves of sufficient weight to tear off the cornice, unless particular care has been exercised in the design of this detail.

Wind Load Stresses.-The analysis of the stresses in a bent due to wind loads is similar to the analysis of the stresses in the portal of a bridge. The external wind force is taken (I) as horizontal or (2) as normal to all surfaces. The first is the more common assumption, although the second is more nearly correct. For a comparison of the stresses in a bent due to the wind acting horizontal and normal, see Figs. 54, 55, 56 and 57, and Table V. In the discussion which immediately follows, the wind force will be assumed to act horizontally.

The magnitude of the wind stresses in the trusses, knee braces and 
columns will depend (a) upon whether the bases of the columns are fixed or free to turn, (b) upon whether the columns are rigidly fixed to the truss at the top, and (c) upon the knee brace and truss connections. Of the numerous assumptions that might be made, only two, the most probable, will be considered, viz.: (I) columns pin connected (free to turn) at the base and top, and (II) columns fixed at the base and pin connected at the top.

Columns in mill buildings are usually fixed by means of heavy bases and anchor bolts. Where the columns support heavy loads the dead load stress in the columns will assist somewhat in fixing them. Where the dead load stress plus algebraically the vertical component of the wind stress in the column, multiplied by one-half the width of the base of the column parallel to the direction of the wind, is greater than the bending moment developed at the base of the leeward column when the columns are considered as fixed, the columns will be fixed without anchor bolts (see Chapter XII, Fig. 6I). In any case the resultant moment is all that will be taken by the anchor bolts. The dead load stresses in mil! buildings are seldom sufficient to give material assistance in fixing the columns. Unless care is used in anchoring columns it is best to design mill buildings for columns hinged at the base.

The general problem of stresses in a transverse bent for Case $I$ and Case II, in which the stresses and forces are determined by algebraic methods, will now be considered. The application of the general problem will be further explained by the graphic solution of a particular problem.

ALGEBRAIC CALCULATION OF STRESSES: Case I. Columns Free to Turn at Base and Top.-In Fig. 51, $H=H^{1}$ $=\frac{W}{2}=$ horizontal reaction at the base of the column due to externa! wind force, $W$.

$V=-V^{1}=\frac{W l}{2 s}=$ vertical reaction at base of column due to the wind force, $W$.

The wind produces bending in the columns, and also the direct 
stresses $V$ and $V^{\mathbf{1}}$. Maximum bending occurs at the foot of the knee brace and is equal to $\left(H-W_{7}\right) d$ on the windward side, and $H^{1} d$ on the leeward side. These bending moments are the same as the bending moments in a simple beam supported at both ends and loaded with a concentrated load at the point of maximum moment. Since the max-

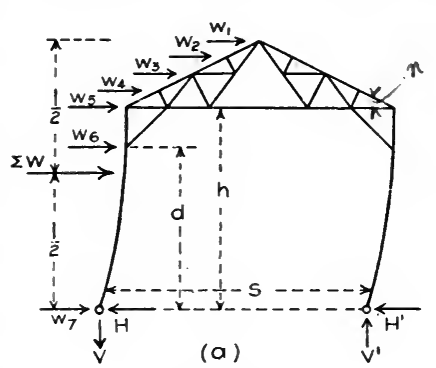

External Forces

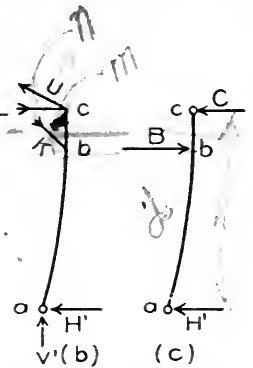

Leeward Col. Beam

FIG. 5I.

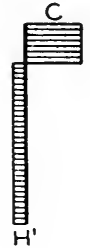

(d)

Shear Moment

imum moment occurs at the foot of the knee brace in the leeward column, we will consider only that side. We will assume that the leeward column (b), Fig. $5 \mathrm{I}$, acts as a simple beam with reactions $H^{1}$ and $C$ and a concentrated load $B$, as in (c). The reaction $C$ and load $B$ will now be calculated.

From the fundamental equation of equilibrium, summation horizontal forces equal zero, we have

$$
B=H^{1}+C
$$

Taking moments about $b$, we have

$$
\begin{gathered}
C(h-d)=H^{1} d \\
C=\frac{H^{1} d}{h-d}
\end{gathered}
$$

The stresses $K, U$ and $L$ can be computed by means of the following formulas :

$$
K=B \text { cosecant } m
$$

where $m=$ angle knee brace makes with column;

$$
U=\left(V^{1}-K \cos m\right) \text { cosecant } n
$$

where $n=$ angle of pitch of roof; and 


$$
L=C-U \cos n \checkmark
$$

In calculating the corresponding stresses on the windward side, the wind components acting at the points (a), (b) and (c) must be subtracted from $H, B$ and $C$.

The shear in the leeward column is equal to $H^{1}$ below and $C$ above the foot of the knee brace, (d) Fig. 5I.

The moment in the column is shown in (e), Fig. $5 \mathrm{I}$, and is a maximum at the foot of the knee brace and is, $M=H^{1} d$.

The maximum fibre stress due to wind moment and direct loading in the columns will occur at the foot of the knee brace in the leeward column, and will be compression on the inside and tension on the outside fibres, and is given by the formula*

$$
f_{2}+f_{1}=\frac{P}{A}+\frac{M y}{I \pm \frac{P h^{2}}{10 E}} .
$$

where $f_{1}=$ maximum fibre stress due to flexure;

$f_{2}=$ fibre stress due to direct load $P$;

$A=$ area of cross-section of column in square inches;

$M=$ bending moment in inch-pounds $=H^{1} d$;

$y=$ distance from neutral axis to extreme fibre of column in inches ;

$I=$ Moment of Inertia of column about an axis at right angles to the direction of the wind;

$P=$ direct compression in the column in pounds;

$h=$ length of the column in inches;

$E=$ the modulus of elasticity of steel $=28,000,000$;

$\frac{P h^{2}}{10 E}$ is minus when $P$ is compression and plus when $P$ is tension.

The maximum compressive wind stress is added to the direct dead and minimum snow load compression and governs the design of the column.

*This formula was first deduced by Prof. J. B. Johnson. For deduction of the formula see Chapter XV, or "Modern Framed Structures" by Johnson, Bryan and Turneaure. 
Having the stresses $K, U$, and $L$, the remaining stresses in the truss can be obtained by ordinary algebraic or graphic methods.

For a simple graphic solution of the stresses in a bent for Case I, in which these stresses are computed graphically, see Fig. 54 for wind horizontal, and Fig. 56 for wind normal to all surfaces.

Case II. Columns Fixed at the Base.-With columns fixed at the base the columns may be (I) hinged at the top, or (2) rigidly fixed to the truss.

(1) Columns fixed at the base and hinged at the top.- It will be further assumed that the deflections at the foot of the knee brace and the top of the column, Fig. 52, are equal.

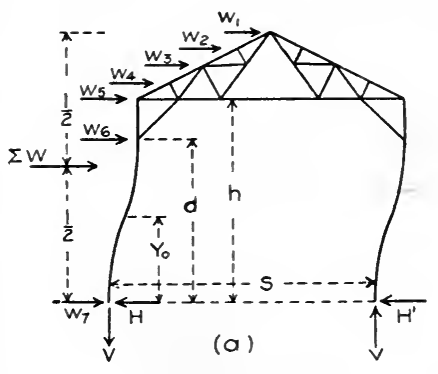

External Forces

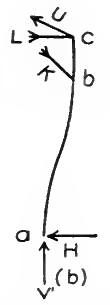

Leeward Col. Beam

FIG. 52.

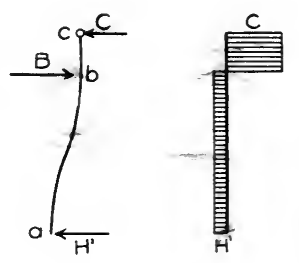

(d)

Shear Moment

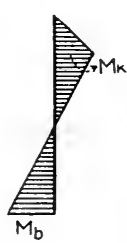

(e) (c)

In Fig. 52 we have as in Case I

$$
H=H^{1}=\frac{W}{2}
$$

$V$ and $V^{1}$ are not as easily found as in Case I, but will be calculated presently.

The leeward column will be considered and will have horizontal external forces acting on it as shown in (c) Fig. 52. For convenience we will consider the leeward column as a beam fixed at $a$ and acted upon by the horizontal forces $B$ and $C$ as shown in (c) Fig. 52, the deflection of the points $b$ and $c$ being equal by hypothesis.

From the fundamental condition of equilibrium, summation horizontal forces equal zero, we have

$$
B=H^{1}+C
$$


To obtain $B$ and $C$ a second equation is necessary.

From the theory of flexure we have for the bending moment in the column at any point $y$, where the origin is taken at the base of the column, when $y \overline{\overline{<}} d$

$$
M=E I \frac{d^{2} x}{d y^{2}}=B(d-y)-C(h-y)
$$

Integrating (32) between the limits $y=o$ and $y=d$, we have

$$
\begin{gathered}
E I \frac{d x}{d y}=\left[B d y-\frac{B y^{2}}{2}-C h y+\frac{C y^{2}}{2}+F\right]_{\begin{array}{l}
y=d \\
y=o
\end{array}} \\
=-C\left(h d-\frac{d^{2}}{2}\right)+\frac{B d^{2}}{2}
\end{gathered}
$$

Now (33) equals $E I$ times the angular change in the direction of the neutral axis of the column from $y=o$ to $y=d$.

When $y \overline{>} d$, we nave

$$
M=E \cdot I \frac{d^{2} x}{d y^{2}}=-C(h-y)
$$

Integrating (34) we have

$$
E I \frac{d x}{d y}=-C h y+\frac{C y^{2}}{2}+F_{2}
$$

Now (35) equals $E I$ times the change in direction of the neutral axis of the column at any point from $y=d$ to $y=h$.

To determine the constant $F_{2}$ in (35) we have the condition that the angle at $y=d$ must be the same whether determined from equation (33) or equation (35). Equating (33) and (35) and making $y=d$, we have

$$
F_{2}=\frac{B d^{2}}{2}
$$

Substituting this value of $F_{2}$ in $(35)$ we have

$$
E I \frac{d x}{d y}=-C h y+\frac{C y^{2}}{2}+\frac{B d^{2}}{2 \eta}
$$

Integrating (37) between the limits $y=d$ and $y=h$, we have

$$
\begin{aligned}
& E I x=\left[-\frac{C h y^{2}}{2}+\frac{C y^{3}}{6}+\frac{B d^{2} y}{2}\right]_{\begin{array}{l}
y=h \\
y=d
\end{array}} \\
& =C\left(\frac{h d^{2}}{2}-\frac{d^{3}}{6}-\frac{h^{3}}{3}\right)+B\left(\frac{d^{2} h}{2}-\frac{d^{3}}{2}\right)
\end{aligned}
$$


Now (38) equals $E I$ times the deflection of the column from $y^{\prime}=d$ to $y=h$, which equals zèro by hypothesis.

Solving (38) we have

$$
\begin{aligned}
\frac{C}{B} & =\frac{3 d^{2} h-3 d^{3}}{-3 h d^{2}+d^{3}+2 h^{3}} \\
& =\frac{3 d^{2}}{2 h_{2}^{2}+2 d h-d^{2}}
\end{aligned}
$$

In a beam fixed at one end there is a point of inflection at some point, between $y=o$ and $y=d$, where the bending moment equals zero. Now if $y_{0}$ equals the value of $y$ for the point of inflection, we have from $\left(3^{2}\right)$

$$
\begin{aligned}
B\left(d-y_{0}\right) & =C\left(h-y_{0}\right) \\
\frac{C}{B} & =\frac{d-y_{0}}{h-y_{0}^{\prime}}
\end{aligned}
$$

and

Equating the second members of equations (39) and (40) and solving for $y_{0}$, we have

$$
y_{0}=\frac{d}{2}\left(\frac{d+2 h}{2 d+h}\right)
$$

To find the relations between $y_{0}$ and $d$, we will substitute $h$ in terms of $d$ in (4I) and solve for $y_{0}$.

$$
\text { For } \begin{array}{rlrl}
d & =\frac{h}{2}, & y_{0}=\frac{5}{8} d \\
d=\frac{2}{3} h, & y_{0}=\frac{4}{7} d \\
d=h, & y_{0}=\frac{1}{2} d
\end{array}
$$

Solving (3I) and (39) for $C$, we have

$$
C=\frac{H^{1}}{2} \frac{d^{2}-}{(h-d)(h+2 d)}
$$

To find the moment $M_{\mathrm{b}}$ at the base of the leeward column, we have from (32)

$$
M_{\mathrm{b}}=B d-C h
$$

6 
Substituting the value of $B$ given in (3I) we have

$$
M_{\mathrm{b}}=H^{1} d+C d-C h
$$

Eliminating $h$ and $d$ by means of (4I) and (42) we have finally

$$
M_{\mathrm{t}}=H^{1} y_{0}
$$

In like manner it can be shown that the monent at the base of the windward column is

$$
M_{\mathrm{b}_{1}}=H y_{0}-\frac{w d^{2}}{8}
$$

where $w$ equals the wind load per foot of height.

To find $V$ we will take moments about the leeward column. The moments $M_{\mathrm{b}}$ and $M_{\mathrm{b}_{1}}$ at the bases of the columns respectively, resist overturning and we have

$$
V=-V^{1}=\frac{1}{s}\left[\frac{w l^{2}}{2}-M_{\mathrm{b}}-M_{\mathrm{b}_{1}}\right]
$$

and since

$$
H=\frac{w l}{2}
$$

$$
V=\frac{1}{s}\left[H l-2 H y_{0}+\frac{w d^{2}}{8}\right]
$$

Now if $\frac{d}{2}$ is taken equal to $y_{0}$, we have after transposing

$$
V=-V^{1}=\frac{1}{s}\left[2 H-w y_{0}\right]\left[\frac{l-y_{0}}{2}\right] .
$$

It will be seen that (45) is the same value of $V$ and $V^{1}$ that we would obtain if the bent were hinged at the point of contra-flexure.

From (43) and (45) it will be seen that we can consider the columns as hinged at the point of contra-flexure and solve the problem as in Case I, taking into account the wind above the point of contraflexure only. The maximum shear in the colimn is shown in (d) Fig. $5^{2}$.

The maximum positive moment occurs at the foot of the leeward knee brace and is $M_{\mathrm{k}}=H\left(d-y_{0}\right)$; the maximum negative moment occurs at the base of the leeward column and is equal to $M_{\mathrm{b}}=H y_{0}$. 
The maximum fibre stress occurs at the foot of the knee brace; and is given by the formula

$$
f_{2}+f_{1}=\frac{P}{A}+\frac{M y}{I \pm \frac{P h^{2}}{10 E}}
$$

The nomenclature being the same as for (30) except $h$, which is the distance in inches from the point of contra-flexure to the top of the column.

(2) Columns fixed at the base and top.-In this case it can be seen by inspection that the point of inflection is at a point $y_{0}=\frac{d}{2}$ and we have for this case

$$
\begin{gathered}
B=H^{1}+C \\
M_{\mathrm{b}}=\frac{H^{2} d}{2}=M_{\mathrm{k}} \\
C=\frac{H^{1} d}{2(h-d)}
\end{gathered}
$$

It is difficult to realize the exact conditions in either (I) or (2), in Case II, and it is probable that when an attempt is made to fix columns at the base, the actual conditions lie some place between (I) and (2). It would therefore seem reasonable to assume the minimum value, $y_{0}=\frac{d}{2}$ as the best value to use in practice. This assumption is commonly made and will be made in the problems which follow.

Having the external forces $H^{1}, B, C$ and $V^{1}$ the stresses $K, U$ and $L$ are computed by formulas (27), (28) and (29). The remaining stresses in the truss can then be computed by the ordinary algebraic or graphic methods.

For a simple graphic solution of this problem, where the ex ternal forces $B$ and $C$ are not computed, see Fig. 55 and Fig. 57 .

Maximum Stresses.-It is not probable that the maximum snow and wind loads will ever come on the building at the same time, and it is therefore not necessary to design the structure for the sum of the maximum stresses due to dead load, snow load and wind load. A 
common method is to combine the dead load stresses with the snow or the wind load stresses that will produce maximum stresses in the members. It is, however, the practice of the author to consider that a heavy sleet may be on the roof at the time of a heavy wind, and to design the structure for the maximum ştresses caused by dead and snow load; dead load, minimum snow load and wind load; or dead load and wind load. It should be noted that the maximum reversals occur when the dead and wind load are acting. For a comparison of the stresses due to the different combinations see Table VI.

A common method of computing the stresses in a truss of the Fink type for small steel frame mill buildings is to use an equivalent uniform vertical dead load; the knee braces and the members affected directly by the knee braces being designed according to the judgment of the engineer. This method is satisfactory and expeditious when used by an experienced man, but like other short cuts is dangerous when used by the inexperienced. For a comparison of the stresses in a 6o-foot Fink truss by the exact and the approximate method above, see Table VI.

Stresses in End Framing.-The external wind force on an end bent will be one-half what it would be on an intermediate transverse bent, and the shear in the columns may be taken as equal to the total external wind force divided by the number of columns in the braced panels. The stresses in the diagonal rods in the end framing, as in Fig. I, will then be equal to the external wind force $H$, divided by the number of braced panels, multiplied by the secant of the angle the diagonal rod makes with a vertical line, (For analysis of Portal Bracing see Chapter XII).

Bracing in the Upper Chord and Sides.-The intensity of the wind pressure is taken the same on the ends as on the sides, and the wind loads are applied at the bracing connection points along the end rafters and the corner columns. The shear transferred by each braced panel is equal to the total shear divided by the number of braced panels. The stresses in the diagonals in each braced panel are com- 
puted by applying, wind loads at the points above referred to, the wind loads being equal to the total wind loads divided by the number of panels. The stresses are computed as in a cantilever truss. The bracing in the plane of the lower chord is designed to prevent undue deflection of the end columns and to brace the lower chords of the trusses. All wind braces should be designed for, say, 5,000 pounds initial stress in each member, and the struts and connections should be proportioned to take the resulting stresses.

It should be noted that a mill building can be braced so as to be rigid without knee braces if the bracing be made sufficiently strong.

\section{GRAPHIC CALCULATION OF STRESSES.-Data.-To il-} lustrate the method of calculating the stresses in a transverse bent by graphic methods, the following data for a transformer building similar to one designed by the author will be taken.

The building will consist of a rigid steel frame covered with corrugated steel and will have the following dimensions: Length of building, $8 \mathrm{o}^{\prime} \mathrm{o}^{\prime \prime}$; width of building, $6 \mathrm{o}^{\prime} \mathrm{o}^{\prime \prime}$; height of columns, $20^{\prime} \mathrm{O}^{\prime \prime}$; pitch of truss, $1 / 4$ ( $6^{\prime \prime}$ in $\left.12^{\prime \prime}\right)$; total height of building, $35^{\prime} \mathrm{O}^{\prime \prime}$; the trusses will be spaced $\mathrm{I}^{\prime} \mathrm{O}^{\prime \prime}$ center to center. The trusses will be riveted Fink trusses. Purlins will be placed at the panel points of the trusses and will be spaced for a normal roof load of $30 \mathrm{lbs}$. per square foot. The roof covering will consist of No. 20 corrugated steel with $21 / 2$-inch corrugations, laid with 6 -inch end laps and two corrugations side lap, with anti-condensation lining (see Chapter XVIII). The side covering will consist of an outside covering of No. 22 corrugated steel with $2 \frac{1}{2}$-inch corrugations, laid with 4 -inch end laps and one corrugation side lap; and an inside lining of No. 24 corrugated steel with $\mathrm{I} / 4$-inch corrugations, laid with 4 -inch end laps and one corrugation side lap. For additional warmth two layers of tar paper will be put inside of the lining. Three $3^{6-i n c h}$ Star ventilators placed on the ridge of the roof will be used for ventilation. The general arangement of the framing and bracing will be as in Fig. $\mathrm{I}$ and Fig. 8r. 
The approximate weight of the roof per square foot of horizontal projection wili be as follows :

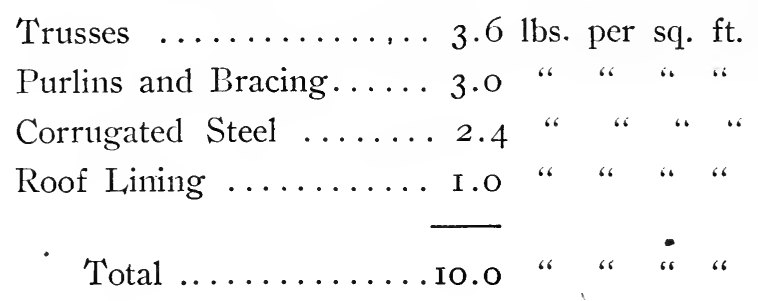

The maximum snow load will be taken at 20 pounds, and the minimum snow load at Io pounds per square foot of horizontal projection of roof.

The wind load will be taken at 20 pounds per square foot on a vertical projection for the sides and ends of the building, 20 pounds per square foot on a vertical surface when the wind is considered as acting horizontally on the vertical projection of the roof, and 30 pounds per square foot on a vertical surface when the wind is considered as acting normal to the roof.

The stresses in an intermediate transverse bent will be calculated for the following:

CASE I. Permanent dead and snow loads.

is 4 CASE 2. A horizontal wind load of 20 pounds per square foot on the sides and vertical projections of the roof, with the columns hinged at the base.

CASE 3. Same wind load as in Case 2, with columns fixed at the base.

CASE 4. A horizontal wind load of 20 pounds per square foot on the sides, and the normal component of a horizontal wind load of 30 pounds per square foot on the roof, with columns hinged at the base. N. Case 5. Same wind load as in Case 4, with columns fixed at the base.

Case I. Permanent Dead and Snow Load Stresses.-On account of the limited size of the stress diagram the secondary members have been omitted and the loads applied as shown in Fig. 53. The 
loads producing stresses in the truss are laid off to the prescribed scale, $x_{1}-y$ being the left, and $y-x_{8}$ the right reaction. The stresses are calculated as follows: Beginning with the left reaction, $x_{1}-y$, draw lines through $x_{1}$ and $y$, parallel to the upper and lower chords of the truss, respectively, and the line $x_{1}-2$ will represent the compressive stress in the member $x_{1}-2$ and $y-2$ will represent the tensile stress in the member $y-2$ to the scale of the stress diagram.

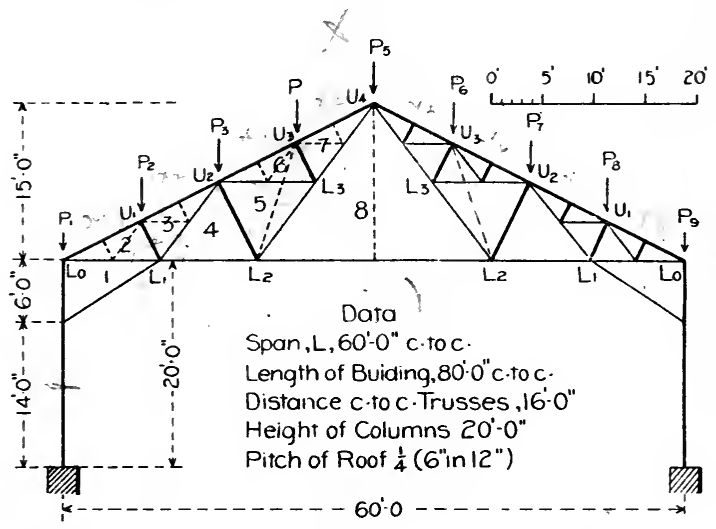

\section{CASE 1}

Dead Load $10 \mathrm{Ibs}$.per sq.ft. hor. projection Dead Load Stress Diagram o $2000 \quad 4000 \quad 6000$

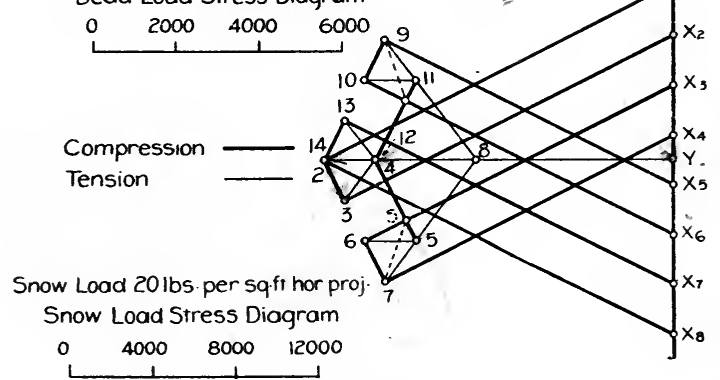

Fig. 53. Defad and Snow Load Stress Diagram.

Calculate the stresses in the remaining members in like manner, being careful to take the members in order around a joint in completing any polygon. The indeterminate case at the joint $U_{2}$, can be 
solved by calculating the stress in $5^{-6}$ and substituting it in the diagran, or by substituting an auxiliary member as shown. Compression and tension in the truss and stress diagram in Fig. 53 are indicated by heavy and light lines respectively.

The stress in each column is equal to one-half the sum of the vertical loads, plus the load carried directly by the column.

Case 2. Wind Lcad Stresses: Wind Horizontal; Columns Hinged.-The wind will be considered as acting at the joints, as shown in Fig. 54. Replace the columns with trusses as indicated by the dotted lines. This makes the bent a two-hinged arch (see Chapter XIV), and the stresses will be statically determinate as soon as the horizontal reactions $H$ and $H^{1}$ at the bases of the columns, have been determined. The usual assumption in mill buildings and portals of bridges is that $H=H^{1}=\frac{W}{2}$ where $W=$ the horizontal component of the external wind force (see Chapter XII). To calculate $V$ and $V^{1}$ graplically, produce the line of resultant wind until it inersects a vertical line through the center of the truss, and connect the intersection $A$ with the bases of the columns $B$ and $C$. From $A$ lay off $H=H^{1}=\frac{W}{2}$, as shown in Fig. 54, and complete the triangles by drawing vertical lines through the ends of these lines. The vertical closing lines will be $V=-V^{1}$, as shown in Fig. 54 .

The stresses are calculated as follows: Beginning with the foot of the column $B$, lay off the dotted line $A-B=R$. At $B$, lay off the load $a-B=2240$ lbs. ; through $a$ draw a line parallel to auxiliary truss member $a-b$, and through $A$ draw a line parallel to the column $b-A$, completing the polygon $A-B-a-b$.

The line $a-b$ in the stress diagram will be the compression in the auxiliary member $a-b$, and $A-b$ will be the tension in the column $A-b$. It should be noted that $V$ is equal to the algebraic sum of the vertical components of the stresses in $a-b$ and $A-b$. Next lay off $x-a=3200$ lbs. and complete the polygon $a-x-c-b$ by drawing lines through $x$ and $b$ parallel to the auxiliary truss members $x-c$ and $b-c$ respectively. In like manner determine the stresses at the foot of the knee brace by con- 
structing the polygon $A-b-c-I$; and at the top of the column by constructing the polygon $c-x-x-2-1$, etc., until the diagram is cnecked up at $C$ with $C-A=R^{1}$. The indeterminate case at the joint $U_{2}$, can be solved
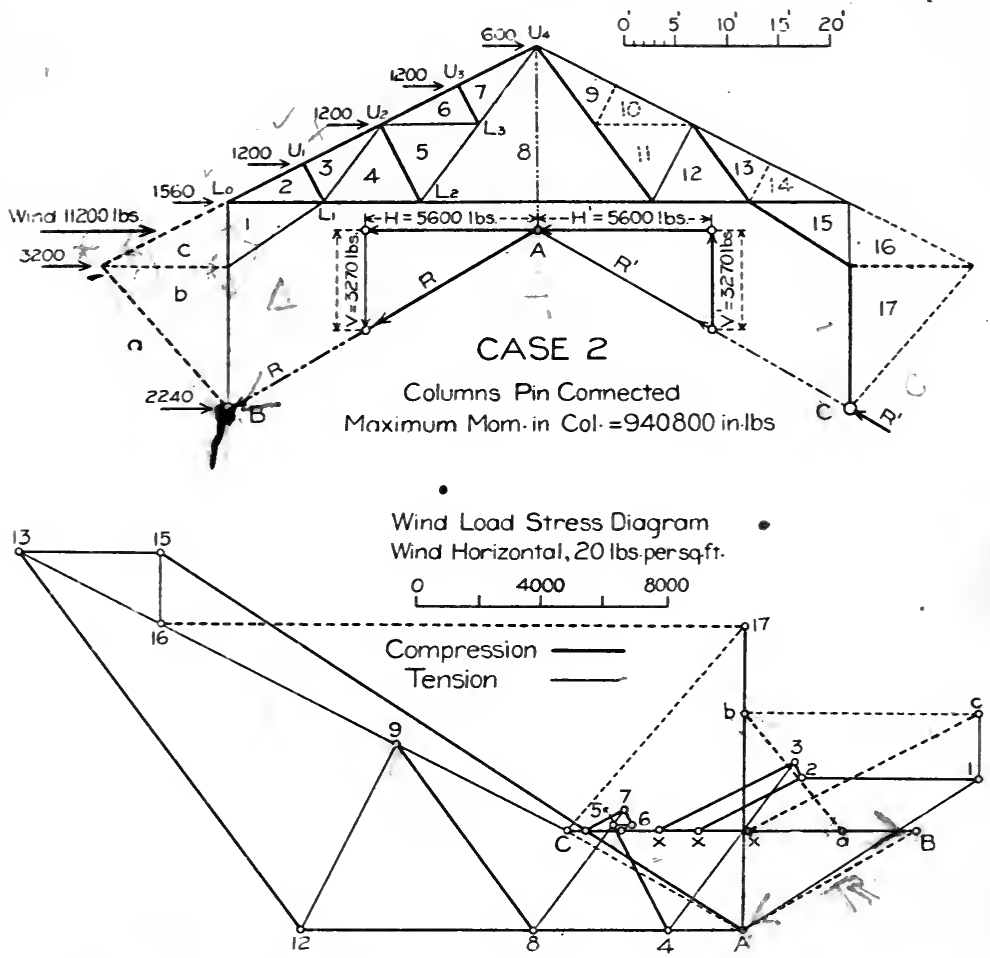

Fig. 54. Wind LOAD STRESS DIAGRAM, CASF 2.

by computing the stress in 5-6 (component due to stress in 6-7), and substituting it in the diagram, or by substituting an auxiliary member.

The stresses in the auxiliary members are represented by dotted lines and are of no value in designing the bent. It should be noted that the auxiliary members do not affect the stresses in the trusses and knee braces, which are correctly given in the stress diagram.

The maximum stress in the knee brace $A-15$ is compression, and occurs on the leeward side. 
The maximum shea: in the leeward column below the knee brace is $H^{1}=5600$ lbs.; the maximum shear above the knee brace is I3, IOo lbs. The maximum moment occurs at the foot of the knee brace and is $H^{1} \times \mathrm{I}_{4} \times \mathrm{I}_{2}=940,800$ inch-1bs.

\section{Case 3. Wind Load Stresses: Wind Horizontal; Columns} Fixed at Base.--This is Case 2 with the base of the column hinged at the point of contra-flexure. In calculating $H$ and $V$, Fig: 55 , the wind
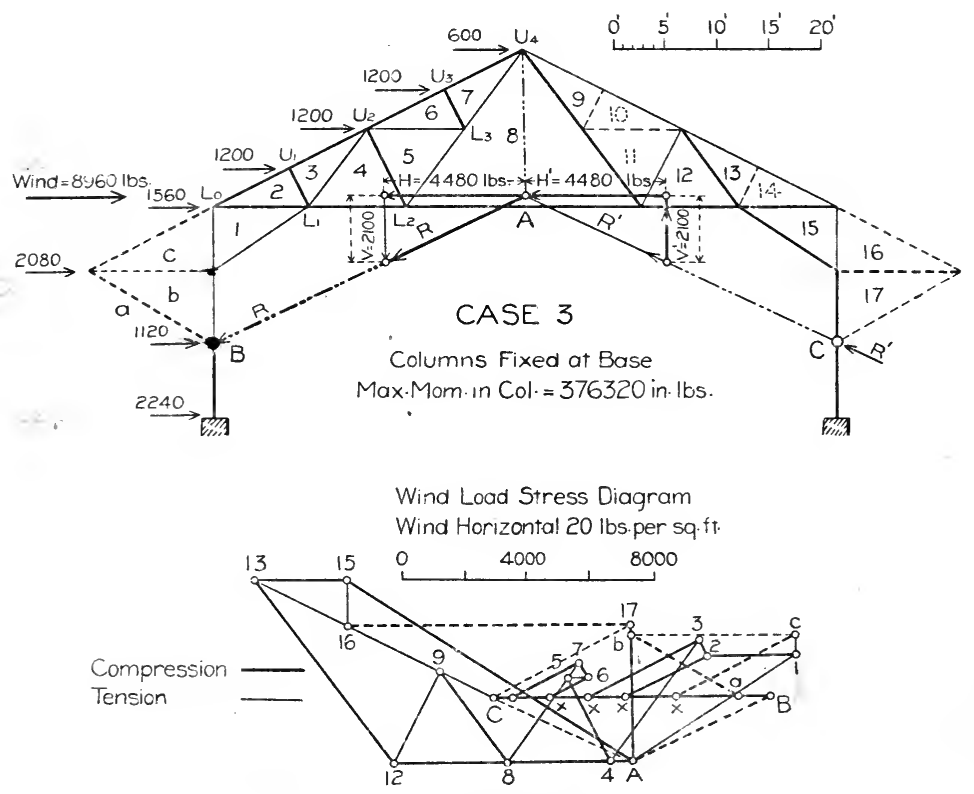

Fig. 55. WIND I.OAD STRESS DIAGRAM, CASE 3.

above the point of contra-flexure only (see formula (45)) produces stresses in the bent. The value of fixing the columns at the base is seen by comparing the stresses in Case 2 with those in Case 3, both being drawn to the same scale. Maximum shear in the leeward column below the knee brace is $H^{1}=4480$ 1bs.; above the knee brace is 5230 lbs. The maximum positive moment occurs at the foot of the knee brace and negative moment at the foot of the column, and is $H^{1} \times T$ $\times 12=376,320$ inch-1bs. 
Case 4. Wind Load Stresses: Wind Normal; Columns Hinged. - In Fig. 56 the resultant of the external wind forces on the sides and the roof acts through tineir intersection, and is parallel to $C B$ in the stress diagram (line $C B$ is not drawn). To calculate $V$ and $V^{1}$ connect the point of intersection, $A$, of the resultant wind and the vertical line through the center of truss, with the bases of the columns $B$ and $C$

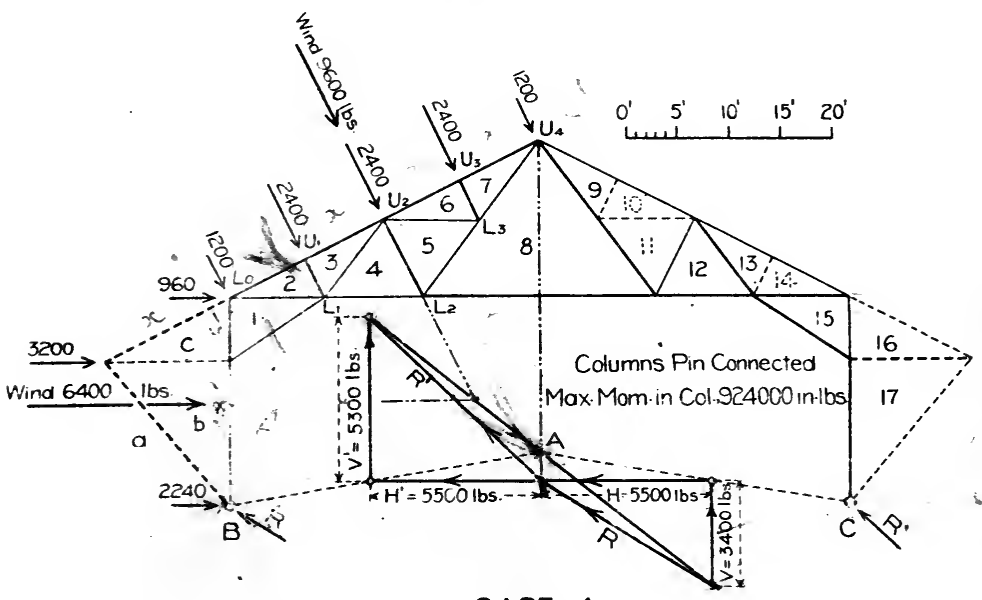

CASE 4

Wind Load Stress Diagram

Wind Normal, Roof $18 \mathrm{lbs}$.Sides $20 \mathrm{lbs}$ sq ft.
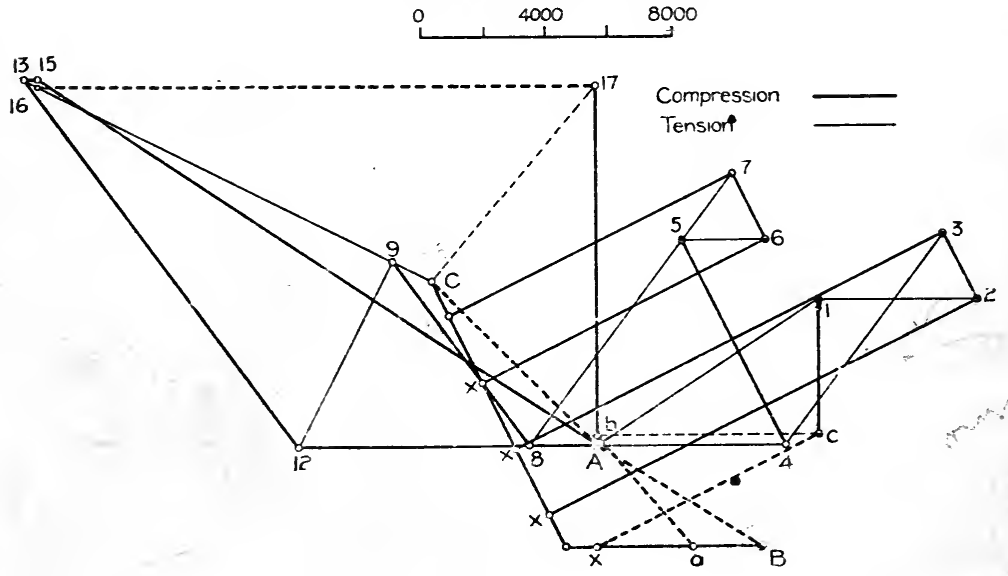

Fig. 56. WINI IOA') STRESS DIAGRAM, C.ISE 4 . 
From $A$ lay off one-half of resultant wind on each side, and from the extreme ends drop vertical lines $V$ and $V^{1}$ to the dotted lines $A B$ and $A C$. The vertical lines $V$ and $V^{1}$ will be the vertical reactions, the horizontal lines will be $H$ and $H^{1}$, and $R$ and $R^{1}$ will be the resultants of the horizontal and verticai reactions at $B$ and $C$ respectively. The stresses are calculated by beginning at the base of the column $B$ as in Case 2. In the polygon $a-B-A-b$ at $B, A-B=R, a-B=2240$ lbs., and $a-b$ and $A-b$ are the stresses in $a-b$ and $A-b$ respectively.

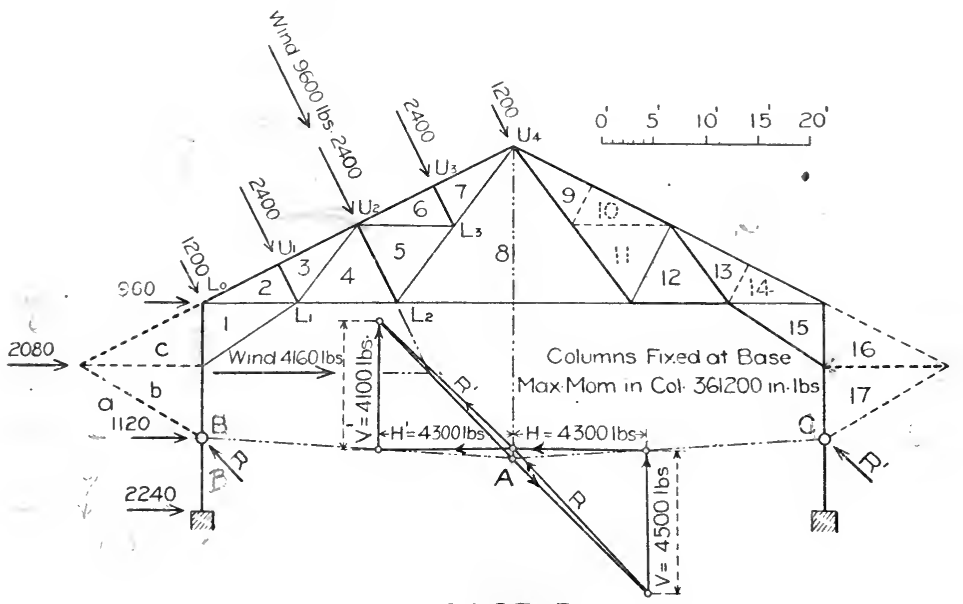

CASE 5

Wind Load Stress Diagram

Wind Normal, Roof $18 \mathrm{lbs}$. Sides $20 \mathrm{lbs}$. sq.ft.

0 4000 8000

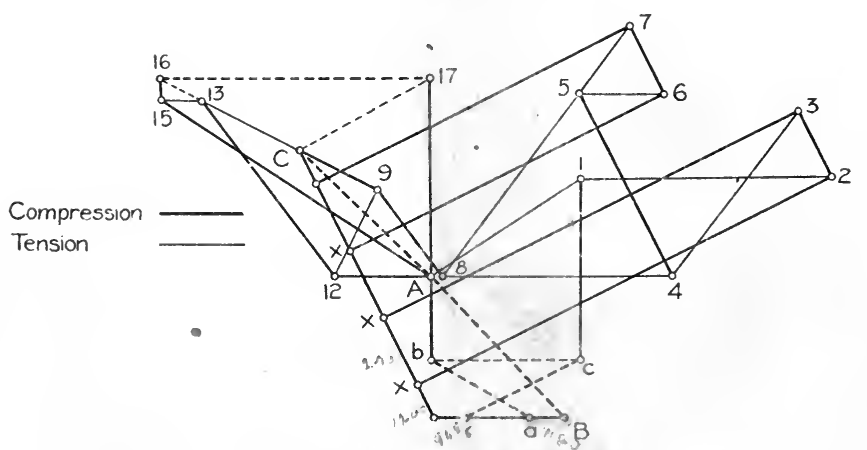

FIG. 57. WIIND I,OAD STRI SS DIAGRAM, CASE 5 . 
The maximum shear in the leeward column below the knee brace is $H^{1}=5500$ lbs., above the knee brace is $12,800 \mathrm{lbs}$. ; the maximum moment occurs at the foot of the knee brace and is $H^{1} \times 14 \times 12=$ 924,000 inch-lbs.

Case 5. Wind Load Stresses: Wind Normal; Columns Fixed at Base.-This is Case 4 with the base of the column moved up to the point of contra-flexure The maximum shear in the leeward column below the knee brace is 4300 lbs., above the knee brace is $5000 \mathrm{lbs}$.; the maximum positive moment occurs at the foot of the knee brace and negative moment at the foot of the column and is $H^{1} \times 7 \times 12=361,200$ inch-lbs. For analysis see Fig. 57.

Maximum Stresses.-The stresses in the different members cf the bent for the different cases are given in Table $V$. The maximum

TABLE V.

\begin{tabular}{|c|c|c|c|c|c|c|}
\hline & \multicolumn{6}{|c|}{ Stresses in a Bent For } \\
\cline { 2 - 7 } Name & Dead & Snow & \multicolumn{5}{|c|}{ Wind } & Load \\
\cline { 4 - 7 } Piece & Load & Load & Case 2 & Case & Case 4 Case \\
\hline$X-2$ & +9300 & +18900 & +3700 & +2900 & +15400 & +14900 \\
$X-3$ & +8800 & +17600 & +4900 & +4000 & +15400 & +14900 \\
$X-6$ & +8200 & +16400 & +400 & +1400 & +10200 & +11200 \\
$X-7$ & +7700 & +15400 & +1400 & +3400 & +10200 & +11200 \\
$X-9$ & +7700 & +15400 & -6100 & -1900 & -1400 & +2800 \\
$X-13$ & +9300 & +18600 & -19800 & -8600 & -14600 & -3600 \\
$1-2$ & -8300 & -16600 & +5700 & +2800 & -5100 & -8000 \\
$2-3$ & +1100 & +2200 & +500 & +500 & +2400 & +2400 \\
$3-4$ & -1200 & -2400 & -6800 & -4900 & -8500 & -6700 \\
$4-5$ & +2200 & +4400 & +3800 & +3000 & +7300 & +6600 \\
$5-6$ & -1200 & -2400 & -600 & -600 & -2600 & -2600 \\
$6-7$ & +1100 & +2200 & +500 & +500 & +2400 & +2400 \\
$5-8$ & -2400 & -4800 & -4300 & -3300 & -8200 & -7400 \\
$7-8$ & -3600 & -7200 & -4900 & -3900 & -10800 & -10000 \\
$8-9$ & -3600 & -7200 & +7500 & +3600 & +7400 & +3500 \\
$9-12$ & +2200 & +4400 & -5700 & -3200 & -6700 & -3200 \\
$12-13$ & -1200 & -2400 & +15200 & +7400 & +14800 & +7000 \\
$Y-4$ & -7100 & -14200 & +2400 & +800 & -6000 & -7700 \\
$Y-8$ & -4700 & -7400 & +6800 & +4000 & +2200 & -400 \\
$Y-12$ & -7100 & -14200 & +14200 & +7700 & +9700 & +2100 \\
$13-15$ & -8300 & -16600 & +4600 & +3000 & +500 & -1300 \\
$A-1$ & + & & -9000 & -6200 & -8500 & -6700 \\
$A-15$ & & & +22300 & +11000 & +21500 & +10400 \\
$A-b$ & +4800 & +9600 & -3200 & -2100 & +3400 & +4500 \\
$C-1$ & +4800 & +9600 & +1700 & +1300 & +8000 & +7500 \\
$A-17$ & +4800 & +9600 & +3200 & +2100 & +5300 & +4100 \\
$15-16$ & +4800 & +9600 & -8600 & -3800 & -6400 & -2400 \\
\hline
\end{tabular}


stresses in the different members of the bent for (I) dead load plus maximum snow load; (2) dead load plus wind load, Case 4; (3) dead load plus minimum snow load plus wind load, Case 4 ; and (4) a vertical dead load of $40 \mathrm{lbs}$. per sq. $\mathrm{ft}$. horizontal projection of the roof are given in Table VI. 'The stresses which control the design of the members may be seen in Table VI. By comparing these values with the stresses given in the last column the accuracy of the equivalent load method can be seen.

TABLE VI.

\begin{tabular}{|c|c|c|c|c|}
\hline \multicolumn{5}{|c|}{ Maximum Stresses ina Bent For } \\
\hline $\begin{array}{l}\text { Name } \\
\text { of } \\
\text { Piece }\end{array}$ & $\begin{array}{l}\text { Dead Load } \\
\text { +Max.Snow } \\
\text { Load }\end{array}$ & $\begin{array}{l}\text { Dead Load } \\
\text { Wind Load } \\
\text { Case } 4\end{array}$ & $\begin{array}{l}\text { Dead Load+Min. } \\
\text { Snow Load+Wind } \\
\text { Load. Case } 4\end{array}$ & $\begin{array}{l}\text { Vert.Dead Load } \\
\text { of } 40 \text { lbs.per Sq } \\
\text { Ft.of Hor.Proj. }\end{array}$ \\
\hline$x-2$ & +28200 & +24700 & +34300 & +37200 \\
\hline$\hat{x}-3$ & +26400 & $+24200^{\prime}$ & +33000 & +35200 \\
\hline$x-6$ & +26400 & +18400 & +26600 & +32800 \\
\hline$x-7$ & +23100 & +17900 & +25600 & +30800 \\
\hline$x-9$ & +23100 & +6300 & +14000 & +30800 \\
\hline$x-13$ & +28200 & -5300 & +4000 & +37200 \\
\hline $1-2$ & -24900 & -13400 & -21700 & -33200 \\
\hline $2-3$ & +3300 & +3500 & +4600 & +4400 \\
\hline $3-4$ & -3600 & -9700 & -10900 & -4800 \\
\hline $4-5$ & +6600 & +9500 & +11700 & +8800 \\
\hline $5-6$ & -3600 & -3800 & -5000 & -4800 \\
\hline $6-7$ & +3300 & +3500 & +4600 & +4400 \\
\hline $5-8$ & -7200 & -10600 & -13000 & -9600 \\
\hline $7-8$ & -10800 & -14400 & -18000 & -14400 \\
\hline $8-9$ & -10800 & +3800 & +200 & -14400 \\
\hline $9-12$ & +6600 & -4500 & -2300 & +8800 \\
\hline $12-13$ & -3600 & +13600 & +12400 & -4800 \\
\hline$Y-4$ & -21300 & -13100 & -20200 & -28400 \\
\hline$Y-8$ & -14100 & -2500 & -5200 & -14800 \\
\hline$Y-12$ & -23100 & +2600 & -4500 & -28400 \\
\hline $13-15$ & -24900 & -7800 & -16100 & -32400 \\
\hline$A-1$ & & -8500 & -8500 & \\
\hline$A-15$ & & +21500 & -21500 & \\
\hline$A-b$ & +14400 & +8200 & +13000 & +19200 \\
\hline$C-1$ & +14400 & +12800 & +17600 & +19200 \\
\hline A-17 & +14400 & +10100 & +14900 & +19200 \\
\hline $15-16$ & +14400 & -1600 & +3200 & +19200 \\
\hline
\end{tabular}




\section{CHAPTER XII.}

\section{StREsSes IN PoRTALS.}

Introduction.-Portal bracing is frequently used for bracing the sides of mill buildings and open sheds. There are many forms of portal bracing in use, a few of the most common of which are shown in Fig. $5^{8}$.

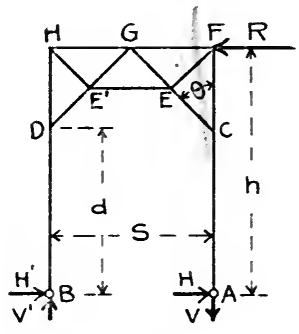

(a)

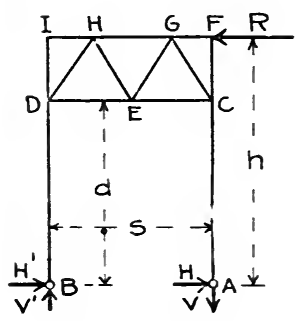

(d)

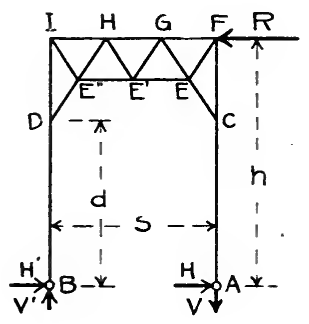

(b)

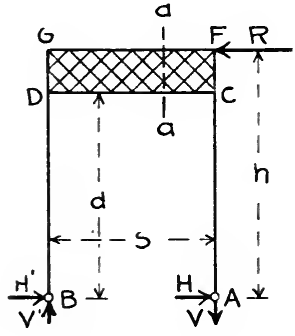

(e)

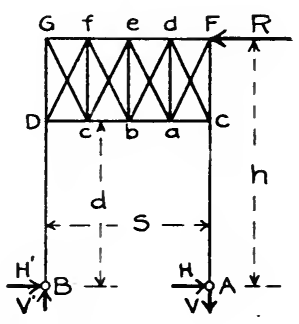

(c)

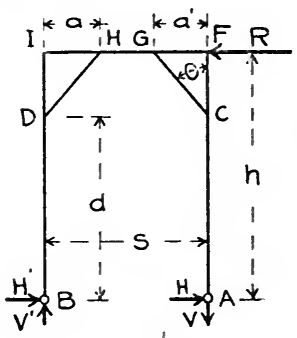

$(f)$

FiG. 58.

Portal bracing may be in separate panels or may be continuous. The columns may be hinged or fixed at the base in either case. 
CASE I. STRESSES IN SIMPLE PORTALS: Columns Hinged.-The deflections of the columns ir the portals shown in Fig. $5^{8}$ are assumed to be equal and

$$
H=H^{1}=\frac{R}{2}
$$

Taking moments about the foot of the windward column

$$
V^{1}=-V=\frac{R h}{s}
$$

Having found the external forces, the stresses in the members may be found by either algebraic or graphic methods.

Algebraic Solution.-Portal $(a)$.- To obtain the stress in nember $G C$, (a) Fig. 58, pass a section cutting $G F, E F$ and $G C$, and take moments of the external forces to the right of the section about point $F$ as a center.

$$
G C=-\frac{H h}{(h-d) \sin \theta}
$$

But $H=\frac{R}{2}$. and $(h-d) \sin \theta=\frac{s}{2} \cos \theta$. Substituting these values in (46) we have

$$
G C=-\frac{R h}{s \cos \theta}=-V \sec \theta
$$

Resolving at $C$ and $F$ we have, stress in $E F=0$, and also stresses $E_{i}^{\prime} E^{\prime}$ and $H E^{\prime}=0$.

To obtain stress in $G D$, pass section cutting $H G, H E^{\prime}$ and $G D$, and take moments of the external forces to the left of the section about point $H$ as a center.

$$
G D^{\prime}=\frac{H h}{(h-d) \sin \theta}=+V \sec \theta
$$

To obtain stress in $G F$, pass a section cutting $G F, E F$ and $G C$, and take moments of the external forces to the right of the section about point $C$ as a center.

$$
G F=+\frac{R(h-d)+H d}{h-d}
$$


To obtain stress in $H G$, pass a section cutting $H G, H E^{\prime}$ and $G D$, and take moments of the sxternal forces to the left of the section about the point $D$ as a center.

$$
H G=-\frac{H d}{h-d}
$$

The stress in the windward post, $A F$, is zero above and $V$ below the foot of the knee brace $C$; the stress in the leeward pust is zero above and $V^{1}$ below the foot of the knee brace $D$.'

The shear in the posts is $H$ below the foot of the knee brace, and above the foot of the kriee brace is given by the formula

$$
' S=\frac{H d}{h-d}{ }^{\prime}=\text { stress in } H G
$$

The maximum moment in the posts occurs at the foot of the knee braces $C$ and $D$ and is

$$
M=H d
$$

For the actual stresses, moments and shears in a portal of this type, see Fig. 59.

Portal (b).-The stresses in portal (b) Fig. 58, are found in the same manner as in portal (a). The graphic solution of a similar portal with one more panel is given in Fig. 60, which see. It should be noted that all members are stressed in portals (b) and (d).

Portal (c).-The stresses in portal (c) Fig. 58 , may be obtained (I) by separating the portal into two separate portals with simple bracing, the stresses found by calculating the separate simple portals with a load $=1 / 2 R$ beng combined algebraically, to give the stresses in the portal; or (2) by assuming that the stresses are all taken by the system of bracing in which the diagonal ties are in tension. The latter method is the one usually employed and is the simpler.

Maximum moment, shear, and stresses in the columns are given by the same formulas as in (a) Fig. 58 .

Portal (e).-In portal (e) Fig. 58, the flanges $G F$ and $D C$ are assumed to take all the bending moment, and the lattice web bracing 
is assumed to take all the shear. The maximum compression in the upper flange $G F$ occurs at $F$, and is

$$
G F=+\frac{R(h-d)+H d}{h-d}
$$

The maximum stress in the lower flange $D C$ is

$$
G F=-\frac{H d}{h-d}
$$

The maximum stress in the lower flange $D C$ is

$$
D C= \pm \frac{H h}{h-d}
$$

maximum tension occurring at $C$, and maximum compression occurring at $D$.

The maximum shear in the portal strut is $V$, which is assumed as taken equally by the lattice members cut by a section, as $a$ a.

Maximum moment, shear, and stresses in the columns are given by the same formulas as in (a) Fig. $5^{8}$.

Portal $(f)$.- The maximum moment in the portal strut $I F$ in (f) Fig. 58 , occurs at $H$ and $G$, and is

$$
M=+H h-V a
$$

The maximum direct stress in $H G$ is $+R$, and in $I H$ is

$$
I H=-\frac{H d}{h-d}
$$

The maximum stress in $G F$ is given by formula (49).

The maximum shear in girder $I F$ is equal to $V$. The stress in $G C$ is $-V \sec \theta$ and in $H D$ is $+V \sec \theta$, as in (a) Fig. $5^{8}$.

Portal strut $I F$ designed as a girder to take the maximum moment, shear and direct stress.

Maximum moment, shear, and stresses in the columns are given by the same formulas as in (a) Fig. $5^{8}$.

Graphic Solution.--To make the solution of the stresses statically determinate, replace the columns in the portal with trussed framework 
as in Fig. 59. The stresses in the interior members are not affected by the change and will be correctly given by graphic resolution.
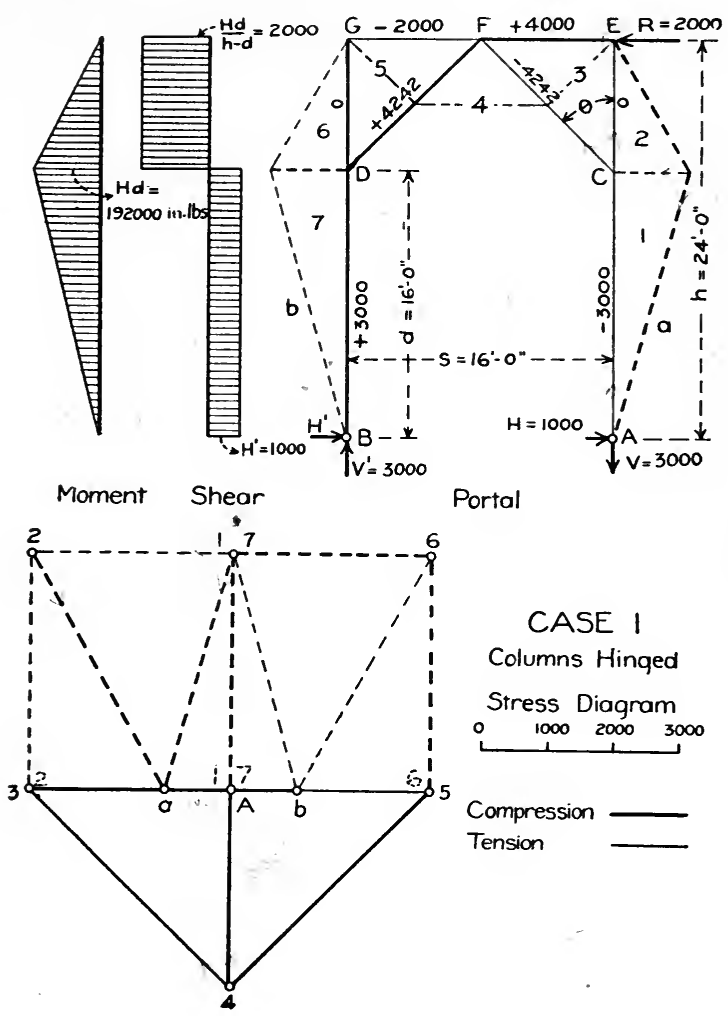

Portal

FIG. 59 .

As before $H=H^{1}=\frac{R}{2}$ and $V=-V^{1}=\frac{R h}{s}$

Having the calculated $H, H^{1}, V$, and $V^{1}$, the stresses are calculated by graphic resolution as follows: Beginning at the base of the column $A$, lay off $A-4=V=3000$ lbs. acting downward, and $A-a=H=1000$ lbs. acting to the right. Then $a-\mathrm{I}$ and $4-\mathrm{I}$ are the stresses in members $a-\mathrm{I}$ and 4-I, respectively, heavy lines indicating compression and light lines tension. At joint in auxiliary truss to right of $C$ the stress in I- $a$ is known and stresses in I-2 and 2- $a$ are found by closing the polygon. 
The stresses in the remaining members are found in like manner, taking joints $C, E, F$, etc. in order, and finally checking up at the base of the column $B$. The full lines in the stress diagram represent stresses in the portal; the dotted lines represent stresses in the auxiliary members or stresses in members due to auxiliary members, and are of no consequence. The shears and moments are shown in the diagram.

b

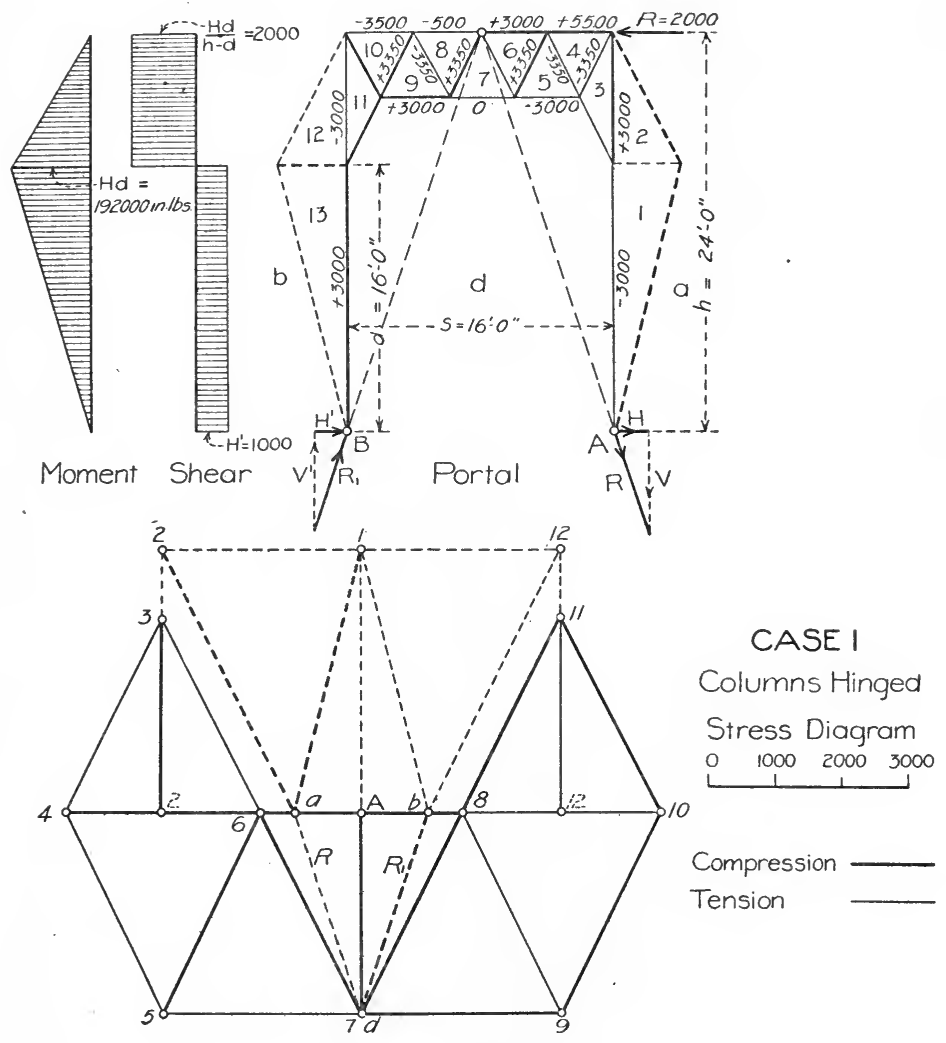

FIG. 60.

Simple Portal as a Three-Hinged Arch.-In a simple portal the resultant reactions and the external load $R$ meet in a point at the middle of the top strut, and the portal then becomes a three-hinged arch 
(see Chapter XIII), provided there is a joint at that point (point $b$, Fig. 60).

In Fig. 60 the reactions were calculated graphically and the stresses in the portal were calculated by graphic resolution. Full lines in the stress diagram represent required stresses in the members. Stresses $3^{-2}$ and I I-1 2 were determined by dropping verticals from points 3 and I I to the load line 4 -Io.

CASE II. STRESSES IN SIMPLE PORTALS: Columns Fixed.-The calculation of the stresses in a portal with columns fixed at the base is similar to the calculation of stresses in a transverse bent with columns fixed at the base. The point of contra-flexure is at the point

$$
y_{\circ}=\frac{d}{2}\left(\frac{d+2 h}{2 d+h}\right)
$$

measured up from the hase of the column. The point of contra-flexure is usually taken at a point a distance $\frac{d}{2}$ above the bases of the columns.

The stresses in a portal with columns fixed may be calculated by considering the columns hinged at the point of contra-flexure and solving as in Case $\mathrm{I}$.

Algebraic Solution.-In Fig. 6I we have

$$
\begin{gathered}
H=H^{1}=\frac{R}{2} \\
\text { and } \quad V=-V^{1}=\frac{R\left(h-\frac{d}{2}\right)}{s}
\end{gathered}
$$

Having found the reactions $H$ and $H^{1}, V$ and $V^{1}$, the stresses in the members are found by taking moments as in (a) Fig. 58, considering the columns as hinged at the point of contra-flexure.

The shear diagram for the columns is as shown in (a) and the moment diagram as in (c) Fig. 6r.

Anchorage of Columns.-In order that the columns be fixed, the anchorage of each column must be capable of developing a resisting moment greater than the overturning moment $M=-\frac{H d}{2}$, shown in 
(c) Fig. 6I. The anchorage required on the windward side is a maximum and may be calculated as follows: Let $T$ be the tension in the windward anchor bolt, $2 a$ be the distance center to center of anchor

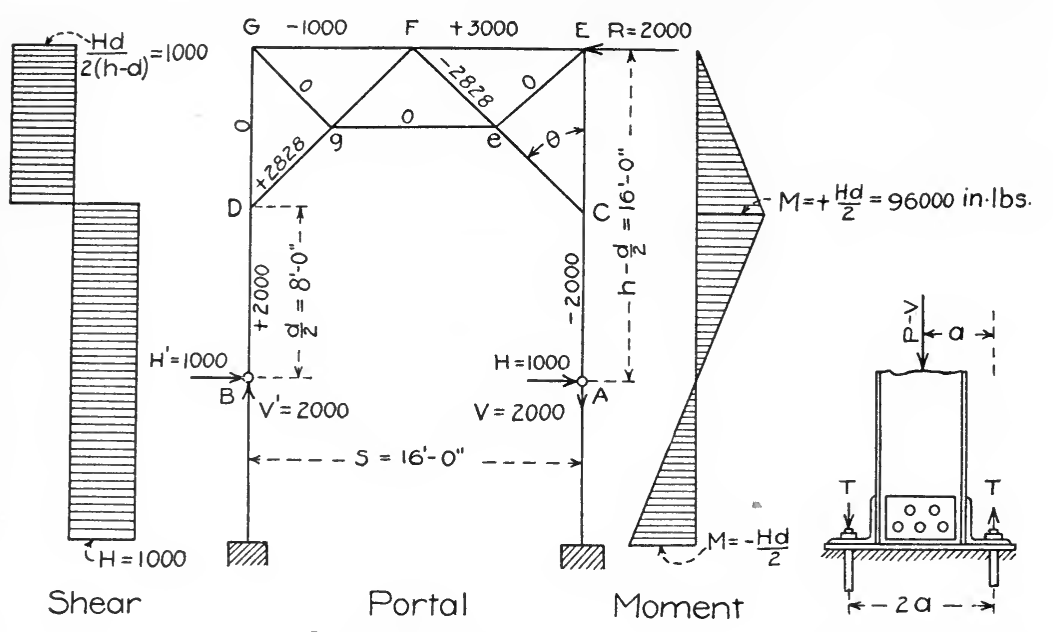

(a)

Columns Fixed

(b)

(c)

Base of Column

(d)

FIG. 6I.

bolts, and $P$ be the direct load on the coltumn. Taking moments about the leeward anchor bolt we have

$$
\begin{gathered}
2 T a-(P-V) a+\frac{H d}{2}=0 \\
T=-\frac{H d}{4 a}+\frac{P-V}{2}
\end{gathered}
$$

If the nuts on the anchor bolts are not screwed down tight, there will be a tendency for the column to rotate about the leeward edge of the base plate, and both anchor bolts will resist overturning.

The maximum pressure on the masonry will occur under the leeward edge of the base plate and will be

$$
S=\frac{W}{A}+\frac{M c}{I}
$$


where $W=$ direct stress in post;

$A=$ area of base of column in sq. ins.;

$M=$ bending moment $=\mathrm{I} / 2 \mathrm{Hd}$;

$c=$ one-half the length of the base plate;

$I=$ moment of inertia of the base plate about an axis at right angles to the direction of the wind.

Graphic Solution.-The stresses in the portal in Fig. 62 have been calculated by graphic resolution. This problem is solved in the same manner as the simple portạl with hinged columns in Fig. 59.

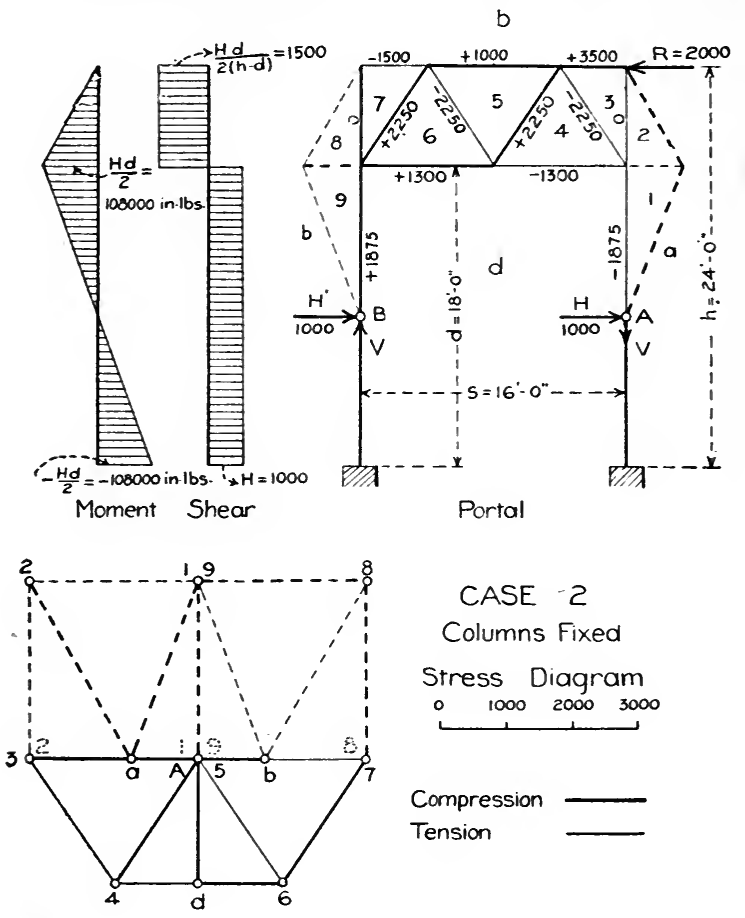

FIG. 62.

STRESSES IN CONTINUOUS PORTALS. - The portal with five bays shown in Fig. 63 will be considered. The columns will all be assumed alike and the deformation of the framework will be neglected. The shears in the columns at the base will be equal, and will 
be

$$
H=\frac{R}{6}
$$

To find the vertical reactions proceed as follows: Determine the center of gravity of the columns by taking moments about the base of one of the columns. Now there will be tension in each one of the columns on the windward side and compression in each one of the columns on the leeward side of the center of gravity of the columns. The sum of the moments of the reactions must be equal to the moment

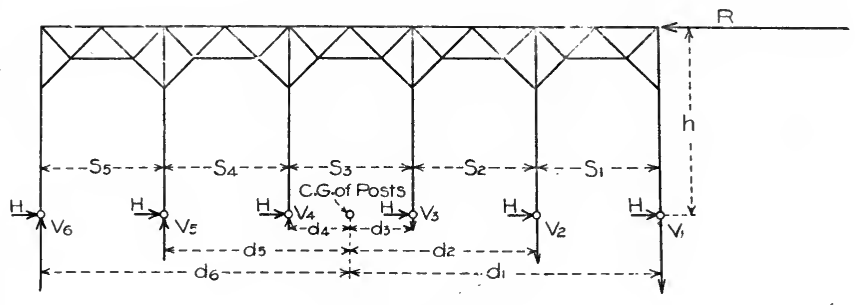

FIG. 63.

of the external wind load, $R$. The reactions at the bases of the columns will vary as the distance from the center of gravity and their moments will vary as the square of the distance from the center of gravity. Now, if $a$ equals the reaction of a column at a units distance from the center of gravity, we will have $V_{1}=-a d_{1}, V_{2}=-a d_{2}, V_{3}=-a d_{3}$, $V_{4}=+a d_{4}, V_{5}=+a d_{5}$, and $V_{6}-+a d_{6}$

and the moment

$$
\begin{gathered}
M=a\left(d_{1}{ }^{2}+d_{2}{ }^{2}+d_{3}{ }^{2}+d_{4}{ }^{2}+d_{5}{ }^{2}+d_{6}{ }^{2}\right)=R h \\
a \Sigma d^{2}=R h \\
a=\frac{R h}{\Sigma d^{2}}
\end{gathered}
$$

Having found $a$, the vertical reactions may be found.

Now having found the external forces $H$ and $V$, the stresses can be calculated by either algebraic or graphic methods.

Stresses in a Double Portal.-To illustrate the general problem the stresses in a double portal are calculated by graphic resolution in Fig. 64. In this case 
and

$$
H=H=H=\frac{R}{3}=1000 \mathrm{lbs} .
$$

and

$$
V=-V^{1}=\frac{R h}{2 s}=2250 \mathrm{lbs} .
$$

The vertical reaction of the middle column is zero. By substituting the dotted members as shown, the stresses can be calculated as in the case of the simple portal. The full lines represent stresses in the portal members. The shear in the columns is equal and is $H$ below, and $\frac{H d}{h--d}$ above the foot of the knee brace.

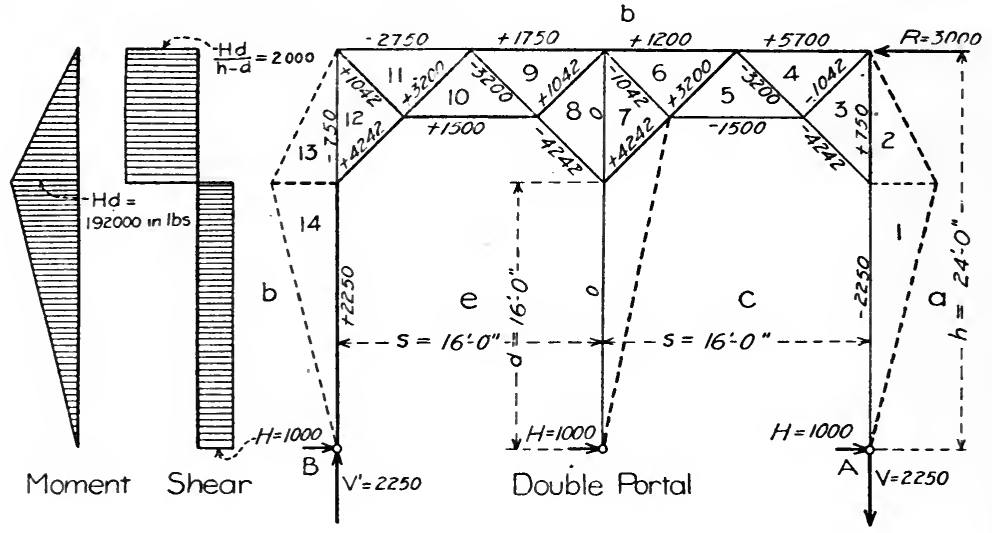

\section{CASE I}

Columns Hinged
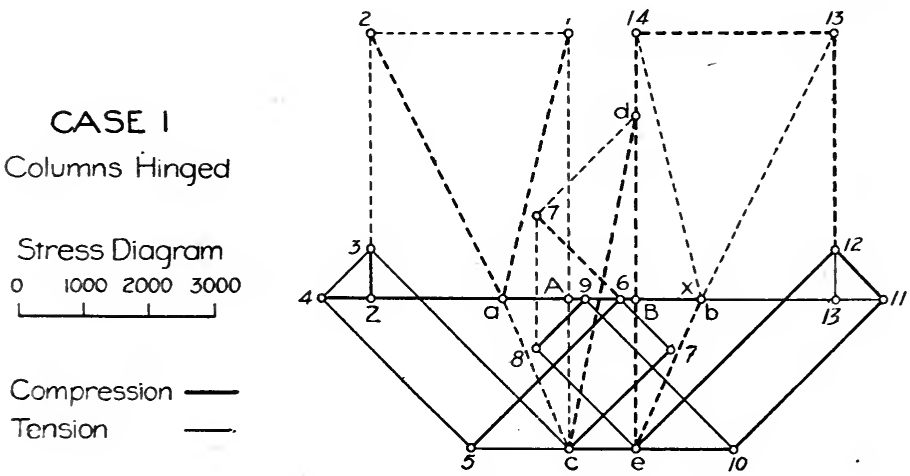

FIG. 64.

The maximum bending moment occurs at the foot of the knee brace and is

$$
M=H d=192,000 \text { inch-lbs. }
$$




\section{CHAPTER XIII.}

Stresses in Three-Hinged Arch.

Introduction.-An arch is a structure in which the reactions are inclined for vertical loads. Arches are divided, according to the number of hinges, into three-hinged arches, two-hinged arches, one-hinged arches, and arches without hinges or continuous arches. Three-hinged arches are in common use for exposition buildings, train sheds and other similar structures. Two-hinged arches are rarely used in this country; continuous arches are used only in dome construction.

A three-hinged arch is made up of two simple beams or trusses. Trussed three-hinged arches, only, will be considered in this chapter, and trussed two-hinged arches in the next.

CALCULATION OF STRESSES.-The reactions for a threehinged arch can be calculated by means of simple statics with slightly more work than that necessary to obtain the reactions in simple trusses. Having determined the reactions the stresses may be calculated by the ordinary algebraic and graphic methods used in the solution of the stresses in simple roof trusses.

Calculation of Reactions: Algebraic Method.---Let $H$ and $V$, $H^{1}$ and $V^{1}$ be the horizontal and vertical reactions at the left and right supports for a concentrated load $P$, placed at a distance $x$ from the center hinge $C$ in the three-hinged arch in Fig. 65 .

From the three fundamental equations of equilibrium

$$
\begin{aligned}
& \Sigma \text { horizontal components of forces }=0 \\
& \Sigma \text { vertical components of forces }=0 \\
& \Sigma \text { moments of forces about any point }=0
\end{aligned}
$$




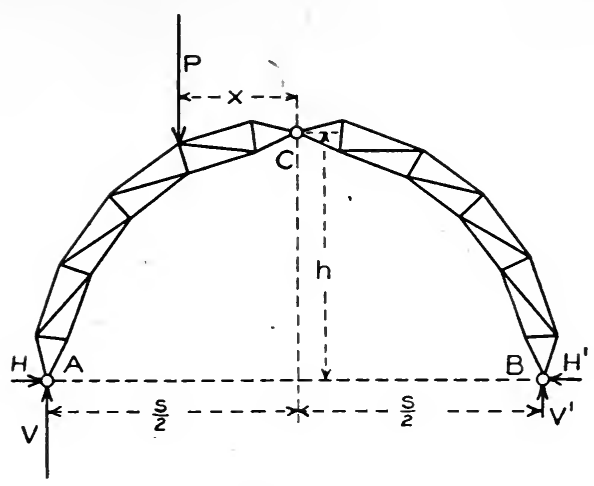

FIG. 65.

we have

$$
\begin{aligned}
& H=H^{1} \\
& V+V^{1}=P
\end{aligned}
$$

and

Taking moments about $B$, we have

$$
v s-P\left(\frac{s}{2}+x\right)=0
$$

and taking moments about center hinge $C$, we have

$$
V \frac{s}{2}-H h-P x=0
$$

Solving (60) we have

$$
V=\frac{P}{s}\left(\frac{s}{2}+x\right)
$$

and

$$
V^{1}=P-V=\frac{P}{s}\left(\frac{s}{2}--x\right)
$$

Substituting (6I) in (62), we have

$$
H=H^{1}=\frac{P}{2 h}\left(\frac{s}{2}-x\right)
$$

The horizontal reactions at the crown are the same as at the supports. Reactions for an inclined load may-be found by substituting the proper moment arms.

Calculation of Reactions: Graphic Method.-Let $P$, Fig. 66, be the resultant of all the loads on the left segment. Since there is no 
bending moment at hinge $C$, the line of action of the reaction $R_{2}$ must pass through the hinge at the crown. This determines the direction of reaction $R_{2}$, and since the three external forces $R_{1}, R_{2}$ and $P$ produce equilibrium in the strusture they must meet in a point. Therefore to find the direction of $R_{1}$ produce $B C$ to $d$ and join $d$ and $A$.

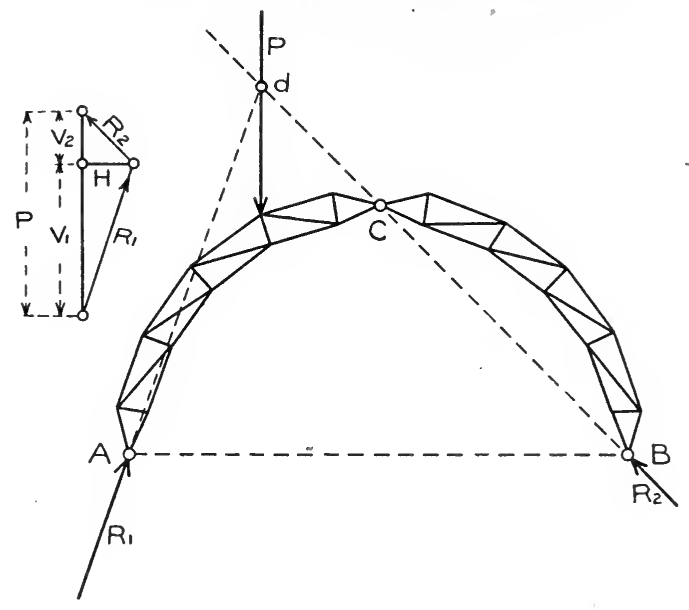

FIG. 66.

The values of $R_{1}$ and $R_{2}$ may then be obtained from the force polygon.

The reactions due to loads on the right segment may be found in the same manner. The two operations may be combined in one as illustrated in the solution of the dead load stresses in a three-hinged arch, Fig. 67 .

Calculation of Dead Load Stresses.-To find the reactions for the dead loads in Fig. 67 , the loads are laid off on the load line of the force polygon in order, beginning at the left reaction $A$, and two equilibrium polygons, one for each segment, are drawn using the same force polygon. The vertical reactions at the crown, $P_{\mathrm{c}}$, and at abutments, $P_{\mathrm{A}}$ and $P_{\mathrm{B}}$, are found by drawing a line through pole $o$ of the force polygon parallel to the closing lines of the equilibrium polygons. The load $P_{\mathrm{c}}$ ' at the crown causes reactions $R_{1}{ }^{1}$ and $R_{2}{ }^{1}$, and combining 
reactions $R_{1}{ }^{1}$ and $P_{\mathrm{A}}$ at $A$, and $R_{2}{ }^{1}$ and $P_{\mathrm{B}}$ at $B$, we have the true reactions $R_{1}$ and $R_{2}$.

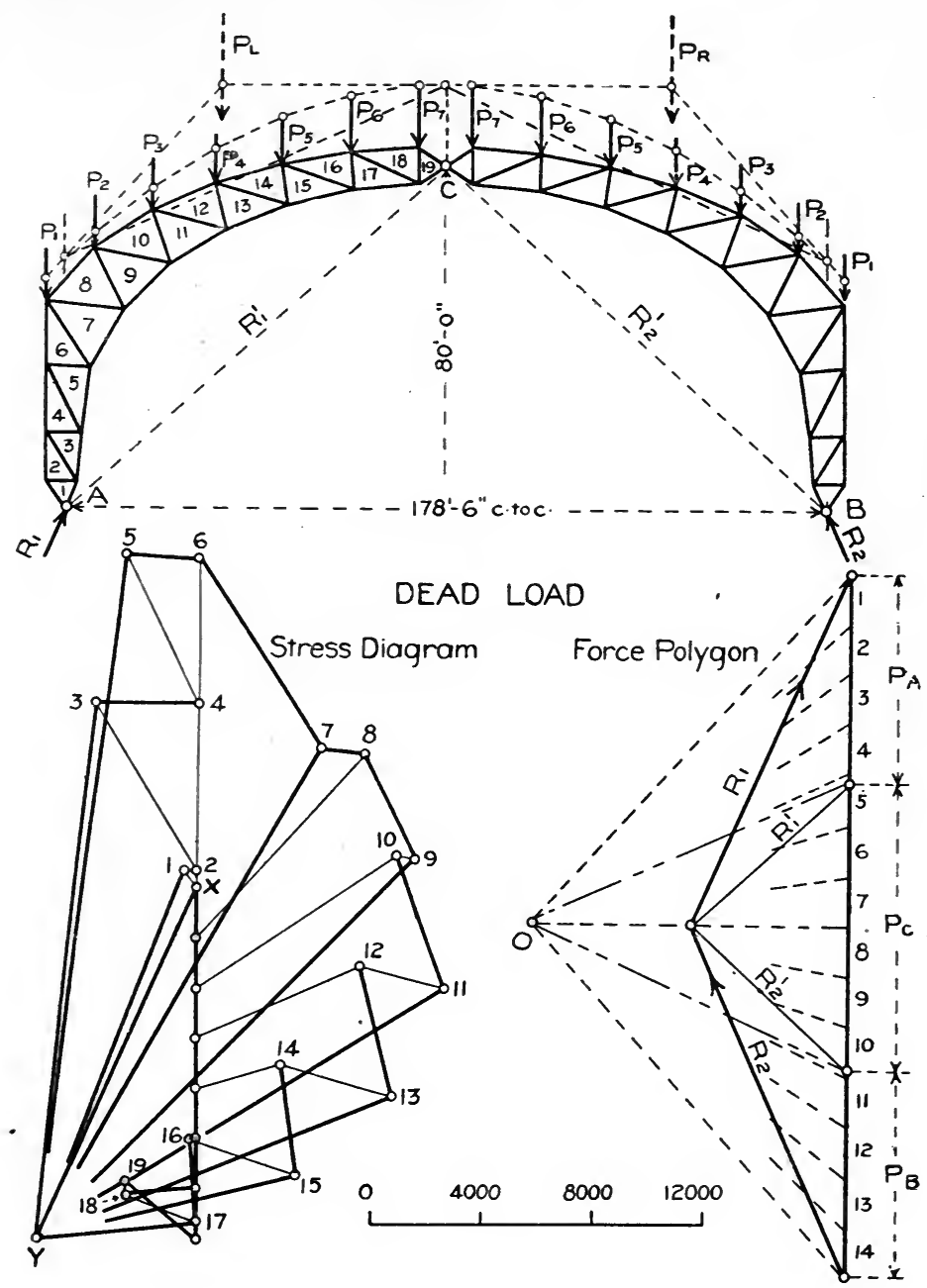

FIG. 67.

Having obtained the reactions, the stresses in the members are found in the same manner as in simple trusses. In Fig. 67 the stresses in the left segment are calculated by graphic resolution. The diagram 
is begun with the left reaction $x-y=R_{1}$. Where the dead load is symmetrical a stress diagram need only be drawn for one segment.

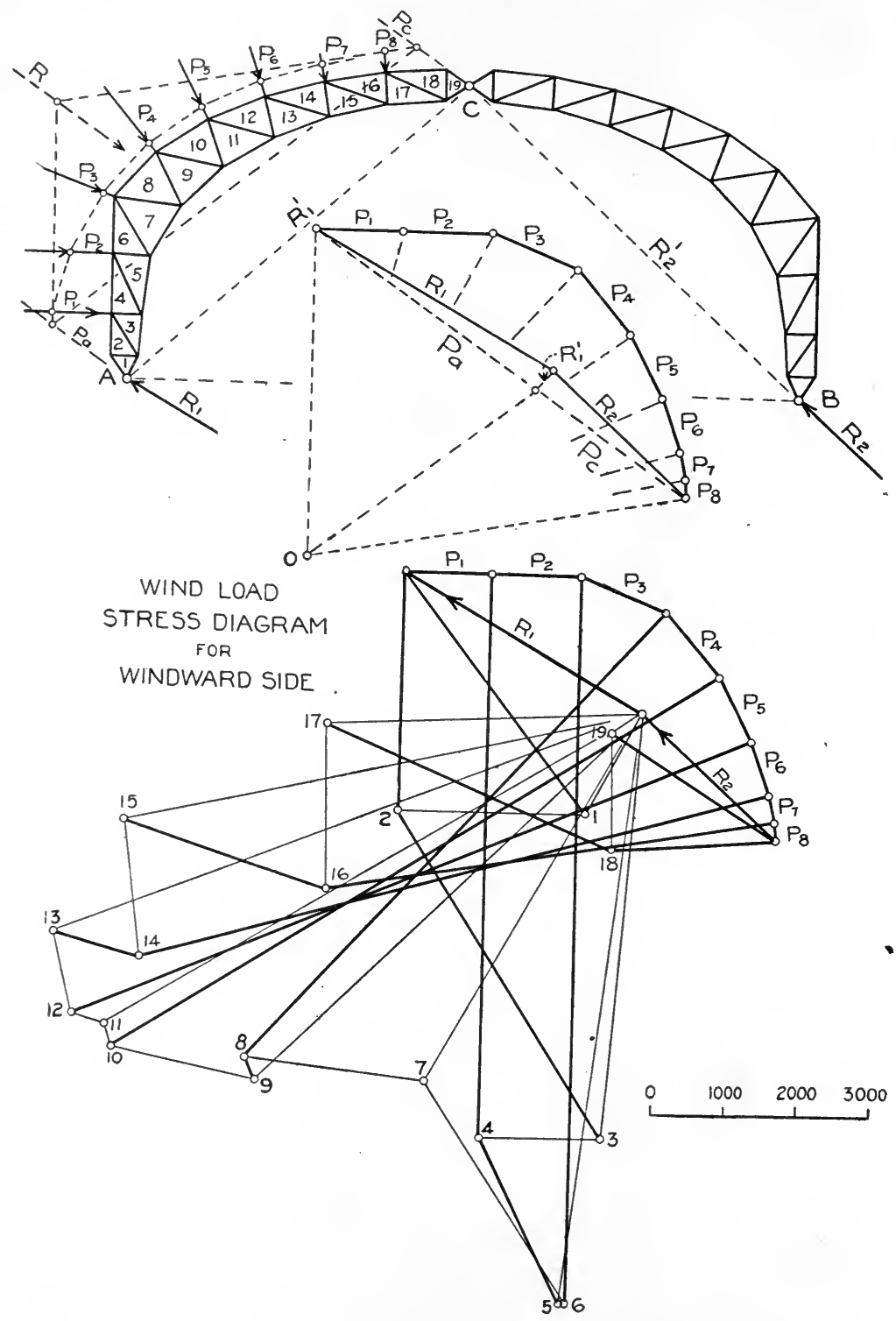

FIG. 68. 
Calculation of Wind Load Stresses.-The reactions for wind load in Fig. 68 are found as follows:

The reactions $P_{\mathrm{a}}$ and $P_{\mathrm{c}}$ for the windward segment, considering it a simple truss supported at the hinges, are found by means of force

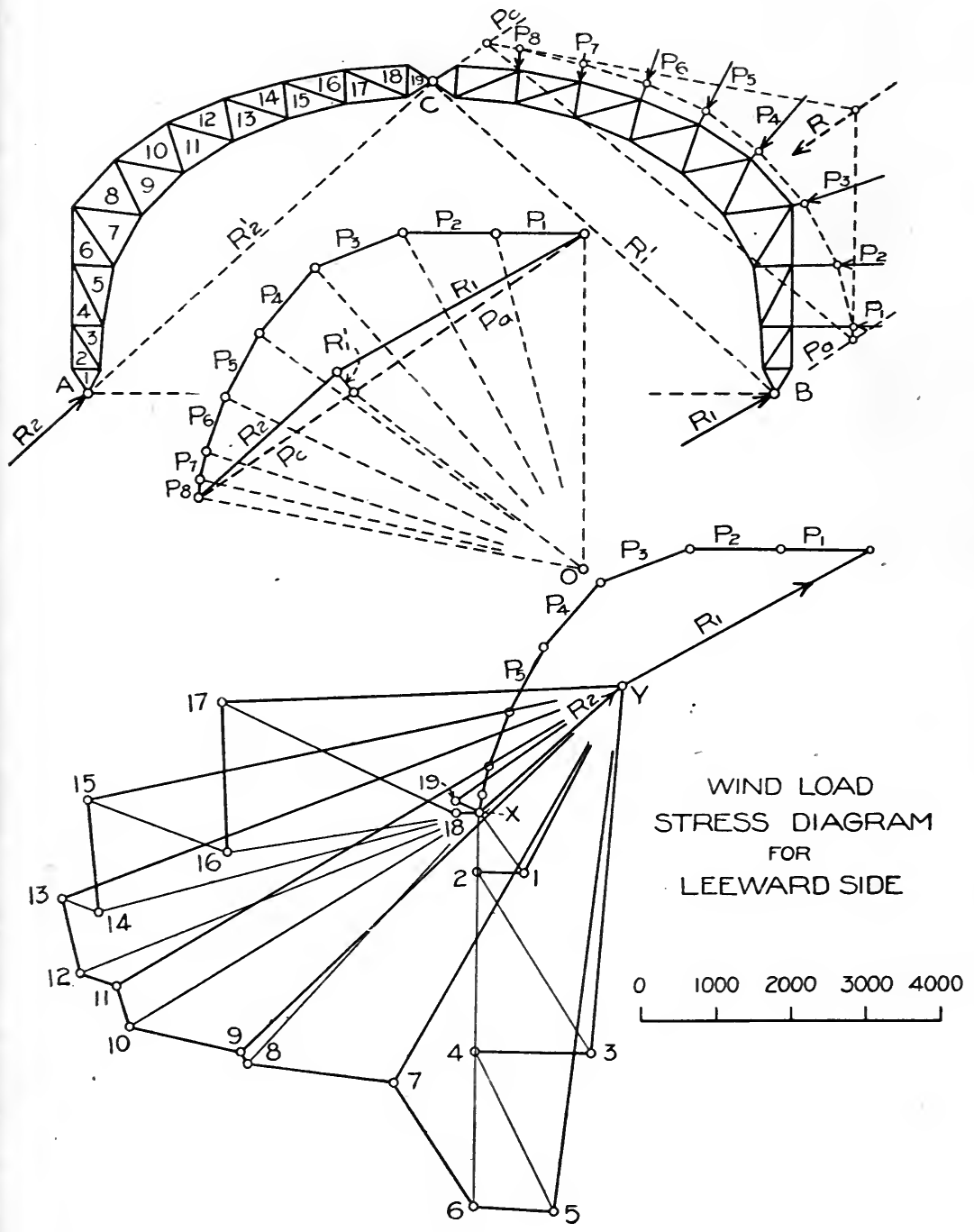

FIG. 69. 
and equilibrium polygons. The lines of action of $P_{\mathbf{a}}$ and $P_{\mathrm{c}}$ are parallel to each other and to the resultant $R$, The line of action of the right reaction, $R_{2}$, must pass through the center hinge $C$, and the reaction $P_{\mathrm{c}}$ will be replaced by two reactions $R_{2}$ and $R_{1}{ }^{1}$ parallel to $R_{2}{ }^{1}$ and $R_{1}{ }^{1}$ in the arch respectively, and the force triangle will be closed by drawing $R_{1}$ in the force polygon. The intersection of force $R$ and reactions $R_{1}$ and $R_{2}$ falls outside the limit of the diagram.

Having obtained the reactions, the stresses in the members are calculated in the same manner as in a simple truss.

The wind load stresses must be calculated in both the windward and leeward segments. The wind load stress diagram for the windward segment is shown in Fig. 68, and for the leeward segment in Fig. 69, compression being indicated in the stress diagrams by heavy lines and tension by light lines. Both wind load stress diagrams and the dead load stress diagram are usually constructed for the same segment of the arch. By comparing wind load stress diagrams in Fig, 68 and Fig. 69, it will be seen that there are many reversals in stress. The maximum stresses found by combining the dead, snow and wind load stresses as in the case of simple trusses and transverse bents, are used in designing the members. 


\section{CHAPTER XIV.}

\section{S'tresses in Two-hinged Arch.}

Introduction.-A two-hinged arch is a frame-work or beam with hinged ends which has inclined reactions for vertical loads. The bottom chords of two-hinged arches are usually cambered, however, a simple truss becomes a two-hinged arch if the ends are fixed to the abutments so that deformation in the direction of the length of the truss is prevented.

The horizontal components of the reactions may be supplied either by the abutments or by a tie connecting the hinges. In the latter case the deformation of the tie must be considered in determining the horizontal reactions. Two-hinged arches are statically indeterminate structures and their design is subject to the same uncertainties as continuous and swing bridges.

Two-hinged roof arches are rigid and economical, but have been used to a very limited extent on account of the difficulties experienced in their design. The methods outlined in this chapter are quite simple in principle, although they necessarily require quite extended calculations. Two-hinged roof arches with open framework, only, will be considered in this chaptcr.

CALCULATION OF STRESSES.-The vertical reactions in a two-hinged arch are the same as in a simple truss or a three-hinged arch having the same loads and span. The horizontal reactions, however, depend upon the deformation of the framework and cannot be determined by simple statics alone. Before the deformations can be calculated, the sizes of the members must be known, and conversely, before the sizes 
of the members can be calculated, the stresses which depend upon the deformations must be known. Any method for the calculation of the stresses in a two-hinged arch is, therefore, necessarily a method of successive approximations. With a skilled computer, however, it is rarely necessary to make more than two or three trials before obtaining satisfactory results in designing roof arches. Two-hinged bridge arches require somewhat more work to design than roof arches on account of the greater number of conditions for maximum stresses in the members.

Having determined the correct value of the horizontal thrust, $H$, the stresses in a two-hinged arch may be calculated by the ordinary algebraic or graphic methods used in the solution of the stresses in simple trusses.

Calculation of the Reactions.-In Fig. 70 the vertical reactions, $V_{1}$ and $V_{2}$, are the same as for a simple truss. The horizontal reactions, $H$, will be equal and will be the forces which would prevent change in length of span if the ends of the arch were free to move. The horizontal thrust, $H$, will therefore be the force which, applied at the roller end of a simple truss, will prevent deformation and make the truss a twohinged arch.

An expression for $H$ may be determined as follows: In Fig. 70 assume that all members are rigid except the member $I-y$, which is increased in length $\delta$, inder the action of the external load, $W$. The

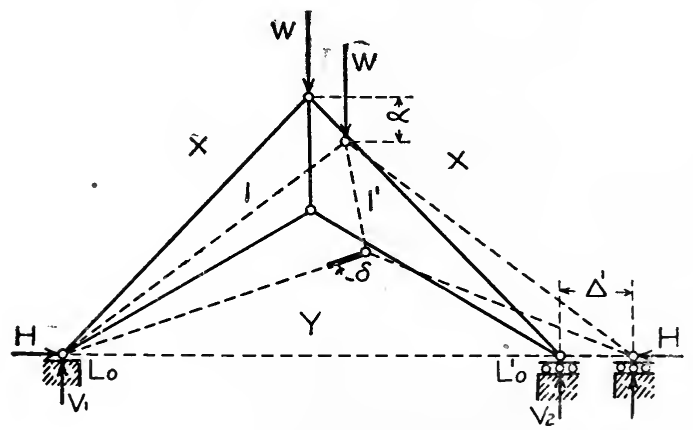

Fig. 70. 
movement of the truss $\Delta^{\prime}$ at the hinge $L_{0}^{\prime}$ will then be due to the change in length, $\delta$, o $\bar{i}$ the member $\mathrm{I}-\boldsymbol{y}$.

Let $h^{1}$ be the horizontal reaction necessary to bring $L_{1}^{1}{ }_{0}$ back to its original position, and let $U h^{\mathbf{1}}$ be the stress in the member I- $y$ due to the horizontal thrust $h^{1}$. Now the internal work, $1 / 2 \delta h^{1} U$, in shortening the member $I-y$ to its original length will be equal to the external work, $1 / 2 h^{1} \Delta^{\prime}$, required to bring the hinge $L_{0}{ }^{1}$ back to its original position,

and

$$
\begin{aligned}
1 / 2 h^{1} \Delta^{\prime} & =1 / 2 \delta h^{1} U \\
\Delta^{\prime} & =\delta U
\end{aligned}
$$

but $\delta=\frac{P L}{E}$, where $P$ is the unit stress in the member $\mathrm{I}-y$ due to the external load $W, L$ is the length of the member $\mathrm{I}-y$, and $E$ is the modulus of elasticity of the material of which the member is composed. Substituting this value of $\delta$ in $\left(6_{5}\right)$ we have

$$
\Delta^{\prime}=\frac{P U L}{E}
$$

where $U$ is the stress in $I-y$ due to a load $\frac{h^{1}}{h^{1}}=$ unity at $L_{0}^{1}$

Now if each one of the remaining members of the arch is assumed to be distorted in turn, the others meanwhile remaining rigid, the distortion in each case at $L_{1}{ }_{0}$ will be represented by the general equation (66) and the total deformation, $\Delta$, at $L_{1}{ }_{0}$ will be

$$
\Delta=\Sigma \frac{P U L}{E}
$$

Let $P^{1} h^{1}$ be the unit stress in the member I- $y$ due to a horizontal thrust $h^{1}$, then by the same reasoning

$$
\Delta^{\prime}=\delta U
$$

but

$$
\delta=\frac{P^{1} h^{1} L}{E}
$$

and

$$
\Delta^{\prime}=\frac{h^{1} P^{1} U L}{E} .
$$

and the total deformation, $\Delta$, will be 


$$
\Delta=\Sigma \frac{h^{1} P^{1} U L}{E}=H \Sigma \frac{P^{1} U L}{E}
$$

Now for equilibrium, the values of $\Delta$ as given in equations (67) and (68) must be equal, and we have, after solving for $H$

$$
H=\frac{\Sigma \frac{P U L}{E}}{\Sigma \frac{P^{1} U L}{E}}
$$

which is an expression for computing the horizontal thrust in any twohinged arch due to external loads. This formula holds for any system of loading as long as $P$ is the unit stress due to that loading, $U$ is the stress in the member and $P^{1}$ is the unit stress in the member due to a unit load acting at the point at which the deformation is desired, and parallel to the direction in which the deformation is to be measured.

The method of fincling the correct value of the horizontal reaction, $H$, is as follows: (I) calculate the stresses in the arch for the given loading on the assumption that it is a simple truss with one end supported on frictionless rollers; (2) calculate the stresses in the arch for an assumed horizontal reaction, $H^{1}=$, say, 20000 lbs. on the assumption that it is a simple truss on frictionless rollers; (3) calculate the deformation, $\Delta$, of the free end of the truss for the given loads by means of formula $(67)$; (4) calculate the deformation, $\Delta^{\prime}$ of the free end of the truss for the assumed horizontal reaction $H^{1}=20000$ lbs. by means of formula (68). The true value of $H$ is then by formula (69) given by the proportion

$$
\begin{gathered}
H: H^{1}:: \Delta: \Delta^{\prime} \\
H=\frac{H^{1} \Delta}{\Delta^{\prime}}=\frac{20000 \Delta}{\Delta^{\prime}}
\end{gathered}
$$

The calculation of the horizontal reaction, $H$, and the stresses can be made by algebraic methods alone or by a combination of graphic and algebraic methods. The first requires less work, while the second 
is probably easier to understand. The algebraic solution will be given first.

Algebraic Calculation of Reactions.-In Table VIl the values of the unit stress, $P$, in each member due to the external loads are given in column 5 ; values of $\frac{P L}{E}$ are given in column 6 ; values of the stress, $U$, in each member due to a unit horizontal thrust are given in column 8; and values of $\frac{P U L}{E}$ are given in column 9. The algebraic sum of the quantities in column 9 gives the total deformation, $\Delta=.956$ inches at the point where the unit horizontal thrust was applied measured parallel to the line of action of the thrust.

In Table VIII similar values are given for the arch as a truss with an assumed horizontal reaction of $H^{1}=20000$ lhs. The algebraic

\section{TABLE VII.}

Simple Truss with Vertical Loads

\begin{tabular}{|c|c|c|c|c|c|c|c|c|}
\hline$\stackrel{1}{\text { lember }}$ & $\begin{array}{l}2 \\
\text { Areo } \\
\text { Sq.in. }\end{array}$ & $\begin{array}{c}3 \\
\text { Length, } \\
\text { inches }\end{array}$ & $\begin{array}{c}4 \\
\text { Stress } \\
\text { lbs. }\end{array}$ & \begin{tabular}{|c|}
5 \\
UnitStress \\
$P$ lbs.
\end{tabular} & $\frac{P^{6}}{E}$ & $\begin{array}{c}7 \\
\text { No.of } \\
\text { Mem }\end{array}$ & $\begin{array}{l}8 \\
U\end{array}$ & $\frac{\begin{array}{c}9 \\
\text { PUL }\end{array}}{E}$ \\
\hline \multirow[t]{2}{*}{$\begin{array}{l}1-X \\
2-X \\
4-X \\
2^{\prime}-X \\
1^{1}-X \\
1-Y \\
3-Y \\
3^{\prime}-Y \\
1^{\prime}-Y \\
1-2 \\
2-3 \\
3-4 \\
3^{\prime}-4 \\
2^{\prime}-3^{\prime} \\
1^{\prime}-2^{\prime}\end{array}$} & $\begin{array}{l}5.3 \\
5.3 \\
5.3 \\
5.3 \\
5.3 \\
5.3 \\
5.3 \\
5.3 \\
5.3 \\
2.0 \\
4.0 \\
4.0 \\
4.0 \\
4.0 \\
2.0\end{array}$ & $\begin{array}{l}252 \\
192 \\
180 \\
192 \\
252 \\
216 \\
192 \\
192 \\
216 \\
150 \\
204 \\
150 \\
150 \\
204 \\
150\end{array}$ & $\begin{array}{l}+60000 \\
+41000 \\
+67000 \\
+41000 \\
+60000 \\
-25000 \\
-57000 \\
-57000 \\
-25000 \\
-30000 \\
+32000 \\
-22000 \\
-22000 \\
+32000 \\
-30000\end{array}$ & $\begin{array}{l}+11320 \\
+7740 \\
+12650 \\
+7740 \\
+11320 \\
-4720 \\
-10760 \\
-10760 \\
-4720 \\
-15000 \\
+8000 \\
-5500 \\
-5500 \\
+8000 \\
-15000\end{array}$ & $\begin{array}{l}+.095 \\
+.050 \\
+.076 \\
+.050 \\
+.095 \\
-.034 \\
-.069 \\
-.069 \\
-.034 \\
-.075 \\
+.054 \\
-.028 \\
-.028 \\
+.054 \\
-.075\end{array}$ & $\begin{array}{r}9 \\
6 \\
1 \\
12 \\
15 \\
8 \\
4 \\
10 \\
14 \\
7 \\
5 \\
2 \\
3 \\
11 \\
13\end{array}$ & $\begin{array}{l}-0.90 \\
-0.80 \\
-1.45 \\
-0.80 \\
-0.90 \\
+1.60 \\
+2.05 \\
+2.05 \\
+1.60 \\
+0.75 \\
-0.45 \\
+0.80 \\
+0.80 \\
-0.45 \\
+0.75\end{array}$ & $\begin{array}{l}-.086 \\
-.040 \\
-.110 \\
-.040 \\
-.086 \\
-.054 \\
-.141 \\
-.141 \\
-.054 \\
-.056 \\
-.024 \\
-.022 \\
-.022 \\
-.024 \\
-.056\end{array}$ \\
\hline & & & & & & & & .956 \\
\hline
\end{tabular}

sum of the quantities in column 9 gives the total deformation, $\Delta^{\prime}=$ .574 inches at the point where the horizontal thrust was applied. 
TABLE VIII.

Simple Truss with $\mathrm{H}=20000$ lbs.

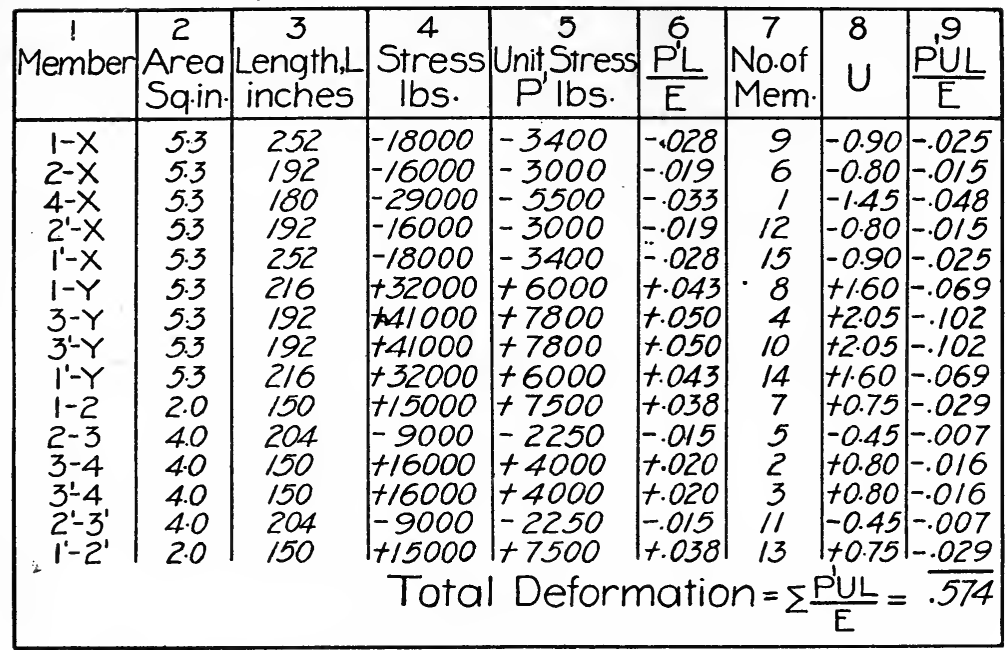

TABLE IX.

Simple Truss with Dead and Wind Loads

\begin{tabular}{|c|c|c|c|c|c|c|c|c|}
\hline Member & $\begin{array}{c}2 \\
\text { Area } \\
\text { Sq.in. }\end{array}$ & $\begin{array}{c}3 \\
\text { Length, L } \\
\text { inches }\end{array}$ & $\begin{array}{c}4 \\
\text { Stress } \\
\text { lbs. }\end{array}$ & $\begin{array}{c}5 \\
\text { Unit Stress } \\
\text { P lbs. }\end{array}$ & $\frac{6}{P L}$ & $\begin{array}{c}7 \\
\text { No.of } \\
\text { Mem. }\end{array}$ & $\begin{array}{l}8 \\
U\end{array}$ & $\frac{9}{P U L}$ \\
\hline $\begin{array}{l}1-X \\
2-X \\
4-X \\
2^{\prime}-X \\
1^{\prime}-X \\
1-Y \\
3-Y \\
3-Y \\
3^{\prime}-Y \\
1^{\prime}-Y \\
1-2 \\
2-3 \\
3-4 \\
3^{\prime}-4 \\
2^{\prime}-3^{\prime} \\
1^{\prime}-2^{\prime}\end{array}$ & $\begin{array}{l}5.3 \\
5.3 \\
5.3 \\
5.3 \\
5.3 \\
5.3 \\
5.3 \\
5.3 \\
5.3 \\
2.0 \\
4.0 \\
4.0 \\
4.0 \\
4.0 \\
2.0\end{array}$ & $\begin{array}{l}252 \\
192 \\
180 \\
192 \\
252 \\
216 \\
192 \\
192 \\
216 \\
150 \\
204 \\
150 \\
150 \\
204 \\
150\end{array}$ & $\begin{array}{l}+87000 \\
+72000 \\
+95000 \\
+52000 \\
+72000 \\
-58000 \\
-87000 \\
-74000 \\
-30000 \\
-36000 \\
+28000 \\
-22000 \\
-42000 \\
+46000 \\
-42000\end{array}$ & $\begin{array}{l}+16400 \\
+13600 \\
+17800 \\
+9800 \\
+13600 \\
-10900 \\
-16400 \\
-14000 \\
-5650 \\
-18000 \\
+7000 \\
-5500 \\
-10500 \\
+11500 \\
-21000\end{array}$ & $\begin{array}{l}+.138 \\
+.087 \\
+.107 \\
+.063 \\
+.114 \\
-.078 \\
-.105 \\
-.090 \\
-.041 \\
-.090 \\
+.048 \\
-028 \\
-.053 \\
+.078 \\
-.105\end{array}$ & $\begin{array}{r}9 \\
6 \\
1 \\
12 \\
15 \\
8 \\
4 \\
10 \\
14 \\
7 \\
5 \\
2 \\
3 \\
11 \\
13\end{array}$ & $\begin{array}{l}-0.90 \\
-0.80 \\
-1.45 \\
-0.80 \\
-0.90 \\
-1.60 \\
+2.05 \\
+2.05 \\
-1.60 \\
+0.75 \\
-0.45 \\
+0.80 \\
+0.80 \\
-0.45 \\
+0.75\end{array}$ & $\begin{array}{l}-.124 \\
-.065 \\
-.155 \\
-.050 \\
-.103 \\
-.125 \\
-.215 \\
-.185 \\
-.064 \\
-.067 \\
-.022 \\
-.022 \\
-.042 \\
-.035 \\
-.079 \\
\end{array}$ \\
\hline \multicolumn{8}{|c|}{ Total Deformation $=\Sigma \frac{P U L}{E}=$} & 1.357 \\
\hline
\end{tabular}


The correct value of $H$ is given by the proportion

$$
\begin{aligned}
& H: H_{1}^{1}:: \Delta: \Delta^{\prime} \\
& H=\frac{20000 \times .956}{.574}=33400 \mathrm{lbs} \text {. }
\end{aligned}
$$

In Table IX the deformation, $\Delta$, for the same arch considered as a simple truss and acted upon by dead and wind loads is I. 357 inches, and

$$
H=\frac{20000 \times 1.357}{.574}=47300 \mathrm{lbs} .
$$

Graphic Calculation of Reactions.-In the graphic solution of the horizontal reactions the total amount of the deformations, $\Delta$ and $\Delta^{\prime}$ are found by means of deformation diagrams. Before constructing the deformation diagrams the quantities in the first seven columns in Tables VII and VIII or VIII and IX must be

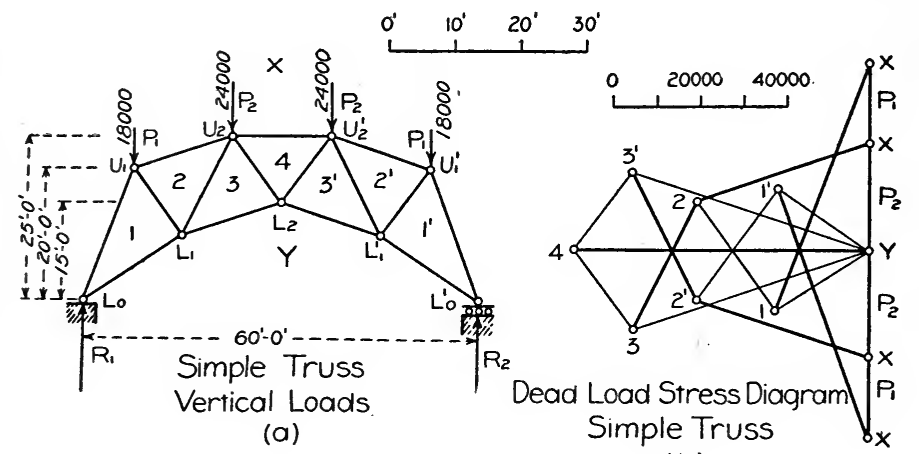

(b)

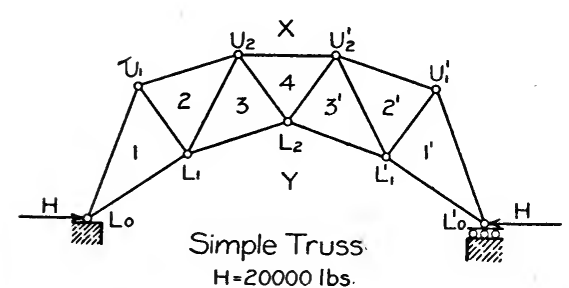

(c)

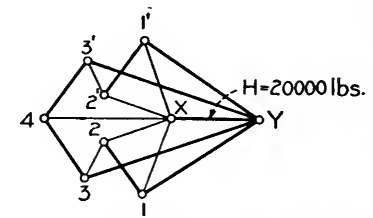

Stress Diagram, $\mathrm{H}=20000 \mathrm{lbs}$.

(d)

Fig. 7I. 
calculated. The stresses given in column 4 are calculated as shown in Fig. 7 I. Column 6, giving deformations of each member, and column 7 , giving the order in which these deformations are used, are, however, the only values used in constructing the deformation diagrams.

Deformation Diagram.-The principle upon which the construction of the deformation diagram is based is as follows: Take the two members $a-c$ and $c-b$ in (d) Fig. 72, meeting at the point $c$. Assume that $a-c$ is shortened and $b-c$ is lengthened the amounts indicated. It is required to find the new position, $c^{\prime}$, of the point $c$. With center at $a$ and a radius equal to the new length of $a-c=a-c^{\prime}$, describe an arc. The new position of $c$ must be some place on this arc. Then with a center at $b$ and a radius equal to the new length of $b-c=b-c^{\prime}$, describe an arc cutting the first arc in $c^{\prime}$. The new position of $c$ must be some place on this arc and will therefore be at the intersection of the two arcs, $c^{\prime}$. Since the deformations of the members are always very small as compared with the lengths of the members, the arcs may be replaced by perpendiculars, and the members themselves need not be drawn, (e) Fig. 72.

To draw the deformation diagram, (b) Fig. 72, for the arch as a truss with one end on frictionless rollers and loaded with vertical loads, proceed as follows: Begin with the member marked I, lay off its deformation $=+.076$ inches (Table VII., column 6) to scale and parallel to member I. Now lay off the deformation of $2=-.028$ inches away, from the joint $U_{2}$ and parallel to the member 2, and lay off deformation of $3=-.028$ inches, away from the joint $U^{\prime}{ }_{2}$ and parallel to the member 3 . Perpendiculars erected at the ends of deformations 2 and 3 will meet in the new position of $I_{22}$. The vertical distance between the deformation I and point $L_{2}$ represents to scale the change in position of $L_{2}$ relative to the member $U_{2} U^{1}{ }_{2}$. At $L_{2}$ in the deformation diagram lay off deformation of $4=-.069$ inches, away from the joint and parallel to the member 4 , and at $U_{2}$ lay off deformation of $5=+.054$ inches, toward the joint and parallel to the member 5. The perpendiculars erected at the ends of the deformations 4 and 5 

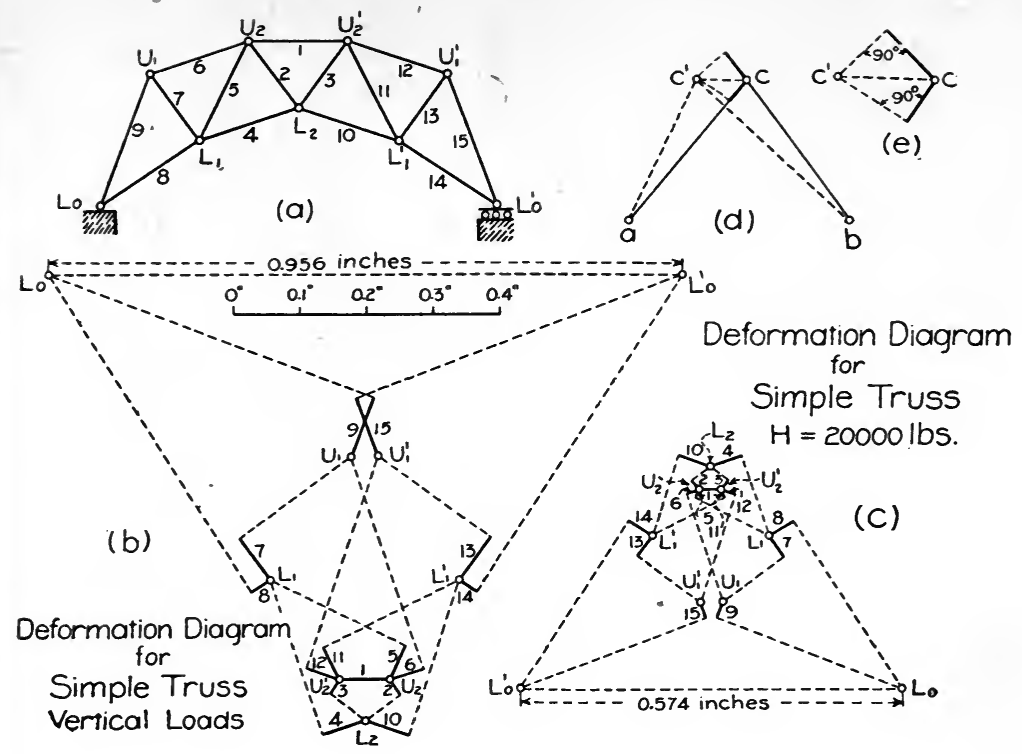

FIG. 72.

determine the new position of joint $L_{1}$ relative to the other points. In like manner perpendiculars erected at the ends of deformations 6 and 7 determine $U_{1}$, and finally perpendiculars erected at the ends of deformations 8 and 9 determine $L_{0}$. The deformation diagram for the right half of the truss is constructed in the same manner. The horizontal line joining $L_{0}$ and $L_{1}^{1}{ }_{0}$ represents to scale the movement of the joint $L_{1}{ }_{0}$.

In drawing the deformation diagram it is immaterial whether plus deformations are laid off toward the joints and minus deformations away from the joints as was done in the preceding problem, or the reverse. The former method is more common, but the latter is probably more consistent. The deformation diagram (b) if drawn in the latter way would be turned upside down and inside out.

Calculation of Dead Load Stresses in Arch.-In Fig. 7I, (b) is the stress diagram for the arch as a simple truss with vertical loads as shown in $(a)$; and $(d)$ is the stress diagram for the arch as a simple 
truss with a horizontal thrust, $H^{1}$, of 20000 lbs. as shown in $(c)$. The quantities for calculating the deformations of the simple truss with vertical loads are given in Table VII, and the deformation diagram is shown in (b) Fig. 72. The quantities for calculating the deformations of the simple truss with a horizontal thrust of 20000 lbs. are given in Table VIII, and the deformation diagram is shown in (c) Fig. 72. The true value of $H$ is found by the proportion

$$
\begin{aligned}
& H: 20000:: .956: .574 \\
& H=33400 \mathrm{lbs} .
\end{aligned}
$$

The stress diagram for the two-hinged arch with $V=V^{\prime}=42000$ lbs., and $H=H=33400$ lbs. is shown in (b) Fig. 73 .

The difference in the stresses in the members of a simple truss and a two-hinged arch may be seen by comparing stress diagram $(b)$ Fig. 7I, and stress diagram (b) Fig. 73, both diagrams being drawn

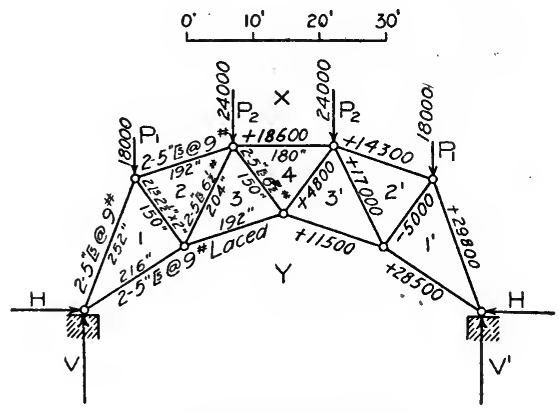

Two Hinged Arch

(a)

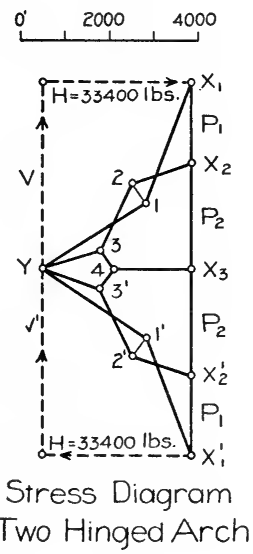

(b)

FIG. 73.

to the same scale. The stresses in the arch may be found from the stresses given in Tables VII and VIII by adding the stresses in column 4, Table VII, to the corresponding stresses in column 4, Table VIII, multiplied by 1.67 , the ratio between the actual and as- 
sumed horizontal reactions. For example, the stress in I- $x$ in the arch equals $+60000-18000 \times 1.67=+29800$ lbs. Stress in $1-y$ equals $-25000+32000 \times 1.67=+28440$ lbs.

Dead and Wind Load Stresses in Arch.-In Fig. 74, $(b)$ is the stress diagram for the arch as a simple truss loaded with dead and wind loads as shown in $(a)$. Table IX gives the same data for this case as

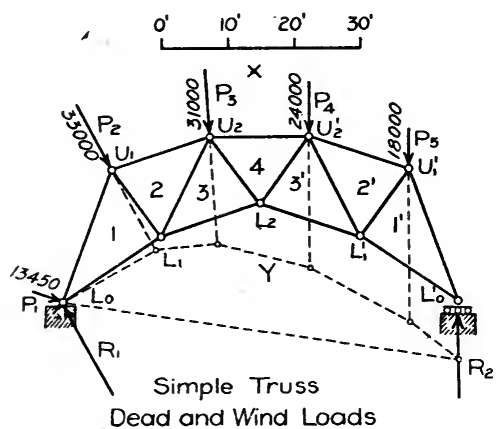

(a)

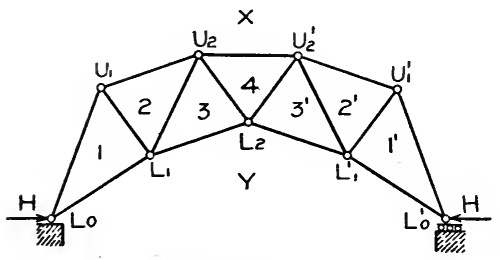

Simple Truss

$\mathrm{H}=20000 \mathrm{lbs}$.

(C)

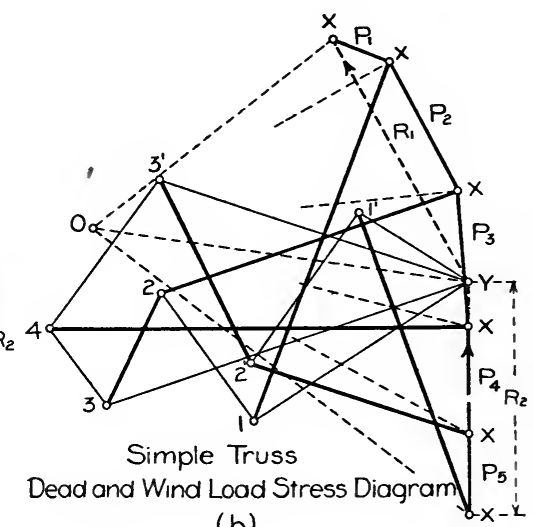

(b)

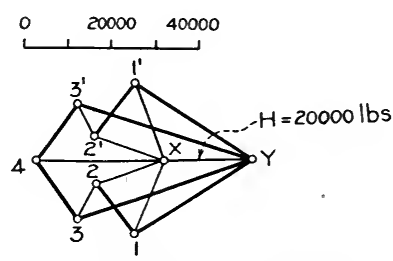

Stress Diagram, $\mathrm{H}=20000$ lbs.

(d)

FIG. 74.

are given in Table VII for the simple truss with vertical loads. The deformation diagram for the deformations given in column 6, Table IX, is shown in (b) Fig. 75. In drawing the deformation diagram for this case the member marked I was assumed to be fixed in position and the other members were assumed free to move. The horizontal distance between $L_{0}$ and $L_{0}^{\prime}$ will be the total deformation required. 
The deformation diagram for the simple truss with a horizontal

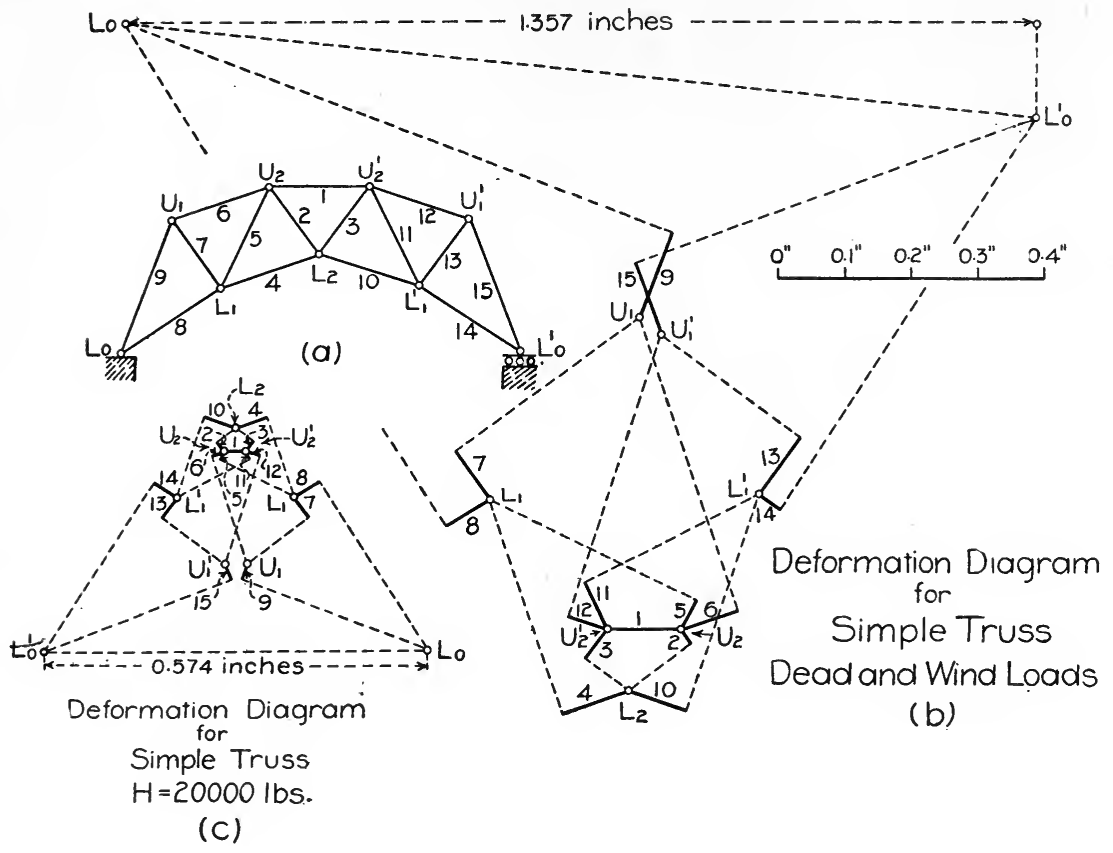

FIG. 75 .

thrust, $H^{1}$, of 20000 lbs. is given in (c) Fig. 75 and is the same as that given in (c) Fig. 72 .

The true value of $H$ is found by the proportion

$$
\begin{aligned}
& H: 20000:: \mathrm{I} \cdot 357: 574 \\
& H=47300 \mathrm{lbs} .
\end{aligned}
$$

The stress diagram for the two-hinged arch with dead and wind loads and a horizontal thrust, $H$, of 47300 lbs. is given in (b) Fig. 76. The stresses in the arch for this case may be found from the stresses in Tables IX and VIII by adding the stresses in column 4, Table IX, to the corresponding stresses in column 4, Table VIII, multiplied by 2.865 , the ratio between the actual and assumed horizontal reactions. 


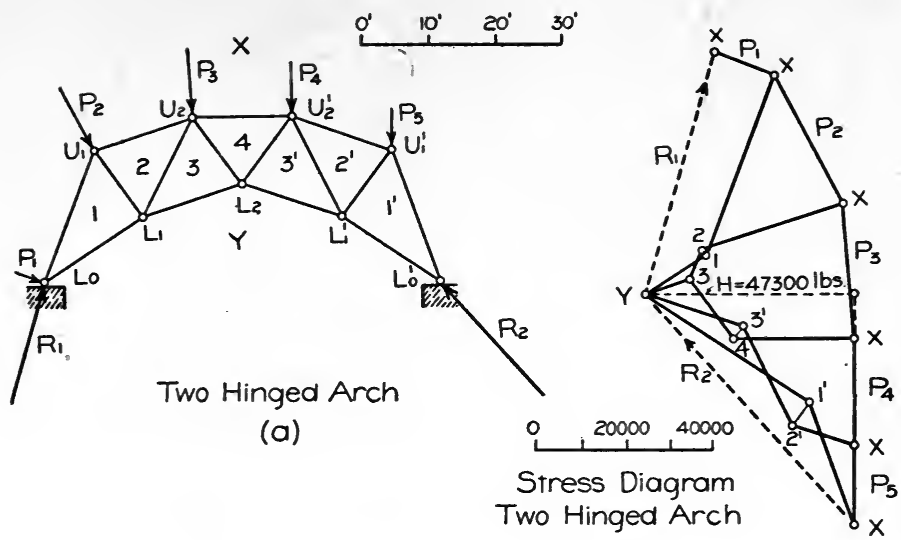

(b)

FIG. 76.

As a check on the accuracy of the calculations the movement at $L_{0}{ }^{\prime}$ in the arch was calculated in Tahle $\mathrm{X}$ and was found to be zero as it should be.

Arch With Horizontal Tie.-If a horizontal tie is used the final deformation of the arch will be equal to the deformation of the tie.

\section{TABLE X.}

Two Hinged Arch with Dead and Wind Loads

\begin{tabular}{|c|c|c|c|c|c|c|c|}
\hline $\begin{array}{c}\text { I } \\
\text { Member }\end{array}$ & $\begin{array}{c}2 \\
\text { Area } \\
\text { Sq.in. }\end{array}$ & $\begin{array}{c}3 \\
\text { Length,L } \\
\text { inches }\end{array}$ & $\begin{array}{c}4 \\
\text { Stress } \\
\text { Ibs. }\end{array}$ & $\begin{array}{c}5 \\
\text { UnitStres } \\
\text { P Ibs. }\end{array}$ & $\frac{P_{L}}{E}$ & $\begin{array}{l}8 \\
U\end{array}$ & $\frac{9}{9 U L}$ \\
\hline \multirow[t]{2}{*}{$\begin{array}{l}1-X \\
2-X \\
4-X \\
2:-X \\
1-X \\
1-Y \\
3-Y \\
3-Y \\
1-Y \\
1-2 \\
2-3 \\
3-4 \\
3-4 \\
2-3^{\prime} \\
1^{\prime}-2^{\prime}\end{array}$} & $\begin{array}{l}5.3 \\
5.3 \\
5.3 \\
5.3 \\
5.3 \\
5.3 \\
5.3 \\
5.3 \\
5.3 \\
2.0 \\
4.0 \\
4.0 \\
4.0 \\
4.0 \\
2.0\end{array}$ & $\begin{array}{l}252 \\
192 \\
180 \\
192 \\
252 \\
216 \\
192 \\
192 \\
216 \\
150 \\
204 \\
150 \\
150 \\
204 \\
150\end{array}$ & $\begin{array}{l}+43500 \\
+34200 \\
+26500 \\
+14200 \\
+29500 \\
+18000 \\
+10000 \\
+23000 \\
+46000 \\
-500 \\
+6500 \\
+15800 \\
-4200 \\
+22800 \\
-5000\end{array}$ & $\begin{array}{l}+8220 \\
+6450 \\
+5000 \\
+2660 \\
+5550 \\
+3400 \\
+1890 \\
+4350 \\
+8700 \\
-250 \\
+1625 \\
+3950 \\
-1050 \\
+5700 \\
-2300\end{array}$ & $\begin{array}{l}+.069 \\
+.041 \\
+.030 \\
+.017 \\
+.047 \\
+.024 \\
+.012 \\
+.028 \\
+.062 \\
-.001 \\
+.011 \\
t .020 \\
-.005 \\
+.039 \\
-.013\end{array}$ & $\begin{array}{l}-0.90 \\
-0.80 \\
-1.45 \\
-0.80 \\
-0.90 \\
+1.60 \\
+2.05 \\
+2.05 \\
+1.60 \\
+0.75 \\
-0.45 \\
+0.80 \\
+0.80 \\
-0.45 \\
+0.75\end{array}$ & $\begin{array}{l}-.063 \\
-.033 \\
-.045 \\
-.014 \\
-.042 \\
+.038 \\
+.025 \\
+.057 \\
+.099 \\
-.001 \\
-.005 \\
+.016 \\
-.004 \\
-.018 \\
-.010\end{array}$ \\
\hline & & Tota & CTu & & & & \\
\hline
\end{tabular}


Assume that the joints $L_{0}$ and $L_{00}{ }^{\prime}$ in (a) Fig. 73 are connected by a tie having 3 sq. in. cross-section. A force of a $1000 \mathrm{lbs}$. will stretch the tie

$$
\Delta^{\prime}=\frac{1000 \times 720^{\prime \prime}}{3 \times 29,000,000}=.0083 \text { inches. }
$$

The movement for Iooo lbs. applied as $H$ is equal to $\frac{.574}{20}=.0287$ inches. The value of $H$ therefore which will produce equilibrium for the arch with vertical loads will be

$$
\begin{aligned}
& +.0083 H+.0287 H=.956 \times \text { I000 lbs. } \\
& H=\frac{.956 \times 1000}{.0370}=25840 \mathrm{lbs} .
\end{aligned}
$$

The stresses in the arch for this case may be found from the stresses in Table VII and Table VIII as previously described.

Temperature Stresses.-Where a horizontal tie is used and all parts of the structure are exposed to the same conditions and range of temperature, the entire arch will contract and expand freely and temperature stresses will not enter into the calculations. Where the tie is protected and where rigid abutments are used the temperature stresses must receive careful attention.

The deformation $\Delta^{\prime}$ due to a uniform change of temperature of $t$ degrees Fahr. when the arch is assumed to be a truss supported on frictionless rollers, will be $e t L$, where $e$ is the coefficient of expansion of steel per degree Fahr. $=.0000066_{5} ; t$ equals change in temperature in degrees Fahr.; and $L$ equals the length of the span.

For a change of 75 degrees Fahr. from the mean, the deformation will be

$$
\begin{aligned}
\Delta^{\prime} & = \pm .00000665 \times 75 L \\
& = \pm \frac{L}{2000}
\end{aligned}
$$


For the arch in Fig. 73

$$
\Delta^{\prime}= \pm \frac{720^{\prime \prime}}{2000}= \pm .36 \text { inches }
$$

This will be equivalent to a change in $H$ of $\pm \frac{.36}{.574} \times 20000= \pm$ 12540 lbs. The stresses due to temperature in the two-hinged arch will be equal to the stresses in column 4 , Table VIII, multiplied by \pm .627. The maximum stresses due to external loads and temperature will be found by adding algebraically the temperature stresses to the stresses due to the external loads. If the arch is not erected at a mean temperature this fact must be taken into account in setting the pedestals.

Design of Two-Hinged Arch.-In designing a two-hinged roof arch proceed as follows: (I) With one end free to move, calculate the stresses in the arch as a simple truss; (2) with an assumed horizontal reaction, $H^{1}$, of, say, $20000 \mathrm{lbs}$., calculate the stresses in the arch as a simple truss; (3) calculate the stresses in the arch for some assumed value of $H$, this value of $H$ may be guessed at or often may be estimated with considerable accuracy; (4) design the members for approximate stresses in the arch ; (5) calculate the deformation of the arch as a truss for the approximate sections and stresses; (6) calculate the deformation of the arch as a truss for an assumed horizontal reaction of 20000 lbs.; (7) determine a more accurate value of $H$ from the deformations as previously described; (8) recalculate the stresses in the arch, redesign the members, recalculate the deformations, recalculate a new value of $H$, etc., until satisfactory sections are obtained. The second approximation is usually sufficient. Corrections for horizontal tie and temperature should be applied in making the approximations. The gross area of the sections of all members should be used in determining the deformation of the members. If riveted tension members are much weakened, a somewhat smaller value of $E$, say, 26,000,000, may be used than the 29,000,000 commonly used for the compression members.

The method just described is much more expeditious than the usual method of designing the members for the stresses found by con- 
sidering the arch a simple truss with allowable stresses, say, twice those to be finally allowed. In the latter case the first approximation is usually worthless on account of the reversal of stresses in the members which have been designed as tension members. If the value of $H$ in the first method is taken large enough to make members in compression that the designer's judgment or experience says should be in compression, the second approximation is usually final. 


\section{CHAPTER XV.}

Combined and Eccentric Stresses.

Combined Direct and Cross Bending Stresses. - Thus far members of trusses and frameworks have been considered as acted on by direct forces, parallel to the axis of the member. While this is the more common case, it often becomes necessary to design members which support loads as in (a), (b), (c), or (d), Fig. 77, or in which the line of action of the external force does not coincide with the : neutral axis of the member, (e), (f), (g), or (h), Fig. 77.

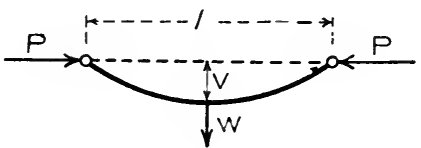

(a)

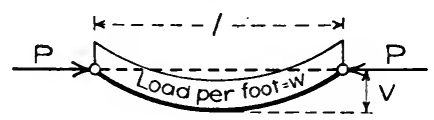

(c)

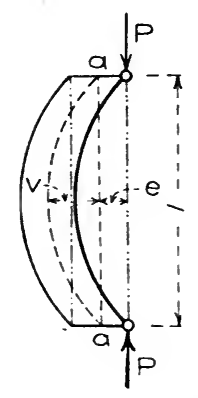

(e)

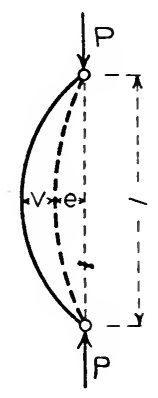

(f)

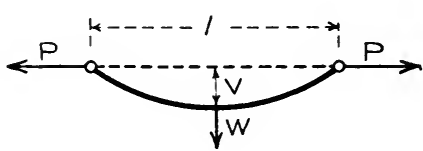

(b)

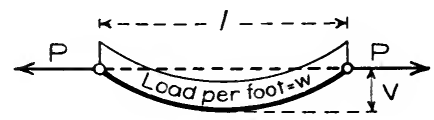

(d)

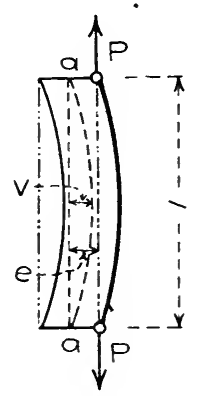

(g)

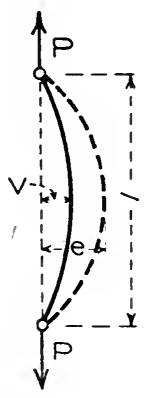

(h)

FIG. 77. 
The following nomenclature will be used:

Let $P=$ total direct loading on member in pounds;

$l=$ length of member in inches;

$L=$ length of member in feet;

$I=$ moment of inertia of member;

$y_{1}=$ distance from neutral axis to remote fibre on side for which stress is desired;

$E=$ modulus of elasticity of the material;

$e=$ eccentricity of $P$, i.e. distance from line of action of $P$ to neutral axis of member in inches;

$v=$ deflection of member in inches;

$A=$ area of member in square inches;

$f_{1}=$ fibre stress due to cross bending;

$f_{2}=\frac{P}{\boldsymbol{A}}=$ direct fibre stress;

$M=$ total bending moment;

$M_{2}=$ bending moment due to deflection, $=P v$;

$M_{1}=$ bending moment due to external forces and is equal to $\mathrm{I} / 4 \mathrm{~W} \cdot \mathrm{l}$ in (a) and (b) ; I/8 $w l^{2}$ in (c) and (d) ; and $P \mathcal{C}$ in (e), (f), (g) and (h) Fig. 77 .

Now

$$
M=M_{2} \pm M_{1}=P v \pm M_{1}=\frac{f_{1} I}{y_{1}}
$$

But

$$
v=\frac{f_{1} l^{2}}{c E y_{1}}
$$

in which $c$ is a constant depending upon the condition of the ends, and the manner in which the beam is loaded.

Substituting this value of $v$ in $(72)$ we have

$$
\frac{P f_{1} l^{2}}{c E y_{1}} \pm M_{1}=\frac{f_{1} I}{y_{1}}
$$


and reducing, the stress due to cross bending is

$$
f_{1}=\frac{M y_{1}}{I \pm \frac{P l^{2}}{c E}}
$$

where the minus sign is to be used when $P$ is compression and the plus sign is to be used when $P$ is tension.

The factor $c$ may be taken equal to ro for columns, beams and bars with hinged ends as in Fig. 77; equal to 24 where orye end is hinged and the other end is fixed; and equal to 32 where both ends are fixed.

The total stress in the member due to direct stress and cross bending will therefore be for columns with hinged ends

$$
f_{1}+f_{2}=\frac{M_{1} y_{1}}{I \pm \frac{P l^{2}}{10 E}}+\frac{P}{A}
$$

Formula (74) is general, and applies to all forms of sections and all forms of loading. The second term in the denominator is minus when $P$ is compression, and plus when $P$ is tension

In finding the stress due to weight of member and direct loading, the value for $f_{1}$ given by formula (73) must be multiplied by the sine of the angle that the member makes with a vertical line.

Combined Compression and Cross Bending.--The method of calculating direct and cross bending stresses will be illustrated by calculating the stresses in the end post of a bridge due to direct comprèssion, weight, eccentricity of loading, and wind moment.

The end post is composed of two Io-inch channels weighing I $_{5}$ lbs. per foot with a $14^{\prime \prime} \times 1 / 4$ " plate riveted on the upper side and laced on the lower side with single lacing. The pins are placed in the center of the channels giving an eccentricity of $e=\mathrm{I} .44$ inches. The compressive stress $P$ produces a uniform compression on all fibres of the section ;weight of the member causes tension on the lower and compression on the upper fibres; eccentricity of the load $P$ causes compression on lower and tension on upper fibres ; and wind moment causes com- 


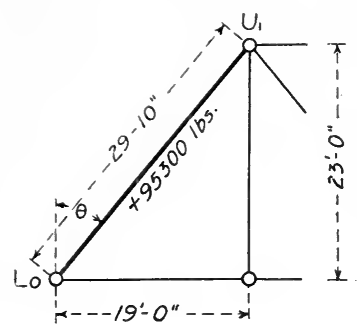

(a)

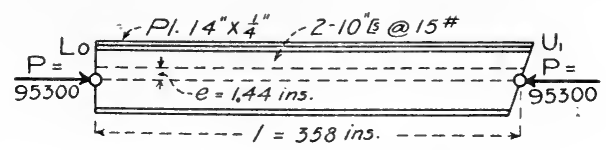

(b)
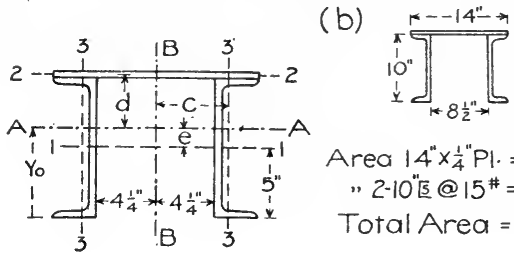

Area $14 " \times \frac{1}{4} " \mathrm{Pl} \cdot=3.50$ sq.in "2-10"5 @15"=8.92" " Total Area $=\overline{12.42} "$ "

(C)

To locate neutral axis A-A take moments about loweredge of channels

$$
Y_{0}=\frac{8.92 \times 5+3.5 \times 10.125}{12.42}=6.44^{\prime \prime}
$$

Eccentricity, $\mathrm{e}=6.44-5.00=1.44^{\prime \prime}$

Moment of Inertia, $I_{A}$, about A-A Let $I_{\text {E }}=I$ of $\underline{\underline{5}}$ about axis $1-1=133.8$

$\mathrm{I} \mathrm{pl}=$ I of Pl.about axis $2-2=.02$

$A_{\underline{E}}=$ Area of $\underline{\underline{s}}=8.92 \mathrm{sq} \cdot \mathrm{in}$.

$A$ pl.=Area of $\mathrm{Pl} .=3.50 \mathrm{sq} \cdot \mathrm{in}$.

Then $I_{A}=I_{[5}+A_{[5} e^{2}+I$ pl. $+A_{p l} \cdot d^{2}$

$=133.8+8.92 \times(1.44)^{2}+.02+3.5(3.685)^{2}$

$=199.8$

Radius of gyration, $r_{A}=\sqrt{\frac{199.8}{12.42}}=4.0^{\prime \prime}$
Moment of Inertia, $I_{B}$, about B-B Let $I_{\overline{5}}=I$ of $[$ about axis $3-3=4.6$ $\mathrm{Ipl}=\mathrm{I}$ of Pl.about axis B-B = 57.17 $A_{E s}=$ Area of $[\underline{s}=8.92 \mathrm{sq} \cdot \mathrm{in}$. Apl. $=$ Area of $\mathrm{Pl}=3.50 \mathrm{sq}$ in . Then $I_{B}=I_{E_{5}}+A_{E_{5}}(4.25+.64)+I_{p l}$. $=4.6+8.92(4.89)^{2}+57.17$ $=275.0$ Radius of gyration, $r_{B}=\sqrt{\frac{275.0}{12.42}}=4.7$ "

Stress due to weight Of Member The total weight of the member is as follows:-

$$
\begin{aligned}
& \text { 2-10" } 5 \text { @15\#-30'-0'long = 900.lbs. } \\
& \text { 1-14"x } \frac{1}{4} \text { PI.@11.9\#30-0' " = } 357 " \\
& \text { Details and Lacing- } 26 \%=328 " \\
& \text { Total weight, } W_{1}=\overline{1585} \text { " }
\end{aligned}
$$

Bénding Moment due to weight of the member, $M=\frac{1}{8} W I \sin \theta$

Stress due to weight, $f_{W}=\frac{M Y_{1}}{I-\frac{\left.P\right|^{2}}{1 O E}}=\frac{\frac{1}{8} W \mid \sin \theta_{1} Y_{1}}{I-\frac{P I^{2}}{I O E}}$

Stress due to weight in upper fibre

$$
f_{w}=\frac{\frac{1}{8} \times 1585 \times 358 \times .633 \times 3.81}{199.8-\frac{95300 \times 358^{2}}{10 \times 28000000}}=+1100 \mathrm{lbs} \text {. (compression) }
$$

Stress due to weight in lower fibre

$$
f_{w}^{\prime}=\frac{6.44}{3.81} \times 1100=-1860 \mathrm{lbs} \text { (tension) }
$$


Stress DUE TO ECCENTRIC LOADING

The stress in the extreme fibre due to eccentric loading will be

$$
f_{e}=\frac{M Y_{1}}{I-\frac{\left.P\right|^{2}}{I O E}}=\frac{P e Y_{1}}{I-\frac{P I^{2}}{I O E}}
$$

Eccentric stress in upper fibre

$$
f_{e}=\frac{95300 \times 1.44 \times 3.81}{199.8-\frac{95300 \times 358^{2}}{10 \times 28000000}}=-3347 \text { lbs.(tension) }
$$

Eccentric stress in lower fibre

$$
f_{e}^{\prime}=\frac{6.44}{3.81} \times 3347=+5657 \text { lbs. (compression) }
$$

The resultant stress due to eccentric loading and weight will be

$$
\begin{aligned}
f_{1} & =f e+f w \\
& =-3347+1100=-2247 \text { lbs. in upper fibre. } \\
& =+5657-1860=+3797 \text { lbs. in lower fibre. }
\end{aligned}
$$

The maximum stress in the member due to direct loading, weight of member and eccentric loading will occur in the lower fibre and will be

$$
\begin{aligned}
f_{2}+f_{1} & =\frac{P}{A}+f_{e}+f_{w} \\
& =\frac{95300}{12.42}+3797=+11470 \mathrm{lbs}
\end{aligned}
$$

To determine the position of the pin so that stress due to weight will neutralize stress due to eccentric loading make below the neutral axis.

$P e^{\prime}=\frac{1}{8} W /$ sine, where $e^{\prime}$ is the distance of the pin

Substituting and solving, $95300 \times e^{\prime}=\frac{1}{8}(1585 \times 358 \times .633)$

$$
e^{\prime}=.48^{\prime \prime}
$$

\section{Stress Due To Wind Moment}

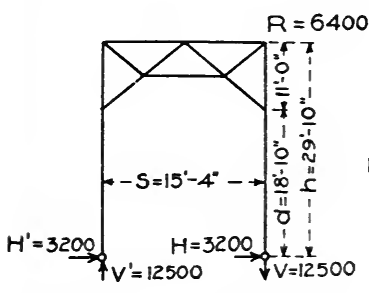

Portal, Columns Hingea.

(a)
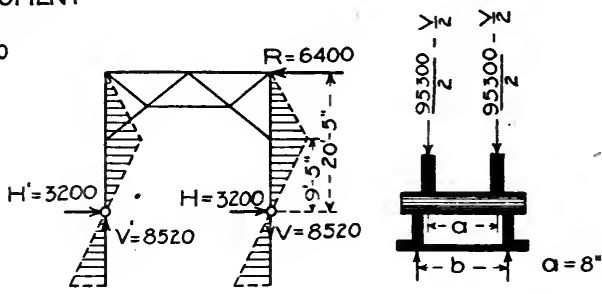

Portal, Columns Fixed. Windward Pedestal. (b)

(c) 
Before calculating the stress due to wind moment, it will be necessary to determine whether the end post is fixed or hinged.

If the end post is fixed, the negative moment developed at the lower pin will be $M=\frac{H d}{2}=\frac{3200 \times 226}{2}=361600$ in lbs.

- In order to obtain this condition of fixidity, the stress in the member must develop a resisting moment equal in amount.

Therefore the post may be considered fixed if

$$
\begin{aligned}
&\left(\frac{95300-\mathrm{V}}{2}\right) a \geqq \frac{\mathrm{Hd}}{2} \\
& \text { or } \quad\left(\frac{95300-8520}{2}\right) 8 \geqq 361600
\end{aligned}
$$

but $\quad 347120<361600$ and the end post will not be fixed.

(While this is the usual solution, the resisting moment certainly reduces the bending moment and the bending stress is less than computed below.)

The maximum moment will then occur at the foot of the portal knee brace and will be $M=3200 \times 226=723200$ in lbs.

Stress due to wind moment is a maximum in the leeward post and is

$$
\begin{aligned}
& f_{w}=\frac{M y_{1}^{\prime}}{I-\frac{\left.P\right|^{2}}{10 E}}=\frac{723200 \times 7}{27.5-\frac{(95300+12500) 358^{2}}{10 \times 28000000}} \\
& f_{w}= \pm 22480 \mathrm{lbs} .
\end{aligned}
$$

Stress, $f_{W}$, is compression on the windward side and tension on the leeward side of the member.

pression on the windward and tension on the leeward fibres. The maximum fibre stress will come at the foot of the knee brace either on the upper or lower fibres on the windward side of the post, depending upon whether the stress due to weight is greater than the stress due to eccentric loading, or the reverse. In this case the maximum stress comes on the lower fibres of the windward side of the post.

Combined Tension and Cross Bending.-The stress due to cross bending when the member is also subjected to direct tension is given by the formula

$$
f_{1}=\frac{M_{1} y_{1}}{I+\frac{P l^{2}}{c E}}
$$

the nomenclature being the same as in (74). The constant $c$ is taken equal to Io where the ends are hinged. 
Stress in a Bar Due to its Own Weight:-

Let $b=$ breadth of bar in inches;

$h=$ depth of bar in inches;

$w=$ weight of bar per lineal inch $=0.28 b h^{\prime}$;

$f_{2}=\frac{P}{b h}:=$ direct unit stress.

We will also have

$y_{1}=1 / 2 h$;

$M_{1}=1 / 8 w l^{2}$;

$P=f_{2} b h$.

Substituting in (75) we have

$$
\begin{aligned}
f_{.1} & =\frac{\frac{1}{8} w l^{2} \frac{h}{2}}{\frac{b h^{3}}{12}+\frac{f_{2} b h l^{2}}{10 \times 28,000,000}} \\
& =\frac{4,900,000 h}{f_{2}+23,000,000\left(\frac{h}{l}\right)^{2}}
\end{aligned}
$$

where $f_{1}$ is the extreme fibre stress in the bar due to weight, and is tension in lower fibre and compression in upper fibre.

If the bar is inclined, the stress obtained by formula $(76)$ must be multiplied by the sine of the angle that the bar makes with a vertical line.

Formula $(76)$ is much more convenient for actual use than formula $(75)$.

Diagram for Stress in Bars Due to Their Own Weight.--Taking the reciprocal of $(76)$ we have

and

$$
\begin{gathered}
\frac{1}{f_{1}}=\frac{f_{2}}{4,900,000 h}+\frac{23,000,000\left(\frac{h}{l}\right)^{2}}{4,900,000 h} \\
=y_{1}+y_{2} \\
f_{1}=\frac{1}{y_{1}+y_{2}}
\end{gathered}
$$


Fig. 78 gives values of $y_{1}$ for different values of $f_{2}$, and values of $y_{2}$ for different values of the length in feet, $L$. The values of $y_{1}$ and $y_{2}$ can be read off the diagram directly for any value of $h, f_{2}$, and L. And then, if the sum of $y_{1}$ and $y_{2}$ be taken on the lower part of the

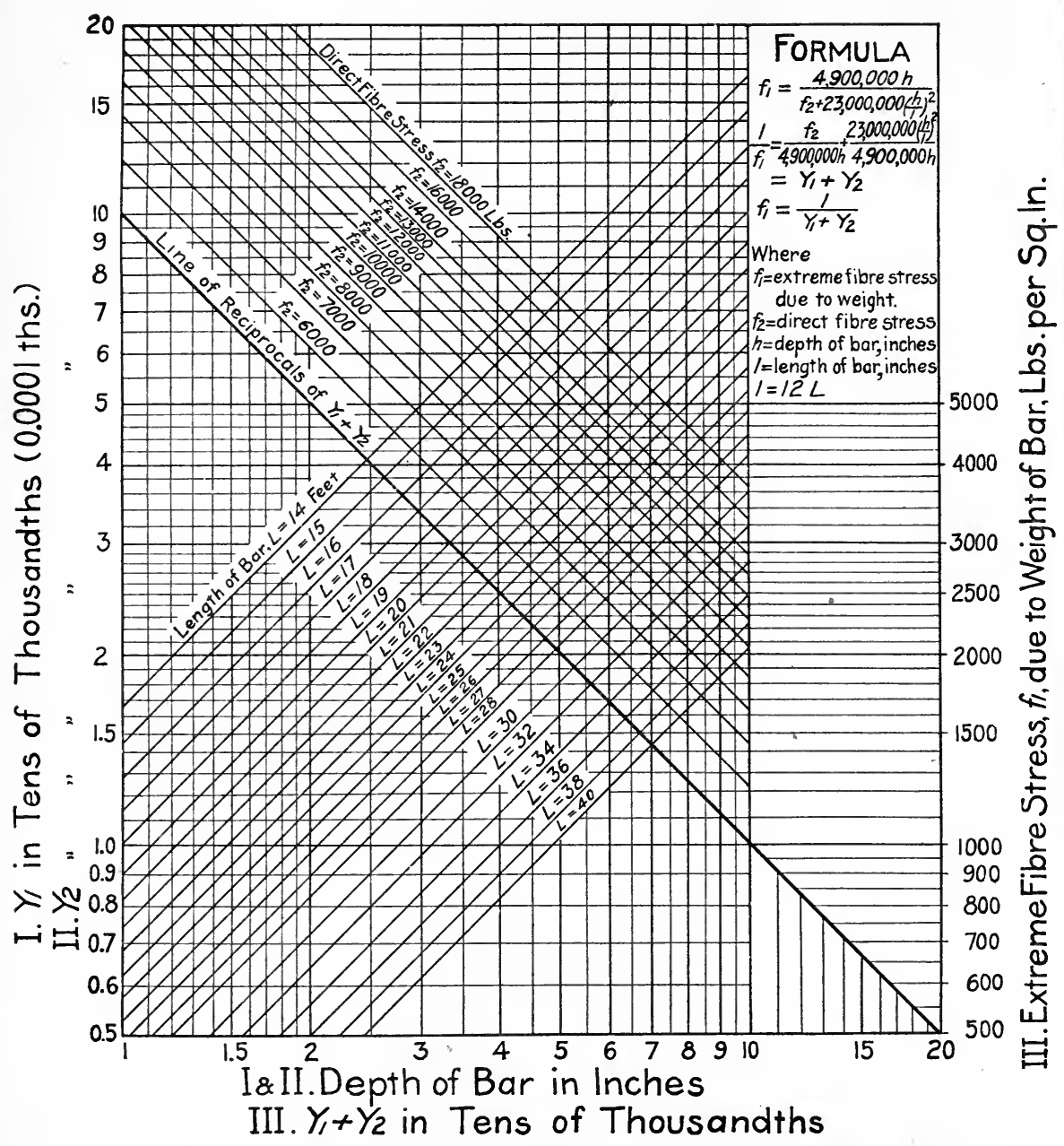

Fig. 78. Diagram For FINDING STRESS IN bars DUE to TIIEIR OWN WEIGH'T. 
diagram, the reciprocal, which is the fibre stress $f_{1}$, may be read off the right hand side.

The use of the diagram will be illustrated by two problems:

Problem I. Required the stress in a $4^{\prime \prime} \times \mathrm{I}^{\prime \prime}$ eye-bar, 20 feet long, which has a direct tension of $56,000 \mathrm{lbs}$.

In this case, $h=4^{\prime \prime}, L=20 \mathrm{ft}$., and $f_{2}=\mathrm{I} 4,000 \mathrm{lbs}$. per sq. in. The stress due to weight, $f_{1}$, is found as follows: On the bottom oi the diagram find $h=4$ inches, follow up the vertical line to its intersection with inclined line marked $L=20$, and then follow the horizontal line passing through the point of intersection out to the left margin and find $y_{2}=3.3$ tens of thousandths; then follow the vertical line $h=4$ inches, up to its intersection with inclined line marked $f_{2}=14,000$, and then follow the horizontal line passing through the point of intersection out to the left margin and find $y_{1}=7.2$ tens of thousandths.

Now to find the reciprocal of $y_{1}+y_{2}=7.2+3.3=10.5$, find value of $y_{1}+y_{2}=$ I0.5 on lower edge of diagram, follow vertical line to its intersection with inclined line marked "Line of Reciprocals" and find stress $f_{1}$ by following horizontal line to right hand margin to be

$$
f_{1}=950 \text { lbs. per sq. in. }
$$

By substituting in $(76)$ and solving we get $f_{1}=960$ lbs. per ;q. in.

Problem 2. Required the stress in a $5^{\prime \prime} \times 3 / 4$ " eye-bar, 30 feet long, which has a direct tension of 60,000 lbs., and is inclined so that it makes an angle of $45^{\circ}$ with a vertical line.

In this case, $h=5^{\prime \prime}, L=30$ feet, $f_{2}=16.000 \mathrm{lbs}$., and $\theta=45^{\circ}$. From the diagram as in Problem I, $y_{2}=1.8$ tens of thousandths, and $y_{1}=6.5$ tens of thousandths, and

$$
\begin{gathered}
f_{1}=\frac{1}{y_{1}+y_{3}} \sin \theta=1200 \times \sin \theta \\
=850 \text { lbs. per sq. in. }
\end{gathered}
$$

Relations beticen $h, f_{1}, f_{2}$ and $L$. For any values of $f_{2}$ and $L, f_{1}$ w:ll be a maximum for that value of $h$ which will make $y_{1}+y_{2}$ a min- 
imum. This value of $h$ will now be determined. Differentiating equation (76) with reference to $f_{1}$ and $h$, we have after solving for $h$ after placing the first derivation equal to zero

$$
h=\frac{l}{4800} \sqrt{f_{2}}
$$

in which $h$ is the depth of bar which will have a maximum fibre stress for any given values of $l$ and $f_{2}$.

Now if we substitute the value of $h$ in (78) back in equation (76), we find that $f_{1}$ will be a maximum when $y_{1}=y_{2}$.

Now in the diagram the values of $y_{1}$ and $y_{2}$ for any given values of $f_{2}$ and $L$ will be equal for the depth of bar, $h$, corresponding to the intersection of the $f_{2}$ and $L$ lines.

It is therefore seen that every intersection of the inclined $f_{2}$ and $L$ lines in the diagram, has for an abscissa a value of $h$, which will have a maximum fibre stress $f_{1}$, for the given values of $f_{2}$ and $L$.

For example, for $L=30$ feet and $f_{2}=12,000$ lbs. we find $h=$ 8.3 inches and $f_{1}=1700 \mathrm{lbs}$. For the given length $L$ and direct fibre stress $f_{2}$, a bar deeper or shallower than 8.3 inches will give a smaller value of $f_{1}$ than $1700 \mathrm{lbs}$.

Eccentric Riveted Connections.-The actual shearing stresses in riveted connections are often very much in excess of the direct shearing stresses. This will be illustrated by the calculation of the shearing stresses in the rivets in the standard connection shown in Fig. 79 and Fig. 8o.

The eccentric force, $P$, may be replaced by a direct force, $P$, acting through the center of gravity of the rivets and parallel to its original direction, and a couple with a moment $M=P \times 3^{\prime \prime}=60,000$ inch-lbs. Each rivet in the connection will then take a direct shear equal to $P$ divided by $n$, where $n$ is the total number of rivets in the connection, and a shear due to bending moment $M$.

The shear in any rivet due to moment will vary as the distance, 
and the resisting moment exerted by each rivet will vary as the square of the distance of the rivet from'the center of gravity of all the rivets.

Now, if $a$ is taken as the resultant shear due to bending moment in a rivet at a unit's distance from the center of gravity, we will have the relation

$$
\begin{aligned}
& \begin{aligned}
M & =a\left(d_{1}{ }^{2}+d_{2}{ }^{2}+d_{6}{ }^{2}+d_{4}{ }^{2}+d_{5}{ }^{2}\right) \\
& =a \Sigma d^{2} \\
\text { and } \quad a & =\frac{M}{\Sigma d^{2}}
\end{aligned}
\end{aligned}
$$

The remainder of the calculations are shown in Fig. 79. The resultant shears on the rivets are given in the last column of the table

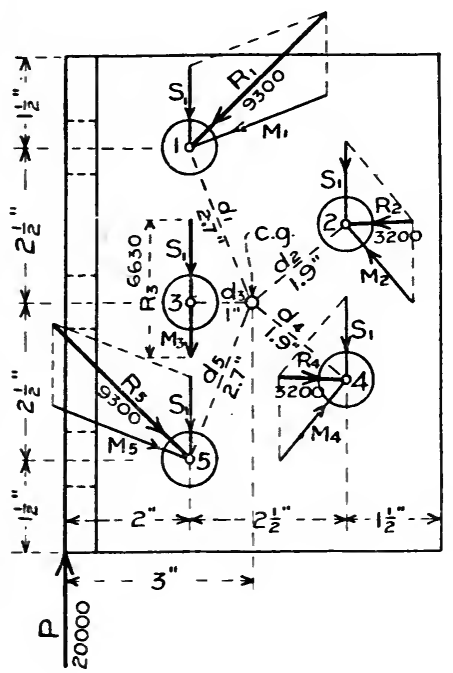

Direct Shear $S=20000 \div 5=4000 \mathrm{lbs}$.

Moment $=20000 \times 3=60000$ in $\cdot$ lbs .

$=a\left(d_{1}^{2}+d_{2}^{2}+d_{3}^{2}+d_{4}^{2}+d_{5}^{2}\right)$

\begin{tabular}{|c|c|c|c|c|c|c|}
\hline Rivet & $d$ & $d^{2}$ & Moment & $M$ & $\mathrm{~S}$ & $R$ \\
\hline \begin{tabular}{|l|}
1 \\
\end{tabular} & 2.70 & 7.29 & 19185 & 7100 & 4000 & 9300 \\
\hline 2 & 1.90 & 3.61 & 9500 & 5000 & 4000 & 3200 \\
\hline 3 & 1.00 & 1.00 & 2630 & 2630 & 4000 & 6630 \\
\hline 4 & 1.90 & 3.61 & 9500 & 5000 & 4000 & 3200 \\
\hline 5 & 2.70 & 7.29 & 19185 & 7100 & 4000 & 9300 \\
\hline \multicolumn{6}{|c|}{$a \Sigma d^{2}=22.80 a=60000$ in.lbs. 20000} & \\
\hline
\end{tabular}

Where $a=$ Moment shear on rivet 3

$=2630 \mathrm{lbs}$.

$M=$ Shear due to Moment .

$S=$ Shear due to Direct Load, $P$

$R=$ Resultant Shear .

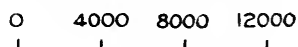

FIG. 79.

and are much larger than would be expected.

The force and equilibrium polygons for the resultant shears and load $P$, drawn in Fig. 8o, close, which shows that the connection is in equilibrium. 

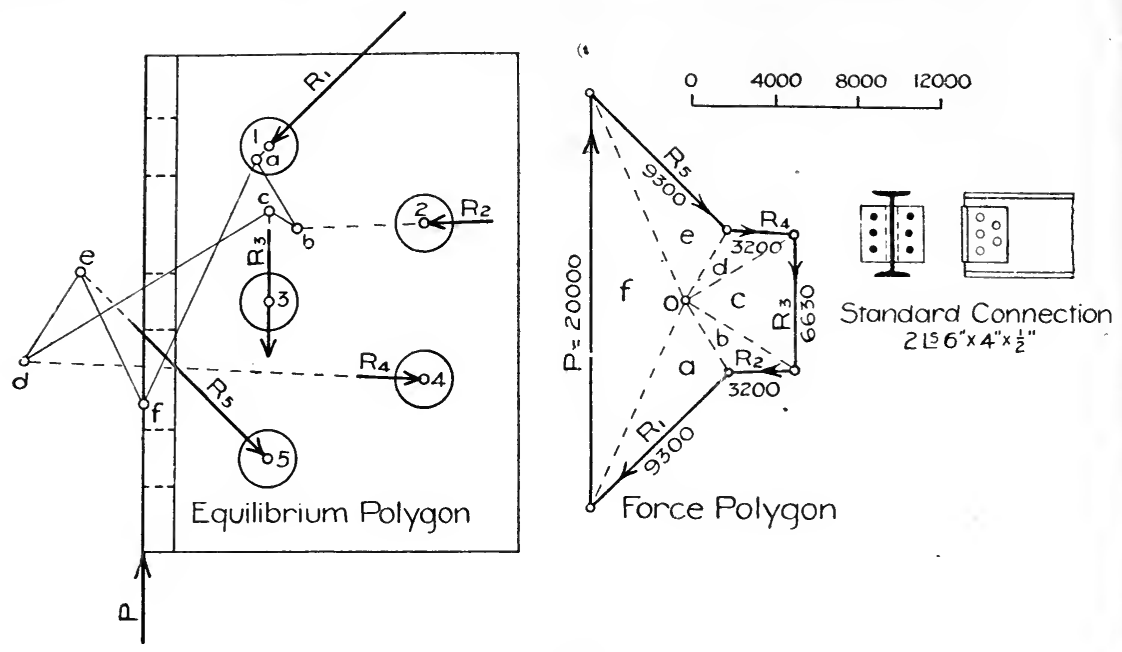

FIG. 80. 


\section{PART III.}

\section{DESIGN OF MILL BUILDINGS.}

\section{CHAPTER XVI.}

\section{General Design.}

General Principles.-The general dimensions and outline of a mill building will be governed by local conditions and requirements. The questions of light, heat, ventilation, foundations for machinery, handling of materials, future extensions, first cost and cost of maintenance should receive proper attention in designing the different classes of structures. One or two of the above items often determines the type and general design of the structure. Where real estate is high, the first cost, including the cost of both land and structure, causes the adoption in many cases of the multiple story building, while on the other hand where the site is not too expensive the single story shop or mill is usually preferred. In coal tipples and shaft houses the handling of materials is the prime object; in railway shops and factories turning out heavy machinery or a similar product, foundations for the machinery required, and convenience in handling materials are most important; while in many other classes of structures such as weaving sheds, textile mills, and factories which turn out a less bulky product with light machinery, and which employ a large number of men, the principle items to be considered in designing are light, heat, ventilation and ease of superintendence. 
Shops and factories are preferably located where transportation facilities are good, land is cheap and labor plentiful. Too much care cannot be used in the design of shops and factories for the reason that defects in design that cause inconvenience in handling materials and workmen, increased cost of operation and maintenance are permanent and cannot be removed.

The best modern practice inclines toward single floor shops with as few dividing walls and partitions as possible. The advantages of this type over multiple story buildings are (I) the light is better, (2) vertilation is better, (3) buildings are more easily heated, (4) foundations for machinery are cheaper, (5) machinery being set directly on the ground causes no vibrations in the building, (6) floors are cheaper, (7) workmen are more directly under the eye of the superintendent, (8) materials are more easily and cheaply handled, (9) buildings admit of indefinite extension in any direction, (IO) the cost of construction is less, and (II) there is less danger from damage due to fire.

The walls of shops and factories are made (I) of brick, stone, or concrete; (2) of brick, hollow tile or concrete curtain walls between steel columns; (3) of expanded metal and plaster curtain walls and glass; (4) of concrete slabs fastened to the steel frame; and (5) of corrugated iron fastened to the steel frame.

The roof is commonly supported by steel trusses and framework, and the roofing may be slate, tile, tar and gravel or other composition, tin or sheet steel, laid on board sheathing or on concrete slabs, tile or slate supported directly on the purlins, or corrugated steel supported on board sheathing or directly on the purlins. Where the slope of the roof is flat a first grade tar and gravel roof, or some one of the patent composition roofs is used in preference to tin, and on a steep slope slate is commonly used in preference to tin or tile. Corrugated steel roofing is much used on boiler houses, smelters, forge shops, coal tipples, and similar structures.

Floors in boiler houses, forge shops and in similar structures are generally made of cinders; in round houses brick floors on a gravel or 
concrete foundation are quite common; while in buildings where men have to work at machines the favorite floor is a wooden floor on a foundation of cinders, gravel, or tar concrete. Where concrete is used for the foundation of a wooden floor it should be either a tar or an asphalt concrete, or a layer of tar should be put on top of the cement concrete to prevent decay. Concrete or cement flcors are used in many cases with good results, but they are not satisfactory where men have to stand at benches or machines. Wooden racks on cement floors remove the above objection somewhat. Where rough work is done, the upper or wearing surface of wooden floors is often made of yellow pine or oak plank, while in the better classes of structures, the top layer is commonly made of maple. For upper floors some one of the common types of fireproof floors, or as is more common a heavy plank floor supported on beams may be used.

Care should be used to cbtain an ample amount of light in buildings in which men are to work. It is now the common practice to make as much of the roof and side walls of a transparent or translucent material as practicable; in many cases fifty per cent of the roof surface is made of glass, while skylights equal to twenty-five to thirty per cent of the roof surface are very common. Direct sunlight causes a glare, and is also objectionable in the summer on account of the heat. Where windows and skylights are directly exposed to the sunlight they may best be curtained with white muslin cloth which admits much of the light and shades perfectly. The "saw tooth" type of roof with the shorter and glazed tooth facing the north, gives the best light and is now coming into quite general use.

Plane glass, wire glass, factory ribbed glass, and translucent fabric are used for glazing windows and skylights. Factory ribbed glass should be placed with the ribs vertical for the reason that with the ribs horizontal, the glass emits a glare which is very trying on the eyes of the workmen. Wire netting should always be stretched under skylights to prevent the broken glass from falling down, where vire glass is not used. 
Heating in large buildings is generally done by the hot blast system in which fans draw the air across heated coils, which are heated by exhaust steam, and the heated air is conveyed by ducts suspended from the roof or placed under the ground. In smaller buildings, direct radiation from steam or hot water pipes is commonly used.

The proper unit stresses, minimum size of sections and thickness of metal will depend upon whether the building is to be permanent or temporary, and upon whether or not the metal is liable to be subjected to the action of corrosive gases. For permanent buildings the author would recommend 16,000 lbs. per square inch for allowable tensile, and I6,000 - 70 $\frac{l}{r}$ bs. per square inch for allowable compressive stress for dirèct dead, snow and wind stresses in trusses and columns; $l$ being the center to center length and $r$ the radius of gyration of the member, both in inches. For wind bracing and flexural stresses in columns due to wind, add 25 per cent to the allowable stresses for dead, snow and wind loads. For temporary structures the above allowable stresses may be increased 20 to 25 per cent.

The minimum size of angles should be $2^{\prime \prime} \times 2^{\prime \prime} \times 1 / 4^{\prime \prime}$, and the minimum thickness of plates $1 / 4^{\prime \prime}$, for both permanent and temporary structures. Where the metal will be subjected to corrosive gases as in smelters and train sheds, the allowable stresses should be decreased 20 to 25 per cent, and the minimum thickness of metal increased 25 per cent, unless the metal is fully protected by an acid-proof coating (at present the best paints do little more in any case than delay and retard the corrosion).

The minimum thickness of corrugated steel should be No. 20 gage for the roof and No. 22 for the sides; where there is certain to be no corrosion Nos. 22 and 24 may be used for the roof and sides respectively.

The different parts of mill buildings will be taken up and discussed at some length in the following chapters. 


\section{CHAPTER XVII.}

FRAMEWORK.

Arrangement.-The common methods of arranging the framework in simple mill buildings are shown in Fig. I, Fig. 8I and Fig. 82. The different terms which are used in the discussion that follows will be made clear by an inspection of Fig. I and Fig. 8I.

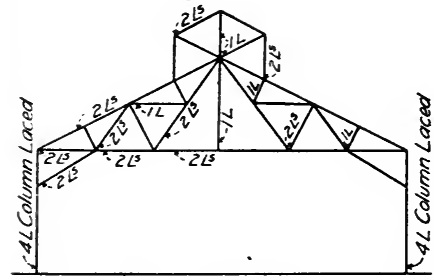

Transverse Bent

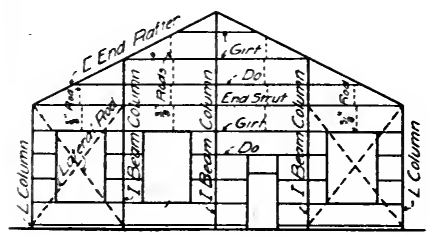

End Framing

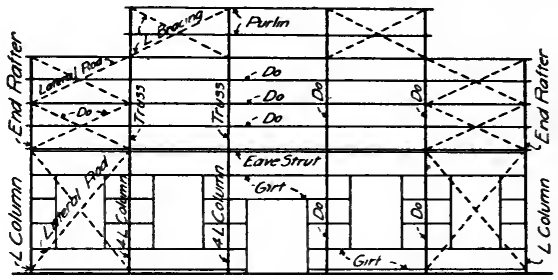

Side Elevotion

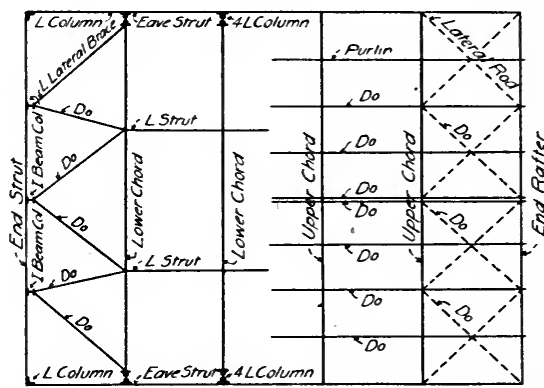

Plan Lower Chord Plan Upper Chord

Fig. 8I.

The three types of mill buildings-steel frame mill buildings, mill buildings with masonry filled walls, and mill buildings with masonry walls-have been discussed in the Introduction.

Fig. 82. A. T. \& S. F. R. R. Blacksmith Shop, Topeka, Kas. The end post bent, shown in (a) Fig. I and in Fig. 8I, usually requires 
less material than the end trussed bent shown in (b) Fig. I and in Fig. 82 , and is commonly used for simple mill buildings. Extensions can be made with about equal ease in either case, and the choice of methods will usually be determined by the local conditions of the problem and

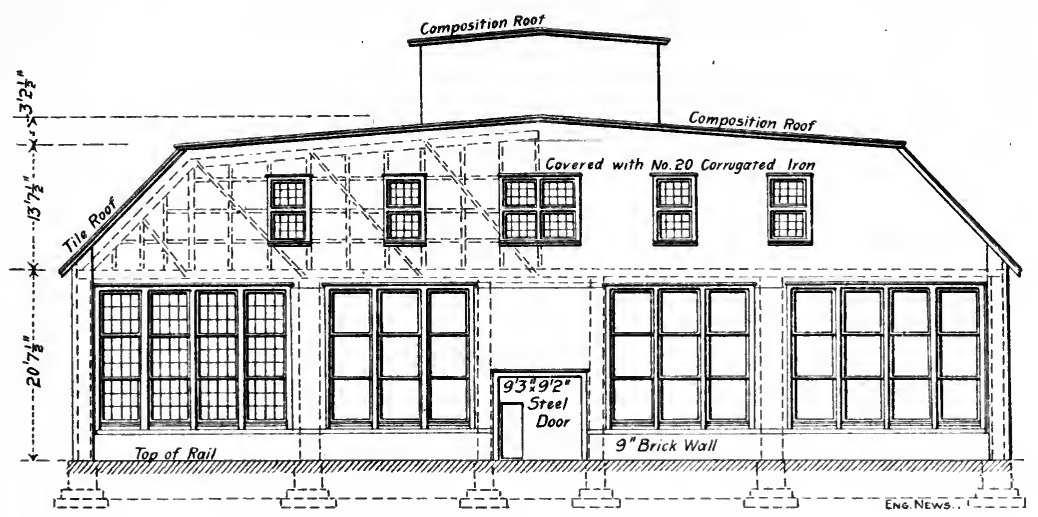

the fancy of the designer. In train sheds and similar structures the end trussed bent (b), Fig. I, is used. Where the truss span is quite long, as in train sheds, the end trusses are often designed for lighter loads than are the intermediate trusses, thus saving considerable material. In the case of simple mill buildings of moderate size all trusses are, however, commonly made alike, the extra cost of detailing being usually more than the amount saved in material.

In train sheds, coliseums, and similar structures requiring a large floor space, the three-hinged arch is very often used in place of the typical transverse bent system.

The various parts of the framework of mill buildings will be taken up and discussed in order.

TRUSSES.-Types of Trusses.-The proper type of roof truss to use in any particular case will depend upon the span, clear headroom, style of truss preferred, and other conditions. For spans up to about Ioo feet, the Fink type of truss is commonly used. This type of truss has the advantage of short struts, simplicity of details and economy. The stresses that control the design are with but a very few exceptions 
those caused by an equivalent uniform dead load, thus simplifying the calculation of stresses (see Table VI).

The outline of the truss will depend upon the spacing of the purlins, and upon whether or not the purlins are placed at the panel points of the truss. The most economical and pleasing arrangement is to make a panel point in the truss under each purlin. Taking the normal wind load on the roof at from 25 to $30 \mathrm{lbs}$. per sq. ft., it will be seen in Fig. I 2 that for Nos.20 and 22 corrugated steel, when used without sheathing, the purlins should be spaced from 4 to 5 feet. If this spacing is exceeded corrugated steel roofing supported directly on the purlins is almost certain to leak. Where sheathing is used the purlin spacing can be made greater. Many designers, however, pay no attention to the matter of placing the purlins at the panel points, the upper chord of the truss being stiffened to take the flexural stress.

In Fig. 83, (a) shows the form of a Fink truss for a span of 30 feet; (b) for a span of 40 feet; (c) for a span of 50 feet; (d) for a span of 60 feet ; and (e) for a span of 80 feet, on the assumption that the purlins are spaced from 4 to 5 feet, and come at the panel points of the truss. If trusses with vertical posts are desired the triangular trusses $(h)$ and $(j)$, or Fink truss ( $f$ ) may be used. The truss shown in (i) is occasionally used for long spans, althaugh it has little to recommend it except novelty. The truss shown in $(k)$ is used where there is ample headroom. The quadrangular truss shown in (1) and the camels back truss shown in $(\mathrm{m})$, are used for long spans where the appearance of the truss is an important feature, as in convention halls and train sheds. The lower chords of mill building trusses are usually made horizontal, but by giving the lower chord a camber, as in $(\mathrm{g})$, the appearance from the side is greatly improved.

The "saw tooth" or "weaving shed" roof shown in (a) Fig. 84, has been used abroad for many years and is now coming into quite general use in this country for shops and factories as well as for weaving sheds, as indicated by the name. The short leg of the roof is made inclined as in (a), or vertical as in (b), and is glazed with glass or 
translucent fabric. The glazed leg of the roof is made to face the north, thus giving a constant and agreeable light and doing away with the use of window shades.

The principal difficulty in saw tooth roof construction is in obtain-

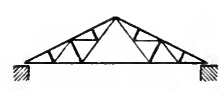

(a) $30 \mathrm{Ft}$. Span

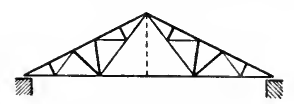

(b) $40 \mathrm{Ft} \cdot$ Span

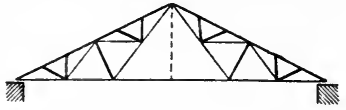

(c) 50 Ft.Span

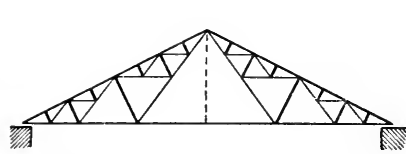

(d) $60 \mathrm{FT}$ Span

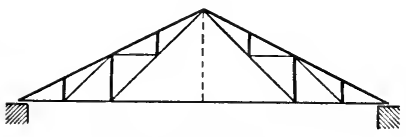

(f) Modified Fink

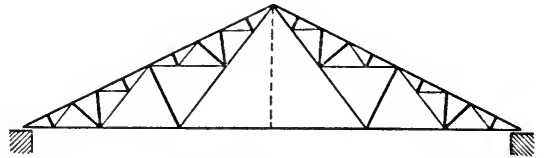

(e) 80 Fi Span

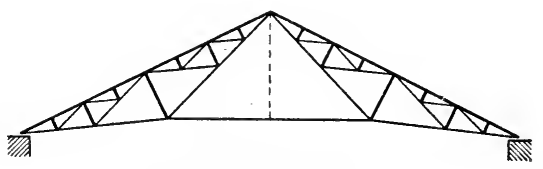

(g) Cambered Fink

FINK TRUSSES

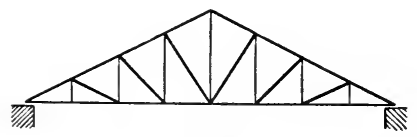

(h) Howe

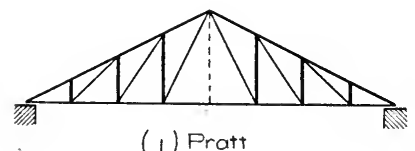

(j) Pratt

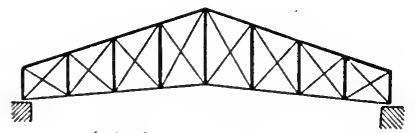

(1) Quadrangular

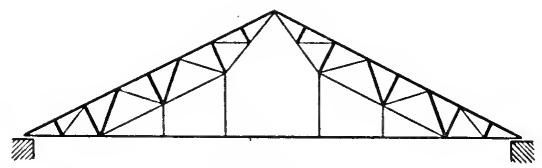

(i) Hybria

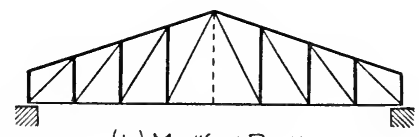

(k) Modified Pratt

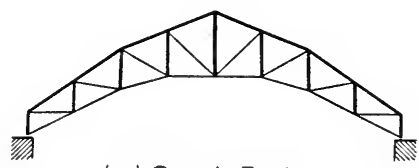

(m) Comels Back

Fig. 83. Types of ROOF trusses. 
ing satisfactory and efficient gutters, and in preventing condensation on the inner surface of the glass and gutters. Another objection to the use of saw tooth roofs in localities having a heavy snowfall is that the snow drifts the roof nearly full and shuts off the lighr. The common method of preventing the snow from collecting, and for taking care of the roof water, is that given in the description of the Conkey plant, which see.

The modified saw tooth roof shown in (b), Fig. 84 , is proposed by the author as a substitute for the usual type of saw tooth roof shown in (a). This modified saw tooth roof allows the use of ordinary valley gutters, and gives an opportunity to take care of the condensation on the inner surface of the glass by suspending a gutter at the bottom of the monitor leg. Snow will cause very little trouble
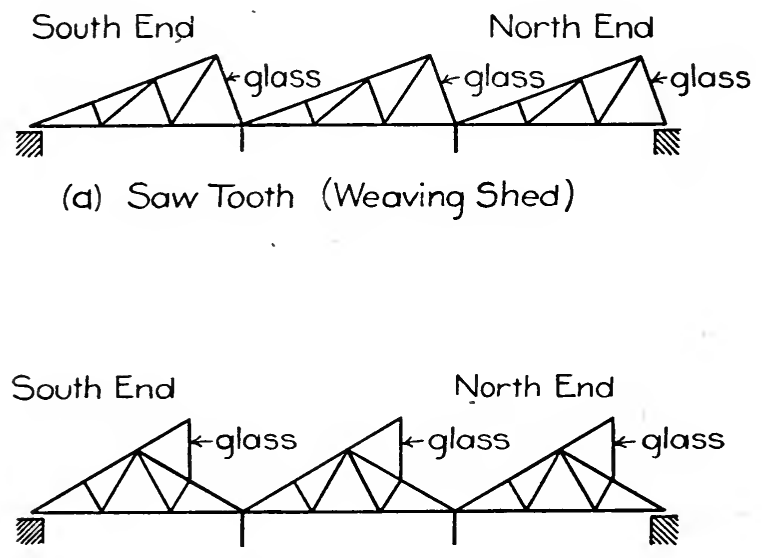

(b) Modified Saw Tooth

FIG. 84 .

with this roof on account of the increased depth of gutter. The modified saw tooth roof has a greater pitch, and has a more economical truss for long spans than the common form shown in (a). Condensation on the inner surface of the glazed leg can be practically prevented by using double gläzing with an air space between the sheets of glass. Double 
glazing in windows and skylights makes the building much easier to heat, the air space making an almost perfect non-conductor.

Brown \& Sharp Foundry.-In the Brown \& Sharp Mfg. Company's Foundry, a modification of the saw tooth roof was adopted in which glass was used on both surfaces of the roof. 'The skylights extend east and west and have a pitch of 45 degrees. The southerly pitch is glazed with opaque glass, the other with ordinary rough glass. The ventilator monitor, which surmounts the skylights, is glazed with opaque glass on the southerly side, and extends high enough so that no light up to an angle of 70 degrees reaches the glass below. By this arrangement no direct sunlight is admitted to the shop from above excepting for a few minutes at noon during the longest days of the year. The result of this overhead light, combined with the almost wholly glass svalls of the room is that the floor below is as light as out of doors, to all intents and purposes, yet diffused light only is admitted. A rod placed upright on the floor of one of these rooms casts no shadow.

Conkey Printing Plant*.-The printing plant of the W. B. Conkey Co., Hammond, Ind., consists of a single story building, $540 \times 450 \mathrm{ft}$. The roof is of the weaving shed or saw tooth type and all windows are glazed with frosted glass and are placed at an angle, looking toward the north. Every 29 feet of roof space provides II feet of light. Owing to the angle of the roof the direct rays of light are kept out of the building, which is thus lighted by the soft reflected rays from the northern sky. The entire roof is built up out of light structural steelwork resting on cast iron columns spaced $29 \mathrm{ft}$. c. to c. one way, and $\mathrm{I} 6$ ft. c. to c. in the other direction. The height of the trusses above the floor is $\mathrm{I} 2 \mathrm{ft}$. To prevent the snow collecting in the valleys between the skylights, the bottom of the gutter and the glass are kept heated so that the snow melts as it falls. This method produces condensation on the inner surface of the glass, which is collected in a system of condensation gutters and carried outside the building.

The heating and ventilating of the building is accomplished by a blast system, with the heating ducts under the floor, which supply registers throughout the plant, arranged on the side walls of each department. The heating system can be made to produce a mild heat for the seasons of spring and fall, and can also be turned into a cooling system in the summer, by running cold water through the steam pipes at

*Engineering News, Dec. 8, 1898. 
the fan and changing the air every 15 minutes with cool air in hot weather.

The floor is built of heavy plank and finished maple laid on sleepers which are bedded in cinders. The walls are made of heavy tile and the openings are closed with iron fire doors. The building is practically fireproof and takes a very low rate of insurance.

Boyer Plant.-The Boyer Plant of the Chicago Pneumatic Tool Co., at Detroit, Mich., is $325 \times 185 \mathrm{ft}$., with the longer dimension extending north and south. The roof of the building is divided into two sections, having spans of about $92 \mathrm{ft}$. each, a pitch of about $1 / 4$, and is covered with Patent Asbestos Roofing-manufactured by W. H. JohnsManville Co., Milwaukee, Wis.-laid on $1 \mathrm{r} / 8$-in. plank sheathing. The building is lighted by means of saw tooth skylights facing north and extending from the ridge of the roof to within about $6 \mathrm{ft}$. of the eaves on the outside and the valley gutter on the inside. The trusses are spaced I $6 \mathrm{ft}$. apart, and there are three saw tooth skylights between each pair of trusses, making 240 skylights in the roof. The north leg of the saw tooth is vertical and is glazed with double corrugated glass, the south leg is covered with asbestos roofing. The building is ventilated by means of circular ventilators placed in the ridge of the roof and spaced $16 \mathrm{ft}$. apart. The lighting in this building is almost perfect. The roofing has given satisfaction with the exception of the large valley gutters, which will be covered with copper or lead in the near future. There has been a little trouble with condensation, but not enough to make it necessary to go to the expense of putting in condensation gutters.

This building is described in the Railway and Engineering Review, March 9, I90r.

For additional details of saw tooth roofs see Fig. 97.

The cross-section of a locomotive shop for the Eastern Railway of France is shown in Fig. 85. The entire building is made of fireproof materials, the framework is of iron and the roof of sheet metal and glass. The building extends from east to west and has a saw tooth roof, with the shorter leg facing north, and glazed with crinkled glass. The floor is made of treated oak cubes measuring 3.94 in. on the edge, set with the grain vertical, on a bed of river sand about 8 in. thick. The saw tooth roof is well suited to structures of this class. 


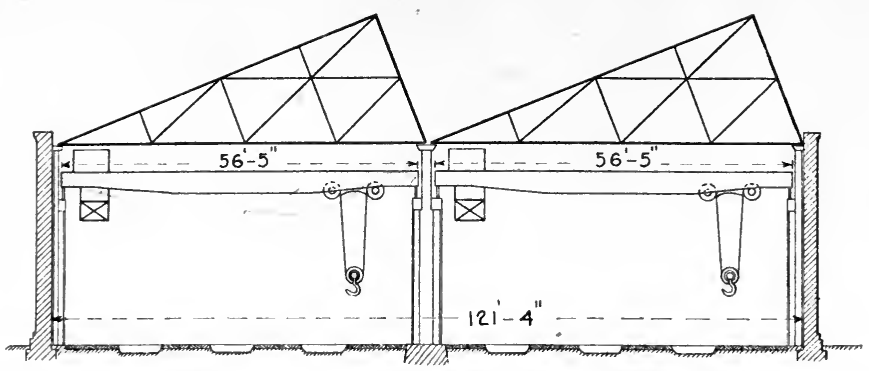

Fig. 85. Locomotive Shop, Eastern Railway of France.

A few of the forms of trusses in common use where ventilation and light are provided for are shown in Fig. 86. The Fink truss with

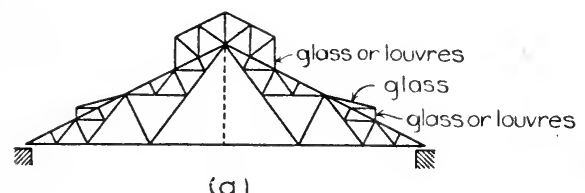

(a)

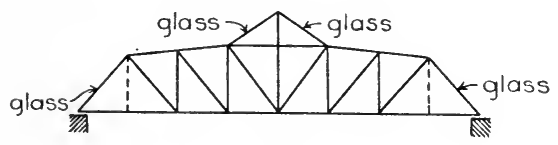

(C)

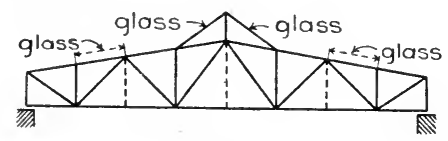

(e)

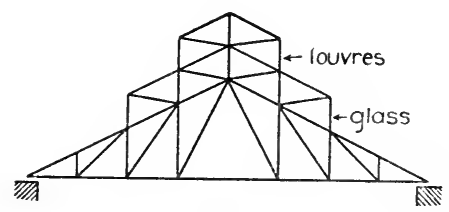

(b)

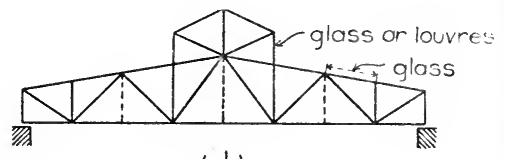

(d)

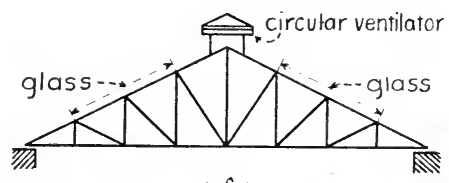

$(f)$

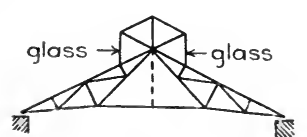

( $g$ )

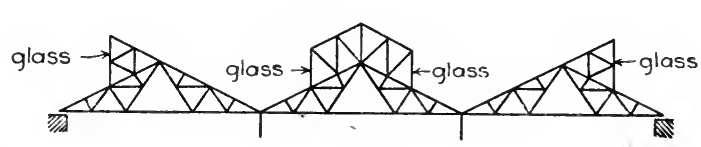

(h) Silk Mill

FIG. 86. 
monitor ventilator and skylights in the roof shown in (a), is a favorite type for shops; truss (b) with double monitor ventilator is especially adapted to round house construction; trusses (c) and (e) are adapted to shop and factory construction where a large amount of light is desired, ventilation being obtained by means of circular ventilators; truss (d) is similar to (c) and (e), but allows of better ventilation; truss has skylights in the roof and has circular ventilators placed along the ridge of the roof; truss $(\mathrm{g})$ is the type in common use for blacksmith shops, boiler houses, and roofs of small span. The "silk nill" roof shown in (h) was used by the Klots Throwing Co. in their silk mill at Carbondale, $\mathrm{Pa}$. The spans of the three trusses are $48^{\prime} 8^{\prime \prime}$ each, with a clerestory of $13^{\prime} 9^{\prime \prime}$ in the monitor ventilators, which are glazed with glass $\mathrm{II}^{\prime} \mathrm{O}^{\prime \prime}$ high. The monitors face east and west, allowing a maximum amount of direct sunlight in the morning and evening, and none at midday. This roof has given very satisfactory results, however, it would seem to the author that it would be necessary to use shades, and that there would be shadows in the building. The trusses in this building are spaced $10^{\prime} 6^{\prime \prime}$ apart and support the plank sheathing which carries the roof, no purlins being used. The shafting to run the machinery in this building is placed in a sub-basement; a method much more economical and convenient than the common one of suspending the shafting from the trusses.

Pitch of Roof.- The pitch of a roof is given in terms of the center height divided by the span; for example a 6o-ft. span truss with $1 / 4$ pitch will have a center height of $15 \mathrm{ft}$. The minimum pitch allowable in a roof will depend upon the character of the roof covering, and upon the kind of sheathing used. For corrugated stee! laid directly on purlins, the pitch should preferably be not less than $1 / 4\left(6^{\prime \prime}\right.$ in $\left.12^{\prime \prime}\right)$, and the minimum pitch, unless the joints are cemented, not less than $1 / 5$. Slate and tile should not be used on a less slope than $1 / 4$ and preferably not less than $1 / 3$. The lap of the slate and tile should be greater for the less pitch. Gravel should never be used on a roof with a greater pitch than about $1 / 5$, and even then the composition is very liable to run. As- 
phalt is inclined to run and should not be used on a roof with a pitch of more than, say, 2 inches to the foot. If the laps are carefully made and cemented a gravel and tar or asphalt roof may be practically flat; a pitch of $3 / 4$ to $\mathrm{I}$ inch to the foot is, however, usually preferred. Tin may be used on a roof of any slope if the joints are properly soldered. Most of the patent composition roofings give better satisfaction if laid on a roof with a pitch of $1 / 5$ to $1 / 4$. Shingles should not be used on a roof with a pitch less. than $1 / 4$, and preferably the pitch should be $1 / 3$ to $1 / 2$.

Pitch of Truss.- There is very little difference in the weight of Fink trusses with horizontal bottom chords, in which the top chord has a pitch of $1 / 5,1 / 4$, or $1 / 3$. The difference in weight is quite noticeable, however, when the lower chord is cambered; the truss with the $1 / 3$ pitch being then more economical than either the $1 / 5$ or the $1 / 4$ pitch. Cambering the lower chord of a truss more than, say, I-40 of the span adds considerable to the weight. For example the computed weights of a 6o-ft. Fink truss with a horizontal lower chord, and a 6o-ft. span Fink truss with a camber of 3 feet in the lower chord, showed that the cambered truss weighed 40 per cent more for the $1 / 4$ pitch and 15 per cent more for the $1 / 3$ pitch, than the truss having the same pitch with horizontal lower chord. It is, however, desirable for appearance sake to put a slight camber in the bottom chords of roof trusses, for the reason that to the eye a horizontal lower chord will appear to sag if viewed from one side.

In deciding on the proper pitch, it should be noted that while the I/3 pitch gives a better slope and has a less snow load than a roof with $1 / 4$ or $1 / 5$ pitch, it has a greater wind load and more roof surface. Taking all things into consideration $\mathrm{I} / 4$ pitch is probably the most economical pitch for a roof. A roof with $1 / 3$ pitch is, however, very nearly as economical, and should preferably be used where corrugated steel roofing is used without sheathing, and where the snow load is large.

Economic Spacing of Trusses.-The weight of the trusses and columns per square foot of area decreases as the spacing increases, while 
the weight of the purlins and girts per square foot of area increases as the spacing increases. The economic spacing of the trusses is a function of the weight per square foot of floor area of the truss, the purlins, the side girts and the columns, and also of the relative cost of each kind of material. For any given conditions the spacing which makes the sum of these quantities a minimum will be the economic spacing. It is desirable to use simple rolled sections for purlins and girts, and under these conditions the economic spacing will usually be between $\mathrm{I} 6$ and 25 feet. The smaller value being about right for spans up to, say, 60 feet, designed for moderate loads, while the greater value is about right for long spans, designed for heavy loads.

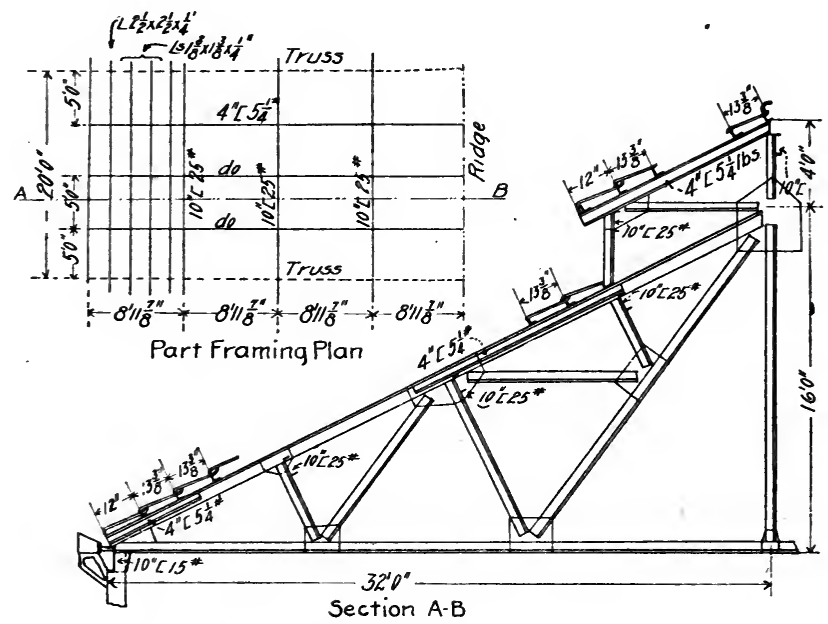

Fig. 87. STEEL ROOF COVERED With LUdOWICI TILE.

Calculations of a series of simple Fink trusses resting on walls and having a uniform span of 60 feet, and different spacings gave the least weight per square foot of horizontal projection of the roof for a spacing of 18 feet, and the least weight of trusses and purlins combined for a spacing of ro feet. The weight of trusses per square foot was, however, more for the Io-ft. spacing than for the I8-ft. spacing, so that the actual cost of the steel in the roof was a minimum for a 
spacing of about i6 feet; the shop cost of the trusses per pound being several times that of the purlins. Local conditions and requirements

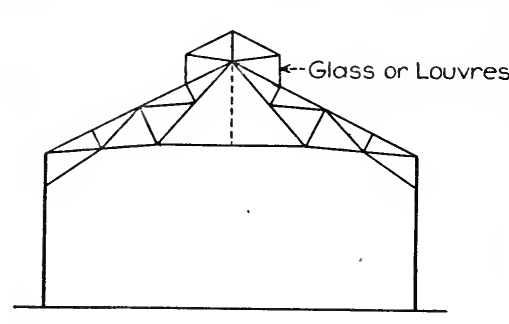

(a)

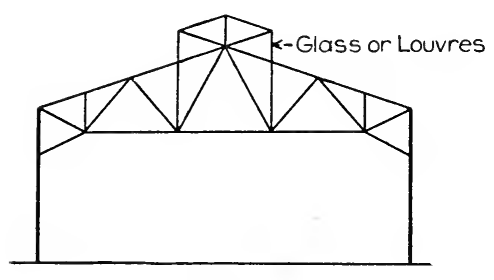

(b)

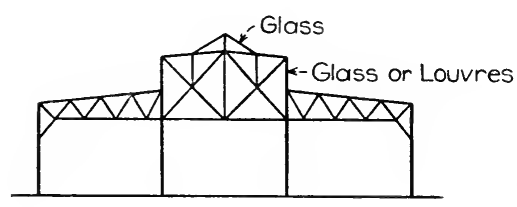

(c)

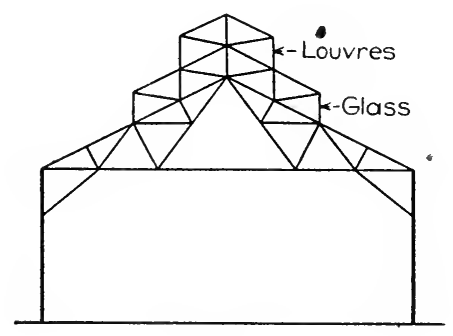

(d)

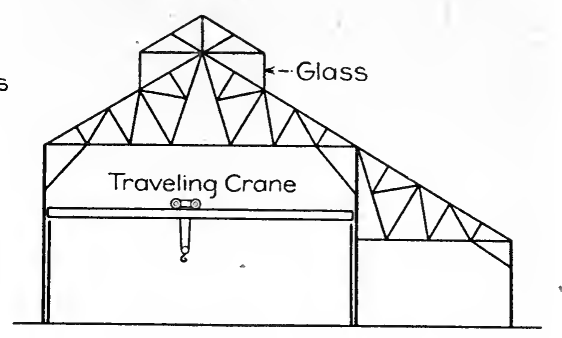

(e)

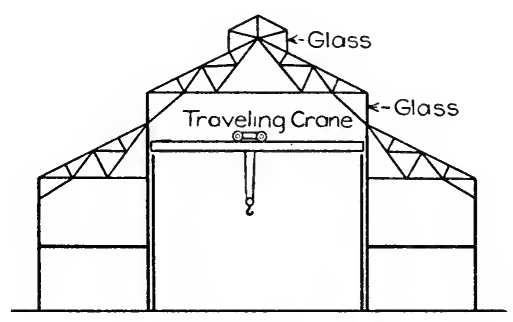

(f)

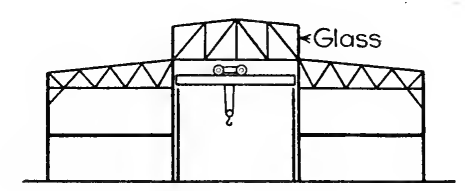

(g)

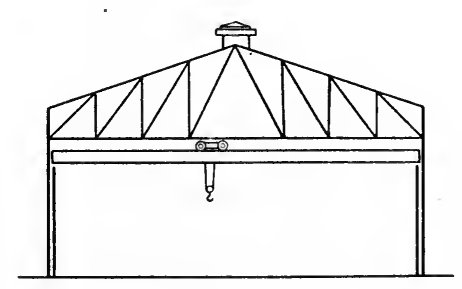

(h)

Fig. 88. Types of transverse bents. 
usually control the spacing of the trusses so that it is not necessary that we know the economic spacing very definitely.

For long spans the economic spacing can be increased by using rafters supported on heavy purlins, placed at greater distances than would be required if the roof were carried directly by the purlins. This method is frequently used in the design of train sheds and roofs of buildings where plank sheathing is used to support slate or tile coverings, or where the tiles are supported by angle sub-purlins spaced close together as shown in Fig. 87.

TRANSVERSE BENTS.-The proper cross-section for a mill building will depend upon the use to which the finished structure is to

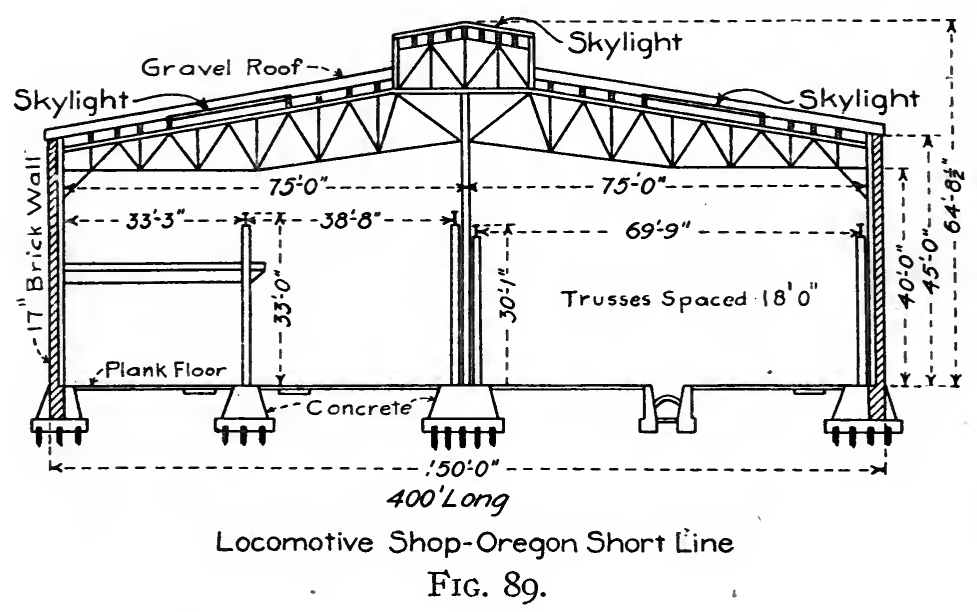

be put. A number of the common types of transverse bents are shown in Fig. 88. Transverse bents (a), (b), (d) and (h) are commonly. used for boiler houses, shops and small train sheds. Where a trave!ing crane is desired, the crane girders are commonly suspended from the trusses in the bents referred to, although the crane may be made to span the entire building as in ( $h$ ). Transverse bent (d) was used for a round house with excellent results. Transverse bents (f) and (g) are quite commonly used where it is desired that the main part of the building be open and be provided with a traveling crane that will sweep 
the building, while the side rooms are used for lighter tools and miscellaneous work. Transverse bent (c) may be used in the same way as (g), by supplying a traveling crane. Transverse bent (e) is very often used for shops.

Cross-sections of the locomotive shops of several of the leading railways are shown in Figs. 89 to 92, inclusive, and the locomotive shops of the A. T. \& S. F., and the Philadelphia and Reading Railroads are described in detail in Part IV. For the most part these buildings

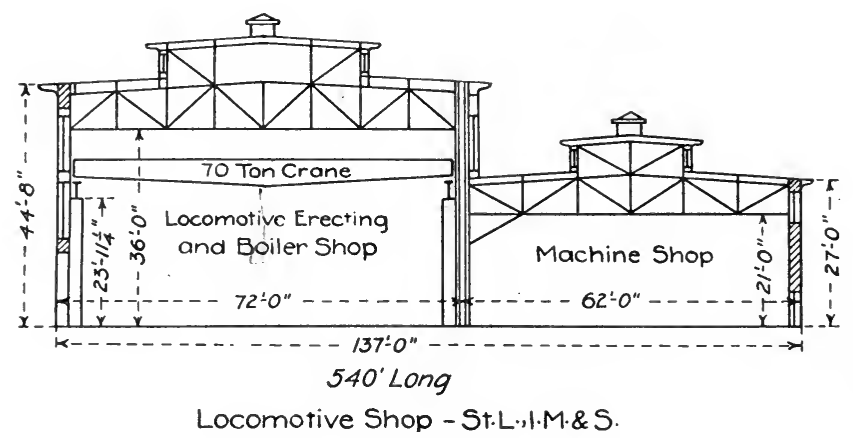

FIG. 90.

are built with self-supporting frames, and have brick walls built outside the framing. The arrangement of the cranes, provisions for light-

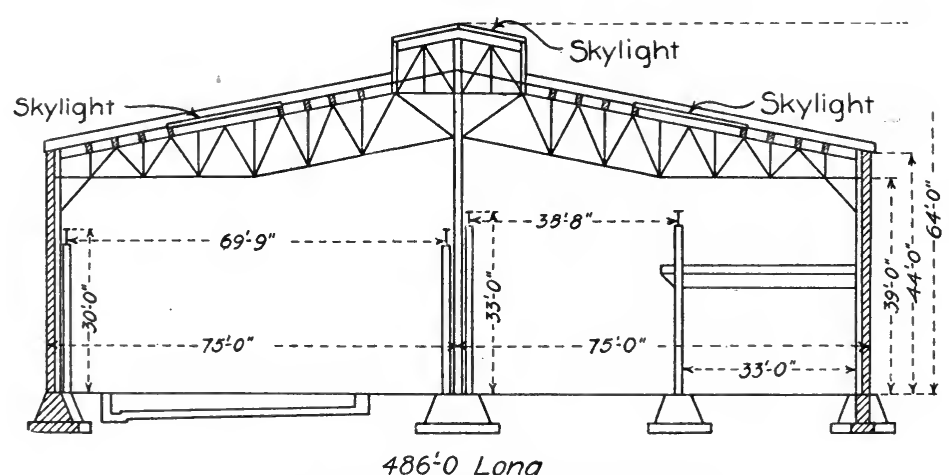

Locomotive Shop-Union Pacific.

FIG. 9I. 
ing and ventilating, and the main dimensions are shown in the cuts and need no explanation.

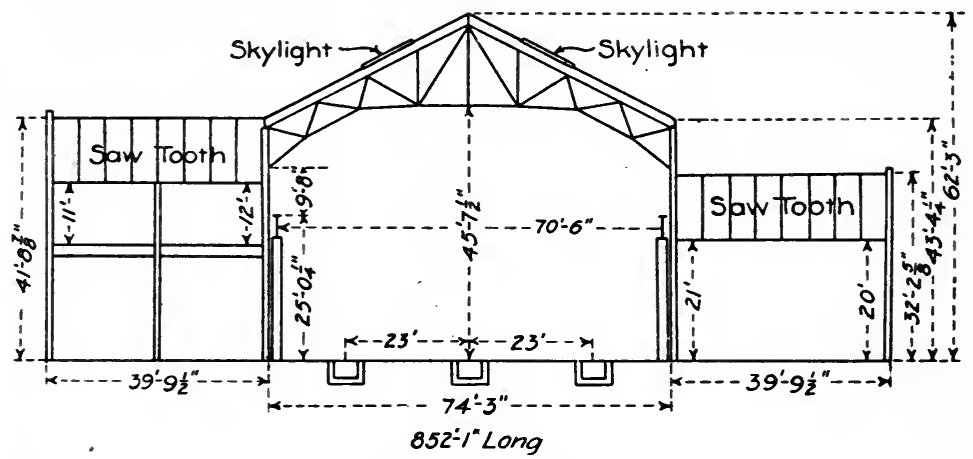

Locomotive Shop-A.T.\& S.F.

FIG. 92.

A cross-section and end view of the train shed of the Richmond Union Passenger Station are shown in Fig. 93. Riveted trusses are

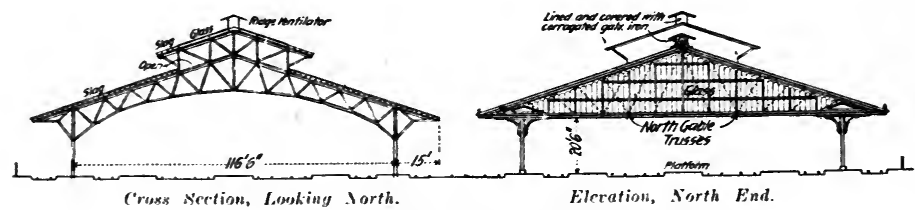

Train Shed-Richmond Union Passenger Station.

FIG. 93.

quite s nerally used in train sheds; a notable exception to this statement, however, being the trusses for the new train shed of the C. R. I. \& P., and L. S. \& M. S. Railways in Chicago. The trusses in this structure have a length of span of $207 \mathrm{ft}$., a rise of the bottom chord of $40 \mathrm{ft}$. and a depth of truss at the center of $25 \mathrm{ft}$. The trusses are pin connected, the compression members being built up channels and the tension members eye-bars. The building is described in detail in Engineering News, August 6, rgo3.

Truss Details.-Riveted trusses are commonly used for mill buildings and similar structures. For ordinary loads, the upper and lower 
chords, and the main struts and ties are commonly made of two angles placed back to back, forming a $T$-section, the connectrons being made by means of plates. The upper chord should preferably be made of unequal legged angles with the short legs turned out. Sub-struts and ties are usually made of one angle. Flats should not be used. Where a truss member is made of two angles placed back to back, the angles should always be riveted together at intervals of 2 to 4 feet.

Trusses that carry heavy loads or that support a traveling crane or hoist, are very often made with a lower chord composed of two channels placed back to back and laced or battened, and are sometimes made with channel chord sections throughout (see Fig. 175).

When the purlins are not placed at the panel points of the truss the upper chord must be designed for flexure as well as for direct stress. The section in most common use for the upper chord, where the purlins are not placed at the panel points, is one composed of two angles and a plate as shown in (c) Fig. 96.

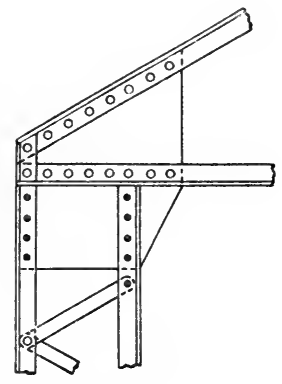

(a)

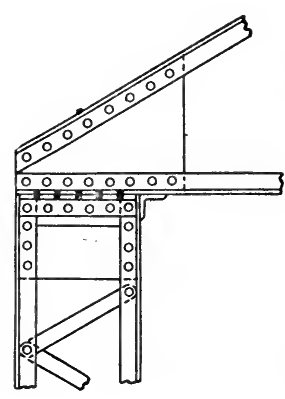

(b)

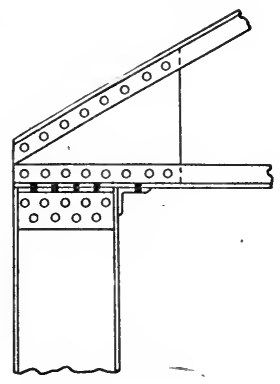

(c)

FIG. 94.

Trusses may be fastened to the columns by means of a plate as shown in (a) Fig. 94, or by means of connection angles as shown in (b) and (c). The first method is to be preferred on account of the rigidity of the connection, and the ease with which the field connection can be made. 


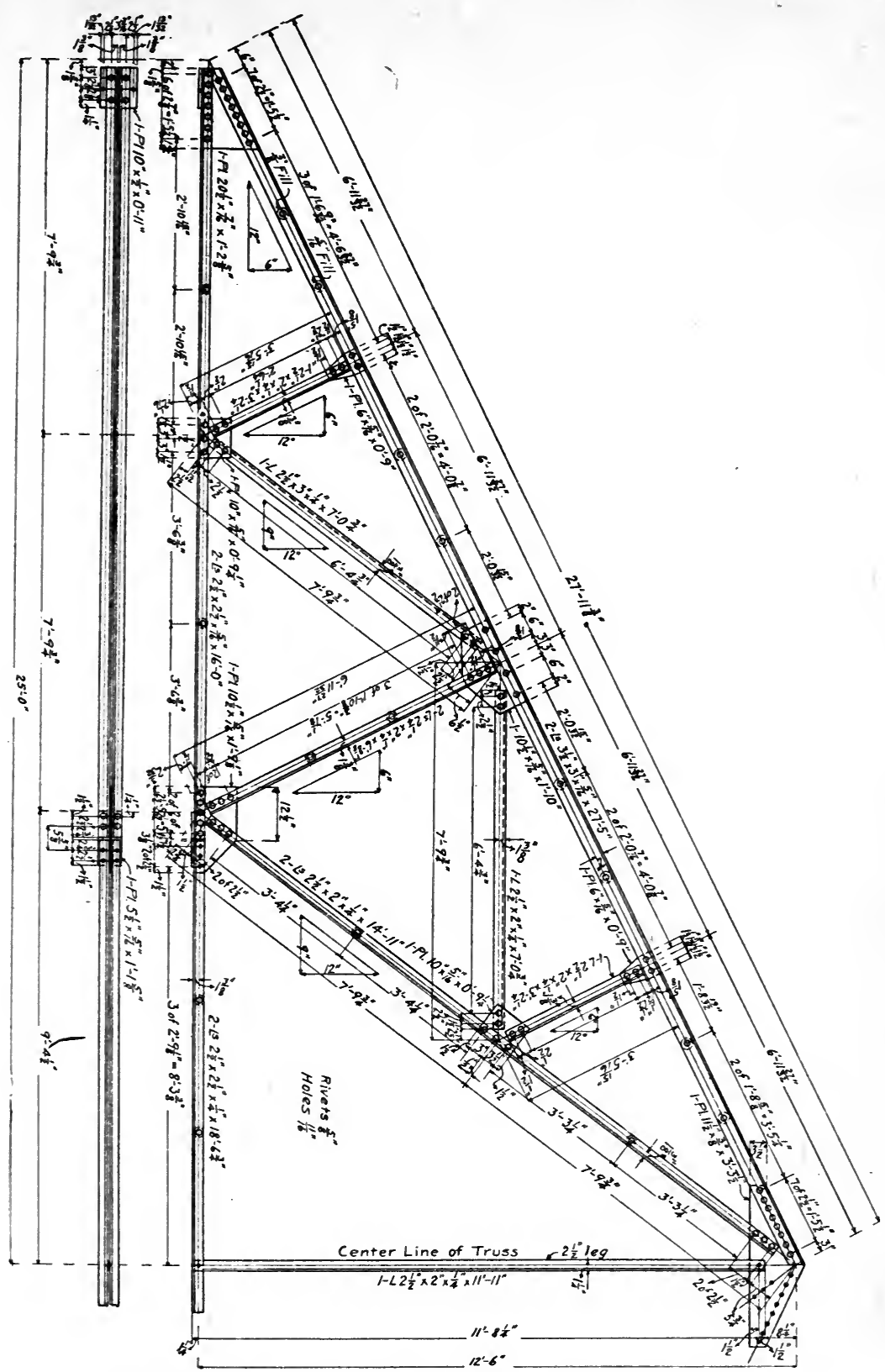

Fig. 95. SHOP DRAWINGS FOR A STEEL, ROOF TRUSS. 
Trusses supported directly on masonry walls have one end supported on sliding plates for spans up to about 70 feet; for greater lengths of span one end should be placed on rollers, or should be hung on a rocker. Trusses for mill buildings should be made with riveted rather than with pin connections, on account of the greater. rigidity of the riveted structure. The complete shop drawings of a truss for the machine shop at the University of Illinois, are shown in Fig. 95. This truss is more completely detailed than is customary in most bridge shops. The practice in many shops is to sketch the truss, giving main dimensions, number of rivets and lengths of members, depending on the

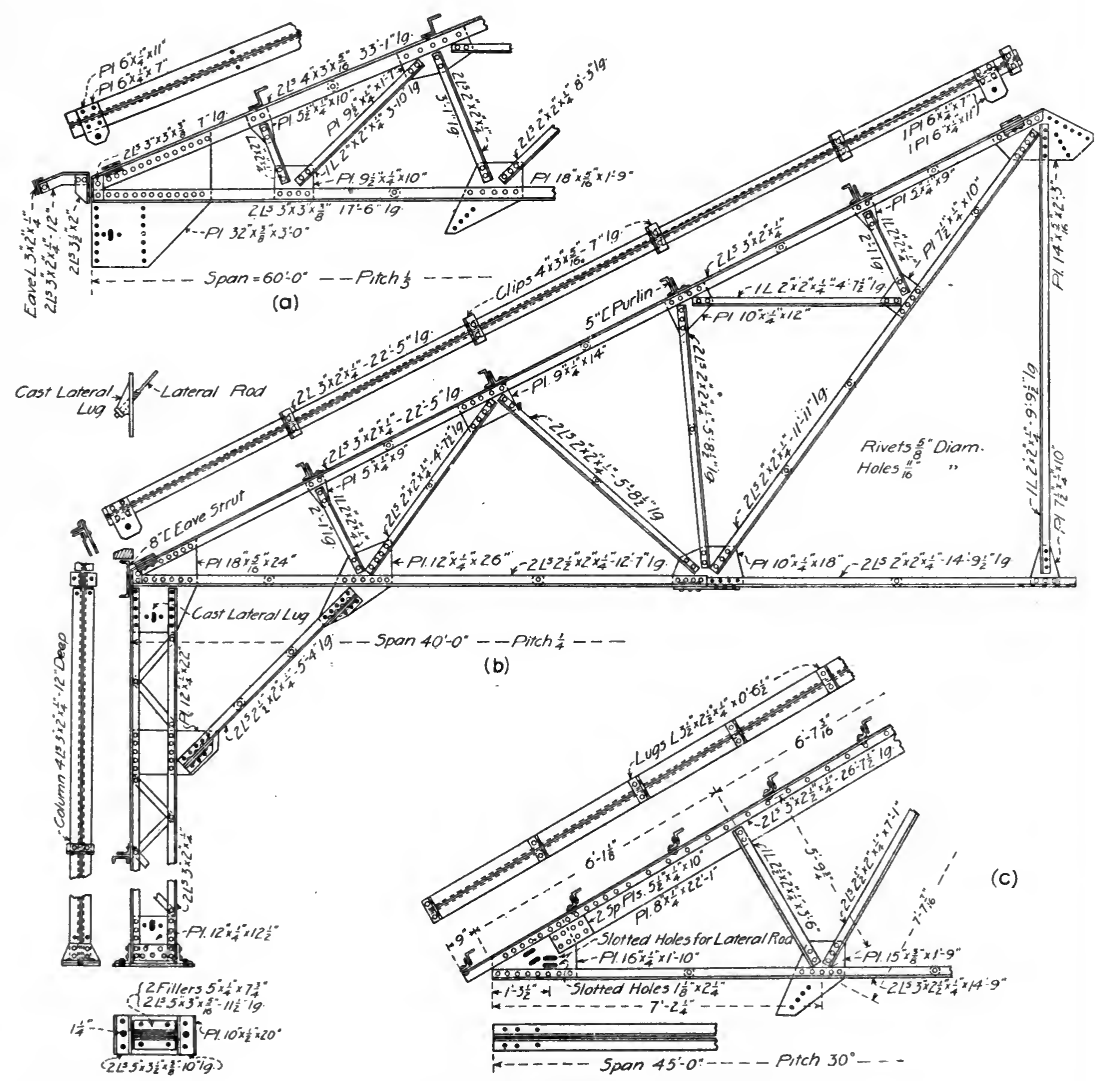

FIG. 96. 
templet maker for the rest. In Fig. 95 the rivet gage lines are taken as the center lines. This is the most common practice, although many use one leg of the angle as the center line in secondary members. The latter method has the advantage of reducing the length of connection plates without introducing secondary stresses that are liable to be troublesome.

The detail drawings of a transverse bent are shown in Fig. 96. The common methods of attaching purlins and girts. and of making lateral connections are also shown. The fan type of Fink Truss shown in Fig. 96 is quite commonly used where an odd number of panels is desired, and makes a very satisfactory design. The details of the end connection of a $60-\mathrm{ft}$. span truss are shown in (a), and of a 45-ft. span truss with a reinforced top chord are shown in (c), Fig. 96. The method of reinforcing the top chord shown (c) is the one most commonly employed where purlins are not placed at the panel points. The method of making lateral connections for the lateral rods shown in (c) is not good, for the reason that it brings bending stresses in a plate which is already badly cut 1 p.

The detail drawings of a saw tooth roof bent for the Mathiessen \& Hegeler Zinc Works, LaSalle, Ill., are shown in Fig. 97. This building was erected in 1899 along the lines suggested by an experience with a similar saw tooth roof building erected in 1874 . The building was designed by Mr. August Ziesing, Vice President American Bridge Co., and was erected by the American Bridge Co.

The following description is from a personal letter from Mr. Julius Hegeler of the firm of Mathiessen \& Hegeler, to the author in reply to a request for plans: "The cast iron gutters are fastened to the purlins and roof boards by spikes through holes in the gutters (holes are not shown in the drawing) ; on account of their slope, however, hardly any fastening is necessary. These gutters are so placed that the galvanized iron down spouts are next to the posts, there being two down spouts at each post. The condensation gutters are fastened to the gutters and empty into the down spouts. Ice has never caused any trouble by forming in the gutters." 


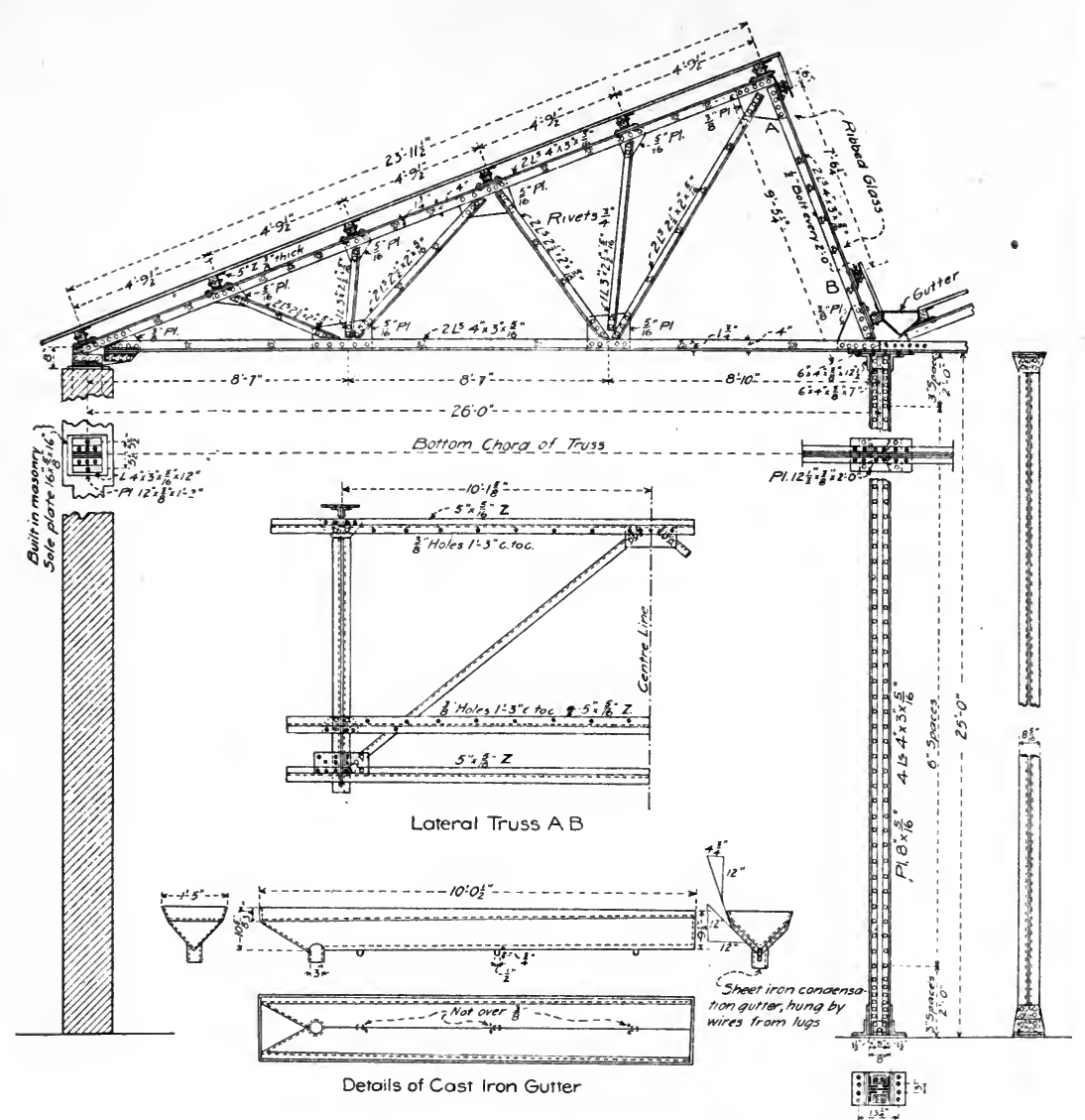

Fig. 97. Cross-Section of THE SHops of the Mathiéssen \& Hegeler Zinc Works, LaSalle, Ill.

The original saw tooth roof shop built by this firm in 1874 is still in use, and is one of the first, if not the first, saw tooth roofs built in America.

COLUMNS.--The common forms of columns used in mill buildings are shown in Fig. 98. For side columns where the loads are not excessive, column ( $\mathrm{g}$ ) composed of four angles laced is probably the best. In this column a large radius of gyration about an axis at right angles to the direction of the wind is obtained with a small amount 
of metal. The lacing should be designed to take the shear, and should be replaced by a plate, (f) Fig. 98, where the shear is excessive, or where the bending moment developed at the base of the column requires the use of excessive flanges. The I beam column ( $h$ ) makes a good side column where proper connections are made, and is commonly used for end columns (see Fig. 8I). The best corner column is made of an equal legged angle with 4, 5 or 6-in. legs, (i) Fig. 98. Details for the bases of the three columns above described are shown in Fig. 99.

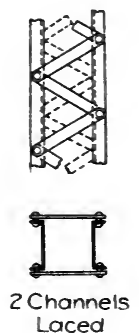

(a)
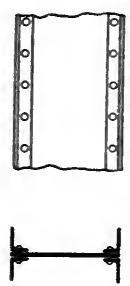

4 Angles

I Plote

(f)

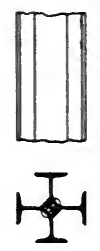

Larimer

(k)

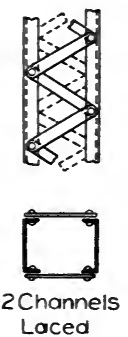

(b)
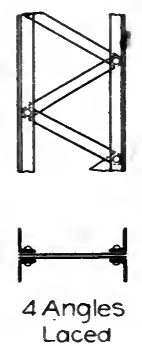

(g)
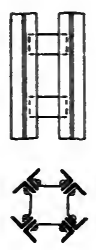

Gray

(1)

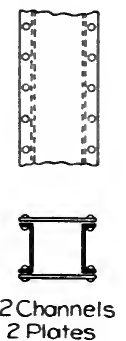

(C)
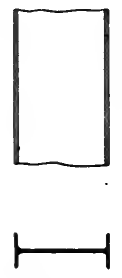

I I Beam

(h)
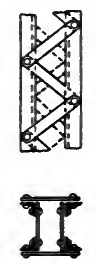

4 Angles

Box Laced

(m)
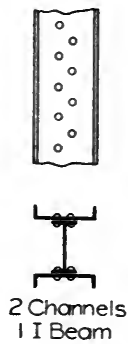

(d)
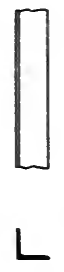

IAngle

(i)
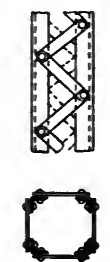

4 Angles

Box Laced

(n)

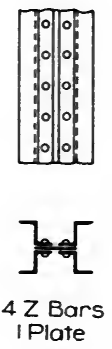

(e)
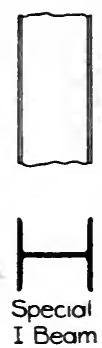

(j)
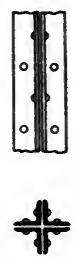

4 Angles

Starred

(o)

Fig. 98. TyPes OF Mill BUILdiNg COLUMNS. 
Columns made of two channels laced, or two channels and two plates, are used where moderately heavy loads are to be carried. Channel column (a), with channels turned back to back and laced, is the form most commonly used; column (b), with the backs of the channels turned out and laced, gives a better chance to make connections and can be made to enter an opening without chipping the legs of the channel; column (c) is a closed section and is seldom used on that account. The cost of the shop work on column (b) was formerly considerably more than for column (a), for the reason that it was impossible to use a power riveter for driving all the rivets. A pneumatic riveter is now made, however, that will drive all the rivets in column (b), and the shop cost for columns (a) and (b) are practically the same.

Where very heavy loads are to be carried, columns (d) or (e) are often used. Column (d), composed of two channels and one I beam, is a very economical column and is quite often used as a substitute for the Z-bar column shown in (e), for the reason that it can be built up out of the material that is in stock or that can be easily obtained. Connections for beams are easily and effectively made with either columns (d) or (e). The special I beam column ( $j$ ), with flanges equal to the depth of the beam, is now being rolled in Germany by the use of a process patented by an American, Mr. Henry Grey. This column makes an almost ideal column for heavy loads, since it has all the advantages of the Z-bar column with a very much smaller shop cost. The Larimer column ( $\mathrm{k}$ ) is a patented column manufactured by Jones \& Laughlins, and is used by their patrons quite extensively. The Gray column(1) is a patented column and is but little used. Columns made of four angles box-laced, are used where extremely light loads are carried by very long columns. The shop cost of column (m) is somewhat less than that of column ( $n$ ), although with small angles there is no difficulty in riveting (n) with a machine riveter. Column (o) is a very poorly designed column, for the reason that the radius of gyration is very small for the area of a cross-section of the column. Columns made of two angles "starred" and fastened at intervals of two or three 
feet by means of batten plates, are quite frequently used for light loads.

Column Details.-The detàils of a 4-angle laced column attached to a truss are shown in Fig. 96 ; and the details of a 4-angle plate column are shown in Fig. 97. The details of bases for 4-angle, I beam and angle columns are shown in Fig. 99.
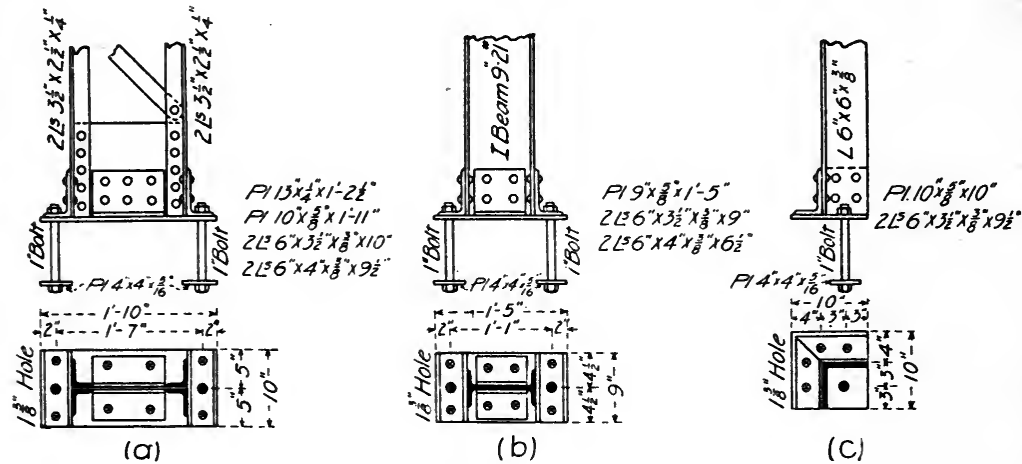

FIG. 99.

Shop details of a 4-angle column are shown in Fig. Ioo. This column was designed for a mill building with a span of 60 feet, trusses spaced I6 feet apart. The long legs of the angles are placed out, to give a larger radius of gyration about an axis at right angles to the direction of the wind. The details of a 4-angle and plate column, designed to carry a crane girder as well as the roof, are shown in Fig. Ior.

The details of a heavy column composed of two channels placed back to back and laced, are shown in Fig. IO2; the lacing is heavy and is well riveted. The bent plate connections for the anchor bolts on this column are very satisfactory. This is one of the columns used in the A. T. \& S. F. R. R. shops at Topeka, Kas., to carry the crane girders.

The shop details of a light channel column are shown in Fig. IO3. The single lacing alternates on the two sides of the column. The various details of the columns can be seen, and require no explanation. 


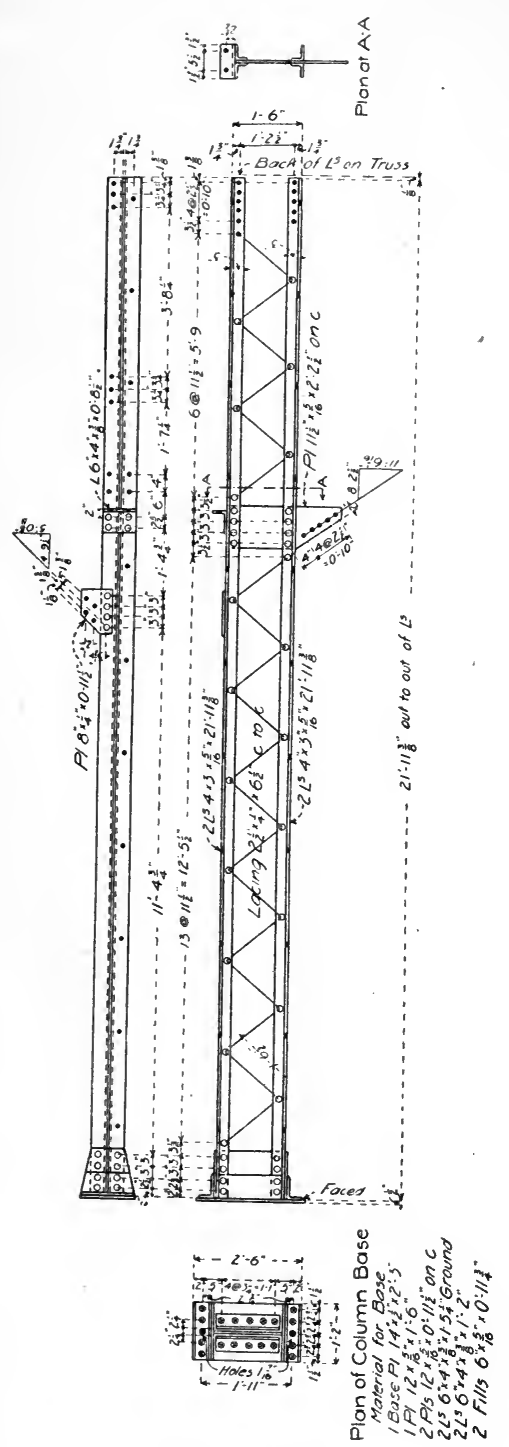

FIG. IOO.

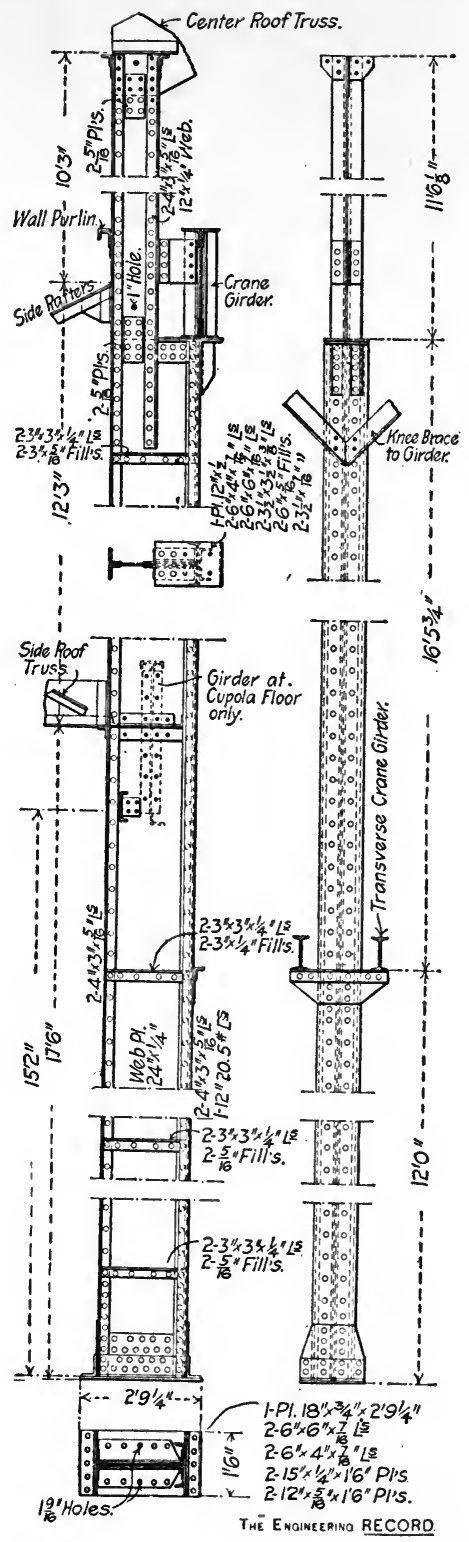

FIG. IOI. 


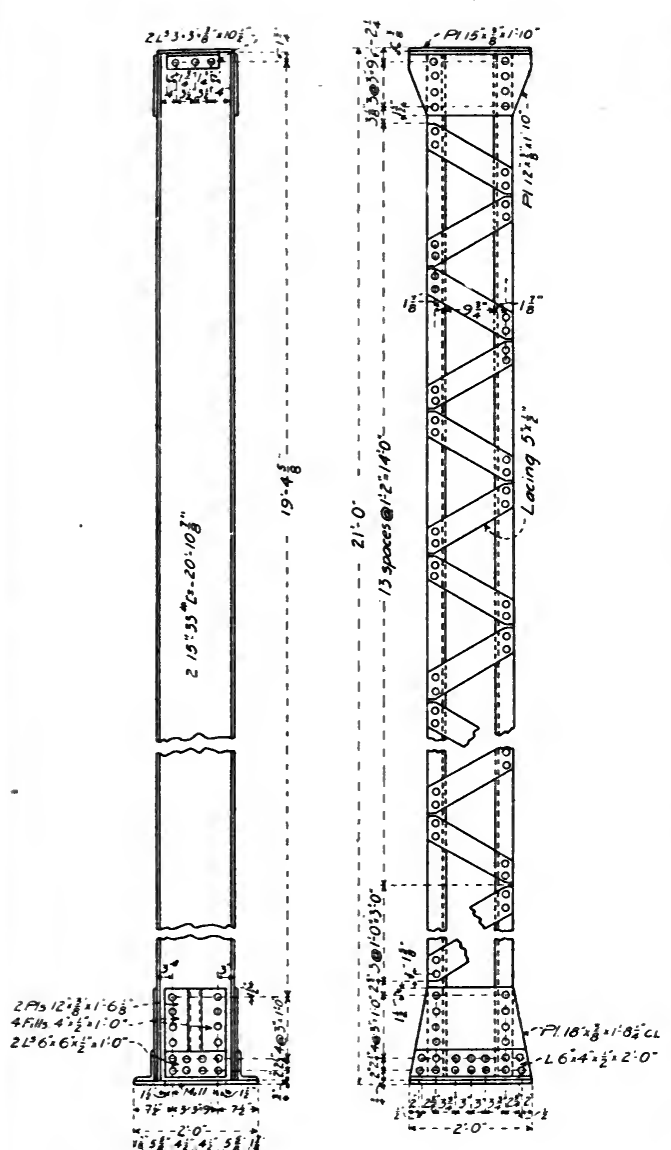

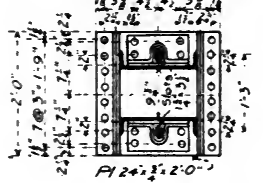

FIG. 102.
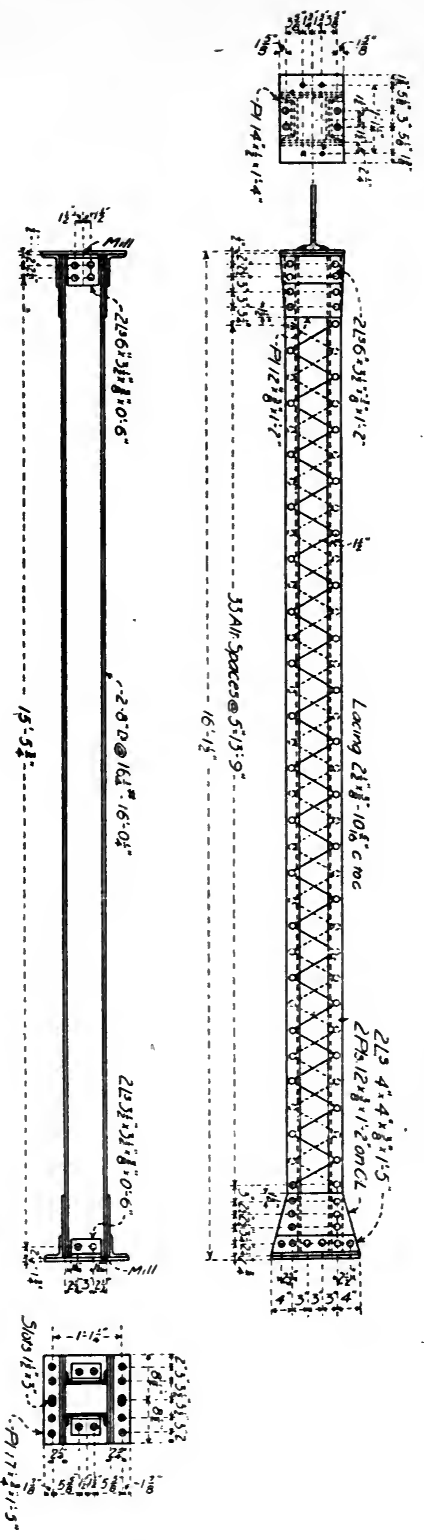

FIG. IO3. 
The American Bridge Company's specifications for lattice bars for single and double lacing are shown in Fig. Io4.
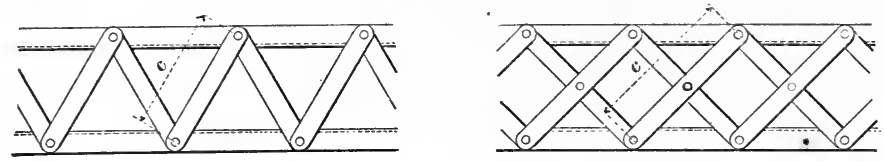

Maximum Distance $c$ for given thickness of bar.

\begin{tabular}{|c|c|c|c|}
\hline \multicolumn{2}{|c|}{ SINGLE LACING $t-\frac{c}{40}$} & \multicolumn{2}{|c|}{ DOUBLE I.ACING $t-\frac{c}{G 0}$} \\
\hline $\begin{array}{c}\text { THICK. } \\
t\end{array}$ & $\begin{array}{c}\text { OISTANCE } \\
\boldsymbol{c}\end{array}$ & $\begin{array}{c}\text { DISTANCE } \\
\boldsymbol{c}\end{array}$ & $\begin{array}{c}\text { THICK. } \\
t\end{array}$ \\
\hline$\frac{1}{4}$ & $0-10$ & $1-3$ & $\frac{1}{4}$ \\
\hline$\frac{5}{10}$ & $1-0 \frac{1}{2}$ & $1-6 \frac{3}{4}$ & $\frac{5}{18}$ \\
\hline$\frac{3}{8}$ & $1-3$ & $1-10 \frac{1}{2}$ & $\frac{3}{8}$ \\
\hline$\frac{7}{18}$ & $1-5 \frac{1}{2}$ & $2-2 \frac{1}{4}$ & $\frac{7}{18}$ \\
\hline$\frac{1}{2}$ & $1-8$ & $2-6$ & $\frac{1}{2}$ \\
\hline$\frac{9}{16}$ & $1-10 \frac{1}{2}$ & $2-9 \frac{3}{4}$ & $\frac{9}{16}$ \\
\hline$\frac{5}{8}$ & $2-1$ & $3-1 \frac{1}{2}$ & $\frac{5}{8}$ \\
\hline
\end{tabular}
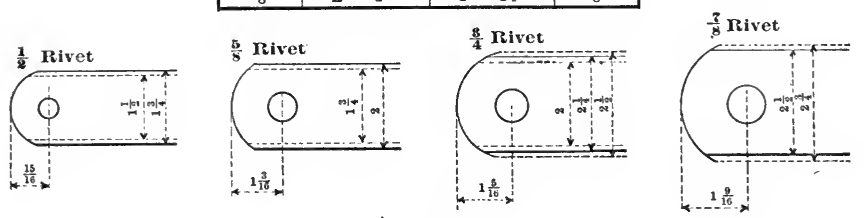

FIG. 104.

Single lacing should make an angle of not less than 6o degrees, and double lacing, riveted at the center, not less than 45 degrees with the axis of the member. These specifications are standard.

The properties of angles, I beams and channels, and of Z-bar, Larimer and Gray columns are given in the manufacturers handbooks. The moment of inertia of two channels placed back to back and laced, as in (a) or (b) Fig. 98, about an axis parallel to the webs and through the center of gravity of the section, is given by the formula

$$
I=2 I^{\prime}+2 A d^{2}
$$

where $I^{\prime}=$ moment of inertia of one channel about an axis through its center of gravity and parallel to the given axis, $A=$ the area of one channel, and $d=$ distance from the center of gravity of one channel to the center of gravity of the column. The lacing is omitted in fincling the moment of inertia and the area of the section. The moment of inertia of the column about an axis perpendicular to the webs is equal 
to twice the moment of inertia of one channel, which may be found in the table of properties of channels given in the handbooks.

Having the moment of inertia $I$, the radius of gyration of the column is given by the formula

$$
r=\sqrt{ } \frac{I}{A}
$$

With channels placed back to back and laced, the radii of gyration about the two axes are equal when the clear distance is equal to about 3 inches for 5 -in. channels, and ro inches for 15 -in. channels. A common rule is to space the channels about eight-tenths the depth. With channels placed with backs out and laced, the radii of gyration about the two axes are equal when the clear distance is about equal to 5 inches for 5-in. channels, and 13 inches for 15 -in. channels (see Cambria Steel, r903 Edition, p. 217).

The moment of inertia of a 4 -angle laced column, about an axis perpendicular to the lacing and through the center of the post, is given by the formula

$$
I=4 I^{\prime}+4 A d^{2}
$$

where $I^{\prime}=$ moment of inertia of one angle about an axis through its center of gravity and parallel to the given axis, $A=$ the area of one angle and $d=$ the distance from the center of gravity of the separate angles to the center of gravity of the column. The moment of inertia about the other axis is found in a similar manner.

STRUTS AND BRACING.-Eave struts are very commonly made of four angles laced, made in the same way as the 4 -angle posts, Fig. Ioo. Eave struts made of single channels are more economical, and are equally as good as the laced struts for most cases. End rafters are commonly made of channels. The sides, ends, tipper and lower chords are commonly braced as shown in Fig. 8I. The bracing in the plane of the lower chords should preferably be made of members capable of taking compression as well as tension. The diagonal bracing in the plane of sides, ends, and upper chords is commonly composed of rods. Initial tension should always be thrown into diagonal rods by 
screwing up the turnbuckles or adjustable ends. Stiff bracing should be made short, and should be brought into position for riveting by using drift pins; to accomplish this there should be not less than three rivet holes in each lateral connection. A connection for lateral rods to the chords of trusses is shown in Fig. I05.
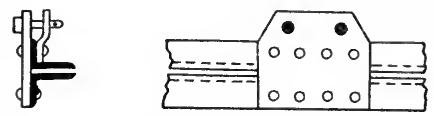

Lateral Connection

FIG. I05.

Cast lateral lugs for connecting lateral rods to the webs of I beams and to heavy plates are shown in (a) and (b), Fig. Io6.

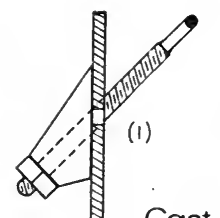

Cast Lateral Lug

(a)

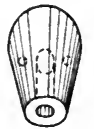

(2)

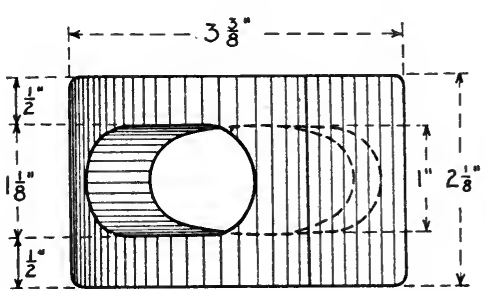

(1)

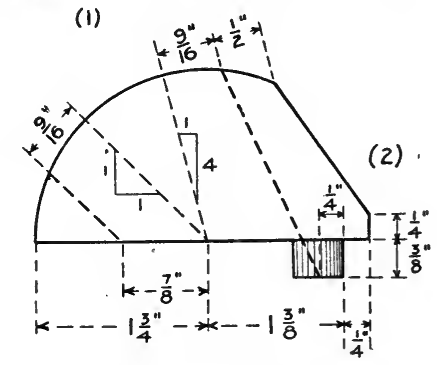

Cast Lateral Lug

(b)

FIG. 106.

Where rod bracing in the ends and sides of buildings interferes with windows and doors, or where the building is to be left open, portal bracing is used. In the latter case the bents are usually braced in pairs, 
although the portal bracing is sometimes made continuous. Stiff bracing is often placed between the trusses in the plane of the center of the building and materially stiffens the structure (see Fig. 175).

PURLINS AND GIRTS.-Purlins are made of channels, angles, $Z$-bars and I beams, Fig. III, where simple shapes are used. Channel and angle purlins should be fastened by means of angle lugs as shown in Fig. 107. I beam purlins are very often fastened as shown in the A. T. \& S. F. R. R. shops, Fig. 175: Z-bar purlins are bolted directly to the upper chords of the trusses. The channel purlin is the most economical, and the I beam purlin is the most rigid. Girts are made of channels, angles, and Z-bars, and are fastened as shown in Fig. II I. Where the distance between trusses is more than 15 or 16 feet the purlins and girts should be kept from sagging by running $3 / 8$ or $1 / 2$-inch rods through the centers to act as sag rods, the ends of the rods being fastened to the eaves and ridge (see Fig. 8I).

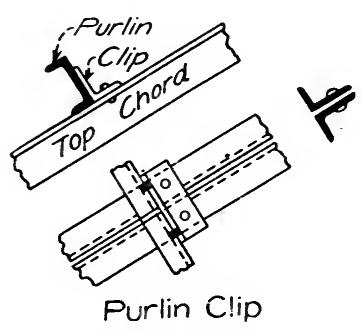

FIG. 107.

Where the columns and trusses are placed so far apart that the use of simple rolled shapes is no longer economical, purlins and girts are trussed.

DESIGN OF PARTS OF THE STRUCTURE.-The methods of determining the sizes of the various members in a mill building will be illustrated by a few examples. For a more detailed treatment of this subject, see "Modern Framed Structures" by Johnson, Bryan and Turneaure; "Roofs and Bridges" by Merriman and Jacoby ; and other standard works on bridge design.

Manufacturers of structural material issue handlooks which con- 
tain tables that give weights, areas of sections, positions of centers of gravity, moments of inertia, radii of gyration, etc., for the shapes manufactured by the different companies. Tables are also given for the resisting moments on pins, the shearing and bearing values of rivets, standard bolts, eye-bars, bridge pins, standard connection angles, bearing plates, minimum size of rivets, spacing of rivets, and many other useful tables. The handbooks best known are as follows, the popular name being given in brackets: Cambria Steel (Cambria), issued by the Cambria Steel Company, Johnstown, Pa.; Pocket Companion (Ca1negie), issued by the Carnegie Steel Company, Pittsburg, Pa.: Standard Steel Construction (Jones \& Laughlins), issued by Jones \& Laughlins, Limited, Pittsburg, Pa.; Steel in Construction (Pencoyd), issued by A. and P. Roberts Company, Philadelphia; and Structural Steel and Iron (Passaic), issued by the Passaic Rolling Mill Company, Paterson, N. J. These books can be obtained for from 50 cts. to $\$ 2.00$. The American Bridge Company issued, in I9OI, a book entitled Standards for Structural Details, for use at its various plants.

The Carnegie handbook was formerly very generally used in designing offices, but recently the supply has been limited so that the Cambria handbook has taken its place in schools and in many offices, and for this reason references will be made to Cambria in obtaining weights, properties of sections, etc. All references to Cambria will be to the Ig03 edition.

Design of Trusses.-The method of determining the proper sizes of the truss members will be illustrated by designing a few of the members of the truss in the transverse bent of the mill building shown in Fig. 53; the stresses in which are given in Table VI. The secondary members will be omitted from the truss in the design, as they were in obtaining the stresses.

The material will be assumed to be medium steel and the allowable stresses as given in Appendix I, will be taken. The allowable stresses are as follows:

Tension ............ 6 ,ooo lbs. per sq. in.

Compression.......... $6,000-70 l \div r$ lbs. per sq. in. 
where $l=$ the length of the member in inches, and $r=$ radius of gyration of member in inches.

Rivets and Pins, bearing. ............22,000 lbs. per sq. in. Rivets and Pins, shear...............II,000 " " " " "

Pins, bending on extreme fibre.........24,000 " " " " " " " "

Plate Girder webs, shear on net section....... I0,000 " " " " " " "

Compression Members.

Piece $x-2$. Maximum stress $=+34,300 \mathrm{lbs}$.

The upper chord will be made of two angles with unequal legs placed back to back, with the shorter legs turned out, and separated by $3 / 8$-inch gusset or connection plates.

Try two $4^{\prime \prime} \times 3^{\prime \prime} \times 5^{-1} 6^{\prime \prime}$ angles. From table on page 187 Cambria, the least radius of gyration, $r$, is 1.27 inches. The unsupported length of the member is 8.5 feet, and $l \div r=102 \div 127=80$. The allowable stress per square inch $=16,000-70 l \div r=16,000-5,600=$ Io,400 lbs. The area required will be $34,300 \div$ Io,400 $=3 \cdot 3$ sq. in. The combined area of the two angles is 4.18 sq. ins. (page ryo Cambria), which is somewhat large.

Try two $3^{1} / 2^{\prime \prime} \times 3^{\prime \prime} \times 5^{-1} 6^{\prime \prime}$ angles. From the table on page 186 Cambria, $r=\mathrm{I}$. Io inches; then $l \div r=93$, and allowable stress is $16,000-70 \times 93=9,490$ lbs. per sq. in. Required area $=3.62$ sq. in. The area of the two angles is 3.88 sq. in., so the section is sufficient.

To make the two angles act together as one piece it is necessary to rivet them together at intervals, such that the two angles acting singly will be stronger than the two angles acting together. On page 170 Cambria, the least radius of gyration of a $3^{\mathrm{I} / 2^{\prime \prime}} \times 3^{\prime \prime} \times 5^{-1} 6^{\prime \prime}$ angle about a diagonal axis is 0.63 inches. The angles must therefore be riveted at least every $0.63 \times 93=58.6$ inches. It is the common practice to rivet angles in compression about every $2 \frac{1}{2}$ to 3 feet.

The truss will be shipped in two parts and in order to avoid a splice, and because the difference in the stresses is small, the entire top chord will be made of two $3^{1 / 2} 2^{\prime \prime} \times 3^{\prime \prime} \times 5^{-16^{\prime \prime}}$ angles. 
Tension Members.

Member I-2.

Maximum stress $=-24,900$ lbs.

The net area required is $24,900 \div \mathrm{I} 6,000=\mathrm{I} .56 \mathrm{sq}$. in. The gross area of the section must be such, that there will be a net area of not less than $I .56$ sq. in. after the area of the rivet holes in any section has been deducted.

Try two $3^{\prime \prime} \times 3^{\prime \prime} \times 1 / 4^{\prime \prime}$ angles. It will be necessary to deduct the area of one rivet hole from each angle. (The diameter of the rivet hole deducted is taken $1 / 8$ inch larger than the diameter of the rivet before driving. Assuming the rivets as $5 / 8$ inch, it will be neressary to deduct o. I9 sq. in. from each angle (page 3 Io Cambria). The net area of two $3^{\prime \prime} \times 3^{\prime \prime} \times 1 / 4^{\prime \prime}$ angles is $2.88-0.38=2.50$ sq. in. The section is somewhat large, but will be used, for the reason that angles much smaller than these will be deficient in rigidity.

The angles will be riveted together about every 3 feet to make them act as one member.

\section{Member 5-6. $\quad$ Maximum stress $=-5,000 \mathrm{lbs}$.}

The net area required is $5,000 \div 16,000=0.32 \mathrm{sq}$. in. The gross area of the section must be such that there will be a net area of at least $0.32 \mathrm{sq}$. in. after the area of the rivet holes in any section has been deducted.

Try two $2^{\prime \prime} \times 2^{\prime \prime} \times 1 / 4 "$ angles - the minimum angles that can be used under the specifications. Deducting the area of one rivet the net area is $\mathrm{I} .88-0.38=\mathrm{I} .5^{\mathrm{O}} \mathrm{sq}$. in. The section appears to be excessively large and one $2^{\prime \prime} \times 2^{\prime \prime} \times 1 / 4 "$ angle will be trierl. Where angles in tension are fastened by one leg the specifications require that (paragraph 35) only one leg shall be counted as effective, or the eccentric stress shall be calculated. The net area of the one $2^{\prime \prime} \times 2^{\prime \prime} \times 1 / 4$ " angle when fastened by one leg, will then be $1 / 20.94-0.19=0.28$ sq. ins., which is insufficient. One $2^{\mathrm{I} / 2^{\prime \prime}} \times 2^{\mathrm{I} / 2^{\prime \prime}} \times \mathrm{I} / 4^{\prime \prime}$ angle will have a net area of 0.40 sq. in., which will be sufficient. However, since it is preferable to make tension members of symmetrical sections, the member will be made of two $2^{\prime \prime} \times 2^{\prime \prime} \times 1 / 4$ " angles. 
Alternate Tension and Compression.-Where members are subject to alternate tension and compression the specifications require that they be designed to take each kind of stress, (paragraph 32).

Member 4-y. Maximum stresses $=(-2 \mathrm{I}, 300$ and $+2600 \mathrm{lbs})$.

Try two $3^{\prime \prime} \times 3^{\prime \prime} \times 1 / 4^{\prime \prime}$ angles - the same as member $1-2$. The net area required for tension is $21,300 \div 16,000=1.34$ sq. in.

The net area of two $3^{\prime \prime} \times 3^{\prime \prime} \times 1 / 4^{\prime \prime}$ angles is $2.88-0.38=2.50$ sq. in. which is ample for tension.

The least radius of gyration is $r=0.93$ inches (page $185 \mathrm{Cam}$ bria). Length $=108$ inches, and $l \div r=117$. The allowable stress per square inch $=16,000-70 \times 117=8,810 \mathrm{lbs}$. Required area $=$ 0.30 sq. in. The section appears to be large, but it can not be made much smaller without exceeding the maximum limit of 125 for $l \div r$. Two $3^{\prime \prime} \times 2^{1} / 2^{\prime \prime} \times 1 / 4^{\prime \prime}$ angles will be found by a similar calculation to be sufficiently large, and will be used.

Member 3-4. Maximum stresses $=(-10,900$ and $+13,600 \mathrm{lbs})$.

Try two $2^{\prime \prime} \times 2^{\prime \prime} \times 1 / 4 "$ angles. The area required to take the tension is $10,900 \div 16,000=0.69$ sq. in. The net area of the two angles is $1.88-0.38=1.50 \mathrm{sq}$ in., which is ample for tension. The least radius of gyration is $r=0.6 \mathrm{I}$ inches (page 185 Cambria). The length is 108 inches, and $l \div r=177$. This is greater than the maximum allowed of 125, and a larger section must be used.

Try two $3^{\prime \prime} \times 2^{\prime \prime} \times 1 / 4^{\prime \prime}$ angles, with short legs out. In this case $\because \div r$ equals $108 \div 0.89=120$. The allowable stress per sq. in. is $16,000-70 \times 120=7,600 \mathrm{lbs}$. The required area for compression is $13,000 \div 7,600=1.79$ sq. in. The area of the two angles is 2.38 sq. in., which is ample. The section is sufficiently large to take both tension and compression, and will be used.

Design of Columns.-Columns must be designed to take the stress due to direct loading, to eccentric loading, and to wind moment. The method of column design will be illustrated by the design of the leeward column in the transverse bent shown in Fig. 56; the stresses for which are given in Table VI. 
Direct stress in $A$-I $7=\mathrm{I} 4,900$ lbs.; and bending moment $=$ 924,000 inch-lbs. A 4-angle laced column will be used.

Try four $4^{\prime \prime} \times 3^{\prime \prime} \times 5^{-1} 6^{\prime \prime}$ angles, long legs out, and a depth of I 8 " out to out of angles; $3 / 8$ " lacing and connection plates will be used.

The radius of gyration of two $4^{\prime \prime} \times 3^{\prime \prime} \times 5$-16" angles with the long legs out, is found on page 189 Cambria to be 1.93 inches.

The moment of inertia of a section of the post about the shorter axis is

$$
\begin{aligned}
I & =4 I^{\prime}+4 A d^{2} \\
& =4 \times 1.65+4 \times 2.09(9.00-0.76)^{2} \\
& =574.24
\end{aligned}
$$

and the radius of gyration is

$$
r=\sqrt{\frac{574.24}{8.36}}=8.3 \text { inches. }
$$

The maximum fibre stress will occur on the windward side of the post and will be found by substituting in formula ( $30 a$ ) to be

$$
f=f_{2}+f_{1}=\frac{14,900}{8.36}+\frac{924,000 \times 9}{574.24-\frac{14}{280,0000,000}}
$$

$=\mathrm{I} 780+\mathrm{I} 4,560=\mathrm{I} 6,340 \mathrm{lbs}$. per square inch.

The allowable stress per square inch for direct loads is $16,000-$ $70 l \div r=\mathrm{I} 6,000-70 \times 29=\mathrm{I} 4,000 \mathrm{lbs}$. ; and since the wind moment comes only occasionally we will increase the allowable stress for direct loads by 25 per cent when wind loads are considered, making an allowable stress of $14,000 \times 1.25=17,500 \mathrm{lbs}$. per square inch. The section chosen is therefore sufficiently large.

The direct load will have to be carried by the column, and it will be necessary to investigate the column about its longer axis. For this case $l \div r=240 \div \mathrm{I} .93=\mathrm{I} 25$, which is allowable under the specifications, and the section is ample.

The lacing will be designed to take the shear, which is $5,500 \mathrm{lbs}$. below and $12,800 \mathrm{lbs}$. above the foot of the knee brace. The maximum stress in the lacing will be $12,800 \times \sec 30^{\circ}=14,700 \mathrm{lbs}$. The allowable tensile stress per square inch will be $16,000 \times 1.25=20,000$ 
TABLE XI.

RIVET SPACING IN ANGLES.

\begin{tabular}{l|l||c|c|c|c}
\hline & & & & \\
\hline
\end{tabular}

TABLE XII.

MAximum SIZE OF RIVETS IN BEAMS, CHANNELS, AND ANGLES.

\begin{tabular}{|c|c|c|c|c|c|c|c|c|c|c|c|c|}
\hline \multicolumn{6}{|c|}{ I-BEAMS. } & \multicolumn{3}{|c|}{ CHANNELS. } & \multicolumn{4}{|c|}{ ANGLES. } \\
\hline $\begin{array}{l}\text { Derth } \\
\text { uf } \\
\text { anam. } \\
\text { Insk's. }\end{array}$ & $\begin{array}{l}\text { Woight } \\
\text { per } \\
\text { Foot. } \\
\text { Pounds. }\end{array}$ & $\begin{array}{c}\text { Size } \\
\text { of } \\
\text { Rivet. } \\
\text { Inehes. }\end{array}$ & $\begin{array}{l}\text { Depth } \\
\text { of } \\
\text { Beam. } \\
\text { Inches. }\end{array}$ & $\begin{array}{c}\text { Weight } \\
\text { pep } \\
\text { Fcot. } \\
\text { Pounds. }\end{array}$ & $\begin{array}{l}\text { Size } \\
\text { of } \\
\text { Rivet. } \\
\text { inches. }\end{array}$ & $\begin{array}{c}\text { Depth } \\
\text { of } \\
\text { Thannel } \\
\text { Inctez. }\end{array}$ & $\begin{array}{l}\text { Woight } \\
\text { per } \\
\text { Foot. } \\
\text { Pounde. }\end{array}$ & $\begin{array}{l}\text { Sire } \\
\text { of } \\
\text { Rivet. } \\
\text { Inehes. }\end{array}$ & $\begin{array}{l}\text { Length } \\
\text { of } \\
\text { Leg. } \\
\text { Inobes. }\end{array}$ & $\begin{array}{l}\text { Size } \\
\text { of } \\
\text { Rivet. } \\
\text { Inches. }\end{array}$ & $\begin{array}{l}\text { Length } \\
\text { of } \\
\text { Leg. } \\
\text { Inches. }\end{array}$ & $\begin{array}{c}\text { Size } \\
\text { of } \\
\text { Rizet. } \\
\text { Inches. }\end{array}$ \\
\hline $\begin{array}{r}3 \\
4 \\
5 \\
6 \\
7 \\
8 \\
9 \\
10 \\
12 \\
12\end{array}$ & $\begin{array}{r}5.5 \\
7.5 \\
9.75 \\
12.25 \\
15.0 \\
18.0 \\
21.0 \\
25.0 \\
31.5 \\
40.0\end{array}$ & $\begin{array}{l}3 / 8 \\
1 / 2 \\
1 / 2 \\
5 / 8 \\
5 / 8 \\
3 / 4 \\
3 / 4 \\
3 / 4 \\
3 / 4 \\
3 / 4\end{array}$ & $\begin{array}{l}15 \\
15 \\
15 \\
18 \\
20 \\
20 \\
24\end{array}$ & $\begin{array}{l}42.0 \\
60.0 \\
80.0 \\
55.0 \\
65.0 \\
80.0 \\
80.0\end{array}$ & $\begin{array}{l}3 / 4 \\
3 / 4 \\
7 / 8 \\
7 / 8 \\
1 \\
1 \\
1\end{array}$ & $\begin{array}{r}3 \\
4 \\
5 \\
6 \\
7 \\
8 \\
9 \\
10 \\
12 \\
15\end{array}$ & $\begin{array}{l}4.0 \\
5.25 \\
6.5 \\
8.0 \\
9.75 \\
11.25 \\
13.25 \\
15.0 \\
20.50 \\
33.0\end{array}$ & $\begin{array}{l}3 / 8 \\
1 / 2 \\
1 / 2 \\
5 / 8 \\
5 / 8 \\
3 / 4 \\
3 / 4 \\
3 / 4 \\
3 / 4 \\
3 / 4\end{array}$ & $\begin{array}{l}1^{3 / 4} \\
11 / 4 \\
1 \frac{5}{16} \\
13 / 8 \\
11 / 2 \\
13 / 4 \\
2 \\
21 / 4 \\
2 \frac{5}{16}\end{array}$ & $\begin{array}{l}1 / 4 \\
3 / 8 \\
1 / 2 \\
1 / 2 \\
1 / 2 \\
1 / 2 \\
58 \\
5 / 8 \\
3 / 4 \\
3 / 4\end{array}$ & $\begin{array}{l}21 / 2 \\
23 / 4 \\
3 \\
31 / 2 \\
4 \\
41 / 2 \\
5 \\
6 \\
7\end{array}$ & $\begin{array}{l}1 \\
1 \\
1 \\
1 \\
1 \\
1\end{array}$ \\
\hline
\end{tabular}




\section{TABLE XIII.}

RIVET SPACING.

\begin{tabular}{|c|c|c|c|c|c|}
\hline $\begin{array}{l}\text { Size } \\
\text { of } \\
\text { Biyet }\end{array}$ & $\begin{array}{l}\text { Minimum } \\
\text { Pitoh. }\end{array}$ & $\begin{array}{c}\text { Maximum Pitch at } \\
\text { Ends of } \\
\text { Compression }\end{array}$ & $\left\{\begin{array}{l}\text { Minimum Pitch in } \\
\text { Flanges of } \\
\text { Chords and Gird's. }\end{array}\right.$ & $\begin{array}{r}\text { Distance from } \\
\text { Centero }\end{array}$ & $\begin{array}{l}\text { of Piese to } \\
\text { et Hole. }\end{array}$ \\
\hline Inches. & Inohes. & $\begin{array}{l}\text { Members. } \\
\text { Inches. }\end{array}$ & Inches. & $\begin{array}{l}\text { Minimum. } \\
\text { Inches. }\end{array}$ & $\begin{array}{l}\text { Usual. } \\
\text { Inohes. }\end{array}$ \\
\hline $\begin{array}{c}1 / 4 \\
3 / 8 \\
1 / 2 \\
5 / 8 \\
3 / 4 \\
7 / 8 \\
1\end{array}$ & $\begin{array}{l}3 / 4 \\
11 / 8 \\
11 / 2 \\
17 / 8 \\
21 / 4 \\
25 / 8 \\
3\end{array}$ & $\begin{array}{l}\cdots \\
\cdots \\
3 \ldots \\
21 / 2 \\
3 \\
31 / 2 \\
4\end{array}$ & $\begin{array}{l}\cdot \ldots \\
\ldots \\
\cdots \\
4 \\
4 \\
4 \\
4\end{array}$ & $\begin{array}{c}\cdots \\
\cdots \cdots \\
\cdots \cdots \\
\frac{15}{16} \\
11 / 8 \\
\mathrm{I}_{1}^{5} \\
11 / 2\end{array}$ & $\begin{array}{l}\cdots \\
\cdots \cdots \\
\cdots \\
11 / 4 \\
11 / 2 \\
13 / 4 \\
2\end{array}$ \\
\hline
\end{tabular}

\section{TABLE XIV.}

SheARING AND BEARING VALUE OF RIVE'TS IN POUNDS.

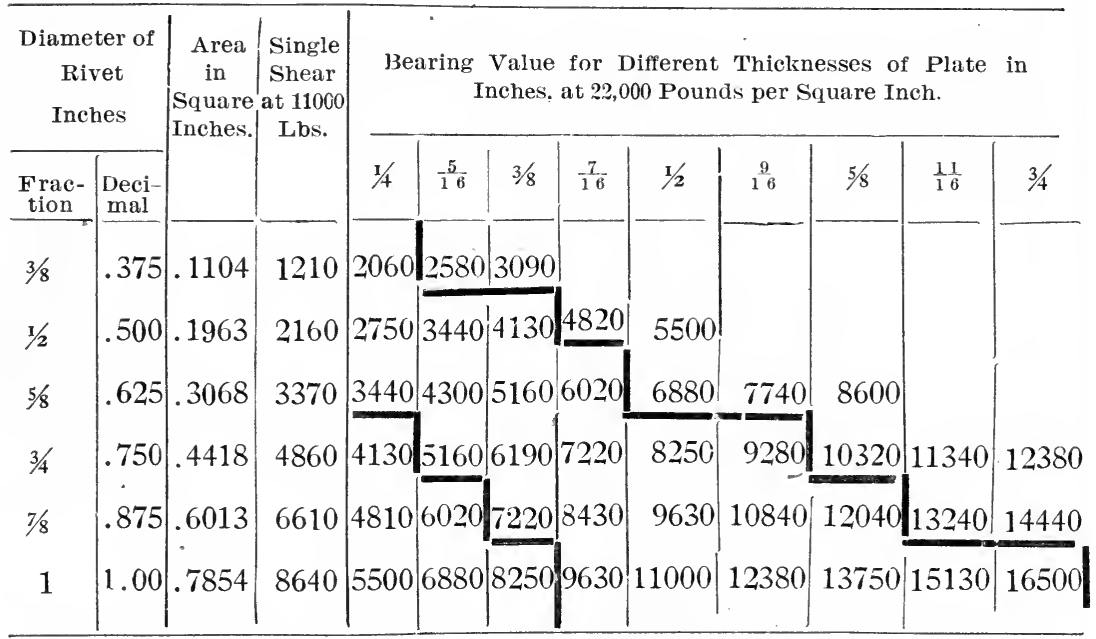

All bearing values above or to right of upper zizgag lines are greater than double shear. Values below or to left of low er zigzag lines are less than single shear.

1bs. The required net area for tension will be $14,700 \div-20,000=0.74$ square inches. The gross area of a $3^{\prime \prime} \times 3 / 8^{\prime \prime}$ bar is I. I25 square inches (page 388 Cambria) and the net area after deducting for one $3 / 4$ " rivet is 0.895 square inches (page 3 IO Cambria) which is sufficient for tension. 
The allowable stress for compression is $(16,000-70 l \div r)$ I.25. The moment of inertia of a $3^{\prime \prime} \times 3 / 8^{\prime \prime}$ bar is 0.0135 , and the radius of gyration is $0 . I I$ inches. The ends of the lacing bars are practically fixed, and it will be assumed that the length c. to c. of rivets will as a result be shortened by one-half. Then $l \div r=75$, the allowable stress will be 13,340 lbs. and the required area I. Io square inches. The lacing bars are therefore sufficient to take either the tension or compression. Lacing bars $2{ }^{1} 2^{\prime \prime} \times 3 / 8^{\prime \prime}$ will be found sufficient below the foot of the knee brace.

The allowable shear on each rivet in the lacing will be (Table XIV) $4860 \times \mathrm{I} .25=6,075 \mathrm{lbs}$; and the allowable bearing will be $6,190 \times$ $\mathrm{I} .25=7,740 \mathrm{lbs}$. The stress in the lacing bars below the foot of the knee brace is $5,500 \times \sec 30^{\circ}=6,300 \mathrm{lbs}$; 估 $3 / 4$-rivets are all right for bearing but are not quite large enough for shear, however it is so near, that they will be used. Above the foot of the knee brace it will be necessary to increase the thickness of the lacing bars and put two rivets in each connection as shown in Fig. IO2, or use a solid plate.

In designing the bases of columns hinged at the base, part of the stresses may be assumed to pass directly to the base plate if the abutting surfaces have been milled; but in columns fixed at the base all of the stresses must be transferred by the rivets. The rivets must be designed to take the direct stress and the stress due to bending moment; the solution is similar to that for anchorage (Fig. 6I) and will not be given.

Design of Plate Girders.-The maximum moments and shears are found as described in Chapter $X$. If the plate girder were designed by means of its moment of inertia, as in the case of rolled sections, about $1 / 6$ of the web would be effective as flange area to take the bending moment; or deducting rivets about $1 / 8$ would be found effective. It is, however, the common practice to assume that all the moment is taken by the flanges, and that all the shear is taken by the web; and this assumption will be made in the discussion which follows.

Flange Stress.-The stress, $F$, in the flanges at any point in a plate girder is

$$
F=M \div h
$$


where $M=$ bending moment in inch-pounds, and $h=$ the distance between centers of gravity of the flange areas (effective depth), (a) Fig. I08.

The net flange area, $A$, will be $A=F \div f$ where $f=$ the allowable unit stress. The tension flanges of plate girders are designed as above, and the compression flanges are made with the same gross area.

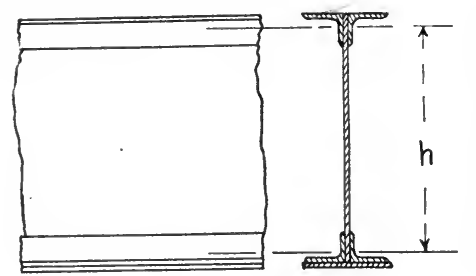

(a)

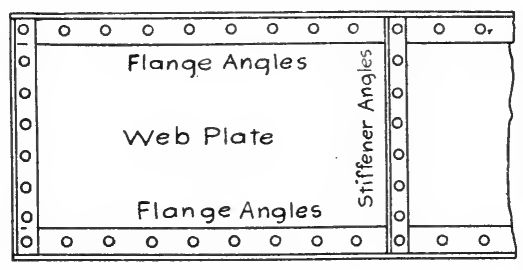

(b)
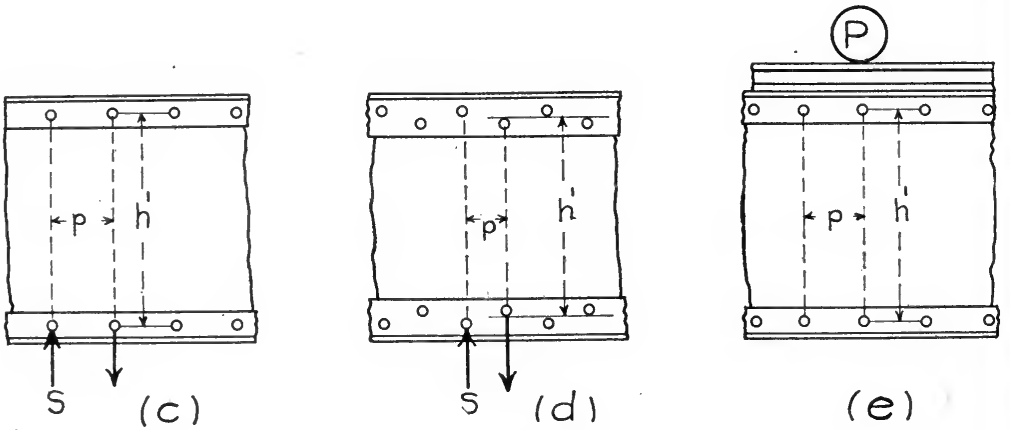

FIG. 108.

$W e b$. - The web plate should not be less than $5^{-16}$ of an inch in thickness although $\mathrm{x} / 4$-inch plates may be used if provided with sufficient stiffeners. The shear in the web is commonly assumed as uniformly distributed over the entire cross-section of the plate.

Stiffeners.-There is no rational method for the design of stiffeners. If they are placed at distances apart not exceeding the depth of the girder, nor more than 5 feet, where the shearing stress is greater 
than given by the formula - allowed shearing stress $=12,500-90 H$, where $H=$ ratio of depth to thickness of web plate, the stiffeners will be near enough together. Where the shearing stress is less than given by the above formula, stiffeners may be omitted or spaced as desired.

Stiffeners are commonly designed as columns, free to move in a direction at right angles to the web, with an allowed stress $P=12,000-$ $55 l \div r$. Stiffeners should be provided at all points of șupport and under all concentrated loads, and should contain enough rivets to traansfer the vertical shear.

Web Splice.-In the plain web splice shown in Fig. 108, the rivets take a uniform shear equal to $S \div n$, where $S$ is total shear, and $n$ is number of rivets on one side of splice, and a shear due to the shearing stress not being applied at the center of gravity of the rivets. This is the problem of the eccentric riveted connection, which has been discussed in Chapter XV.

If the web is assumed to take part of the bending moment there will be an additional shear due to bending moment.

Rivets in the Flanges.- In Fig. 108, let $S=$ the shear in the girder at the given section, $h^{\prime}=$ distance between rivet lines, $p=$ the pitch of the rivets, and $r=$ the resistance of one rivet ( $r$ is usually the safe bearing on the rivet in the web).

Then taking moments about the lower right hand rivet, we have

$$
S p=r h^{\prime} \text {, and } p=r h^{\prime} \div S
$$

Where the rivets are in double rows as shown in (d), the distance $h^{\prime}$ is taken as a mean of the distances for the two lines.

The crane loads produce an additional shear in the rivets, (e) Fig. I08, which will now be investigated. We will assume that the rail distributes the load over a distance of 25 inches; this distance will be less for light rails and more for heavy rails. The maximum vertical shear on one rivet will be $P p \div 25=0.04 P p$. The horizontal stress due to bending moment is $r=S p \div h^{\prime}$, and the resultant stress from the two sources will be 
${ }_{184}$

$$
r^{\prime}=\sqrt{(0.04 P p)^{2}+\left(\frac{S p}{h^{\prime}}\right)^{2}}
$$

and solving for $p$

$$
p=\sqrt{\frac{r^{\prime}}{(0.04 P)^{2}+\left(\frac{S}{h^{\prime}}\right)^{2}}}
$$

Crane Girders.-The maximum moments and shears in crane girders are found as explained in Chapter X. For small cranes I beam girders are commonly used, and are designed by the use of their moments of inertia. Plate girders are designed as previously described. In designing both rolled and plate girders care must be used to properly support the girder laterally. 


\section{CHAPTER XVIII.}

\section{Corrugated Steel.}

Introduction.-Corrugated steel is made from sheet steel of standard gages, and is either galvanized at the mill or is left black. The black corrugated steel is usually painted at the mill and is always painted after erection. Paint will not adhere well to the galvanized steel until after it has weathered unless a portion of the coating is removed by the application of an acid. The common standard for the gage of sheet steel in the United States is the United States Standard Gage, and this should be used in specifying the weight and thickness. The thickness and weights per square of 100 square feet, for bläck and galvanized sheet and corrugated steel are given in Table XV. The weights of the corrugated steel given in the table are for standard corrugations, approximately $21 / 2$ inches wide and $5 / 8$ of an inch deep. If black sheet steel is painted, add about 2 lbs. per square.

\section{TABLE XV.}

WEIGHT OF FLAT, AND CORRUGATED STEEL SHEETS WITH $2 \frac{1}{2} / 2$-INCH CORRUGATIONS.

\begin{tabular}{|c|c|c|c|c|c|}
\hline \multirow{3}{*}{ Gage No. } & \multirow{3}{*}{$\begin{array}{c}\text { Thickness } \\
\text { in } \\
\text { inches }\end{array}$} & \multicolumn{4}{|c|}{ Weight per Square ( 100 sq.ft.) } \\
\hline & & Flat & Sheets & Corrugated & Sheets \\
\hline & & Black & Galvanized & Black Painted & Galvanized \\
\hline 16 & .0625 & 250 & 266 & 275 & 291 \\
\hline 18 & .0500 & 200 & 216 & 220 & 236 \\
\hline 20 & .0375 & 150 & 166 & 165 & 182 \\
\hline 22 & $.03 / 3$ & 125 & 141 & 138 & 154 \\
\hline 24 & .0250 & 100 & 116 & $1 / 1$ & 127 \\
\hline 26 & .0188 & 75 & 91 & 84 & 99 \\
\hline 28 & .0156 & 63 & 79 & 69 & 86 \\
\hline
\end{tabular}

Corrugated steel is also made with corrugations 5,3 and $I / 4$ inches wide approximately. Corrugated steel with corrugations $I / 4$ 
inches wide and $3 / 8$ of an inch deep is frequently used for lining buildings. Corrugated steel with $\mathrm{I} / 4$-inch corrugations weighs about 4 per cent more than steel of the same gage with $2 \frac{1}{2}$-inch corrugations. Corrugated sheets are commonly made from flat bessemer steel sheets, by rolling one corrugation at a time. Iron and open hearth steel corrugated sheets can be obtained, but are veiy hard to get and cost extra.

The standard sheets of corrugated steel with $2 \frac{1}{2}$-inch corrugations, are 28 inches wide before, and 26 inches wide after corrugating, and will cover a width of 24 inches with one corrugation side lap, and approximately $2 \mathrm{I} / 2$ inches with two corrugations side lapp, (c) and (a) Fig. I09. Special corrugated steel can usually be obtained that will cover a width of 24 inches with $1 \frac{1}{2}$ corrugations side lap, (b). Corrugated steel should be laid with 6 inches end lap on the roof and 4 inches end lap on the sides of buildings.

Corrugated Roof Steel

Side Lap 2 Corrugations

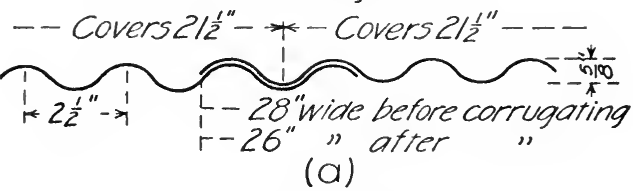

Special Cor. Roof Steel

Side Lap $I_{\frac{1}{2}}$ Corrugations

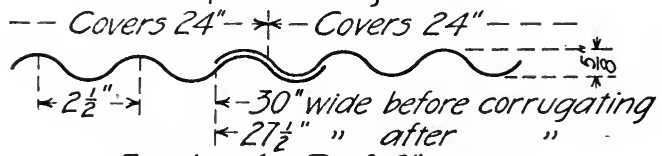

End Lap for Poof 6"

(b)

Corrugated Siding Steel

Side Lap 1 Corrugation

- - Covers 24"- $-\frac{1}{*}$-Covers 24

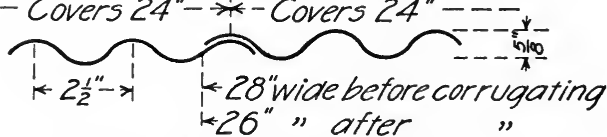

End Lap for Sides 4"

(C)

FIG. I09. 
Stock lengths of corrugated steel sheets can be obtained from 5 to Io feet, varying by one-half foot. Sheets of any length between 4 and Io feet can usually be obtained directly from the mill without extra charge. Sheets from 48 to 5 inches long, cost from I-Io to $1 / 2$ cents per pound extra. Sheets from Io to I 2 feet long are very hard to obtain and cost extra. Sheets cannot be obtained longer than 12 feet. Stocklengths of sheets should be used whenever possible as odd lengths often delay the filling of the order. Bevel sheets should preferably be orderer in multiple lengths and should be cut in the field. Sheets to fit around windows and doors should be cut in the field; no part of a sheet less than $1 / 4$ the width of a full sheet should ever be used.
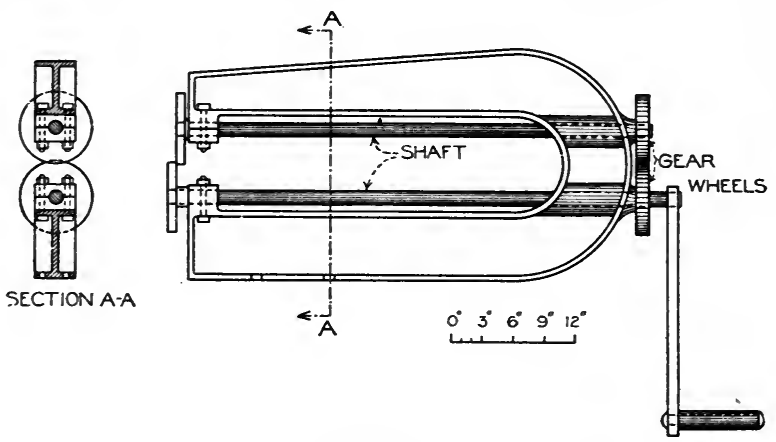

FIG. IIO.

For cutting and splitting corrugated sheets in the field the rotary shear shown in Fig. I Io is invaluable. It will make square or bevel cuts, or will split sheets without denting the corrugations. The shear shown in Fig. I Io is one made by the Gillete-Herzog Mfg. Co., Minneapolis, Minn., and was used by the author in the erection of a steel stamp mill in Northern Michigan, while in the employ of the above named company. The shear is not on the market, but can be made in any ordinary machine shop at a comparatively small cost.

Fastening Corrugated Steel.-Where spiking strips are used, the corrugated steel is fastened with $8 \mathrm{~d}$ barbed roofing nails $3 / 4$ to $2 \mathrm{~T} / 2$

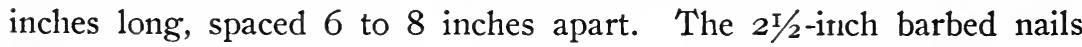
should be used for nailing to spiking strips and to sheathing whenever possible. For weight of barbed roofing nails see Table XVI. 


\section{TABLE XVI.}

NUMBER OF BARBED ROOFING NAILS IN ONE POUND.

\begin{tabular}{|c|c|c|c|c|c|c|c|}
\hline Size & $\begin{array}{l}\text { Length } \\
\text { inches }\end{array}$ & $\begin{array}{l}\text { Gage } \\
\text { No. }\end{array}$ & $\begin{array}{l}\text { No. in } \\
\text { one lb. }\end{array}$ & Size & $\begin{array}{l}\text { Length } \\
\text { inches. }\end{array}$ & $\begin{array}{l}\text { Gage } \\
\text { No. }\end{array}$ & $\begin{array}{l}\text { No. in } \\
\text { one lb. }\end{array}$ \\
\hline $4 \mathrm{~d}$ & $11 / 2$ & 13 & 339 & $20 d$ & 4 & 6 & 30 \\
\hline $6 d$ & 2 & 12 & 205 & $30 d$ & $4 \mathrm{r} / 2$ & 5 & 23 \\
\hline $8 d$ & $21 / 2$ & 10. & 96 & $40 \mathrm{~d}$ & 5 & 4 & 17 \\
\hline $10 \mathrm{~d}$ & 3 & 9 & 63 & $.50 \mathrm{~d}$ & $51 / 2$ & 3 & 13 \\
\hline $12 \mathrm{~d}$ & $31 / 2$ & 8 & 52 & $60 \mathrm{~d}$ & 6 & 2 & 10 \\
\hline $16 d$ & $31 / 2$ & 7 & 38 & & & & \\
\hline
\end{tabular}

The common methods of fastening corrugated steel directly to the purlins and girts are shown in Fig. I I I. Nailing pieces should preferably be used where anti-condensation roofing, Fig. I27, is used, or where the sides are lined with corrugated steel. The clinch nail is prob-

- Pivets and clinch nails go through top of corrugations

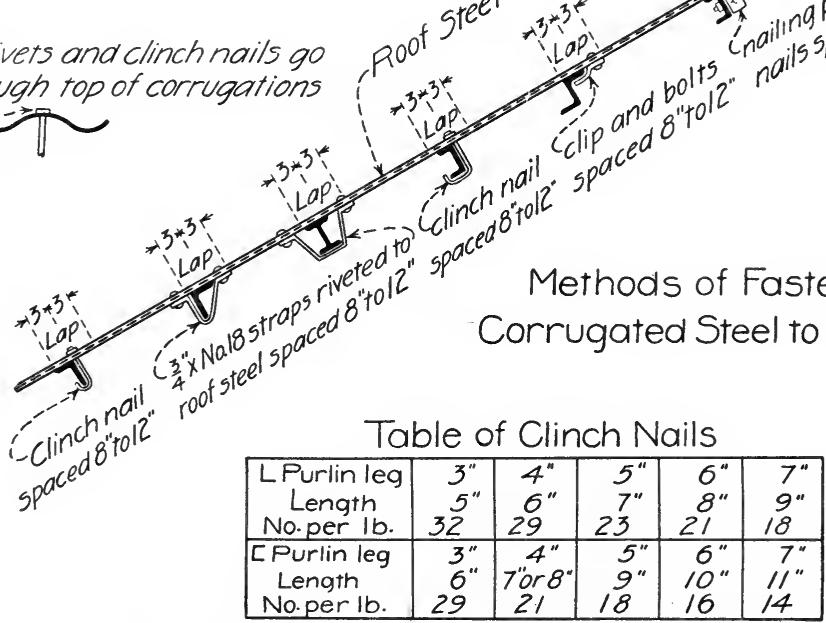

Fig. III. METHODS OF FASTENING CORRUGATED STEEL TO PURLINS AND GIR'TS.

ably the most satisfactory fastening for the usual conditions. The side laps are fastened together by means of copper or galvanized iron clos- 
ing rivets, spaced about 8 to 12 inches apart on the roof and about 2 feet apart on the sides.

Clinch nails are made of $1 / 8$ inch or No. Io soft iron wire and are clinched around the purlin. The usual sizes and weights of clinch nails for different lengths of angle and channel purlins are given in Fig. I I I. Care should be used in punching the holes in the corrugated steel for clinch nails and rivets to get them in the top of the corrugations and to avoid making the hole unnecessarily large. Clinch nails are spaced from 8 to 12 inches apart. Two clinch nails are usually furnished for each lineal foot of purlin and girt.

Straps are made of No. 18 gage steel, $3 / 4$ inches wide, and are TABLE XVII.

NUMBER OF COPPER RIVETS IN ONE POUND.

\begin{tabular}{|c|c|c|c|c|c|c|c|c|c|c|c|c|c|c|}
\hline \multirow{2}{*}{$\begin{array}{c}\text { Diam- } \\
\text { eter. } \\
\text { Gage } \\
\text { No. }\end{array}$} & \multicolumn{14}{|c|}{ Length of Rivets in inches. } \\
\hline & B & $1 / 4$ & $\frac{5}{16}$ & $3 / 8$ & $i_{16}^{7}$ & $1 / 2$ & $\frac{9}{16}$ & $5 / 8$ & $3 / 4$ & $2 / 8$ & 1 & $11 / 6$ & $1 \frac{1}{4}$ & $11 / 2$ \\
\hline 3 & 70 & & & & & & & & & & & & & \\
\hline 4 & 78 & & & & & & & & & & & & & \\
\hline 5 & 85 & & & & & 64 & 60 & 53 & 48 & 46 & 44 & 39 & 36 & 32 \\
\hline 6 & 180 & & & 105 & 100 & 96 & 90 & 74 & 68 & 61 & 56 & 54 & 50 & 46 \\
\hline 7 & 368 & 211 & 180 & 171 & 160 & 150 & 140 & 132 & 110 & 97 & 91 & 79 & 72 & 63 \\
\hline 8 & 417 & 266 & 248 & 227 & 200 & 172 & 157 & 147 & 136 & 116 & 100 & 93 & 88 & 71 \\
\hline 9 & 600 & 365 & 336 & 261 & 248 & 228 & 220 & 184 & 169 & 156 & 133 & 124 & 113 & 99 \\
\hline 10 & 820 & 411 & 376 & 336 & 305 & 257 & 249 & 223 & 206 & 180 & 162 & & & \\
\hline 11 & 944 & 416 & 400 & 360 & 338 & 320 & & & & & & & & \\
\hline 12 & 1167 & 545 & 475 & 400 & 342 & 325 & 308 & 292 & 257 & 221 & 190 & & & \\
\hline 13 & 1442 & 799 & 640 & 547 & 502 & 448 & 400 & 392 & 316 & & & & & \\
\hline 14 & 1620 & 1040 & 995 & 816 & 784 & 616 & 550 & 528 & & & & & & \\
\hline 15 & 3512 & & & & & & & & & & & & & \\
\hline
\end{tabular}

fastened with two 3 -16-inch stove bolts $3 / 8$ inches long. Straps are spaced 8 to 12 inches apart. One strap and two bolts are usually furnished for each lineal foot of purlin and girt: One bundle of hoop steel for making straps contains 400 lineal feet and weighs 50 lbs.

Clips are made of No. 16 gage steel, $11 / 2^{\prime \prime} \times 21 / 2^{\prime \prime}$, and are fastened with two $3^{-16-i n c h ~ s t o v e ~ b o l t s ~} 1 / 2$ inches long. Clips are spaced from 8 to 12 inches apart. One clip and two bolts are usually furnished for each lineal foot of purlin and girt. 
Copper rivets weighing about 6 pounds per Iooo rivets have commonly been used for closing rivets; but galvanized iron rivets made of very soft wire and weighing about 7 pounds per Ioon rivets are fully as good, and cost 7 cents per pound in 1903 as compared with about 25 cents per pound for copper rivets. The weight of copper rivets is given in Table XVII.

Strength of Corrugated Steel.-The safe load per square foot for corrugated steel supported as a simple beam, for sheets with $2 \frac{\mathrm{T}}{2} \mathrm{2}^{-\mathrm{inch}}$ corrugations and of various gages is given in Fig. II2. This diagram is based on Rankine's formula

$$
W=\frac{4}{15} \frac{S h b t}{l}
$$

where $W=$ safe load in lbs.;

$S=$ working stress in 1bs.;

$h=$ depth of the corrugations in inches;

$b=$ width of the sheet in inches;

$t=$ thickness of the sheet in inches;

$l=$ clear span in inches.

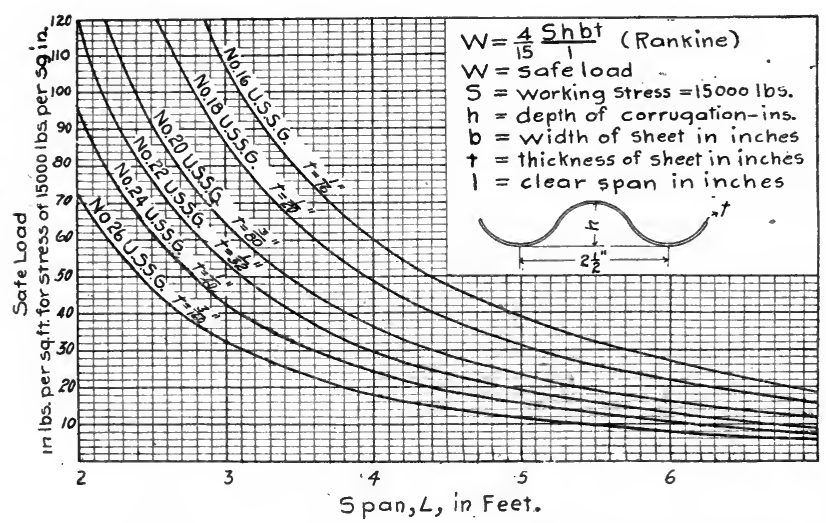

Fig. II2. SAFE UNIFORM LOAD IN POUNDS FOR CORRUGATED STEEL, FOR DIFFERENT SPANS IN FEET.

A summary of experiments to determine the strength of corrugated steel made by the author's assistant, Mr. Ralph H. Gage, is given in 
Table XVIII. The coefficient $C$ in column 8 depends on the angle that the metal makes with the horizontal axis and varies as follows: angle of $30^{\circ}, C=0.278 ; 45^{\circ}, C=0.293 ; 60^{\circ}, C=0.312$, and for $90^{\circ}, C=$ 0.393 .

\section{TABLE XVIII.}

SUMMARY OF EXPERIMENTS TO DETERMINE THE STRENGTH OF CORRUGATED STEEL.*

\begin{tabular}{|c|c|c|c|c|c|c|c|c|c|}
\hline No. & $\begin{array}{c}2 \\
\text { Width } \\
\text { of } \\
\text { Corru- } \\
\text { gations } \\
\text { Ins. }\end{array}$ & \begin{tabular}{|c|}
$\mathbf{3}$ \\
Depth \\
$h$ \\
Ins.
\end{tabular} & $\begin{array}{c}4 \\
\text { Thick- } \\
\text { ness } \\
t \\
\text { Ins. }\end{array}$ & $\begin{array}{c}\mathbf{5} \\
\text { Angle } \\
\text { of } \\
\text { Metal } \\
\text { with } \\
\text { Axis }\end{array}$ & $\begin{array}{l}\text { Span } \\
\qquad \\
\text { Ins. }\end{array}$ & $\begin{array}{c}7 \\
\text { Tensile } \\
\text { Strength } \\
\text { lbs. per } \\
\text { sq. in. }\end{array}$ & $\begin{array}{c}8 \\
\text { Gage }{ }^{\circ} \\
\text { Formula } \\
W=\frac{C S h b t .}{l} \\
\text { lbs. }\end{array}$ & $\begin{array}{c}9 \\
\text { Actual } \\
\text { Brkng } \\
\text { Load } \\
W \\
\text { lbs. }\end{array}$ & $\begin{array}{c}10 \\
\text { Rankine's } \\
\text { Formula. } \\
W=\frac{t}{15}-\frac{S h b t}{l} \\
\text { lbs. }\end{array}$ \\
\hline $\begin{array}{l}1 \\
2 \\
3 \\
4\end{array}$ & $\begin{array}{l}2.50 \\
2.50 \\
2.50 \\
2.50\end{array}$ & $\begin{array}{l}0.6025 \\
0.612 \\
0.625 \\
0.606\end{array}$ & $\begin{array}{l}.0588 \\
.0568 \\
.066 \\
.0655\end{array}$ & $\begin{array}{l}39^{\circ} 11^{\prime} \\
39^{\circ} 10^{\prime} \\
39^{\circ} 30^{\prime} \\
40^{\circ} 42^{\prime}\end{array}$ & $\begin{array}{l}44.0 \\
44.0 \\
44.0 \\
44.0\end{array}$ & $\begin{array}{l}58,000 \\
58,000 \\
58,000 \\
58,000\end{array}$ & $\begin{array}{l}643 \\
632 \\
745 \\
725\end{array}$ & $\begin{array}{l}630 \\
630 \\
720 \\
703\end{array}$ & $\begin{array}{l}597 \\
587 \\
692 \\
670\end{array}$ \\
\hline $\begin{array}{l}5 \\
6 \\
7 \\
8\end{array}$ & $\begin{array}{l}2.88 \\
2.88 \\
2.50 \\
2.50\end{array}$ & $\begin{array}{l}0.650 \\
0.650 \\
0.630 \\
0.61\end{array}$ & $\begin{array}{l}.0367 \\
.0366 \\
.0366 \\
.0365\end{array}$ & $\begin{array}{ll}36^{\circ} & 0^{\prime} \\
36^{\circ} & 0^{\prime} \\
36^{\circ} & 0^{\prime} \\
36^{\circ} & 0^{\prime}\end{array}$ & $\begin{array}{l}43.25 \\
44.0 \\
44.0 \\
44.0\end{array}$ & $\begin{array}{l}67,000 \\
67,000 \\
50,000 \\
50,000\end{array}$ & $\begin{array}{l}505 \\
494 \\
358 \\
344\end{array}$ & $\begin{array}{l}500 \\
490 \\
350 \\
340\end{array}$ & $\begin{array}{l}475 \\
465 \\
335 \\
324\end{array}$ \\
\hline $\begin{array}{r}9 \\
10 \\
11 \\
12\end{array}$ & $\begin{array}{l}1.25 \\
1.25 \\
1.25 \\
1.25\end{array}$ & $\begin{array}{l}0.27 \\
0.27 \\
0.27 \\
0.27\end{array}$ & $\begin{array}{l}.0365 \\
.0365 \\
.0293 \\
.0293\end{array}$ & $\begin{array}{ll}36^{\circ} & 0^{\prime} \\
36^{\circ} & 0^{\prime} \\
36^{\circ} & 0^{\prime} \\
36^{\circ} & 0^{\prime}\end{array}$ & $\begin{array}{l}24.0 \\
24.0 \\
24.0 \\
24.0\end{array}$ & $\begin{array}{l}50,000 \\
50,000 \\
50,000 \\
50,000\end{array}$ & $\begin{array}{l}281 \\
281 \\
225 \\
225\end{array}$ & $\begin{array}{l}300 \\
295 \\
200 \\
195\end{array}$ & $\begin{array}{l}262 \\
262 \\
211 \\
211\end{array}$ \\
\hline $\begin{array}{l}13 \\
14 \\
15 \\
16\end{array}$ & $\begin{array}{l}1.00 \\
1.00 \\
1.00 \\
1.00\end{array}$ & $\begin{array}{l}0.18 \\
0.18 \\
0.18 \\
0.18\end{array}$ & $\begin{array}{l}.0291 \\
.0291 \\
.026 \\
.026\end{array}$ & $\begin{array}{ll}36^{\circ} & 0^{\prime} \\
36^{\circ} & 0^{\prime} \\
36^{\circ} & 0^{\prime} \\
36^{\circ} & 0^{\prime}\end{array}$ & $\begin{array}{l}24.0 \\
24.0 \\
24.0 \\
24.0\end{array}$ & $\begin{array}{l}50,000 \\
50,000 \\
50,000 \\
50,000\end{array}$ & $\begin{array}{l}298 \\
298 \\
266 \\
266\end{array}$ & $\begin{array}{l}310 \\
300 \\
280 \\
260\end{array}$ & $\begin{array}{l}279 \\
279 \\
250 \\
250\end{array}$ \\
\hline
\end{tabular}

The actual breaking load agrees in most cases more closely with Gage's formula than with Rankine's, although the latter is more often on the safe side.

Purlins are commonly spaced for a safe load of $30 \mathrm{lbs}$. per square foot as given in Fig. II2; if the purlins are spaced farther apart than this, the steel will deflect a dangerous amount when walked on, and will leak snow and rain. Girts should be spaced for a safe load of about 25 lbs. per square foot. From an inspection of Fig. I12, it is evident that corrugated steel lighter than No. 24 is of little use for mill buildings. No. 17.

*For details of experiments see article by Ralph H. Gage, in the Technograph, 
Corrugated steel of No. 26 or 28 gage is so thin that it soon rusts out and should never be used unless for lining cheap buildings.

Corrugated Steel Details.-Ridge Roll.-The ridge roll most commonly used is made from No. 24 flat steel, and has a $2^{\mathrm{I}} / 2^{-}$-inch roll and 6-inch aprons. It comes in 96-inch lengths and should be laid with 3 inches end lap. Plain and corrugated ridge roll are used (see Fig.
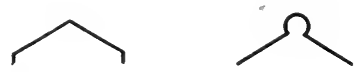

Ridge Roll
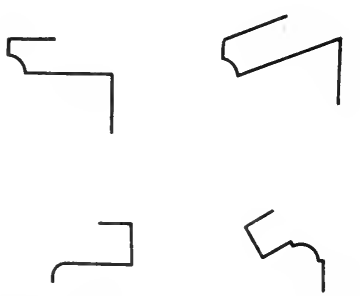

Gable Cornice Eave Cornice

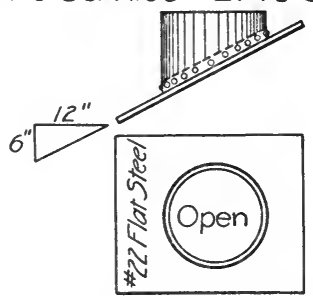

Flashing for Stack

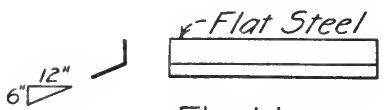

Flashing

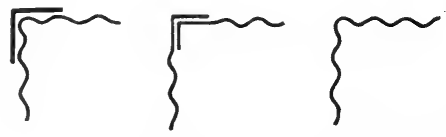

Outside Corner Finish

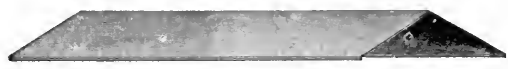

PLAIN RIDGE CAP.

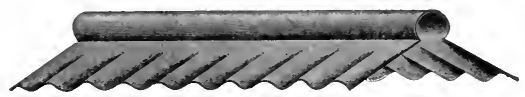

CORRUGATED RIDGE ROLL.

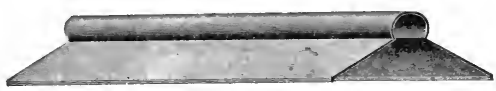

PLAIN RIDGE ROLL.

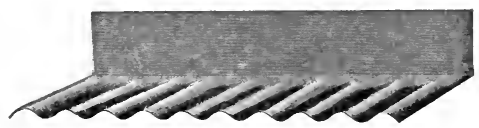

CORRUGATED END WALL FLASHING.

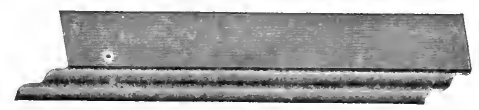

CORRUGATED SIDE FLASHING.

FIG. II3. 
I13). Ridge roll is fastened with rivets or nails spaced 6 to 8 inches apart.

Flashing.-Flashing is used where the roof changes slope, around chimneys and openings in the roof, and over windows and doors, and should be of sufficient dimensions and so arranged that at least 3 inches vertical height is obtained between the edge of the flashing and the end of the corrugated steel roofing. Vertical and horizontal seams of all flashing should be closely riveted. Flashing is made from flat sheets
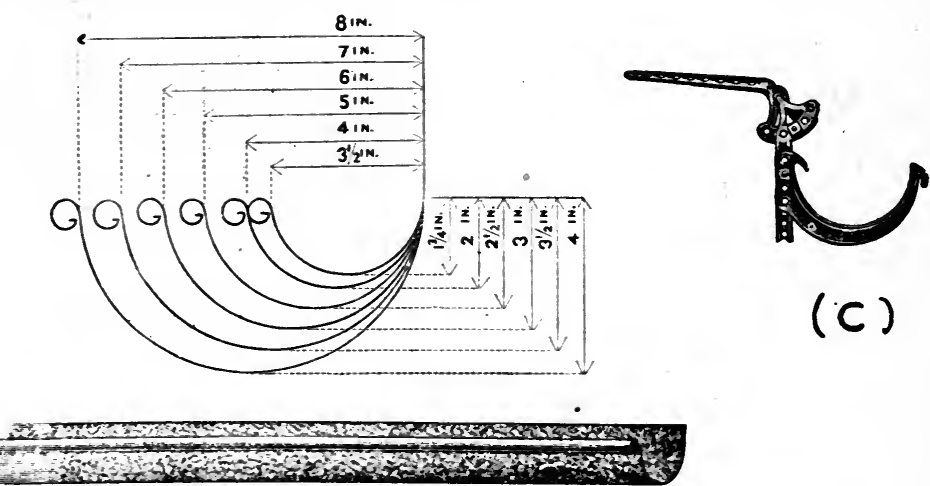

HALF-ROUND GUTTER; LAP JOINT OR SLIP JOINT.
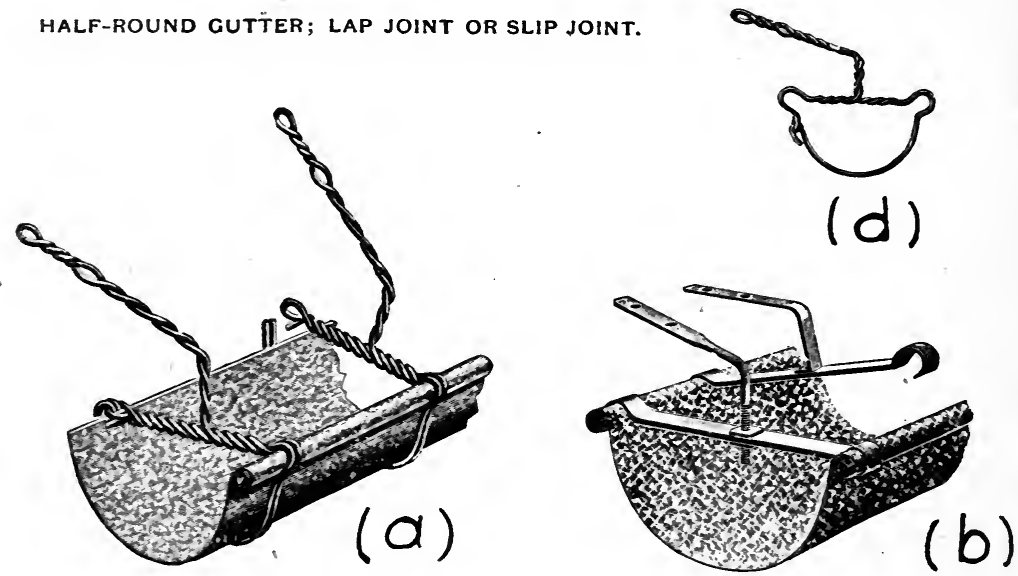

EAVES TROUGH HANGERS

FIG. II4. 
of the same gage as the corrugated steel, and can be obtained up to 96 inches in length. Flashing is made both plain and corrugated (see Fig. II3).

Corner Finish.-Corner finish is made in various ways, three of which are shown in Fig. II3. Other methods are shuwn on the succeeding pages.

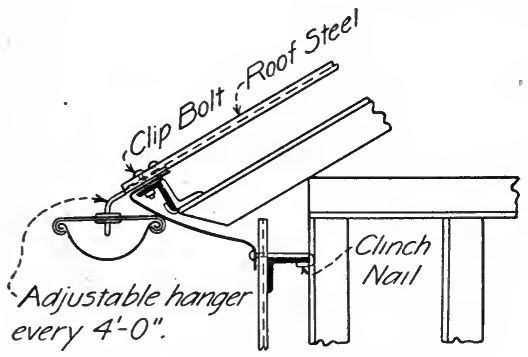

Hanging Gutter

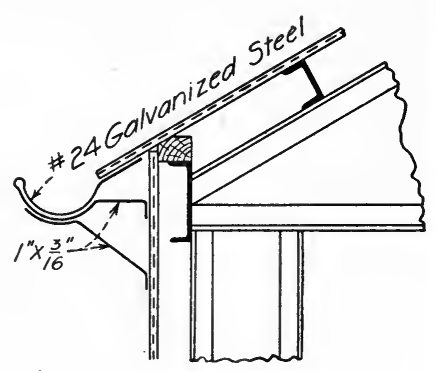

Hanging Gutter

FIG. I 15.

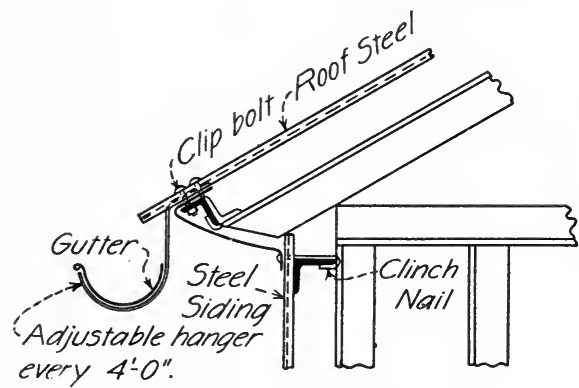

Hanging Gutter

FIG. II6.

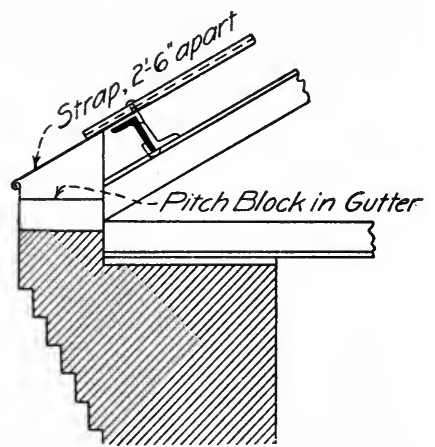

Box Gutter

Gutters and Conductors.-Gutters for eaves are ordinarily made from No. 24, and valley gutters from No. 20 galvanized steel. Gutters may be obtained in even foot lengths up to Io feet, and should have 4 -inch end laps. Special flat sheets up to 42 inches in width can be obtained for making gutters and details. 
The common sizes of half round gutters made by the Garry Iron and Steel Roofing Co., Cleveland, Ohio, are shown in Fig. II4. Two common forms of adjustable hangers are shown in (a) and (b) in Fig. I 14 .

Two forms of hanging gutters are shown in Fig. II 5 and one form of a hanging, and a box gutter used with brick walls are shown in Fig. I I6.

A standard form of valley gutter is shown in Fig. II7. Extreme care should be used in making valley gutters to see that the sides are carried well up, and that the laps are well soldered.

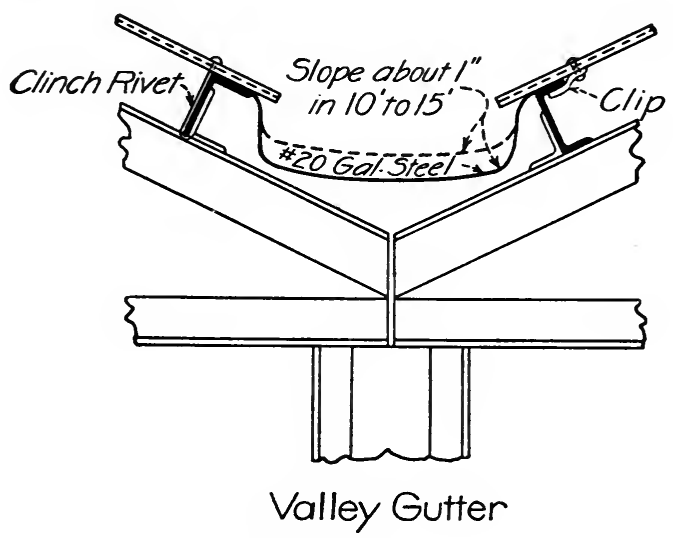

FIG. II7.

Conductors are made plain round or square, and corrugated round or square. Corrugated conductors are to be preferred to plain conductors for the reason that they will give when the ice freezes inside of them, and will not burst as the others often do. Common sizes of round pipe are $2^{\prime \prime}, 3^{\prime \prime}, 4^{\prime \prime}, 5^{\prime \prime}$, and 6" diameter. Common sizes of square pipe are $13 / 4^{\prime \prime} \times 21 / 4^{\prime \prime}, 23 / 8^{\prime \prime} \times 34^{1}{ }^{\prime \prime}, 23 / 4^{\prime \prime} \times 4 \frac{1}{4^{\prime \prime}}$ and $33 / 4^{\prime \prime} \times 5^{\prime \prime}$, equal to $2^{\prime \prime}, 3^{\prime \prime}$ and $4^{\prime \prime}$ round pipe, respectively. Conductor pipes are fastened with hooks or by means of wire.

Design of Gutters and Conductors.-The specifications of the American Bridge Company for the design of gutters and conductors are as follows: 
Span of roof.

up to $5 \mathrm{O}^{\prime}$
$5 \mathrm{O}^{\prime}$ to $7 \mathrm{O}^{\prime}$
$7 \mathrm{O}^{\prime}$ to $10 \mathrm{O}^{\prime}$
Gutter.

$6 "$

$7^{\prime \prime}$

$8^{\prime \prime}$
Conductor.

$4^{\prime \prime}$ every $40^{\prime}$

5 " “ $4 \mathrm{O}^{\prime}$

$5^{\prime \prime}$ “ $4 \mathrm{O}^{\prime}$

Hanging gutters should have a slope of at least ' I inch to ${ }_{5} 5$ feet.

The diagram in Fig. I 8 for the design of gutters and conductors was described in Engineering News, April I7, I902, by Mr. Emmett Steece, Assoc. M. A. Soc. C. E., City Engineer of Burlington, Iowa, as follows :-

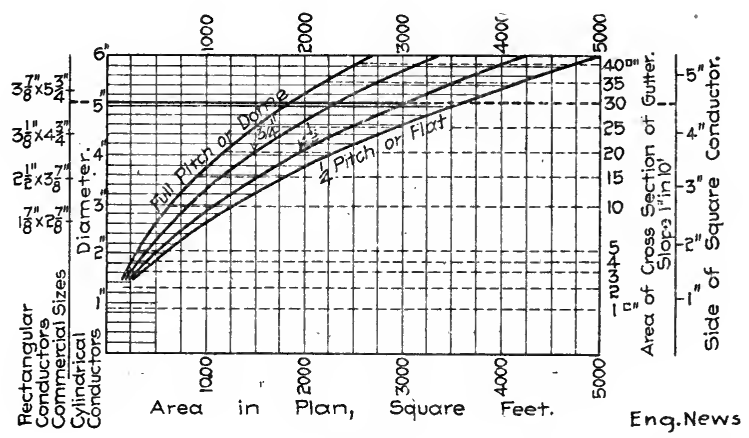

FIG. II8.

"The curves are for $1 / 4$ pitch or flat roofs, to full pitch or domes. The areas are reduced to plan as shown. The minimum sizes of circular and commercial rectangular conductors are given on the left side of the diagram and the sizes and the minimum cross-sectional areas of square gutters are given on the right hand side.

To use the diagram: Assume an area of roof, say $30 \times 100 \mathrm{ft}$., or 3000 sq. ft., $1 / 2$ pitch and one conductor for the whole area. Note the intersection of the vertical over area 3000 and the curve of $1 / 2$ pitch; following thence the horizontal line to the left it strikes a diameter of 5 ins. for circular, or over $3 / 8 \times 43 / 4$ ins. for commercial size. The next larger size would be used. The minimum cross-sectinnal area of gutters is shown on the right to be about 30 sq. ins., and the side of a square conductor about 4.5 ins."

This diagram was based on a maximum rạinfall of 1.98 inches per hour. 
English practice is as follows: Rain-water or down-pipes should have a bore or internal area of at least one square inch for every 60 square feet of roof surface in temperate, climates. and about 35 square feet in tropical climates. They should be placed not more than 20 feet apart, and should have gutters not less in width than twice the diameter of the pipe.

The practice among American architects is to provide about one square inch of conductor area for each 75 square feet of roof surface; no conductor less than 2 inches in diameter being used in any case.

Cornice.-There are many methods of finishing the gables and eaves of buildings. A gable finish for a steel end, and for a brick end

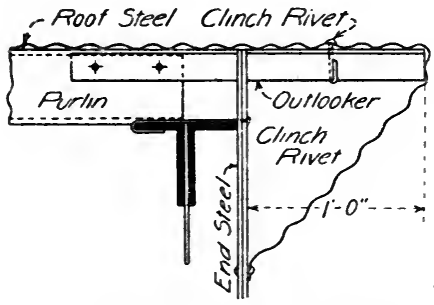

Gable Finish for Steel End

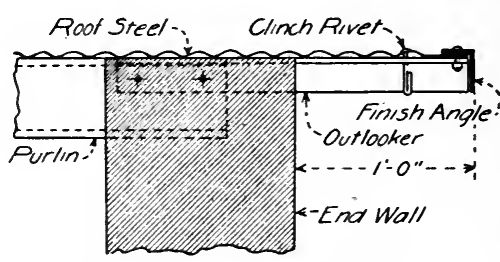

Gable Finish with Brick Wall'

FIG. II9.

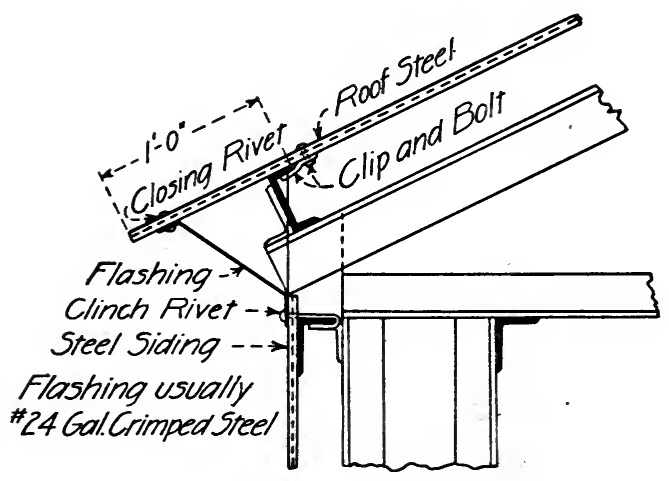

Flashed. Finish

FIG. I20. 
as used by the American Bridge Company, are shown in Fig. II9. The steel end may have a cornice made by bending the corrugated steel as shown, or a molded cornice.

The flashed finish shown in Fg. I20, is used by the American Bridge Company; it is quite effective and gives a very neat appearance. The corrugated steel siding should preferably be carried up to the roof steel.

The cornice and ridge finish shown in Fig. I2I, designed by $\mathrm{Mr}$. H. A. Fitch, Minneapolis, Minn., is very neat, efficient and economical.

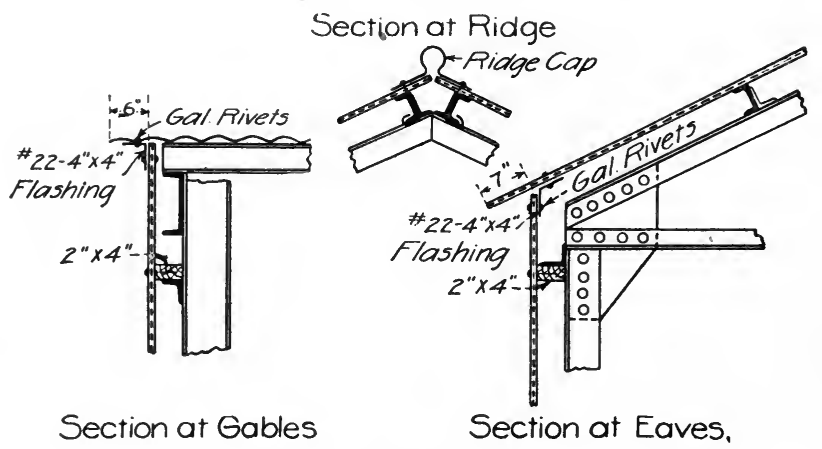

FIG. 121.

The galvanized rivets are much cheaper than copper rivets, and are preferred by many to the copper rivets. The detail shown was for a small dry house in which the eave strut was omitted.

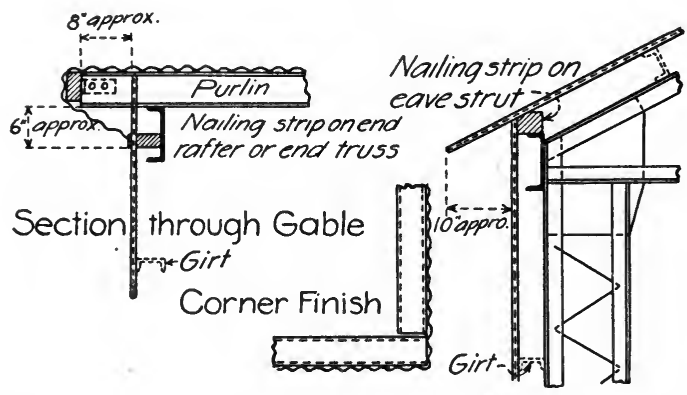

FIG. I22. 
In Fig. 122, the eave cornice is made by simply extending the roofing steel, while the gable cornice is made by bending a sheet of corrugated steel over the ends of the purlins and nailing to wooden strips as shown.

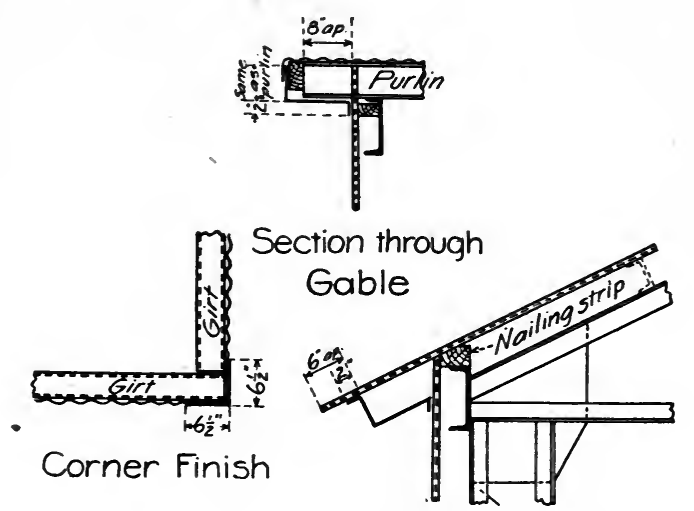

Section through Eaves

FIG. I23.

Sheets heavier than No. 22 should not be bent in the field. The corner finish is made by bending a sheet of corrugated steel.

In Fig. I23, the eave and gable cornice are made 'of plain flat steel bent in the shop as shown. The eave cornice is made to mitre with the gable cornice, thus giving a neat finish at the corner. The corner finish is made by using sheets at the corners in which one-half is left plain.

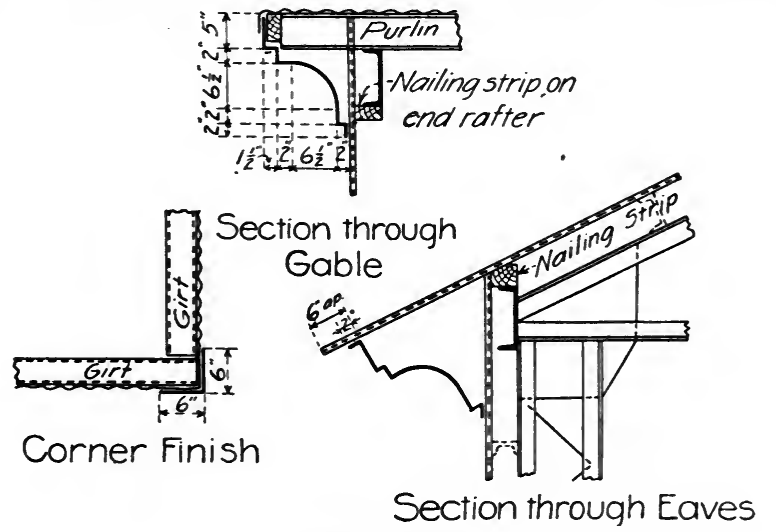

FIG. 124. 
In Fig. I24, the eave strut and gable cornice are molded. The two cornices are so made as to mitre at the corners, the mitres being made in the field. A plain corner cap is put on as shown, after bending the corrugated steel around the corner.

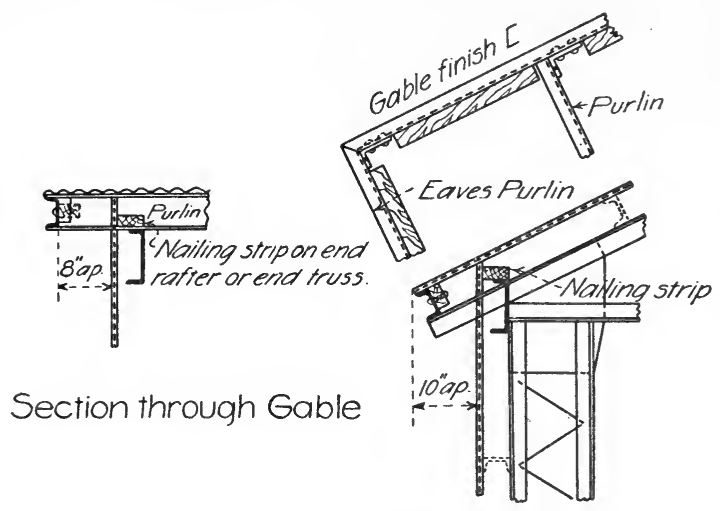

FIG. I25;
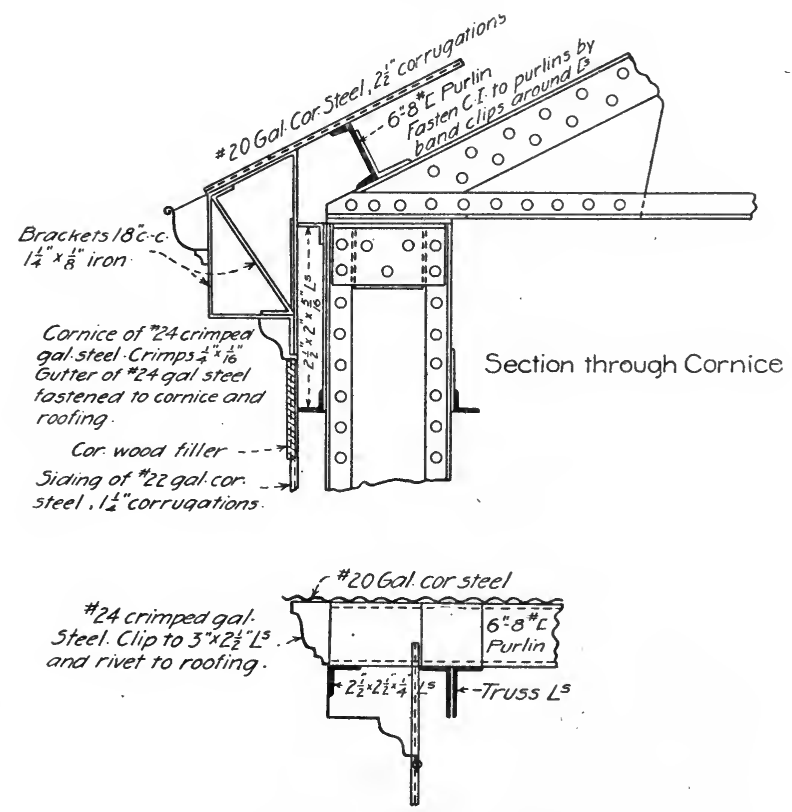

Section through Gable

FIG. I26. 
In Fig. I25, an eave purlin is used and a channel is placed along the ends of the purlins. Spiking strips should always be used as shown, and the eave purlin should be fastened to the rafter by means of angle clips.

The finish shown in Fig. 126, was used by the U. S. Government and needs no explanation.

Anti-condensation Roofing.- To prevent the condensation of moisture on the inner surface of a steel roof, and the resulting dripping, the anti-condensation roofing shown in Fig. I27 and in Fig. I29 is frequently used. The usual method of constructing this roofing is as follows: Galvanized wire poultry netting is fastened to one eave purlin

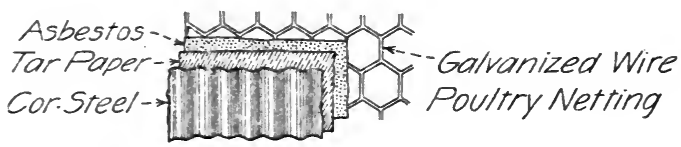

\section{Anti-Condensation Roofing}

FIG. I27.

and is passed over the ridge, stretched tight and fastened to the other eave purlin. The edges of the wire are woven together, and the netting is fastened to the spiking strips, where used, by means of small staples. On the netting are laid one or two layers of asbestos paper I-I6-inch thick, and sometinies one or two layers of tar paper. The corrugated steel is then fastened to the purlins in the usual way. Stove bolts, 3 -I $6^{\prime \prime}$ diameter, with $\mathrm{I} \times \mathrm{I} / 8 \times 4$-inch plate washers on lower sice, are used for fastening the side laps together and for supporting the lining (see Fig. I29). The author would recommend that purlins be spaced one-half the usual distance where anti-condensation lining is used; the stove bolts could then be omitted. Asbestos paper I-I6inch thick comes in rolls, and weighs about 32 pounds per square of roo square feet. Galvanized poultry netting comes in rolls 60 inches wide and weighs about Io pounds per square.

The corrugated steel used with anti-condensation roofing should never be less than No. 22, and the purlins should be spaced for not leșs 


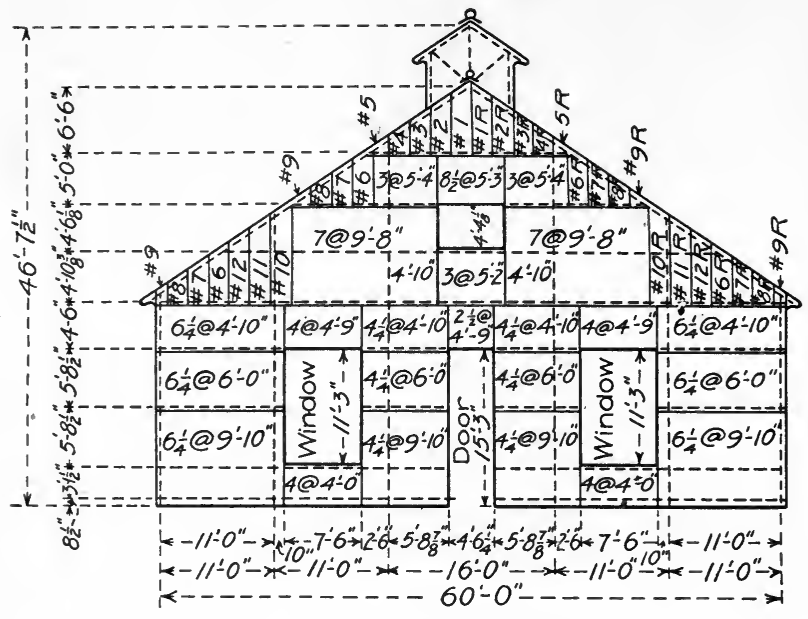

End Elevation

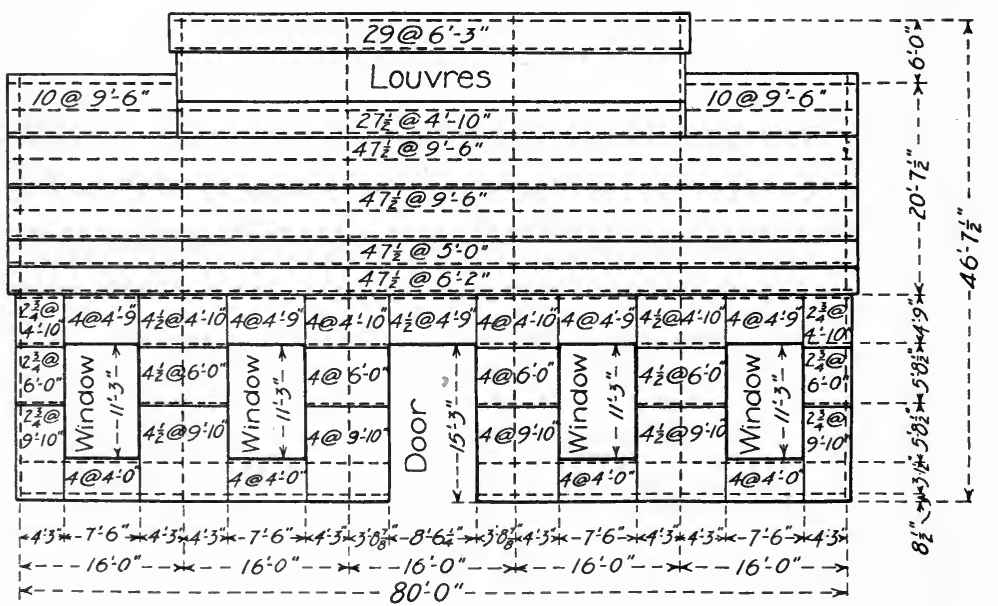

\section{Side Elevation}

FIG. I28. CORRUGATED STEEL PLANS FOR A TRANSFORMER BUILDING. 


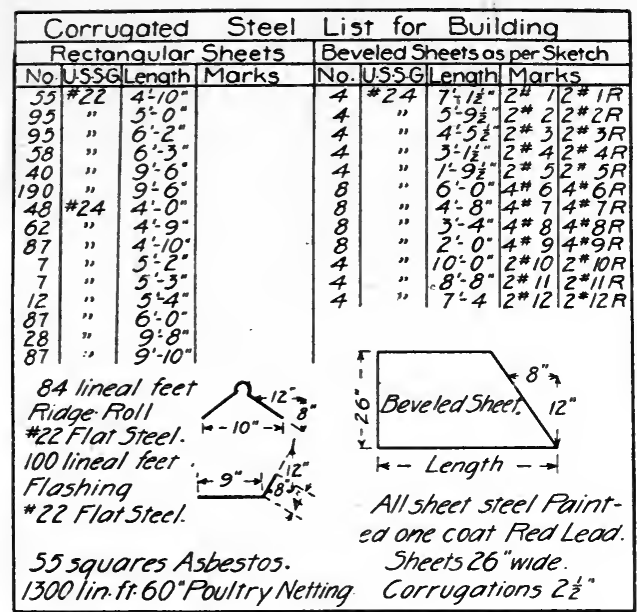

Corrugated Steel on Sides, No.24 Black. Fainted, 1 Corrugation Side lap and 4 "End lap.

Corrugated Steel on Foot; No.22 Black, Painted, 2 Corrugations Side lap and 6 "End lap

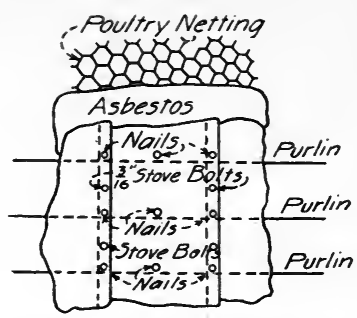

Method of Fastening Steel and Lining on Roof

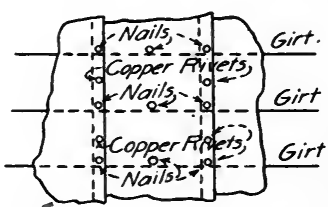

Method of Fastening Steel on the Sides

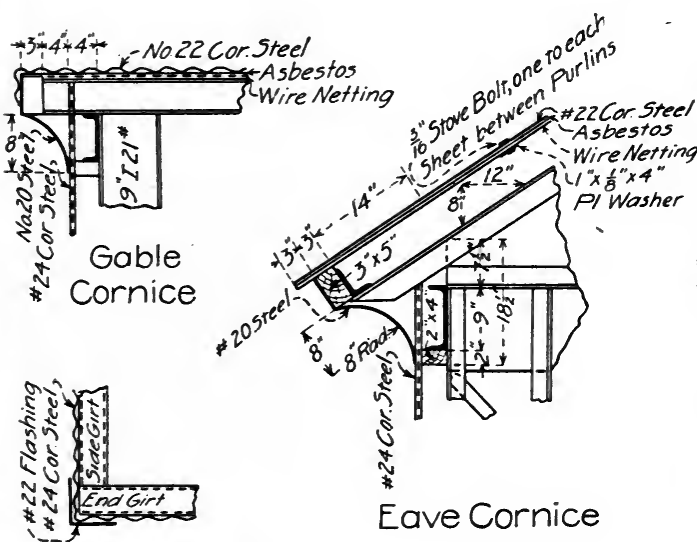

Finish at Corner

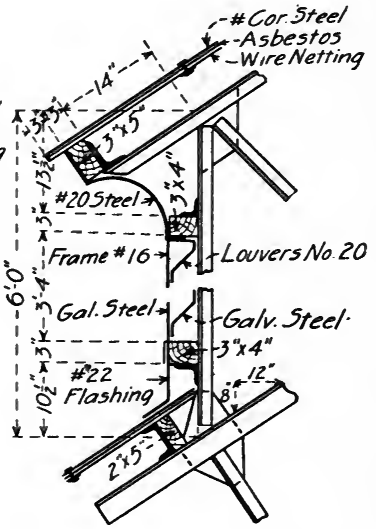

Detail of Louvres

Fig. I29. CORRUGATED STEEL LIST AND DETAILS FOR TRANSFORMER BUILDING. 
than 30 pounds per square foot. A less substantial roof will not usually be satisfactory.

An engine house with anti-condensation lining on the roof and sides has been in use in the Lake Superior copper country for several yèars, and has been altogether satisfactory under trying conditions. The covering and lining of roof and sides are fastened by clinch nails to angle purlins and girts spaced about two feet apart.

A transformer building designed by the author and built by the Gillelle-Herzog Mfg. Co., at Eàst Helena, Montana, has anti-condensation lining on the roof as shown in Fig. I29, and is lined on the sides with one layer of asbestos paper, and I I/4-inch No. 26 corrugated steel. The black framework, the red side lining, and white roof lining made a very pleasing interior. This building after several years is giving entire satisfaction.

Corrugated Steel Plans.-The shop plans, list of steel and details of the corrugated steel for a mill building are shown in Fig. I28 and Fig. I29 (for the general plans and a detailed estimate of this building see Chapter XXVIII). Corrugated steel sheets shouid be ordered to cover two purlins or girts if possible. Bevel sheets should be ordered by number, and sheets should be split and reentrant cuts should be made in the field. All sheets should be plainly marked with the number or length. Sheets No. 22 or lighter can be bent in the field, heavier metal should always be bent at the mill. In preliminary estimates of corrugated steel allow 25 per cent for laps where two corrugations side lap and 6 inches end lap are required, and $5_{5}$ per cent for laps where one corrugation side lap and 4 inches end lap are required.

Cost of Corrugated Steel.-Galvanized steel in 1903 is quoted at about 75 per cent off the standard list, f. o. b. Pittsburg; list price of flat galvanized steel being as follows:

No. Io to 16 inclusive $\ldots \ldots \ldots \ldots \ldots$ I2c. per Ib.

No. I7 to $2 \mathrm{I}$ inclusive ............ I3c. " "

No. 23 to 24 inclusive ..............4c. " "

No. 25 to 26 inclusive ........... 5 c. " "

No. $27 \ldots \ldots \ldots \ldots \ldots \ldots \ldots \ldots \ldots$........... " " 
The net cost of corrugated galvanized steel is found by adding $.05 \mathrm{c}$. per pound to the net cost of flat galvanized sheets.

The standard card of extras used in 1903 is given below. These extras are to be added to the net price of flat black or galvanized sheets to obtain the cost. These extras are not subject to discount.

CARD OF EXTRAS FOR BLACK OR GALVANIZED SHEETS.

For corrugating $\ldots \ldots \ldots \ldots \ldots \ldots \ldots . .05 \mathrm{c}$. per $1 \mathrm{~b}$.

For painting with red oxide ........... 10c. " "

For painting with Dixon's graphite........20c. " “

For painting with Goheen's carbonizing coating .30c. " “

For all trimmings, etc., flashings, ridge caps, and louvres ..................... “ "

For flat sheets rolled from reworked muck bar .50c. " “

For sheets rolled from iron scrap mixture... .25c. " "

For arches ..................25 " "

Plack corrugated steel in IgO3 is quoted about as follows, f. o. b. Pittsburg:

No. I6 to 18 inclusive $\ldots \ldots \ldots \ldots 2.2 \mathrm{c}$. per $1 \mathrm{~b}$.

No. 20 to 22 inclusive ..........2.6c. " "

No. 24 to 26 inclusive ..........7c. " " 


\section{CHAPTER NIX.}

\section{Roof Coverings.}

Introduction.-Mill buildings are covered with corrugated steel supported directly on the purlins; by slate or tile supported by subpurlins; or by corrugated steel, slate, tile, shingles, gravel or other composition roof, or some one of the various patented roofings supported on sheathing. The sheathing is commonly made of a single thickness of planks, I to 3 inches thick. The planks are sometimes laid in two thicknesses with a layer of lime mortar between the layers as a protection against fire. In fireproof buildings the sheathing is commonly made of reinforced concrete constructed as described in Chapter XX. Concrete slabs are sometimes used for a roof covering, being in that case supported directly by the purlins, and sometimes as a sheathing for a slate or tile roof.

The roofs of smelters, foundries, steel mills, mine structures and similar structures are commonly covered with corrugated steel. Where the buildings are to be heated or where a more substantial roof covering is desired slate, tile, tin or a good grade of composition roofing is used, or the roof is made of reinforced concrete. For very cheap and for temporary roofs a cheap composition roofing is commonly used. The following coverings will be described in the order given; corrugated steel, slate, tile, tin, sheet steel, gravel, slag, asphalt, shingle, and also the patent roofings ; asbestos, Carey's, Granite, Ruberoid and Ferroinclave. The construction of reinforced concrete roofing is described in Chapter XX.

Corrugated Steel Roofing.-Corrugated steel roofing is laid on plank sheathing or is supported directly on the purlins as described in Chapter XVIII. For the cost of erecting corrugated steel roofing see Chapter XXVIII. 
Corrugated steel roofing should be kept well painted with a good paint. Where the roofing is exposed to the action of corrosive gases as in the roof of a smelter reducing sulphur ores, ordinary red lead or iron oxide paint is practically worthless as a protective coating; better results being obtained with graphite and asphalt paints. Graphite paint has been quite extensively used for painting corrugated steel in the Butte, Mont., district. The corrosion of corrugated steel is sometimes very rapid. In I 898 the author saw at the Trail Smelter, Trail, B. C., a corrugated steel roof made of No. 22 corrugated steel and painted with oxide of iron paint that had corroded so badly in one year that one could stick his finger through it as easily as through brown paper. The climate in that locality is moist and the smelter was used for reducing sulphur ores. Galvanized corrugated steel is quite extensively used in the Lake Superior district.

Slate Roofing.-There are many varieties of roofing slate; among which the Brownville and Monson slates of Maine, and the Bangor and Peach Bottom slates of Pennsylvania are well known and are of
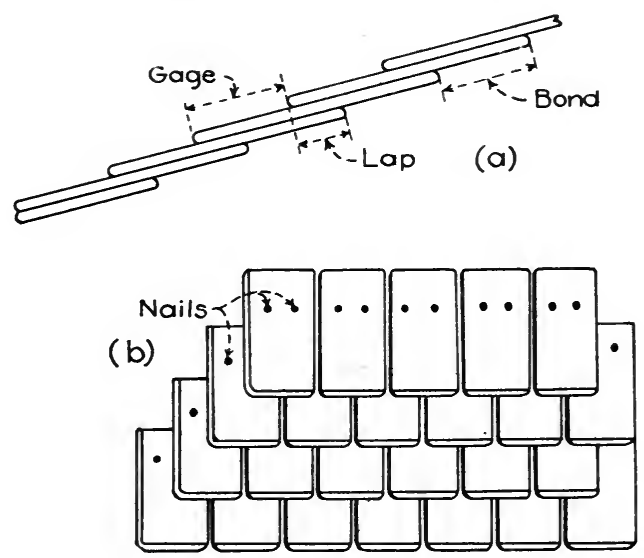

FIG. I3O.

excellent quality. Besides the characteristic slaty color, green, purple, red and variegated roofing slates may be obtained. The best quality of slate has a glistening semi-metallic appearance. Slate with a dull 
earthy appearance will absorb water and is liable to be destroyed by the frost.

Roofing slates are ustually made from $1 / 8$ to $1 / 4$ inches thick; $3^{-16-}$ inch being a very common thickness. Slates vary in size from $6^{\prime \prime} \times 12^{\prime \prime}$ to $24^{\prime \prime} \times 44^{\prime \prime}$; the sizes varying from $6^{\prime \prime} \times 12^{\prime \prime}$ to $12^{\prime \prime} \times 18^{\prime \prime}$ being the most common.

Slates are laid like shingles as shown in Fig. I30. The lap most commonly used is 3 inches; where less than the minimum pitch of $1 / 4$ is used the lap should be increased.

The number of slates of different sizes required for one square of IOO square feet of roof for a 3 -inch lap are given in Table XIX.

The weight of slates of the various lengths and thicknesses required for one square of roofing, using a 3 -inch lap is given in Table XX. The weight of slate is about 174 pounds per cubic foot.

The weight of slate per supericial square foot fo: different thicknesses is given in Table XXI.

The minimum pitch recommended for a slate roof is $1 / 4$; but even with steeper slopes the rain and snow may be driven under the edges of the slates by the wind. This can be prevented by laying the slates in slater's cement. Cemented joints should always be used around eaves, ridges and chimneys.

Slates are commonly laid on plank sheathing. The sheatining should be strong enough to prevent deflections that will break the slate, and should be tongued and grooved, or shiplapped, and dressed on the upper surface. Concrete sheathing reinforced with wire lath or expanded metal is now being used quite extensively for slate and tile roofs, and makes a fireproof roof. Tar roofing felt laid between the slates and the sheathing assists materially in making the roof waterproof, and prevents breakage when the roof is walked on. The use of rubbersoled shoes by the workmen will materially reduce the breakage caused by walking on the roof. Roofing slates may also be supported directly on lath's or sub-purlins. The details of this method are practically the same as for tile roofing, which see. 
TABLE XIX.

NUMBER OF ROOFING SLATES REQURED TO LAY ONE SQUARE OF ROOF WITTH 3-INCH LAP.

\begin{tabular}{|c|c|c|c|c|c|}
\hline $\begin{array}{l}\text { Size in } \\
\text { Inches. }\end{array}$ & $\begin{array}{l}\text { No. of } \\
\text { Slate in } \\
\text { Square. }\end{array}$ & $\begin{array}{l}\text { Size in } \\
\text { Inches. }\end{array}$ & $\begin{array}{l}\text { No of } \\
\text { Slate in } \\
\text { Square. }\end{array}$ & $\begin{array}{l}\text { Size in } \\
\text { Inches. }\end{array}$ & $\begin{array}{l}\text { No. of } \\
\text { Slate in } \\
\text { Square. }\end{array}$ \\
\hline $\begin{array}{ll}6 \times 12 \\
7 & 12 \\
8 & 12 \\
9 & 12\end{array}$ & $\begin{array}{l}533 \\
457 \\
400 \\
355\end{array}$ & $\begin{array}{rr}8 \times 16 \\
9 & 16 \\
10 & 16 \\
12 & 16\end{array}$ & $\begin{array}{r}277 \\
246 \\
221 \\
-\quad 184\end{array}$ & $\begin{array}{ll}12 \times 20 \\
14 & 20 \\
11 & 22 \\
12 & 22\end{array}$ & $\begin{array}{l}141 \\
121 \\
137 \\
126\end{array}$ \\
\hline $\begin{array}{rr}10 & 12 \\
12 & 12 \\
7 & 14 \\
8 & 14\end{array}$ & $\begin{array}{l}320 \\
266 \\
374 \\
327\end{array}$ & $\begin{array}{rr}9 & 18 \\
10 & 18 \\
11 & 18 \\
12 & 18\end{array}$ & $\begin{array}{l}213 \\
192 \\
174 \\
160\end{array}$ & $\begin{array}{ll}14 & 22 \\
12 & 24 \\
14 & 24 \\
16 & 24 .\end{array}$ & $\begin{array}{r}108 \\
114 \\
98 \\
86\end{array}$ \\
\hline $\begin{array}{cc}9 & 14 \\
10 & 14 \\
19 & 14\end{array}$ & $\begin{array}{l}291 \\
261 \\
218\end{array}$ & $\begin{array}{ll}14 & 18 \\
10 & 20 \\
11 & 20\end{array}$ & $\begin{array}{l}137 \\
169 \\
154\end{array}$ & $\begin{array}{ll}14 & 26 \\
16 & 26\end{array}$ & $\begin{array}{l}89 \\
78\end{array}$ \\
\hline
\end{tabular}

TABLE XX.

THE WEIGHT OF SLATE REQUIRED FOR ONE SQUARE OF ROOF.

\begin{tabular}{|c|c|c|c|c|c|c|c|c|}
\hline \multirow{2}{*}{$\begin{array}{l}\text { Length } \\
\text { in } \\
\text { Inches. }\end{array}$} & \multicolumn{8}{|c|}{ Weight in pounds, per square, for the thickness. } \\
\hline & $1 / 8 "$ & ${ }_{16}^{3} "$ & $1 / 4 "$ & $3 / 8 "$ & $1 / 2 "$ & $5 / 8 "$ & $3 / 4 "$ & $1^{\prime \prime}$ \\
\hline $\begin{array}{l}12 \\
14 \\
16 \\
18\end{array}$ & $\begin{array}{l}483 \\
460 \\
445 \\
434\end{array}$ & $\begin{array}{l}724 \\
688 \\
667 \\
650\end{array}$ & $\begin{array}{l}967 \\
920 \\
890 \\
869\end{array}$ & $\begin{array}{l}1450 \\
1370 \\
1336 \\
1303\end{array}$ & $\begin{array}{l}1936 \\
1842 \\
1784 \\
1740\end{array}$ & $\begin{array}{l}2419 \\
2301 \\
2229 \\
2174\end{array}$ & $\begin{array}{l}2902 \\
2760 \\
2670 \\
2607\end{array}$ & $\begin{array}{l}3872 \\
3683 \\
3567 \\
3480\end{array}$ \\
\hline $\begin{array}{l}20 \\
22 \\
24 \\
26\end{array}$ & $\begin{array}{l}425 \\
418 \\
412 \\
407\end{array}$ & $\begin{array}{l}637 \\
626 \\
617 \\
610\end{array}$ & $\begin{array}{l}851 \\
836 \\
825 \\
815\end{array}$ & $\begin{array}{l}1276 \\
1254 \\
1238 \\
1222\end{array}$ & $\begin{array}{l}1704 \\
1675 \\
16 \mathrm{a} 3 \\
1631\end{array}$ & $\begin{array}{l}2129 \\
2093 \\
2066 \\
2039\end{array}$ & $\begin{array}{l}2553 \\
2508 \\
2478 \\
2445\end{array}$ & $\begin{array}{l}3408 \\
3350 \\
3306 \\
3263\end{array}$ \\
\hline
\end{tabular}

TABLE XXI.

WEIGHT OF SLATE PER SQUARE FOOT.

\begin{tabular}{l|c|c|c|c|c|c|c|c}
\hline Thickness-in. . ........ & $1 / 8$ & $\overline{1}^{3} 6^{-}$ & $1 / 4$ & $3 / 8$ & $1 / 2$ & $5 / 8$ & $3 / 4$ & 1 \\
Weight-lbs............. & 1.81 & 2.71 & 3.62 & 5.43 & 7.25 & 9.06 & 10.87 & 14.5 \\
\hline
\end{tabular}


When roofing slates are laid on sheathing they are fastened by two nails, one in each upper corner. When supported directly on subpurlins the slates are fastened by copper or composition wire. Galvanized and tinned steel nails, copper, composition and zinc slate roofing nails are used. Where the roof is to be exposed to corrosive gases copper, composition or zinc nails should be used.

Slate roofs when made from first class slates well laid have been known to last 50 years. When poorly put on or when an inferior quality of slate is used slate roofs are comparatively short-lived. Slates are easily broken by walking over the roof and are sometimes broken by hailstones. Slate roofing is fireproof as far as sparks are concerned, but the slates will crack and disintegrate when exposed to heat. Local conditions have much to do with the life of slate roofs; an ordinary life being from 25 to 30 years.

First class slate $3-16$ to $1 / 4$ inches thick may ordinarily be obtained f. o. b. at the quarry for from $\$ 5.00$ to $\$ 7.00$ per square; common slate for from $\$ 2.00$ to $\$ 4.00$ per square; while extra fine slate may cost from $\$ 10.00$ to $\$ 12.00$ per square.

An experienced róofer can lay from $\mathrm{I} / 2$ to 2 squares of slate in a day of Io hours. In 1903 slater's supplies were quoted as follows: Galvanized iron nails, $2 \frac{\mathrm{T}}{2}$ to 3 cents per $1 \mathrm{~b}$. ; copper nails, 20 cents per li.); zinc nails, Io cents per 1b.; slater's felt, 70 to 75 cents per roll of 500 square feet; two-ply tar roofing felt, 75 cents per square; slater's cement in Io-lb. kegs, I a cents per $1 \mathrm{~b}$.

Trautwine gives the cost of slate roofs as $\$ 7.00$ per square and upwards. The costs of slate, roofs per square is given in the reports of the Association of Railway Superintendents of Bridges and Buildings, as follows: New England, \$9.00 to \$12.00; New York, \$9.00 to \$Io.00; Virginia $\$ 4$. Io to $\$ 5.00$; California, \$Io.00 to $\$ 10.50$.

Tile Roofing.-Baked clay or terra-cotta roofing tiles are made in many forms and sizes. Plain roofing tiles are usually $10 \mathrm{~T} / 2$ inches long, $6 \frac{1}{4}$ inches wide and $5 / 8$ inches thick; weigh from 2 to $2 \frac{1}{2}$ pounds each and lay one-half to the weather. There are many other forms of 
tile among which book tile, Spanish tile, pan tile and Lüdowici tile are well known. Tiles are also madé of glass and are used in the place of skylights.

Tiles may be laid (I) on plank sheathing, (2) on concrete and expanded metal or wire lath sheathing, or (3) may be supported directly on angle sub-purlins as shown in Fig. 87. Tiles are laid on sheathing in the same manner as slates.

The roof shown in Fig. 87 was constructed as follows: 'Terracotta tiles, manufactured by the Ludowici Roofing Tile Co., Chicago, Ill., were laid directly on the angle sub-purlins, every fourth tile being secured to the angle sub-purlins by a piece of copper wire. The tiles were interlocking, requiring no cement except in exceptional cases. The tiles were $9 \times 16$ inches in size; 135 being sufficient to lay a square of 100 square feet of roof. These tiles weigh from 750 to 800 Ibs. per square, and cost about $\$ 6.00$ per square at the factory. Skylights in this roof were made by substituting glass tiles for the terra-cotta tiles. This and similar tile has been used in this manner on a large number of mills and train sheds with excellent results.

Tile roofs laid without sheathing do not ordinarily condense the steam on the inner surface of the roof unless the tiles are glazed, although several cases have been brought to the author's attention where the condensation has caused trouble with tile roofs made of porous tiles. Anti-condensation roof lining should be used where there is danger of excessive sweating, or a porous tile should be used that is known to be non-sweating. The cost of tile roofing varies so much that general costs are practically worthless. The reports of the Association of Railway Superintendents of Bridges and Buildings give the cost in New England as from $\$ 30.00$ to $\$ 33.00$ per square.

Tin Roofs.-Tin plates are made by coating flat iron or steel sheets with tin, or with a mixture of lead and tin. The former is called "bright" tin plate and the latter "terne" plate. Terne plates should not be used where the roof will be subjected to the action of corrosive gases for the reason that the lead coating is rapidly destroyed. Plates are 
covered with tin. (I) by the dipping process in which the plates are pickled in dilute sulphuric acid, annealed, again pickled, dipped in palm oil and then in a bath of molten tin or tin and lead; or (2) by the roller process in which the plates are run through rolls working in a large vessel containing oil, immediately after being dipfred. The latter method gives the better results.

Two sizes of tin plates are in common use, $14^{\prime \prime} \times 20^{\prime \prime}$ and $20^{\prime \prime} \times$ $28^{\prime \prime}$, the latter size being most used. Tin sheets are made in several thicknesses, the IC, or No. 29 gage weighing 8 ounces to the square foot, and the IX, or No. 27 gage weighing Io ounces to the square foot, being the most used. The standard weight of a box of I I 2 sheets, I $4 \times$ 20 size is 108 pounds for IC plate, and 136 pounds for IX plate. Boxes containing imperfect sheets or "wasters" are marked ICW or ICX. Every sheet should be stamped with the name of the brand and the thickness.

The value of tin roofing depends upon the amount of tin used in coating and the uniformity with which the iron has been coated. The amount of tin used varies from 8 to 47 pounds for a box of $20 \times 28$ size containing I I2 sheets.

Tin roofing is laid (I) with a flat seam, or (2) with a standing seam. In the former method the sheets of tin are locked into each other at the edges, the seam is flattened and fastened with tin cleats or is nailed firmly and is soldered water tight. Rosin is the best flux for soldering, although some tinners recommend the use of diluted chloride of zinc. For flat roofs the tin should be locked and soldered at all joints, and should be secured by tin cleats and not by nails. For steep roofs the tin is commonly put on with standing seams, not soldered, running with the pitch of the roof, and with cross-seams double locked and soldered. One or two layers of tar paper should be placed betwen the sheathing and the tin.

In painting tin all traces of grease and rosin should be removed, benzine or gasoline being excellent for this purpose. A paint composed of Io pounds venetian red and one pound red lead to one gallon of 
pure linseed oil is recommended. The under side of the sheets should be painted before laying. Tin roofs should be painted every two or three years. If kept well painted a tin roof should last 25 to 30 years.

For flat seam roofing, using $1 / 2$-inch locks, a box of $14 \times 20$ tin will cover 192 square feet, and for standing seam, using $3 / 8$-inch locks and turning $\mathrm{I} I / 4$ and $\mathrm{I} / 2$-inch edges, making $\mathrm{I}$-inch standing seams, it will lay 168 square feet. For flat seam roofing, using $1 / 2$-inch locks, a box of $20 \times 28$ tin will lay about 399 square feet, and for standing seam, using $3 / 8$-inch locks and turning $1 / 4$ and $1 / 2$-inch edges, making I-inch standing seams, it will lay about 365 square feet.

Current prices in 1903 for tin in small quantities were about as follows :

American Charcoal Plates:

IC, $14 \times 20 \ldots \ldots . \$ 5.50$ to $\$ 6.50$ per box of 112 sheets;

IX, $14 \times 20 \ldots \ldots \ldots \$ 6.60$ to $\$ 8.25$ per box of II 2 sheets.

American Coke Plates, Bessemer :

IC, $14 \times 20 \ldots \ldots \ldots \$ 4.70$ to $\$ 4.80$ per box of 112 sheets;

IX, $14 \times 20 \ldots \ldots \ldots \$ 6.60$ to $\$ 8.25$ per box of I 12 sheets.

American Terne Plates:

IC, $20 \times 28 \ldots \ldots . \$ 9.50$;

IX, $20 \times 28 \ldots \ldots . \$$ II. 50 .

Two good workmen can put on and paint from $2^{1 / 2}$ to 3 squares of tin roofing in 8 hours. Tin roofs cost from $\$ 7.00$ to $\$ 11.00$ or $\$ 12.00$ per square depending upon the specifications and the cost of labor.

Sheet Steel Roofing.-Sheet steel roofing is sold in sheets 28 inches wide and from 4 to 12 feet long, or in rolls 26 inches wide and about 50 feet long. It is commonly laid with vertical standing seams and horizontal flat seams; tin cleats from 12 to 15 inches apart being nailed to the plank sheathing and locked into the seams. Sheet steel plates are also made with standing crimped seams near the edges, which are nailed to $\mathrm{V}$-shaped sticks; the horizontal seams being made by lapping about 6 inches. 
Care should be used in laying sheet steel roofing to see that it does not come in contact with materials containing acids, and it should be kept well painted. The weight of flat steel of different gages is given in Table XV. Nos. 26 and 28 gage sheets are commonly used for sheet steel roofing. No. 26 black sheet steel was quoted in 1903 at about $\$ 3.20$ per Ioo pounds, and No. 26 galvanized sheet steel at about $\$ 4.00$ per 100 pounds in small lots. Sheet steel roofing can be laid at a somewhat less cost than tin roofing.

Gravel Roofing.-Gravel roofing is made by laying and firmly nailing several layers of roofing felt on sheathing so as to break joints from 9 to 12 inches; the laps are mopped and cemented together with roofing cement or tar, and finally the entire surface is covered with a good coating of hot cement or tar. The cement or tar should not be hot enough to injure the fibre of the felt. While the cement or tar is still hot the surface of the roof is covered with a layer of clean gravel that has been screened through a $5 / 8$-inch mesh. It requires from 8 to Io gallons of tar or cement and about $1 / 6$ of a yard of gravel per square of Ioo square feet of roof. When the roof is to be subjected to the action of corrosive gases it should be flashed with copper or composition, or the flashing may be made of felt. The number of layers of felt varies with the conditions, but should never be less than four (4-ply).

The details of laying gravel roofs differ and it is impossible to do more than give a few standard specifications. The foliowing specifications are about standard in the West. In writing specifications for four-ply gravel roofing omit one layer of roofing felt in the specifications for five-ply gravel roofing. Three-ply roofing is sometimes used for temporary structures.

Five (5) Ply Wool Felt, Composition and Gravel Roof.-First cover the sheathing boards with one (I) layer of dry felt and over this put four (4) thicknesses of wool roofing felt, weighing not less than fifteen ( $5_{5}$ ) pounds (single thickness) to the square of one hundred (IOO) feet. This felt to be smoothly and evenly laid and well cemented together the full width of the lap, not less than nine (9) inches between each layer, with best roofing cement or refined tar, using not less than 
one hundred (IOO) pounds of roofing cement or tar to the square of one hundred (IOO) feet. All joinings along walls and around openings to be carefully made. The roof to be then covered with a heavy coating of roofing cement or tar and screened gravel, not less than one (I) cubic yard of gravel to six hundred (600) square feet, gravel to be screened through 5/8-inch mesh and free from sand and loam. All walls and openings to be flashed. All roofing cement and tar is to be applied hot.

Six (6) Ply Cap Sheet Wool Felt, Composition and Gravel Roof. -First cover the sheathing boards with one (I) layer of dry felt and over this put four (4) thicknesses of wool roofing felt, weighing not less than fifteen ( 15 ) pounds (single thickness) to the square of one hundred (IOO) feet. This felt to be smoothly and evenly laid and well cemented together the full width of the lap, not less than nine (9) inches between each layer, with best roofing cement or refined tar, using not less than one hundred and twenty (120) pounds of roofing cement or tar to the square of one hundred (IOO) feet.. The entire surface then to be mopped over with roofing cement or tar and a cap sheet of wool felt applied. All joinings along the walls and around the openings to be carefully made. The roof to be then covered with a heavy coating of roofing cement or tar and screened gravel, not less than one (I) cubic yard of gravel to six hundred (600) square feet, gravel to be screened through $5 / 8$-inch mesh and free from sand and loam. All walls and openings to be flashed. All roofing cement and tar shall be applied hot.

Si.x (6) Ply Combined Flax and Wool Felt, Composition and Gravel Roof.-First cover the sheathing boards with one (I) layer of dry felt and over this put one (I) layer of flax felt and three thicknesses of wool roofing felt, weighing not less than fifteen ( I $_{5}$ ) pounds (single thickness) to the square of one hundred (IOO) feet. This felt to be smoothly and evenly laid and well cemented together the full width cf the lap, not less than eleven (I I) inches between each layer, with best roofing cement or refined tar, using not less than one hundred and twenty (120) pounds of roofing cement or tar to the square of one hundred (IOO) feet. The entire surface then to be mopped over with roofing cement or tar and a cap sheet of wool felt applied. All joinings along walls and around openings to be carefully made. The roof to be then covered with a heavy coating of roofing cement or tar and screened gravel, not less than one (I) cubic yard of gravel to six hundred (600) square feet, gravel to be screened through $5 / 8$-inch mesh and 
free from sand and loam. All walls and openings to be flashed. All roofing cement and tar shall be applied hot.

In Building Construction and Superintendence, Part II, Kidder gives the following specifications for flashing a gravel roof:

"Flashing.-Finish the roofing against fire walls, chimneys, scuttle and skylight by turning the felt up 4 inches against the wall. Over this lay an 8-inch strip of felt with half its width on the roof. Fasten the upper edge of the strip and the several layers of felt to the wall by laths or wooden strips securely nailed, and press the strip of felt into the angle of the wall and cement to the roof with hot pitch. Nail the lower edge of the strip to the roof every 4 or 5 inches. Take special care in fitting around chimneys and skylights. Extend the felt up 6 inches on the pitch of the roof, and secure every 4 inches with 3 d nails with tin washers."

The pitch should not be more than $1 / 4$ and should preferably be about $3 / 4$ to $I$ inch to the foot. Gravel is sometimes used on roofs nearly flat.

Gravel roofing under ordinary conditions will last for from to to I 5 years. With careful attention it can be made to last longer and has been known to last 30 years.

The cost of gravel roofing varies with local conditions and specifications. In various reports of the Association of Railway Superintendents of Bridges and Buildings costs of gravel roofs, not including the sheathing, per square are given as follows: Three-ply gravel roof in California, costs $\$ 3.75$; four-ply (4) gravel roof in Kansas, costs $\$ 3.00$; is Chicago, costs from $\$ 3.00$ to $\$ 4.00$; and in New England, costs from $\$ 4.00$ to $\$ 5.00$. The cost varies greatly with the specifications.

Prepared Gravel Roofing.-Prepared gravel roofings may be bought in the market. Prepared gravel roofing manufactured by the Armitage Manufacturing Company, Richmond, Va., was quoted at $\$ 2.50$ per roll of Io8 square feet and including nails and cement, delivered in central Illinois. This company has discontinued the manufacture of prepared slag roofing.

Slag Roofing.--Slag is sometimes used in the place of gravel in making roofs. The method of constructing the roof and the specifica- 
tions are essentially the same as for a gravel roof. For detailed specifications for laying slag roofing see description of the Locomotive Erectng and Machine Shop, Philadelphia \& Reading R. R., given in Part IV.

Asphalt Roofing.-Asphalt roofing is laid like tar and gravel roofing except that asphalt is used in the place of tar or cement. For discussion of the composition and properties of asphalt see Baker's Roads and Pavements, Chapter XIII. The following specifications will give a good roof :

Five (5) Ply Wool Felt, Trinidad Asphalt and Gravel Roof.-First cover the sheathing boards with one (I) thickness of dry felt, and over this put four (4) thicknesses of No. I wool roofing felt, weighing not less than fifteen (I5) pounds (single thickness) to the square of one hundred (IOO) square feet. The felt to be smoothly and evening laid, and well cemented together the full width of the lap, rot less than nine (9) inches between each layer, with Trinidad asphalt roofing cement, using not less than one hundred (IOO) pounds of asphalt to one square of one hundred (IOO) square feet. All joinings along the wall and around openings to be carefully made. The roof is then to be covered with a coating of asphalt and screened gravel, not less than one (I) cubic yard of gravel to six hundred (600) square feet of roof, gravel to be screened through a $5 / 8$-inch mesh and to be free from loam. All walls to be flashed with old style tin or galvanized iron, or a $2 \times 4$ is to be built into the walls to make roof connections to.

Five (5) Ply Combined Flax and Wool Felt, Trinidad Asphalt and Gravel Roof.-First cover the sheathing boards with one thickness of dry felt, over this put one (I) thickness of flax felt and three (3) thicknesses of No. I wool roofing felt, weighing not less than fifteen (I5) pounds (single thickness) to the square of one hundred (IOO) square feet. The felt to be smoothly and evenly laid, and well cemented together the full width of the lap, not less than eleven (II) inches between each layer, with Trinidad asphalt roofing cement, using not less than one hundred (IOO) pounds of asphalt to the square of one hundred (IOO) square feet. All joinings along the walls and around openings to be carefully made. The roof is then to be covered with a coating of Trinidad asphalt roofing cement and screened gravel, not less than one (I) cubic yard of gravel to six hundred (600) square feet 
of roof, gravel to be screened through a $5 / 8$-inch mesh and to be free from loam. All walls to be flashed with old style tin or galvanized iron, or a $2 \times 4$ is to be built into the wall to make connections to.

Prepared asphalt roofing can be bought in the market. It is sold in rolls 36 inches wide and is laid in courses.

The Arrow Brand Ready Asphalt Roofing, manufactured by the Asphalt Ready Roofing Company, New York, was quoted in 1903 delivered in central Illinois as follows: Arrow Brand No. I, sand surfaced, per roll $\$ 2.75$; rolls contain I Io square feet which will cover Ioo square feet of roof and weigh 80 pounds. Arrow Brand No. 2, gravel surfaced, per roll $\$ 2.75$; rolls contain I Io square feet which will cover IOO square feet of roof and weigh 140 pounds. The necessary nails and asphalt required in laying the roofing are included in the above prices. This roofing is in use by a number of railways.

Shingle Roofs.- Shingle roofs are now very seldom used for mill buildings. Shingles have an average width of 4 inches and with 4 inches laid to the weather 900 are required to lay one square of roof. One thousand shingles require about $5 \mathrm{lbs}$. of nails. One man can lay from $\mathrm{r} 500$ to 2000 shingles in a day of 8 hours. The cost of shingle roofs varies with the locality from, say, $\$ 3.25$ to $\$ 6.25$ per square.

Asbestos Roofing.-The "Standard" Asbestos Roofing, manufactured by the H. W. Johns-Manville Co., New York, is composed of a strong canvas foundation with asbestos felt on the under side, and satturated asbestos felt on the upper side finished with a sheet of plain asbestos; the whole being cemented together with a special cement and compressed together into a flexible roofing. It does not require painting, although it is commonly painted with a special paint, one gallon of which will cover about I5O square feet. The roofing is laid with a lap of 2 inches, beginning at the lower edge of the roof and running parallel to the eaves. The laps are cemented and are nailed with special roofing nails and caps. The roofing is laid on sheathing and is very easily and cheaply laid. It is quite flexible and may be used for flashing and for gutters. It is practically fireproof and makes a very satisfactory roof. Asbestos roofing comes in rolls and weighs about 75 
pounds per square. It costs about \$3.00 per square laid on the roof.

The above named company makes several other brands of asbestos roofing the cost of which is about the same as the "Standard."

Asbestos roofing felts may be purchased which are used for roofing in one, two or three-ply, and are laid in the same way as for gravel roofing.

Carey's Roofing.-Carey's Magnesia Flexible Cement Roofing, manufactured by the Philip Carey Manufacturing Company, Lockland, Ohio, is made by putting a layer of asphalt cement composition on a foundation of woolen felt and imbedding a strong burlap in the upper surface of the cement. After laying, the burlap is covered with a tough elastic paint which when it dries gives a surface similar to slate. The roof is practically acid proof and burns very slowly. It comes in rolls 29 inches wide and containing sufficient material to lay one square of roof. The roofing is made in two weights, standard weighing 90 pounds per square, and extra heavy weighing about II 5 pounds per square. A special flap is provided on one side to cover the nail heads. The roofing is very pliable and can be used for flashing and for gutters. It should be laid on sheathing and is very easily and cheaply applied. It may be laid over an old shingle or corrugated iron roof. It costs about $\$ 2.75$ to $\$ 3.25$ per square laid on the roof.

Granite Roofing.-Granite Roofing, manufactured by the Eastern Granite Roofing Company, New York, is a ready-to-Iay composition roofing with manufactured quartz pebbles imbedded in its upper surface. It is a very satisfactory roofing and is quite extensively used. It costs about $\$ 2.75$ to $\$ 3.75$ per square laid on the roof.

Ruberoid Roofing.-P. \& B. Ruberoid Roofing, manufactured by the Standard Paint Co., New York, is quite extensivily used and has given good satisfaction. The following description is taken from the maker's catalog: "No paper whatever is used in the manufacture of Ruberoid Roofing. It has a foundation of the best wool felt, except in the case of the $1 / 2$-ply grade which is a combination of wool and hair. This is first saturated with the P. \& B. water and acid proof compound, 
and afterwards coated with a hard solution of the same matcrial, thereby making the roofing at once light in weight as well as strong, durable and elastic. It is thoroughly acid and alkali proof, is not affected by coal gas or smoke and can be laid on either pitched or flat roofs, proving equally effectual in both cases. Inasmuch as it contains no tar or asphalt the roofing is not affected by extremes in temperature."

Ruberoid is made $1 / 2$-ply weighing 22 pounds per square; I-ply weighing 30 pounds per square; 2-ply weighing 43 pounds per square; and 3 -ply weighing $5^{\mathrm{I}}$ pounds per square. The 2-ply and the 3-ply roofing are commonly used for factories and mills. The roofing is put up in rolls 36 inches wide, containing two squares (200 square feet), with an additional allowance of 16 square feet for two-inch laps at the seams; sufficient tacks, tin caps and cement are included with each roll.

Ruberoid roofing costs from $\$ 2.75$ to $\$ 3.75$ per square laid on the roof.

Ferroinclave.-This is a patented roofing made by the Brown Hoisting Machinery Co., Cleveland, Ohio, and is described in a letter to the author as follows: "Ferroinclave roofing is made by coating a special crimped or corrugated iron or steel on both sides with a mixture of Portland cement and sand, after which it is painted on the upper side. The sheets are made of No. 22 or No. 24 sheet steel, and full sized sheets are 20 inches wide and Io feet long. The steel is crimped or corrugated with corrugations about 2 inches wide and $1 / 2$ inch deep, the width of the corrugation on the outer side being less than on the inner side, thus forming a key to hold the cement mortar in place. The sheets are laid in the same manner as corrugated steel, and a coating of Portland cement mortar, composed of I part Portland cement and 2. parts sand, is plastered on the upper and lower surfaces to a thickness of $3 / 8$ of an inch above and below the corrugations, making the total thickness of the roofing $I \frac{I}{4}$ inches. The weight of No. 24 sheet steel Ferroinclave is about I $_{5} \mathrm{lbs}$. per square foot when filled with cement mortar as above. A test of a sheet of Ferroinclave made as above, showed failure with a uniformly distributed load of $300 \mathrm{lbs}$. per square foot with supports $4^{\prime}$ IO" apart, the cement having set ten days. The 
cost of this roofing is about $\$ 21.00$ per square complete in place on the roof." The Brown Hoisting Machinery Co. has also used Ferroinclave quite extensively for floors and side walls of buildings.

Examples of Roofs.-The Boston Manufacturer's Mutual Fire Insurance Co., recommend the following roof for mill buildings: "Roofs of ordinary type may be only of plank covered with composition or other suitable roofing material. In special cases the roof should consist of a 3-inch plank, I inch of mortar, a I-inch top board and a 5-ply composition roof. Such a roof is impervious to heat and cold."

The roof of the machine shop of the Chicago City Railway is composed of $2 \times 6$-in. tongued and grooved sheathing overlaid with 5 layers of "Cincinnati" wool felt, having Ioo pounds of cement to Ioo square feet, and is covered with tar and gravel.

The roof of the Lehigh Valley R. R. Shops at Sayre, Pa., is a slag roofing on armored concrete.

The roof of the Great Northern R. R. shops at St. Paul, Minn., has double sheathing with $\mathrm{I} \times 3$-in. strips between the layers to provide an air pace and prevent sweating. Monarch roofing is laid on the sheathing.

The roof of the Philadelphia \& Reading shops, at Reading, Pa., is felt on plank sheathing covered with tar and slag.

The roof of the A. T. \& S. F. R. R. machine shops at Topeka, Kas., is Ludowici tile laid on $2 \times 2$-in. timber strips.

The roof of the Union Train Shed at Peoria, Ill., is Ludowici tile laid on angle sub-purlins as shown in Fig. 87.

Roof Coverings for Railway Buildings.-The following abstract of the report of the committee on roof coverings presented at the annual meeting of the Association of Railway Superintendents of Bridges and Buildings, 1902, will give a very good idea of the present practice in covering railroad buildings.

"Slate is much used for station buildings where there is not much climbing for repair of skylights or telegraph wires. It has a life of from 35 to 40 years, and the roof should have a pitch of not less than 6 inches per foot. Vitrified tile is very durable where rightly made and laid on steep roofs, but is not adapted for ordinary railroad buildings. Shingle roofs last as long as 28 years, and should be laid with 
6 inches pitch per foot; they are very satisfactory where slate is too expensive. For flat roofs a tar and gravel composition is preferred and will last 12 to 18 , and even 20 years. Slag or broken stone of the size of peas is sometimes used in the place of gravel. In such roofs, much depends upon the paper used, the pitch, and the thoroughness of the work; 3-ply is too light, 4-ply is good, but 5-ply is better. Asphalt pitch is sometimes preferred to coal-tar, but the latter is sufficiently durable. An asphalt-gravel roof must slope not more than $1 / 2$ inch to the foot, on account of the liability to run in hot weather; but tar-gravel roofs may have a pitch of $I$ inch per foot. With such very flat roofs as are required for asphalt, any settlement will form hollows that will hold water.

"Sheet metal roofs, corrugated or flat are not durable. Steel is less durable than iron and will last only about one year, where exposed to engine gases. Tin shingles of good quality give good results. Painted shingles have a short life unless frequently painted.

"Of patented roof coverings, Sparham is pulverized talcose lime rock, mixed with coal-tar pitch and applied hot to the roof with a trowel. This may be used for a flat roof or for a roof with a pitch of 3 or 4 inches per foot. Ruberoid is a wool felt saturated with a parafine preparation. Perfected Granite Roofing is 2-ply tarred paper with sea grit on one side. Both of these last may be used on any roof with a pitch of not less than 2 inches per foot. Cheap roofs made from roofing papers require mopping with tar, and if thus treated every two years (before the paper is bare) will last almost indefinitely. In railway work, however, roofs are generally left without attention until leaks are reported, when it is too late for mopping to do any good.

"Roofs requiring treatment every two years can hardly be considered as permanent. Slate for pitched roofs and tar and gravel for flat roofs are as nearly permanent as can be obtained for railway buildings.

"The cost per square of Ioo square feet for roofs of different kinds in New England is as follows:

Slate ........\$ 9.00 to $\$ \mathrm{I} 2.00$ Tar and gravel... $\$ 4.00$ to $\$ 5.00$ Tile ......... 30.00 to

Shingles

33.00 Sparham ....... 5.00 to

Sawed cedar... 4.50 to

Tinned ...... 5.00 to

Sheet tin, standing

Ruberoid ......2.75 to

3.75

5.00 Prefected Granite.. 2.75 to

3.25

6.50 Paroid .......... 3.00 to 3.50

seam....... 6.50 to 8.00

2-ply double... 2.00 to

2.25

3-ply single .. I.5O to 2.00 " 


\section{CHAPTER XX.}

\section{Side Walis and Concrete, Buildings.}

SIDE WALLS. - The sides of steel frame mill buildings are covered with corrugated steel, expanded metal and plaster, wire lath and plaster, or with Ferroinclave a patent covering made of special corrugated steel and plaster, manufactured by the Brown Hoisting Co., Cleveland, Ohio.

Corrugated Steel.-The methods of fastening corrugated steel to the sides of buildings are the same as on the roof and are described in detail in Chapter XVIII. Where warmth is desired, buildings covered with corrugated steel are often lined with No. 26 corrugated steel with $\mathrm{I} / 4$-inch corrugations. Where this lining is used spiking pieces should be bolted to the girts and intermediate spiking pleces should be placed between the girts to which to nail the lining. If this is not done the corrugated steel will gape open for the reason that it is impossible to rivet the side laps of the lining. Where anti-condensation lining is used on the sides it is made the same as on the roof except that the girts should always be placed not more than one-half the usual distance. The clinch-nail fastening is the best method for fastening the corrugated steel where the anti-condensation lining is used.

Expanded Metal and Plaster.-The methods of making walls of expanded metal and plaster are shown in Fig. I3I and Fig. I32, which show details of the construction of the soap factory buildings of $\mathrm{W} . \mathrm{H}$. Walker, Pittsburg, Pa. These buildings were constructed as follows: The buildings were made with a self-supporting steel frame, all connections except those for the purlins and girts being riveted. Inaccessible surfaces were painted with red lead and linseed oil before erection and the entire framework was painted two coats of graphite paint after 
erection. The trusses are spaced from 14 to 18 feet and carry 6,7 and 8 -inch channel purlins. The purlins are spaced from 6 to 7 feet apart and carry roof slabs $2 \frac{1}{2}$ to 3 inches thick made of expanded metal and concrete. The expanded metal is made from No. I6 B. W. G. steel plate with 4 -inch mesh, and the concrete is composed of I part Portland cement, 2 parts sand and 4 parts screened furnace cinders. The roof slabs are covered with $10 \times$ I2-inch slate nailed directly to the

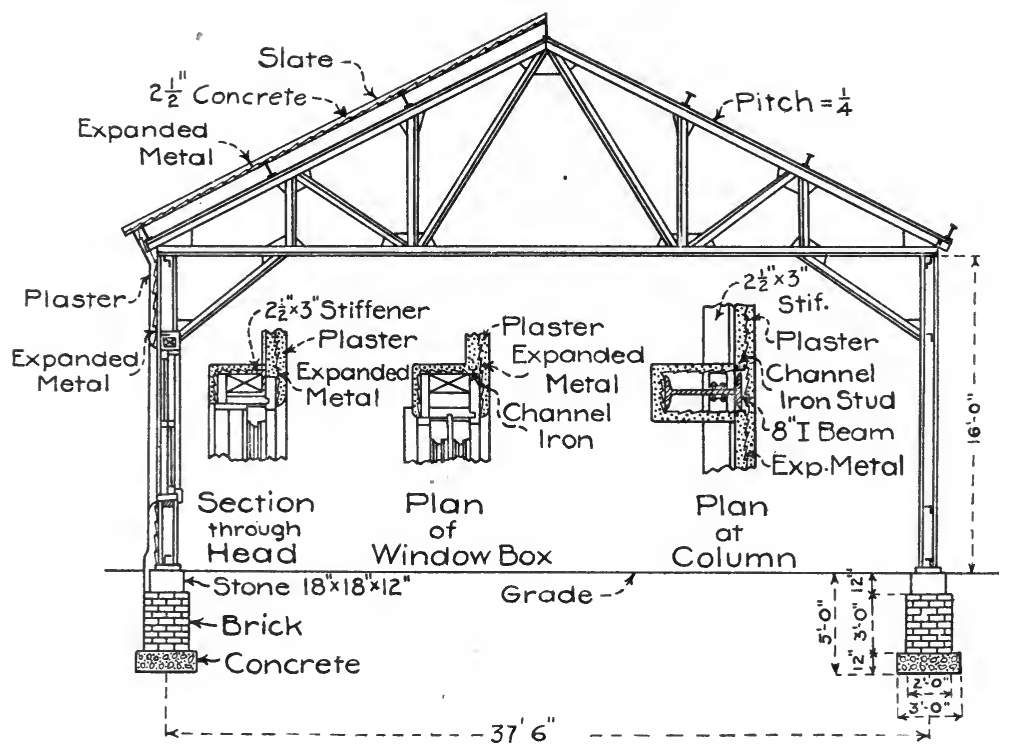

FiG. I3I. CROSS-SECTION OF STEEL BUILDING COVERED WITH EXPANDED METAL AND PLASTER.

concrete, and are plastered smooth on the under side. The side walls were made by fastening $3 / 4$-inch channels at 12 -inch centers to the steel framing, and covering this framework with expanded metal wired on. The expanded metal was then covered on the outside with a coating of cement mortar composed of I part Portland cement and 2 parts sand and on the inside with a gypsum plaster, making a wall about 2 inches thick. The ground floors were made by covering the' surface with a 6 -inch layer of cinders in which were imbedded $2 \times 4$-in. white pine nail- 
ing strips 16 inches apart, and on these strips was laid a floor of tongued and grooved maple boards $I \frac{1}{4}$ inches thick and $2 \frac{1}{2}$ inches wide. The upper floors are made of concrete slabs reinforced with expanded metal, and supported on beams spaced 4 to I 5 feet apart. Where the spans exceed 7 feet suspension bars $7^{\prime \prime} \times 3 / 8^{\prime \prime}$ were placed 3 feet apart and were bent around the flanges of the beams. The concrete filling was composed of I part Portland cement, 2 parts sand and 6 parts cinders. (For another description of this building see Engineering Record, August 25, 1900.)

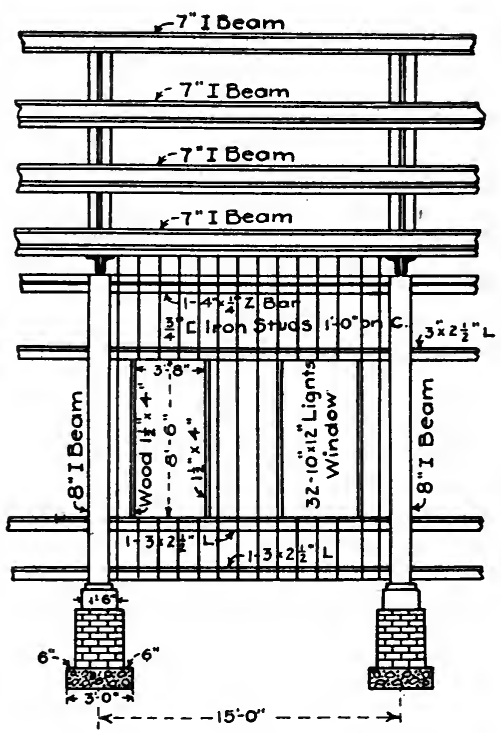

Fig. I32. Side Elevation OF STEEL BUildiNg COVERED With EXPANDED METAL AND PLASTER.

The Northwestern Expanded Metal Co. now recommends that the first coat of the plaster used for curtain walls be composed of two parts lime paste, I part Portland cement and 3 parts sand, and that the wall be finished with a smooth coat composed of I part Portland cement and 2 parts sand.

For coating on wire lath the following has been found to give satisfactory results in Chicago and vicinity: For the first coat use a 
mortar composed of I part Portland cement and 2 parts ordinary lime mortar. The lime should be very thoroughly slaked before using as the presence of any free lime will injure the wall. After the first coat has hardened it is thoroughly soaked and a finishing coat composed of I part Portland cement, 2 parts sand and a small quantity of slaked lime is applied and rubbed smooth.

A method of plastering curtain walls is described by Mr. George Hill in the Transactions of the American Society of Civil Engineers, Vol. 29, as follows: "The external curtain walls were composed of hard plaster, Portland cement and sand in equal parts, the srratch coat being applied to uncoated metallic lath, making the thickness of the scratch coat about I inch; then a surfacing of Portland cement $1 / 2$-inch thick was applied on each side making the curtain walls a total thickness of 2 inches. Good results were obtained in every case except one, where the scratch coat was alternately frozen and thawed several times, and the outer surfacing of the wall peeled off in patches."

The Northwestern Expanded Metal Co. does not recommend the use of hard or patent plasters for curtain walls.

Expanded metal and plaster curtain walls are light, strong and efficient. They do not require the heavy foundations required by brick and stone walls and are fireproof. They can be used to advantage where it is desirable to have a large glass area in the sides of buildings. This type of construction is almost ideal for factory construction and will be much used in the future. There are quite a number of different systems but the methods of construction are essentially the same in all.

Curtain walls are made of wire lath and plaster in the same way as expanded metal and plaster and have all the advantages of the latter.

The cost of curtain walls made as described abore is about \$I.5O to $\$$ r.8o per square yard.

For a detailed description of the construction of small cement and steel buildings see Engineering Record, March 26, 1898.

Concrete Slabs.-The construction of reinforced concrete slabs patented by Milliken Brothers, New York, is described in Engineering 
Record, December 22, 1900, as follows: "The slabs used on the roof of the concrete stable built for the Anglo-Swiss Condensed Milk Company, Brooklyn, N. Y., were 4 feet wide and about I $_{5}$ feet long and were constructed as follows: Each slab has a steel frame with three $2 \times 1 / 4$-inch transverse strips set edgewise at the ends and middle, and connected by longitudinal $1 / 4$-inch rods about $35 / 8$ inches apart so as to form a gridiron. The rods are set in staggered holes in the edge of the bars and form a framework over and under which No. 14 transverse wires are woven 6 inches apart. The lower surface of the frame is covered with open mesh fine-wire netting, wired around the edges, and the frame is filled with $I: 2: 4$ Portland cement concrete made with very fine broken stone. The slab is 2 inches thick and has offset edges to make scarfed joints which are set with cement mortar. Voids are left in the concrete at the edges of the slabs to permit thin flat steel bars or angle clips to be bolted to the frames, and to be bolted to or locked around the framework. Then the holes are flushed with cement mortar and a $1 / 4$-inch surface coat is plastered over the slabs for the final finish. These slabs have been used for side and partition walls as well as for roof sheathing."

Masonry Walls.-Walls for filling in between the columns of mill buildings are commonly made very light, being usually determined by the clearance and the height. For buildings with 20 to $25 \mathrm{ft}$. posts, 8 -inch walls are very commonly used. Where the columns are placed inside of the line of the walls, a greater thickness of wall is used than above; 13 and 17 -inch walls being quite common.

The thickness of factory and warehouse walls which support roof trusses is about as given in Table XXII.

The thickness of the wall may be decreased when pilasters are used to assist in supporting the trusses.

For detailed information on the construction of brick and stone walls see Baker's Masonry Construction and Kidder's Building Construction and Superintendence, Part I. 


\section{TABLE XXII.}

THICKNESS OF WAREHOUSE WALLS.

\begin{tabular}{c|c|c}
\hline $\begin{array}{c}\text { Height } \\
\text { of } \\
\text { Wall. } \\
\text { Feet. }\end{array}$ & \multicolumn{2}{|c}{ Thickness of Wall. } \\
\cline { 2 - 3 } & $\begin{array}{r}\text { Brick. } \\
\text { Inches. }\end{array}$ & $\begin{array}{c}\text { Stone. } \\
\text { Inches. }\end{array}$ \\
\hline 25 & 16 & 20 \\
50 & 20 & 24 \\
75 & 24 & 36 \\
\hline
\end{tabular}

CONCRETE BUILDINGS.-Within the last few years quite a number of factory buildings have been constructed of concrete. Most of these buildings are monolithic, although recently quite a number patents have been issued for concrete building blocks. The walls are usually made hollow when made monolithic or made of concrete blocks; the air space prevents the passage of dampness through the walls, makes the building warmer and is less expensive than to make the wall solid. In monolithic concrete construction the roof, floors and the angles in the walls are reinforced with metal put in according to some one of the many systems now in use.

The following abstract of the description of the construction of a monolithic concrete building, printed in the Engineering Record, July 3oth, and August 20th., 1898, will give the reader an idea of the methods employed.

"The factory of the Pacific Coast Borax Company, at Constable Hook, Bayonne, N. J., is about $200 \times 250$ feet in extreme dimensions, and is partly one story and partly four stories in height. All the floors, floor beams, walls, columns, etc. are constructed of reinforced concrete on the Ransome system, built in molds so as to form a monolithic structure continuous throughout, except for the shrinkage joints dividing it into separate panels.

"The columns are supported on concrete footings reinforced with twisted steel bars. The walls of the building were built solid at the ends of the floor beams and the intermediate portions were made hol- 
low by inserting wooden fillers, which were afterwards removed. The walls of the four story portion are 16 inches in extreme thickness up to the third floor, and are 15 inches above that point. The hollow walls have 3 to 4 inches of concrete on each side of the air space. Both the walls and the columns were bonded by vertical bars of twisted steel $3 / 4$ inch square, extending through them continuously from top to bottom, and similar rods were carried through the buildings from side to side transverse to the beams imbedded in the different floors about 12 feet apart so as to provide a certain transmission of the strain across the building and assure the resistance of the structure as a whole under the action of eccentric loads and pressures.

"At about every 25 feet in the length of the walls a vertical space of $1 / 8$ of an inch was made, extending from top to bottom and separating the wall into distinct sections. At each of these joints a twisted $3 / 4$-inch rod was imbedded from top to bottom on each side of the space. Similar rods were also placed at the corners of the building. Where the vertical shrinkage joints occur in the outside walls the continuity of the structure is preserved by carrying through them horizontal longitudinal pieces of twisted $3 / 4$-inch square rods about 2 feet long and set about 2 feet apart throughout the height of the wall.

"The columns were built in I6-foot sections, each section being one story in height, and were constructed by ramming the concrete inside of forms. The vertical boards composing these forms were made in short lengths, breaking joints over the cross pieces, and were placed in position as the concrete was placed in position. The forms were allowed to stand until required for another story, often remaining in position for several weeks, although it was considered that the concrete was strong enough to permit their removal when 48 hours old. The walls were laid up between vertical surfaces of plain $1 \frac{1}{2}$-inch plank, laid horizontally and secured by tie bolts running through the molds. The wall was built up in sections about four feet in height and the concrete was laid in continuous 6-inch layers, extending entirely around the circumference of the wall, and was thoroughly rammed as deposited. After the concrete had set sufficiently, the bolts were loosened and the boards forming the sides of the mold were pulled up and set in position for building another zone of wall. About 35 men were at work building the walls and constructed an average of 2000 square feet a day. 
"The partitions in the building are 2 inches thick and are made of solid concrete reinforced by a framework of twisted $1 / 4$-inch bars about 2 feet apart, both vertically and horizontally. The partitions were built in molds, and set so that the face comes exactly even with the edge of a shrinkage joint in the floor, and always set over a floor beam.

"The concrete was made of Atlas cement and broken basaltic rock, all of which will pass through a 2-inch ring and most of which will pass through a I-inch ring. The unscreened rock was mixed with cement in the following proportions: For foundations, I to Io ; for the walls, floors and most of the work, I to $6 \frac{1}{2}$; for the columns, I to 5 ; and for the lower chords of the floor beams, I to 6 , using very fine stone."

In constructing the Ingalls office building in Cincinnati, Ohio,described in Engineering News, July 30, 1903, and Engineering Record, scribed above with a few exceptions which will be noted.

"The broken stone included the total product of the crusher and was fine enough to pass through a I-inch screen. The concrete was mixed rather wet to insure complete filling of all interstices around the bars. Enough water was used to always give a semi-fluid consistency which allowed puddling rather than ramming. It was made wetter for the columns than for the floors and girders because the bars interferred with the ramming in the molds for the columns. The columns were built in one-story lengths and the concrete was rammed in the molds in layers not more than 12 inches deep. The concrete was dumped from the floor above into the bottom of the mold. The steel rods were placed in position before the concreting was commenced, and were wired in position. A force of 28 men working with hoisting machines and wheelbarrows placed about Ioo cubic yards of concrete in a day."

The present tendency in concrete building construction is toward the use of a concrete made of Portland cement and finely crushed stone, mixed very wet and deposited in the molds practically without ramming. The concrete must be rich in cement to make a good wall under these conditions. 
Surface Finish.-Where it is desired to imitate stonework, imitation joints are formed in the face of the wall and the surface is either picked while the concrete is yet tender or is tooled after the concrete has hardened. Bush hammering of concrete walls can be done by an ordinary workman for from $I / 2$ to 2 cts. per sq. ft. Where the concrete is coarse a coating of cement mortar may be applied as the concrete is placed in the molds by means of a piece of sheet steel placed from $I$ to 2 inches from the forms; the cement mortar, usually made of I part Portland cement and 2 parts sand, is then rammed into the vacant space, after the main body of the concrete has been rammed in place, and the piece of sheet steel is removed.

The preparation of the forms requires considerable study to obtain a smooth surface and unbroken corners. The use of matched or tongued-and-grooved stuff is not desirable as the concrete fills the openings made by shrinkage and there is no room to expand. Unmatched boards dry apart and let the water in the concrete leak out, carrying with it some of the cement. The best way to build the forms is to use narrow stuff and bevel one edge of the boards; the sharp edge of the bevel lying against the square edge of the adjoining board allows the edge to crush when swelling and closes up the joint. A coat of soft soap applied to the forms before filling, prevents the concrete from adhering. The soap should be scraped and brushed off with a steel brush as the forms are removed. 


\section{CHAPTER XXI.}

\section{FoundaTIONS.}

Introduction.--The design of the foundations for mill buildings is ordinarily a simple matter for the reason that the buildings are usually located on solid ground and the loads on the coinmns are small. Where the soil is treacherous or when an attempt is made to fix the columrs at the base the problem may, however, become quite complicated.

Bearing Power of Soils.-The bearing power of a soil depends upon the character of the soil, its freedom from water, and its lateral support. The downward pressure of the surrounding soil prevents lateral displacement of the material under the foundation and adds materially to the bearing power of treacherous soils.

The safe bearing power of soils given in Table XXIII may be used as an aid to the judgment in determining on a safe load for a foundation. However no important foundations should be built without making careful soundings and bearing tests.

A soil incapable of supporting the required loads may have its supporting power increased (I) by increasing the depth of the foundation; (2) by draining the site; (3) by compacting the soil ; (4) by adding a layer of sand or gravel; (5) by using timber grillage to increase the bearing area; (6) by driving piles through the soft stratum, or far enough into it to support the loads.

A method used in France for compacting foundations is to drive holes with a heavy metal plunger and then fill these holes with closely rammed sand or gravel.

Several kinds of patented concrete piles are now in use to a limited extent in this country for building foundations. 


\section{TABLE XXIII.}

SAFE BEARING POWER OF SOILS.*

\begin{tabular}{|c|c|c|}
\hline \multirow{2}{*}{ Kind of Material. } & \multicolumn{2}{|c|}{$\begin{array}{c}\text { Safe Bearing Power in Tons } \\
\text { per Sq. Ft. }\end{array}$} \\
\hline & Min. & Max. \\
\hline $\begin{array}{l}\text { Rock-hardest in thick layers in bed.... } \\
\text { " equal to best ashler masonry.... } \\
\text { " } \\
\text { " }\end{array}$ & $\begin{array}{r}200 \\
25 \\
15 \\
15\end{array}$ & $\begin{array}{l}30 \\
20 \\
10\end{array}$ \\
\hline $\begin{array}{c}\text { Clay in thick beds, always dry } \ldots \ldots \ldots \ldots \\
\text { " } " \text { " } \text { moderately dry } \ldots \ldots \ldots\end{array}$ & $\begin{array}{l}\mathbf{4} \\
\mathbf{2} \\
\mathbf{1}\end{array}$ & $\begin{array}{l}6 \\
4 \\
2\end{array}$ \\
\hline 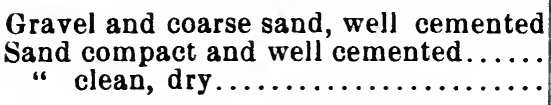 & $\begin{array}{l}8 \\
4 \\
2\end{array}$ & $\begin{array}{r}10 \\
6 \\
4\end{array}$ \\
\hline Quicksand, alluvial soils, etc......... & 0.5 & 1 \\
\hline
\end{tabular}

When foundations are placed on solid rock, the surface of the rock should be carefully cleaned of loose and rotten rock and roughly brought to a surface as nearly perpendicular to the direction of the pressure as practicable. A layer of cement mortar placed directly on the rock surface will assist in bonding the foundations and the footing together.

When foundations are placed on sand, gravel or clay it is usually only necessary to dig a trench and start the foundation below frost. If the soil is somewhat yielding or if the load is heavy the foundation should be carried to a greater depth or the footings should be made wider than for greater depths.

Bearing Power of Piles.-Probably no subject has been more freely discussed and with more conflicting views and opinions than has the safe bearing power of piles. The safe load to put on a pile in any particular case is dependent upon so many conditions that any formula for the safe bearing power is necessarily simply an aid to the judgment of the engineer, and not an infallible rule to be blindly followed. All

*Treatise on Masonry Construction, by Ira O. Baker,-John Wiley \& Sons, Publishers, New York. 
formulas for the bearing power of piles determine the safe bearing power from the weight of the hammer, the length of free fall of the hammer, and the penetration of the pile. The penetration of the pile for any blow of the hammer depends on the condition of the head of the pile, upon whether the pile is driving straight, and upon the rigidity of the pile. The penetration of a slim, limber pile with a broomed head is very misleading, and any formula will give values too large.

The Engineering News formula for the safe bearing power of piles is most used and is certainly the most reliable. It is

$$
P=\frac{2 W h}{s+1}
$$

where $P=$ safe load on pile in tons;

$W=$ weight of hammer in tons ;

$h=$ distance of free fall of the hammer in feet;

$s=$ penetration of the pile for the last blow in inches.

If the pile is driven with a steam hammer the factor unity in the denominator is changed to one-tenth. This formula is supposed to give a factor of safety of about 6 , and has been shown by actual use to give values that are safe.

Where piles are to be driven through gravel or very hard ground the lower ends are often protected with cast iron or steel points. The value of these points is questionable and most engineers now prefer to drive piles without their use, simply making a very blunt point on the pile. In driving piles, care must be used where small penetrations are obtained not to smash or shiver the pile. Piles driven to a good refusal with a penetration of, say, I inch for the last blow, with a fall of $20 \mathrm{ft}$. and a 2000-1b. hammer will safely support almost any load that can be put on them.

Piles are usually driven at about 3 - $\mathrm{ft}$. centers over the bottom of the foundation. After the piles are driven they are sawed off below the water level and (I) concrete is deposited around the heads of the piles, or (2) a grillage or platform is built on top of the piles to support the walls 
or piers. The first method is now the most common one for mill building foundations.

Pressure of Walls on Foundations.-In Fig. 133, let $W=$ resultant weight of the wall, the footing and the load on the wall, $l=$ length of the footing and $b=$ distance from center of gravity of footing to point of application of load $W$, and let the wall be of unit
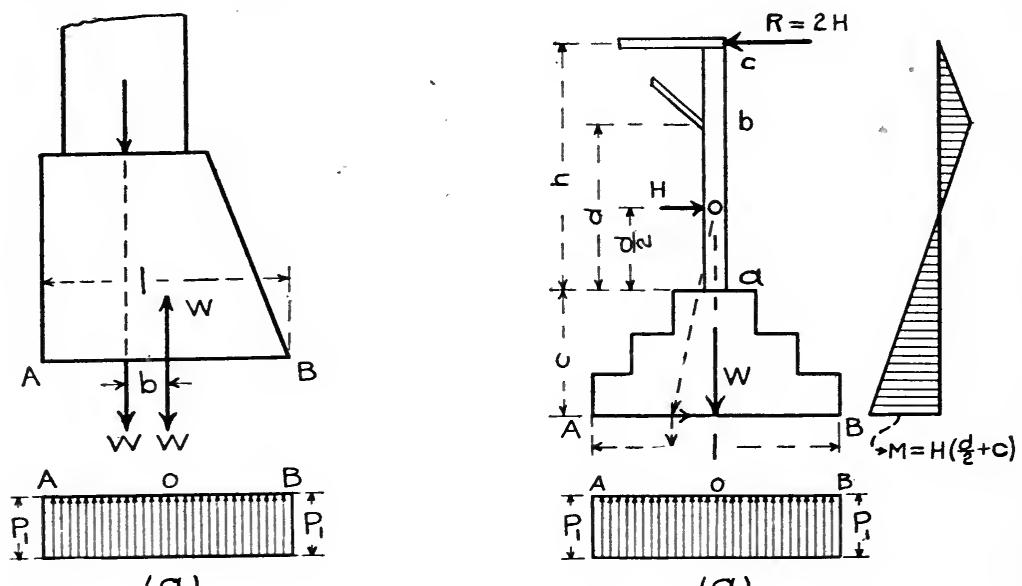

(a)
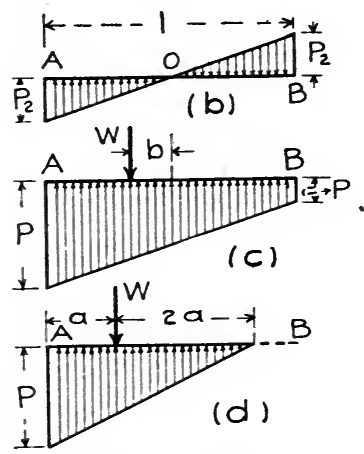

FIG. I33.

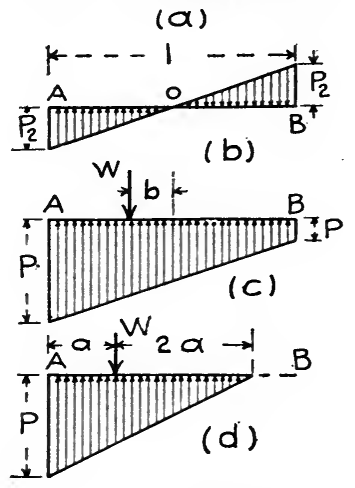

FIG. I34.

length. The pressure on the footing will be that due to direct load $W$, and a couple with an arm $b$ and a moment $=+W b$. The pressure due to the direct $W$ will be

$$
P_{1}=W \div l
$$

as shown in (a), 
and the maximum pressure due to the bending moment, $M=+W b$, will be

$$
P_{2}=\frac{M c}{I}=\frac{6 W b}{l^{2}}
$$

The pressure at $A$ will be

$$
P=P_{1}+P_{2}=\frac{W}{l}+\frac{6 W b}{l^{2}}
$$

and at $B$ will be

$$
P=P_{1}-P_{2}=\frac{W}{l}-\frac{6 W b}{l^{2}}
$$

as shown in (c).

Now if $P_{1}$ is made equal to $P_{2}$ the pressure at $B$ will be zero and at $A$ will be twice the average pressure. Placing $P_{1}=P_{2}$ in (84) and solving for $b$, we have $b=1 / 6 l$. This leads to the theory of the middle third or kern of a section. If the point of application of the load never falls outside of the middle third there will be no tension in the masonry or between the masonry and foundation, and the maximum compression will never be more than twice the average shown in (a).

If the point of application of the load falls outside the middle third ( $b$ greater than $1 / 6 l$ ) there will be tension at $B$, and the compression at $A$ will be more than twice the average. But since neither the masonry nor foundation can take tension, formulas (83) and (84) will give erroneous results.

In (d) Fig. I33, assume that $b$ is greater than $1 / 6 l$, and then as above, the load $W$ will pass through the center of pressures which will vary from zero at the right to $P$ at $A$. If $3 a$ is the length of the foundation which is under pressure, then from the fundamental condition for equilibrium for translation, summation vertical forces equals zero, we will have

$$
\begin{gathered}
W=\mathrm{x} / 2 P_{3} a \\
P=\frac{2 W}{3 a}
\end{gathered}
$$


Pressure of a Pier on Foundation.-In Fig. I34, let $W=$ resultant of the stresses in the column and the weight of the pier, $l=$ length, $c=$ depth and $n=$ the breadth of the footing of the pier in feet. The bending moment at the top of the pier is $M=-1 / 2 H d$ and at the base of the pier is $M_{1}=-H \cdot(1 / 2 d+c)$. Now the pier must be designed so the maximum pressure on the foundation due to $W$ and the bending moment $M_{1}$ will not exceed the allowable pressure. The maximum pressure on the foundation will be

$$
\begin{aligned}
P & =P_{1} \pm P_{2}=\frac{W}{l n} \pm \frac{M_{1} y}{I} \\
& =\frac{W}{l n} \pm \frac{H\left(\frac{d}{2}+c\right) \frac{l}{2}}{\frac{1}{12} n l^{3}} \\
& =\frac{W}{l n} \pm \frac{3 H(d+2 c)}{n l^{2}}
\end{aligned}
$$

It will be seen from (86) that a shallow pier with a long base is most economical.

To find the relations between $l$ and $c$ when the maximum pressure is twice the average, place

and

$$
\begin{aligned}
\frac{W}{l n} & =\frac{3 H(d+2 c)}{n l^{2}} \\
l & =\frac{3 H(d+2 c)}{W}
\end{aligned}
$$

For any given conditions the value of $l$ that will be a minimum may be found by substituting in the second member of (87).

To illustrate the method of calculating the size of a pier we will calculate the pier required to fix the leeward column in Fig: 57 .

The sum of the stresses in column $A-17$ is a minimum for dead and wind load and will be (Table V) equal to $4800+4500=$ 9300 lbs.

Try a pier $3^{\prime} 0^{\prime \prime} \times 3^{\prime} \mathrm{o}^{\prime \prime}$. on top, $6^{\prime} \mathrm{o}^{\prime \prime} \times 6^{\prime} \mathrm{o}^{\prime \prime}$ on the base and 6 feet deep, weighing about I6,700 lbs.

Substituting in (86) we have

$$
\begin{aligned}
P & =\frac{26.000}{36} \pm \frac{3 \times 4300(14+12)}{6 \times 36} \\
& =722 \pm 1553
\end{aligned}
$$


This gives tension on the windward side which will not do, and so we will reinforce the footing with beams and make $l=\mathrm{Io} \mathrm{ft}$., and then

$$
\begin{aligned}
P & =722 \pm 559 \\
& =\mathrm{I} 28 \mathrm{I} \text { or } 163 \mathrm{lbs} . \text { per square foot, which }
\end{aligned}
$$

is safe for ordinary soils.

If it had been necessary to drive piles for this pier, a small amount of tension might have been allowed on the windward side if the tops of the piles had been enclosed in concrete.

Design of Footings.- The thickness and length of the offsets in a concrete or masonry footing are commonly calculated as for a beam fixed at one end and loaded with a uniform load over the projecting part equal to the maximum pressure on the footing. If $p=$ projection of the footing in inches; $t=$ the thickness of the footing in inches ; $P=$ pressure on foundation in pounds per sq. ft.; and $S=$ safe working load of the material of which the footing is made in pounds per square inch, by substituting in the fundamental formula for flexure and solving for $p$,

$$
p=2 t \sqrt{\frac{3 S}{P}}
$$

The values of $S$ in common use are: first class Portland cement concrete $50 \mathrm{lbs}$.; ordinary concrete $30 \mathrm{lbs}$.; limestone ${ }_{50} \mathrm{lbs}$.; granite I80 lbs.; brickwork in cement 50 lbs.

The projection and thickness of the footing course is sometimes calculated on the assumption that the footing course is a beam fixed at the center, in place of as above. This solution hardly appears to be justified.

Pressure of Column on Masonry.-The following pressures in pounds per square inch are allowed by the building laws of New York.-Portland cement concrete 230 lbs.; Rosendale cement concrete I 25 lbs.; Rubble stonework laid in Portland mortar cement I40 1bs.; brickwork laid in Portland cement mortar 250 lbs.; brickwork laid in lime mortar I Io lbs. ; granite Iooo lbs. ; limestone $700 \mathrm{lbs}$. It is very com. mon to specify 250 lbs. per square inch for bearing on good Portland cement pedestals, and $300 \mathrm{lbs}$. per square inch is not uncommon. 


\section{CHAPTER XXII.}

FLOORS.

Introduction.-The requirements and the local conditions governing the design of floors for shops and mills are so varied and diversified that the subject of floor design can be treated only in a general way. Floors will be discussed under the head of (I) ground floors and (2) floors above ground.

GROUND FLOORS.-Types of Floors.-There are three general types of ground floors in tse in mills and shops: (I) solid heat conducting floors as stone, brick or concrete; (2) semi-elastic, semiheat conducting floors as earth, macadam or asphalt; (3) elastic nonheat conducting floors of wood or with a wooden wearing surface.

(I) Floors of the first class have been used in Europe and formerly in this country to quite an extent in shops and mills, and at present are much used in round houses, smelters, foundries and in other buildings where the wear and tear are considerable or where men are not required to stand alongside a machine. Floors of this class are cold and damp and make workmen uncomfortable. The wooden shoes of the continental workmen or the wooden platforms in use in many of our shops which have floors of this class, overcome the above objections to some extent. The gritty dust arising from most concrete floors is very objectionable where delicate machinery is used. The noise and danger from breakage and first cost are additional objections to floors of this class.

(2) Floors of this class have many of the objections and defects of floors of the first class. These floors are liable to be cold and damp unless properly drained, and give rise to a gritty dust that is often intolerable in a machine shop. 
Earth and cinder floors are very cheap and are adapted to forge shops and many other places where concrete and brick floors are now put down. Floors of this class should be well tamped in layers and should be carefully drained. Tar-concrete and asphalt floors are more elastic and conduct less heat than any of the floors above mentioned, but the surface is not sufficiently stable to support machinery directly, and foors of this class are very much improved by the addition of a continuous wooden wearing surface.

(3) Floors of wood or with a wooden wearing surface appear to be the most desirable for shops, mills and factories. Wooden floors are elastic, non-heat conducting and are pleasant to work on. They are cheap, easily laid, repaired and renewed. They are easily kept clean and do not give rise to grit and dust.

The most satisfactory wearing surface on a woorlen floor is rock maple $7 / 8$ to $I \frac{T}{4}$ inches thick and $2 \mathrm{I} / 2$ to 4 inches wide, matched or not as desired. The matched flooring makes a somewhat smoother floor and is on the whole the most satisfactory. The wearing floor should be laid to break joints and should be nailed to planking or stringers laid at right angles to the surface layer. The thickness of the planking will lepend upon the foundation and upon the use to which the floor is to be put.

The different classes of floors will now be briefly discussed and illustrated by examples of floors in use.

Cement Floors.-The construction of cement or concrete floors is similar to the construction of cement sidewalks, the only difference being that the floor usually requires the better foundation. The foundation will depend upon the use to which the floor is to be put, and upon the character of the material upon which the foundation is to rest. The excavation should be made to solid ground or until there is depth enough to allow a sub-foundation of gravel or cinders. Upon this base a layer of cinders or gravel 6 to 8 inches thick is placed and thoroughly rammed. The cement concrete base, made of I part Portland cement, 3 parts sand and 5 to 6 parts broken stone or gravel, is then placed on 
the sub-foundation and thoroughly rammed. The cement and sand should be mixed dry until the mixture is of a uniform color, the gravel or broken stone is then added, having previously been wet down, and the concrete is thoroughly mixed, sufficient water being added during the process of mixing to make a moderately wet concrete. The concrete is of the proper consistency if the moisture will just flush to the top when the concrete is thoroughly rammed. The concrete should be mixed until the ingredients are thoroughly incorporated and each particle of the aggregate is thoroughly coated with mortar.

The wearing coat is usually made of I part Portland cement and one or two parts of clean sharp sand or granite screenings that will pass through a $1 / 4$-inch screen. The thickness of the wearing coat will depend upon the wear, and varies from $1 / 2$ to 2 inches thick, $I$ inch being a very common thickness. The mortar for the wearing surface should be rather dry and should be applied before the cement in the concrete base has begun to set. Care should be used to see that there is not a layer of water on the upper surface of the base or that a film of clay washed out of the sand or gravel has nct been deposited on the surface, for either will make a line of separation between the base and the wearing surface. The mortar is brought to a uniform surface with a straight edge, and is rubbed and compressed with a float to expel the water and air bubbles. As the cement sets it is rubbed smooth with a plastering trowel. Joints should be formed in the floor making it into blocks about 4 to 8 feet square.

Cement floors are said to be a failure for railway round houses for the reason that they flake and crack after they have been used a short time, on account of the varying changes to which they are subjected.

Cement floors vary in cost, depending upon the thickness of the floor and upon local conditions. In central Illinois a cement floor having a I-inch surface coat and 3 inches of concrete laid on a cinder foundation 6 to 8 inches thick can be obtained (1903) for about 12 cents per square foot. A very substantial concrete floor can usually be obtained for about 20 cents per square foot. 
Tar Concrete Floors.-The following specifications for tar concrete floors are given in circulars Nos. 54 and 55 of the Boston Manufacturer's Mutual Fire Insurance Co., and are reprinted in Engineering News, March 21, I895.

"The floor to be 6 inches' thick, and to be put down as follows: The lower 5 inches to be of clean coarse gravel or broken stone, with sufficient fine gravel to nearly fill the voids, thoroughly coated with coal-tar and well rammed into place. On this place a layer $\mathrm{I}$ inch thick of clean, fine gravel and sand heated and thoroughly coated with a mixture of coal-tar and coal-tar pitch in the proportions of I part of pitch and 2 parts of tar. This layer is to be rolled with a heavy roller and brought to a true and level surface ready to receive the floor plank. No sand or gravel to be used while wet.

"A floor of the kind above specified should always be protected by a floor of wood over it, and the plank should be laid and bedded in the top surface while it is warm and before it becomes hard.

"For light work the thickness of the lower layer of concrete may be reduced one or more inches if upon a dry gravelly or sandy soil. For storage purposes where the articles stored are light and trucks are little used, the following specification has been found to give a satisfactory floor:

"The lower layer being mixed and put down as above specified, the top layer will be of fine gravel and sand, heated and thoroughly mixed with a mixture of equal parts of coal-tar, coal-tar pitch and paving cement, so that each particle of sand and gravel is completely coated with the mixture, using not less than one gallon of the mixture to each cubic foot of sand and gravel. This layer should be well rolled with a heavy roller and allowed to harden several days before being used."

Brick Floors.-Brick floors are recommended as the most satisfactory floors for round houses. Round house floors on the Boston \& Maine R. R. are made as follows: *Brick is laid flat on a 2 -inch layer of bedding sand on well compacted earth, gravel or cinders. Joints are left open $3 / 8$ of an inch and are swept full of cement grout.

Round house floors are made on the Chicago, Milwaukee \& St. Paul R. R., as follows: *Vitrified brick is laid on edge on a layer of sand I

*Eighth Annual Report of the Association of Railway Superintendents of Bridges and Buildings. 
to 2 inches thick on a cinder foundation 6 inches thick. Fine sand is broomed into the cracks after the brick are in place.

The cost of this floor per square yard is about as follows: Material.

Firebox cinders cost nothing ........\$00.00

Paving brick ............... 0.50 Labor.

Preparing the foundation $\ldots \ldots \ldots \ldots \ldots \ldots 0.20$

Laying the brick ............... o. 5

Total cost per square yard..........\$0.85

Total cost per square foot......... $1 / 2$ cents.

The cost of brick floors as given in the reports of the Association of Railway Superintendents of Bridges and Buildings varies from $91 / 2$ to 13 cents per square foot.

The Southern \& Southwestern Railway Club-Eng. News, Jan. I6, I896-recommends that round house floors be made of vitrified brick laid as follows: Make a bed surface of slag or chert about 18 inches thick, then put a coat of sand over slag, lay brick on edge and levei them up by tamping. After this is done a coat of hot tar is applied which enters the space between the bricks and cements them together.

Wooden Floors.-Coal-tar or asphalt concrete makes the best foundation for a shop floor. If Portland cement is used, the planking will decay very rapidly unless the top of the concrete is mopped with coal-tar or asphalt. A floor laid by Pratt \& Whitney Co., of Hartford, Conn., is described as follows: "In laying a basement floor about 18 years since of 10,000 square feet, 8,000 square feet were laid over coaltar and pitch concrete in about equal proportions, and about 2,000 square. feet were laid over cement concrete. The latter portion of the floor was removed in about ten years, the timbers and the plank being completely rotted out; while the other was in a perfect state of preservatoin and has continued so until the present time." The floor with tar concrete foundations was constructed as follows: "Excavation was made about one foot below the floor and six inches of coarse stone 
was filled in, then five inches of concrete made of coarse gravel, coaltar and pitch, and finally about one inch of fine gravel tar concrete. Before the concrete was laid, heavy stakes were driven about three feet apart to which the $4^{\prime \prime} \times 4^{\prime \prime}$ floor timbers were nailed and leveled up. The concrete was then filled in around the floor timbers and thoroughly tamped. A layer of hot coal-tar was then spread on top of the concrete and the flooring was laid and nailed to the timbers. It is very essential that the gravel be perfectly dry before mixing and this is accomplished by mixing it with hot coal-tar. What is known as distilled or refined coal-tar must be used as that which comes from the gas house without being refined does not work in a very satisfactory manner."

The following paragraph is abstracted from Report No. V., Insurance Engineering Experiment Station, Boston, Mass:

"Floors over an air space or on cement are subject to a dry rot. Asphalt or coal-tar concrete is softened by oil, and the dust will wear machinery unless the concrete is covered by plank flooring. Floors made by laying sleepers on 6 inches of pebbles, tarred when hot, then 2 inches tarred sand packed flush with the top of the sleepers, and covered with a double flooring, have remained sound for 37 years. Double flooring at right angles can be laid on concrete without the use of sleepers. It is usually preferable to secure nailing strips to stakes 4 feet apart each way and driven to grade, concrete flush to top of strips, and lay $\mathrm{I} / 2$-inch flooring."

The floor shown in Fig. I35 was laid in an extensive shop on the Boston \& Maine Railway. The earth was well compacted and brought to a proper surface and a 4 -inch bed of coal-tar concrete put down in

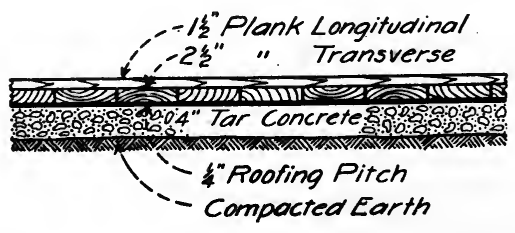

FIG. 135 . 
three courses. The stones in the lower course were to be not less than I inch in diameter. Stones in each course were well covered with tar before laying and were well tamped and rolled afterwards. The third and finishing course was composed of good clean sharp sand well dried, heated hot and mixed with pitch and tar in proper proportions. This was then carefully rolled and brought to a true level to fit a straight edge. On the finished surface of the foundation was spread a coating $1 / 4$-inch thick of best roofing pitch put on hot and into which the lower course of the plank was laid before the pitch cooled.

Care was taken to have the planks thoroughly bedded in the pitch and after laying, the joints were filled with pitch. If vacant spaces appeared under the plank, they were filled up with pitch by boring through the plank. The cost of this flooring was about I8 cents per square foot, using spruce lumber.

A cheap but serviceable floor may be made as shown in Fig. 136. The soil is excavated to a depth of 12 to ${ }_{5} 5$ inches and cinders are filled in and carefully tamped. The flooring planks are nailed to the sills which are bedded in the cinders. The life of the planls flooring can be increased by putting a coating of slaked lime on top of the cinders.

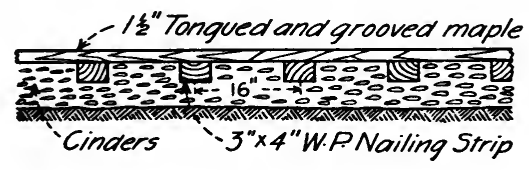

FIG. 136.

The floor shown in Fig. I37 was used in the factory of the Atlas Tack Company, Fairhaven, Mass., and needs no explanation.

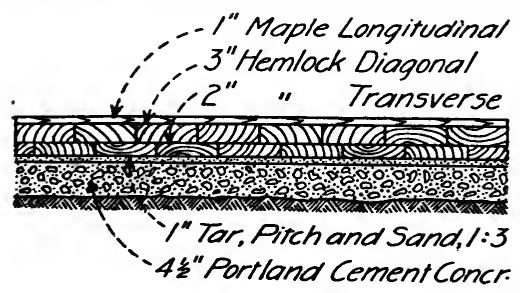

Fig. 137. 
A very good floor for mills and factories is shown in Fig. I38.

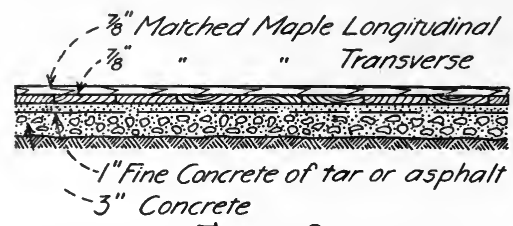

FIG. I38.

The pitch or asphalt will prevent the decay of the plank and will add materially to the life of the floor. Maple flooring makes the best wearing surface for floors and should be used if the cost is not prohibitive.

The floor shown in Fig. I 39 was constructed as follows: Two-inch plank, matched and planed on one side, were laid on $3^{\prime \prime} \times 3^{\prime \prime}$ chestnut joists. The surface of the cinders was kept $2^{\prime \prime}$ away from the wood and

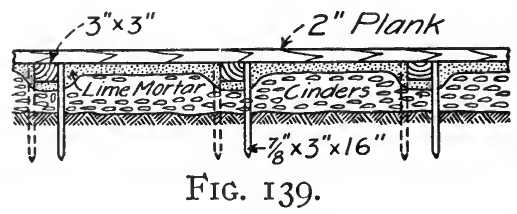

this space was filled with lime mortar. After the surface of the cinders had been graded, the $3^{\prime \prime} \times 3^{\prime \prime}$ joists were held in place by stakes nailed to the joists about three feet apart. The lime mortar was then filled in around and slightly above the surface of the joists to allow for shrinkage. Before laying the floor a thin layer of slaked lime was spread over the surface. This floor in an eastern city cost about 85 cents per square yard; and has a life of Io to I2 years.

Examples of Floors.-The floor of the Locomotive Shop of the A. T. \& S. F. R. R., at Topeka, Kas., is as follows: The floor foundation is formed of 6 inches of concrete resting on the natural soil well tamped. On the concrete are laid $3^{\prime \prime} \times 4^{\prime \prime}$ yellow pine stringers at 18 inch centers, the whole being covered with 2-inch No. I hard maple, surfaced on one side and two edges and milled for $1 / 4^{\prime \prime} \times I^{\prime \prime}$ pine splines. 
The flooring in the Great Northern Shops at St. Paul, Minn., is $3^{\prime} \times 12^{\prime \prime}$ plank on $6^{\prime \prime} \times 8^{\prime \prime}$ sleepers bedded in 18 inches dry sand filling.

The floor of the locomotive shops of the Philadelphia and Reading R. R., is made of bituminous concrete on which are a solid course of $3^{\prime \prime} \times 8^{\prime \prime}$ hemlock and a top wearing surface of $\mathrm{I} / 8^{\prime \prime} \times 4^{\prime \prime}$ maple.

The machine shop floors of the Lehigh Valley R. R. at Sayre Pa., are of concrete with a maple wearing surface in the high grade buildings and yellow pine in the others.

The Southern Railway has a vitrified brick floor in a round house at Knoxville, Tenn., which is giving good satisfaction. The cost of this floor was about $\$ 1.00$ per square yard.

Shop floors for the American Locomotive Works, Schenectady, N. Y., are described in Engineering Record, May 30, I903 ,as follows :

"On a sand fill was laid from 4 to 6 inches of $2^{\mathrm{T}} / 2$-inch broken stone, rammed dry and then flushed with about one gallon of hot tar for every square yard of floor. This course was covered with 2 inches of hot sand and tar mixed to the consistency of dry mortar, shoveled into place and thoroughly rammed to a level surface. Spiking strips made of $3^{\prime \prime} \times 4^{\prime \prime}$ timbers were imbedded in the sand at about 3 -ft. centers. To these strips were spiked 2 -in. rough hemlock planks, which were in turn covered with transverse tongued and grooved $7 / 8$-in. maple boards 4 inches wide."

Cedar Blocks form a neat, clean and durable floor. Care should be used where heavy jacking is to be done on wouden block floor that the blocks are not forced down through the plank foundation.

A cedar block floor in the Chicago Ave. round house of the $\mathrm{C} \&$ N. W. R. R., laid on planks on a gravel foundation cost about I I cents per square foot.

*A cedar block floor on the C. \& E. I. R. R., laid directly on a gravel foundation cost 8 cents per square foot.

*A floor constructed of 6 to 8-inch blocks sawed from old bridge timbers, set on 2 -inch hemlock plank, which in turn rested on 3 inches

* Reports Association of Railway Superintendents of Bridges and Buildings. 
of dry gravel or sand, has been used on the Ashland division of the C. \& N. W. R. R., and cost about 4 cents per square foot exclusive of the cost of the old timbers. This floor has proved to be quite satisfactory.

FLOORS ABOVE GROUND.-The type of floor used for the upper stories of mill buildings will depend upon the character of the structure and the use to which the floor is to be put. In fireproof buildings the floors should preferably be constructed of fireproof materials, although there is comparatively little risk from fire under ordinary conditions with a heavy plank floor. Where the load on the floor is very heavy some form of trough or buckled plate floor is very often used.

Timber Upper Floors.-Where steel floor beams are used the floor is often made by placing $2^{\prime \prime} \times 6^{\prime \prime}$ or $2^{\prime \prime} \times 8^{\prime \prime}$ planks on edge and spiking them together, the wearing surface being made of hard wood boards. Where there is much danger from fire this floor can be fireproofed by plastering it below with wire lath and hard plaster and by putting a layer of cement or lime mortar between the plank and the wearing surface. The upper surface is also sometimes finished with a wearing coat of cement or asphalt.

The standard floor recommended by the Boston Manufacturer's Mutual Fire Insurance Co., for mill buildings constructed of heavy timbers, calls for a layer of spruce plank, generally 3 inches thick, laid to cover two floor beam spaces and breaking joints every 3 feet; on this are laid 3 thicknesses of rosin sized paper, each layer being mopped with tar. The top floor is $1 / 8$-in. hard wood, preferably maple. The main beams are spaced 8 to ro feet. "The floor is smoother if laid across the line of the plank in the under floor, but traveling loads are better distributed when moved in and out of the store house if the top floor is laid parallel to the lower plank."

Brick Arch Floor.-The brick arch floor shown in Fig. I40 was formerly much used in fireproof buildings and is still used to some extent in mills and factories. The arch is commonly made of a single 


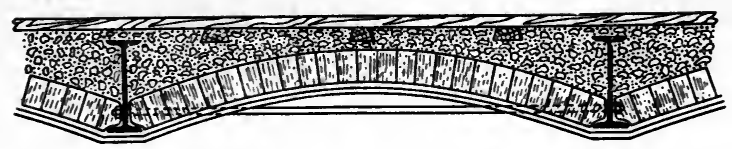

Brick Arch Construction

FIG. I40.

layer of brick about 4 inches thick, with a span of 4 to 8 feet and a center rise of preferably not less than $1 / 8$ the span. The space above the brick arch is filled with concrete and a wearing floor is nailed to strips imbedded in the surface of the concrete. The most desirable span is from 4 to 6 feet. Tie rods are commonly placed at about $1 / 3$ the height of the beam and are spaced from 4 to 6 feet apart. The thrust of the arch per lineal foot can be found by the formula

$$
T=\frac{1 . \dot{5} W L^{2}}{R}
$$

where $T=$ thrust of arch in lbs. per lineal foot;

$W=$ load on arch in lbs. per square foot;

$L=$ span of the arch in feet;

$R=$ rise of arch in inches.

The weight of this floor is about 75 lbs. per square foot.

Corrugated Iron Arch Floor.-The corrugated iron arch shown in Fig. I4I makes a very strong floor for shops and mills. The corrugated iron acts as a center for the concrete filling above it, and in connection with the concrete makes a composite arch. The corrugated iron or steel is ordinarily the standard $2 \mathrm{r} / 2$-inch corrugations, and the gages are Nos. 16, 18 or 20 , depending upon the load and the length of span. The rise of the arch should not be less than I-I2 the span and

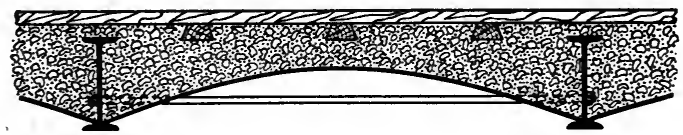

Corrugated Iron Arch

- FIG. I4I. 
should have a thickness of from 2 to 4 inches of concrete over the center of the arch. Beams are spaced from 4 to 7 feet apart for this floor, and tie rods are used as in the brick arch floor.

Expanded Metal Floors.-The floor shown in Fig. I42 is constructed as follows: A wood centering is suspended irom the beams, with the upper surface of the centering about $I$ inch above the top of the beams, a layer of expanded metal is stretched across the beam in sheets and the concrete is spread over and tamped so that the expanded metal becomes imbedded in the lower inch of the concrete. The

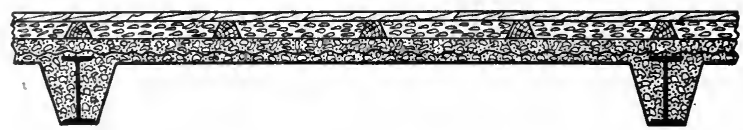

FIG. I42.

concrete is usually made of I part Portland cement, 2 parts sand and 6 parts cinders, and weighs 80 to 90 pounds per cubic foot. Beams were formerly spaced from 5 to 8 feet apart, but have recently been spaced much farther; spacings as wide as I8 to 20 feet having been successfully employed. Expanded metal with 3 -inch mesh cut from No. Io gage sheet steel is commonly used for floors, which are made from 3 to 5 or 6 inches thick. There is at present no rational method for the design of expanded metal floors-descriptions of floors in actual use, and tests of floors may be found by consulting the volumes of the Engineering News, the Engineering Record, and other technical papers. The companies controlling the patents will erect floors for specified loads under a guarantee.

Expanded metal floors are also made as shown in Fig. I43. This type is adapted to very heavy floor loads. The arch should have a rise

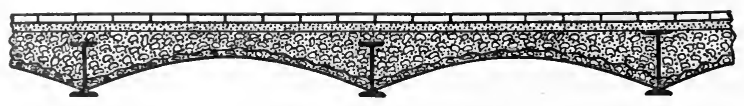

Fig. I43. 
of I-IO to $\mathrm{I} / \mathrm{s}$ the span. Tests have shown that the steel work in expanded metal floors is not ordinarily affected by the cinder concrete. If care is used when erecting the floor to coat the expanded metal with a coating of Portland cement mortar before the metal has become rusted, the protection against corrosion will be almost perfect.

Roebling Floor.-The floor shown in (c) Fig. I44 consists of a wire cloth arch, stiffened by woven-in stiff steel rods $3 / 8$ to I-inch in diameter, at about 9 -inch centers, which is sprung between the floor beams and abuts on the seat formed by the lower edge of the floor beam.

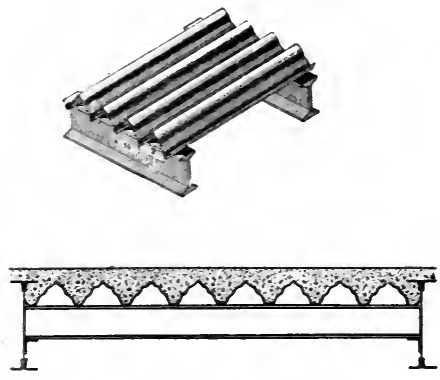

“BUCKEYE" FIREPROOF FLOORING.

(a)

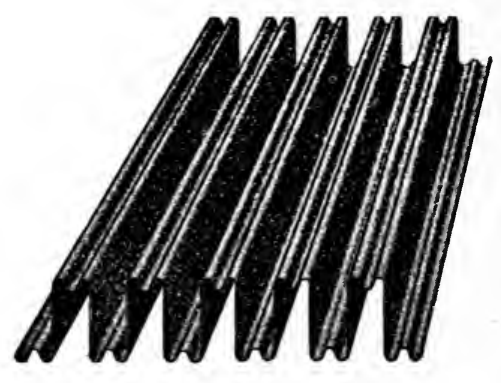

MULTIPLEX STEEL PLATE FLOOR

(b)
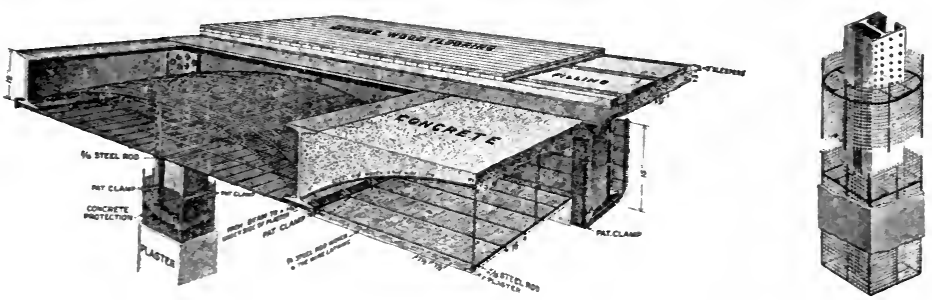

Roebling Fire-proof System

(C)

Fig. I44.

On this wire centering Portland cement concrete is filled in and is finished with a wearing coat of cement or a wooden floor as shown. The beams are held in position by $3 / 4$ or $7 / 8$-inch tie rods, placed from 4 to 
6 feet apart. The concrete is commonly composed of I part Portland cement, $2 \mathrm{~T} / 2$ parts sand and 6 parts clean cinders, and is laid with a thickness of not less than 3 inches over the crown of the arch. The weights and safe loads for floors constructed on this system are given in the manufacturer's catalog.

The Roebling Construction Company also makes a floor with flat construction as follows: A light framework is made of flat steel bars set on edge and spaced 16-inch centers, with 1/4-turn at both ends where the bars rest on the steel beams; braces of half round iron are spaced at intervals to brace the bars. The Roebling standard lathing with $1 / 4$-inch steel stiffening ribs woven in every $7 \frac{1}{2}$ inches, is then applied to the under side of the bars and laced to them at each intersection. On.this wire lathing cinder concrete from 3 to 4 inches thick is deposited.

"Buckeye" Fireproof Flooring.-The steel flooring shown in (a) Fig. I44 is manufactured by the Youngstown Iron \& Steel Roofing Co., Youngstown, Ohio. This floor is made in two sizes, one for bridge floors and the other for building floors. The flooring shown in (a) is for buildings, is made in sections of four triangles each in lengths up to ro feet, and will lay a width of $2 \mathrm{I}$ inches. Each triangle is $5 \frac{1}{4}$ inches wide and $2 \frac{1}{2}$ inches deep. The flooring when complete with a concrete filling and a $1 / 2$-inch wearing surface will weigh from $3^{2}$ to 35 pounds per square foot. 'The weights of the metal troughs laid in place are given in the following table:

WEIGHTS OF METAL TROUGHS $2 \frac{1}{2}$ INCHES DEEP BY 51/4 INCHES WIDE, INCLUDING SIDE LAPS.

GALVANIZED TROUGHS.

BLACK IRON TROUGHS.

No. 16-386 lbs. per 100 square feet. No. 16-363 lbs. per 100 square feet.

\begin{tabular}{|c|c|c|c|c|c|c|c|c|c|c|}
\hline No. $17-350$ & “ & “ & “ & “ & “ & No. $17-327$ & “ & “ & “ & “ \\
\hline No. $18-313$ & “ & “ & “ & “ & “ & No. $18-290$ & “ & “ & “ & “ \\
\hline No. $19-278$ & “ & “ & “ & “ & “ & No. $19-254$ & “ & “ & “ & “ \\
\hline No. $20-241$ & “ & “ & “ & “ & “ & No. $20-218$ & “ & “ & “ & “ \\
\hline No. $22-204$ & “ & “ & “ & “ & “ & No. $22-181$ & “ & “ & “ & “ \\
\hline No. $24-168$ & “ & “ & “ & “ & “ & No. $24-145$ & “ & “ & “ & “ \\
\hline
\end{tabular}


The safe loads in addition to the weight of the floor as given in . the manufacturer's catalog are given in the following table:

SAFE LOADS FOR "BUCKEYE” FIREPROOF FLOOR.

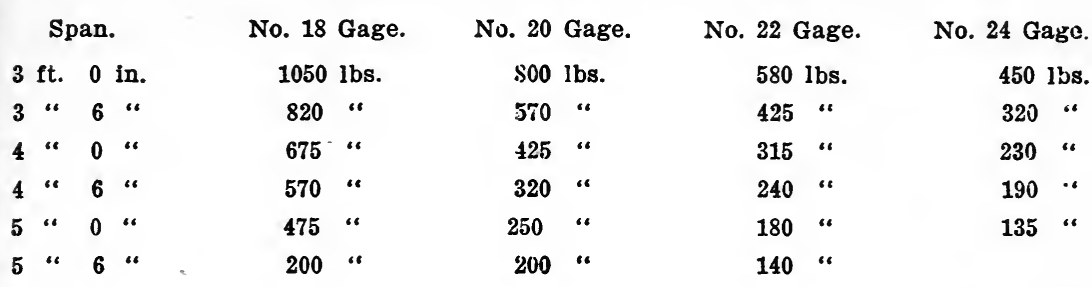

Multiplex Steel Floor.-The steel flooring shown in (b) Fig. I44, is manufactured by the Berger Mfg. Co., Canton, Ohio. This floor is made with corrugations from 2 to 4 inches deep and of Nos. 16, I8, 20 and 24 gage steel. The triangles are filled with concrete and the floor is given a cement finish, or is covered with a wooden wearing surface. Tables of safe loads for Multiplex Steel Floor are given in the manufacturer's catalog, and are larger than for the "Buckeye" Flooring for the same span.

Ferroinclave.-Ferroinclave is fully described in Chapter XIX. It has been used by the Brown Hoisting Company for floors as well as for roofing and siding. It should make a very satisfactory flooring where light loads are to be carried.

Corrugated Flooring.-Corrugated flooring or trough plates shown in (a) and (b) Fig. 145, are used for fireproof floors where extra heavy loads are to be carried in mill buildings, in train sheds and for bridge floors. The troughs are filled with concrete, which is given a finishing coat of cement and sand or is covered with a plank floor; the planks being laid directly on the plates or spiked to spiking pieces imbedded in the filling. The details, weights and safe loads for corrugated plates are given in Pencoyd Iron Works' handbook, in Carnegie Steel Company's handbook, and in Trautwine's Pocket-book. Details of corrugated plates are also given in the American Bridge Company's "Standards for Structural Details." 
Corrugated flooring or trough plates are usually very hard to get and the Z-bar and plate floor shown in (c) Fig. I45, and the angle and

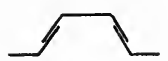

Pencoyd Corrugated Flooring

(a)

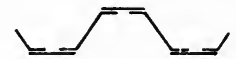

(b)

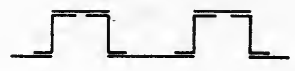

Z Bar Floor

(c)

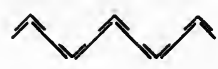

Angle and Plate Floor

(d)

FIG. I45.

plate floor shown in (d) are substituted. The details, weights and safe loads for Z-bar and plate flooring are given in the handbooks above named. Angle and plate flooring is made of equal leyged angles and plates, and the safe loads are not given in the handbooks but must be calculated. The moment of inertia, $I$, of a section of flooring containing two angles and two plates is given by the formula

$$
I=2 I^{\prime}+2 A d^{2}+2 I^{\prime \prime}
$$

where $I^{\prime}=$ moment of inertia of one angle about an axis through the center of gravity of the angle parallel to the neutral axis of the flooring;

$A=$ area of one angle;

$d=$ distance from center of gravity of the angle to the neutral axis of the flooring;

$I^{\prime \prime}=$ moment of inertia of the plate about the reutral axis.

The properties of the angles required in the calculations may be cbtained from the handbooks, and $I^{\prime \prime}$ is equal to one-half the sum of the moments of inertia of the plate about its long and its short diametersince the sum of the moments of inertia about any pair of rectangular axes is a constant.

Buckled Plates.-Buckled plates are made from soft steel plates from 3 to 5 feet wide, and are from $1 / 4$ to 7 -I 6 inches thick. Buckled plates are made in lengths having from one to 15 buckles or domes in one plate. Buckles vary in depth from 2 to $3 \frac{\mathrm{T}}{2}$ inches, however, different depths should not be used in the same plate. Buckled plates are usually supported along the edges and the ends and are bolted to the floor beams. The details, weights and safe loads are given in the handbooks named above and in the Passaic Steel Company's handbook. The 
buckled plates are covered with concrete, which is given a finishing coat of cement or is covered with plank flooring.

Steel Plate Flooring.-Fireproof floors around smelters, etc., are often made of steel plates. Flat steel plates do not make a very satisfactory floor for the reasons that the plates will bulge up in the center when fastened around the edges, and because they become dangerously smooth.

Neverslip Wrought Steel Floor Plates are made from $24^{\prime \prime} \times 72^{\prime \prime}$ to $36^{\prime \prime}$ $\times 120^{\prime \prime}$, and from 3-16" to $\mathrm{I}^{\prime \prime}$ thick. These plates are designed to take the place of the cast iron checkered plates formerly used for floors, weigh about 50 per cent less and last much longer. The stock sizes, weights and safe loads for Neverslip floor plates are given in the Stock List of the Scully Steel Co., Chicago. These lists are issued about six times a year and will be sent free upon request. 


\section{CHAPTER XXIII.}

\section{Windows ANd Skylights.}

Glazing.-For glazing windows and skylights, two substances, glass and translucent fabric are in common use.

GLASS.-The principal kinds of glass used in windows and skylights are (I) plane or sheet glass; (2) rough plate or hammered glass; (3) ribbed or corrugated glass; (4) maze glass; (5) wire glass-glass with wire netting pressed into it; (6) ribbed wire glass; and (7) prisms.

(I) Plane Glass.-Plane or common window glass is technically known as sheet or cylinder glass. It is made.by dipping a tube in molten glass and blowing the glass into a cylinder, which is then cut and pressed out flat. Without regard to quality sheet glass is divided according to thickness into "single strength" and "double strength" glass. Double strength glass is $1 / 8$-inch thick while single strength glass is about I-I6-inch thick. In mill buildings, lights larger than $12^{\prime \prime} \times 14^{\prime \prime}$ are usually made of double strength glass. With reference to quality. sheet glass is divided into three grades AA, A, and B. The AA is the best quality, the $\mathrm{A}$ is good quality while the $\mathrm{B}$ is very poor. The $\mathrm{B}$ grade is suitable only for stables, cellars, etc. For residences, offices, and similar purposes nothing poorer than AA should be specified. The A grade does very well for ordinary mills, although the AA grade should be used if practicable.

(2) Plate Glass.-Plate glass is made by casting and not by blowing, and is finished by grinding and polishing on both sides until a smooth surface is obtained. It is usually $1 / 4$ or $3-16$ inches thick. The price depends upon the size of the plate and the quality of the glass. The rough plate glass used in mills is not finished as carefully as for glass fronts, and it may contain many flaws that would not be allow- 
able in the former case. The roughened surface of the glass prevents the entrance of direct sunlight and does away with the use of sunshades. The only value of rough plate glass is in softening the light, the loss of light in passing through it being very great.

(3) Ribbed or Corrugated Glass.-Ribbed or corrugated glass is usually smooth on one side and has $5,7, \mathrm{I}$ I or $2 \mathrm{I}$ ribs on the other side, (a) Fig. 146. It varies in thickness and shape of ribs. "Factory ribbed" glass with $2 \mathrm{I}$ ribs to the inch is distinctly the most effective of the ribbed glasses.

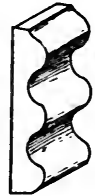

RIBBED (a)

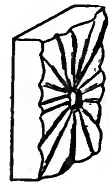

FIGURED

(b)

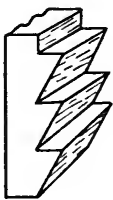

SHEET PRISM

(C)

FIG. I46.

(4) Maze Glass.-Maze glass has one side smooth and has a raised pattern on the other side roughening practically the entire surface, (b) Fig. I46. It is quite effective.

(5) Wire Glass.-Wire glass is made by pressing wire netting into the molten glass. It is made either plane or with ribs or prisms on one side. Wire glass is injured but not destroyed by the action of fire and water, and is now accepted by insurance companies as fireproof construction.

(7) Prisms.-Prisms are made in smáll sections which are set in a frame of lead or other metal, or are made in sheets as shown in (c) Fig. 146. Luxfer sheet prisms, manufactured by the American Luxfer Prism Co., Chicago, will be cut in any size desired up to 84 inches wide (parallel with the saw teeth) by 36 inches high.

Diffusion of Light.*_The light entering a room through a window or skylight comes for the most part from the sky and has, thereMass.

*Report No. III. Insurance Engineering Experiment Station, Boston, 
fore, a general downward direction, varying with the time of day and the position of the window. The portion of the room which receives the most light ordinarily is the floor near the windows, but if we interpose a dispersive glass in this beam the light will no longer fall to the floor but will be spread out into a broad divergent beam falling with nearly equal intensity on walls, ceiling and floor. There is of course no gain in the total amount of light admitted, the light being simply redistributed, taking up from the floor that which fell there and was comparatively useless, and sending it where it is of more service.

Experiments have shown that the diffusion of light in a room lighted by means of windows or skylights depends upon the kind and position of the glass used. The relative intensity of the light admitted in per cents of the light outside the window for plane glass, factory ribbed glass, Luxfer and canopy prisms is shown in Fig. I $47^{*}$.

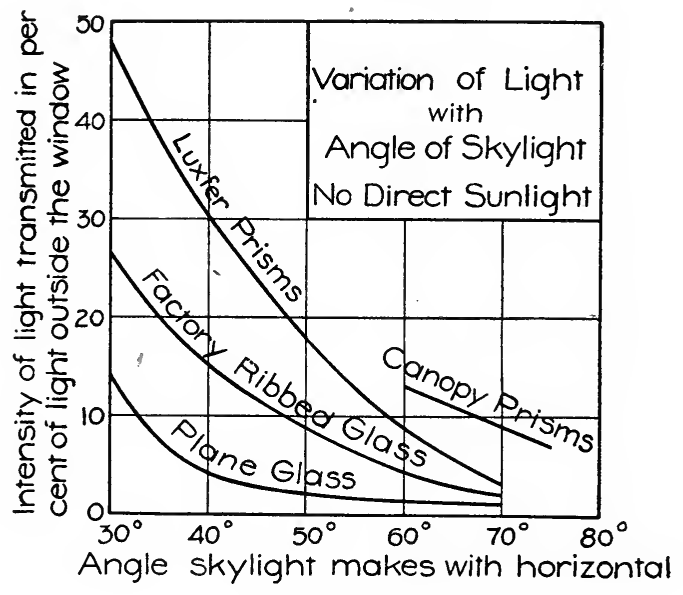

FIG. 147.

Fig. I47 shows a great increase in efficiency of factory ribbed glass and prisms as the sky angle diminishes.

*Report No. III. Insurance Englneering Experiment Station, Boston, Mass. 
The equivalent areas required to give the same intensity of light with the kinds of glass shown in Fig. 147, are given in Table XXIV for sky angles of $30^{\circ}$ and $60^{\circ}$.

TABLE XXIV.

EQUIVALENT AREAS FOR DIFFERENT KINDS OF GLASS.

\begin{tabular}{|c|c|c|}
\hline \multirow{2}{*}{ Kinds of Glass. } & \multicolumn{2}{|c|}{ Angle Skylight makes with the Horizontal. } \\
\hline & $30^{\circ}$ & $60^{\circ}$ \\
\hline Plane & $100 \mathrm{sq} . \mathrm{ft}$ & $100 \mathrm{sq} . \mathrm{ft}$. \\
\hline Factory Ribbed & 2566 & $40 \quad 66$ \\
\hline Luxfer Prisms & $17 ، 6$ & 3064 \\
\hline Luxfer Canopy Prisms & 1366 & \\
\hline
\end{tabular}

The American Luxfer Prism Co., recommends that Luxfer prisms be set at an angle of about 57 degrees with the vertical when used in skylights.

Relative Value of Different Kinds of Glass.-Ground glass is of little value except as a softening medium for bright sunlight. It becomes opaque with moisture and makes an undesirable window glass. Roughened plate glass has very little value as a diffusing medium. Of the ribbed glasses, the factory ribbed glass with $2 \mathrm{I}$ ribs to the inch gives the widest and most uniform distribution and is distinctly the best. There is no apparent gain in corrugating both sides. Ribbed wire glass is about 20 per cent less effective than the factory ribbed glass. When a glass of a slightly better appearance than the factory ribbed glass is wanted the maze glass is the best; the raised pattern imprinted on the back of this glass giving wide diffusion, especially in bright sunlight. The prisms are very much more effective than any of the glasses mentioned above, but their cost prevents their use under ordinary conditions.

Kind of Glass to Use.-Where the amount of skylight is large and the light is not obstructed by buildings plane glass is very satisfactory. Where a superior light is desired, or where the skylight area is less than ample, use factory ribbed glass in skylights and in the upper 
panes of windows. Where the skylight area is very small, the light is obstructed, or a very superior light is desired, use prisms. Wire glass should be used where there is danger from fire and in skylights, where it removes the necessity of stretching wire netting under the glass to protect it and to prevent it from falling into the building when broken.

Placing the Glass.-Factory ribbed glass is somewhat more effective if the ribs are placed horizontal, but the lines of light deflected from the horizontal ribs may become injurious to the workmen's eyes and it is now the custom to set the ribs vertical. Ribbed glass should have the ribs on the inside for ease in keeping it clean, and where double glass is used the ribs should face each other and be crossed. Care should be used in setting thick wire glass in metal frames; the lower edge must bear directly on the frame, but the top and sides should fit loosely so that the differential expansion of the glass and frame will not crack the glass. Plane glass and small panes of other kinds of glass are set with glaziers' tacks and putty. In skylights and large windows some method must be used that will allow the glass to expand and contract freely and at the same time will be free from leakage. Several methods of glazing skylights without putty are shown in Fig. I48. Skylight bar (a) manufactured by Vaile \& Young, Baltimore Md., is made of heavy galvanized iron and lead.

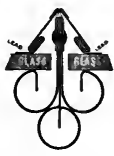

(a)

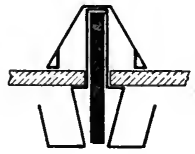

(b)

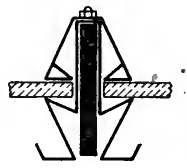

(C)

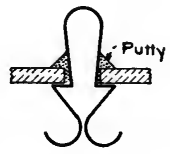

(d)

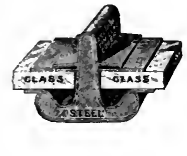

(e)

FIG. I48.

Bars (b) and (c) are made of zinc or galvanized iron, supported by a steel bar. Bar (c) is adapted to small panes of glass and is made of galvanized iron; it is made water tight by the use of putty. The skylight bars in Fig. I48, all have condensation gutters to catch the moisture that leaks through or forms on the inner surface of the glass. 


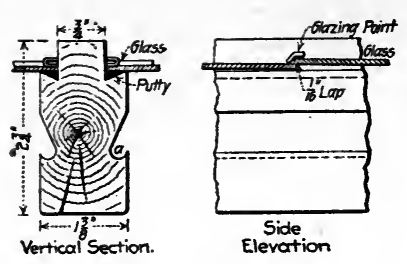

(a)

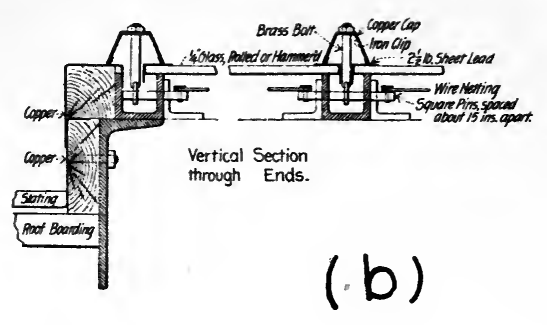

FIG. I49.

The glass in a large greenhouse at Edgely $\mathrm{Pa}$., was secured to the sash-bars as shown in (a), Fig. I49. It will be seen that the glass is imbedded in putty on the under side only, and that any water that can possibly leak through between the bar and the glass will be caught in the drip trough "a", and be carried to the eaves. The lights are $16^{\prime \prime} \times 24^{\prime \prime}$ and the sash-bars are spaced $243 / 4$ ins., c. to c. The lights are held in place by two patent glazing points per light, driven in such a way as to prevent the glass from moving. The lights overlap but I-I6-in., the leakage having been found to be smaller and less liable to occur with this than with a larger lap.

The Paradigm system of glazing is shown in (b) Fig. I49. This system is in use in a large number of shops, among which the steam engineering buildings for the Brooklyn Navy Yard, described in Part IV, is one of the best examples. The patents for the Paradigm skylight are controlled by Arthur E. Rendle, New York.

Skylights are of two types; (I) box skylights covering a small area and placed on a curb raising the glass above the roof, and (2) continuous skylights usually placed in the plane of the roof. The glass used for skylights varies from $1 / 4$ to $1 / 8$ inch thick and should preferably be wire glass. The glass used for skylights usually comes in sheets about 20 inches wide and up to 8 feet long.

The details of a box skylight manufactured by Vaile \& Young, Baltimore, Md., is shown in Fig. 150 .

Use of Window Shades.-Where factory ribbed glass is placed so as to throw light on the ceiling, screens or shades are seldom required, 


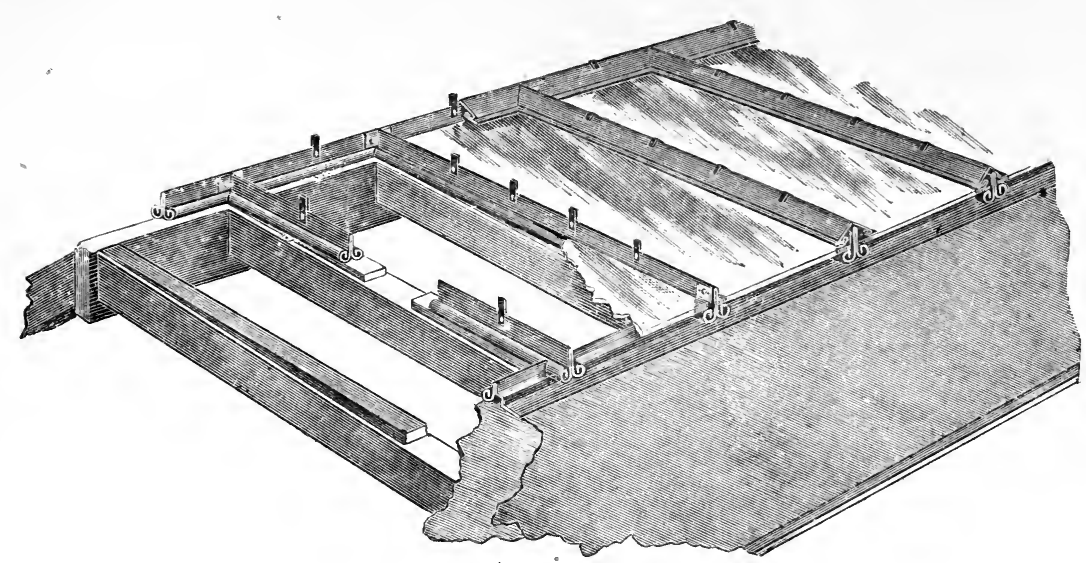

FIG. I5O.

however, under ordinary conditions shades are necessary when bright sunlight strikes the window. The glass used in factory ribbed and rough plate glass as made in England is somewhat opaque, and the atmosphere is somewhat hazy, so that the use of shades in their shops is in most cases unnecessary. The glass made in this country is so clear and our atmosphere is so translucent that it has been found necessary to use shades where windows and shades are exposed to direct sunlight. The most effective and satisfactory shade is a thin white cloth, which cuts off about 60 per cent of the light.

Size and Cost of Glass.-The regular stock sizes of plane glass varies from $6 \times 16$ inches by single inches up to $24 \times 30$ inches, and above that by even inches up to $60 \times 70$ inches for double strength glass and $30 \times 50$ inches for single strength glass.

The weights of different thickness of glass, assuming 156 pounds as the weight of one cubic foot of glass are given in the following table:

WEIGHT OF GLASS PER SQUARE, FOOT.

$\begin{array}{lllllllll}\text { Thickness-in. } \ldots \ldots \ldots \ldots \ldots \ldots \ldots & 1 / 8 & 3-16 & 1 / 4 & 3 / 8 & 1 / 2 & 5 / 8 & 3 / 4 & 1\end{array}$

Weight-lbs. ...................62 $2.43 \quad 3.25 \quad 4.88 \quad 6.50 \quad 8.13 \quad 9.7513$

The cost varies with the quality and the size, being about twice as much to glaze a given area with $30 \times 36$-inch lights as with Io $\times$ I2inch lights. The discounts given from the standard price list vary so 
much that prices are of very little value except to give an idea of the relative cost of different sizes of glass and to serve as a basis for estimates.

In 1903 American window glass was quoted ahout as given in Table XXV.

\section{TABLE XXV.}

COST OF WINDOW GLASS IN CENTS PER SQUARE FOOT.

\begin{tabular}{c|c|c|c|c|c|c|c}
\hline $\begin{array}{c}\text { Size of Lights } \\
\text { in Inches. }\end{array}$ & \multicolumn{3}{|c|}{ Single Strength. } & \multicolumn{3}{|c|}{ Double Strength. } \\
\cline { 2 - 7 } & AA & A & B & A A & A & B \\
\hline $10 \times 12$ & 5.1 & 4.3 & 4.0 & 6.8 & 6.0 & 5.5 \\
$14 \times 20$ & 5.4 & 4.5 & 4.3 & 7.5 & 6.6 & 6.1 \\
$16 \times 24$ & 5.8 & 4.8 & 4.5 & 8.3 & 7.3 & 6.7 \\
$20 \times 30$ & 6.0 & 5.1 & 4.7 & 8.9 & 7.9 & 7.4 \\
$24 \times 36$ & 6.4 & 5.5 & 4.9 & 9.4 & 8.3 & 7.6 \\
\hline
\end{tabular}

In 1903 the different kinds of glass were quoted in small quantities at the factory about as follows:

Wire glass $1 / 4$ inch thick..........23 cents per sq. ft.

Factory ribbed glass $1 / 8$ inch thick...... 9

Maze glass $1 / 8$ inch thick........... 12

Maze glass $3-16$ inch thick.......... " " " " "

Prismatic glass from 25 to $5^{\circ}$ cents per sq. ft.

Refrax glass (sheet prisms) made by the Union Plate Glass Co., Limited, Pocket Nook, St. Helens, England, was quoted in 1903 as follows at the factory: Ordinary refrax glass $1 / 4$ " thick with 5 prisms to the inch, cut to any size up to $60^{\prime \prime} \times 90^{\prime \prime}, 20$ cents per sq. ft.; wired refrax glass $5^{-1} 6$ inch thick with 5 prisms to the inch, cut to any size up to $40^{\prime \prime} \times 90^{\prime \prime}, 25$ cents per sq. ft.

Maltby prisms, made by Geo. K. Maltby, Boston Mass., 3-16" thick with 6 prisms to the inch costs about 25 to 30 cents per sq. $\mathrm{ft}$.

Cost of Windows.-Windows with frames for mill buildings will cost from 15 to 25 cents per square foot, depending upon the size and quality of the sash, the size of the opening, and cost of glass and frames. In 1900 the cost was about 16 cents per square foot for D. S. 
glass with box frames and sash, and 9 cents for S. S. glass with plank frames and sash. In I900 skylights cost from 23 to 30 cents per square foot with D. S. glass. Windows are commonly estimated at 25 cents per square foot and skylights at from 40 to 50 cents per square foot in making preliminary estimates.

The American Luxfer Prism Company manufacture sheet prisms for factory purposes that can be cut to fit any opening up to $36^{\prime \prime} \times 84^{\prime \prime}$. The cost of sheet prisms to fit ordinary windows is about 40 cents per square foot. The improved skylight prisms made by this company cost about \$I.50 per square foot.

TRANSLUCENT FABRIC.-Translucent fabric consists of a wire cloth imbedded in a translucent, impervious, elastic material, probably made of linseed oil. The fabric may be bent double without cracking and is so elastic that changes due to temperature or vibrations do not affect it. If a sheet of translucent fabric is suspended and a fire applied to the edge, it will burn up leaving a carbonaceous covering on the wire. But if the edges are protected it will burn only with great difficulty. Live coals falling on skylights of this material will char and burn holes but will not set fire to the fabric. It is therefore practically fireproof.

Translucent fabric will not transmit as much light as glass, but makes a most excellent substitute therefore. It shuts off sufficient light so that the lighting is uniform throughout the shop and makes it possible for men to work directly under it without shading. Where one-quarter of the roof is covered with the fabric the lighting is practically perfect. The fabric should be washed with castile soap and warm water occasionally, and should be varnished every year or two. with a special varnish furnished by the manufacturers. It is said to become less opaque with age. When properly cared for the fabric has been known to give good service for ten years. The fabric is manufactured in sheets $3^{\prime} 3^{\prime \prime}$ wide and in lengths from $4^{\prime} 6^{\prime \prime}$ to $9^{\prime} \mathrm{O}^{\prime \prime}$. The framework for translucent fabric is the best made of wood. A standard frame for sheets $3^{\prime} 3^{\prime \prime} \times 6^{\prime} 3^{\prime \prime}$ is shown in Fig. I51. The fabric must be stretched tight and carefully. nailed around the edges of the sheet. The capped joint with metal cap shown in Fig. I5I is very 
satisfactory as it holds the fabric tight, and will give slightly to accommodate changes in temperaturs.

Cost of Translucent Fabric.-The fabric costs from I 3 to I 5 cents per square foot at the factory at Quincy, Mass. The framework, freight and cost of laying will probably be as much more, making the entire cost of skylights from 25 to 30 cents per square foot.

Translucent fabric has been quite widely used and has given uniformly good results. It has been used recently in the A. T. \& S. F. R. R. shops at Topeka, Kas.

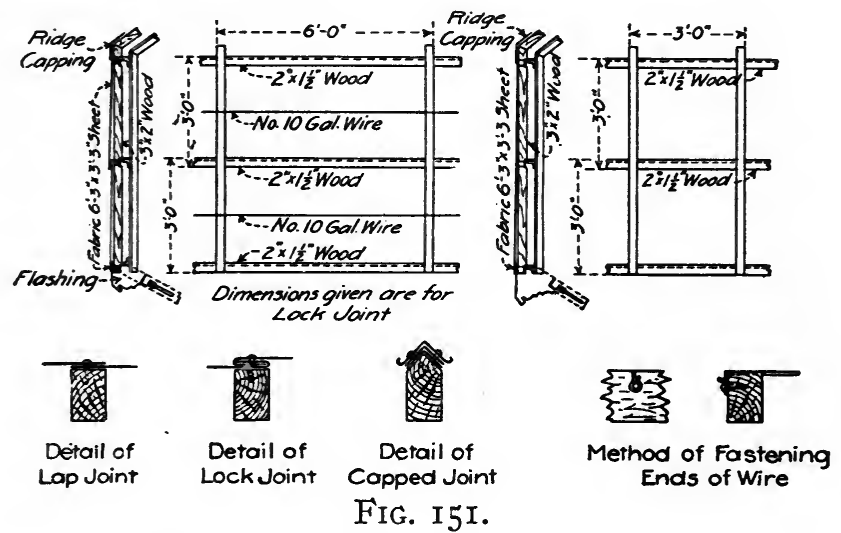

Double Glazing.-The condensation on the inner surface of glass can be prevented by double glazing the windows and skylights. Buildings with double glazing are also very much easier to heat than those with single glazing, the air space between the sheets of glass acting as an almost perfect non-conductor of heat.

Details of Windows and Skylights.-The details of windows in use in different sections of the country vary a great deal on aceount of the varied conditions. In buildings that have to be heated and ventilated through the windows at the same time, it is necessary to provide some means of opening and closing the windows quickly and easily; while in many other cases the sash can remain fixed. The author would call especial attention to the saving in fuel by the use of double glazing; the loss of heat through a double glazed skylight has been shown by 
experiment to be only about one-half what it is through a single glazed skylight.

Details of windows for use in ordinary brick and stone walls can be found in books on architectural construction and will not be given here. A few of the best designs available for windows in buildings with corrugated steel, expanded metal and plaster, and similar walls, have been selected and are given on the following pages.

The different types of windows for buildings covered with corrugated steel siding as used by the American Bridge Company are shown in Figs. $15^{2}$ to 156 inclusive.

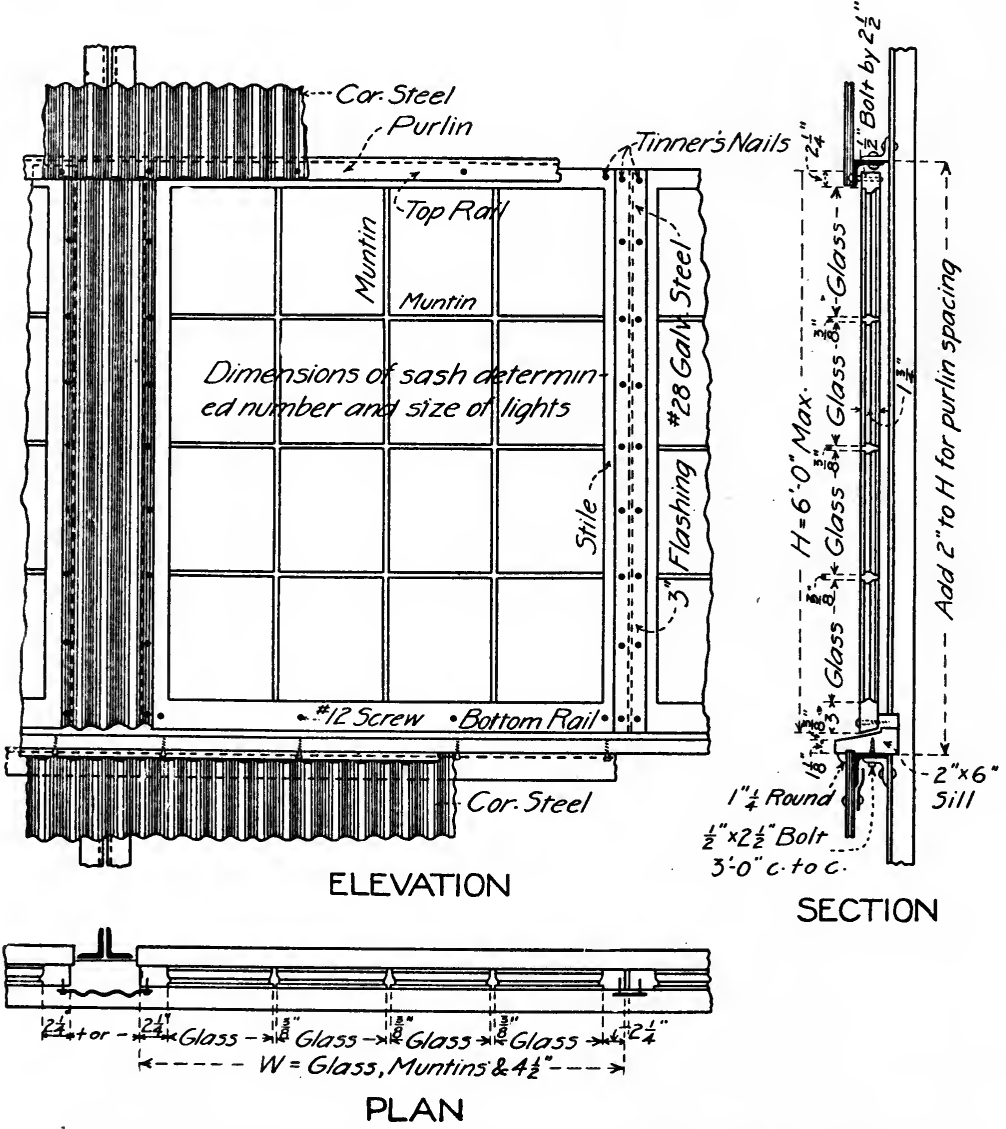

Fig. I52. DESIGN FOR A CONTINUOUS FIXED SASH WINDOW. 
The sash frames are constructed of white pine and are glazed usually with A qualityAmerican glàss. 'The common sizes of glass used in these windows are $10^{\prime \prime} \times 12^{\prime \prime}, 12^{\prime \prime} \times 12^{\prime \prime}, 1^{\prime \prime} \times 14^{\prime \prime}$ and $12 " \times 14 "$ single strength. For lights larger than $12^{\prime \prime} \times 14^{\prime \prime}$, double strength glass is used. The window shown in Fig. I $5^{2}$ is used where light is desired without ventilation. This detail is used principally for monitor ventilators or for windows placed out of reach. Where it is desirable to obtain ventilation as well as light the window frame with sliding sash shown in Fig. 153 is used.
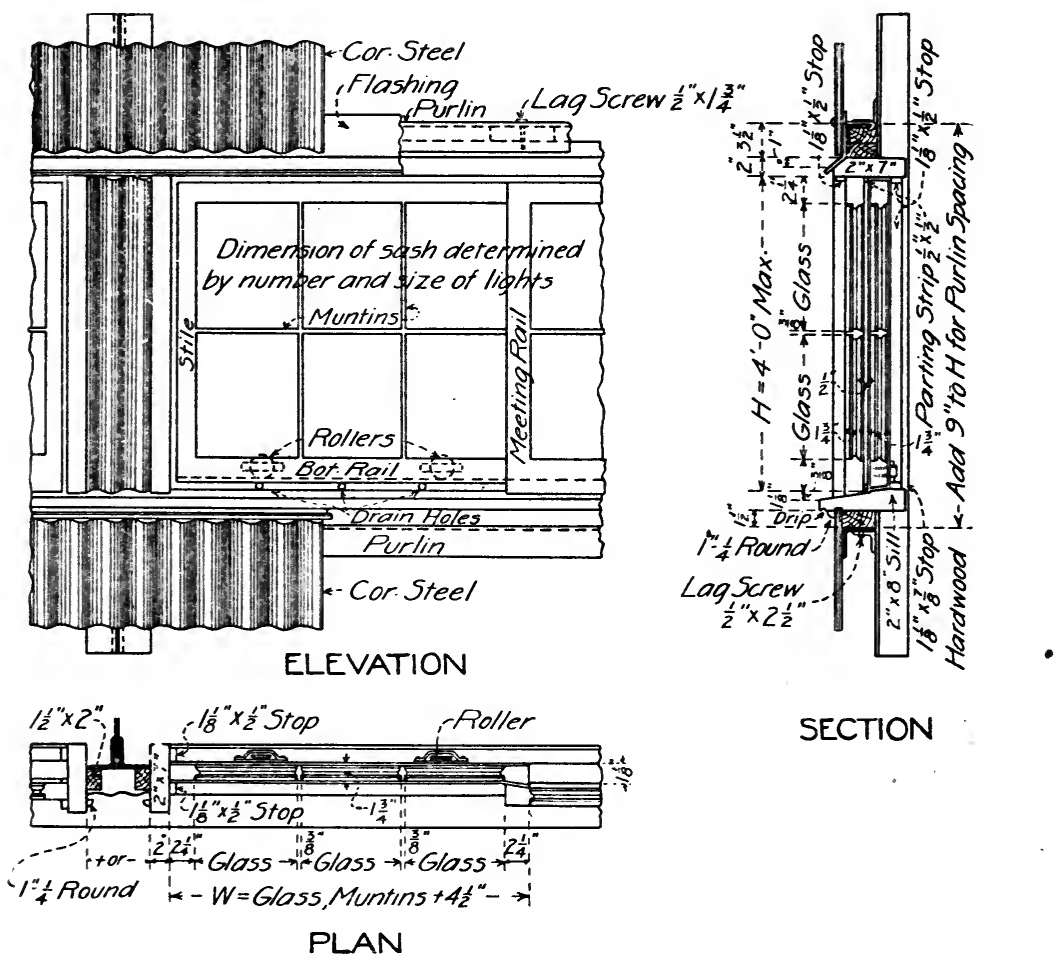

SECTION

FIG. 153. DESIGN FOR WINDOW FRAME WITH SLIDING SASH. 


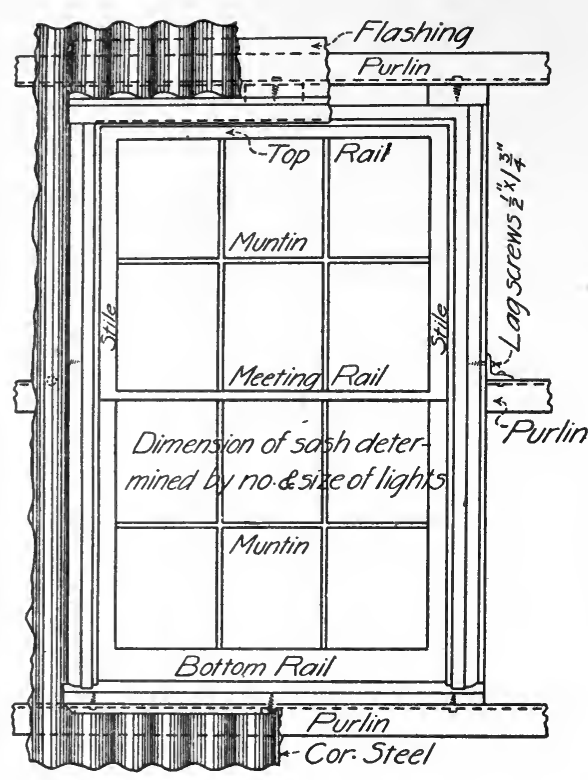

ELEVATION

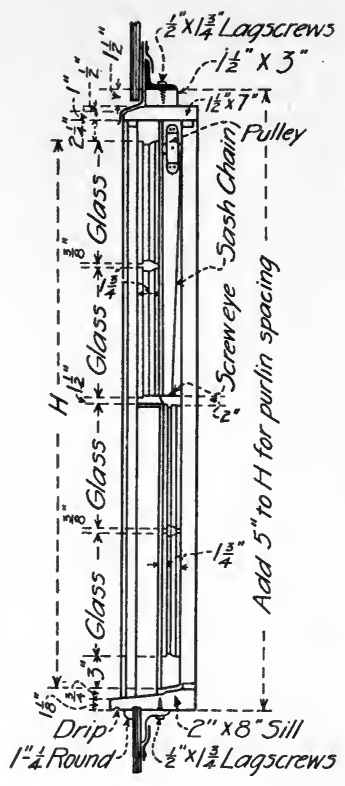

SECTION

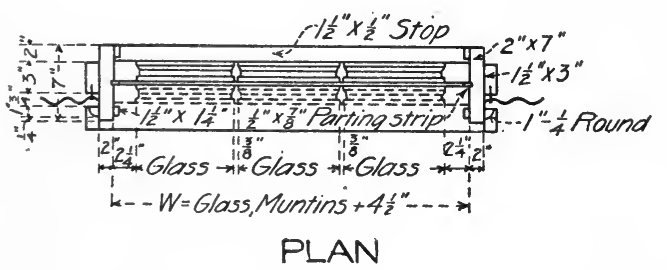

FIG. I54. DESIGN FOR WINDOW FRAME WITH COUNTERBALANCED SASH.

Amount of Light Required.--The amount of glazed surface required in mill buildings depends upon the use to which the building is to be put, the material used in glazing, the location and angle of the windows and skylights, and the clearness of the atmosphere. In glazing windows for mills and factories in which the determination of color is a necessary part of the work, care should be used to obtain a clear white glass for the reason that the ordinary commercial glass breaks up the light passing through it so that the determination of color is difficult. 


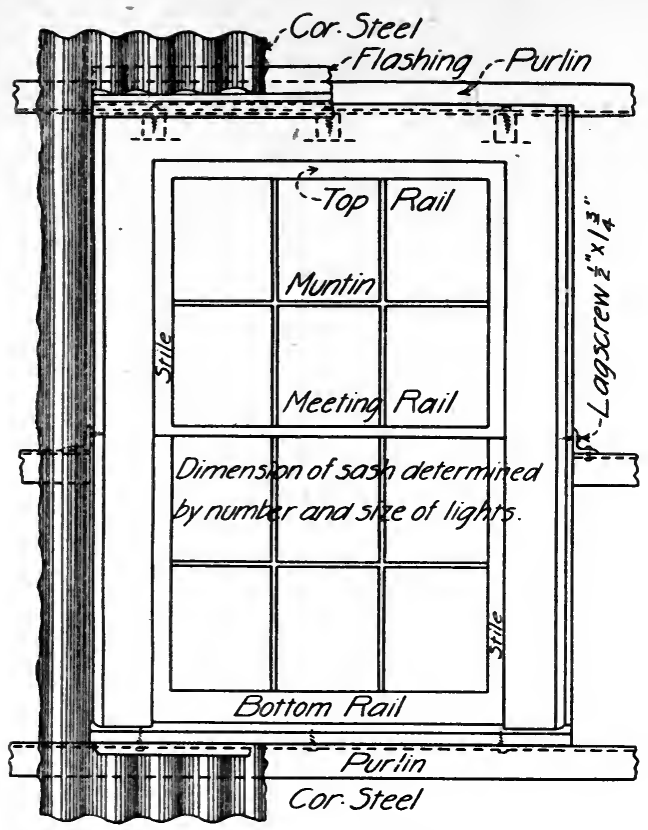

ELEVATION

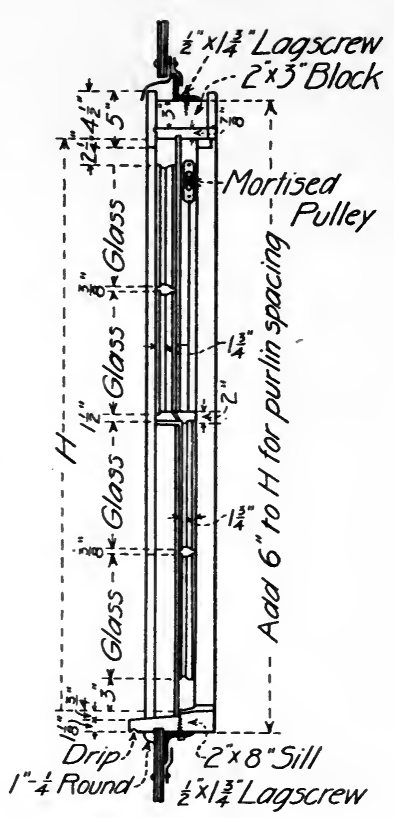

SECTION

$$
\begin{gathered}
\text { PLAN } \\
\text { PLAN }
\end{gathered}
$$

Fig. I55. Design For Window Frame With Weighted SASH.

It is common to specify that not less than Io per cent of the exterior surface of ordinary mill buildings and 25 per cent of the exterior surface of machine shops and similar structures shall be glazed. Onehalf of the glazing is usually required to be in the roof in the form of skylights. With translucent fabric it has been found that the lighting is good where 25 per cent of the roof is glazed.

The present tendency in shop and factory design is to make as 

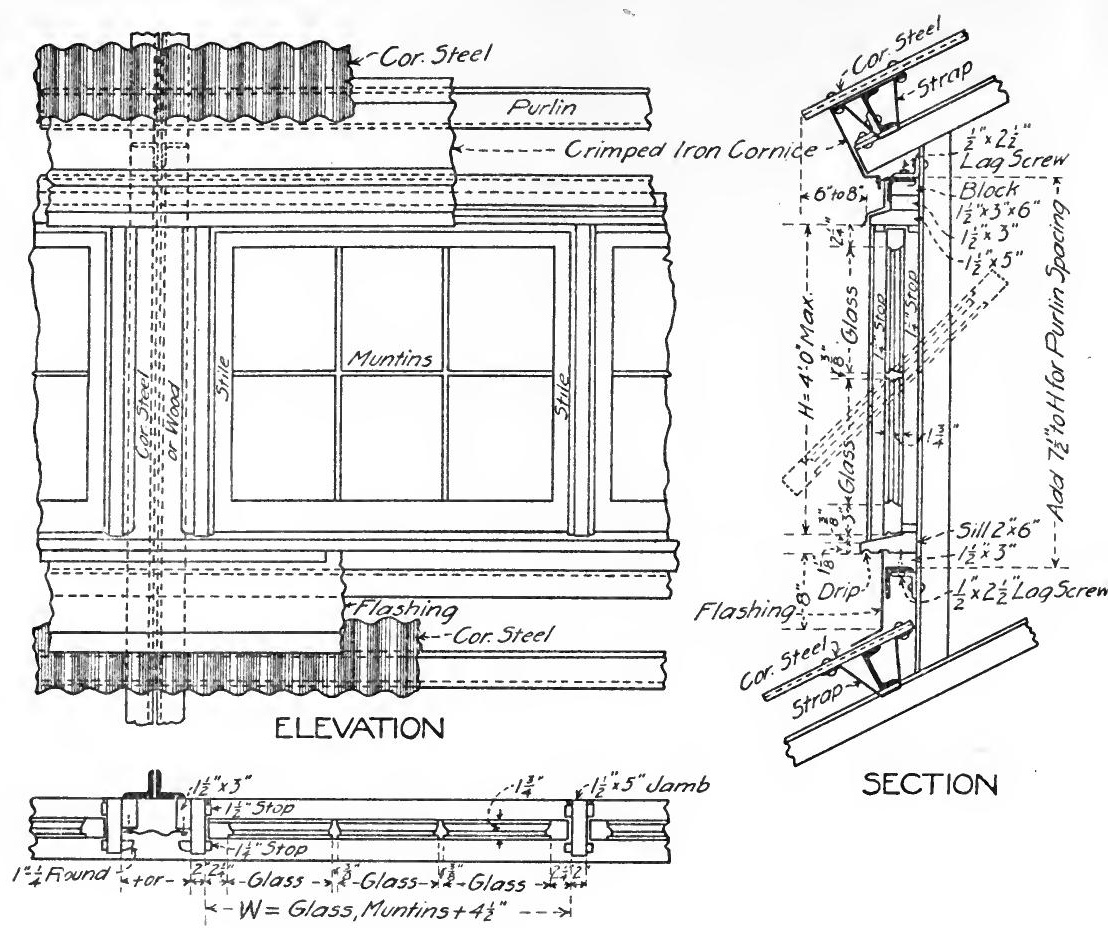

\section{PLAN}

Fig. I56. DESIGN FOR WINDOW FRAME, WITH SWINGING SASH.

much of the side walls and roof of glass as possible; the danger of leakage around and through skylights has prevented many from making use of skylights, although with the present methods of glazing there is no reason why any leakage should occur. The shops of the Grant Tool Company, at Franklin, Pa., shown in Fig. $\mathrm{I}_{57}$, is a good illustration of side wall lighting, while the steam engineering buildings for the Brooklyn Navy Yard, described in Part IV, is a good illustration of side wall and skylight lighting. The A. T. \& S. F. shops described in Part IV, is a good illustration of side wall, skylight and saw tooth roof lighting combined.

The Central Railway of New Jersey shops at Elizabeth, N. J., have skylights made of translucent fabric in the different buildings in 


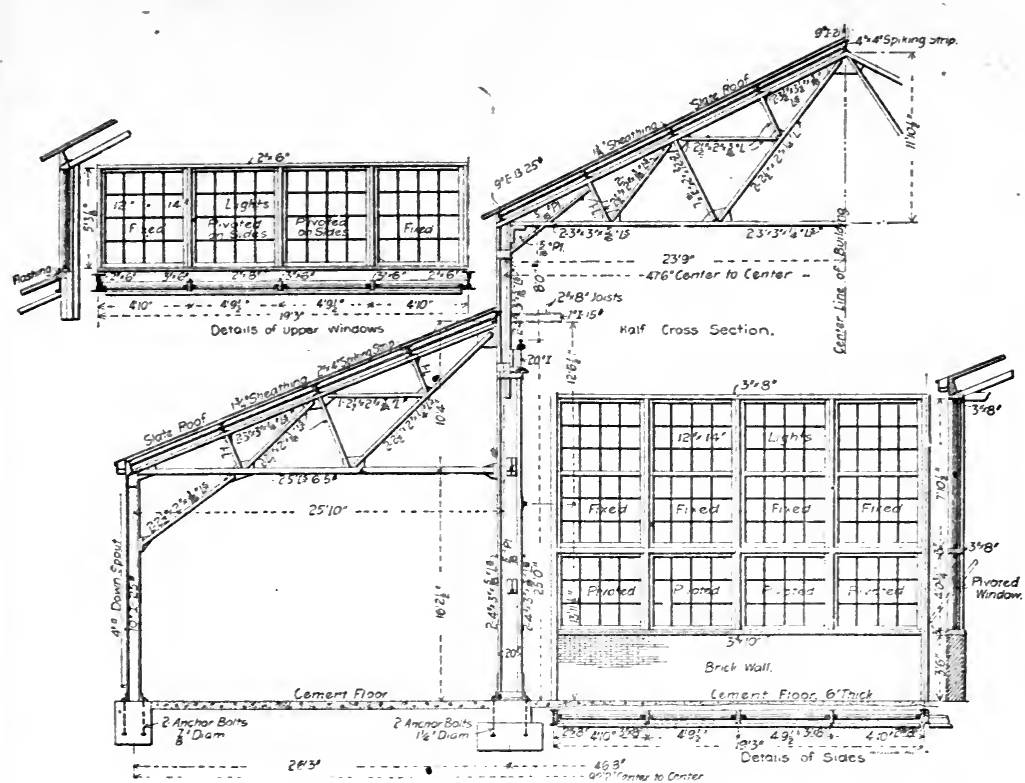

Fig. I57. Shops OF THE GRANT TOOL WORKS, FRANKLIN, PA.

per cents of the entire roof surface as follows: Blacksmith shop 30 per cent; machine shop 36 per cent; and paint and repair shop 55 per cent.

The Lackawanna and Western Railway blacksmith shop has I3 square feet of skylight per Ioo square feet of floor area.

In the Great Northern Railway shops at St. Paul, Minn.,--Railway Gazette, June I6, I903-all skylights have $1 / 4$-inch ribbed glass, below which is double strength window glass. Suitable drainage is provided for the moisture which collects on the upper surface of the latter. Wire netting is stretched under the skylights to prevent broken glass from falling into the shops. The walls are supplied with windows set at I2 feet centers, 55 panes to each sash.

The skylights of the A. T. \& S. F. R. R. shops at Topeka, Kas., are made of translucent fabric, about 20 per cent of the roof surface heing fabric.

The skylights of the machine shop of the Chicago City Railway are made of wire glass, about 35 per cent of the roof being glass. 
The machine shop of the Lehigh Valley Ry., at Sayre, Pa., will have the side windows of plane glass. The locomotive shop will have factory ribbed glass in the side windows and wire glass in the roof and monitor skylights.

About 25 per cent of the roof of the St. Louis Train Shed is skylight.

In the American Car and Foundry Company's shop at Detroit, about 27 per cent of the exterior surface is ribbed glass.

Fully 60 per cent of the exterior surface of the Steam Engineering Buildings for the Brooklyn Navy Yard is of glass. 


\section{CHAPTER XXIV.}

\section{VENTILATORS.}

Ventilation.-Mill buildings are ventilated either by forced draft or by natural ventilation. Natural ventilation is usually sufficient, although forced ventilation is necessary in many factories and mills. The problem of ventilation is too large to consider fully in this place and the natural method of ventilation only will be discussed. The amount of air required depends on the use to which the building is to be put; a common specification for the ventilation of mill buildings being that ventilators shall be provided and located so as to ventilate the building properly, and shall have a net opening for each 100 square feet of floor space of not less than one-fourth square foot for clean machine shops and similar buildings; of not less than one square foot for dirty machine shops; of not less than four square feet for mills; and not less than six square feet for forge shops, foundries and smelters. Ventilators in high buildings are more effective than in low ones. The following table will give an idea of the effect of height on ventilation.* Height above ground.

Machine shop, sq. ft. per Ioo $7 / 8$ Mills, Forge shops,
$2 \mathrm{O}^{\prime}$

$$
78
$$$$
7
$$

9

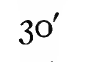
$3 / 4$

6

8
$4 \mathrm{O}^{\prime} \quad 5 \mathrm{O}^{\prime}$

$5 / 8 \quad 1 / 2$ round vents.

5

7
4 Louvre vents.

6 Louvres or open vents.

Monitor Ventilators.-The openings in the clerestory of monitors are fitted with louvres, shutters or sash, or may be left entirely open. Louvres are made in many different ways, the Shiffler Louvres shown in Fig. 158, and the Berlin Louvres shown in Fig. I59, are in common use. The details of these louvres as made by various firms differ somewhat.

*Mill Building Construction, H. G. Tyrrell. 


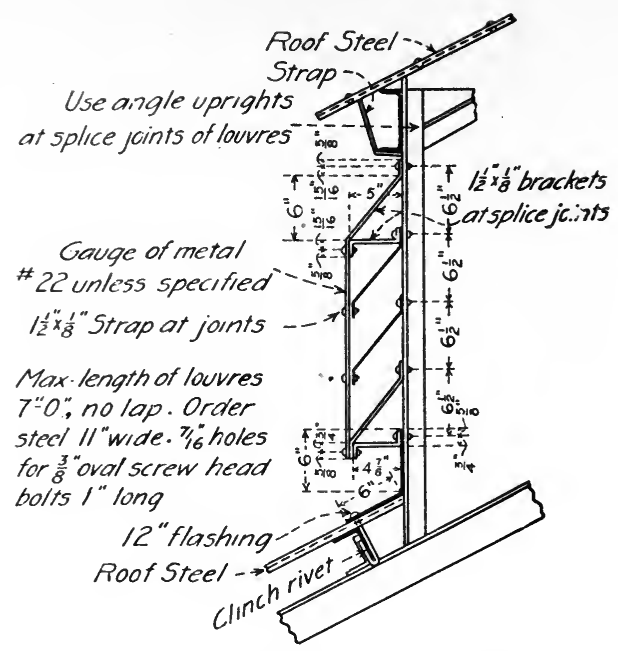

FIG. I58. SHIFFLER LOUVRES.

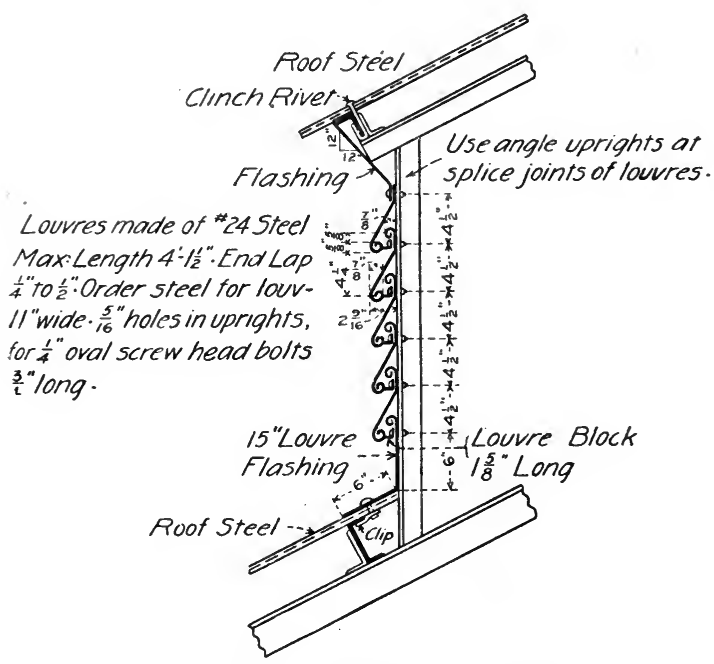

FIG. I59. BerLIN LOUVRES.

The details of the Shiffler louvres shown in Fig. 158 , and of the Berlin louvres shown in Fig. I59 are those adopted by the American Bridge Company. The details of the louvres are shown in the cuts and need no further explanation. 


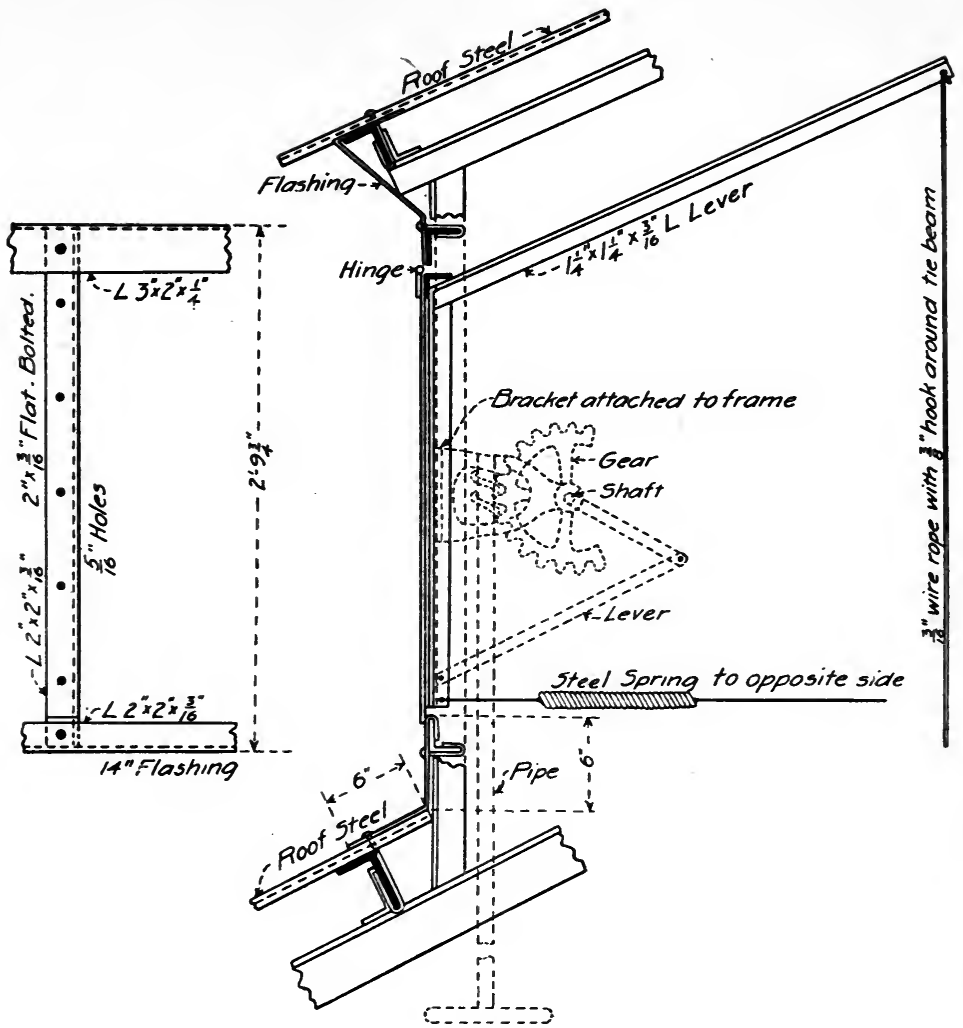

Fig. i6o. Hinged Monitor ShUtTer.

Details of a hinged shutter are shown in Fig. I60. The angle iron frame is covered with a corrugated iron covering. The shutters are made from 6 to Io feet long, with two hinges for shutters 8 feet long and three hinges for shutters more than 8 feet long. Where shutters are to be glazed they are hung as in Fig. ${ }_{5} 6$. The lever gear shown by the dotted lines is used in the better class of structures. This device can be used where the shutters are glazed if care is used in operating.

In smelters the clerestory of the monitor is often left entirely open or is slightly protected by self acting shutters. In the latter case the shutters are hinged at the bottom and are connected at the top with each other and with a counter-weight so that the shutter will ordinarily make 
an angle of about 30 degrees with the vertical. A wind or a storm will close the windward shutter and open the leeward shutter wider. The eaves of the monitor are made to project, so that very little of the storm enters.

Cost.-The shop, cost for louvres is ordinarily about I cent per pound. To this must be added the cost of the sheet steel and the cost of the framework and details. In 1900 louvres without frames cost about 25 cents per square foot.

Circular Ventilators.-Circular ventilators are often used for ventilating mill buildings in place of the monitors, and on buildings requiring a small area for ventilation. They are made of galvanized iron, copper or other sheet metal, and are usually placed along the ridge line of the roof.
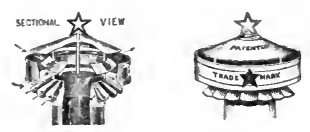

"STAR" VENTILATOR
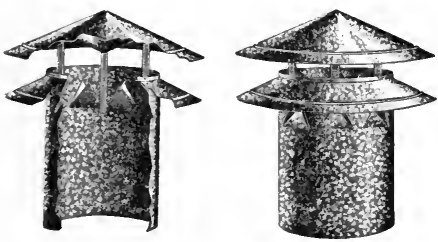

GARRY VENTILATOR
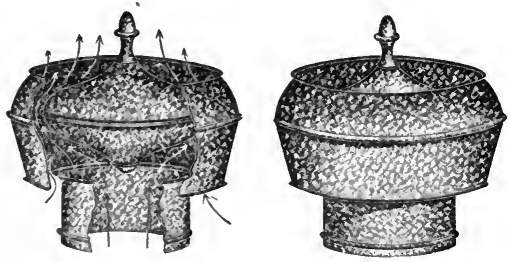

Acorn Ventilator.
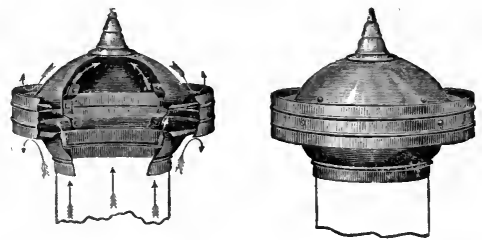

Globe Ventilator
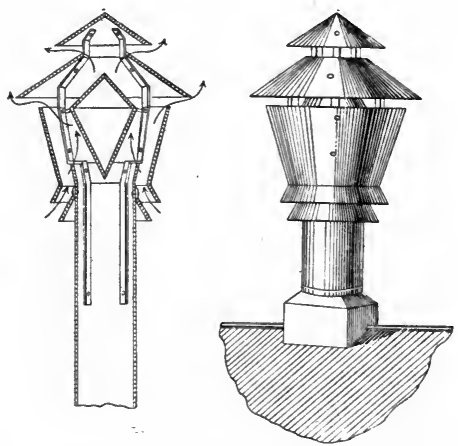

BUCKEYE VENTILATOR.

Fig. i6i. Circular ventilators. 
There are many styles of circular ventilators on the market, a few of which are shown in Fig. I6r. The Star ventilator made by Merchant \& Co., Chicago, is quite often used and is quite efficient. It is made in sizes varying from 2 to 60 inches. In 1903 Star ventilators made of galvanized iron were quoted about as follows: I2-in., \$2.00; I8-in., \$6.75; 24-in., \$10.00; 40-in., \$45.00.

The Globe ventilator made by the Cincinnati Corrugating Company, Cincinnati, Ohio; the Garry ventilator made by the Garry Iron \& Steel Roofing Co., Cleveland, Ohio; and the Acorn and Buckeye ventilators made by the Youngstown Iron \& Steel Roofing Co., Youngstown, Ohio, are quite efficient and all cost about the same as the Star except the Garry ventilator, which is cheaper.

Home-made circular ventilators can be made that are quite as satisfactory as the patented ventilators and are much less expensive. In I900, ten 36-inch circular ventilators cost \$12.25 each, and two 24inch circular ventilators cost $\$ 9.25$ each in Minneapolis, Minn. The cost of the 24-inch ventilators was large on account of the small number made. 


\section{CHAPTER XXV.}

\section{Doors.}

Paneled Doors.-For openings from $2^{\prime} \mathrm{o}^{\prime \prime} \times 6^{\prime} \mathrm{o}^{\prime \prime}$ to $3^{\prime} \mathrm{o}^{\prime \prime} \times 9^{\prime} \mathrm{o}^{\prime \prime}$ ordinary stock paneled doors are commonly used. The stock doors vary in width from $2^{\prime} \mathrm{O}^{\prime \prime}$ to $3^{\prime} \mathrm{O}^{\prime \prime}$ by even inches and in length by $4^{\prime \prime}$ to $6^{\prime \prime}$ up to $7^{\prime} \mathrm{O}^{\prime \prime}$ for $2^{\prime} \mathrm{o}^{\prime \prime}$ doors, and $9^{\prime} \mathrm{o}^{\prime \prime}$ for $3^{\prime} \mathrm{o}^{\prime \prime}$ doors. Stock doors are made $\mathrm{I} 3 / 8$ and $\mathrm{I} 3 / 4$ inches thick, and are made in three grades, $\mathrm{A}, \mathrm{B}$ and $\mathrm{C}$; the $\mathrm{A}$ grade being first class, $\mathrm{B}$ grade fair and $\mathrm{C}$ grade very poor. Paneled doors up to 7 feet wide and $2 \frac{1}{4}$ inches thick can be obtained from most mills by a special order.

Wooden Doors.-Wooden doors are usually constructed of matched pine sheathing nailed to a wooden frame as shown in Fig. 162 and Fig. I63.
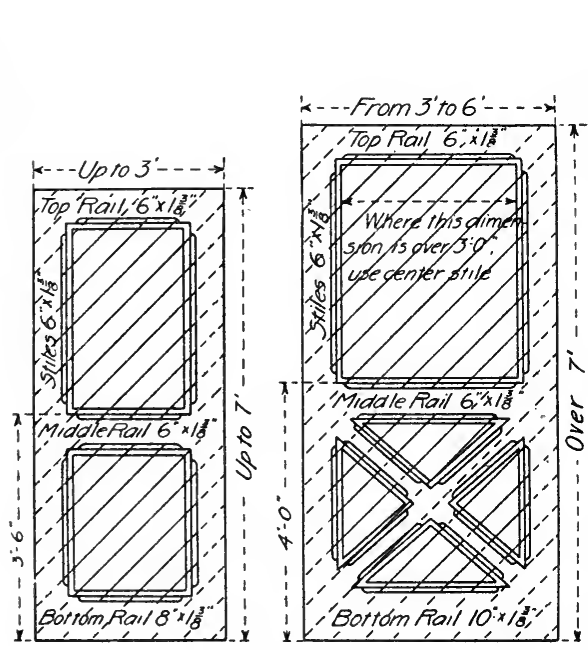

Swing Wooden Doors

FIG. I62.

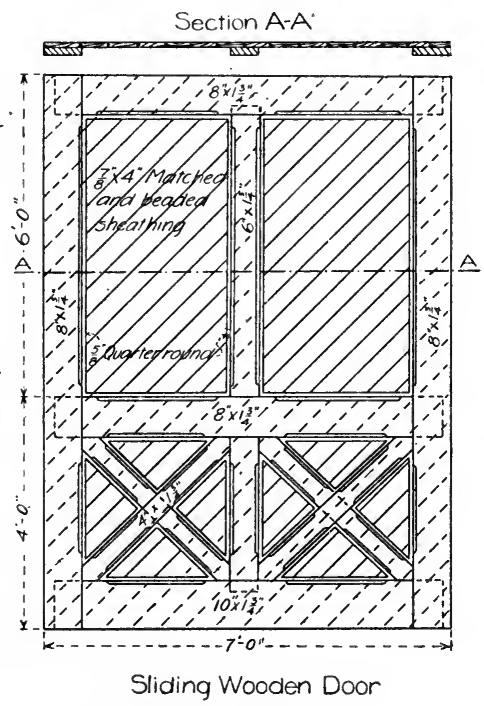

FIG. I63. 
Designs for wooden swing doors are shown in Fig. 162, and for a wooden sliding door in Fig. I63. These doors are made of white pine. Doors up to four feet in width should be swung on hinges; wider doors should be made to slide on an overhead track or should be counterbalanced and raise vertically. Sliding doors should be at least 4 inches wider and 2 inches higher than the clear opening.

"Sandwich" doors are made by covering a wooden frame with flat or corrugated steel. The wooden framework of these doors is com- monly made of two or more thicknesses of $7 / 8$-inch dressed and matched white pine sheathing not over 4 inches wide, laid diagonally and nailed with clinch nails. Care must be used in handling sandwich doors made as above or they will warp out of shape. Corrugated steel with $1 / 1 / 4-$ inch corrugations makes the neatest covering for sandwich doors.

For swing doors use hinges about as follows: For doors $3^{\prime} \times 6^{\prime}$ or less use Io-inch strap or Io-inch 'T hinges; for doors $3^{\prime} \times 6^{\prime}$ to $3^{\prime} \times 8^{\prime}$ use 16 -inch strap or 16-inch $T$ hinges; for doors $3^{\prime} \times 8^{\prime}$ to $4^{\prime} \times 10^{\prime}$ use 24 -inch strap hinges.

Steel Doors.-Details of a steel lift door are shown in Fig. 164. This door is counterbalanced by weights and lifts upward between ver-

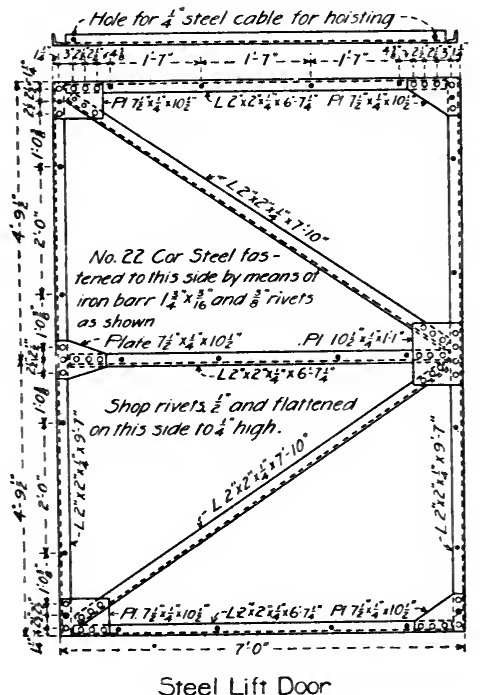

Steel Lift Door

FIG. 164. 
tical guides. This door was covered with corrugated steel with $\mathrm{I}^{\mathrm{I}} / \mathrm{A}^{-}$ inch corrugations as described in the cut.

Details of a steel sliding door are shown in Fig. I65. This door is made to slide inside the building and swing clear of the columns. Where the columns are so close together that there is not room enougin for the door to slide the entire length of the opening, it should be placed on the outside of the building. The track and hangers shown

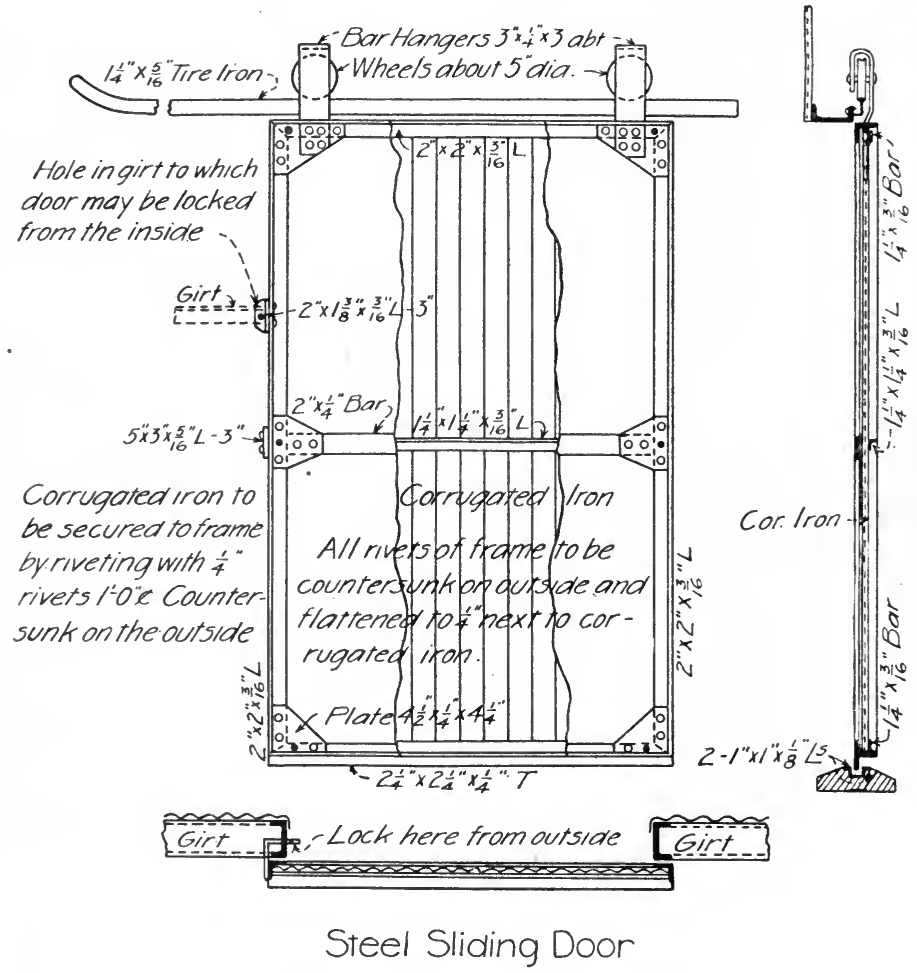

FIG. I65.

make a very satisfactory arrangement; however there is a tendency for the wheels to jump the track unless the grooves in the wheels are made very deep.

There are quite a number of patented devices on the market for hanging sliding doors. The Wilcox trolley door hanger, track and 
bolt latch shown in Fig. I66, are efficient and are quite generally used. The prices of the door fixtures shown in Fig. I66 are about as follows : door hangers, $\$ 2.25$ to $\$ 3.00$ per pair; steel track, Io to $25 \mathrm{cts}$. per $\mathrm{ft}$. ; clips, $I_{5}$ to $25 \mathrm{cts}$. each; door latch, \$1.00, f. o. b. the factory at Aurora, Ill. Discounts for this and several other well known makes of door fixtures are given each week in the Iron Age, New York, and the list prices are given in the manufacturer's catalogs.

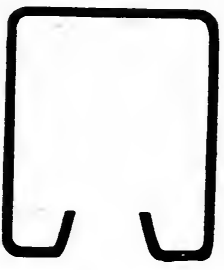

Wilcox 0. K. Steel Track

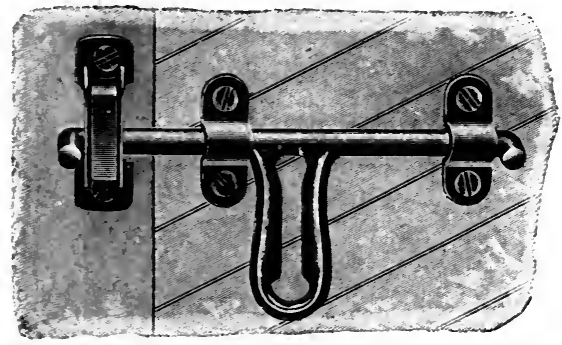

Wilcox Gravity Door Bolt and Latch

FIG. I66.

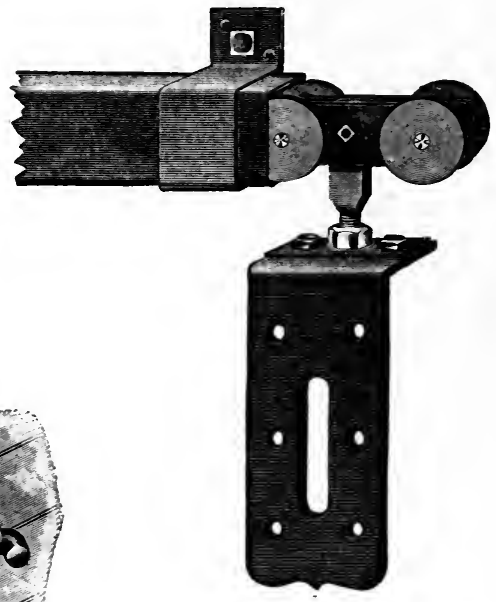

Wilcox Trolley Door Hanger

Cost of Doors.-Stock panel doors cost $\$$ I.50 to $\$ 5.00$ each, depending upon the grade, size and conditions. The details of steel doors vary so much that it is necessary to make detailed estimates in each case. The shop cost of the framework is often quite high and may run as high as 3 or $4 \mathrm{cts}$. per pound. The wooden frames for sandwich doors cost from 20 to 25 cts. per square foot. The cost of hinges, bolts, etc., required for doors can be found by applying the discounts given in the Iron Age to the list prices given in the standard lists (see Chapter XXVIII). 


\section{CHAPTER XXVI.}

\section{Shop Drawings and Rules.}

SHOP DRAWINGS.-The rules for making shop drawings in use by the American Bridge Company are given in their Standards for Structural Details, and are reprinted in part, in Roofs and Bridges, Part III, by Merriman and Jacoby. The following rules are essentially those in common use by bridge companies, for mill buildings and warehouses.

Make sheets for shop details 24 by 36 inches, with two border lines, $1 / 2$ and $I$ inch from the edge, respectively. For mill details use special beam sheets. The title should come in the lower right hand corner, and should contain the name of the job, the contract number, and the initials of the draftsman and checker.

Detail drawings should be made to a scale of $3 / 4$ to $\mathrm{I}$ inch to the foot. Members should be detailed as nearly as practicable in the positions in which they occur in the structure. Show all elevations, sections, and views in their proper positions. Holes for field connections should always be blackened. Members that have been cut away to show a section, may be either blackened or cross-hatched. Members, the ends of which are shown in elevation or plan, should be neither blackened nor cross-hatched. Holes for field connections should be located independently, and should be tied to a gage line of the member. When metal is to be planed, the ordered and finished thickness should be given.

In making shop drawings for mill buildings two methods are in use.

The first method is to make the drawing so complete that templets can be made for each individual piece, separately on the bench.

The second method is to give on the drawings only sufficient dimensions to locate the interior of the members and the position of the 
pieces, leaving the templet-maker to work out the details on the layingout floor.

The first method is illustrated in Fig. 96, and the second in Fig. 95. In the second method sufficient figures should be given to properly locate the main points in the truss; the interior pieces should be located by center-lines corresponding to the gage lincs of the rivets, the centers of gravity lines or the outside edges of the pieces, as the case may be. The drawings should always indicate the number of rivets to be used in each connection, the size of rivets, the usual rivet pitch, and the minimum pitch allowed.

Erection Plan.- The erection plan should be made very complete. All the notes that it is necessary for the erecter to have, should be put on the erection plans; how much of the structure is to be riveted and how much bolted, whether it is to be painted after erection or not, whether the windows and doors are to be erected or not, etc. Center line drawings are usually sufficient for the erection plans. The name and the size of the piece should be given and every piece should have a name.

The following method was used by the Gillete-Herzog Mfg. Co., for mill buildings, and was very satisfactory:

If the points of the compass are known, mark all pieces on the north side with the letter " $N$ ", those on the south side with the letter "S", etc. Mark girts N. G. I; N. G. 2; etc. Mark all posts with a different number, thus: N. P. I ; N. P. 2 ; etc. Mark small pieces which are alike with the same mark; this would usually include everything except posts, trusses and girders, but in order to follow the general marking scheme, where pieces are alike on both sides of a building, change the general letter; e. g. N. G. 7 would be a girt on the north side and S. G. 7 the same girt on south side. Then in case the north and south sides are alike, only an elevation of one side need be shown, and under it a note thus: "Pieces on south side of building, in corresponding positions have the same number as on this side, but prefixed by the letter "S" instead of the letter "N." Mark trusses T. I; T. 2 ; etc. Mark roof pieces R. I ; R. 2 ; etc. 
The above scheme will necessarily have to be modified more or less according to circumstances; for example, where a building has different sections or divisions applying on the same order number, in which case each section or division should have a distinguishing letter which should prefix the mark of every piece. In such cases it will perhaps be well to omit other letters, such as N., S., etc., so that the mark will not be too long. for easy marking on the piece. In general, however, the scheme should be followed of marking all the large pieces, whether alike or not, with a different mark. This would refer to pieces which are liable to be hauled immediately to their places from the cars. But for all smaller pieces which are alike, give the same mark.

For architectural buildings adopt the following general scheme of marking: The basement "A"; first floor " $\mathrm{B}$ "; second floor " $\mathrm{C}$ "; then mark all the pieces on the first floor B. I ; B. 2 ; etc. ; columns between first and second floors B. C. I; B. C. 2 ; etc.

It will greatly aid the detailing, checking and erection if small sections are made showing the principal connections, such as girt connections, purlin connections, etc.

The erection plans of a mill building drawn in accordance with these rules are shown in Fig. I67 and Fig. I68.

CHOICE OF SECTIONS.-In designing, it will be found economical to use minimum weights of sections, and to use sections that can be most easily obtained. As small a number of sizes should be used as is practicable where material is to be ordered from the mill, ir good delivery is to be expected. The ease with which any section can be obtained in a mill order, depends upon the call that that particular mill is having for the given section. If there is a large demand for the section, it will be rolled at. frequent intervals, while if there is little or no demand for the section, the rollings are very infrequent and a small order may have to wait for a long time before enough orders for the section will accumulate that will warrant a special rolling. The ease with which sections can be obtained will, therefore, depend upon the mill and the conditions of the market. The standard and permissible 
sizes of. sections in use by the American Bridge Company, are given in the following table.

Standard Angles.

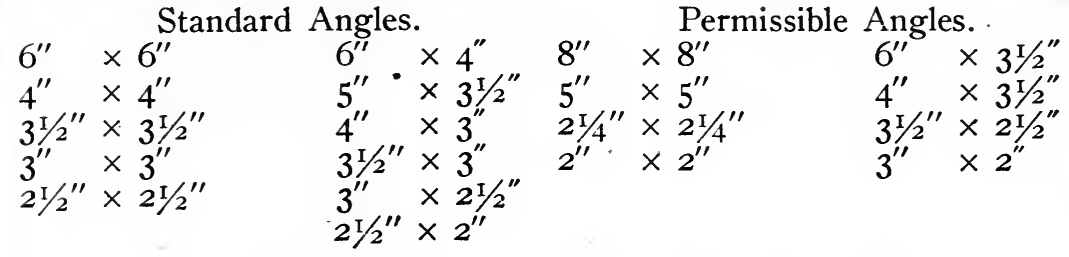

Standard Channels.

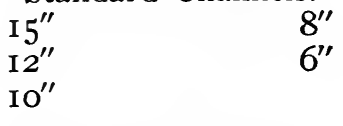

Standard I Beams.

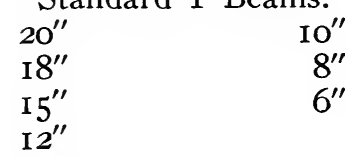

Permissible Channels

$$
\begin{aligned}
& 9^{\prime \prime} \\
& 7^{\prime \prime} \\
& 5^{\prime \prime}
\end{aligned}
$$

Permissible I Beams.

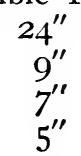

Permissible Tees.

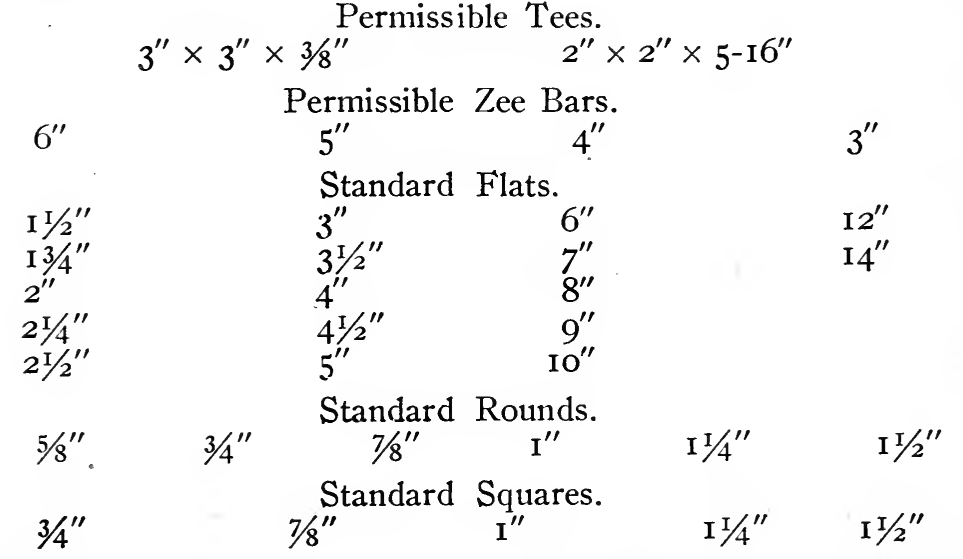

Other sizes than those specified may be obtained, but the time of delivery will be very uncertain unless the order is large enough to warrant a rolling.

Deck beams, bulb angles and special section Z-bars are hard to get unless ordered in large quantities. Flats $1 / 2^{\prime \prime}$ thick and under are very hard to get.

Flats under 4 " should "be ordered by $1 / 2$ " variation in width; flats and universal plates over 4 " should be ordered by $\mathrm{I}^{\prime \prime}$ variation in width. 


\section{CHAPTER XXVII.}

\section{Paints and Painting.}

Corrosion of Steel.-If iron or steel is left exposed to the atmosphere it unites with oxygen and water to form rust. Where the metal is further exposed to the action of corrosive gases the rate of rusting is accelerated, but the action is similar to that of ordinary rusting. Rust is a hydrated oxide of iron, and forms a porous coating on the surface of the metal that acts as a carrier of oxygen and moisture, thus promoting the action of corrosion. If nothing is done to prevent or retard the corrosion of the iron and steel used in metal structures, the metal rapidly rusts away and the structure is short lived. Wrought iron is affected by corrosion more than cast iron, and steel is affected more than wrought iron.

The corrosion of iron and steel may be prevented or retarded by covering it with a coating that is not affected by the corroding agents. This is very effectually accomplished by galvanizing; but on account of the cost it is impracticable to use the process for coating anything but sheet steel and small pieces of structural steel. The most common methods of protecting iron and steel are by means of a coating of paint, or by imbedding it in concrete.

PAINT.-The paints in use for protecting structural steel may be divided into oil paints, tar paints, asphalt paints, varnishes, lacquers, and enamel paints. The last two mentioned are too expensive for use on a large scale and will not be considered.

OIL PAINTS.-An oil paint consists of a drying oil or varnish and a pigment, thoroughly mixed together to form a workable mixture. "A good paint is one that is readily applied, has good covering powers, 
adheres well to the metal, and is durable." The pigment should be inert to the metal to which it is applied and also to the oil with which it is mixed. Linseed oil is commonly used as the varnish or vehicle in oil paints, and is unsurpassed in durability by any other drying oil. Pure linseed oil will, when applied to a metal surface, form a transparent coating that offers considerable protection for a time, but is soon destroyed by abrasion and the action of the elements. To make the coating thicker, harder and more dense, a pigment is added to the oil. An oil paint is analogous to concrete, the linseed oil and pigment in the paint corresponding to the cement and the aggregate in the concrete. The pigments used in making oil paints for protecting metal may be divided into four groups as follows: (I) lead; (2) zinc; (3) iron; (4) carbon.

Linseed Oil.-Linseed oil is made by crushing and pressing flaxseed. The oil contains some vegetable impurities when made, and should be allowed to stand for two or three months to purify and settle before being used. In this form the oil is known as raw linseed oil, and is ready for use. Raw linseed oil dries (oxidizes) very slowly and for that reason is not often used in a pure state for structural iron paint. The rate of drying of raw linseed oil increases with age; an old oil being very much better for paint than that which has been but recently extracted. Raw linseed oil can be made to dry more rapidly by the addition of a drier or by boiling. Linseed oil dries by oxidation and not by evaporation, and therefore any material that will make it take up oxygen more rapidly is a drier. A common method of making a drier for linseed oil is to put the linseed oil in a kettle, heat it to a temperature of 400 to 500 degrees Fahr., and stir in about four pounds of red lead or litharge, or a mixture of the two, to each gallon of oil. This mixture is then thinned down by adding enough linseed oil to make four gallons for each gallon of raw oil first put in the kettle. The addition of four gallons of this drier to forty gallons of raw oil will reduce the time of drying from about five days to twenty-four hours. A drier made in this way costs more than the pure linseed oil, so that driers are very often made by mixing lead or manganese oxide with 
rosin and turpentine, benzine, or rosin oil. These driers can be made for very much less than the price of good linseed oil, and are used as adulterants; the more of the drier that is put into the paint, the quicker it will dry and the poorer it becomes. Japan drier is often used with raw oil, and when this or any other drier is added to raw oil in barrels, the oil is said to be "boiled through the bung hole."

Boiled linseed oil is made by heating raw oil, to which a quantity of red lead, litharge, sugar of lead, etc., has been added, to a temperature of 400 to 500 degrees Fahr., or by passing a current of heated air through the oil. Heating linseed oil to a temperature at which merely a few bubbles rise to the surface makes it dry more rapidly than the unheated oil; however, if the boiling is continued for more than a few hours the rate of drying is decreased by the boiling. Boiled linseed oil is darker in color than raw oil, and is much used for outside paints. It should dry in from 12 to 24 hours when spread out in a thin film on glass. Raw oil makes a stronger and better film than boiled oil, but it dries so slowly that it is seldom used for outside work without the addition of a drier.

Lead.-White Lead (hydrated carbonate of lead-specific gravity 6.4) is used for interior and exterior wood work. White lead forms an excellent pigment on account of its high adhesion and covering power, but it is easily darkened by exposure to corrosive gases and rapidly disintegrates under these conditions, requiring frequent renewal. It does not make a good bottom coat for other paints, and if it is to be used at all for metal work it should be used over another paint.

Red Lead (minium; lead tetroxide-specific gravity 8.3 ) is a heavy, red powder approximating in shade to orange; is affected by acids, but when used as a paint is very stable in light and under exposure to the weather. Red lead is seldom adulterated, about the only substance used for the purpose being red oxide. Red lead is prepared by changing metallic lead into monoxide litharge, and converting this product into minium in calcining ovens. Red lead intended for paints must be free from metallic lead. One ounce of lampblack added to one pound of red lead changes the color to a deep chocolate and increases the 
time of drying. This compound when mixed in a thick paste will keep 30 days without hardening.

Zinc.-Zinc white (zinc oxide-specific gravity $\dot{5 \cdot 3}$ ) is a white loose powder, devoid of smell or taste and has a good covering power. Zinc paint has a tendency to peel, and when exposed there is a tendency to form a zinc soap with the oil which is easily washed off, and it therefore does not make a good paint. However, when mixed with red oxide of lead in the proportions of I lead to 3 zinc, or 2 lead to I zinc, and ground with linseed oil, it makes a very durable paint for metal surfaces. This paint dries very slowly, the zinc acting to delay hardening about the same as lampblack.

Iron Oxide.-Iron oxide (specific gravity 5) is composed of anhydrous sesquioxide (hematite) and hydrated sesquioxide of iron (iron rust). The anhydrous oxide is the characteristic ingredient of this pigment and very little of the hydrated oxide should be present. Hydrated sesquioxide of iron is simply iron rust, and it probably acts as a carrier of oxygen and accelerates corrosion when it is present in considerable quantities. Mixed with the iron ore are various other ingredients, such as clay, ocher and earthy materials, which often form 5o to 75 per cent of the mass. Brown and dark red colors indicate the anhydrous oxide and are considered the best. Bright red, bright purple. and maroon tints are characteristic of hydrated oxide and make less durable paints than the darker tints. Care should be used in buying iron oxide to see that it is finely ground and is free from clay and ocher.

Carbon.-The most common forms of carbon in use for paints are lampblack and graphite. Lampblack (specific gravity 2.6) is a great absorbent of linseed oil and makes an excellent pigment. Graphite (blacklead or plumbago-specific gravity 2.4) is a more or less impure form of carbon, and when pure is not affected by acids. Graphite does not absorb nor act chemically on linseed oil, so that the varnish simply holds the particles of pigment together in the same manner as the cement in a concrete. There are two kinds of graphite in common use for paints-the granular and the flake graphite. The Dixon Graphite Co., of Jersey City, uses a flake graphite combined with silica, 
while the Detroit Graphite Manufacturing Co., uses a mineral ore with a large percentage of graphitic carbon in granulated form. On account of the small specific gravity of the pigment, carbon and graphite paints have a very large covering capacity. The thickness of the coat is, however, correspondingly reduced. Boiled linseed oil should always be used with carbon pigments.

Mixing the Paint.-The pigment should be finely ground and should preferably be ground with the oil. The materials should be bought from reliable dealers, and should be mixed as wanted. If it is not possible to grind the paint, better results will usually be obtained from hand mixed paints made of first class materials than from the ordinary run of prepared paints that are supposed to have been ground. Many ready mixed paints are sold for less than the price of linseed oil. which makes it evident that little if any oil has been used in the paint. The paint should be thinned with oil, or if necessary a small amount of turpentine may be added; however turpentine is an adulterant and hsould be used sparingly. Benzine, gasoline, etc., should never be used in paints, as the paint dries without oxidizing and then rubs off like chalk.

Proportions.-The proper proportions of pigment and oil required to make a good paint varies with the different pigments, and the methods of preparing the paint; the heavier and the more finely ground pigments require less oil than the lighter or coarsely ground while ground paints require less oil than ordinary mixed paints. A common rule for mixing paints ground in oil is to mix with each gallon of linseed oil, dry pigment equal to three to four times the specific gravity of the pigment, the weight of the pigment being given in pounds. This rule gives the following weights of pigment per gallon of linseed oil: white lead, I9 to $26 \mathrm{lbs}$. ; red lead, 25 to $33 \mathrm{lbs}$.; zinc, I5 to $2 \mathrm{I}$ lbs.; iron oxide, I 5 to $20 \mathrm{lbs}$; lampblack, 8 to ro lbs.; graphite, 8 to Io $1 \mathrm{bs}$. The weights of pigment used per gallon of oil varies about as follows: red lead, 20 to $33 \mathrm{lbs}$.; iron oxide, 8 to $25 \mathrm{lbs}$.; graphite, 3 to I $2 \mathrm{lbs}$.

Covering Capacity.-The covering capacity of a paint depends upon the uniformity and thickness of the coating; the thinner the coat- 
ing the larger the surface covered per unit of paint. To obtain any given thickness of paint therefore requires practically the same amount of paint whatever its pigment may be. The claims often urged in favor of a particular paint that it has a large covering capacity may mean nothing but that an excess of oil has been used in its fabrication. An idea of the relative amounts of oil and pigment required, and the covering capacity of different paints may be obtained from the following table.

AVERAGF, SURFACE COVERED PER GALLON OF PAINT.*

\begin{tabular}{|c|c|c|c|c|c|}
\hline \multirow[b]{2}{*}{ Paint. } & \multirow{2}{*}{$\begin{array}{c}\text { Volume of } \\
\text { oil. }\end{array}$} & \multirow{2}{*}{$\begin{array}{l}\text { Lbs. } \\
\text { of l'ig- } \\
\text { ment. }\end{array}$} & \multirow{2}{*}{$\begin{array}{c}\text { Volume and } \\
\text { Weight } \\
\text { of Paint. }\end{array}$} & \multicolumn{2}{|c|}{ Square Feet. } \\
\hline & & & & $\begin{array}{c}1 \\
\text { Coat. }\end{array}$ & $\begin{array}{c}2 \\
\text { Coats. }\end{array}$ \\
\hline $\begin{array}{l}\text { Iron Oxide (powdered) } \\
\text { “" (ground in oil) } \\
\text { Red Lead (powdered).. } \\
\text { White I.ead (g'rd in oil). } \\
\text { (Graphite (ground in oil). } \\
\text { Black Asphalt.......... } \\
\text { Linseed oil (no pigment) }\end{array}$ & $\begin{array}{ll}1 & \text { gal } \\
1 & \text { “6 } \\
1 & \text { “6 } \\
1 & \text { “ } \\
1 & \text { “ } \\
1 & \text { “(turp.) } \\
1 & \text { “ }\end{array}$ & $\begin{array}{r}8.00 \\
24.75 \\
22.40 \\
25.00 \\
12.50 \\
17.25 \\
\cdots\end{array}$ & $\begin{array}{c}\text { Gals. 1.bs. } \\
1.2=16.00 \\
2.6=32.75 \\
1.4=30.40 \\
1.7=33.00 \\
2.0=26.50 \\
4.0=30.00 \\
\ldots \ldots \ldots\end{array}$ & $\begin{array}{l}600 \\
630 \\
630 \\
500 \\
360 \\
515 \\
875\end{array}$ & $\begin{array}{l}350 \\
375 \\
375 \\
300 \\
215 \\
310 \\
\cdots\end{array}$ \\
\hline
\end{tabular}

Light structural work will average about 250 square feet, and heavy structural work about I50 square feet of surface per net ton of metal.

It is the common practice to estimate $1 / 2$ gallon of paint for the first coat and $3 / 8$ gallon for the second coat per ton of structural steel, for average conditions.

Applying the Paint.-The paint should be thoroughly brushed out with a round brush to remove all the air. The paint should be mixed only as wanted, and should be kept well stirred. When it is necessary to apply paint in cold weather, it should be heated to a temperature of 130 to 150 degrees Fahr.; paint should not be put on in freezing weather. Paint should not be applied when the surface is damp, or during foggy weather. The first coat should be allowed to stand for three or four days, or until thoroughly dry, before applying

*Pencoyd Handbook page 293. 
the second coat. If the second coat is applied before the first coat has dried, the drying of the first coat will be very much retarded.

Cleaning the Surface.-Before applying the paint all scale, rust, dirt, grease and dead paint should be removed. The metal may be cleaned by pickling in an acid bath, by scraping and brushing with wire brushes, or by means of the sand blast. In the process of pickling the metal is dipped in an acid bath, which is followed by a bath of milk lime, and afterwards the metal is washed clean in hot water. The method is expensive and not satisfactory unless extreme care is used in removing all traces of the acid. Another objection to the process is that it leaves the metal wet and allows rusting to begin before the paint can be applied. The most common method of cleaning is by scraping with wire brushes and chisels. This method is slow and laborious. The method of cleaning by means of a sand blast has been used to a limited extent and promises much for the future. The average cost of cleaning five bridges in Columbus, Ohio, in 1902, was $3 \mathrm{cts}$. per square foot of surface cleaned.* The bridges were old and some were badly rusted. The painters followed the sand blast and covered the newly cleaned surface with paint before the rust had time to form.

Mr. Lilly estimates the cost of cleaning light bridge work at the shop with the sand blast at $\$ I .75$ per ton, and the cost of heavy bridge work at \$1.oo per ton. In order to remove the mill scale it has been recommended that rusting be allowed to start before the sand blast is used. One of the advantages of the sand blast is that it leaves the surface perfectly dry, so that the paint can be applied before any rust has formed.

Cost of Paint.-The following costs of paints will give an idea of costs and proportions used:**

Oxide of Iron (Prince's Metallic Brown). One gallon of paint.

$6 \mathrm{r} / 4 \mathrm{lbs}$. mineral at $\mathrm{I}$ cent............... 6 cts.

$6 \mathrm{r} / 4 \mathrm{lbs}$. raw linseed oil $-5-6$ gallon at 56 cents......47

Cost of materials per gallon of paint.........

*Sand Blast Cleaning of Structural Steel, by G. W. Lilly, Transactions A. Soc. C. E., Feb., 1903.

**Walter G. Berg, Engineering News, June 6, 1895. 
Red Lead (National Paint Co.). One gallon of paint.

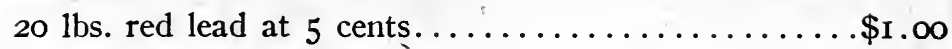

$51 / 2$ lbs. raw linseed oil $-3 / 4$ gallon at 56 cents. . ... .42

Cost of materials per gallon of paint......... $\overline{\$ 1.42}$

Graphite Paint (Dixon's Graphite). Five pounds of graphite paste and I gallon of oil make $\mathrm{I} / 2$ gallons of paint.

$33 / 4$ lbs. graphite paste at 12 cents $\ldots \ldots \ldots \ldots \ldots \ldots 45$ cts.

$3 / 4$ gallon boiled linseed oil at 59 cents.........44 "

Cost of materials per gallon of paint.........8 cts.

Mr. A. H. Sabin in a paper read before the American Society of Civil Engineers, June, 1895, gives the following as the minimum costs of paints: Iron Oxide paint, $61 / 4$ lbs. of oxide worth $91 / 2$ cents $; 6^{1} / 4$ lbs. of oil worth $46 \mathrm{~T} / 2$ cents; mixing in a mill, barrels, etc., 5 cents; making the actual cost of the paint 55 cents per gallon. The cost of a gallon of pure lead paint using 20 lbs. of red lead per gallon and oil at 56 cents per gallon will cost not less than $\$ 1.50$ per gallon.

Cost of Painting.-The cost of applying the paint depends upon the condition of the surface to be painted, and upon other conditions. A common rule for ordinary work is that the cost of painting is about two to three times the cost of a good quality of paint required for the job. The cost of labor may not be more than the cost of the paint, and may be four or five times as much. The cost of painting light structural work in which considerable climbing has to be done is very difficult to estimate. The average cost of painting four bridges in Denver, Col., with a finishing coat of Goheen's Carbonizing, in I899, was $5 \mathrm{I}$ cents for paint and 80 cents for labor, per ton of metal painted.

Priming Coat.-Engineers are very much divided as to what makes the best priming coat; some specify a first coat of pure linseed oil and others a priming coat of paint. Linseed oil makes a transparent coating that allows imperfections in the workmanship and rusted spots to be easily seen; it is not permanent however, and if the metal is exposed for a long time the oil will often be entirely removed before the second coat is applied. It is also claimed that the paint will not adhere 
as well to linseed oil that has weathered as to a good paint. Linseed oil gives better results if applied hot to the metal. Another advantage of using oil as a priming coat is that the erection marks can be painted over with the oil without fear of covering them up. Red lead paint toned down with lampblack is probably used more for a priming coat than any other paint; the B. \& O. R. R., uses Io ozs. of lampblack to every i2 lbs. of red lead.

Without going further into the controversy it would seem that there is very little choice between linseed oil and a good red lead paint for a priming coat.

Finishing Coat.-From a careful study of the question of paints, it would seem that for ordinary conditions, the quality of the materials and workmanship is of more importance in painting metal structures than the particular pigment used. If the priming coat has been properly applied there is no reason why any good grade of paint composed of pure linseed oil and a very finely ground, stable and chemically noninjurious pigment will not make a very satisfactory finishing coat. Where the paint is to be subjected to the action of corrosive gases or blasts, however, there is certainly quite a difference in the results obtained with the different pigments. The graphite and asphalt paints appear to withstand the corroding action of smelter and engine gases better than red lead or iron oxide paints; while red lead is probably better under these conditions than iron oxide. Portland cement paint is the only paint that will withstand the action of engine blasts, and its use is now entirely in the experimental stage.

Conclusion.- It is urged against red lead paint, that the oil and the lead form a lead soap which is unstable; against iron oxide paint, that since the paint contains more or less iron rust it is necessarily a promoter of rust; against graphite paint, that there is not enough body in the pigment to make a substantial paint; etc. There is more or less truth.in all the accusations made against the different kinds of paint, if the paint be bought ready mixed, or if made out of poor materials ; however, with a good pigment and pure linseed oil, none of the above objections are of weight. 
To obtain the best results in painting metal structures therefore, proceed as follows: (I) prepare the surface of the metal by carefully removing all dirt, grease, mill scale, rust, etc., and give it a priming coat of pure linseed oil or a good paint-red lead seems to be the most used for this purpose; (2) after the metal is in place carefully remove all dirt, grease, etc., and apply the finishing coats-preferably not less than two coats-giving ample time for each coat to dry before applying the next. Painting should not be done in rainy weather, or when the metal is damp, nor in cold weather unless special precautions are taken to warm the paint. The best results will usually be obtained if the materials are purchased in bulk from a responsible dealer and the paint ground as wanted. Good results are obtained with many of the patent or ready mixed paints, but it is not possible in this place to go into a d.1scussion of their respective merits.

ASPHALT PAINT.-Many prepared paints are sold under the name of asphalt that are mixtures of coal tar, or mineral asphalt alone, or combined with a metallic base, or oils. The exact compositions of the patent asphalt paints are hard to determine. Black bridge paint made by Edward Smith \& Co., New York City, contains asphaltum, linseed oil, turpentine and Kauri gum. The paint has a varnish-like finish and makes a very satisfactory paint. The black shades of asphalt paint are the only ones that should be used.

COAL-TAR PAINT.-Coal-tar used for painting iron work should be purified from all constituents of an acid nature; for this reason it is preferable to employ coal-tar pitch and convert it into paint by solution in benzine or petroleum. Tar paint should preferably be applied while hot. Oil paint will not stick to tar, and when repainting a surface that has been painted with tar it is necessary to scrape the surface if a good job is desired. Tar paint does not become hard and will run in hot weather; it is therefore not a desirable paint to use for many purposes.

CEMENT AND CEMENT PAINT.-Experiments have shown that a thin coating of Portland cement is effective in preventing rust ; that a concrete to be effective in preventing rust must be dense and made very wet. The steel must be clean when imbedded in the concrete. There is quite a difference of opinion as to whether the metal should be painted before being imbedded or not. It is probably best to paint the 
metal if it is not to be imbedded at once, or is not to be used in concrete-steel construction where the adhesion of the cement to the metal is an essential element. When the metal is to be imbedded immediately it is better not to paint it.

Portland Cement Paint.-A Portland cement paint has been used on the High St. viaduct in Columbus, Ohio, with good results. The viaduct was exposed to the fumes and blasts from locomotives, so that an ordinary paint did not last more than six months even on the least exposed portions. The method of mixing and applying the paint is described in Engineering News, April 24th and June 5th, 1902, as follows: "The surface of the metal was thoroughly cleaned with wire brushes and files - the bridge had been cleaned with a sand blast the previous year. A thick coat of Japan drier was then applied and before it had time to dry a coating was applied as follows: Apply with a trowel to the minimum thickness of $\mathrm{I}-\mathrm{I} 6$ inch and a maximum thickness of $1 / 4$ inch (in extreme cases $1 / 2$ inch) a mixture of $32 \mathrm{lbs}$. Portland cement, I2 lbs. dry finely ground lead, 4 to 6 lbs. boiled linseed oil, 2 to 3 lbs. Japan drier." After a period of about two years the coating was in almost perfect condition and the metal under the coating was as clean as when painted. The cost of the coating including the hand cleaning, materials and labor was 8 cents per square foot.

While this method of protecting metal is somewhat expensive it will certainly pay for itself in many places around smelters and shops.

References on Paint and Painting.-For a more complete discussion of the subject of paints the reader should consult the following:

Iron Corrosion by Louis E. Andes.

The Painting and Sand Blast Cleaning of Steel Bridges and Viaducts, by George W. Lilly, Engineering News, April 24th, Igo2.

Rustless Coatings of Iron and Steel, by M. P. Wood, Transactions American Society of Mechanical Engineers, Vols. I5 and I6.

Preservation of Iron Structures Exposed to the Weather, by $\mathbf{E}$. Gerber, Transactions American Society of Civil Engineers, May, I895.

Painting Iron Railway Bridges, by Walter G. Berg, Engineering News, June 6, I895.

Paints and Varnishes, by A. H. Sabin, Association of Engineering Societies, February, I900.

Application of Paints, Varnishes, and Enamels for the Protection of Iron and Steel Structures and Hydraulic Work--a pamphlet for free distribution by Edward Smith \& Company, New York. 


\section{CHAPTER XXVIII.}

\section{Estimate of Wfight and Cost.}

ESTIMATE OF WEIGHT.-The contract drawings for mill buildings are usually general drawings about like those in Fig. 167 and Fig. 168, in which the main members and the outline of the building are shown, togethier with enough sketch details to enable the detailer to properly detail the work. In making an estimate of weight from general drawings it is necessary that the estimater be familiar with the style of the details in use at the shop, and with the per cent of the main members that it is necessary to add, to provide for details and get the total shipping weight of the structure. There are two methods of allowing for details : (I) to add the proper per cent for details to the weight of each main member in the structure, and (2) to add a per cent for details to the total weight of the main members in the structure. The first method is the safest one to follow, although the second gives good results when used by an experienced man. The best way to obtain data on the per cents of details of different members in buildings and other structures is to make detailed estimates from the shop drawings. By checking these data with the actual shipping weights, the engineer will soon have information that will be invaluable to him. Second hand data on estimating are of comparatively little value for the reason that the conditions under which they hold good are rarely noted, and it is better that the novice work out his own data and depend on his own resources, at least until he has developed his estimating sense. In short the only way to learn to estimate, is to estimate.

The method of making estimates will be illustrated by making an estimate from the working drawings of a steel transformer building, the general plans of which are shown in Figs. 167 and 168. The 
members marked "Main Members" are those given on the general drawing, and the "Details" are those members whose sizes are supplied by the detailer. The building is a steel frame building, $60^{\prime} \mathrm{o}^{\prime \prime}$ wide, $8 \mathrm{o}^{\prime}$ $\mathrm{O}^{\prime \prime}$ long, 20' $\mathrm{O}^{\prime \prime}$ posts, pitch of roof $\mathrm{I} / 5$, and is covered with corrugated

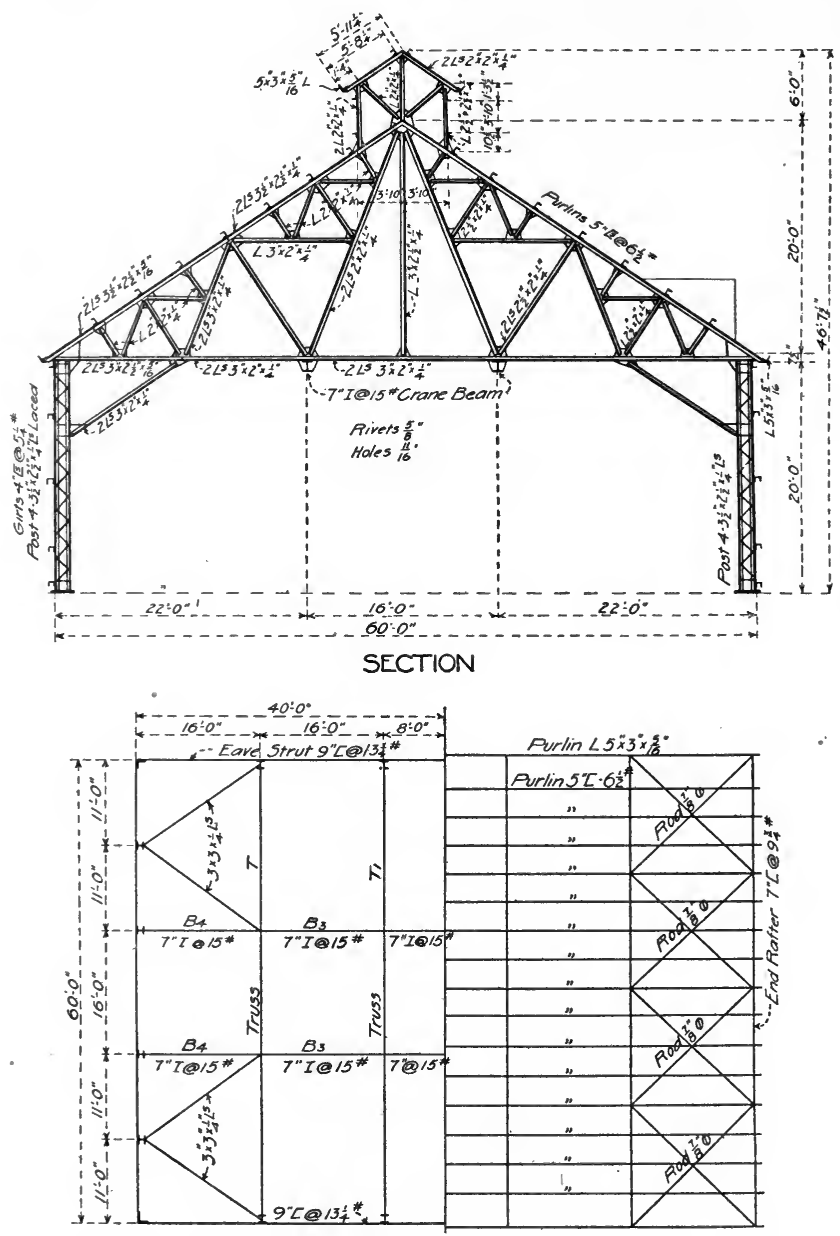

Bracing in Plane of Bottom Chord Bracing in Plane of Top Chord

Fig. i67. Cross-SeCtion AND PLAN OF STEEL TRANSFORMER BUILDING. 
steel. The general plans of the framework are shown in Figs. 167 and I68, and the plans and details of the corrugated steel are shown in Figs. I 28 and 129.

The weights of the different sections were obtained from Cambria Steel. The estimate is self explanatory.
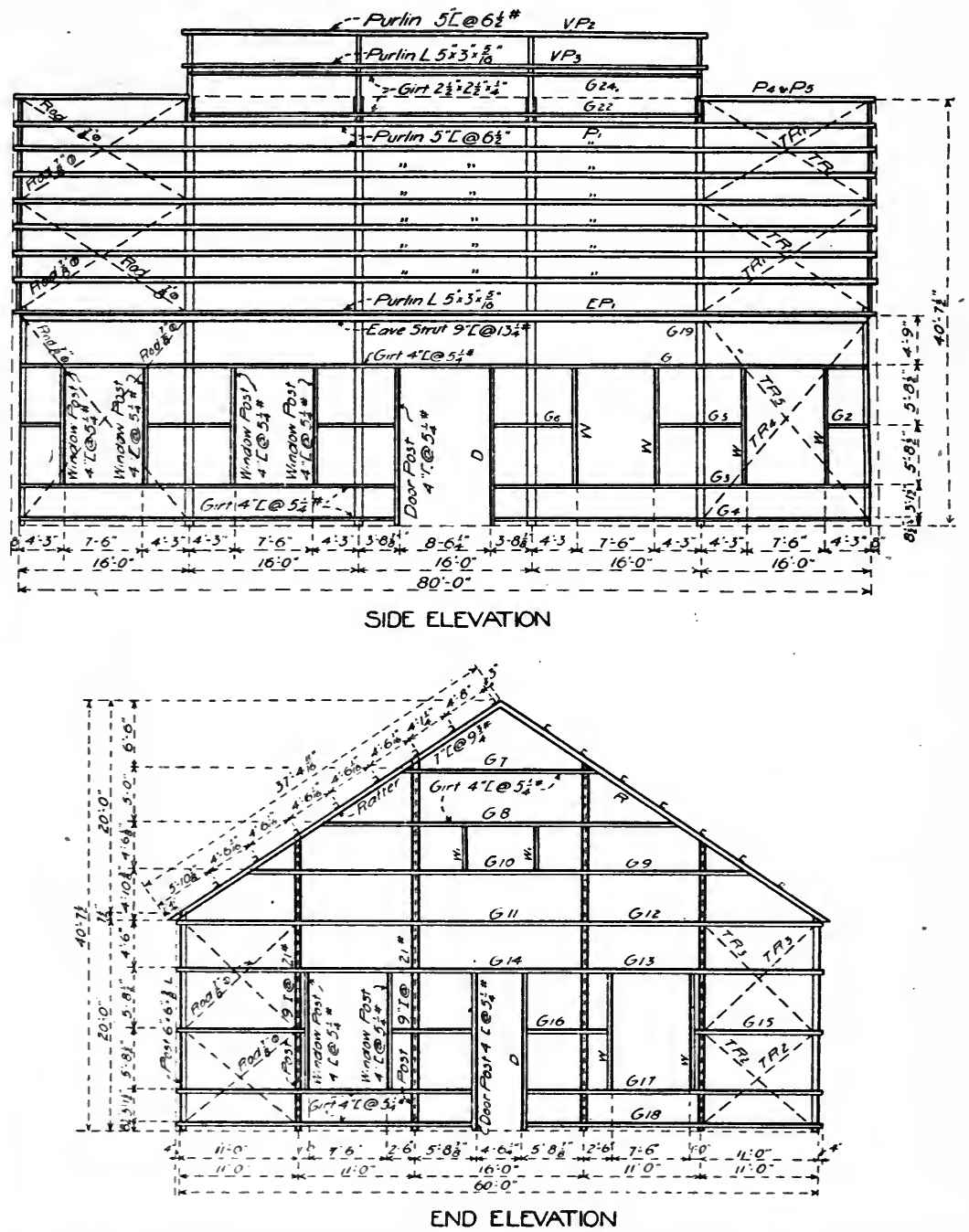

Fig. I68. Side AND END ELEVATIONS OF STEEL 'TRANSFORMER BUILDING. 
ESTIMATE OF WEIGHT

Steel Frame Transformer Building, 60'-0" Wide, 80'-0"Long, 20'-0" Posts. Pitch of Roof $\frac{1}{3}$. Covered with Corrugated Iron.

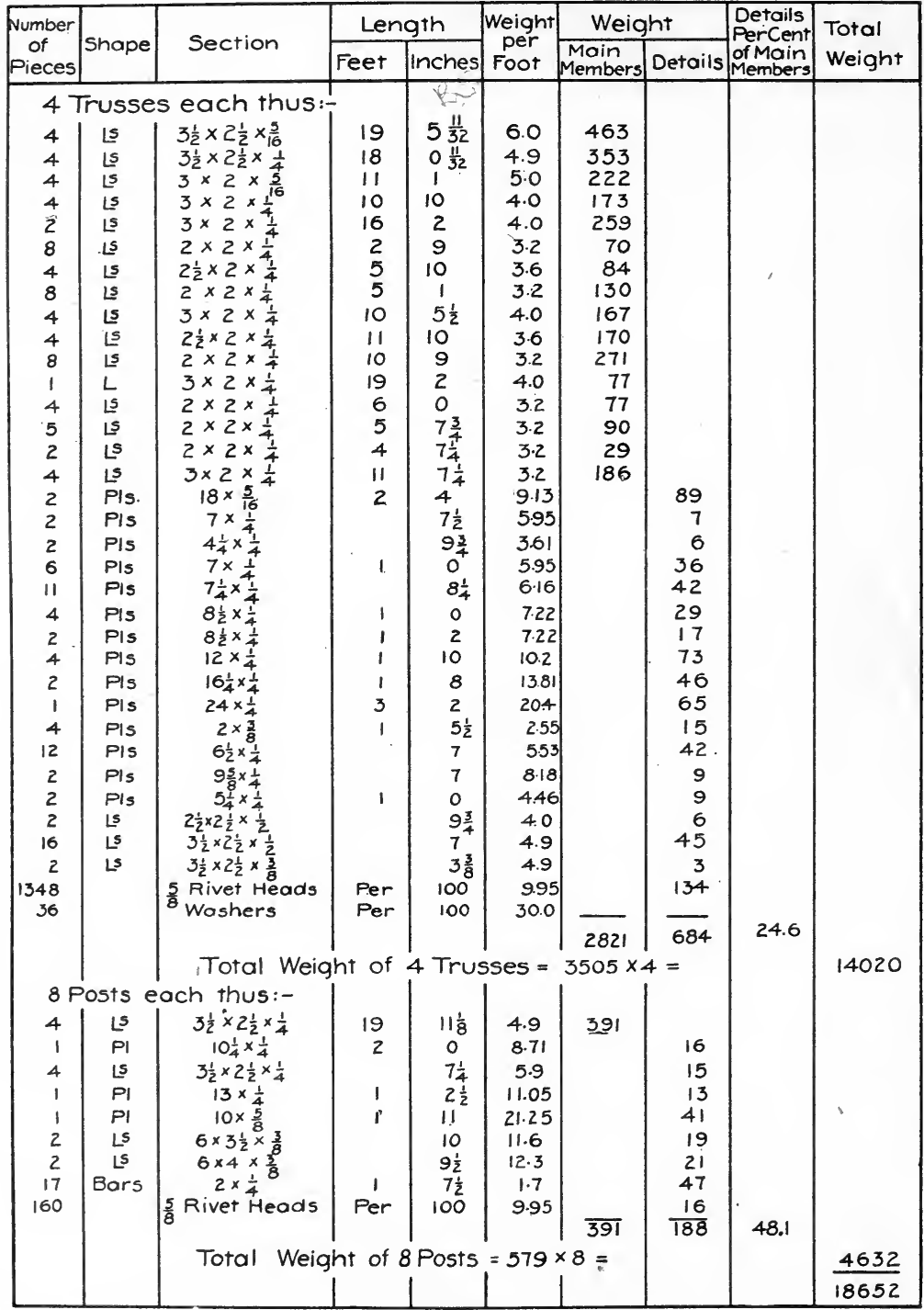




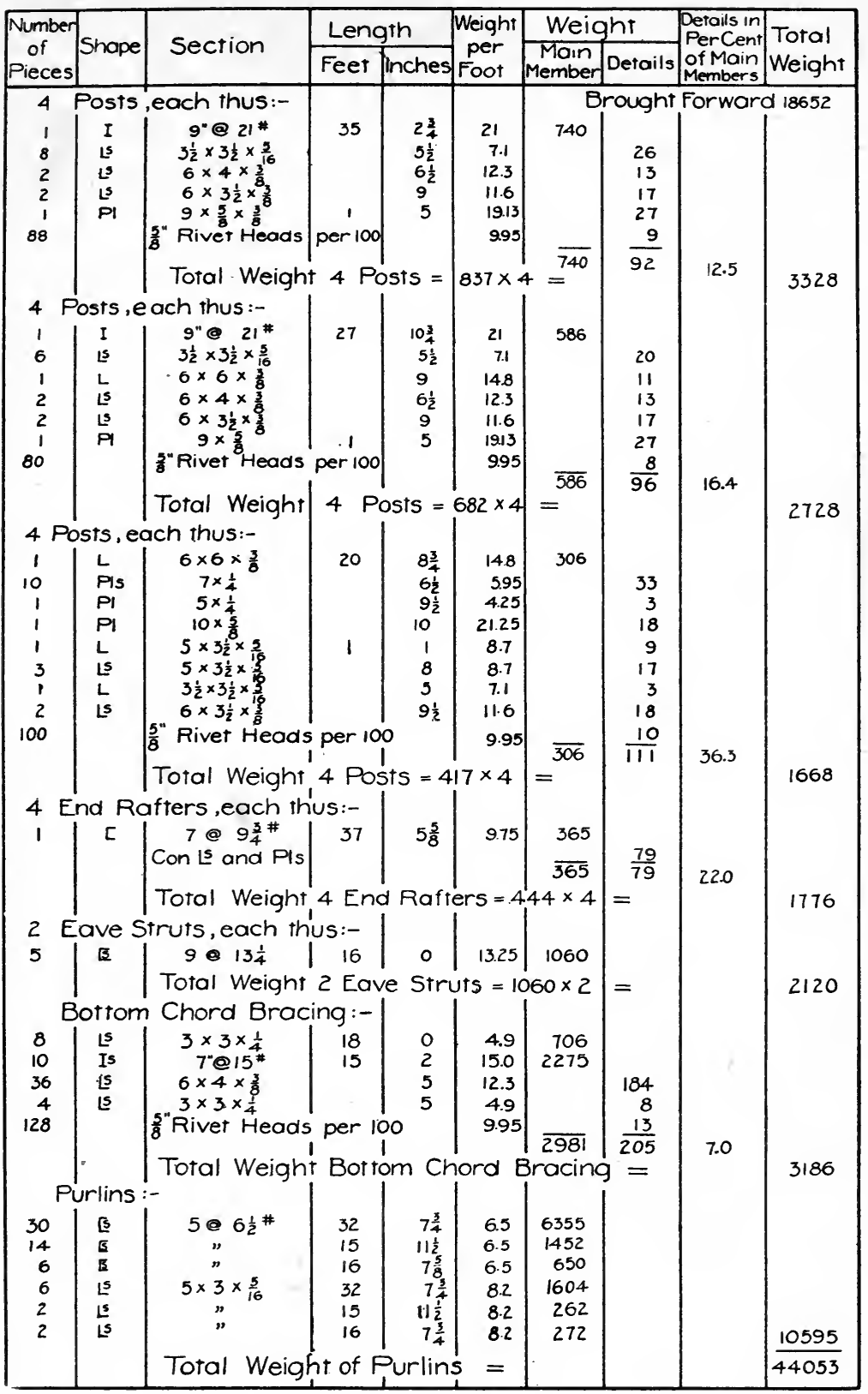




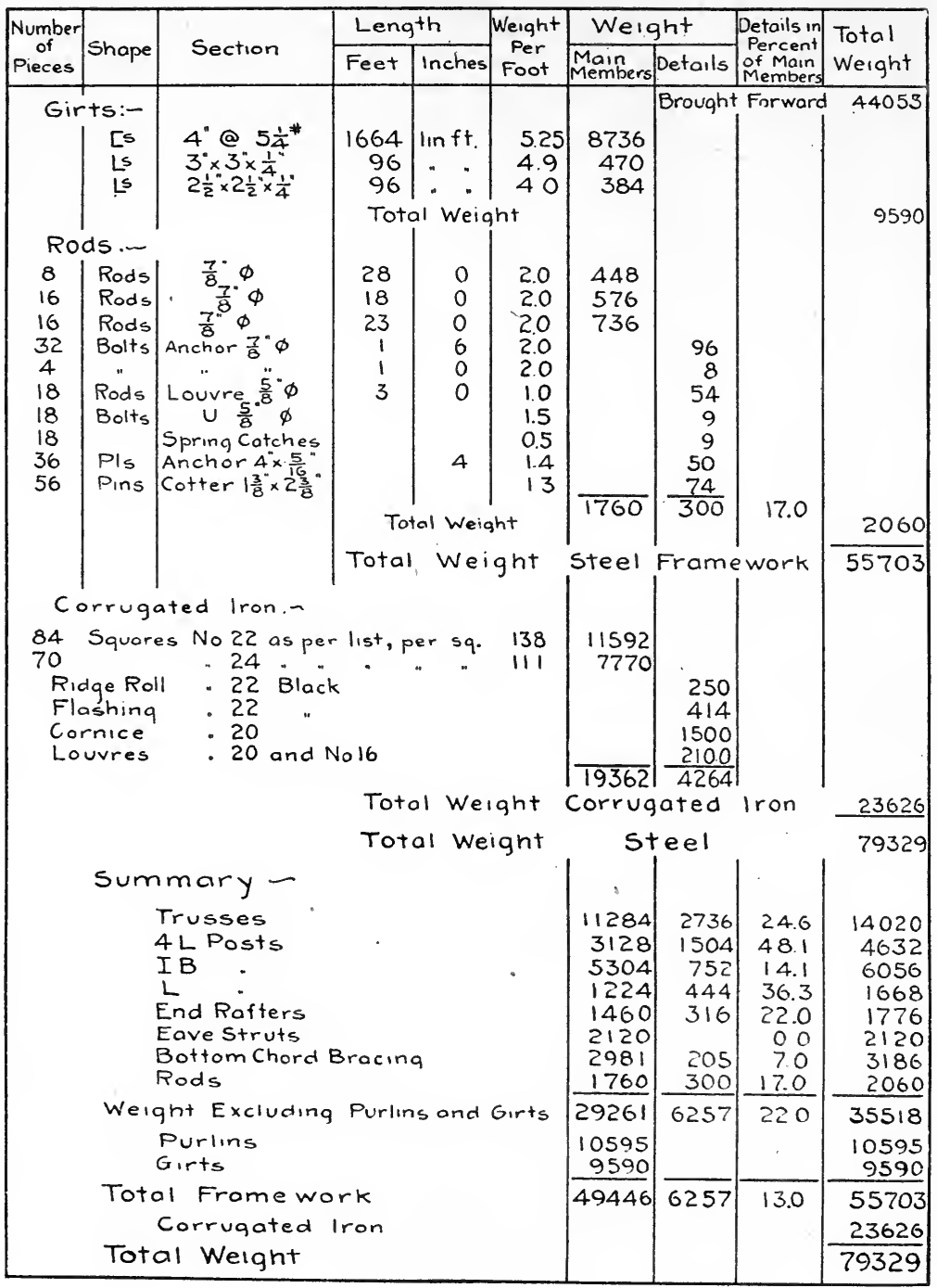

The weights and per cents of three other buildings, are shown in Table XXVI. The estimates for these buildings were made from the shop drawings, and were checked with the shipping weights. These buildings are of light construction with end post bents, (a) Fig. I. 
ESTIMATE OF COST

\begin{tabular}{|c|c|c|c|c|c|}
\hline \multirow{2}{*}{ Classification of Material } & \multicolumn{3}{|c|}{ Cost of Material } & \multicolumn{2}{|c|}{ Cost of Labor } \\
\hline & Weight & Price & Amount & Price & Amount \\
\hline 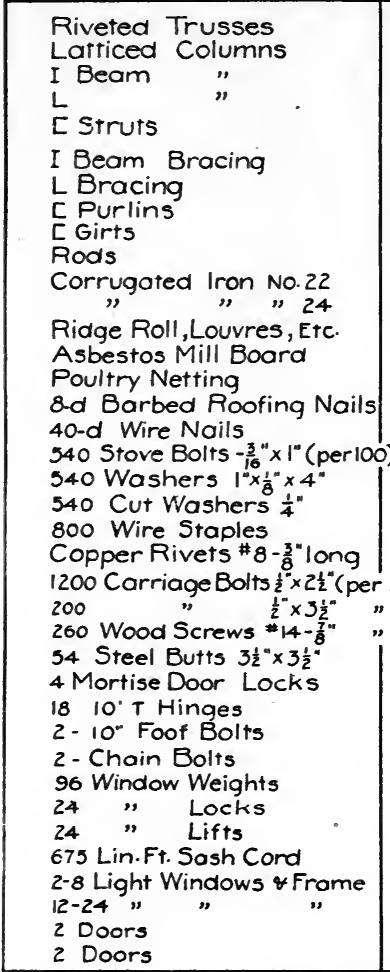 & \begin{tabular}{|r|r|r}
14020 \\
4632 \\
6056 \\
1668 \\
3896 \\
2480 \\
706 \\
10595 \\
9590 \\
2060 \\
11592 \\
7770 \\
4264 \\
1760 \\
400 \\
32 \\
5 \\
5 \\
76 \\
2 \\
5 \\
6 \\
$0)$ \\
210 \\
46 \\
10 \\
60 \\
10 \\
40 \\
5 \\
5 \\
1440 \\
16 \\
10 \\
30 \\
80 \\
1600 \\
800 \\
200
\end{tabular} & \begin{tabular}{|r|}
1.60 \\
1.60 \\
1.65 \\
1.60 \\
1.60 \\
1.65 \\
1.60 \\
1.60 \\
1.60 \\
1.80 \\
2.60 \\
2.70 \\
2.50 \\
2.50 \\
3.00 \\
2.50 \\
36.00 \\
6.00 \\
7.00 \\
4.00 \\
25.00 \\
$\$ 1.10$ \\
1.50 \\
$\$ 60$ \\
48.00 \\
75.00 \\
12.00 \\
50.00 \\
50.00 \\
2.00 \\
15.00 \\
10.00 \\
15.00 \\
$\$ 4.00$ \\
8.00 \\
$\$ 15.00$ \\
4.00 \\
\end{tabular} & $\begin{array}{r}224.32 \\
74.11 \\
99.92 \\
2669 \\
62.34 \\
40.92 \\
11.30 \\
169.52 \\
15344 \\
37.08 \\
301.39 \\
209.79 \\
106.60 \\
44.00 \\
32.50 \\
.96 \\
.13 \\
1.94 \\
4.56 \\
.14 \\
.20 \\
1.50 \\
13.20 \\
3.00 \\
1.56 \\
4.32 \\
3.00 \\
2.16 \\
1.00 \\
1.00 \\
28.80 \\
3.60 \\
2.40 \\
4.50 \\
8.00 \\
96.00 \\
30.00 \\
8.00\end{array}$ & \begin{tabular}{|c|}
$\Phi_{1.00}$ \\
1.00 \\
.50 \\
.50 \\
.26 \\
.25 \\
.25 \\
.15 \\
.15 \\
1.00
\end{tabular} & $\begin{array}{r}14020 \\
4632 \\
30.28 \\
834 \\
9.74 \\
6.20 \\
1.77 \\
15.90 \\
14.39 \\
20.60\end{array}$ \\
\hline Total Weig & ght 87212 & $\cos t$ & Mat', 1813.89 & $\cos t \mathrm{~L}$ & abor $3 \overline{36.38}$ \\
\hline $\begin{array}{c}\text { SUMMARY } \\
\text { Cost of Material } \\
\text { Cost of Shop Labor } \\
\text { Cost of Details } \\
\text { Cost of Shop Painting } \\
\text { Total Shop Cost } \\
\text { Freight, Mill to Shop } \\
\text { Freight, Shop to Site } \\
\text { Erection,Structural } \\
\text { ", Corrugated } \\
\text { s, Miscellaneous } \\
\text { Pointing } 76 \text { gals. Paint }\end{array}$ & $\begin{array}{l}30 \text { tons } \\
30 \text { tons } \\
44 " \\
30 \text { tons } \\
60 \text { sqs. R } \\
60 " \text { Si }\end{array}$ & $\begin{array}{l}0^{5} 3.60 \\
05.00 \\
@ 16.00 \\
\text { @ } 8.00 \\
\text { Poofing } \\
\text { jiding }\end{array}$ & $\begin{array}{r}1813.89 \\
336.38 \\
108.00 \\
40.00 \\
2398.27 \\
150.00 \\
704.00 \\
240.00 \\
75.00 \\
.75 \quad 45.00 \\
75.00 \\
76.00 \\
75.00 \\
3813.27\end{array}$ & & 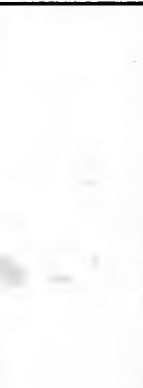 \\
\hline
\end{tabular}




\section{TABLE XXVI.}

WEIGHTS AND PER CENTS OF DETAILS OF MILL BUILDINGS.

\begin{tabular}{|c|c|c|c|c|c|c|c|c|}
\hline \multicolumn{9}{|c|}{$\begin{array}{l}\text { Steel Mill Buildings with Self Supporting Frames covered } \\
\text { on Roof and Sides with one thickness of Corrugated Iron }\end{array}$} \\
\hline \multirow{3}{*}{$\begin{array}{c}\text { Part } \\
\text { of } \\
\text { Structure }\end{array}$} & \multicolumn{2}{|c|}{ 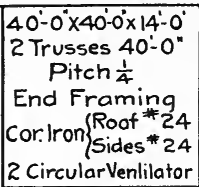 } & \multicolumn{2}{|c|}{ 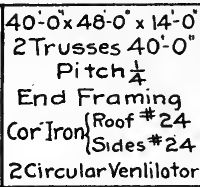 } & \multicolumn{2}{|c|}{$\begin{array}{c}60^{\prime}-0^{\prime \prime} \times 75^{\prime} 0^{\prime \prime} \times 18^{\prime}-0^{\circ} \\
4 \text { Trusses } 60^{\prime}-0^{\circ} \\
\text { Pitch } 5 \\
\text { End Framing } \\
\text { Cor'Tron }\left\{\begin{array}{l}\text { Roof }{ }^{*} 22 \\
\text { Sides } 24\end{array}\right. \\
3 \text { Circulor Ventilator. }\end{array}$} & \multicolumn{2}{|c|}{$\begin{array}{l}60^{\circ}-0^{\circ} \times 80^{\circ} 0^{\circ} \times 20^{\prime}-0^{\prime \prime} \\
4 \text { Trusses } 60^{-} 0^{\prime \prime} \\
\text { Pitch } \frac{1}{3} \\
\text { End Framing } \\
\text { Cor: Iron }\left\{\begin{array}{l}\text { Roof } \\
\text { sides } 22\end{array} 24\right. \\
\text { Monitor Ventilators }\end{array}$} \\
\hline & Weight & $\begin{array}{l}\text { Details in } \\
\text { per cent } \\
\text { of Main } \\
\text { Members }\end{array}$ & Weight & $\begin{array}{l}\text { Details in } \\
\text { per cent } \\
\text { of Main } \\
\text { Members }\end{array}$ & Weight & $\begin{array}{l}\text { Details in } \\
\text { per cent } \\
\text { of Main } \\
\text { Members }\end{array}$ & Weight & $\begin{array}{l}\text { Details in } \\
\text { per cent } \\
\text { of Main } \\
\text { Members }\end{array}$ \\
\hline & lbs & percent & Ibs. & percent & lbs. & percent & Ibs & percent \\
\hline $\begin{array}{l}\text { Trusses } \\
4 \text { LColumns } \\
\text { IBeam - } \\
\text { L Columns } \\
\text { End Rafters } \\
\text { Eave Struts } \\
\text { LowerChord Bracing } \\
\text { Rods } \\
\text { Purlins } \\
\text { Girts }\end{array}$ & $\begin{array}{r}2848 \\
1428 \\
1148 \\
912 \\
1036 \\
900 \\
930 \\
900 \\
2281 \\
3170\end{array}$ & $\begin{array}{r}25 \\
70 \\
15 \\
36 \\
17 \\
0 \\
22 \\
15 \\
5 \\
2\end{array}$ & $\begin{array}{r}2848 \\
1428 \\
1148 \\
952 \\
1076 \\
1080 \\
1049 \\
920 \\
3516 \\
3252\end{array}$ & $\begin{array}{l}25 \\
70 \\
15 \\
36 \\
22 \\
0 \\
20 \\
17 \\
7 \\
2\end{array}$ & $\begin{array}{l}13940 \\
3476 \\
4251 \\
1470 \\
3314 \\
3117 \\
2763 \\
1737 \\
6713 \\
9895\end{array}$ & $\begin{array}{r}34.4 \\
52.5 \\
33.0 \\
14.0 \\
11.6 \\
33.2 \\
9.7 \\
6.2 \\
47 \\
10.0\end{array}$ & $\begin{array}{r}14020 \\
4632 \\
6056 \\
1668 \\
1776 \\
2120 \\
3186 \\
2060 \\
10595 \\
9590\end{array}$ & $\begin{array}{r}24.6 \\
481 \\
14.1 \\
36.3 \\
200 \\
0.0 \\
7.0 \\
12.0 \\
0.0 \\
0.0\end{array}$ \\
\hline $\begin{array}{l}\text { Weight of Framework } \\
\text { Weight per Sq.Ft }\end{array}$ & $\begin{array}{c}15553 \\
9.8\end{array}$ & 19 & $\begin{array}{c}17269 \\
9.0\end{array}$ & 20 & $\begin{array}{l}50676 \\
11.2\end{array}$ & 24.0 & $\begin{array}{c}55703 \\
11.7\end{array}$ & 13,0 \\
\hline Corrugated Iron & 5880 & & 6892 & & 17000 & & 23626 & \\
\hline $\begin{array}{l}\text { Total of Steel } \\
\text { Weight per Sq.Ft. }\end{array}$ & $\begin{array}{r}21433 \\
13.4\end{array}$ & & $\begin{array}{c}24161 \\
12.6\end{array}$ & & $\begin{array}{r}67676 \\
15.1\end{array}$ & & $\begin{array}{c}29329 \\
16.5\end{array}$ & \\
\hline
\end{tabular}

Channel eave struts were used in all except the third building in which 4-angle laced struts were used. A very good idea of the per cent of details in the different parts of the structures can be obtained from Table XXVI. The details of riveted mill building trusses will commonly vary between the limits of 25 and 35 per cent as given in the table; being more often near 25 than 35 per cent. The per cent of details in trusses is practically independent of the length of span, and is larger for being more often near 25 than 35 per cent. The per cents of details in columns is mostly due to the bases and connections-the per cents of details will therefore decrease as the length of the column increases. The weights of the other parts are so variable that no general rules can be given. Where a uniform per cent is added to the total weight of main members to provide for details, it is common to add about 30 
per cent to the weight of the framework exclusive of the purlins and girts where end bent (b) Fig. I, is used.' In the estimate given it will be seen that the per cent is only 22, the small value being due in part to the use of channel eave struts and the end post framing.

In estimating the weight of corrugated steel add 25 per cent for laps where two corrugations side lap and 6 inches end lap are required, and 5 per cent where one corrugation side lap and 4 inches end lap are required.

The weights of the sections, rods, bolts, turnbuckles, etc., are obtained from Cambria Steel, or other handbook.

The engineer should use every care to check his work in making estimates, the material should be checked off the drawings, and the calculations should be carefully checked and rechecked. Slide rules and adding machines are invaluable in this work. No results should, however, be allowed to pass until they have been roughly checked by the engineer by aliquot parts, or by making a mental estimate of each quantity. The engineer can soon develop a sense of estimate, so to speak, and will often detect blunders intuitively. Accuracy is of more value in estimating than precision. While the method outlined may seem somewhat crude at first glance, it is nevertheless true that a preliminary estimate made by a skilled man will commonly be within I or 2 per cent of the shipping weight, and if off more than $2 \mathrm{l} / 2$ per cent it is pretty certain that there was something wrong either with the estimate or with the estimater. The estimated weight should be a little heavy rather than light, say $\mathrm{I}$ to 2 per cent.

ESTIMATE OF COST.-The cost of the different parts of a mill building varies with the local conditions, cost of labor, and cost of materials. The discussion of this subject will be divided into (I) cost of material, (2) cost of shop work, and (3) cost of erection. The cost of transportation must also be included in arriving at the total cost. The subject of costs is a very difficult one to handle and the author would caution the reader to use the data given on the following pages with care, for the reason that costs are always relative and what may 
be a fair cost in one case may be sadly in error in another case which appears an exact parallel. The price of labor will be given in each case, or the costs will be based on a charge of 40 cents per hour which includes labor, cost of management, tools, etc.

Cost of Material.-The cost of structural steel can be obtained from the current numbers of the Iron Age, Engineering News, etc., or may be obtained direct from the manufacturers or dealers. In 1903 beams, channels, angles, plates, and bars were quoted at about I.60 cents per pound f. o. b. Pittsburg. Beams I8, 20 and 24 inches deep take o. Io cents per pound higher price than the base price for beams. The mills at present quote a delivered price only, equal to the mill price plus the usual freight charge. This price is often more than the customer could obtain by paying the freight himself, on account of the freight rebates that are often allowed.

Cost of Mill Details.-Mills are allowed a variation in length of sections of $3 / 4$ of an inch; which means that beams, channels, etc., may come $3 / 8$ of an inch shorter or $3 / 8$ of an inch longer than the length called for. When a less variation than this is required a special price is charged for cutting to exact length. The following list of mill extras adopted January, 1902, is now in force:

LIST OF EXTRAS TO BE ADDED TO PRICE OF PLAIN BEAMS AND CHANNELS.

I. For cutting to length with less variation than plus or minus $3 / 8$ inch..........

2. Plain punching one size hole in web only \$o. I5

3. Plain punching one size hole in one or both

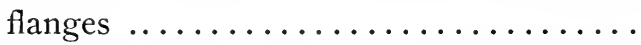

4. Plain punching one size hole in either web and one flange or web and both flanges

5. Plain punching each additional size hole in either web or flange, web and one flange or web and both flanges............

6. Plain punching one size hole in flange and another size hole in web of the same beam

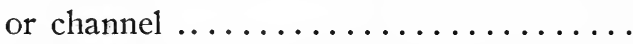

7. Punching and assembling into girders... 
8. Coping, ordinary beveling, including cutting to exact length, with or without punching, including the riveting or bolting of standard connection angles..........

9. For painting or oiling one coat with

Io. Cambering Beams and Channels and other shapes for ships or other purposes. .

II. Bending or other unusual work....... Shop rates

I2. For fittings, whether loose or attached, such as angle connections, bolts and sepa-

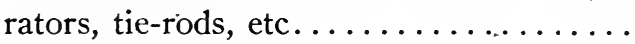

The above prices are per Ioo lbs. of steel.

In ordering material from the mill the following items should be borne in mind. Where beams butt at each end against some other member, order the beams $1 / 2$ inch shorter than the figured lengths; this will allow a clearance of $1 / 4$ inch if all beams come $3 / 8$ of an inch too long. Where beams are to be built into the wall, order them in full lengths making no allowance for clearance. Order small plates in multiple lengths. Irregular plates on which there will be considerable waste should be ordered cut to templet. Mills will not make reentrant cuts in plates. Allow $1 / 4$ of an inch for each milling for members that have to be faced. Order web plates for girders $1 / 4$ to $1 / 2$ inch narrower than the distance back to back of angles. Order as nearly as possible every thing cut to required length, except where there is liable to be changes made, in which case order long lengths.

It is often possible to reduce the cost of mill details by having the mills do only part of the work, the rest being done in the field, or by sending out from the shop to be riveted on in the field connection angles and other small details that would cause the work to take a very mucli higher price. Standard connections should be used wherever possible. and special work should be avoided.

The classification of iron and steel bars is given in Table XXVIJ. The full extra charges for sizes other than those taking the base rate are seldom enforced; one-half card extras being very common. 


\section{Iron Classification.}

Adopted Dec 3,1895 , by National Bar Iron Association

Adopted March 16, 1899, by Eastern Bar Iron Manufacturers' Association.

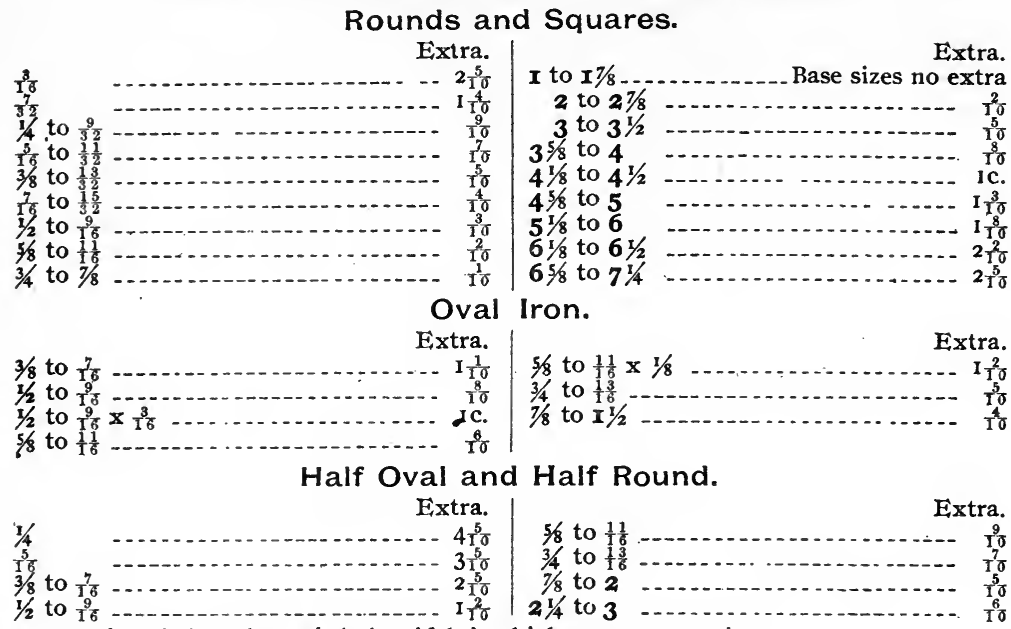

Half ova's less than $1 / 4$ their width in thickness, extra price.

Flats.

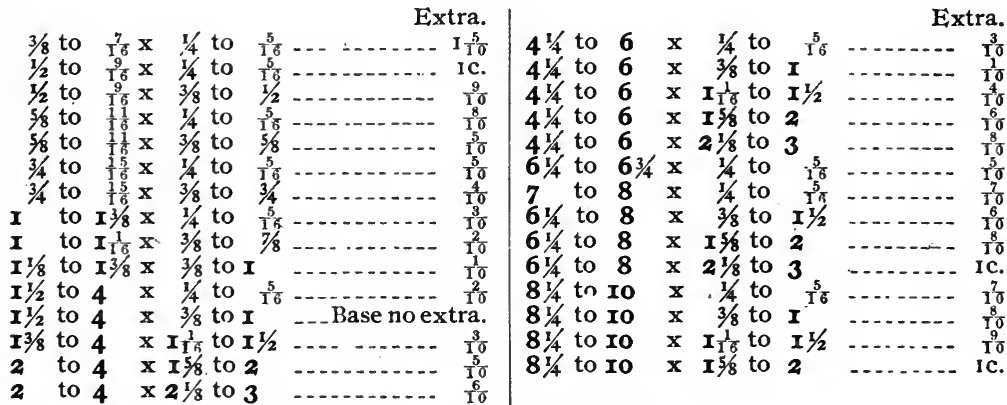

Flats $\frac{7}{3 \frac{1}{2}}$ thick $\frac{1}{10}$ c. per to higher than $1 / 4$ to $\frac{5}{16}$ thick.

Bevel edge Shaft Iron $\frac{1}{10} c$. higher than same size of Flats.

All round edge iron $\frac{1}{10} \mathrm{c}$. per th extra.

Horse Shoe Iron all sizes Ic. extra.

\section{Light Bands.}

Extra.

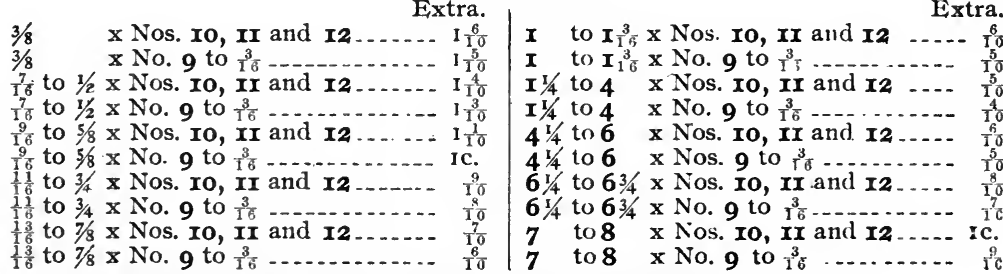

Bevel Edge Box Iron same as Light Bands of same sizes.

Beaded Band Iron $I \frac{1}{4}$ inch to 2 inch $\frac{7}{10}$ extra.

Sand Band Iron $\frac{1}{10}$ c. above same sizes of Light Bands. 
Shop Cost.-The shop cost of the various classes of work is a variable quantity, depending upon the equipment and capacity of the shop, the number of pieces made alike, the familiarity of the shop men with the particular class of work, and with the cost of labor. The costs given below are the average costs for a shop with a capacity of about IOOO tons per month that has made a specialty of mill building work. The costs given are based on a charge of 40 cents per hour for the number of hours actually consumed in getting out the contract. This charge is assumed to cover the cost of management, cost of operation and maintenance, as well as the cost of labor. The cost of management in a small shop is very small, but in a large concern it may amount to as much as 35 to 40 per cent of all the other charges combined. For this reason small structural shops can often fabricate light structural steel for a less cost than the large shops. The prices given are about an average of those used by the agents of the company above, and have been checked against actual costs for the greater part.

Columns.-In lots of at least six, the shop cost of columns is about as follows: Columns made of two channels and two plates, or two channels laced cost about 0.80 to 0.70 cents per $1 b$., for columns weighing from 600 to Iooo lbs. each; channels made of 4 -angles laced cost from 0.80 to I. Io cents per $1 \mathrm{~b}$.; channels made of two channels and one I beam, or three channels cost from 0.65 to 0.90 cents per $1 \mathrm{~b}$.; columns made of single I beams, or single angles cost about 0.50 cents per lb. ; and Z-bar columns cost from 0.70 to 0.90 cenis per lb.

Plain cast columns cost from $\mathrm{I} .5 \mathrm{O}$ to 0.75 cents per $1 \mathrm{~b}$., for columns weighing from 500 to 2500 lbs., in lots of at least six.

Roof Trusscs.-In lots of at least six, the shop cost of ordinary riveted roof trusses in which the ends of the members are cut off at right angles is about as follows: Trusses weighing rooo lbs. each, I.I 5 to $\mathrm{I} .25$ cents per $1 \mathrm{~b}$; ; trusses weighing $\mathrm{I}_{500} \mathrm{lbs}$. each, 0.90 to $\mathrm{I} .00$ cents per $\mathrm{lb}$; ; trusses weighing $2500 \mathrm{lbs}$. each, 0.75 to 0.85 cents per lb.; and trusses weighing 3500 to $7500 \mathrm{lbs}$. 0.60 to 0.75 cents per $1 \mathrm{~b}$. Pin connected trusses cost from 0.10 to 0.20 cents per $1 \mathrm{~b}$. more than riveted trusses. 
Eave Struts.-Ordinary eave struts made of 4 -angles laced, whose length does not exceed 20 to 30 feet, cost for shop work from 0.80 to I. oo cents per $1 \mathrm{~b}$.

Plate Girders.-The shop work on plate girders ior crane girders and floors will cost from 0.60 to I. 25 cents per 1b., depending upon the weight, details and number made at one time.

Eye-Bars.-The shop cost of eye-bars varies with the size and length of the bars and the number made alike. The following costs are a fair average: Average shop cost of bars 3 inches and less in width and $3 / 4$ inches and less in thickness, is from $\mathrm{I} .20$ to $\mathrm{I} .85$ cents per lb., depending on length and size. A good order of bars running from $21 / 2^{\prime \prime} \times 3 / 4^{\prime \prime}$ to $3^{\prime \prime} \times 3 / 4^{\prime \prime}$, and from I6 to $30 \mathrm{ft}$. long, with few variations in size, will cost about $\mathrm{I} .20$ cents per $1 \mathrm{~b}$. Large bars in long lengths ordered in large quantities can be fabricated at from 0.55 to 0.75 cents per $1 \mathrm{~b}$.

To get the total cost of eye-bars the cost of bar steel must be added to the shop cost.

Cost of Drafting.-The cost per ton for making details of mill buildings varies with the character of the work and the tonnage that is to be fabricated from one detail, so that costs per ton may mean very little. The following will give an idea of the range of costs. Details for headworks for mines cost from $\$ 4.00$ to $\$ 6.00$ per ton; details for church and court house roofs having hips and valleys cost from $\$ 6.00$ to $\$ 8.00$ per ton; details for ordinary mill buildings cost from $\$ 2.00$ to $\$ 4.00$ per ton. The details for all work fabricated by the Gillete-Herzog Mfg. Co., with the exception of plain beams and complicated tank work, were made in I 896 by contract, by Mr. H. A. Fitch, now structural engineer for the Minneapolis Steel and Machinery Co., Minneapolis, for $\$ 2.06$ per ton. This price netted the contractor a fair profit.

Actual Costs of Detailing.-The details of the building for which the estimate is made in this chapter cost $\$ 3.60$ per ton. The details for the Basin \& Bay State Smelter, Basin, Montana, containing 270 tons of steel cost $\$ 2.00$ per ton. 
Actual Shop Costs.-The following actual shop costs will give an idea of the range of costs: The shop cost of the transiormer building of which the estimate is made in this chapter was about \$20.00 per ton including drafting; the Carbon Tipple building at Carbon, Montana, weighing 86 tons, cost $\$ 18.60$ per ton. The shop cost of the structural work of the East Helena transformer building, the estimate of which is given in the next to the last column in Table XXVI, cost \$21.80 per ton including details. The shop cost of the Basin \& Bay State smelter, weighing 270 tons, was $\$ 17.20$ per ton including details which cost $\$ 2.00$ per ton. The shop cost of six gallows frames made by the Gillete-Herzog. Mfg. Co., varied from $\$ 21.80$ to $\$ 41.80$ per ton, with an average of $\$ 32.20$ per ton including details.

Cost of Erection.-With skilled labor at $\$ 3.50$ and common labor at $\$ 2.00$ per day of 9 hours, small buildings like those given in Table XXVI will cost about $\$ 10.00$ per ton for the erection of the steel framework, if trusses are riveted and all other connections are bolted. The cost of laying corrugated steel is about $\$ 0.75$ per square when laid on plank sheathing, \$I.25 per square when laid directly on the purlins, and $\$ 2.00$ per square when laid with anti-condensation roofing. The erection of corrugated steel siding costs from $\$ 0.75$ to $\$ 1.00$ per square. The cost of erecting heavy machine shops, all material riveted and including the cost of painting but not the cost of the paint, is about $\$ 8.50$ to $\$ 9.00$ per ton. Small buildings in which all connections are bolted may be erected for from $\$ 5.00$ to $\$ 6.00$ per ton. The cost of erecting the East Helena transformer building (next to the last building in Table $\mathrm{XXVI}$ ) was $\$ 12.80$ per ton including the erection of the corrugated steel and transportation of the men. The cost of erecting the Carbon Tipple was $\$ 8.80$ per ton including corrugated steel. The cost of erection of the Basin \& Bay State Smelter was $\$ 8.20$ per ton including the hoppers and corrugated steel. The cost of erecting 6 galiows frames in Montana varied from $\$ 1 \mathrm{I} .20$ to $\$ 15.20$ per ton, with an average of \$13.00 per ton, all connections being riveted.

COST OF MISCELLANEOUS MATERIAL.-In making an estimate for a mill building the engineer needs to be familiar with the 
costs of building hardware, lumber, etc. Prices of building hardware are usually quoted at a certain discount from standard lists. These standard lists and the discounts can be obtained from the dealers, or the method described in the following paragraph may be used.

The following method of obtaining costs of building hardware and other miscellaneous materials, has been found very satisfactory: Obtain standard lists from the dealers, or a very complete one entitled "The Iron Age Standard Hardware Lists" may be obtained from the David Williams Co., New York, for \$I.oo, postpaid. To find the current discount, consult the current number of the Iron Age, or a similar publication-the Iron Age is published by the David Williams Co., New York, at $\$ 5.00$ per year, or Io cents per single copy, and gives each week the current hardware prices and discounts. By applying the discount to the prices given in the standard lists the current price of the material can be obtained. The standard lists of machine bolts, carriage bolts, nails, and turnbuckles are given for convenience in estimating and to illustrate what is meant by lists.

To illustrate the method just described the current prices (I903) will be obtained for a few items :

2-in. Barbed Roofing Nails. - The base, price of nails is $\$ 2.65$ per keg of Ioo lbs., and from standard nail list (Table XXVIII) we see that 2 -in. barbed roofing nails take $\$ 0.35$ per Ioo $1 \mathrm{bs}$. advance over the base price making the price $\$ 3.00$ per roo lbs.

Carriage Bolts. $-2 \mathrm{I} / 2^{\prime \prime} \times 1 / 2^{\prime \prime}$ carriage bolts are listed (Table XXVIII) at $\$ 3.00$ per 100, from which a discount of 60 and $10 \%$ is allowed. A discount of 60 and $10 \%$ is equivalent to a discount of $64 \%$, making the price of the bolts $\$ \mathrm{I} .08$ per Ioo $1 \mathrm{bs}$.

Machine Bolts. $-4^{\prime \prime} \times 1 / 2^{\prime \prime}$ machine bolts are listed (Table XXIX) at $\$ 4.90$ per 100, from which a discount of 65 and $5 \%$ is allowed. A discount of 65 and $5 \%$ is equivalent to a discount of $663 \% 4 \%$, making the price of the bolts $\$ 1.36$ per roo. The weight of machine bolts and nuts is given, from which the price per $1 \mathrm{~b}$. can be obtained for any size of bolt. 
The following approximate prices of materials will assist in making preliminary estimates: rivets, $\$ 2.25$ to $\$ 3.00$ per roo lbs.; boat spikes, $\$ 2.25$ to $\$ 3.00$ per. I00 Ibs.; washers, cut, $\$ 6.00$ per $100 \mathrm{lbs}$.; washers, cast, $\$ \mathrm{I} .50$ to $\$ 2.00$ per I00 lbs. ; sash weights, $\$ \mathrm{I}$.00 to $\$ \mathrm{I}$. 50 per IOO lbs.; pins $\$ 3.50$ to $\$ 4.00$ per IOO lbs.; pin nuts, $\$ 4.00$ per 100 lbs.; wire poultry netting, \$o. 50 per square; asbestos felt, $32 \mathrm{lbs}$. to the square, $\$ 2.75$ to $\$ 3.00$ per 100 lbs. ; turnbuckles, $50 \%$ discount. Other prices and costs will be found in the descriptions of the various articles on the preceding pages.

\section{TABLE XXVIII.}

LIST ADOPTED DECEMBER 1, 1896. STEEL WIRE NAILS.

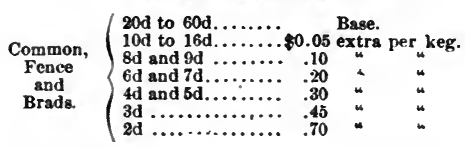

Barbed Common and Barbed Car Nalls, 15c. advance over Common.

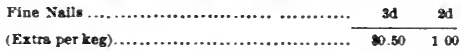

Cesing and Smooth Box Nails-(Extrâ per keg).

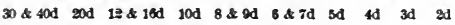

$\begin{array}{llllllllll}80.15 & .15 & .15 & .15 & .25 & .35 & .50 & .50 & .70 & 1.00\end{array}$

Finishing........20d 12 \& 16d $10 \mathrm{~d} 8$ \& $9 \mathrm{~d} 6 \mathrm{k}$ id 5d 4d sd 2d $\begin{array}{llllllllll}\text { (Extra per keg).80.25 } & .25 & .25 & 35 & .45 & .65 & .65 & .85 & 1.15\end{array}$

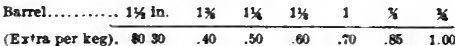
Clinch ........... 20d 12\&16d 10d $8 \& 9 d 6 \& 7 d$ 4\&5d 3d $2 d$

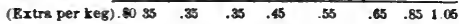

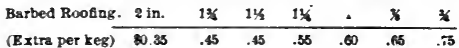
Wire splkes, all sizes

LENGTH AND APPAOXIMATE GAUGE OF COMMON wIRE MaILs.

\begin{tabular}{|c|c|c|c|c|c|c|c|}
\hline $2 d$ & 81 & $4 d$ & $5 d$ & 6d & $7 d$ & $8 d$ & Dd \\
\hline $\begin{array}{l}1 \text { in. } \\
\text { No. } 15\end{array}$ & $\begin{array}{l}11 / 4 \\
14\end{array}$ & $\begin{array}{l}13 / 4 \\
12 \%\end{array}$ & $13 / 6$ & $\stackrel{2}{1116}$ & $\begin{array}{l}21 / 4 \\
11 \% / 2\end{array}$ & $\begin{array}{l}21 / 2 \\
10 \% / 4\end{array}$ & $\begin{array}{r}23 \\
10 \%\end{array}$ \\
\hline $10 \mathrm{~d}$ & $12 d$ & $16 d$ & $20 \mathrm{~d}$ & $30 d$ & sod & sod & $60 \mathrm{~d}$ \\
\hline $\begin{array}{l}\text { sin. } \\
\text { No. } 9\end{array}$ & $31 / 4$ & $3 \frac{312}{8}$ & 4 & $5^{4 \frac{1}{2}}$ & 5 & $3^{51 / 2}$ & $\begin{array}{l}6 \\
2 \\
2\end{array}$ \\
\hline
\end{tabular}

Turnbuckles.

\begin{tabular}{|c|c|c|c|c|c|}
\hline 胥爮 & 总 & 迩焉 & 今ึ & 选总 & ยูं \\
\hline $3 / 8$ & $\$ 0.40$ & $13 / 8$ & $81.3^{8}$ & 25 & $\$ 5.0$ \\
\hline$\frac{7}{18}$ & .42 & $1,1 / 2$ & 1.50 & $23 / 4$ & \\
\hline $1 / 2$ & .45 & 1 & 1.75 & $27 / 3$ & $6 . c$ \\
\hline ? & .48 & 13 & 2.00 & 3 & 6.5 \\
\hline 78 & .50 & $13 / 8$ & $\begin{array}{l}2.25 \\
265\end{array}$ & $31 / 8$ & $\begin{array}{l}7.50 \\
3.00\end{array}$ \\
\hline & .63 & 216 & 2.65 & & 9.00 \\
\hline 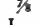 & .75 & $\begin{array}{l}21 / 3 \\
21 / 6\end{array}$ & 3.10 & $\begin{array}{l}378 \\
31 / 2\end{array}$ & 10.00 \\
\hline $11 / 8$ & 1.00 & $23 / 8$ & $\begin{array}{l}3.50 \\
4.00\end{array}$ & $3 \frac{1}{4}$ & 15.00 \\
\hline $11 / 4$ & 1.25 & $21 / 2$ & 4.50 & 4 & 20.00 \\
\hline
\end{tabular}

Common Carriage Bolts. List Feb'y 1 .

Length in Inches.

\begin{tabular}{|c|c|c|c|}
\hline $\begin{array}{l}\text { Inches. } \\
11 / 2 \\
13 / 4 \\
\mathbf{3} \\
91 / 4 \\
21 / 2 \\
933 / 4 \\
3 \\
31 / 4 \\
31 / 2 \\
33 / 4 \\
4 \\
41 / 4 \\
41 / 2 \\
433 \\
5 \\
51 / 2 \\
6 \\
61 / 2 \\
7 \\
71 / 2 \\
8 \\
81 / 2 \\
9 \\
91 / 2 \\
10 \\
11 \\
12 \\
13 \\
14 \\
15 \\
16 \\
17 \\
18 \\
19\end{array}$ & $\begin{array}{r}14 \\
11.00 \\
1.04 \\
1.08 \\
1.12 \\
1.16 \\
1.20 \\
1.24 \\
128 \\
1.42 \\
1.36 \\
1.40 \\
1.44 \\
1.48 \\
152 \\
1.56 \\
1.64 \\
1.72 \\
1.69 \\
1.88 \\
196 \\
2.04 \\
2.12 \\
2.20 \\
2.28 \\
2.36 \\
2.52 \\
2.68 \\
2.84 \\
3.00 \\
316 \\
3.32 \\
3.48 \\
3.64 \\
3.80 \\
396\end{array}$ & $\begin{array}{r}516 \\
81.20 \\
1.25 \\
1.30 \\
135 \\
1.40 \\
1.45 \\
150 \\
1.55 \\
160 \\
1.65 \\
1.70 \\
1.75 \\
1.80 \\
1.85 \\
1.90 \\
2.00 \\
2.10 \\
2.20 \\
230 \\
2.40 \\
250 \\
260 \\
270 \\
2.80 \\
2.90 \\
3.10 \\
8.30 \\
3.50 \\
3.70 \\
3.90 \\
4.10 \\
4.30 \\
450 \\
470 \\
4.90\end{array}$ & $\begin{array}{r}3-8 \\
81.60 \\
3.68 \\
1.76 \\
1.84 \\
1.92 \\
200 \\
2.08 \\
2.16 \\
2.24 \\
2.32 \\
240 \\
2.48 \\
2.56 \\
2.64 \\
2.72 \\
2.84 \\
3.04 \\
3.20 \\
336 \\
3.52 \\
36 \\
3.84 \\
400 \\
416\end{array}$ \\
\hline
\end{tabular}

$\begin{array}{lllll}716 & 1-2 & 9 & 16 & \\ 2 & 58 & 34\end{array}$

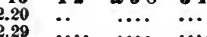

$2.38 \quad \cdots \cdots, \quad \cdots \cdots$

$247 \quad \because \ddot{0}$

$\begin{array}{rrrrr}2.56 & \$ 300 & \$ 5.20 & \$ 7.20 \\ 2.65 & 3 & 11 & 5.37 & 743\end{array}$

$\begin{array}{llll}2.74 & 3.22 & 5.54 & 7.66\end{array}$

$\begin{array}{llll}283 & 333 & 5.71 & 7.89\end{array}$

$\begin{array}{llll}292 & 3.44 & 5.88 & 8.12\end{array}$

$\begin{array}{llll}3.01 & 355 & 6.05 & 8.35\end{array}$

$\begin{array}{llll}3.10 & 3.66 & 6.22 & 8.58\end{array}$

$\begin{array}{llll}3.19 & 3.77 & 6.19 & 8.81\end{array}$

$\begin{array}{llll}3.28 & 3.88 & 6.56 & 904\end{array}$

$\begin{array}{llll}\mathbf{3} 37 & 3.99 & \mathbf{6 . 7 3} & \mathbf{9 . 2 7} \\ \mathbf{3 . 4 6} & \mathbf{4 . 1 0} & \mathbf{6 . 9 0} & \mathbf{9 . 5 0}\end{array}$

$\begin{array}{llll}3.64 & 4.32 & 7.24 & 9.96\end{array}$

$\begin{array}{lllll}3.82 & 4.54 & 758 & 10.42\end{array}$

$\begin{array}{llll}4.00 & 4.76 & 7.92 & 10.89\end{array}$

$\begin{array}{llll}4.00 & 4.76 & 7.92 & 10.8\end{array}$

$\begin{array}{llll}4.36 & 520 & 8.60 & 11.80\end{array}$

$\begin{array}{llll}4.54 & 5.42 & 8.94 & 12.26\end{array}$

$\begin{array}{llll}4.72 & 5.64 & 928 & 12.72\end{array}$

$\begin{array}{lllll}4.90 & 5.86 & 962 & 1318\end{array}$

$\begin{array}{lllll}5.08 & 6.08 & 996 & 13.64\end{array}$

$\begin{array}{llllll}5.26 & 6.30 & 10.30 & 14 & 10\end{array}$

$\begin{array}{llll}5.62 & 6.74 & 1098 & 1502\end{array}$

$\begin{array}{llll}\mathbf{5} .98 & 7.18 & 11.66 & 15.94 \\ \mathbf{6 3 1} & \mathbf{7 . 6 2} & \mathbf{1 2 . 3 4} & \mathbf{1 6 . 8 6}\end{array}$

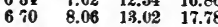

$\begin{array}{lllll}7.06 & 8.50 & 13.70 & 18.70\end{array}$

$\begin{array}{lllll}\mathbf{7 . 4 2} & \mathbf{8} 94 & 14.38 & 19.62\end{array}$

$\begin{array}{llll}7.78 & 9.34 & 15.06 & \mathbf{2 0 . 5 4}\end{array}$

$\begin{array}{llll}7.78 & 9.3 \times & 15.06 & 20.54 \\ 814 & 9.82 & 15.74 & 21.46\end{array}$

$\begin{array}{llll}814 & 9.82 & 15.74 & 21.46\end{array}$ $\begin{array}{llll}8.86 & 10.70 & 17.10 & 23.30\end{array}$

SPIKES, NAILS AND TACKS.

\begin{tabular}{|c|c|c|c|c|c|c|c|c|}
\hline \multicolumn{6}{|c|}{ STANDARD STEEL WIRE NAILS. } & \multirow{2}{*}{\multicolumn{3}{|c|}{ STEEL, WIRE SPIKES. }} \\
\hline \multirow[b]{2}{*}{ Sires. } & \multirow[b]{2}{*}{ Leagth. } & \multicolumn{2}{|c|}{ Common. } & \multicolumn{2}{|c|}{ Finishing. } & & & \\
\hline & & $\begin{array}{l}\text { Diam., } \\
\text { inches. }\end{array}$ & $\begin{array}{l}\text { No. per } \\
\text { pound. }\end{array}$ & $\begin{array}{l}\text { Diam, } \\
\text { inches. }\end{array}$ & $\begin{array}{l}\text { No. per } \\
\text { pound. }\end{array}$ & Length & $\begin{array}{l}\text { Diam., } \\
\text { inches. }\end{array}$ & $\begin{array}{l}\text { No. pea } \\
\text { pound. }\end{array}$ \\
\hline $\begin{array}{l}2 d \\
3 d \\
4 d \\
5 d \\
\end{array}$ & 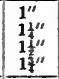 & $\begin{array}{l}.0524 \\
.0588 \\
.0720 \\
.0764 \\
\end{array}$ & $\begin{array}{r}1060 \\
640 \\
380 \\
275 \\
\end{array}$ & $\begin{array}{l}.0453 \\
.0508 \\
.0508 \\
.0571 \\
\end{array}$ & $\begin{array}{r}1558 \\
913 \\
761 \\
500 \\
\end{array}$ & $\begin{array}{l}3^{\prime \prime} \\
32_{2}^{\prime \prime} \\
4^{\prime \prime} \\
4_{2}^{\prime \prime}\end{array}$ & $\begin{array}{l}.1620 \\
.1819 \\
.2043 \\
.2294 \\
\end{array}$ & $\begin{array}{l}11 \\
30 \\
23 \\
17 \\
\end{array}$ \\
\hline $\begin{array}{l}6 \mathrm{~d} \\
7 \mathrm{~d} \\
8 \mathrm{~d} \\
9 \mathrm{~d} \\
\end{array}$ & $\begin{array}{l}2^{\prime \prime} \\
2_{4}^{\prime \prime \prime} \\
2_{2}^{\prime \prime \prime} \\
2_{4}^{\prime \prime \prime}\end{array}$ & $\begin{array}{r}.0808 \\
.0858 \\
.0935 \\
.0963 \\
\end{array}$ & $\begin{array}{r}210 \\
160 \\
115 \\
93 \\
\end{array}$ & $\begin{array}{l}.0641 \\
.0641 \\
.0720 \\
.0720 \\
\end{array}$ & $\begin{array}{l}350 \\
315 \\
214 \\
195 \\
\end{array}$ & $\begin{array}{l}5^{\prime \prime} \\
5_{2}^{\prime \prime \prime} \\
6^{\prime \prime} \\
6_{2}^{\prime \prime}\end{array}$ & $\begin{array}{l}.2576 \\
.2893 \\
.2893 \\
.2249 \\
\end{array}$ & $\begin{array}{c}13 \\
11 \\
10 \\
7 \frac{1}{2} \\
\end{array}$ \\
\hline $\begin{array}{l}10 \mathrm{~d} \\
12 \mathrm{~d} \\
16 \mathrm{~d} \\
20 \mathrm{~d}\end{array}$ & $\begin{array}{l}3^{\prime \prime} \\
3 f^{\prime \prime} \\
3_{2}^{\prime \prime} \\
4^{\prime \prime}\end{array}$ & $\begin{array}{l}.1082 \\
.1144 \\
.1285 \\
.1620\end{array}$ & $\begin{array}{l}77 \\
60 \\
48 \\
31\end{array}$ & $\begin{array}{l}.0808 \\
.0808 \\
.0907 \\
.1019 \\
\end{array}$ & $\begin{array}{r}137 \\
127 \\
90 \\
62\end{array}$ & $\begin{array}{l}7^{\prime \prime} \\
8^{\prime \prime} \\
9^{\prime \prime}\end{array}$ & $\begin{array}{l}.2249 \\
.3648 \\
.3648\end{array}$ & $\begin{array}{l}7 \\
5 \\
4 \frac{1}{2}\end{array}$ \\
\hline $\begin{array}{l}30 \mathrm{~d} \\
40 \mathrm{~d} \\
50 \mathrm{~d} \\
60 \mathrm{~d}\end{array}$ & $\begin{array}{l}41_{2 \prime \prime}^{\prime \prime} \\
5^{\prime \prime} \\
5_{2}^{\prime \prime \prime} \\
6^{\prime \prime}\end{array}$ & $\begin{array}{l}.1819 \\
.2043 \\
.2244 \\
.2576\end{array}$ & $\begin{array}{l}22 \\
17 \\
13 \\
11\end{array}$ & & & & & \\
\hline
\end{tabular}




\section{TABLE XXIX.}

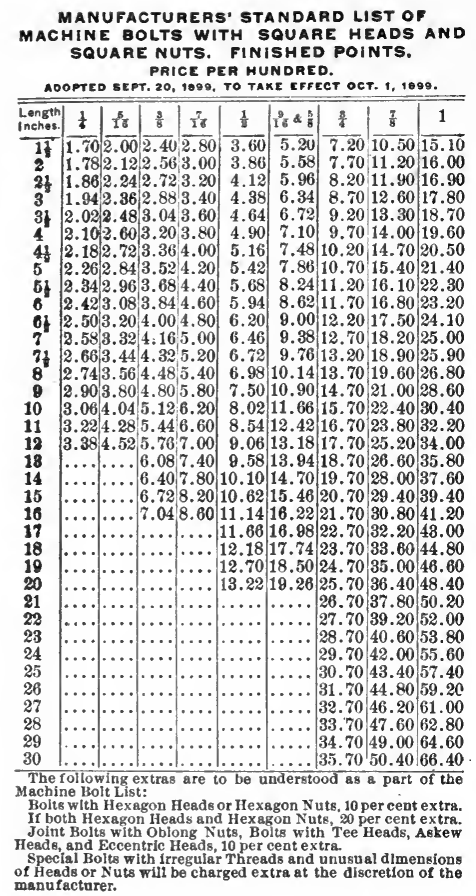

AVERAGE WEIGHT OF SQUARE HEAD MACHINE BOLTS PER 100.

\begin{tabular}{|c|c|c|c|c|c|c|c|c|c|}
\hline \multirow{2}{*}{ Length. } & \multicolumn{9}{|c|}{ DIAM ETER. } \\
\hline & $3 / 6$ & to & $\%$ & so & $1 / 3$ & $\%$ & 3 & $\%$ & 1 \\
\hline & 4.0 & 6.8 & 10.6 & 15.0 & 23.9 & 40.5 & 70.0 & & \\
\hline & & & 11.3 & 16.1 & 2.1. & 42.7 & 73.1 & $\cdots$ & ;....... \\
\hline & & 7.8 & 12.0 & 17.2 & 26.3 & 44.8 & 76.2 & & $\cdots \cdots \cdot$ \\
\hline 314 & $\begin{array}{l}5.1 \\
5.4\end{array}$ & 8.4 & $\begin{array}{l}12.6 \\
13.3\end{array}$ & $\begin{array}{l}18.2 \\
192\end{array}$ & $\begin{array}{l}27.7 \\
29.0\end{array}$ & $\begin{array}{l}47.0 \\
49.2\end{array}$ & 79.3 & 120.... & $\cdots \cdots . .$. \\
\hline & $\begin{array}{l}0.4 \\
5.8\end{array}$ & 9.5 & $\begin{array}{l}14.0 \\
14.0\end{array}$ & 20.2 & 30.4 & 51.4 & $\begin{array}{l}85.4 \\
85.5\end{array}$ & 124.7 & $\cdots \ldots$. \\
\hline & & 10.0 & 14.7 & 21.2 & 31.8 & 63.5 & 88.7 & 128.9 & 185.0 \\
\hline $31 / 2$ & 6.8 & 11.1 & 16.0 & 23.2 & 34.7 & 57.9 & 95.0 & 137.4 & 196.0 \\
\hline & $\begin{array}{l}7.5 \\
8.2\end{array}$ & $\begin{array}{l}12.2 \\
13.2\end{array}$ & 17.4 & $\begin{array}{l}25.2 \\
27.2\end{array}$ & $\begin{array}{l}37.5 \\
40.2\end{array}$ & $\begin{array}{l}62.3 \\
66.7\end{array}$ & 101.2 & 145.8 & 207.0 \\
\hline & 8.2 & 14.3 & 20.0 & 29.1 & 40.4 & 7.1 .0 & 113.7 & 167.7 & $\begin{array}{l}280.0 \\
229.0\end{array}$ \\
\hline $51 / 2$ & 9.6 & 15.4 & 21.4 & 81.2 & 45.7 & 75.4 & 120.0 & 176.1 & 240.0 \\
\hline & 10.3 & 16.5 & 22.8 & 33.1 & 48.4 & 79.8 & 126.2 & 184.6 & 251.0 \\
\hline $61 / 2$ & 11.0 & 17.6 & 24.1 & 85.1 & 51.2 & 841 & 132.5 & 193.0 & 262.0 \\
\hline & 11.7 & 18.6 & 25.9 & 37.1 & 54.0 & 88.5 & 138.7 & 201.4 & 273.0 \\
\hline $71 / 2$ & 12.4 & 197 & 27.7 & 39.1 & 56.7 & 92.9 & 145.0 & 209.9 & 284.0 \\
\hline & 18.1 & 20.8 & 29.5 & 41.0 & 59.4 & 97.2 & 151.2 & 218.3 & 295.0 \\
\hline 9 & & & 33.1 & 45.0 & 64.8 & 106.0 & 163.7 & 240.2 & 317.0 \\
\hline 10 & . & ..... & 38.7 & 49.0 & 78.8 & 114.7 & 178.2 & 257.1 & 899.0 \\
\hline & & $\cdots$ & 40.4 & 53.0 & 75.8 & 123. & 188. & 273.9 & 360 . \\
\hline & $\cdots$ & …... & 44.0 & 55.0 & 81.8 & 182. & 201.0 & 290. & 382 \\
\hline & $\ldots$ & ........ & $\mid . \ldots$. & ....... & 86.7 & 140. & 213.4 & 307.7 & 404. \\
\hline 14 & $\ldots$. & $\mid \ldots \ldots$. & $\mid . . .$. & ..... & 92.2 & 149.2 & 225.9 & 324.5 & 426.0 \\
\hline 15 & ....... & ........ & ....... & .... & 97.7 & 157.6 & 298.8 & 341.4 & 448.0 \\
\hline 16 & {$[\ldots . .$.} & $\therefore \ldots$ & $\ldots$ & $\ldots . .$. & 103.1 & 166.1 & 250.8 & 358.3 & 170.0 \\
\hline 17 & ........ & $\ldots \cdot$. & $\cdots .$. & ........ & 108.6 & 174.6 & 263.2 & 375.2 & 192.0 \\
\hline 18 & ........ & $\ldots$ & $\ldots \ldots$ & ....... & 114.1 & 183.1 & 275.6 & 392.0 & 514.0 \\
\hline 19 & $\cdots \cdot$ & $\ldots . .$. & $\ldots \ldots$ & $\cdots \cdots$ & 119.5 & 191.5 & 288.1 & 408.9 & 536.0 \\
\hline 20 & & $\cdots \cdot$. & ........ & ....... & 125.0 & 200.0 & $300 . \overline{5}$ & 423.8 & \\
\hline $\begin{array}{c}\text { Per } \\
\text { toch ad. } \\
\text { dituonal }\end{array}$ & 1.4 & 2.2 & 8.6 & 4.0 & 5.5 & 8.5 & 12.4 & 16.9 & 22.0 \\
\hline
\end{tabular}

APPROXIMATE WEIGHT OF NUTS AND BOLT HEADS, IN POUNDS.

\begin{tabular}{|c|c|c|c|c|c|c|c|}
\hline Diam. of Bolt in Inches, & $1 / 6$ & sis & $\%$ & is & $1 / 2$ & $\%$ & * \\
\hline 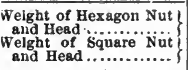 & $\begin{array}{l}.017 \\
.021\end{array}$ & $\begin{array}{l}.012 \\
.019\end{array}$ & $\begin{array}{l}.057 \\
.069\end{array}$ & $\begin{array}{l}.109 \\
.120\end{array}$ & $\begin{array}{r}.128 \\
.164\end{array}$ & $\begin{array}{l}.267 \\
.320\end{array}$ & .55 \\
\hline Diam of Bolt in inches. & $\%$ & 1 & $11 / 4$ & $11 / 2$ & $1 \%$ & 2 & $21 / 2$ \\
\hline 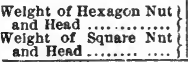 & $\begin{array}{l}.73 \\
.88\end{array}$ & $\begin{array}{l}1.10 \\
1.81\end{array}$ & $\begin{array}{l}2.14 \\
2.56\end{array}$ & $\begin{array}{l}8.78 \\
4.42\end{array}$ & $\begin{array}{l}5.6 \\
7.0\end{array}$ & $\begin{array}{c}8.75 \\
10.5\end{array}$ & $\begin{array}{l}17.0 \\
21\end{array}$ \\
\hline
\end{tabular}




\section{PART IV.}

\section{Miscfilianfous Structures.}

The descriptions of the different structures given in this part have been abstracted from descriptions published in the Engineering News, Engineering Record, etc. Figs. I7I and I72 are from the Railroad Gazette; and Fig. I69 and Figs. I72 to I8I, inclusive, are reproduced from originals kindly loaned by the Engineering News.

\section{Stefl Dome for the West Baden, Ind., Hotel.*}

The dome of the new hotel at West Baden, Ind., is remarkable for its size. This dome has a steel framework and is larger than any other ever built, its span exceeding by about I 5 feet that of the Horticultural Building of the Chicago Exposition of 1893 .

The dome is about 200 feet in outside diameter and rises about 50 feet above the bed plates. Its frame consists of 24 steel ribs, all connected at the center or crown to a circular plate drum, and tied together at the bottom by a circular plate girder tie. Each rib foots at its outside end on a built up steel shoe, resting on a masonry pier. The rib is connected to the shoe by a steel pin, and the outside plate girder toe is attached to the gusset plate at this point, just above the shoe. The shoes of all the girders are constructed as expansion bearings, being provided with rollers in the usual manner.

The dome is therefore virtually an aggregation of two-hinged arches with the drum at the center forming their common connection. Their thrust at the foot goes into the circular tie-girder, and only vertical loads (and wind loads) come upon the shoes and the bearing piers. At the same time any temperature stresses are avoided, since the expansion rollers under the shoes permit a uniform outward motion of the lower ends of all the ribs.

The outline of the dome and part of the dome framing are shown

*Engineering News, Sept, 4, 1.902. 


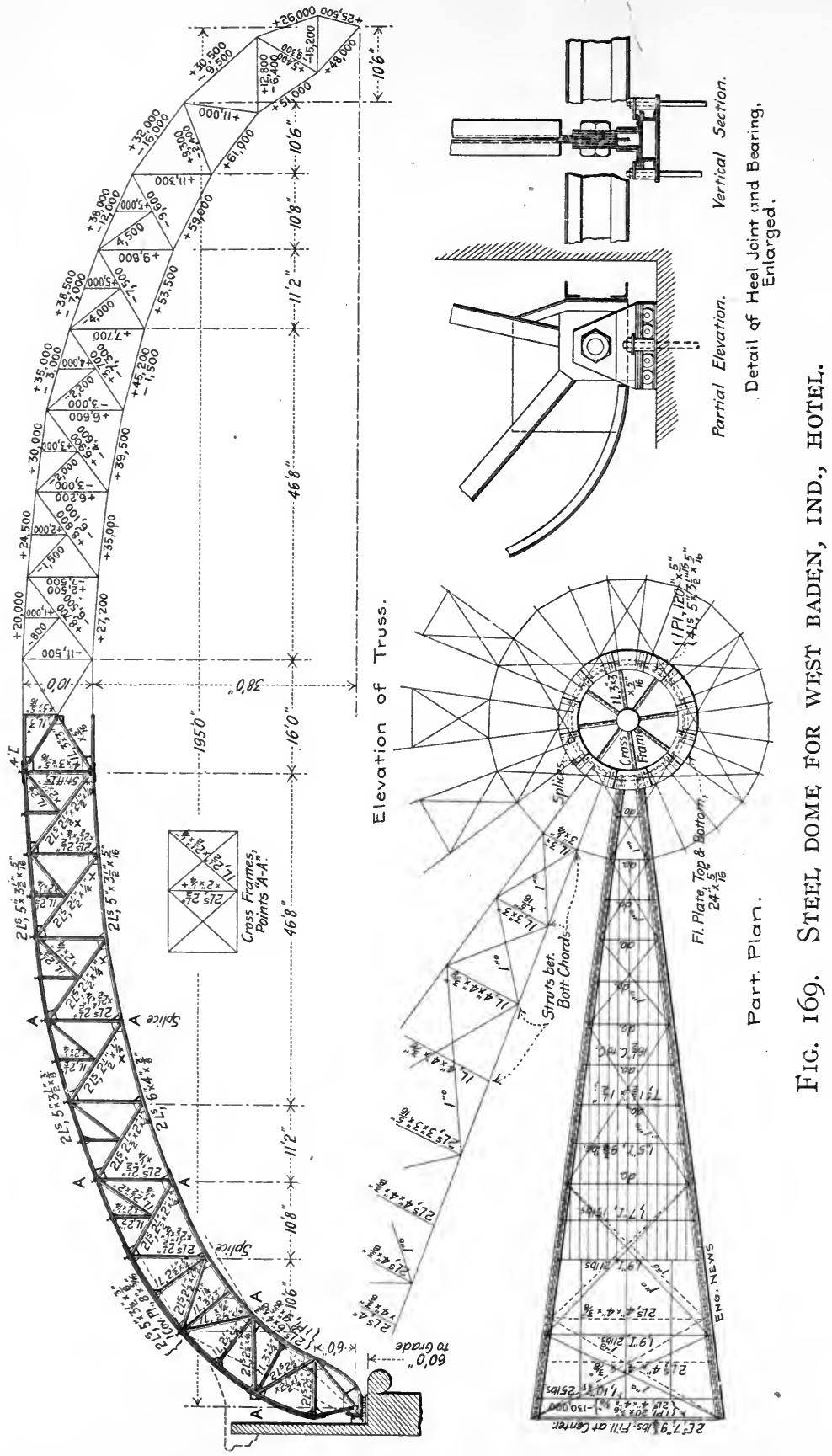


i1. Fig. 169 . The rise is between $1 / 4$ and $1 / 5$ of the span. The outline of the top chord approximates an elliptical curve, and the bottom chord is parallel to the top chord throughout its length, except in the three end panels on either side; the depth of the arch being Io ft. back to back of chord angles. The web members are arranged as a single system of the Pratt type, with substruts to the top chord as purlin supports. In the end sections the arrangement is necessarily modified, the sharper curvature of the chords being allowed for by more frequent strutting.

The maximum stresses in the different members of the arch are given on the right half of the rib in Fig. 169. They are obtained by properly combining the dead load stresses with the stresses due to wind blowing successively in oppnsic directions in the plane of the rib in question. The loads used in the calculation were at dead load separaie ?y. estimated for each panci point, a variable snow load, heaviest at the center of the roof, a wincl loa!l of 30 lbs. per sq. $\mathrm{ft}$. on a normal surface reduced for inclination of the roof to the vertical. The makeup of the members is given on the left half of the rib in Fig. I69. In the plan part of the dome the method of bracing the ribs is fully shown. Successive pairs of ribs are connected by bays of bracing in both upper and lower chords. In the upper chord the I beam purlins are made use of as struts, angle struts being used in the lower chord. The bracing consists throughout of crossed adjustable rods. At the center, these rods are carried over to a tangential attachment to the central drum, so as to give more rigidity against twisting at the center.

The central drum, $16 \mathrm{ft}$. in diameter by Io $\mathrm{ft}$. deep, has a web of $3 / 8$ inch plate, with stiffener angles to which the ribs are attached. At top and bottom the drum carries a flange plate 24 ins. $\times 3^{-16}$ ins. for lateral stiffeners. In addition it is cross braced internally by four diametrical frames intersecting at the center. The outer tie-girder, which takes the thrust of the arch ribs, is a simple channel-shaped plate girder, 24 ins. deep, as shown on the plan. The weight of the dome complete, including framework and covering was 475,000 lbs. This makes the dead load about ${ }_{5} 5$ lbs. per square foot of horizontal projection of roof surface.

Mr. Harrison Albright, of Charleston, W. Va., was the architect of the building and the design of the steel dome was worked out by Mr. Oliver J. Westcott, while in charge of the estimating department of the Illinois Steel Company. The structural steel was furnished by the Illinois Steel Co. 


\section{The St. Louis Coliseum.*}

The St. Louis Coliseum Building is a rectangular brick building $186^{\prime} 2^{\prime \prime} \times 322^{\prime} 3^{\prime \prime}$. The steel framework is made entirely independent of the masonry walls and consists of three-hinged arches properly braced. The Coliseum has an area of $222 \times$ II 2 feet clear of the curb wall. Ordinarily there are seats for 7,000 persons on the main floor and the galleries, but for convention purposes with seats in the arena the number can be increased to 12,000 persons.

The steel framework consists of a central arched section adjoined at each end by a half dome formed by six radial arched trusses. The main arches forming the central section have a span $178^{\prime} 6^{\prime \prime}$ c. to c. of shoe pins, are spaced $36^{\prime} 8^{\prime \prime}$ apart, and are connected by lateral bracing in pairs. The pins at the foot of the arches are 47 - $16^{\prime \prime}$ diameter, and at the crown the pin is $25^{-1} 6^{\prime \prime}$ diameter. The rise of the arches is $80^{\prime} \mathrm{o}^{\prime \prime}$, the lower chord points being in the curve of a true ellipse.

The end radial trusses correspond essentially to the semi-trusses of the main arches except for their top connection, where their top chords are attached to a semicircular frame supported by the end main trusses and designed to receive thrust, but no vertical reaction, as shown in Fig. I70.

The roof covering of asphalt composition is laid on $13 / 8$-inch boards, resting on $2 \frac{1}{2} \times 16$-inch wood joists, 3 feet apart and ceiled underneath. These, in turn, are carried by the steel purlins of the structure, which are spaced about 16 feet apart. The gallery floor beams are carried on stringers of 8 -inch channels spaced $3^{\prime} 8^{\prime \prime}$ center to center, carried by girders running between, and supported by the arches. The rear stringer is a plate girder; the front one is a latticed girder, the gallery beams running through the latter and cantilevering out $5^{\prime} 4^{\prime \prime}$. The main floor beams, supporting the lower tier of seats, consist of 9 -inch $I$ beams, spaced $3^{\prime} 8^{\prime \prime}$ center to center, which are similarly carried on girders, and their lower ends rest on a brick wall.

\footnotetext{
*Engineering Nèws, Aug. 10, 1899, and Engineering Record, 1899.
} 


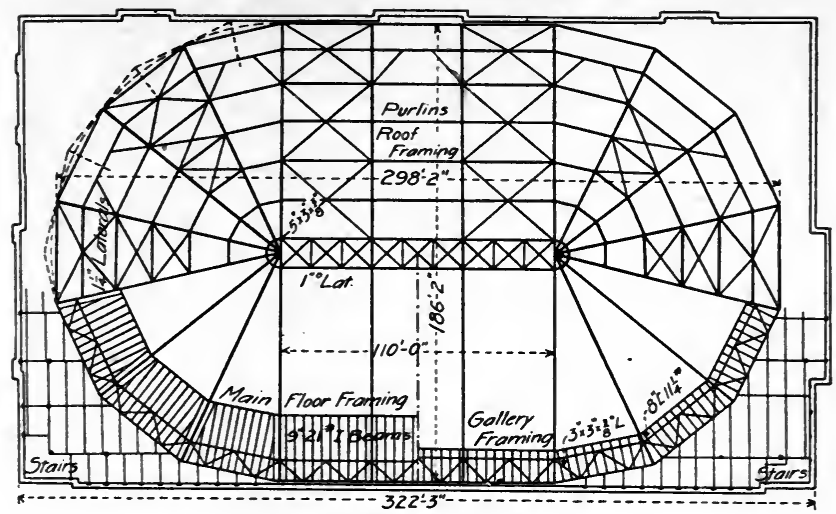

Sectional Plan

Figure 1. General Plan of Trusses\& Framing

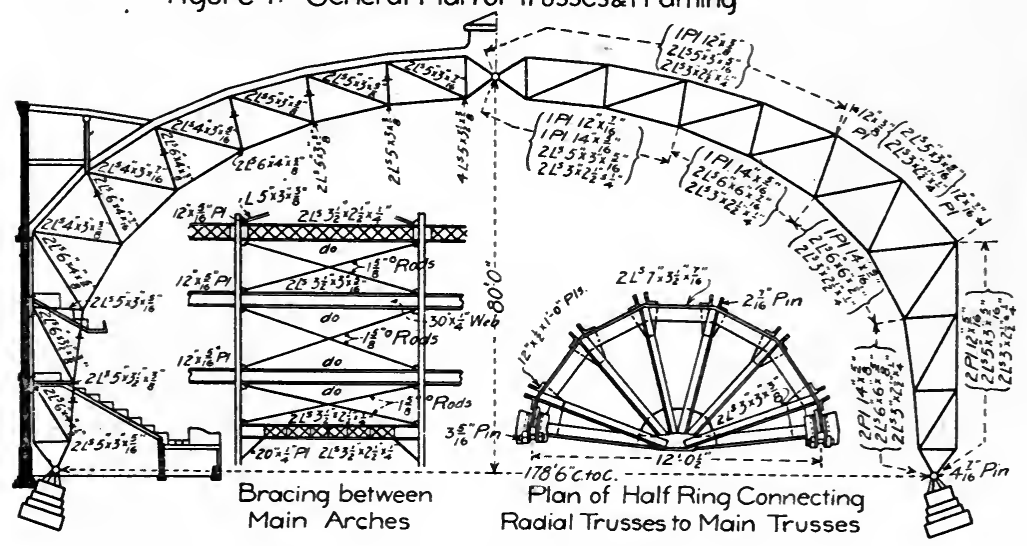

Main Arches

Figure 2 - Cross Section Showing Construction of Main Arches

FIG. I70.

The loads, in accordance with which the trusses were figured, are as follows:

\section{CASE I.}

Wooden deck and gravel of roof....... 7.5 lbs. per sq. ft., vertically Steel ....................

Snow and wind $\ldots \ldots \ldots \ldots \ldots \ldots .25 .0$ " " " " " 
Add for floors, viz.:

Main floors, banks and galleries....... I05.0 “

Attic floors ...............6. 60.0

\section{Case II.}

Wooden deck and gravel of roof....... I7.5 lbs. per sq. ft., vertically

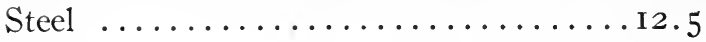

Snow $\ldots \ldots \ldots \ldots \ldots \ldots \ldots \ldots \ldots \ldots$. $\ldots \ldots \ldots$

Total .................4. " " " " "

Wind pressure over entire elevation of

wall and roof of $\ldots \ldots \ldots \ldots \ldots 30.0$ lbs. per sq. ft., horizontally

LoAds ON PURLins.

Wooden deck and gravel of roof........ 7.5 lbs. per sq. ft., vertically Steel ........................ 3.5 "

Snow and wind

$3 \cdot 5$

(1)

Total 46.0 " " " " “ ................... $25 \cdot 0$ " 6406

Loads on Floor Beams, Girders and Colunins of Main Floors. Banks and galleries, beams .......................... Banks and galleries, girders ............. " " " " " " Banks and galleries, columns ............. " " " " " " " " " " Attic floors beams, columns and girders........60 " " " " " " "

For the main trusses, in addition to the stresses of Case II., there was added the stress due to the wind bracing between these trusses.

For the radial trusses, in addition to loading of Case II., there was assumed an additional load of 50,000 pounds supposed to act up or down at the upper point of truss; this load being what was assumed probable in case there was slight unequal settlement of the footings.

For the half ring connecting the tops of the radial trusses there was another case assumed, beside Cases I. and II.-viz., a thrust of 50,000 pounds at any point of the half ring; this being the thrust of a radial truss under its full live and wind load.

All the material used was of medium steel, excepting the rivets, which were made of soft steel. Both material and workmanship conform to manufacturer's standard specifications. 


\section{Unit Strains.}

Tension $\ldots \ldots \ldots \ldots \ldots \ldots \ldots \ldots \ldots \ldots \ldots \ldots, 0 \ldots \ldots$ lbs. per sq. in. Compression, for lengths of 90 radii or under....12,000 Compression, for lengths of over 90 radii.....17,100-57 $l \div r$

Combined stress due to tension or compression

and transverse loading $\ldots \ldots \ldots \ldots \ldots \ldots$ I6,000

Shear on web plates $\ldots \ldots \ldots \ldots \ldots \ldots \ldots \ldots 7,500$

Shear on pins ................. I I,000 "

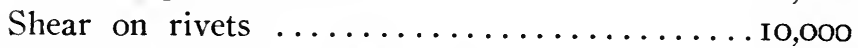

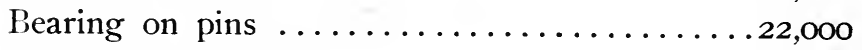

Bearing on rivets $\ldots \ldots \ldots \ldots \ldots \ldots \ldots \ldots \ldots \ldots \ldots \ldots$

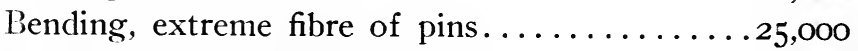

Bending, extreme fibre of beams .......... I6,0no " " " " "

Lateral connections have 25 per cent greater unit strains than the above.

In Case II of trusses, the above unit strains were increased onethird. The main and radial arch trusses are built as shown in Fig. 170 , except that above the haunches the ribs of the radial arches are T-shaped instead of I-shaped, i. e., they have no inside flanges. The purlins are triangular trusses $4 \frac{1}{2}$ feet deep, made of angles. The bracing between main arch trusses terminates at the bottom with heavy portal struts of triangular box section. The lateral rods are not carried to the ground on account of the obstruction they would make. The radial trusses are coupled together in pairs with lateral rods down to the ceiling line. The thrust due to wind is transmitted from them into the line of girders around the structure at this point, and into the adjoining floor systems. The compression ribs of the main and radial arches are stayed laterally by angle iron ties, connecting to the first panel-point in the bottom chord of the purlins. In the planes of the first diagonal braces of the trusses above the haunches, diagonal rods connect the bottom ribs of the trusses to the upper ribs of the next trusses. No struts were used between the bottom chords, as they would have been directly in the line of vision from the rear gallery seats to the farther end of the arena. The front and rear girders supporting the gallery and main floor beams are tied together with a triangular system of angle iron bracing.

To provide for expansion, the radial purlins and all the girders between the arches have slotted hole connections in every alternate bay. The diagonal rods between the two lines of ridge purlins were tightly 
adjusted on a hot day. To prevent secondary strains in the half ring to which the radial trusses are connected at their tops, there is I-I6-inch clearance in all the pin holes. There is also clearance between the pin plates, so that the trusses and the ring can slide a little sideways on their pins. The lines of the arch trusses were laid out full size and the principal points checked by independent measurements in the template shop, and the work was accurately assembled. In order to avoid the handling of large, heavy pieces before the drill press, the foot of the arch, through which the pin hole was bored, was made separately and afterward riveted on.

The total weight of the iron in the entire structure was $1,905,000$ pounds, as follows: Main arches, 64,000 pounds, each; radial arches 2I,OoO pounds, each; purlins between main trusses I, 450 pounds, each; main floor stringers 8Io pounds, each; balcony floor stringers, 280 pounds, each; cast shoes 3,000 pounds, each. There were 4,I88 days labor spent on the work in the shop and 3,550 days labor during erection, the average number of men in the erecting force being about 50 . The stress diagrams and detail plans of the steel frame were made under the supervision of Mr. Stern, in the office of the Koken Iron Works, who were contractors for the ironwork, and were submitted for approval to the consulting engineer, Mr. Julius Baier, Asscc. M. Am. Soc. C. E. Mr. C. K. Ramsey was the architect of the Coliseum, and Mr. L. H. Sullivan was the consulting architect. Mr. A. H. Zeller was consulting engineer for the Board of Public Improvements; Mr. J. D. McKee, C. E., was shop inspector, and the Hill-O'Meara Construction Company was the general contractor. 
The Locomotive Shops of the Atchison, Topeka and Santa Fe R. R., Topeka, Kas.*

This building is intended for all the locomotive work, including boilers and tenders. It is of particular note for its great size and the peculiar features of its design. In general plan it is $852 \mathrm{ft}$. long and I 53 $\mathrm{ft}$. Io ins. wide, the width being divided into a center span of $74 \mathrm{ft} .3$ ins. and two side spans of $39 \mathrm{ft} .9$ ins. It is of self-supporting steel frame construction, with concrete foundations and floor, 13 -in. brick walls, and Ludowici tile roof. There is no sheathing under the tiles, which thus constitute the sole covering. The tiles are laid on $2 \times 2$-in. timber strips to which every fourth tile is fastened by copper wire.

The most striking feature of the design is that the saw tooth or weaving shed type of roof is adopted for the side spans, the glazed vertical sides of the ridges facing northward. This feature was introduced with the view of making the shop as light as possible. The arrangement could not well be used where heavy snows are frequently experienced, as the snow would pack between the ridges, but there are comparatively few heavy snow storms in the vicinity of Topeka. In addition to this arrangement, the greater proportion of the area of the side walls is composed of windows, while the exposed parts of the sides of the central span (between the ridges of the side spans) are also glazed. There are also several windows in the end walls. The roof of the central span has on each side of the ridge a skylight $12 \mathrm{ft}$. wide, extending the full length of the building. These skylights are fitted with translucent fabric instead of glass. By these various means an exceptionally good lighting effect and diffusion of light are obtained and the shop is in fact remarkably light even on a gloomy day. There is no monitor roof, but ventilation is provided for by Star ventilators $25 \mathrm{ft}$. apart along the ridge of the main roof.

The columns are built up of pairs of 15 -in. channels, and independent columns of similar construction carry the double-web box girdes runways for the electric traveling cranes which run the entire length of the central span. Fig. I73 shows the elevations, sections and plans

*Engineering News, Jan. 3, 1903: and Railway Gazette, Nov. 7, 1902. 


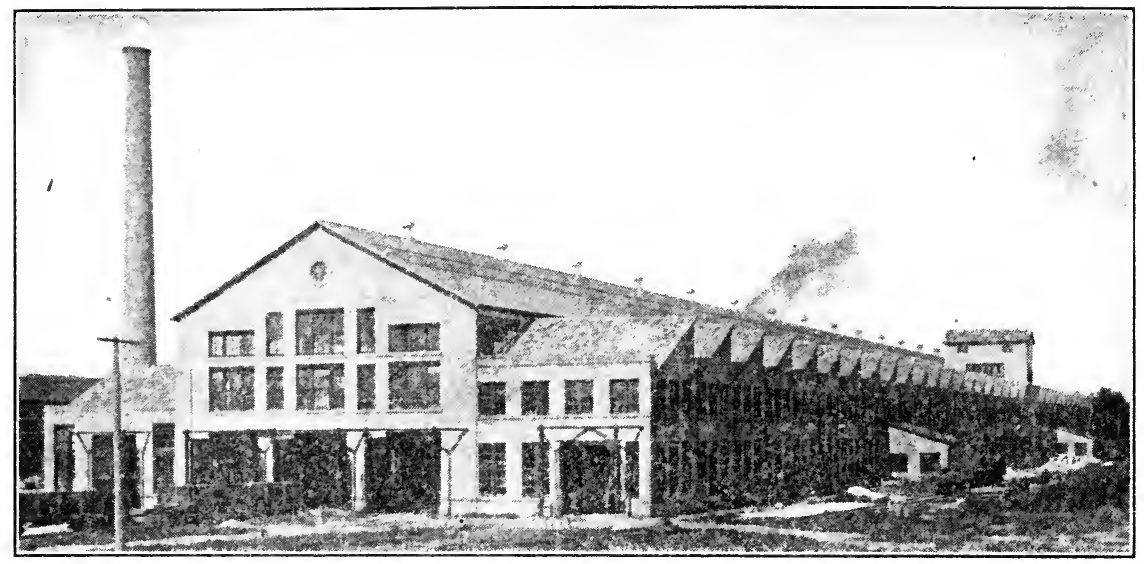

Fig. i7i. Loconotive SHop.

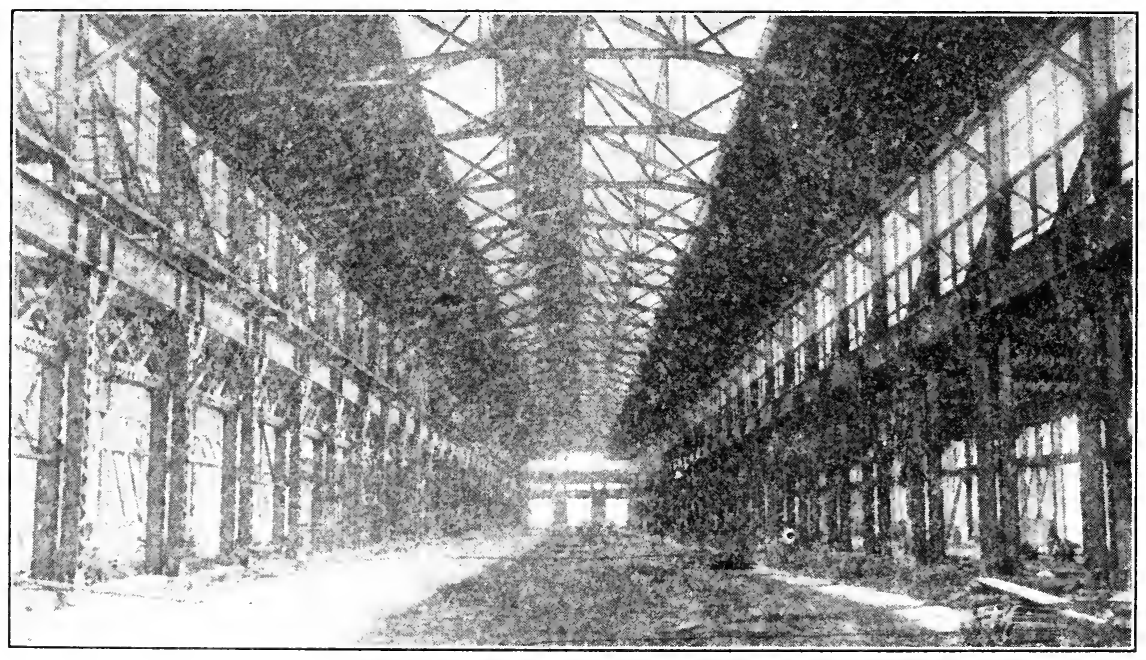

Fig. iz2. Cross-Shetton locomotThe Shor.

of the steel structural framework, and Fig. I74 is a partial elevation on the east side. Fig. I 75 shows the design of the central roof trusses and the lattice girders which form longitudinal bracing between the trusses. 'This longitudinal bracing is not continuous but is fitted only between 
alternate pairs of trusses. End trusses are built into the walls, as these walls are pierced by numerous, windows and dcors and are not relied upon in any way to support the roof. Portal bracing is fitted between the side or wall columns at intervals. No metal less than $3 / 8$-in.
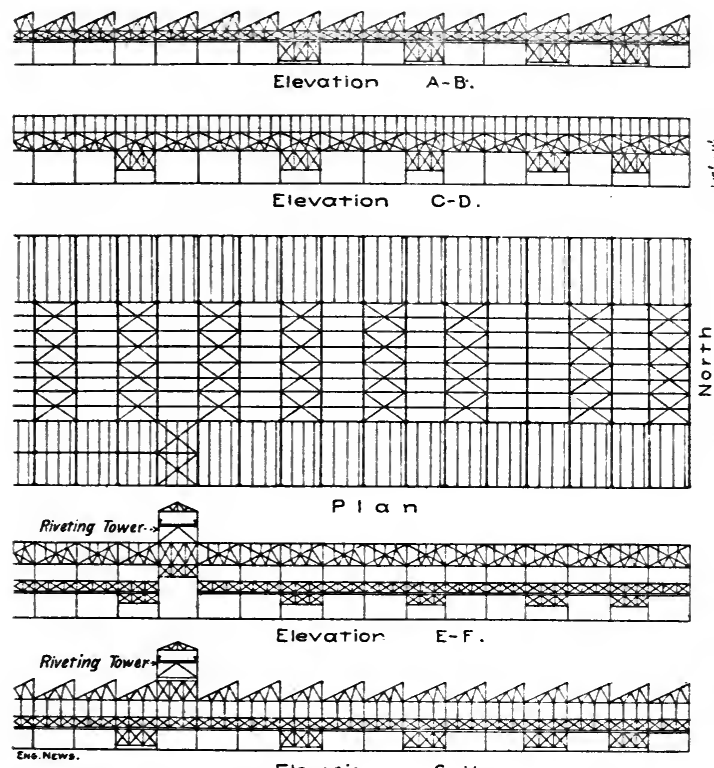

Elevation G-H.

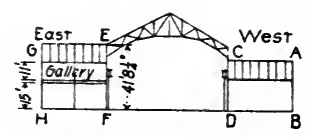

Cross Section of Machine Shop.

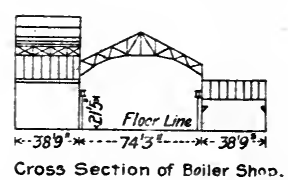

Fig. I73. PART ELEVATIONS AND PLANS OF STEEL STRUCTURAL WORK OF NEW LOCOMOTIVE SHOPS.

thick is used in the structural work.

The roof trusses are proportioned for a load of $\mathrm{I}_{5} \mathrm{lbs}$. per sq. $\mathrm{ft}$. for the weight of the roofing, Io lbs. per sq. ft. for snow, and $25 \mathrm{lbs}$. per sq. ft. for wind pressure, or $50 \mathrm{lbs}$. per sq. ft. in all. The members

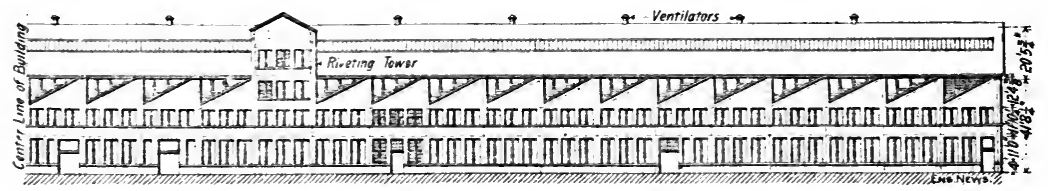

Fig. I74. HALF EAST Elfeyation OF NEW Locomotive Shop. (SHOWING RIVETING TOWER AND WEAVING SHED ROOF.) 
were calculated on a basis of 16,000 lbs. per sq. in. for tension and I 4,000 lbs. per sq. in. for compression. Provision for expansion and contraction is made at intervals of $100 \mathrm{ft}$. The structural work for this shop was built at the Toledo Works of the American Bridge Co. The steel is painted a light grey, and the brick is whitewashed, a pneumatic machine being used for the latter work.

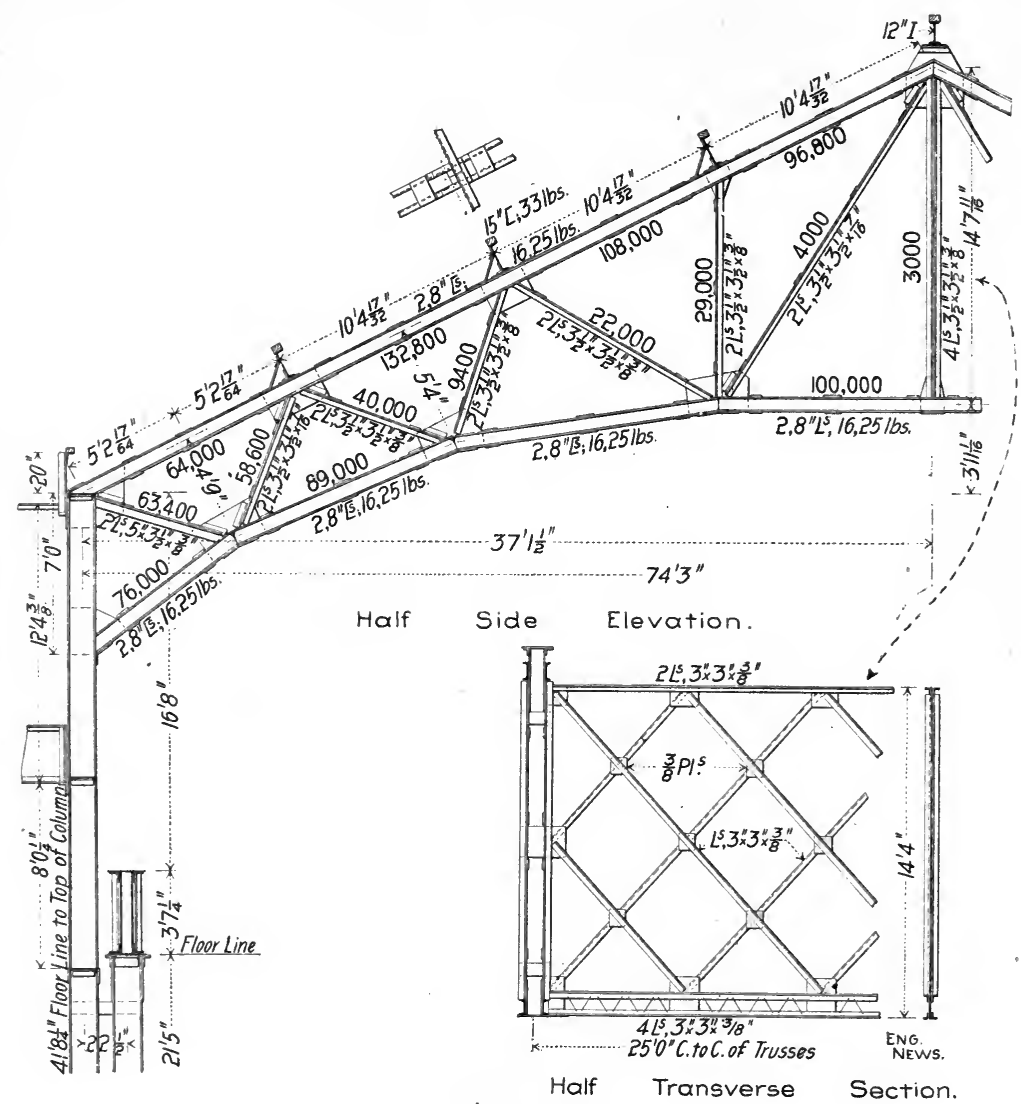

FIG. I75.

The arrangements for lighting the shop by day have already been referred to. For night work there will be arc lights for general lighting and incandescent lamps convenient to the tools, etc. The building is heated by the Sturtevant hot blast system. On each side are two fan rooms, each containing a steam-driven blower fan and a heating 
chamber filled with coils of pipe through which passes the exhaust steam. The hot air is delivered into two longitudinal underground conduits parallel with the lines of columns, with a duct leading to the surface at each column. Each duct is fitted with a vertical sheet iron pipe $7 \mathrm{ft}$. high, with a flaring head to deliver the air horizontally. The plant is guaranteed to maintain a temperature of $70^{\circ} \mathrm{F}$. throughout the shop in zero weather.

The floor foundation is formed of 6 inches of concrete resting on the natural soil well tamped. The concrete is composed of I part Louisville cement, 2 parts sand and 4 parts stone. On the concrete are laid vellow pine nailing strips, $3^{\prime \prime} \times 4^{\prime \prime}$, I8 ins. c. to c., to which is spiked the $13 / 4$-in. splined hard-maple flooring. All tracks in the shop are laid with $75^{-1 b}$. rails on ties of New Mexico pine treated by the zinc-chloride process, the floor concrete being laid only to the ends of the ties, so that adjustment of the track can be made without tearing up the floor. At the engine pits (which are of concrete) the rails are laid on longitudinal timbers. The concrete for column foundations is composed of I part Iola Portland cement, 3 parts sand and 5 parts stone. These foundations are 8 to $15 \mathrm{ft}$. deep, extending to solid clay. They are built up with gas pipe sleeves to form holes for the anchor bolts, and the holes in the bed plates of the columns are slotted longitudinally so as to allow of adjustment for any slight variation. The foundations for the tools, etc., are also of Portland cement concrete, and these are built by the mechanical department to suit its own requirements as to arrangement of tools. This arrangement was only arrived at after careful study, and of course no changes can be made without expensive work in cutting out and replacing concrete. One suggestion for the floor construction was to use a brick floor with no conrete, so as to allow for future changes and putting in new foundations. 
The Locomotive Erecting and Machine Shop, Philadeitifia \& Reading R. R., Reading, PA.*

The combined machine and erecting shop is $204 \mathrm{ft} .4^{\mathrm{T}} / 2$ ins. wide and $749 \mathrm{ft}$. Io ins. long, with provision made for its extension to a total length of I,O0O ft. At its present length it has repair pits for 70 locomotives, and the proposed extension will provide for 30 pits more. Fig. 176 shows the general arrangement of the shop in plan, and Fig. I 77 is a transverse section showing the general character of the construction.

The building, it will be observed, is divided transversely into three bays by means of two rows of intermediate columns running lengthwise of the building. These intermediate columns and the side wall columns carry the roof trusses and the overhead cranes, and are spaced $20 \mathrm{ft}$. apart longitudinally. The walls of the building are entirely independent of the steelwork. Considering the building transversely it will be observed that the two side bays contain the repair pits; one pit be-

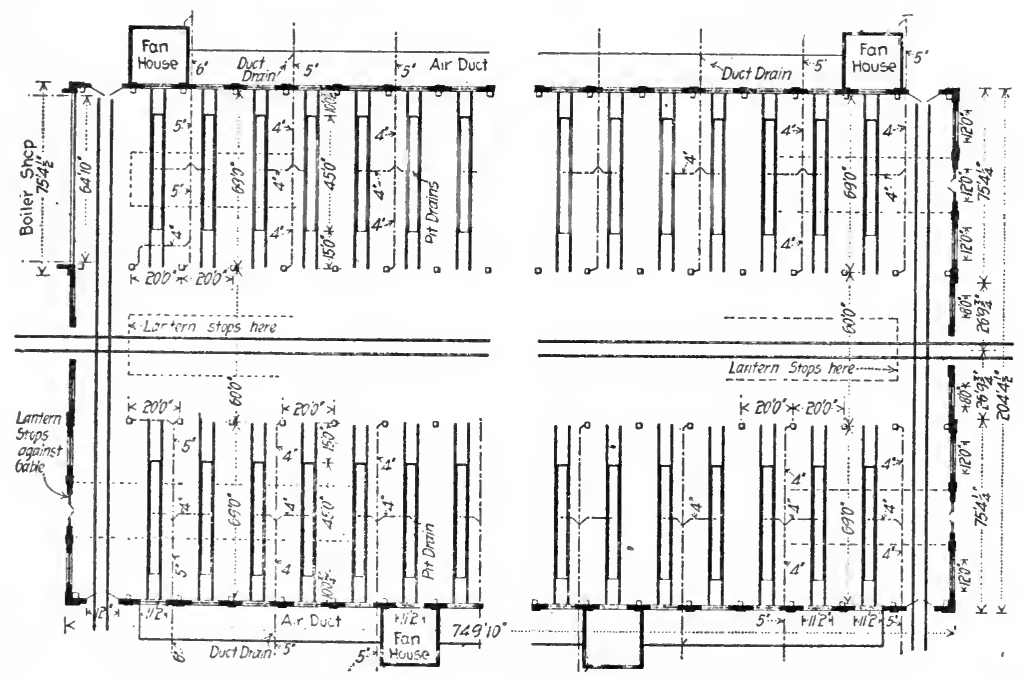

Fig. i76. Part plan, Showing pit and Column arRangement,

${ }^{*}$ Engineering News, May 24, 1900. 
tween each pair of columns, 35 pits on each side spaced 20 feet. apart c. to c. Over each side bay there are two traveling crane tracks, one above the other. The top track will be for a crane of $\mathrm{I} 20$ tons capacity, capable of lifting a locomotive and carrying it the entire length of the building at a height great enough to clear the locomotives standing on the repair pits beneath. On the lower track there will be placed a number of 35 -ton cranes for handling parts of locomotives and material. The middle bay composes the machine shop, and it is also covered by a track for a number of traveling bridge cranes of 10 tons capacity each. A material track runs lengthwise of the middle bay at the center, and for bringing the locomotives into the shop there is a track extending transversely through the shop at each end. These transverse tracks connect by means of turntables with a yard track running parallel with the east side of the shop.

Taking up the construction in detail, the steelwork is the first part perhaps to demand attention. As already stated, the nature and general arrangement of the steel frame is shown by Figs. 176 and 177. It may be divided into two parts for description. The first part comprises

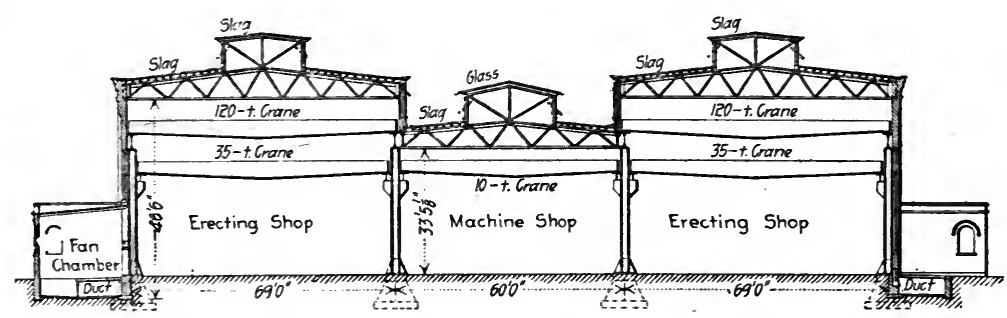

Fig. I77. Transverse Section OF Frameivork.

the main columns and the traveling crane track system which they support directly, and the second part comprises the roof framing. Considering the construction of the main columns first, it will be seen that it had to be devised to withstand an unusually severe combination of loads, including not only the dead and wind loads usual to all building frames, but also a very heavy concentrated moving load from the traveling cranes. Careful attention was also required to provide means for longitudinal expansion of the columns and crane track girder system and still preserve the utmost stiffness possible in the heavily loaded crane tracks. 
The interior and wall columns were substantially similar in construction, both being composed of two channel sections made up of plates and angles, held together by a double lacing of $2 \frac{1}{2} \times 1 / 2$-in. bars. Fig. I80 shows the column construction in detail. Each column is founded on a concrete pier with a granite capstone. The concrete in these piers and for all other foundation work was composed of I part Portland cement, 2 parts clean sharp sand and 5 parts stone broken to pass a 2 -in. ring. In making the concrete the sand and cement will first be mixed dry and then wet, and the wet mortar will then be mixed with the broken stone as it comes moist from washing. The shape of the column piers is indicated in Fig. I77, and the columns are fastened to them by four anchor bolts for each column. The columns are finished by milling machine at both top and bottom, and are capped and stiffened at the tops to provide a bearing for the 4 - $\mathrm{ft}$. $1 \frac{\pi}{3} / 8$-in. plate girders carrying the roo-ton crane tracks.

The track construction for the bridge cranes is shown in detail in Figs. I77 and I80. As already stated, the tracks for the I2O-ton cranes are carried on plate girders resting directly on the tops of the columns, and running lengthwise of the building. These track girders are $4 \mathrm{ft}$. $\mathrm{I} 3 / 8$ ins. deep back to back of flange angles and have spans of $20 \mathrm{ft}$., c. to c. of columns. They are milled square at the ends and the rivets of the end angles have flat heads. To allow for expansion the ends are not butted close together, but are separated by a clear space of $1 / 4$-in., by the construction shown in Fig. I80. From the drawing it will be seen that each girder span has one fixed and one expansion end, the expansion being provided for by the slotted rivet holes in the bearing plate and by the space between the ends of the girders. An exactly similar expansion end construction is provided for the girders carrying the tracks for the 35-ton and Io-ton cranes. These three tracks are on the same level and the girders supporting them are carried by Brackets on the main columns. This bracket and girder construction is shown in Fig. I77.

The crane tracks proper consist of ordinary railway rails laid directly on the special cover plate forming part of the top flange of each track girder, to which they are attached by stamped steel clips riveted to the cover plate. For the I2O-ton cranes the rails weigh I5O lbs. per yard, for the 35 -ton cranes they weigh $85 \mathrm{lbs}$. per yard, and for the roton cranes they weigh $70 \mathrm{lbs}$. per yard. The joints are located over the expansion joints at each column and are spaced $\mathrm{r} / \mathrm{s}$-in. open, the angle 
splices for the rails being arranged to permit expansion and contraction. The rails were rolled to the recommended Am. So. C. E. sections for their respective weights. The specifications require that the crane track rails must be in perfect alinement horizontally and yertically and that the gage must not vary more than $1 / 4$-in. at the maximum. To cbtain vertical alinement it is specified that not more than $1 / 8$-in. thickness of shims, each the full size of the bearings, shall br. placed between the column top and the girder. The idea, it will be seen, has been to provide for the heavy rolling loads by substantial construction and accurate workmanship, and to keep the track smooth and rigid by distributing the expansion over a number of joints instead of having all the allowance made for it at one or two points.

Turning now to the roof framing, it will be seen from Fig. 177 that there is a separate roof over each longitudinal bay of the building. The roof trusses for the middle bay rest directly on the tops of the intermediate rows of columns, but those for the two side bays are carried by special roof columns rising from the main columns, as shown by Fig. 180. The trusses in each bay are connected by purlins and lateral bracing and carry lantern roofs with glazing. Details of the roof trusses, bracing and lantern roof construction are shown in Fig. 178 so fully as to make any further description unnecessary. The roof covering and the glazing in the lanterns, however, deserve brief special notice.

The roof covering consists first of a $\mathrm{I} \times 8$-in. hemlock sheathing, having its upper surface planed. This sheathing is to be covered by four thicknesses of roofing felt spread with granulated slag. The construction is specified to be as follows: Make the outside course next the edge of five thicknesses of felt, then lay each succeeding layer at least three-fourths of its width over the preceding layer, firmly securing it in place, and thoroughly mop the surface underneath each succeeding layer as far back as the edge of the next lap with a thin coating of roofing cement. This cement is in no case to be applied hot enough to injure the wooly fibre of the felt. At least $70 \mathrm{lbs}$. of felt must be used per IOO sq. ft. of roof. Over the entire surface of the felt laid as described there is to be spread a good coating of cement, not less than ro gallons (including what is used between the layers of felt) of cement being employed per IoO sq. $\mathrm{ft}$. of roof. This cement coating is to be covered with a coating of slag, granulated and bolted for the purpose, using no slag larger than will pass through a $5 / 8$-in. mesh and none smaller than will be caught by a $1 / 4-\mathrm{in}$. mesh. This slag must be free 
from sand, dust and dirt and must be applied perfectly dry while the cement is hot.

The structural features of the glazing in the windows and lights of the monitor roofs are fully shown by the drawing of Figs. I 77 and I78. It will be noted that the sash in the side walls of the monitor roofs are hung on pivots at the middle of each side. There is a similar arrangement of sash in the upper side wall windows of the side roofs overlooking the low middle roof, except that the sash in alternate bays only are pivoted. These latter sash are to be provided with "Brand's" sash openers, with chains operated from the crane runways and arranged to open all the sash of one bay at one time. The feature most worthy of note, however, is that the sash in the side walls of the monitor roofs are to be operated by compressed air power from a central point on one of the side walls of the building near the floor. The sash will be operated in sections about 75 feet. long and the piping and valves will be so arranged that any one or all of the sections can be operated at one time.

Next to the framework of the building, the structural features of most interest are perhaps the pit and floor construction. This is shown in detail by Fig. I8o. In constructing the floor the ground inside the building will be carefully leveled and well tamped and puddled if necessary. The entire area of the main building, except under the pits, where cement concrete will be used, and under the railway tracks, where stone ballast will be used, will then be covered with a layer of bituminous concrete. This concrete will be composed of well screened cinders and No. 4 coke oven composition mixed in the proportion of at least one gallon of composition for each cubic foot of cinders. This composition is to be laid hot and well rammed. Yellow pine floor sleepers, $6 \times 6$ ins. square, will be bedded in the bituminous concrete at intervals varying from $4 \mathrm{ft}$. to $5 \mathrm{ft}$. transversely of the building. 'To these stringtrs there will be spiked an under floor, or lining, of hemlock plank planed on both edges and on the upper side. On top of this lining there will be laid a flooring of $\mathrm{I} / 8 \times 4$-in. maple boards of a uniform and regular width, planed on top and both edges, worked on the back: to a depth of I-16-in. and a width of $23 / 4$ ins., laid across hemlock floor, bored on a slant for nailing and face nailed with I2d. nails, the two lines of nails in each board being staggered. The nails will be placed in lines on each side of the board and not over 16 ins. apart, and the nails in one line will be opposite the middle point between the nails in the opposite line. 
The sidewalls and bottoms of the pits are made of cement concrete of the composition already described as being employed in the foundations for the main columns, Fig. I80, and have a facing of $\mathrm{I}$ in. of cement. It will be noticed that the bottoms of the pits are crowned transversely and have longitudinal side drains of "catch basin" type, running into gutters which connect with the tile drain pipe system of the building. The pit rails are carried on $10 \times 12$-in. yellow pine side timbers resting on the concrete pit walls and connected by anchor rods extending into the bituminous concrete floor foundation. The railway tracks in the building consist of $8 \mathrm{o}-1 \mathrm{~b}$. rails spiked to cross-ties laid in stone ballast.

Before taking up the exterior construction of the building, a brief reference may be made to the method adopted for heating it. By referring to Figs. I76 and 177 it will be noticed that an umderground duct extends along each side of the buildings. This duct will contain all the steam, air and other piping entering the building and will also serve as a hot-air duct for heating the building. For the latter purpose the duct connects with fan houses placed at intervals along the side of the building, there being four fan houses on the west side and three on the east side. It is expected that the exhaust steam will be ample to heat the building. The general principle of the operation of the heating apparatus is to use the air over and over again, depending upon the natural ventilation to keep it fresh. Structually the ducts are simple, their bottoms and side walls being of concrete with a cement plaster, and the roof being expanded metal and concrete supported by transverse roof beams. The roofs of the fan houses will consist of I beams carrying T-iron purlins holding book tile, which in turn carry a felt and slag roofing similar to that already described for the main building.

From the structural point of view, the wall construction of the main building presents nothing that is particularly notable. These walls are of brick masonry resting on a concrete footing and are anchored to the wall columns, as shown by Fig. I78, but they are independent structures, receiving no support from these columns. The entire wall area is pretty well taken up with doors and windows, there being one in each panel or between each pair of wall columns. This introduces a considerable amount of arch work, but nothing that is of unusual character.

To illustrate the simple methods which have been adopted to secure a pleasing exterior appearance for the building, the typical details of the wall construction are shown in Fig. I79. 

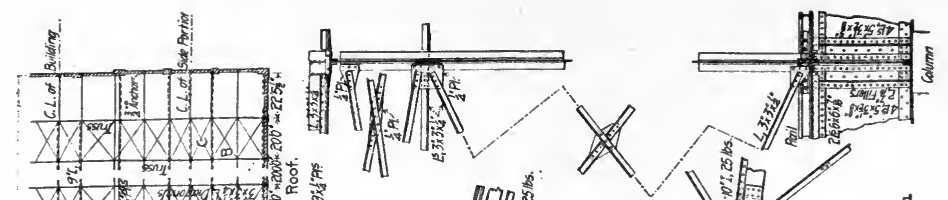

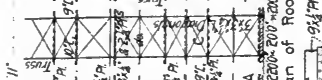

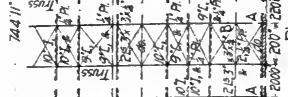
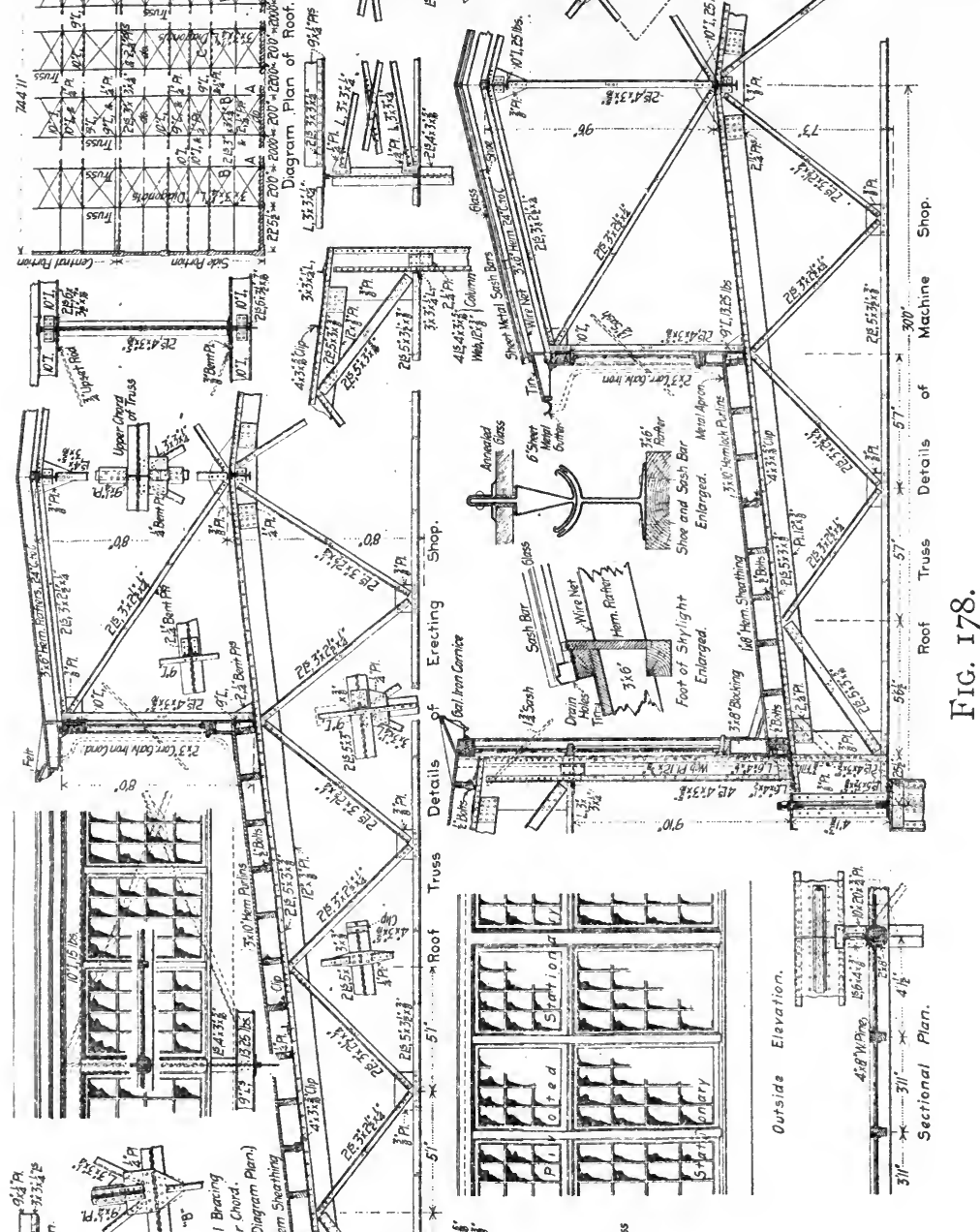

(1)
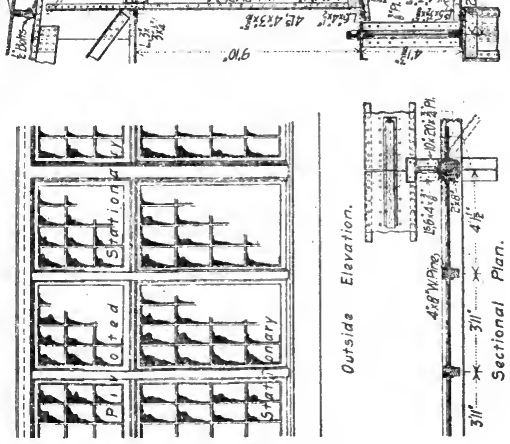

(1) 
Locomotive Erecting Shop, Philadelphia \& Reading R. R. 335
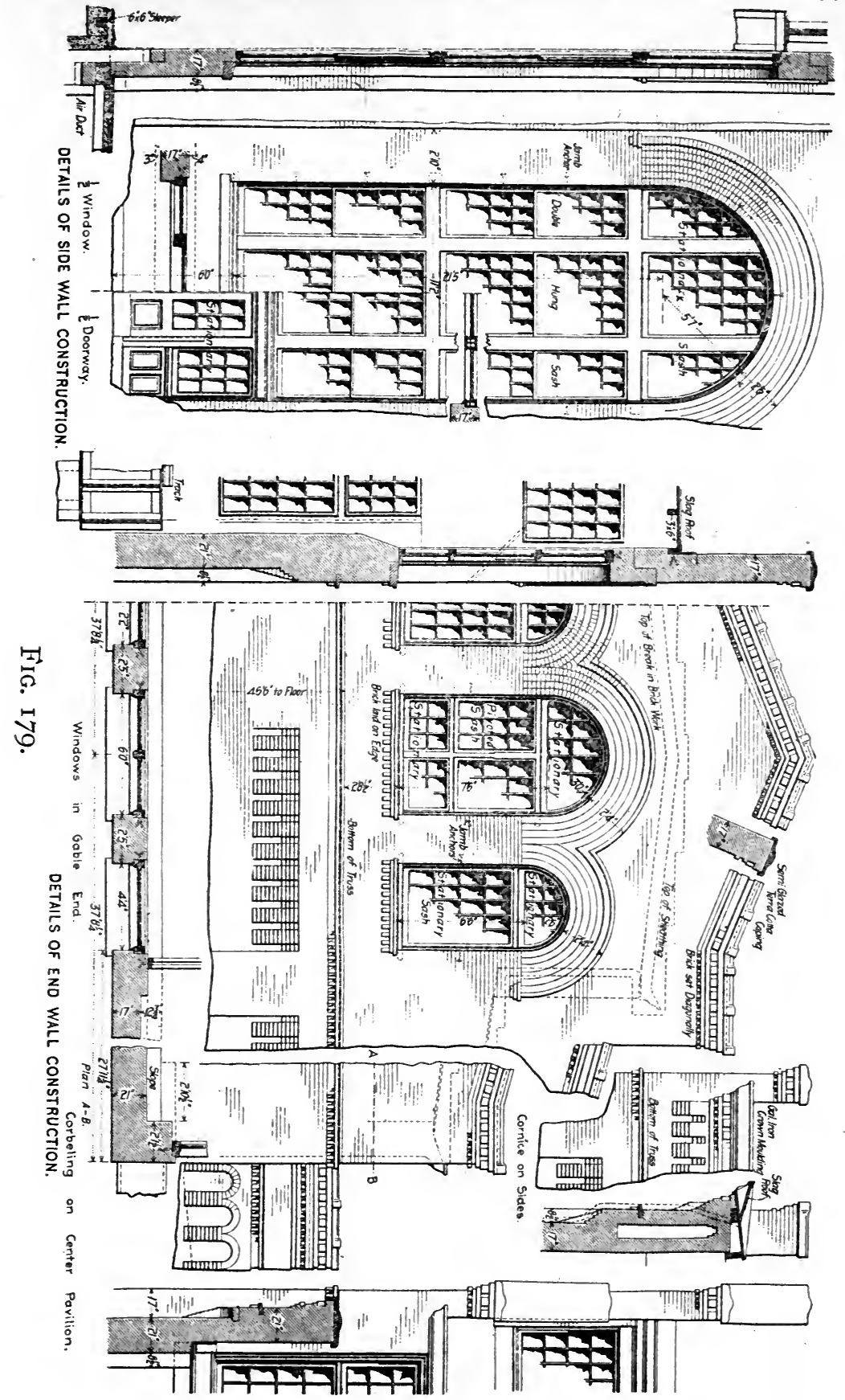

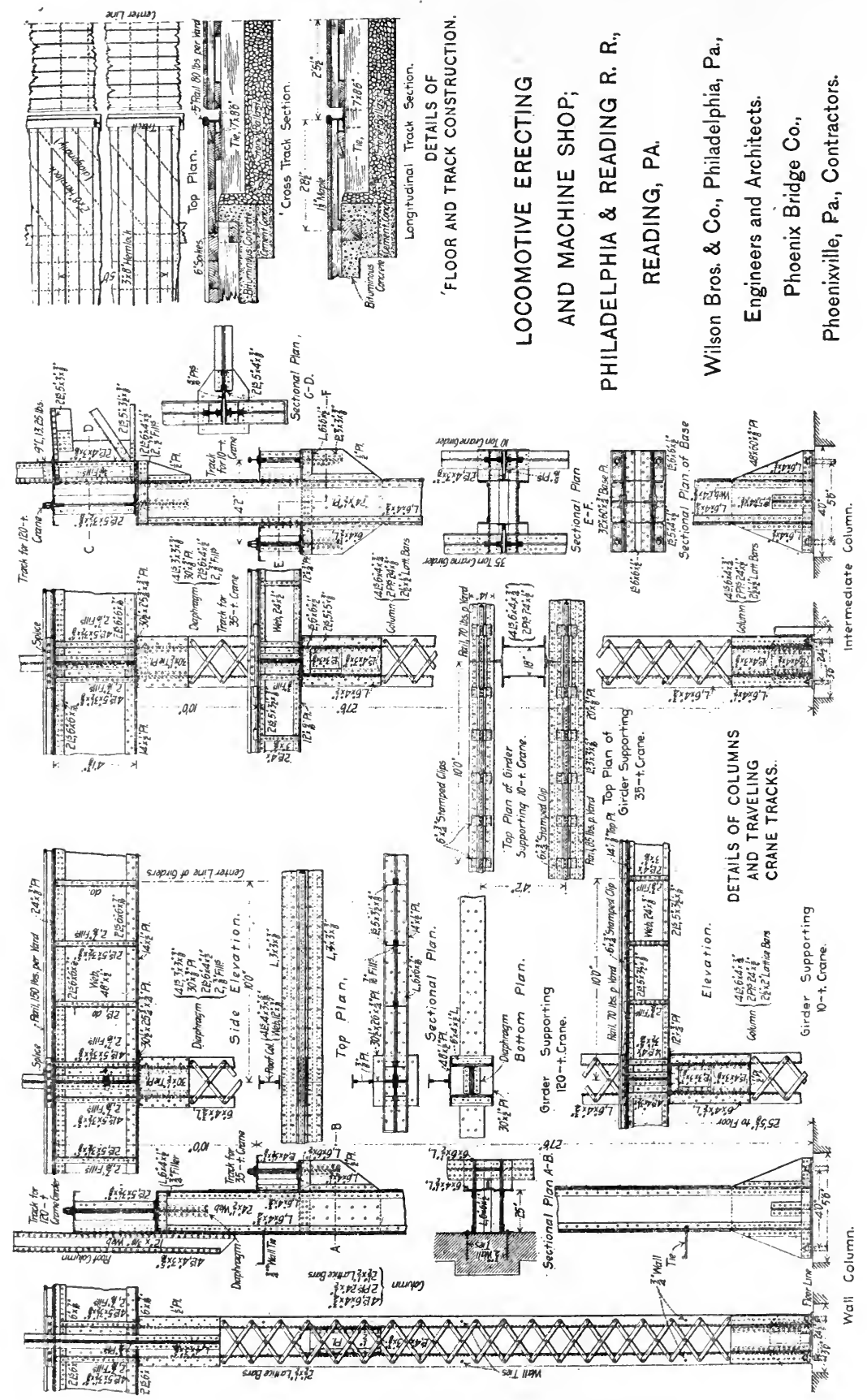


\section{The New Steam Enginefring Building for the Brooklyn NAVY YARD.*}

The new buildings constructed for the steam engineering department of the Brooklyn Navy Yard, at New York City, to take the place of the buildings destroyed by fire on Feb. 15, 1899, consist of a machine shop, an erecting shop and a boiler shop, arranged to occupy a $\mathrm{U}$-shaped area. The erecting shop is $130 \times 252 \mathrm{ft}$., the machine shop is $130 \times 350 \mathrm{ft}$., and the boiler shop is $96 \times 300 \mathrm{ft}$.

The general framework details of the machine, and the erecting shops are shown by Fig. 181. The construction of the boiler shop is similar, but the dimensions are, of course, smaller. Referring to the drawings of Fig. 18I, it will be observed that the buildings are divided transversely into three bays, a center bay $70 \mathrm{ft}$. wide and two $30-\mathrm{ft}$. side bays. The two side bays are covered by shed roofs, above which rise a clerestory and gable roof to cover the center bay. The side wall columns are I2-in. I beams filled between with a brick wall for a height of about $4 \mathrm{ft}$., and above this point covered with glazing to the cornice line. The intermediate columns are of lattice and channel construction, and are $43 \mathrm{ft}$. 6 ins. high, reaching to the level of the junction of the shed roof and the clerestory. They carry between them, longitudinally of the buildings a double intersection truss $15 \mathrm{ft}$. deep, and support a box girder crane runway and the roof columns of the clerestory.

The framework is entirely of steel of from 60,000 lbs. to 70,000 lbs. ultimate strength, and an elastic limit of one-half the ultimate strength. The specifications for workmanship and other essentials correspond to ordinary first-class practice in these respects. The notable feature of the building is the extent to which glazing has been employed in the side walls and roofing, rather than irx any novelty in the framework structure.

The foundations consist of concrete column pedestals carried on piles, the column base plates being anchor-bolted dircitly to the concrete. The concrete used was mixed according to the Navy Yard specifications, which require that the cement exceed the voids in the sand about $25 \%$, and that the dry mixture of cement and sand pxceeds

*Engineering News, April 25, 1901. 
the voids in the aggregate about $25 \%$. The piles were driven to a final penetration of $\mathrm{I}$ in. under a 3,000-1b. hammer falling $\mathrm{I}_{5} \mathrm{ft}$. The usual requirements as to soundness of timber and character of cement, sand, aggregate and water were enforced.

The side wall construction for the shed bays, as already stated, consists of a brick base wall with glazing above. This glazing is put

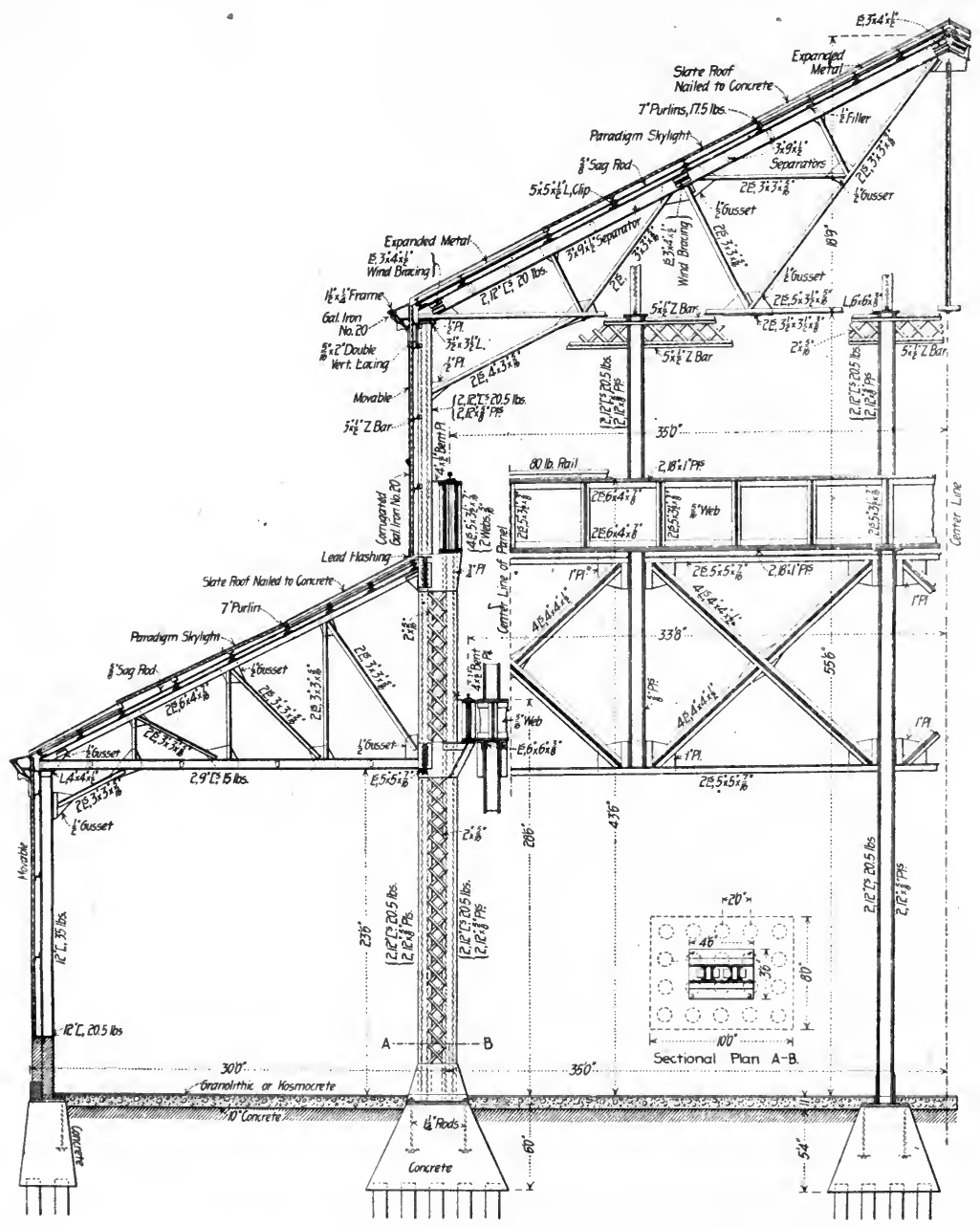

Fig. i8I. Half transverse Section Showing Ste tel Frame detail,s, STEAM ENGINEERING BUILDINGS, BROOKLYN NAVY YARD. 
on in panels or sections; each is capable of being swung out to provide ventilation. The side walls of the clerestory consist of corrugated iron covering for the lower part, and glazing above. The bulk of the area of the shed roofs is skylight, and wide skylights are also placed in the. clerestory roof. Fully 60 per cent of the area of the external walls and roof is glazed.

The large proportion of glazing to the total wall and roof area makes the interior of the shops extremely well-lighted. The entire glazing is on the Paradigm skylight and side light system and was carried out by Arthur E. Rendle, of New York City, who controls the system.

The entire construction is of incombustible materials. There is no wood used in the building, except for the body of the doors, and here it is covered with tin plate. In this respect, and in respect to the amount of glazing used, the buildings are somewhat remarkable, even among modern shop buildings.

Turning now to some of the special details, it will be noticed from Fig. 18 1 that a somewhat unusual construction has been adopted for the main columns. Each column consists of two main members, each composed of two channels riveted back to back, the two main members being connected by double latticing. The resulting section is rather remarkable for its length, as compared with its width, but its purpose was evidently to give ample flexural strength to withstand eccentric load of the bridge crane girders. Details of the crane girders and crane tracks are shown by Fig. $18 \mathrm{I}$; there being one 40-tor crane and two -ten cranes. It will also be observed from Fig. 18I that the lower portion of the clerestory roof has a concrete and expanded metal covering with roofing slate nailed direct to the concrete. The concrete is composed of Portland cement and cinder, and is $3 \frac{1}{2}$ ins. thick. The floor construction throughout will be Io ins. of concrete covered with I in. of granolithic or Kosmocrete. In the tool and testing rooms off the machine shop, and between the boiler and erecting shops, an effort lias been made to secure a dust-proof construction, and a roof which will be free from drippings due to condensed moisture. Over these rooms the skylight roofs consist of double-glazed Paradigm skylights, with a I-in. air space betwen them. 


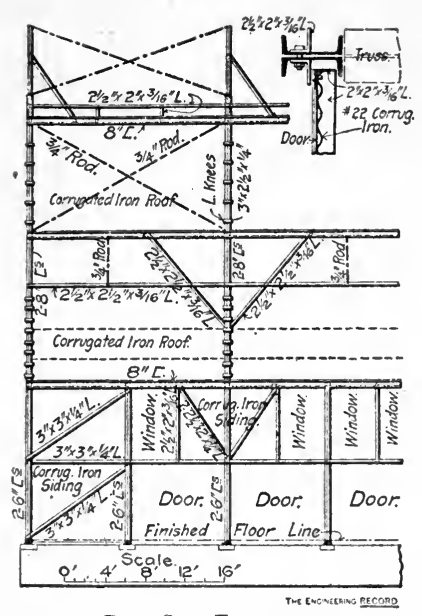

Part Side Elevation.

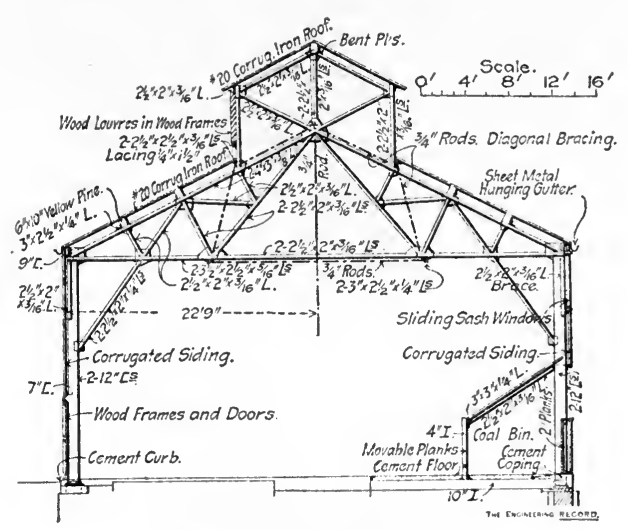

Cross-Section of Boiler House.

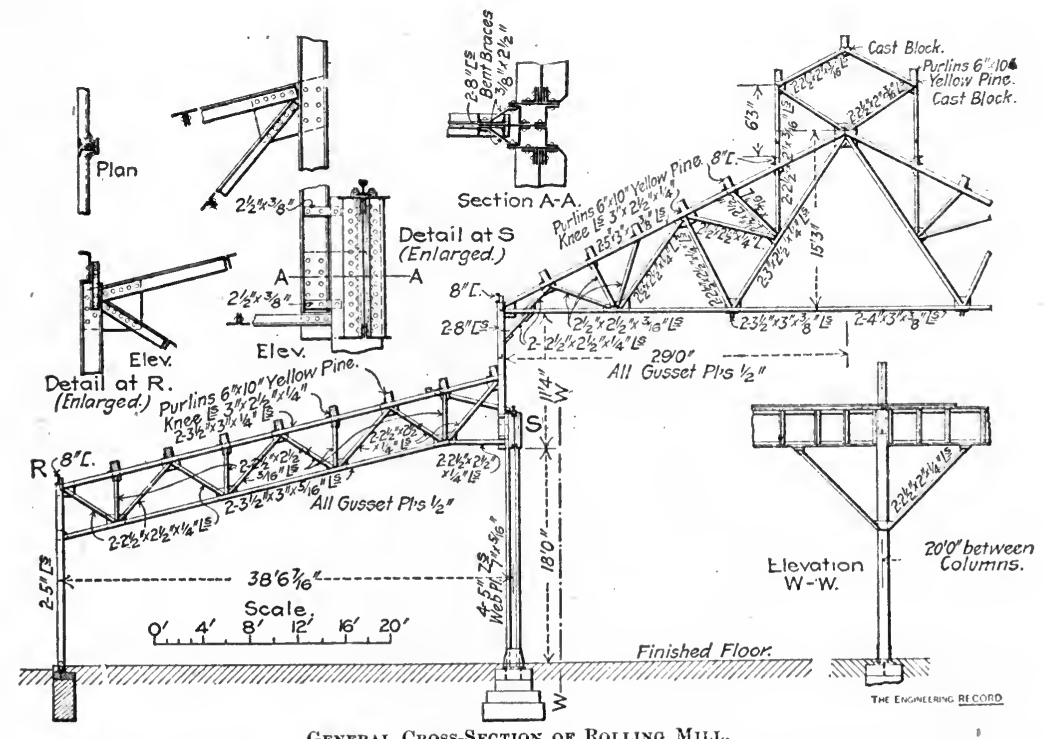

General Cross-Section of Rollina Mill.

FIG. I8々 * STEEL ROLLING MILL BUILDING FOR THE AMERICAN ROLLING MILL COMPANY, MIDDLETOWN, OHIO.

*Engineering Record, July 20, 1901. 


\section{APPENDIX I.}

\section{GENERAL SPECIFICATIONS FOR}

\section{STEEL FRAME MILL BUILdiNGS}

Milo S. Kfitchum, Assoc. M. Am. Soc. C. E.

1903

\section{GENERAL DESCRIPTION}

I. The height of the building shall be the distance from Height of Building. the top of the masonry to the under side of the bottom chord of the truss.

2. The width and length of the building shall be the extreme distance out to out of framing or sheathing.

3. The length of trusses and girders in calculating stresses shall be considered as the distance from center to center of end bearings when supported, and from end to end when fastened between columms by connection angies.

4. The pitch of roof for corrugated steel shall preferably be not less than $1 / 4\left(6^{\prime \prime}\right.$ in $\left.12^{\prime \prime}\right)$, and in no case less than $1 / 5$. For a pitch less than $1 / 5$ some other covering than corrugated steel shall be used.

5. Trusses shall be spaced so that simple shapes may be used for purlins. The spacing should be about 16 feet for spans of, say, 50 feet and about 20 to 22 feet for spans of, say, Ioo feet. For longer spans than Ioo feet the puriins may be trussed and the spacing may be increased.

Dimensions of Building.

Length of Span.

Pitch of Roof. 
Spacing of Purlins.

Form of Trusses.

Bracing.

Proposals.

Detail Plans.

Approval of Plans.

Dead Loads.
6. Purlins shall be spaced not to exceed $4^{\prime} 9^{\prime \prime}$ where corrugated steel is used, and shall be placed at panel points of the trusses.

7. The trusses shall preferably be of the Fink type with panels so subdivided that panel points will come under the purlins. If it is not practicable to place the purlins at panel points, the upper chords of the trusses shall be designed to take both the flexural and direct stresses. Trusses shall preferably be riveted trusses.

8. Bracing in the plane of the lower chord shall be stiff; bracing in the planes of the top chords, the sides and the ends may be made adjustable.

9. Contractors in submitting proposals shall furnish complete stress sheets, general plans of the proposed structures giving sizes of material, and such detail plans as will clearly show the dimensions of the parts, modes of construction and sectional areas.

IO. The successful contractor shall furnish all working drawings required by the engineer free of cost. Working drawings will, as far as possible, be made on standard size sheets $24^{\prime \prime} \times 36^{\prime \prime}$ out to out, $22^{\prime \prime} \times 34^{\prime \prime}$ insidle the inner border lines.

I I. No work shall be commenced or materials ordered until the working drawings are approved in writing by the engineer. The contractor shall be responsible for climensions and details on the working plans, and the approval of the detail plans by the engineer will not relieve the contractor of this responsibility.

\section{LOADS.}

I2. The trusses shall be designed to carry the following loads :

I3. DEAD LOADS. - Weight of Trusses - The weight of trusses per square foot of horizontal projection, up to I 50 feet span shall be calculated by the formula

$$
W=\frac{P}{45}\left(1+\frac{L}{5 \sqrt{ } A}\right)
$$

where $W=$ weight of trusses per square foot of horizontal projection; 
$P=$ capacity of truss in pounds per square foot of horizontal projection;

$L_{1}=$ span of the truss in feet;

$A=$ distance between trusses in feet.

I4. Weight of Covering.-The weight of corrugated Corrugated Steel. steel shall be taken from Table I.

\section{TABLE I.}

\begin{tabular}{|c|c|c|c|c|c|}
\hline \multirow{3}{*}{ Gage No. } & \multirow{3}{*}{$\begin{array}{c}\text { Thickness } \\
\text { in } \\
\text { inches }\end{array}$} & \multicolumn{4}{|c|}{ Weight per Square ( 100 sq.ft.) } \\
\hline & & Flat & Sheets & Corrugated & Sheets \\
\hline & & Black & Galvanized & Black Painted & Galvanized \\
\hline 16 & .0625 & 250 & 266 & 275 & 291 \\
\hline 18 & .0500 & 200 & 216 & 220 & 236 \\
\hline 20 & .0375 & 150 & 166 & 165 & 182 \\
\hline 22 & .0313 & 125 & 141 & 138 & 154 \\
\hline 24 & .0250 & 100 & 116 & $1 / 1$ & 127 \\
\hline 26 & .0188 & 75 & 91 & 84 & 99 \\
\hline 28 & .0156 & 63 & 79 & 69 & 86 \\
\hline
\end{tabular}

When two corrugations side lap and six inches end lap are used add 25 per cent to the above weights; when one corrugation side lap and four inches end lap are used add 15 per cent to the above weights to obtain weight of corrugated steel laid. For paint add 2 pounds per square. The weight of covering shall be reduced to weight per square foot of horizontal projection before combining with weight of trusses.

I5. Slate laid with 3 -inch lap shall be taken at a weight of $7 \frac{1}{2}$ pounds per square foot of inclined roof surface for $3^{-1} 6^{\prime \prime}$ slate $6^{\prime \prime} \times 12$ ", and $61 / 2$ pounds per square foot of inclined roof surface for 3 -I $6^{\prime \prime}$ slate $12^{\prime \prime} \times 24$ ", and proportionately for other sizes.

I6. Terra-cotta tile roofing weighs about 6 pounds per square foot for tile I inch thick; the actual weight of tile and other roof coverings not named shall be used.

I7. Sheathing of clry pine lumber shall be assumed to weigh 3 pounds per foot and dry oak purlins 4 pounds per foot board measure.

I8. The exact weight of sheathing, purlins, bracing, ventilators, cranes, etc., shall be calculated.

Slate.

Tile.

Sheathng and Purlins

Miscellaneous Loads. 
Snow Loads.

Wind Loads.

Mine Buildings.

Concentrated

Loads.

Purlins.

Roof Covering.

Minimum Loads.
19. SNOW LOADS.-Snow loads shall be taken from the diagram in Fig. I.

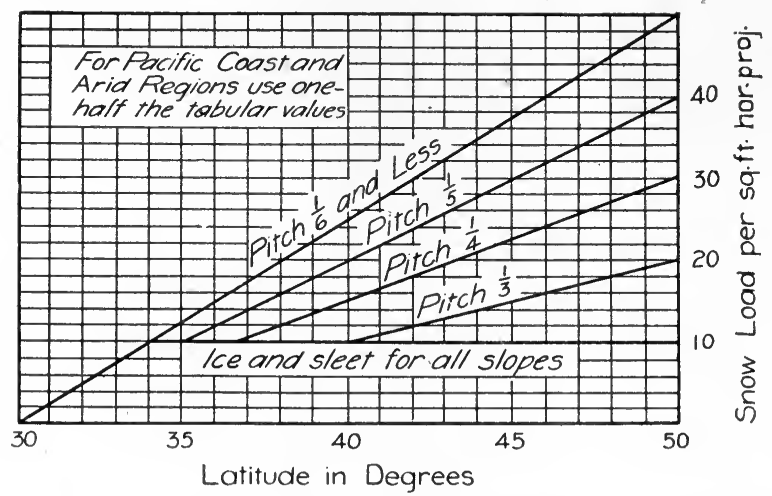

FiG. I. SNOW I,OAD ON ROOFS FOR DIFFEREN'T IA ATITUDES, IN LRS. PER SQUARE FOOT.

20. WIND LOADS.-The normal wind pressure on trusses shall be computed by Duchemin's formula, Fig. 2, with $P=30$ pounds per square foot, except for buildings in exposed locations, where $P=40$ pounds per square foot shall be used.

2I. The sides and ends of buildings shall be computed for a normal wind load of 20 pounds per square foot of exposed surface for buildings 30 feet and less to the eaves; 30 pounds per square foot of exposed surface for buildings 60 feet to the eaves, and in proportion for intermediate heights.

22. Mine, smelter and other buildings exposed to the action of corrosive gases shall have their dead loads increased 25 per cent.

23. Concentrated loads and crane girders shall be considered in determining dead loads.

24. Purlins shall be designed for a normal load of not less than 30 lbs. per square foot.

25. Roof covering shall be designed for a normal load of not less than $30 \mathrm{lbs}$. per square foot.

26. No roof shall, however, be designed for an equivalent load of less than 30 pounds per square foot of horizontal projection. 


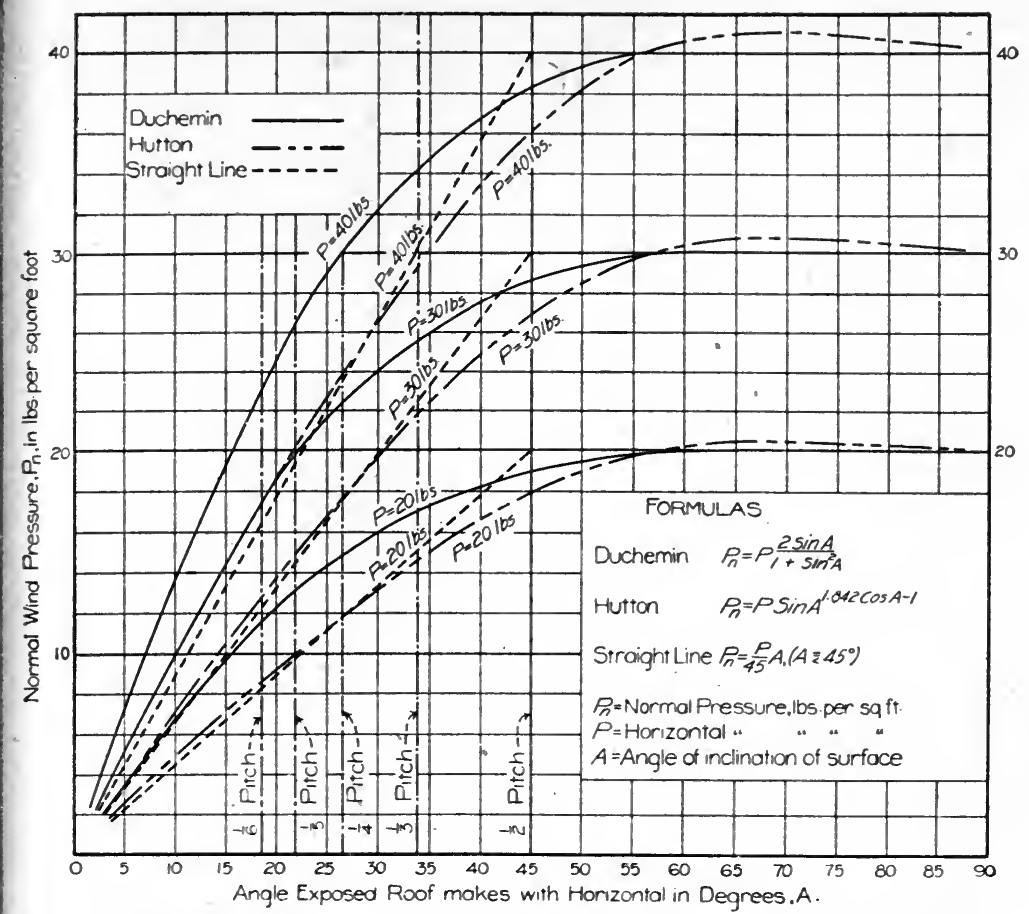

Fig. 2. NORMAI, WIND LOAD ON ROOF ACCORDING TíO DIFFERENT FORMULAS.

PROPORTION OF PARTS.

27. In proportioning the different parts of the structure the maximum stresses due to the combinations of the dead and wind load; dead and snow load; or dead, minimum snow and wind load are to be provided for. Concentrated loads where they occur must be provided for.

28. Allowable Unit Tensile Stresses for Medium Steel.

Shapes, main members, net section........ 6,000

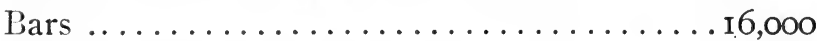

Bottom flanges of rolled beams......... . 16,000

Shapes, laterals, net section..........20,000

Iron rods for laterals . . . . . . . . . . 20,000

Plate girder webs, shearing on net section.... I0,000 
Compressive Stress.

Plate Girders.

Alternate Stress.

Combined Stress.
Shapes liable to sudden loading as when used for crane girders............... Io,000

Expansion rollers per lineal inch........ oo $\times D$

where $D=$ diameter of roller in inches.

Laterals shall be designed for the maximum stresses due to 5,000 pounds initial tension and the maximum stress due to wind.

29. Allowable Unit Compressive Stress for Medium Steel. For direct dead, snow and wind loads

$$
S=\mathrm{r} 6,000-70 \frac{l}{r}
$$

where

$S=$ allowabl unit stress in pounds per square inch;

$l=$ length of member in inches c. to c. of end connections ;

$r=$ least radius of gyration of the member in inches.

30. Top flanges of plate girders shall have the same gross area as the tension flanges.

3I. Shear in webs of plate girclers shall not exceed Io,ooo pounds per square inch.

32. Members and connections subject to aiternate stresses shall be designed to take each kind of stress.

33. Nembers subject to combined direct and bending stresses shall be proportioned according to the following formula :

$$
S=\frac{P}{A}+\frac{M y_{1}}{I \pm \frac{P l^{2}}{1 \cup E}}
$$

where

$S=$ stress per square inch in extreme fibre;

$P=$ direct load;

$A=$ area of member;

$M=$ bending moment in inch-pounds :

$y_{1}^{\prime}=$ distance from neutral axis to extreme fibre;

$I=$ moment of inertia of member;

$l=$ length member, or distance from point of zero moment to end of member in inches;

$E=$ modulus of elasticity $=28,000,000$. 
When combined direct and flexural stress due to wind is considered add 25 per cent to the above allowable tensile and compressive stresses.

34. Soft steel may be used in mill buildings with unit stresses ten per cent less than those allowed for medium steel.

35. Where the stress due to the weight of the member or due to an eccentric load exceeds the allowable stress for direct loads by more than ten per cent, the section shall be increased until the total stress does not exceed the above allowable stress for direct loads by more than ten per cent.

The eccentric stress caused by connecting angles by one leg when used as ties or struts shall be calculated, or only one leg will be considered effective.

36. Rivets shall be so spaced that the shearing stress shall not exceed I I,OOO pounds per square inch; nor the pressure on the bearing surface (diameter $\times$ thickness of piece) of the rivet hole exceed 22,000 pounds per square inch.

Rivets in lateral connections may have stresses 25 per cent in excess of the above.

Field rivets shall be spaced for stresses two-thirds those allowed for shop rivets.

Field bolts, when allowed, shall be spaced for stresses two-thirds those allowed for field rivets.

Rivets and bolts must not be used in direct tension.

37. Pins shall be proportioned so that the sinearing stress shall not exceed II,Ooo pounds per square inch; nor the pressure on the bearing surface (diameter $\times$ thickness of piece) of the pin hole exceed 22,000 pounds per square inch; nor the extreme fibre stress due to cross bending exceed 24,000 pounds per square inch when the applied forces are assumed as acting at the center of the members.

38. Rolled beams shall be proportioned by their moments of inertia.

39. Plate girders shall be proportioned on the assumpion that the flanges take all the bending moment, and that the shear is resisted by the web.

The distance between centers of gravity of the flange areas hall be considered as the effective depth of all girders.

40. The webs of plate girders shall be stiffened at bearngs and at all points of concentrated loading, and at inter-
Soft Steel.

Stress due to

Weight of Member.

Rivets.

Pins.

Rolled Beams.

Plate Girders.

Stiffeners. 
mediate points, wherever the shearing per square inch exceeds the stress allowed by the following formula:

Allowed shearing stress $=12,500-90 d \div t$

where $d=$ depth, and $t=$ thickness of web plate.

4I. Compression flanges of plate girders shall be stayed transversely when their length is more than thirty times their width.

Timber.

42. The allowable stresses in timber purlins and other timbers shall be taken from Table II.

TABLE II.

Alifowable Working Unit Strresses, in Pounds, per Square Inch.

\begin{tabular}{|c|c|c|c|c|c|c|c|c|c|}
\hline \multirow{3}{*}{ Kind of Timber. } & \multicolumn{2}{|c|}{ Tension. } & \multicolumn{3}{|c|}{ Compression. } & \multicolumn{2}{|c|}{ Transverse. } & \multicolumn{2}{|c|}{ Shearing. } \\
\hline & & & & With r & in. & & & & \\
\hline & $\begin{array}{l}\text { With } \\
\text { Grain. }\end{array}$ & $\begin{array}{l}\text { Across } \\
\text { Grain. }\end{array}$ & $\begin{array}{c}3 \\
\text { End } \\
\text { Beap- } \\
\text { in }:\end{array}$ & $\begin{array}{c}4 \\
\text { Columns } \\
\text { Urder 15 } \\
\text { Disms. }\end{array}$ & $\begin{array}{c}5 \\
\text { Aoross } \\
\text { Grain. }\end{array}$ & $\begin{array}{l}\text { Extreme } \\
\text { Fibre } \\
\text { Strass. }\end{array}$ & $\begin{array}{c}\text { Moduius } \\
\text { of } \\
\text { Elastlcity. }\end{array}$ & $\begin{array}{l}\text { With } \\
\text { arain. }\end{array}$ & $\begin{array}{c}\text { Aoross } \\
\text { Grain. }\end{array}$ \\
\hline Fautor of Safetv. & Ten. & Ten. & Flve. & Five. & Four. & Six. & Two. & Four. & Four \\
\hline White Oak.... & 1000 & 200 & 1400 & $9 \div 0$ & 500 & 1000 & 550000 & 200 & 1000 \\
\hline White Pine...... & 700 & 50 & 1100 & 700 & 200 & 700 & $5000 \mathrm{co}$ & 100 & 500 \\
\hline South. Long-leaf or Georgia Yellow Pine & 1200 & 60 & 1600 & 1000 & 350 & $120 \mathrm{~s}$ & 850000 & 150 & 1250 \\
\hline Douglas. Oregon and Yellow Fir......... & 1200 & & $160 \mathrm{~J}$ & 1200 & 300 & 1100 & $70.00 \mathrm{~J}$ & 150 & \\
\hline W ashington Fir or Pine (Red Fir)....... & 1000 & & & & & 800 & & & \\
\hline Northern or Short-leaf Yellow Pine..... & 900 & 50 & 1200 & 800 & 250 & 1000 & 600000 & 160 & 1000 \\
\hline Red Pine......................... & 900 & 50 & 1200 & 800 & 200 & $80^{\circ} 0$ & 600000 & $\ldots .$. & \\
\hline Norway Pine..... $\ldots . . . . . . .$. & 800 & $\ldots .$. & 1200 & 800 & 200 & 700 & 600000 & & \\
\hline Canadian (Ottawa) White Pine.............. & 100 & ....... & $\ldots \ldots$ & 1000 & & & & $10 u$ & \\
\hline Canadian (Ontario) Red Pine............. & 1100 & & & 1000 & & 800 & 000 & 100 & \\
\hline 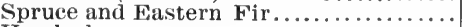 & 800 & 50 & 1200 & 800 & 20 & 700 & 60000 & 100 & 750 \\
\hline 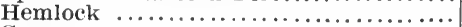 & 600 & & & 800 & 150 & 600 & 45,0000 & 100 & 600 \\
\hline 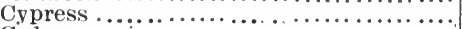 & 60 & & 120 & 800 & - 200 & 800 & $45000 \mathrm{~J}$ & & \\
\hline Cedar $\ldots \ldots \ldots \ldots \ldots \ldots \ldots \ldots \ldots$ & 800 & & $1 \cdot 300$ & 800 & 200 & 800 & 350460 & & 400 \\
\hline Chestnut......................... & 900 & $\ldots \ldots$ & & 1000 & 2.50 & 800 & 500000 & 150 & $4 \cup 0$ \\
\hline 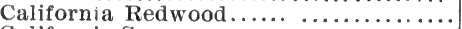 & $\tau 00$ & & $\ldots . .$. & 800 & 200 & 700 & 35000 & 100 & \\
\hline California Spruce.................... & & & & 800 & & 800 & 60000 & & \\
\hline
\end{tabular}

The allowable stress, $P$, in timber columns longer than ${ }_{5} 5$ diameters shall be obtained by means of the formula

$$
P=C-\frac{C}{100} \frac{l}{d}
$$

where $C=$ value in column 4 above $;=$ length of column and $d$ least width of column, both in feet.

\section{COVERING.}

Corrugated Steel.

43. Corrugated steel shall generally have $2 \frac{1}{2}$ inch corrugations when used for roof and sides of buildings, and $I^{I} / 4$ inch corrugations when used for lining buildings. The mini- 
mum gage of corrugated steel shall be No. 22 for roofs, No. 24 for sides and No. 26 for lining.

The gage of corrugated steel in U. S. Standard Gage, and weight per square foot shall be shown on the general plan.

44. The span, or center to center distance of purlins, shall not exceed the distance given in Fig. 3 for a safe load of 30 pounds per square foot. Corrugated steel sheets shall preferably span two purlin spaces.

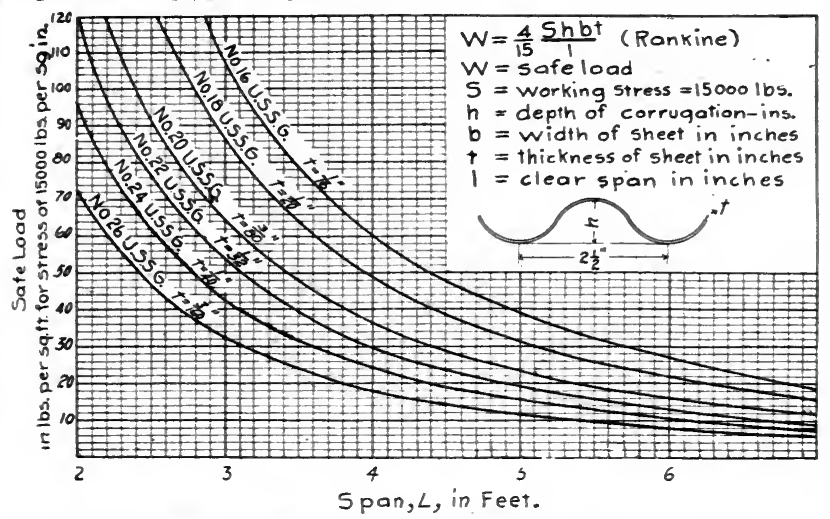

FIG. 3. SAFE UNIFORA I.OAD IN POUNDS FOR CORRUGA'TED STEEL

FOR DIFFERENT SPANS IN FEET.

.5. Corrugated steel shall be laid with two corrugations side lap and six inches end lap when used for roofing, and one corrugation side lap and four inches end lap when used for siding.

46. Corrugated steel shall be fastened to the purlins by means of galvanized iron straps $3 / 4$ inches wide by No. I 8 gage, spaced 8 to I 2 inches apart; by clinch nails spaced 8 to 12 inches apart; or by nailing directly to spiking strips with $8 \mathrm{~d}$ barbed nails, spaced 8 inches apart. Spiking strips shall preferably be used with anti-condensation lining. Bolts, nails and rivets shall always pass through the top of corrugations. Side laps shall be riveted with copper or galvanized iron rivets 8 to 12 inches apart on the roof and $1 \frac{1}{2}$ to 2 feet apart on the sides.

47. Corrugated steel lining on the sides shall be laid with one corrugation side lap and four inches end lap. Girts for corrugated steel lining shall be spaced for a safe load of 25 pounds per square foot as given in Fig. 3 .

End and side Laps.

Fastening.

Corrugated Steel Lining. 
Anti-Condensation Lining.

Flashing.

Ridge Roll.

Corner Finish.

Cornice.

Gutters.

Ventilators.
48. Anti-condensation roof lining shall preferably be used to prevent dripping in engine houses and similar buildings and shall be constructed as follows: Galvanized wire poultry netting is fastened to one eave puriin and is passed over the ridge, stretched tight and fastened to the other eave purlin. The edges of the wire are woven together, and the netting is fastened to the spiking strips, where used, by means of small staples. On the netting are laid two layers of asbestos paper I-16-inch thick, and two layers of tar paper. The corrugated steel is then fastened to the purlins in the usual way. Threesixteenth-inch stove bolts with $I^{\prime \prime} \times 1 / 8^{\prime \prime} \times 4^{\prime \prime}$ plate washers on the lower side are used for fastening the side laps together and for supporting the lining; or the purlins may be spaced onehalf the usual distance where anti-condensation lining is used, and the stove bolts omitted.

49. Valleys or corners around stacks shall have flashing extending at least $\mathrm{I} 2$ inches above where water will stand, and shall be riveted or soldered if necessary, to prevent leakage.

Flashing shall be provided above doors and windows.

50. All ridges shall have a ridge roll securely fastened to the corrugated steel.

51. All corners shall be covered with standard corner finish securely fastened to the corrugated steel.

52. At the gable ends the corrugated steel on the roof shall be securely fastened to a finish angle or channel connected to the end of the purlins or, where molded cornices are used, to a piece of timber fastened to the ends of the purlins.

53. Gutters and conductors shall be furnished at least equal to the requirements of the following table:

\begin{tabular}{rcccc} 
Span of Roof & Gutter & \multicolumn{2}{c}{ Conductor } \\
Up to $50^{\prime}$ & $6^{\prime \prime}$ & $4^{\prime \prime}$ & every $40^{\prime}$ \\
$50^{\prime}$ to $70^{\prime}$ & $7^{\prime \prime}$ & $5^{\prime \prime}$ & “ & “. \\
$70^{\prime}$ to $100^{\prime}$ & $8^{\prime \prime}$ & $5^{\prime \prime}$ & “ & .
\end{tabular}

Gutters shalt have a slope of at least $\mathrm{I}^{\prime \prime}$ in $15^{\circ}$. Gutters and conductors shall be made of galvanized steel not lighter than No. 24 .

54. Ventilators shall be provided and located so as to properly ventilate the building. They shall have a net opening for each 100 square feet of floor space of not less than one- 
fourth square foot for clean machine shops and similar buildngs; of not less than one square foot for dirty machine shops; of not less than four square feet for mills; and not less than ix square feet for forge shops, foundries and smelters.

55. Openings in ventilators shall be provided with shuters, sash, or louvres, or may be left open as specified.

Shutters must be provided with a satisfactory device for ppening and closing.

Louvres must be designed to prevent the blowing in of ain and snow, and must be made stiff so that no appreciable agging will occur. They shall be made of not less than No. fo gage galvanized steel for flat louvres and No. 24 gage galanized steel for corrugated louvres.

56. Circular ventilators when used must be designed so s to prevent down drafts. Net opening only shall be used in alculations.

57. Windows shall be provided in the exterior walls equal not less than Io per cent of the entire exterior surface in nill buildings, and of not less than 25 per cent in machine hops, factories and similar buildings.

Winclow glass up to $12 \times 14$ " may be single strength, over $12^{\prime \prime} \times 14^{\prime \prime}$ the glass shall be double strength. Window glass hall be A grade except in smelters, foundries, forge shops, and imilar structures where it may be $B$ grade. The sash and rames shall be constructed of white pine.

58. At least half of the lighting shall preferably be by peans of skylights, or sash in the sides of ventilators.

Skylights shall be glazed with wire glass, or wire netting hall be stretched beneath the skylights to prevent th broken lass from falling into the building. Where there is danger of the kylight glass being broken by objects falling on it, a wire etting guard shall be provided on the outside.

Skylight glass shall be carefully set, special care being sed to prevent leakage. Leakage and condensation on the iner surface of the glass shall be carried to the down-spouts, or utside the building by condensation gutters.

59. Windows in sides of buildings shall be made with punterbalanced sash, and in ventilators shall be made with iding or swing sash.
Shutters and

Louvres.

Circular Ventilators.

Windows.

Skylights. 
Doors.

Details.

Pitch of Rivets.

Diameter of Punch.

Net Sections.

Minimum Stetions 6o. Doors are to be furnished as specified and are to b provided with hinges, tracks, locks and bolts. Single doors u to 4 feet and double doors up to 8 feet shall preferably b swung on hinges; large doors, double and single, shall be ar ranged to slide on overhead tracks, or may be counterbalancer to lift up between vertical guides.

Steel doors shall be firmly braced and shall be coverer with No. 24 corrugated steel with I $1 / 4$-inch corrugations.

The frames of sandwich doors shall be made of two layer of $7 / 8$-in. matched white pine, placed diagondly, and firml: nailed with clinch nails. The frame shall be covered on eact side with a layer of No. 26 corrugated steel with $\mathrm{I} / 4$-inch cor rugations.

\section{Detralls of Construdtion.}

6r. All connections and details shall be of sufficien strength to develop the full strength of the member.

62. The pitch of rivets shall not exceed 6 inches, or six teen times the thickness of the thinnest outside plate in the lint of stress, nor forty times the thickness of the thinnest outside plate at right angles to the line of stress. The pitch shall neves be less than three diameters of rivet. At the ends of compression members the pitch shall not exceed four diameters of the rivet for a length equal to twice the width of the member.

63. The distance between the edge of $\mathrm{ar}_{2} \mathrm{y}$ piece and the center of a rivet hole must never be less than $1 / 1 / 4$ inches, except in angles having a $2^{\prime \prime}$ leg, where it shall be $\mathrm{J} / 8$ inches.

64. The diameter of the punch shall not exceed the diameter of the rivet; nor the diameter of the die exceed the diameter of the punch by more than I-I6 inch.

65. The effective diameter of a driven rivet will be assumed the same as its diameter before driving. In deducting the rivet holes to obtain net sections in tension members, the diameter of the rivet-holes will be assumed as $1 / 8$ inch larger than the undriven rivet.

66. No metal of less thickness than $1 / 4$ inch shall be used except for fillers; and no angles less than $2^{\prime \prime} \times 2^{\prime \prime} \times 1 / 4^{\prime \prime}$. No upset rod shall be less than $5 / 8$ inch in diameter. Sag rods may be as small as $3 / 8$-inch. 
67. All rods with screw ends except sag rods must be upset at the ends so that the diameter at the base of the threads shall be $1-16$ inch larger than any part of the body of the bar.

68. Upper chords shall have symmetrical cross-sections, Upper Chords. and shall preferably consist of two angles back to back.

69. All other compression members except sub-struts shall be composed of sections symmetrically placed. Sub-struts may consist of a single section.

7o. Side posts which take flexure shall preferably be composed of 4 angles laced, or 4 angles and a plate. Where side posts do not take flexure and carry heavy loads they shall preferably be composed of two channels laced.

Posts in end framing shall preferably be composed of I beams or 4 angles laced. Corner columns shall preferably be composed of one angle.

The cross-bending stress due to eccentric loading in columms carrying cranes shall be calculated.

7 I. Laced compression nembers shall be stayed at the ends by batten plates placed as near the end of the member as practicable and having a length not less than the greatest width of the member. The thickness of batten plates must not be less than I-4O of the distance between rivet lines at right angles to axis of member.

72. Single lattice bars shall hảve a thickness of not less than $\mathrm{I}-40$, and double bars connected by a rivet at the intersection of not less than $1-60$ of the distance between the rivets connecting them to the member; they shall make an angle not less than $45^{\circ}$ with the axis of the member; their width shall be in accordance with the following standards, generally:

Sizf, of Member. WidTH OF LACING BARS.

For I5-inch channels, or built sections with $3^{\mathrm{T} / 2}$ and $\left.4^{-}\right\} 2^{\mathrm{T} / 2}$ inches ( $7 / 8$-inch rivets). inch angles.

For 12, Io and 9-inch channels, or built sections with $\} 2 \frac{1}{4}$ inches ( $3 / 4$-inch rivets). 3 -inch angles.

Compression Members.

Columns.

Crane Posts.

Lacing. 
Pin Plates.

Maximum Length.

Splices.

Splices.

Tension Members.

Eye-Bars.

Pins.
For 8 and 7 -inch channels, or built sections with $2 \frac{1}{2}$-inch
angles.

For 6 and 5 -inch channels, or built sections with 2 -inch
angles.

Where laced members are subjected to bending, the size of lacing bars or angles shall be calculated or a solid web plate shall be used.

73. All pin holes shall be reenforced by additional material when necessary, so as not to exceed the allowable pressure on the pins. These reenforcing plates must contain enough rivets to transfer the proportion of pressure which comes upon them, and at least one plate on each side shall extend not less than 6 inches beyond the edge of the tie plate.

74. No compression member shall have a length exceeding I25 times its least radius of gyration for main members, nor I50 times its least radius of gyration for laterals and submembers.

75. In compression members joints with abutting faces planed shall be placed as near the panel points as possible, and must be spliced on all sides with at least two rows of rivets on each side of the joint. Joints with abutting faces not planed must be fully spliced.

76. Joints in tension members shall be fully spliced.

77. Tension members shall preferably be composed of angles or shapes capable of taking compression as well as tension. Flats riveted at the ends shall not be used.

78. Main tension members shall preferably be made of 2 angles, 2 angles and a plate, or 2 channels laced. Secondary tension members may be made of a single shape.

79. Heads of eye-bars shall be so proportioned as to develop the full strength of the bar. The heads shall be forged and not welded.

8o. Pins must be turned true to size and straight, and must be driven to place by means of pilot nuts.

The diameter of pin shall not be less than $3 / 4$ of the depth of the widest bar attached to it. 
The several members attached to a pin shall be packed so as to produce the least bending moment on the pin, and all vacant spaces must be filled with steel fillers.

8I. Long laterals may be made of rods with clevis or sleeve nut adjustment. Bent loops shall not be used.

82. Trusses shall preferably be spaced so as to allow the use of single pieces of rolled sections for purlins. Trussed purlins shall be avoided if possible.

83. Purlins and girts shall preferably be composed of single sections-channels, angles or Z-bars placed with web at right angles to the trusses and posts and legs turned down.

84. Purlins and girts shall be attached to the top chord of trusses and to columns by means of angle clips with two rivets in each leg.

85. Purlins shall be spaced at distances apart not to exceed the span as given for a safe load of 30 pounds, and girts for a safe load of 25 pounds in Fig. 3 .

86. Timber purlins shall be attached and spaced the same as steel purlins.

87. Base plates shall never be less than $1 / 2$ Inch in thickness, and shall be of sufficient thickness and size so that the pressure on the masonry shall not exceed 250 pounds per square inch.

88. Columns shall be anchored to the foundations by means of two anchor bolts not less than $I^{\prime \prime}$ in diameter upset, placed as wide apart as practicable in the plane of the wind. The anchorage shall be calculated to resist the bending moment at the base of the columns.

89. Lateral bracing shall be provided in the plane of the top and bottom chords, side and ends; knee braces in the transverse bents; and sway bracing wherever necessary. Lateral bracing shall be designed for an initial stress of 5,000 pounds in each member, and provision must be made for putting this initial stress into the members in erecting.

90. Variations in temperature to the extent of 150 degrees F. shall be provided for,
Rods.

Spacing Trusses.

Purlins and Girts.

Fastening.

Spacing.

Timber Purlins.

Base Plates.

Anchors.

Lateral Bracing.

Temperature. 
Workmanship.

Riveted Work Punching.

Holes for

Field Rivets.

Planing and Reaming.

Rivets.

Riveters.

Bolts.

Neat Finish.

Contact Surfaces.

\section{WORKMANSHIP.}

9I. All workmanship shall be first-class in every particular. Due regard must be had for the neat and attractive appearance of the finished structure, and details of an unsightly character will not be allowed.

92. All riveted work shall be punched accurately with holes I-I6 of an inch larger than the size of tine rivet, and when the pieces forming one built member are put together, the holes must be truly opposite; no drifting to distort the metal will be allowed; if the hole must be enlarged to admit the rivet, it must be reamed.

93. All holes for field rivets in splices in tension members shall be accurately drilled to an iron templet or reamed while the connecting parts are temporarily put together.

94. In medium steel over $5 / 8$ of an inch thick, all sheared edges shall be planed, and all holes shall be drilled or reamed to a diameter of $1 / 8$ of an inch larger than the punched holes, so as to remove all the sheared surface of the metal. Steel which does not satisfy the drifting test must have holes drilled.

95. The rivet heads must be of approved hemispherical shape, and of a uniform size for the same size rivets throughout the work. They must be full and neatly finished throughout the work and concentric with the rivet hole.

96. All rivets when driven must completely fill the holes, the heads be in full contact with the surface, or countersunk when so required.

97. Rivets shall be machine driven wherever possible. Power riveters shall be direct-acting machines, worked by steam, hydraulic pressure, or compressed air.

98. When members are connected by bolts which transmit shearing strains, such bolts must have a driving fit.

99. The several pieces forming one built member must fit closely together, and when riveted shall be free from twists, bends, or open joints.

Ioo. All portions of the work exposed to view shall be neatly finished.

IOI. All surfaces in contact shall be painted before they are put together. 
102. The heads of eye-bars shall be made by upsetting, rolling, or forging into shape. Wekds in the body of the bar will not be allowed.

103. The bars must be perfectly straight before boring.

ro4. The holes shall be in the center of the head and on the center line of the bar.

105. All eye-bars shall be annealed.

I06. All abutting surfaces in compression members shall be truly faced to even bearings, so that they shall be in such contact throughout as may be obtained by such means.

107. Pin holes shall be bored truly parallel with one another and at right angles to the axis of the member unless otherwise shown in drawings; and in pieces not adjustable for length, no variation of more than I-64 of an inch for every 20 feet will be allowed in the length between centers of pin holes.

108. Bars which are to be placed side by side in the structure shall be bored at the same temperature, and shall be of such equal length that, upon being piled on each other, the pins shall pass through the holes a both ends at the same time without driving.

109. All pins shall be accurately turned to a gage, and shall be straight and smooth.

1 I0. The clearance between pin and pin hole shall be $\mathrm{I}-50$ of an inch for pins up to $3^{\mathrm{T} / 2}$ inches in diameter, and $1-32$ for larger pins.

I I . All pins shall be supplied with steel pilot nuts, for use during erection.

\section{Quality OF MATERIAL. SteEL.}

I 2. All steel must be made by the open hearth process, and if by acid process, shall contain not more than 0.08 per cent of phosphorus, and if by basic process, not more than 0.06 per cent of phosphorus, nor more than 0.05 per cent of sulphur, and must be uniform in character for each specified kind.

I 3. The finished bars, plates and shapes must be free from injurious seams, flaws, or cracks, and have a clean smooth finish.

Machine Work Facing.

Pin Holes.

Pins.

Play in

Pin Holes.

Pilot Nuts.

Process of

Manufacture

Finish. 
Test Pieces.

Annealed Test Pieces.

Marking.

Physical

Properties.

Rivet Steel.

Soft Steel

Medium Steel.

Full Size Test of Steel Eye-Bars.
No work shall be done on any steel between the temperature of boiling water and of ignition of hard wood saw dust.

I 4 . The tensile strength, limit of elasticity and ductility, shall be determined from a standard test-piece, cut from the finished material, of at least $1 / 2$ square inch section. All broken samples must show a silky fracture of uniform color.

II5. Material which is to be used without annealing or further treatment is to be tested in the condition in which it comes from the rolls. When material is to be annealed or otherwise treated before use, the specimen representing such matrial is to be similarly treated before testing.

I16. Every finished piece of steel shall be stamped with the blow number identifying the melt.

II7. Steel shall be of three grades: Rivet, Soft and Medi:1n.

I 18. Rivet steel shall have: Ultimate strength, 50,000 to 58,000 pounds per square inch. Elastic limit, not less than one-half the ultimate strength. Elongation, 26 per cent in 8 inches. Bending test, after or before heating to a light cherry red and cooling in water, 180 degrees flat on itself, without fracture on outside of bent portion.

I 19. Soft steel shall have: Ultimate strength, 54,000 to 62,000 pounds per square inch. Elastic limit, not less than one-half the ultimate strength. Elongation, 25 per cent in 8 inches. Bending test, after or before heating to a light cherry red and cooling in water, I8o degrees flat on itself, without fracture on outside of bent portion.

I20. Medium steel shall have: Ultimate strength, 60,000 to 68,000 pounds per square inch. Elastic limit, not less than one-half the ultimate strength. Elongation, 22 per cent in 8 inches. Bending test, I8o degrees to a diameter equal to thickness of piece tested, without fracture on outside of bent portion.

I2I. Full size test of steel eye-bars shall be required to show not less than ro per cent elongation in the body of the bar, and tensile strength not more than 5,000 pounds below the minimum tensile strength required in specimen tests of the grade of steel from which they are rolled. The bars will be required to break in the body, but should a bar break in the 
head, but develop io per cent elongation and the ultimate strength specified, it shall not be cause for rejection, provided not more than one-third of the total number of bars tested break in the head; otherwise the entire lot will be rejected.

I22. Pins made of either of the above mentioned grades of steel shall, on specimen test pieces cut fron finished material, fill the requirements of the grade of steel from which they are rolled, excepting the elongation, which shall be decreased 5 per cent from that specified.

123. In steel $5 / 8$ inch or less in thickness punched rivet holes, pitched two diameters from a sheared eage, must stand drifting until the diameter is one-third larger than the original hole, without cracking the metal.

124. The slabs for rolling plates shall be rolled from ingots of at least twice their cross-section.

125. Pins up to 7 inches diamater shall be rolled.

126. A variation in cross-section or weight of rolled material of more than $21 / 2$ per cent from that specified, may be cause for rejection, except in the case of plates which will be covered by the manufacturer's sta dard specifications (Cambria Steel, page 345).

\section{Stefel Castings.}

127. Steel castings shall be made of open hearth steel containing from 0.25 to 0.40 per cent, and not over 0.08 per cent of phosphorus nor 0.05 per cent sulphur, and shall be practically free from blow holes.

\section{Cast Iron.}

I28. Except where chilled iron is specified, all castings shall be of tough, gray iron, free from injurious cold shuts or blow holes, true to pattern, and of workmanlike finish. Test bars one inch square, loaded in middle between supports I2 inches apart, shall bear 2,500 pounds or over, and deflect 0. I5 of an inch before rupture.

\section{WrOUGHT IRON.}

129. All wrought iron must be tough, ductile, fibrous and of uniform quality. Finished bars must be thorougnly welded
Pin Steel.

Drifting.

Slabs for Plates.

Pins.

Variation in

Weight.

Steel Castings.

Cast Iron.

Character and Finish. 
Manufácture.

Standard Test Piece.

Elastic Limit.

Tension.

Bending Test.

Timber.

Painting. during the rolling, and be straight, smooth and free from injurious seams, blisters, buckles, cracks or imperfect edges.

I3O. No specific process or provision of manufacture will be demanded, provided the material fulfills the requirements of these specifications.

I3I. The tensile strength, limit of elasticity and ductility, shall be determined from a standard test piece of as near $1 / 2$ square inch sectional area as possible. The elongation shall be measured on an original length of 8 inches.

132. Iron of all grades shall have an elastic limit of not less than 26,000 pounds per square inch.

I33. When tested in specimens of uniform sectional area of at least $1 / 2$ square inch the iron shall show a minimum ultimate strength of 50,000 pounds per square inch, and a minimum elongation of $\mathrm{I} 8$ per cent in 8 inches.

I34. All iron for tension members must bend cold through 90 degrees to a curve whose diameter is not over twice the thickness of the piece, without cracking. When nicked on one side and bent by a blow from a sledge, the fracture must be mostly fibrous.

\section{TIMBER.}

I35. The timber shall be strictly first-class spruce, white pine, Douglas fir, Southern yellow pine, or white oak timber; sawed true and out of wind, full size, free from wind shakes, large or loose knots, decayed or sapwood, wormholes or other defects impairing its strength or durability.

\section{Painting.}

136. All iron work before leaving the shop shall be thoroughly cleaned from all loose scale and rust, and be given one good coating of pure boiled linseed oil or paint as specified, well worked into all joints and open spaces.

I37. In riveted work, the surfaces coming in contact shall each be painted before being riveted togetiner.

I38. Pieces and parts which are not accessible for painting after erection shall have two coats of paint. 
139. The paint shall be a good quality of red lead or graphite paint, ground with pure linseed oil, or such paint as may be specified in the contract.

140. After the structure is erected, the iron work shall be thoroughly and evenly painted with two additional coats of paint, mixed with pure linseed oil, of such quality and color as may be selected. Painting shall be done only when the surface of the metal is perfectly dry. No painting shall be done in wet or freezing weather unless special precautions are taken.

14I. Pins, pin holes, screw threads and other finished surfaces shall be coated with white lead and tallow before being shipped from the shop.

\section{INSPECTION.}

142. All facilities for inspection of material and workmanship shall be furnished by the contractor to competent inspectors, and the engineer and his inspectors shall be allowed free access to any part of the works in which any portion of the material is made.

I43. The contractor shall furnish, without charge, such specimens (prepared) of the several kinds of material to be used as may be required to determine their character.

I44. Full sized parts of the structure may be tested at the option of the purchaser; but, if tested to destruction, such material shall be paid for at cost, less its scrap value, if it proves satisfactory.

145. If it does not stand the specified tests, it will be considered rejected material, and be solely at the cost of the contractor.

\section{ERECTION.}

146. The contractor shall furnish at his own expense all necessary tools, staging and material of every description required for the erection of the work, and remove the same when the work is completed.

147. The contractor shall assume all risks from storms or accidents, unless caused by the negligence of the owner,

Inspection.

Testing.

Tools.

Risks. 
and all damage to adjoining property and to persons until the work is completed and accepted.

The contractor shall comply with all ordinances or regulations appertaining to the work.

The erection must be carried forward with diligence and must be completed promptly. 


\section{INDEX}

Page.

Aglebraic calcuation of stressessee Stresses.

Allowable sections ...........285

Anchorage of columns...........101

Anti-condensation roofing. . ...201

Arch-see Two-hinged and threehinged arches.

Asbestos roofing $\ldots \ldots \ldots \ldots \ldots .218$

Asphalt paint ..............295

Asphalt roofing $\ldots \ldots \ldots \ldots \ldots \ldots 217$

A. T. \& S. F. Locomotive Shops...323

Bearing power of piles.........233

Bearing power of soils ........232

Bending moment in beams $31,54,55$, 57.

Boyer plant .................15l

Bracing ................... 84

Brick arch floors ...........248

Brick floors ..............248

Bridge trusses, stresses in

Camel Back .............. 70

Pratt $\ldots \ldots \ldots \ldots \ldots \ldots \ldots, 67$

Warren ...............65

Also, see Stresses.

Brown \& Sharp foundry........150

"Buckeye" flooring...........252

Buckled plates .............254

Carbon paint ...............289

Carey's roofing ...............219

Center of gravity............ 32

Cement floors ...............240

Choice of sections ...........284

Circular ventilators .........276

Cleaning the surface of steel...292

Coal-tar paint ..............295

Columns

Design of $\ldots \ldots \ldots \ldots \ldots \ldots 177$

Details .........167, 168, 169, 336

Pressure on masonry .........238

Types of $\ldots \ldots \ldots \ldots \ldots \ldots \ldots . .165$

Combined stresses ............129

Compression and cross bending 131

Tension and crossbending......134

Stress in bars due to weight...135

Jiagram for stress in bars due to weight $\ldots \ldots \ldots \ldots \ldots \ldots$.....

Concentrated moving loads..... 59

Concentrated load shear ....... 54

Concentrated load stresses...... 51

Concrete buildings ...........228

Concrete slabs ..............226

Conkey printing plant..........150

Corrosion of steel ............286

Corrugated floor ..............253

Corrugated steel

Anti-condensation lining......201

Corner finish .................194

Cornice ..............197-201

Cost of $\ldots \ldots \ldots \ldots \ldots \ldots . .204$

Details .................192

Diagram for safe loads.......190

Flashing .................193

Fastening ..............187

Gutters and Conductors........194

Design of .................. 195

Plans $\ldots \ldots \ldots \ldots \ldots \ldots . .204$

Plans for transformer........203

Roofing $\ldots \ldots \ldots \ldots \ldots \ldots \ldots 206$

Rotary shear for cutting......187

Ridge roll .................192

Standard sheets ............186

Steel lists for transformer building

Strength of ...............190

Tests of ................. $=191$

Weight of ............., 185

Cost-see estimate of cost, and cost under different items.

Estimate of ..........302, 305

Of miscellaneous materials.....311

Standard hardware lists.......313

Of material ..............307

Of mill details shop nork.....309

Crane girders ................184

Details of $\ldots \ldots \ldots \ldots . \ldots 336,339$

Deformation diagram .........120

Details-see Article for which de sign is wanted.

Details-secArticle for which details are wanted.

Diagram for stress in bars due to their own weight..........135 
Diffusion of light.........25i

Doors.

Paneled ................278

Wooden ................278

Sandwich ..............279

Steel ..................279

Details for ..............281

Cost of ...............281

Fastening Corrugated Steel.....187

Ferroinclave ..........220, 253

Finishing cost of paint .......294

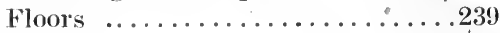

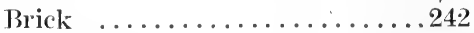

Brick arch ..............248

Buckled plates ...........254

"Buckeye" fireproof .......252

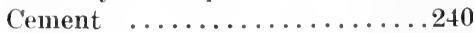

Corrugated .............253

Corrugated iron arch........249

Fixpanded metal ..........250

Ferroinclave. . ...........253

Roebling ..............251

Multiplex steel ..........253

Steel plates .............254

Tar concrete ............242

Wooden ................240

Foundations

Bearing power of piles ......233

Bearing power of soils......232

Design of footings.........23s

Pressure of walls on foundation 235

Pressure of pier on foundation 236

Pressure of column on masonry 239

Hardware lists .........313, 314

Girders, crane ...............184

Girders, design of ...........181 Glass

Anount of light required.....268

Cost of .................262

Details of windows..........265

Diffusion of light .........257

Double glazing ............265

Kinds of...............256

Factory ribbed...........257

Maze ................257

Plane ................256

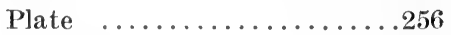

Prisms ...............257

Ribbed .................257

Wire .................257

Window ..............256
Relative value of different kinds

.257

Placing the glass..........260

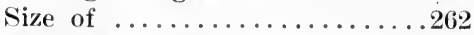

Window shades ......... 261

Granite roofing ............219

Gravel roofing .............214

Ground floors ...............239

Iron oxide . . . . . . . . . . 289

Iron, elassification. . .........308

Iron, corrugated-see Corrugated steel.

Lead .287

Linseed oil ...............287

Lists, standard hardware... .313, 314 Loads

Dead loads ............. 4

Weight of covering ........ 8

Weight of cranes ......... 18

Weight of girts......... 8

Miscellaneous material ..... 19

Weight of purlins........s $\mathrm{s}$

Weight of structure...... 9

Loads on simple roof trusses. 45

Snow loads ............... 10

Wind loads ............... 12

Miscellaneous loads ......... 17

Live loads on floors......... 17

Locomotive shops

A. T. \& S. F..........159, 323

Oregon Short Line...........157

Philadelphia \& Reading........328

St. I. I. M. \& S.............158

Union Pacific ..............158

Methods of calculations

Algebraic moments ......42, 70

Algebraic resolution ........38, 63

Graplic moments ......44, 71

Graphic resolution ......40, 68

Also-see Stresses.

Mill buildings

General design of .........141

Specifications for............ 341

Types ................. 1

Masonry walls ......... 3

Masonry filled walls ....... 2

Steel frame ............. 1

Miscellaneous loads

Live loads on floors.......... 17 
Weight of electric eranes..... 18

Weight of hand eranes........ 18

Weight of miscellaneous material ............... 19

Miscellaneouss structures.

A. T. \& S. F. shops......159, 323

Philadelphia \& Reading shops 328

St. Louis Coliseum ............319

Steam Engineering Buildings

Brooklyn Navy Yard.......337

Steel Dome West Baden Hotel 315

Mixing paint ............290

Moment or inertia of areas..... 36

IIoment of inertia of forces...... 33

Culmann's method......... 33

Mohr's method ........... 34

Moments

Algebraic ...... 42, 54, 55, 70

(iraphic .... 30, 44, 54, 55, 71

Moments in beams.

Concentrated loads .........54

Concentrated moving loads.... 57

Uniform loads ............. 55

Uniform moving loads ....... 5i

Monitor ventilators .........273

Multiplex steel floor ........253

Oil. linseed ...............287

Uil, paint $\ldots \ldots \ldots \ldots \ldots \ldots \ldots 286$

Paint.

Applying the $\ldots \ldots \ldots \ldots \ldots 291$

Aspahlt ...............295

Carbon ...............289

Cement paint ...........295

Cleaning the surface .......292

Coal-tar paint ..........295

Cost of ..............292

Covering capacity ........290

Finishing coat .........294

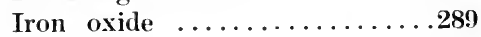

Lead $\ldots \ldots \ldots \ldots \ldots \ldots \ldots 288$

linseed oil .............287

Mixing the ............290

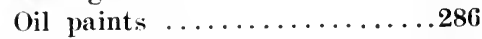

Priming coat ...........293

Proportions ............290

References on paint .......296

Zinc ................289

Painting

Applying the paint $\ldots \ldots \ldots \ldots 291$

Cost of ..............293
Cleaning the surface $\ldots \ldots \ldots 292$

Paneled doors ...........278

Philadelphia \& Reading slops....328

Pitch of roof .............153

Pitch of trusses ...........154

Plate girders ...............181

Polygon.

Equilibrium .............24

Force $\ldots \ldots \ldots \ldots \ldots \ldots \ldots 22$

Moment $\ldots \ldots \ldots 71,54,55,57,59$

Shear $\ldots \ldots \ldots 72,54,55,57,59$

Portals

Anchorage of columns .......101

Stresses in

Continuous portals ........103

Double portal ...........104

Simple portals, columns hinged

Algebraic solution.......96,98

Graphic solution ........98

Simple portals, columns fixed.

Algebraic solution .......101

Graphic solution ........103

Portland cement paint .......296

Pressure of columns on masonry 238

Pressure of pier on foundation. .235

Pressure of wall on foundation..236

Proportions of paint and oil...290

Purlins .................... 173

Reactions of

Beams ...........2 5 , 53

Cantilever truss .......... 28

Overhanging beam ......... 53

Three-hinged arch .......106, 107

Two-hinged arch ...114, 117, 119

Resolution

Algebraic ...........38, 63

Graphic .............40, 68

Red lead ................288

References on paint and painting 296

Roebling floor ...........251

Roof, pitch of ........... 153

Roof trusses, see Trusses.

Stress in-see Stresses.

Roof coverings for railway buildings $\ldots \ldots \ldots \ldots \ldots \ldots \ldots .221$

Roofing.

Asbestos .............131, 218

Asphalt ................217

Carey's ................219

Corrugated stcel ..........206

Cost of ..........206, 222 
Examples of $\ldots \ldots \ldots \ldots \ldots 221$

Ferroinclave ............220

Granite ............219, 222

Gravel .............214, 222

Paroid ................222

Ruberoid ..........219, 222

Slag ..............216, 331

Sheet steel ..........213, 222

Slate .........207, 221, 222

Sparham ..............222

Tile ..........210, 221, 222

Ruberoid roofing ...........219

Saw tooth roofs 143, 149, 150, 151, 151, 152, 164, 324, 325 .

Boyer plant ...............151

Brown \& Sharp foundry .....150

Conkey prntiing plant .......150

Locomotive shop ..........152

Matthessen \& Hegeler shops...164

Sections, choice of .........284

Shear in beams. for

Concentrated loads .........54

Concentrated moving loads .... 59

Uniform moving loads....... 57

Shear polygon, see Polygon.

Sheet steel roofing ...........213

Shingle roofs .............218

Shop cost .........................

Shop costs, actual ..........311

Side nvalls

Concrete slabs ............226

Corrugated steel ..........223

Expanded metal and plaster...223

Masonry walls ...........227

Thickness of ............227

Skylights ..............261

Details of $\ldots \ldots \ldots \ldots \ldots \ldots 265$

Slate roofing $\ldots \ldots \ldots \ldots \ldots 210$

Slag roofing .........216, 331

Snow loads .............. 10

Sparham roofing ...........221

Specifications for Steel Frame

Mill Buildings-Appendix I. .341

Standard hardware lists ....313, 314

Steam engineering buildings for

Brooklyn Navy Yard ........337

Stress in bars due to weight...135

Stresses, allowable ........144, 174

Also-see Appendix I........341

Stresses in

Bracing

Bridge trusses-see Trusses.
Portals-see Portals.

Roof trusses-see Roof trusses.

Transverse bent-see Transverse bent.

Three-hinged arch-see Threehinged arch.

Two-hinged arch-see Twohinged arch.

Stresses.

Calculation of $\ldots \ldots \ldots \ldots \ldots 20$

Combined .................138

Eccentric ..........................

Struts and bracing . . .........173

Tar concrete floors . . . . . . . . 242

Three-hinged arch

Calculation of stresses.......106

Dead load ...............108

Reactions

Algebraic method .......106

Graphic method .........107

Wind load stresses .......111

Timber floors .........248, 243

Tile roofing ............210

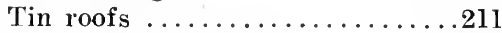

Translucent fabric ..........264

Cost of ..............265

Transverse bent

Details ............162, 164

Transverse bent, stresses in

Dead load ........... 75, 86

Maximum ..........83, 93

Snow load ............. 75

Wind load

Algebraic calculation ...... 76

Columns fixed .........79

Columns hinged ....... 76

Graphic colculation

Case $2 \ldots \ldots \ldots \ldots . \ldots 8$

Case $3 \ldots \ldots \ldots \ldots . \ldots 90$

Case $4 \ldots \ldots \ldots . \ldots 91$

Case 5 ............ 96

Trusses.

Economic spacing of ........154

Design of ............... 174

Details of $\ldots \ldots \ldots 159,161,334$

Pitch of $\ldots \ldots \ldots \ldots \ldots 152,164$

Saw tooth-see Sanv tooth roofs.

Types .............146, 152

Trusses, stresses.

Bridge trusses.

Algebraic moments 
Algebraic resolutions

63 Ventilators .................173

Graphic moments ........71

Ventilators ...............273

Graphic resolutions.........68

Roof trusses.

Algebraic moments .......42

Algebraic resolution $\ldots \ldots \ldots 38$

Graphic moments .......44

Graphic resolution .......40

Concentrated load ........51

Dead load ............45

Dead and ceiling load .....46

Snow load ............4 47

Wind load .......47, 48, 49

Two-hinged arch.

Design of $\ldots \ldots \ldots \ldots \ldots \ldots 127$

Two-hinged arch, stresses.

Calculation of reaction .......114

Algebraic solution ........117

Graphic solution ..........119

Dead load ................121

Dead and wind load ........123

Temperature stresses .......126

Monitor ...............273

Cost of ..............273

Circular ................276

Cost of $\ldots \ldots \ldots \ldots \ldots \ldots 277$

Walls, masonry .............227

Walls, side ...............223

Weight. estimate of .........297

West Baden dome ............315

Window shades ...........26I

windows.

Amount of light .........268

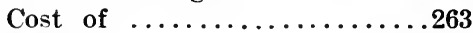

Details of $\ldots \ldots \ldots \ldots \ldots 265,268$

Double glazing ..........265

Glass-see Glass.

Wooden doors ............278

Wooden floors .............243

Zinc paint .............289

With horizontal tie .........125

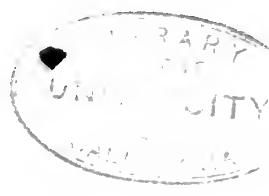






\section{THIS BOOK IS DUE ON THE LAST DATE}

STAMPED BELOW

AN INITIAL FINE OF 25 CENTS WILL BE ASSESSED FOR FAILURE TO RETURN THIS BOOK ON THE DATE DUE. THE PENALTY WILL INCREASE TO 50 CENTS ON THE FOURTH DAY AND TO \$1.00 ON THE SEVENTH DAY OVERDUE.

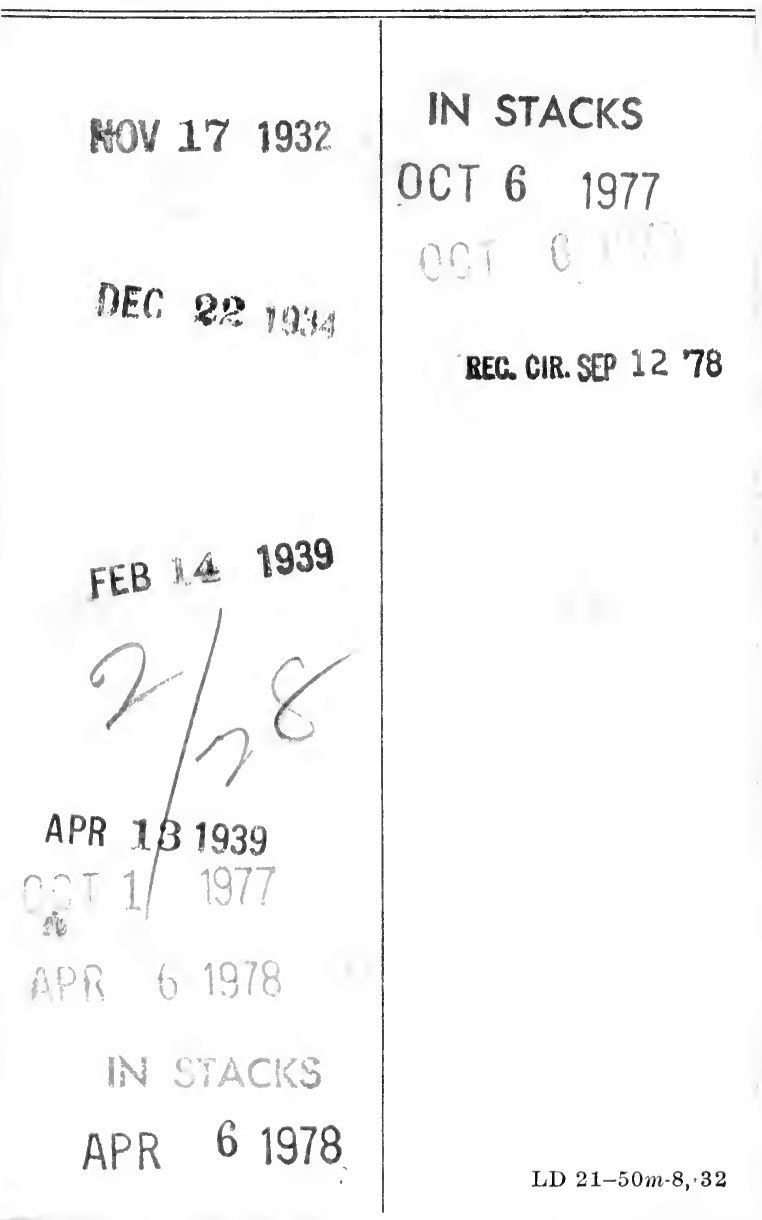




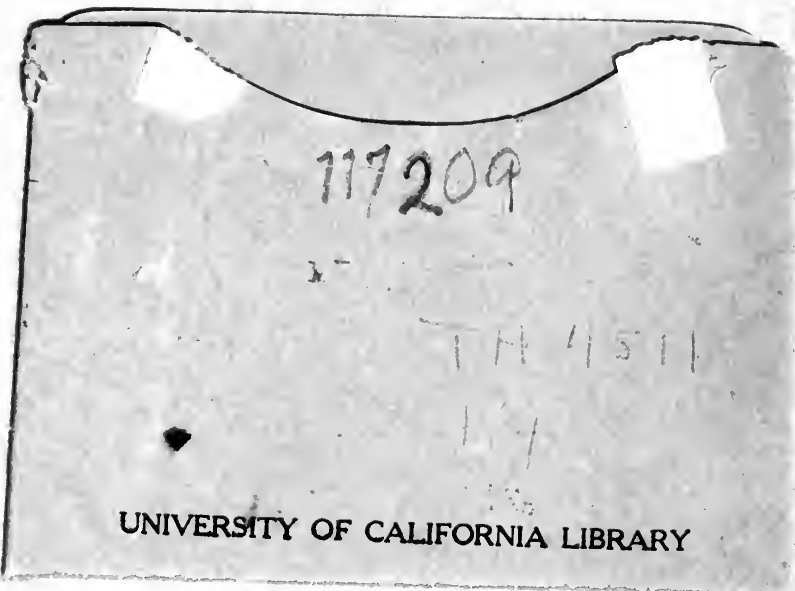




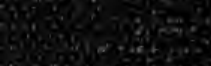
30.0

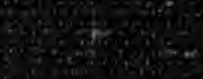
40.4

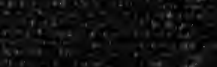

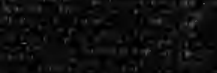
$\log _{0}=280$

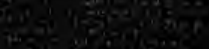

STo

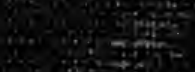

15. 